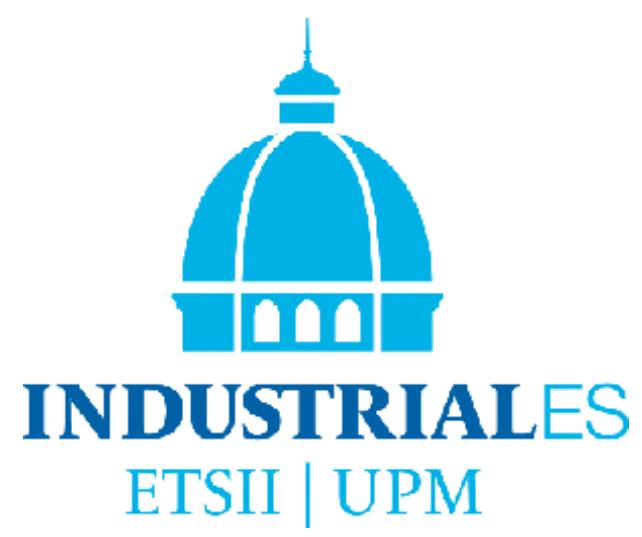

\title{
LA EFECTIVIDAD EN EL E-MAIL MARKETING: MODELO TEÓRICO UNIFICADO Y ESTUDIO DE LAS INFLUENCIAS CULTURALES
}

TESIS DOCTORAL

ÁNGEL JOSÉ LORENTE PÁRAMO 



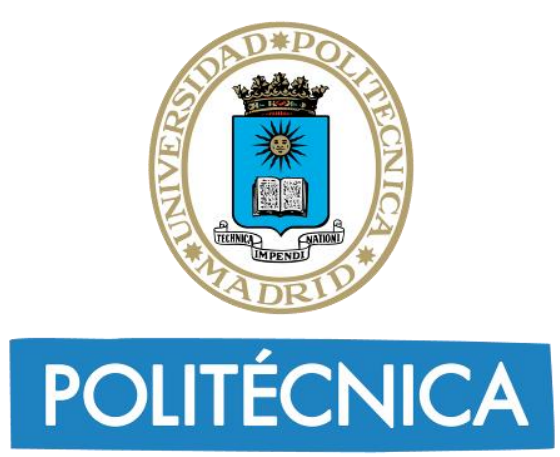

UNIVERSIDAD POLITÉCNICA DE MADRID

ESCUELA TÉCNICA SUPERIOR DE INGENIEROS INDUSTRIALES

\title{
LA EFECTIVIDAD EN EL E-MAIL MARKETING: MODELO TEÓRICO UNIFICADO Y ESTUDIO DE LAS INFLUENCIAS CULTURALES
}

\author{
TESIS DOCTORAL
}

ÁNGEL JOSÉ LORENTE PÁRAMO

Ingeniero Aeronáutico

2020 



\title{
UNIVERSIDAD POLITÉCNICA DE MADRID
}

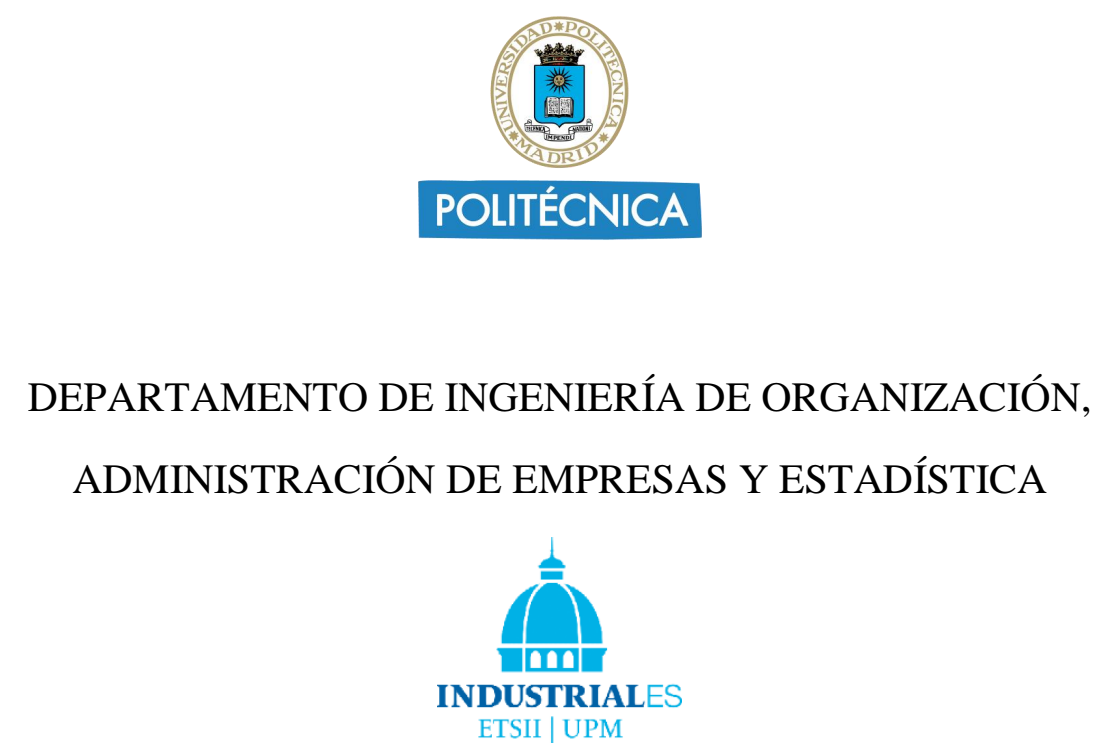

ESCUELA TÉCNICA SUPERIOR DE INGENIEROS INDUSTRIALES

\section{La efectividad en el e-mail marketing: modelo teórico unificado y estudio de las influencias culturales.}

\section{TESIS DOCTORAL}

\author{
Autor: $\quad$ Ángel José Lorente Páramo \\ Ingeniero Aeronáutico \\ Directores: $\quad$ Ángel Hernández García \\ Doctor UPM \\ Julián Chaparro Peláez \\ Doctor Ingeniero de Telecomunicación
}





\title{
TESIS DOCTORAL
}

La efectividad en el e-mail marketing: modelo teórico unificado y estudio de las influencias culturales.

\author{
Autor: $\quad$ Ángel José Lorente Páramo \\ Ingeniero Aeronáutico \\ Directores: $\quad$ Ángel Hernández García \\ Doctor UPM \\ Julián Chaparro Peláez \\ Doctor Ingeniero de Telecomunicación
}

Tribunal nombrado por el Excmo. Y Magfco. Sr. Rector de la Universidad Politécnica el día de de 2020

\section{PRESIDENTE}

\section{VOCAL}

VOCAL

VOCAL

\section{SECRETARIO}

Realizado el acto de defensa el día de de 2020 en la Escuela Técnica Superior de Ingenieros Industriales de la Universidad Politécnica de Madrid.

Calificación obtenida:

EL PRESIDENTE

EL SECRETARIO 



\section{Agradecimientos}

A Ángel, Julián y Santiago, por su paciencia, flexibilidad, comprensión y ayuda.

A Sandra, por motivarme a ser mejor cada día.

A Luis Ángel, por inculcarme la pasión por el conocimiento.

A Pilar, por enseñarme a no tener miedo a nada.

A Beltrán, por todo lo que vendrá. 



\section{RESUMEN}

El auge experimentado por los medios de comunicación digitales en los últimos quince años ha transformado la relación entre empresas y consumidores. Al calor del crecimiento del comercio electrónico y del incremento de penetración de los smartphones, las expectativas de los usuarios han alcanzado nuevas cotas de sofisticación. En un nuevo contexto en el que la bidireccionalidad y la personalización son requisitos fundamentales, el e-mail marketing se ha posicionado como un canal efectivo y enormemente rentable para los anunciantes.

El progresivo incremento de usuarios de correo electrónico, la mayor flexibilidad de este medio y su mínimo coste por envío han hecho que en muy pocos años el e-mail marketing, inicialmente concebido como una extensión de los programas de marketing directo basados en correo postal, se haya convertido en una pieza fundamental de toda campaña de comunicación. A la vista de esto, y dada su influencia directa y medible en las ventas de las compañías, existe un creciente interés tanto por parte de la comunidad científica como de los responsables corporativos en responder a la pregunta "¿Qué factores influyen en la efectividad del e-mail marketing?".

La respuesta a esta pregunta es compleja, puesto que es necesario determinar la manera más adecuada de evaluar la efectividad, así como analizar en conjunto una gran cantidad de factores intrínsecos y extrínsecos al canal, de forma que resulte posible determinar su importancia absoluta y relativa. A diferencia de las investigaciones realizadas hasta la fecha, que han abordado esta tarea concentrándose en etapas o factores concretos, este trabajo aspira a utilizar un planteamiento holístico con el objetivo de proponer un modelo predictivo, teórico y unificado de efectividad en el e-mail marketing.

Con este fin, se ha realizado una investigación científica estructurada en cinco fases: introducción al tema de investigación, exposición del marco teórico, diseño de trabajo de investigación, análisis de resultados y desarrollo de conclusiones. Estas cinco fases han sido desarrolladas a lo largo de nueve capítulos, correspondiendo la primera al capítulo 1, la segunda a los capítulos 2,3 y 4, la tercera a los capítulos 5 y 6 , la cuarta al capítulo 7 y la quinta y última al capítulo 8 . Adicionalmente, en el capítulo 9 se ha incluido la bibliografía consultada.

El capítulo 1 desarrolla una breve introducción al entorno del e-mail marketing para posteriormente enfocarse en plantear el problema de investigación y proponer una serie de objetivos primarios y secundarios. Así, se realiza inicialmente un resumen de la efectividad en el e-mail marketing y de los factores estudiados hasta la fecha, para más tarde presentar los modelos de jerarquías de efectos y de dimensiones culturales. Posteriormente, se justifica la importancia y relevancia de la investigación y se propone un plan de trabajo para alcanzar los objetivos definidos. 
A continuación, el capítulo 2 ahonda en el entorno del e-mail marketing a través de una revisión comentada de la literatura. En primer lugar, se estudia el concepto de efectividad tal $\mathrm{y}$ como ha sido tratado por investigaciones anteriores, para a continuación proponer una definición unificadora compuesta de diversas etapas que resulta a la vez potente y práctica. En segundo lugar, se detallan todos los factores de influencia intrínsecos al canal identificados hasta la fecha, para posteriormente proponer una taxonomía que los ordena de manera coherente.

Una vez examinado el entorno del e-mail marketing, el siguiente paso consiste en vincular las variables identificadas con un modelo de efectividad ya existente con el objetivo de dotar de mayor solidez al trabajo. Así, el capítulo 3 explora diversos modelos teóricos utilizados en el estudio de la efectividad publicitaria. Tras realizar una revisión en detalle de aquellos basados en la jerarquía de efectos, se presenta el modelo AIDA (atención, interés, deseo, acción) y se vinculan sus etapas a la definición de efectividad anteriormente propuesta.

El capítulo 4 se ocupa del estudio de aquellos factores de influencia extrínsecos al canal pero que, sin embargo, resultan relevantes a la vista del carácter plurinacional del entorno digital. Así, se justifica la relevancia de incluir la cultura nacional en el modelo de efectividad para posteriormente vincular, tras haber realizado una revisión de diversos modelos de dimensiones culturales, el modelo de Hofstede con ciertos factores intrínsecos identificados en el capítulo 2.

Una vez el marco teórico ha sido desarrollado íntegramente, el capítulo 5 se concentra en la propuesta de un modelo teórico que sirva como base para el análisis empírico. Así, las relaciones entre factores intrínsecos y efectividad desarrolladas en el capítulo 2 y aquellas entre factores extrínsecos e intrínsecos expuestas en el capítulo 4 son transformadas en hipótesis de trabajo y agrupadas de manera coherente.

Tras concluir esta etapa, el capítulo 6 procede a detallar las características del trabajo empírico desarrollado con el objetivo de contrastar las hipótesis propuestas. En primer lugar, se caracteriza la investigación como deductiva, cuantitativa y perteneciente a la rama de las ciencias sociales. A continuación, se proponen metodologías para operacionalizar las diversas variables que componen el modelo, para posteriormente concluir con el análisis descriptivo de las muestras que serán utilizadas en el estudio empírico.

El capítulo 7 aborda el análisis de resultados. Como primer paso, introduce la técnica estadística de regresión múltiple, detallando las diversas consideraciones relevantes en su aplicación y resumiendo la metodología más adecuada para la interpretación de los resultados obtenidos. A continuación, se procede a realizar el análisis empírico de las dos muestras que utiliza la investigación, concluyendo con un resumen del contraste de hipótesis.

Como colofón, el capítulo 8 se ocupa de las conclusiones. En un primer lugar, se valora el éxito de la investigación en relación a los objetivos inicialmente propuestos, 
detallando las contribuciones teóricas, metodológicas y prácticas alcanzadas. A continuación, se procede a analizar las conclusiones generales relativas a cada etapa de efectividad y las conclusiones específicas en relación a cada factor de influencia. Posteriormente, se presentan recomendaciones prácticas orientadas a la adopción de determinadas técnicas por parte de los responsables de e-mail marketing que permiten mejorar la efectividad de las campañas. En último lugar, se detallan las limitaciones del estudio, posibles líneas de investigación futuras y las publicaciones a las que ha dado origen esta tesis.

Palabras clave: e-mail marketing, marketing digital, marketing online, correo electrónico, e-mail, línea de asunto, comercio electrónico, CTR, tasa de apertura, tasa de conversión, jerarquía de efectos, AIDA, dimensiones culturales, modelo de Hofstede, personalización, segmentación, frecuencia, longitud del correo, longitud del asunto. 



\section{ABSTRACT}

The rising of digital media has transformed the interactions between consumers and companies. Users' expectations have reached new heights fueled by the growth of ecommerce and smartphone penetration. In a context in which bidirectionality and personalized experiences are the new normal, email marketing is perceived by advertisers as an effective and highly profitable communication channel.

Initially designed as an extension of post-based direct marketing programs, email marketing has become a key component of any advertising campaign due to its flexibility, the growing numbers of email users and the negligible cost per email sent. Moreover, recent research has proven the channel's significant contribution to overall sales. Hence, there is a growing interest from both scientist and advertisers on answering the question "What factors influence email marketing effectiveness?".

The answer is relatively complex because of two major difficulties. First, it is unclear what is the best method to measure effectiveness. Second, it is required to consider a great number of intrinsic and extrinsic variables in order to determine their absolute and relative importance. Even though previous research has focused on particular stages or influence factors, the goal of this work is to adopt a holistic approach in order to obtain a unified theoretical predictive model for email marketing effectiveness.

Considering this, the research has been structured in five stages: introduction to the topic, theoretical framework, research design, analysis and conclusions. These stages have been developed throughout nine chapters: the first one is covered in chapter 1 , the second one in chapters 2 to 4 , the third one in chapters 5 and 6 , the fourth one in chapter 7 and the last one in chapter 8. Chapter 9 gathers the bibliography used through the research.

Chapter 1 presents a brief introduction to the email marketing environment, followed by the statement of the research problem, articulated through a set of primary and secondary objectives. Then, the influencing factors and current approaches to the analysis of effectiveness are presented, hierarchy of effects and cultural dimensions models are succinctly described, and the relevance of the research is justified.

Chapter 2 deepens on email marketing through an exhaustive literature review. First, different methodologies to measure effectiveness are described and a new unifying multi-staged definition is suggested. In addition, all influencing factors identified to date are listed, followed by the proposal of a taxonomy to articulate them. 
Upon the examination of the email marketing context, chapter 3 focuses on improving the robustness of the model by linking the definition of effectiveness to an existing effectiveness model. Multiple models of advertising effectiveness are explored, and those based in hierarchy of effects theory are analyzed on detail. The chapter concludes with an exhaustive review of AIDA (Attention, Interest, Desire, Action) model and a justification on why it is the most adequate for the objective pursued by this research.

Chapter 4 focuses on the identification of relevant extrinsic influencing factors that might be relevant after consideration of the multinational nature of email marketing. Following the justification for the relevance of national culture in this research, cultural dimensions models are introduced. Hofstede's model is selected as the most suitable option and its dimensions are then linked to the previously identified influencing factors.

After concluding the theoretical framework, chapter 5 proposes a theoretical model to run the empirical analysis. The hypothesis of the research study are posited, based on the relationships between intrinsic factors and effectiveness presented in chapter 2 and on the links between extrinsic and intrinsic factors detailed in chapter 4 .

Chapter 6 details the features of the empirical research conducted to contrast the research hypothesis. The study is characterized as deductive, quantitative and belonging to the field of social sciences. Then, variable operationalization is performed, and the two study samples used are introduced and described.

Chapter 7 covers the statistical analysis of results. The technique used, multiple regression, is reviewed in detail and all relevant considerations regarding its application are presented. A methodology to interpret results is first proposed and then applied to the two samples used on the research. The chapter closes with a summary of hypothesis supported and not supported.

Finally, chapter 8 reviews the conclusions of the research. The achievement of the research objectives is discussed and the theoretical, methodological and practical contributions are presented. Furthermore, general conclusions related to each of the effectiveness stages are detailed, followed by specific conclusions linked to each of the influence factors. The analysis continues with a detailed review of practical recommendations and techniques that email marketing executives and practitioners can put into practice in order to improve campaigns effectiveness. Finally, the main limitations of the study, as well as future avenues of research and a list of the publications derived from this research are provided.

Keywords: email marketing, digital marketing, online marketing, email, subject, ecommerce, CTR, open rate, conversion rate, hierarchy of effects, AIDA, cultural 
dimensions, Hofstede model, personalization, segmentation, frequency, subject length, email length. 



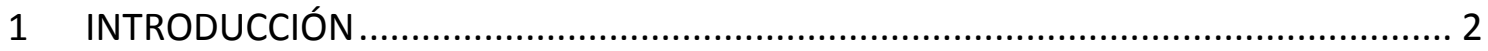

1.1 IMPORTANCIA DEL E-MAIL MARKETING .................................................... 2

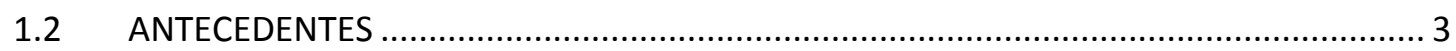

1.2.1 Introducción al e-mail marketing ............................................................ 4

1.2.2 La efectividad en el e-mail marketing ........................................................ 5

1.2.2.1 Factores de influencia en el e-mail marketing ............................................. 6

Introducción a la teoría de la jerarquía de efectos .......................................... 7

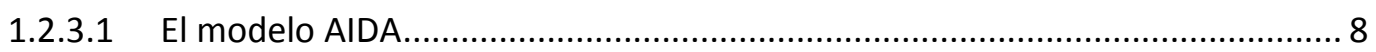

1.2.3.1.1 AIDA en el e-mail marketing ....................................................... 8

1.2.4 Introducción a las influencias culturales en el comportamiento del consumidor 8

1.2.4.1 Dimensiones culturales de Hofstede............................................... 9

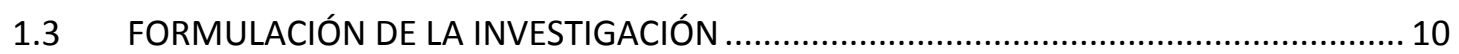

1.3.1 Definición del problema de investigación ................................................... 10

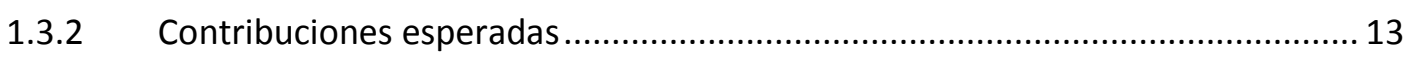

1.3.3 Objetivos de la investigación............................................................... 13

1.3.4 Tesis general......................................................................................... 14

1.4 PROGRAMA, METODOLOGÍA, MEDIOS Y CRONOGRAMA DE TRABAJO .................... 15

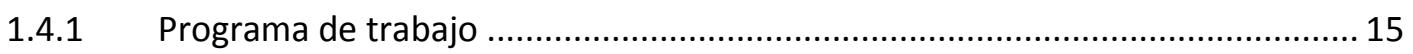

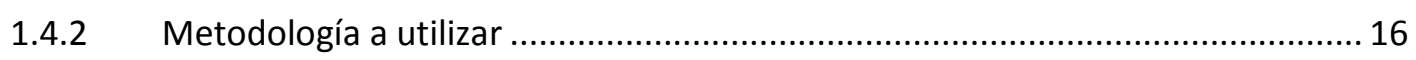

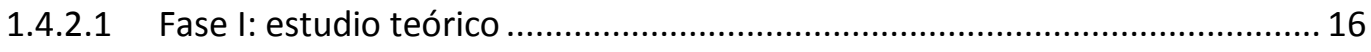

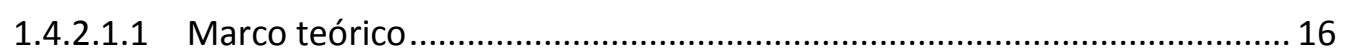

1.4.2.1.2 Identificación de factores relevantes.............................................. 16

1.4.2.2 Fase II: trabajo empírico .......................................................................... 16

1.4.2.2.1 Propuesta de un modelo de efectividad en el e-mail marketing............. 16

1.4.2.2.2 Definición de necesidades de datos...................................................... 16

1.4.2.2.3 Obtención de datos empíricos ......................................................... 16

1.4.2.2.4 Análisis estadístico de datos ............................................................ 17

1.4.2.3 Descripción de los resultados de la investigación ........................................ 17

1.4.2.3.1 Formulación del modelo final ..................................................... 17

1.4.2.3.2 Discusión de resultados.................................................................... 17

1.4.2.3.2.1 Descripción de las implicaciones de la investigación....................... 17

1.4.2.3.3 Exposición de las conclusiones......................................................... 17

1.4.2.4 Medios que utilizará la investigación ................................................ 17

Cronograma de trabajo ........................................................................... 18

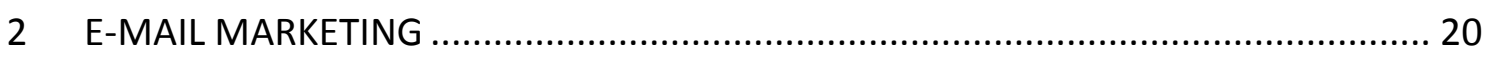

2.1 ANTECEDENTES: EL CORREO ELECTRÓNICO ....................................................... 20

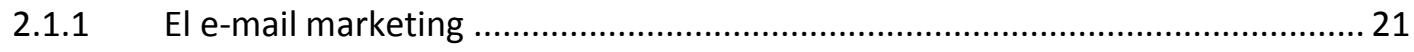

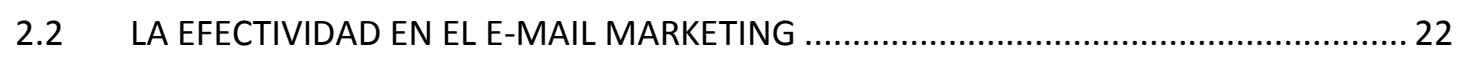

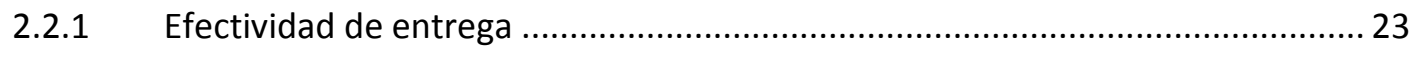




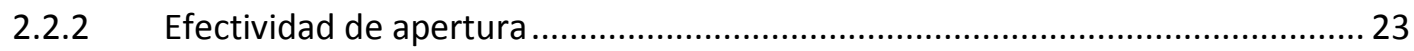

2.2.2.1 Medida de la efectividad de apertura .................................................... 24

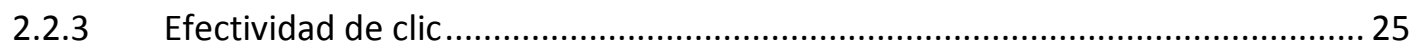

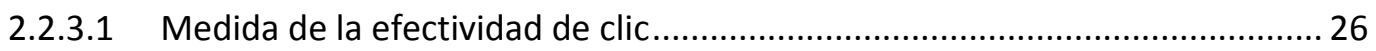

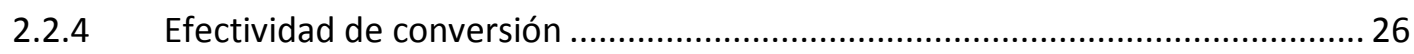

2.2.4.1 Medida de la efectividad de conversión .................................................. 27

2.2.5 Efectividad de retención de suscriptores...................................................... 29

2.2.5.1 Medida de la efectividad de retención de suscriptores ............................... 30

2.2.6 Efectividad en el e-mail marketing............................................................. 30

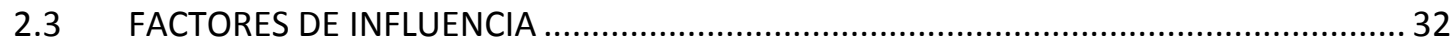

2.3.1 Categorización de factores de influencia .................................................... 32

2.3.2 Variables de contenido visible ................................................................. 33

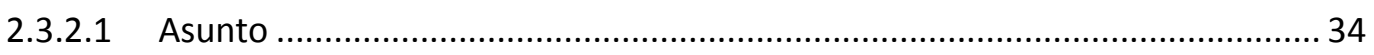

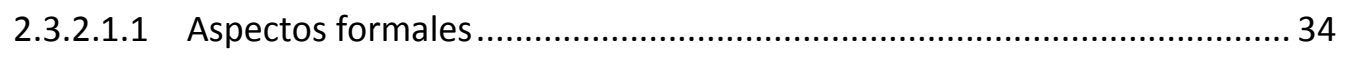

2.3.2.1.2 Aspectos semánticos........................................................................ 35

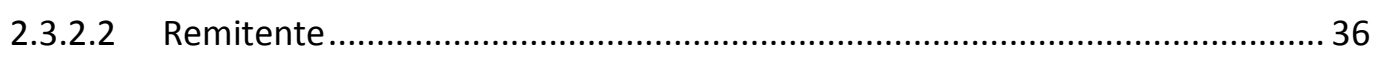

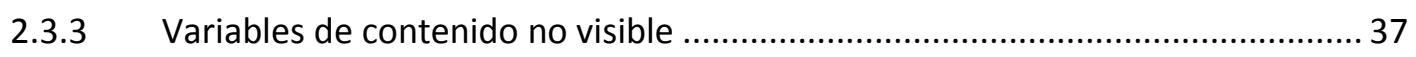

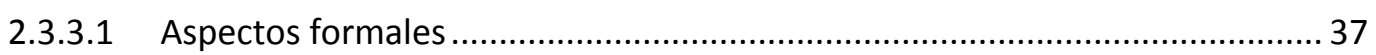

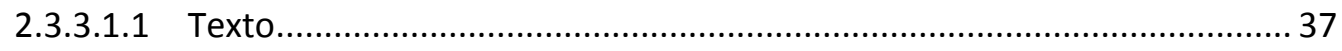

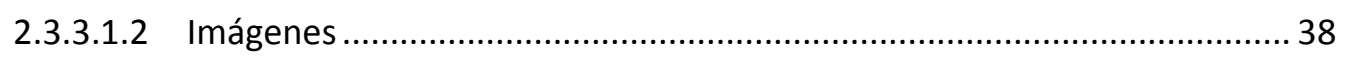

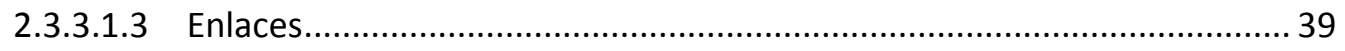

2.3.3.2 Aspectos semánticos ............................................................................ 40

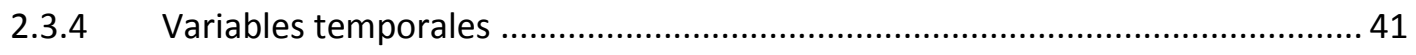

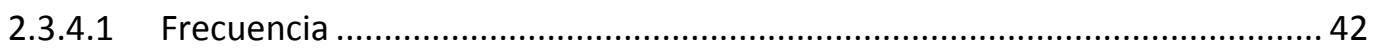

2.3.4.2 Momento de envío.............................................................................. 43

2.3.5 Variables contextuales ........................................................................... 44

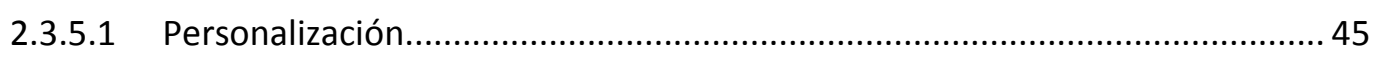

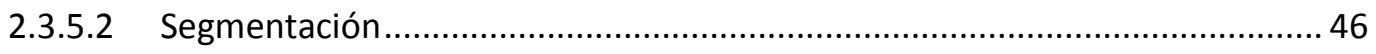

2.3.6 Resumen de factores de influencia ......................................................... 47

3 MODELOS DE JERARQUÍA DE EFECTOS. EL MODELO AIDA................................. 50

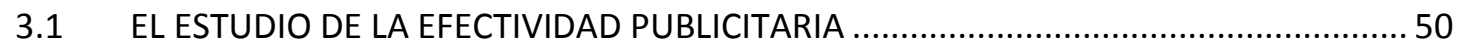

3.1.1 Teorías de jerarquía de efectos..................................................................... 51

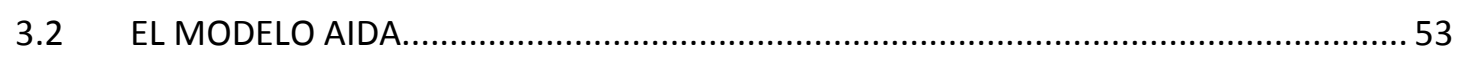

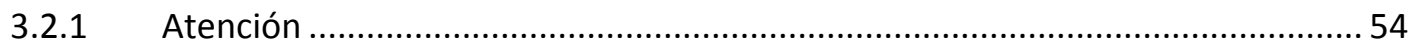

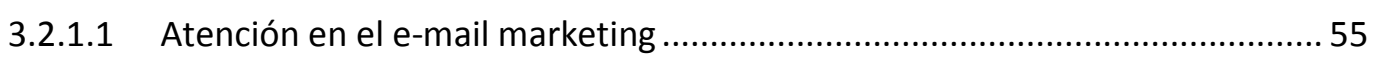

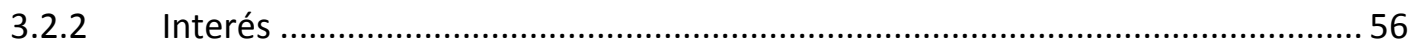

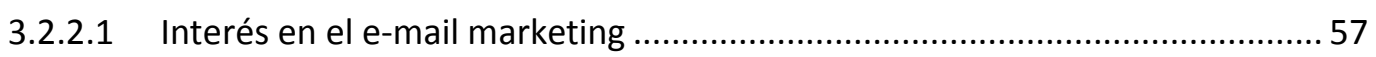

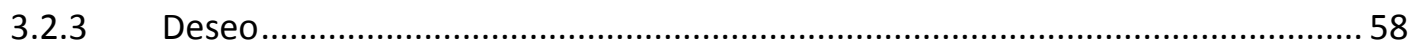

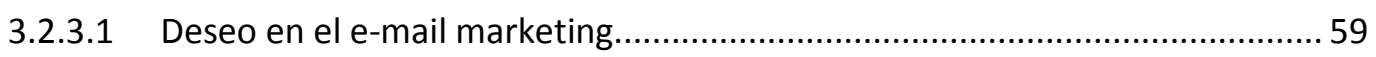

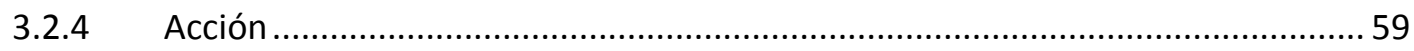

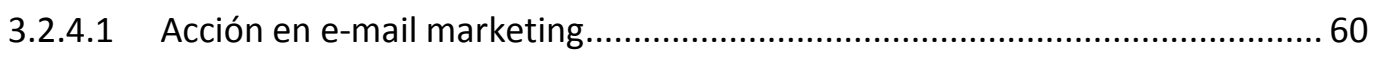


3.3 APLICACIÓN DEL MODELO AIDA EN EL E-MAIL MARKETING ...................................... 60

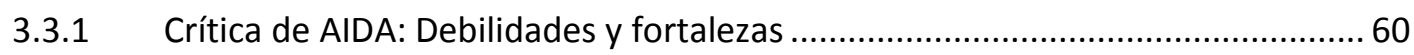

3.3.2 Aplicación de AIDA al e-mail marketing ......................................................... 61

4 MODELOS DE DIMENSIONES CULTURALES. EL MODELO DE HOFSTEDE ................. 66

4.1 LA INFLUENCIA DE LA CULTURA EN EL COMPORTAMIENTO DEL CONSUMIDOR ........66

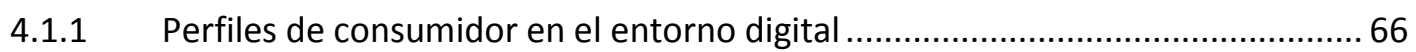

4.1.2 La cultura y su influencia en el comportamiento del consumidor .......................67

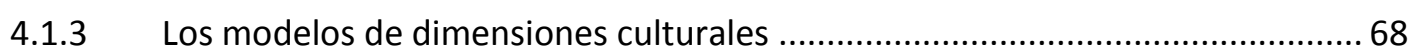

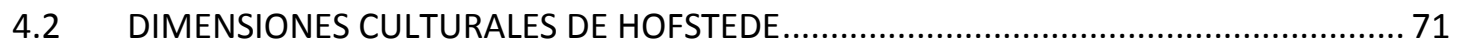

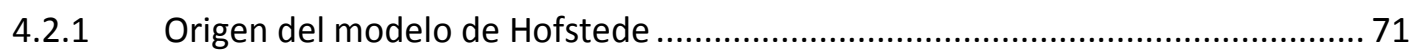

4.2.2 Dimensiones culturales: modelo original.................................................... 72

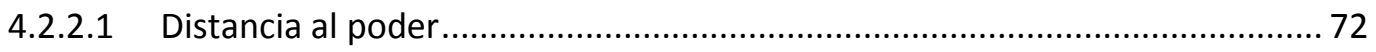

4.2.2.1.1 Distancia al poder en el e-mail marketing .............................................. 73

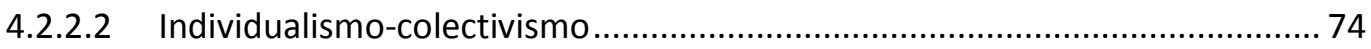

4.2.2.2.1 Individualismo-colectivismo en el e-mail marketing ................................ 75

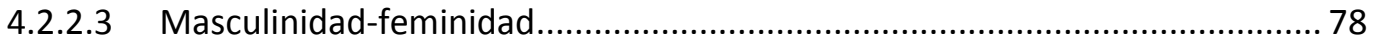

4.2.2.3.1 Masculinidad-feminidad en el e-mail marketing ....................................... 78

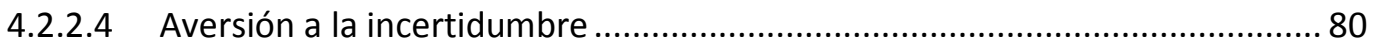

4.2.2.4.1 Aversión a la incertidumbre en el e-mail marketing................................ 81

4.2.3 Dimensiones culturales: extensiones al modelo original .................................... 82

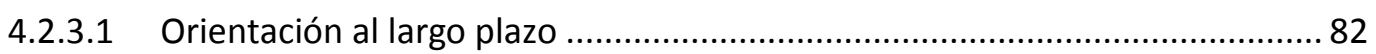

4.2.3.1.1 Orientación al largo plazo en el e-mail marketing ................................... 82

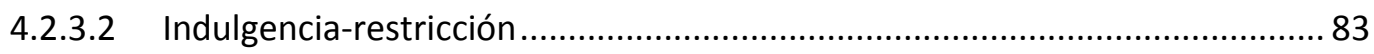

4.3 DIMENSIONES CULTURALES DE HOFSTEDE EN EL E-MAIL MARKETING ....................... 84

4.3.1 Critica del modelo de Hofstede................................................................... 84

4.3.2 Aplicación del modelo de Hofstede al e-mail marketing ..................................... 86

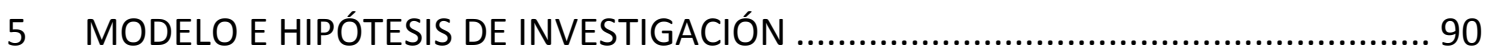

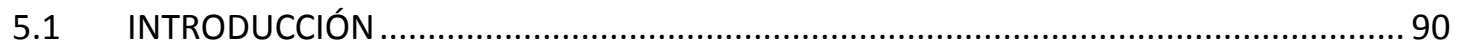

5.2 LA EFECTIVIDAD EN EL E-MAIL MARKETING - VARIABLES DE MEDIDA ...................... 90

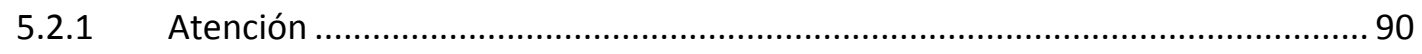

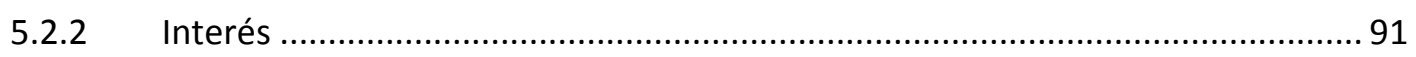

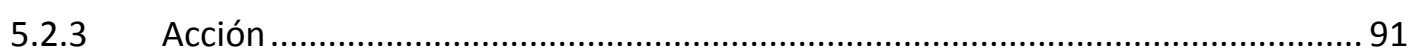

5.3 FACTORES DE INFLUENCIA EN LA EFECTIVIDAD DEL E-MAIL MARKETING ................. 92

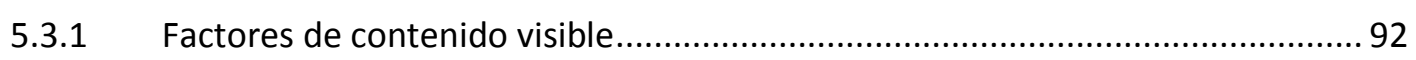

5.3.2 Factores de contenido no visible.................................................................... 93

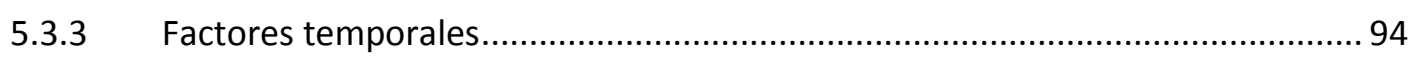

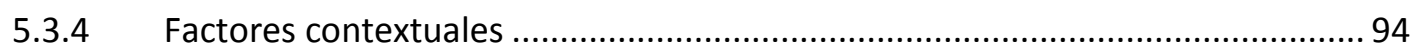

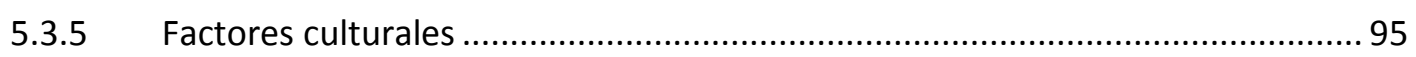

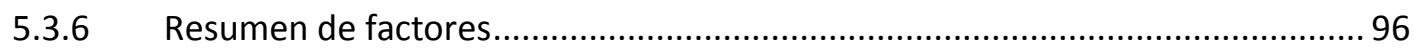

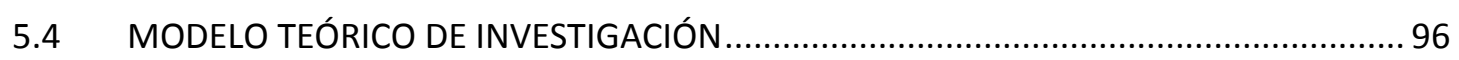




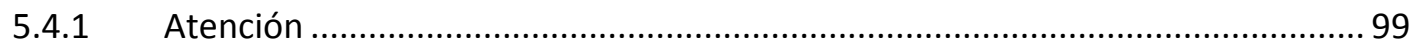

5.4.1.1 Relaciones de las variables de contenido visible ........................................... 99

5.4.1.2 Relaciones de las variables temporales ........................................................ 99

5.4.1.3 Relaciones de las variables contextuales ..................................................... 100

5.4.1.4 Relaciones de las variables culturales ....................................................... 101

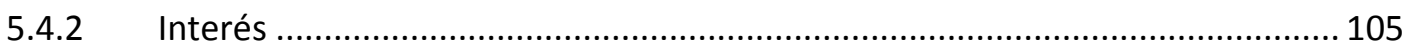

5.4.2.1 Relaciones de las variables de contenido visible ........................................ 105

5.4.2.2 Relaciones de las variables de contenido no visible ...................................... 105

5.4.2.3 Relaciones de las variables temporales ....................................................... 106

5.4.2.4 Relaciones de las variables contextuales .................................................. 106

5.4.2.5 Relaciones de las variables culturales ........................................................ 107

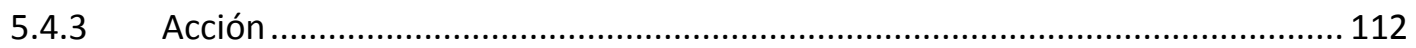

5.4.3.1 Relaciones de las variables de contenido visible ........................................ 112

5.4.3.2 Relaciones de las variables de contenido no visible ................................... 113

5.4.3.3 Relaciones de las variables contextuales ...................................................... 113

5.4.3.4 Relaciones de las variables culturales ........................................................ 114

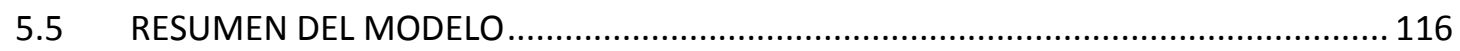

6 DISEÑO DEL TRABAJO EMPÍRICO ................................................................... 120

6.1 CARACTERÍSTICAS DE LA INVESTIGACIÓN ........................................................... 120

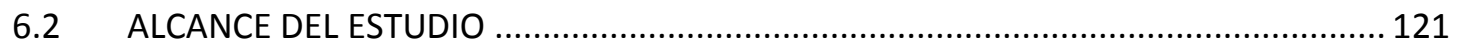

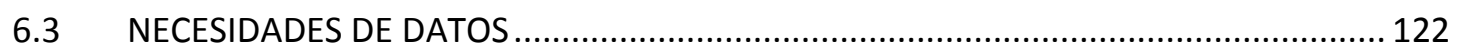

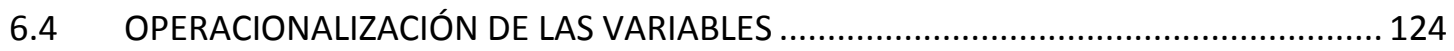

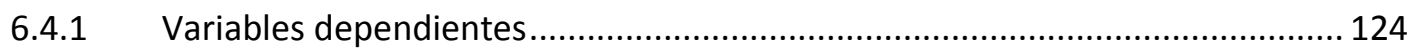

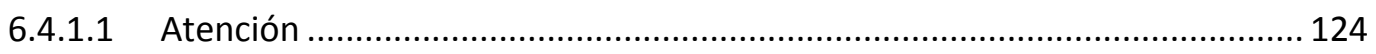

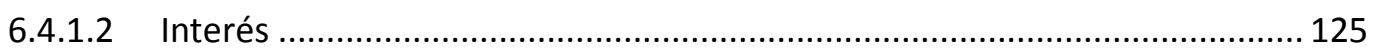

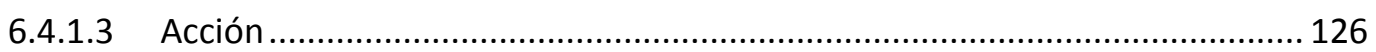

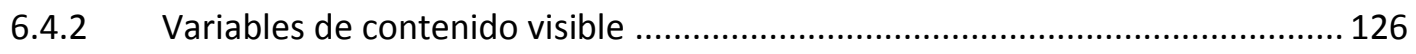

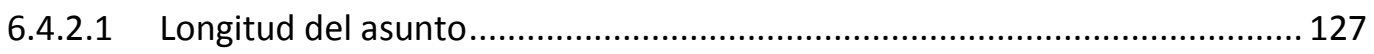

6.4.2.2 Presencia de números en el asunto ........................................................ 127

6.4.2.3 Presencia de caracteres especiales en el asunto ......................................... 127

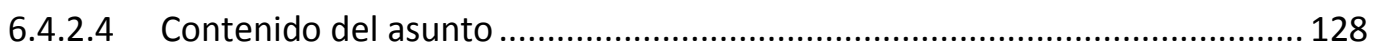

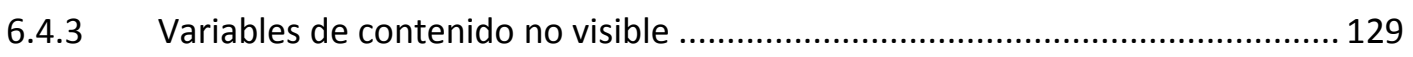

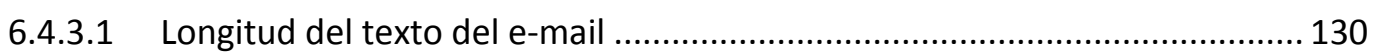

6.4.3.2 Número de enlaces del e-mail................................................................... 131

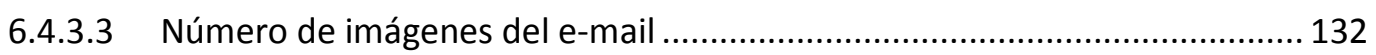

6.4.3.4 Presencia de incentivos económicos en el e-mail........................................ 132

6.4.3.5 Presencia de elementos que crean sensación de escasez en el e-mail ........ 133

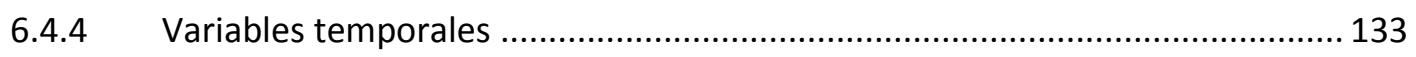

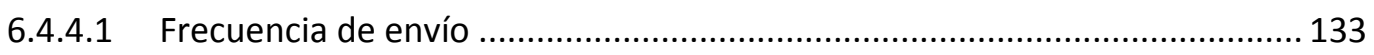

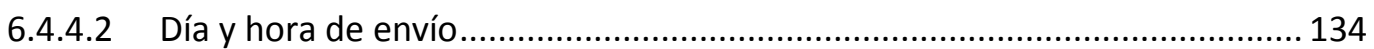

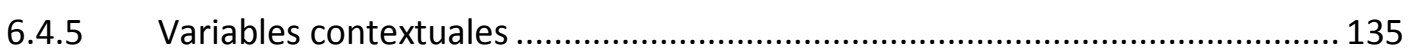




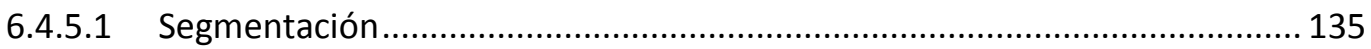

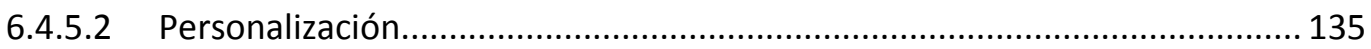

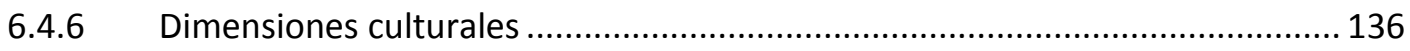

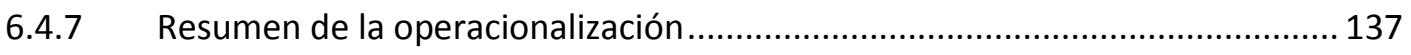

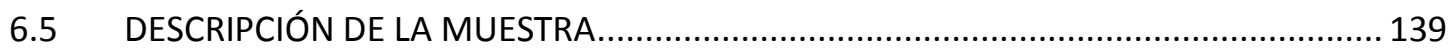

6.5.1 Muestra para el estudio de la etapa de atención (OR) e interés (UR) ............... 140

6.5.1.1 Variables dependientes - tasa de apertura y tasa de retención de

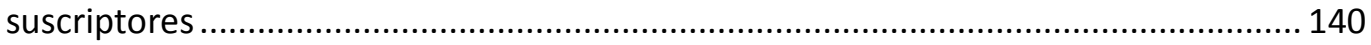

6.5.1.2 Factores de contenido no visible............................................................. 141

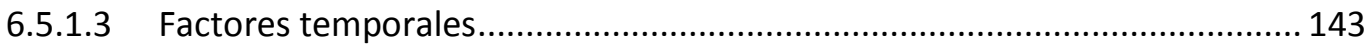

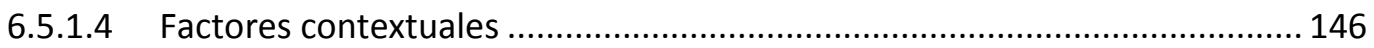

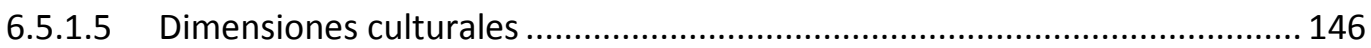

6.5.2 Muestra para el estudio de la etapa de interés (CTOR) y conversión (CR) ........ 147

6.5.2.1 Variables dependientes - tasa de clic y tasa de conversión ......................... 147

6.5.2.2 Factores de contenido visible................................................................... 148

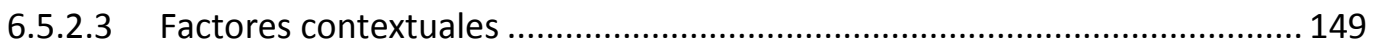

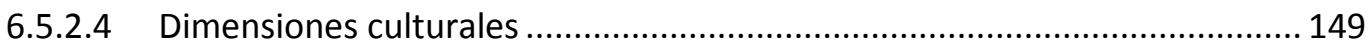

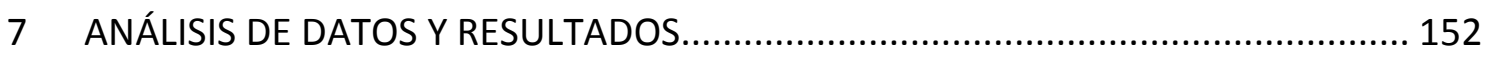

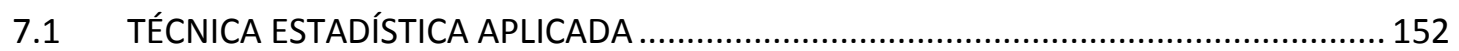

7.1.1 Justificación de la técnica seleccionada ............................................................ 152

7.1.2 Especificación de un modelo de regresión múltiple ........................................ 153

7.1.2.1 Requerimientos en el uso de regresión múltiple ....................................... 154

7.1.2.2 Metodologías de regresión múltiple ........................................................ 155

7.1.2.3 Operacionalización de variables moderadoras en regresión múltiple ......... 156

7.1.3 Análisis e interpretación de regresión múltiple .............................................. 157

7.1.3.1 Varianza explicada y relevancia predictiva ................................................. 158

7.1.3.2 Evaluación de los coeficientes.................................................................. 159

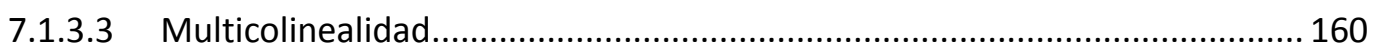

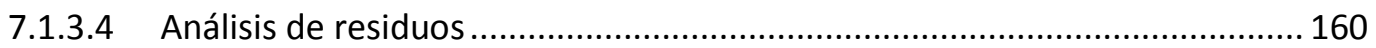

7.1.3.5 Valores extremos y casos influyentes ........................................................ 161

7.1.3.6 Análisis de pendientes simples para variables de interacción ....................... 162

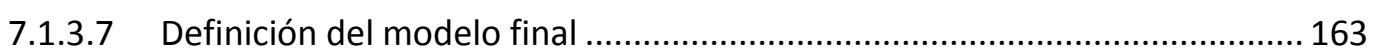

7.1.3.8 Resumen de la metodología de evaluación ................................................ 164

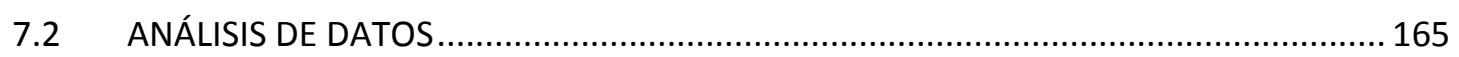

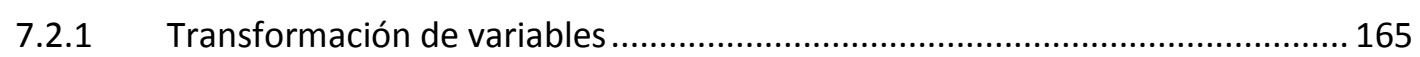

7.2.1.1 Transformación de variables dependientes ................................................ 165

7.2.1.2 Transformación de variables independientes................................................ 167

7.2.1.3 Resumen de transformación de variables.................................................. 167

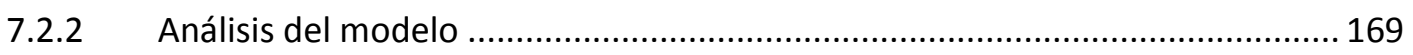

7.2.2.1 Varianza explicada y relevancia predictiva ................................................. 170

7.2.2.1.1 Estudio de la etapa de atención ............................................................. 170 


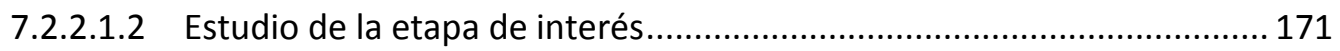

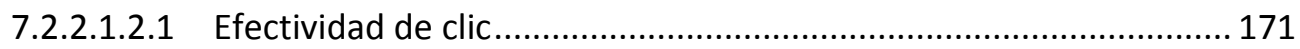

7.2.2.1.2.2 Efectividad de retención de suscriptores...................................... 172

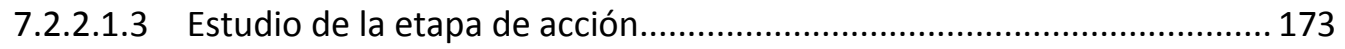

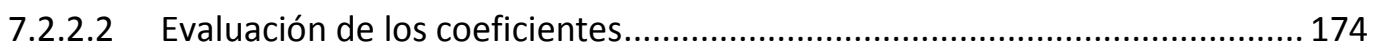

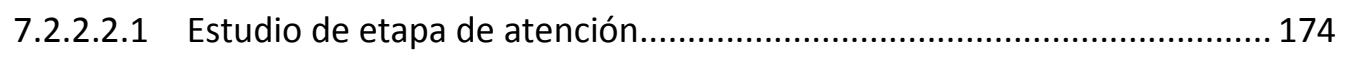

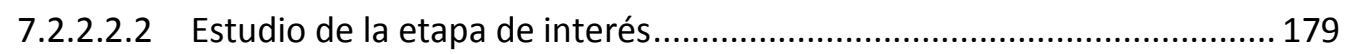

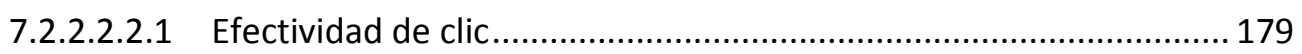

7.2.2.2.2.2 Efectividad de retención de suscriptores.......................................... 181

7.2.2.2.3 Estudio de la etapa de acción................................................................ 182

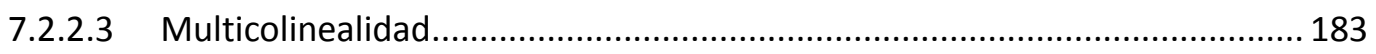

7.2.2.3.1 Estudio de etapa de atención.............................................................. 183

7.2.2.3.2 Estudio de la etapa de interés................................................................ 185

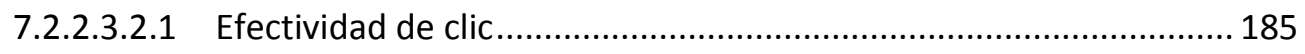

7.2.2.3.2.2 Efectividad de retención de suscriptores ......................................... 186

7.2.2.3.3 Estudio de la etapa de acción................................................................ 187

7.2.2.4 Análisis de residuos, valores extremos y casos influyentes .......................... 187

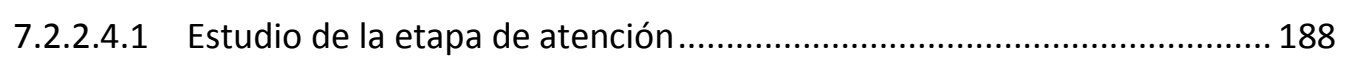

7.2.2.4.2 Estudio de la etapa de interés............................................................... 189

7.2.2.4.2.1 Submuestra efectividad de clic ...................................................... 189

7.2.2.4.2.2 Submuestra efectividad de retención de suscriptores .................... 190

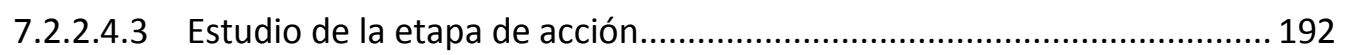

7.2.2.5 Análisis de pendientes simples para variables de interacción ....................... 193

7.2.2.5.1 Estudio de etapa de atención................................................................. 193

7.2.2.5.2 Estudio de la etapa de interés............................................................. 200

7.2.2.5.2.1 Submuestra efectividad de clic ..................................................... 200

7.2.2.5.2.2 Submuestra efectividad de retención de suscriptores ..................... 203

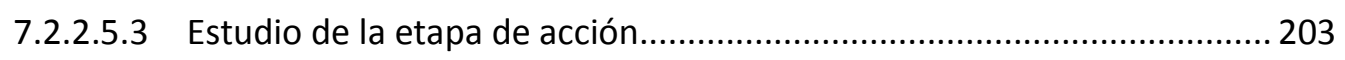

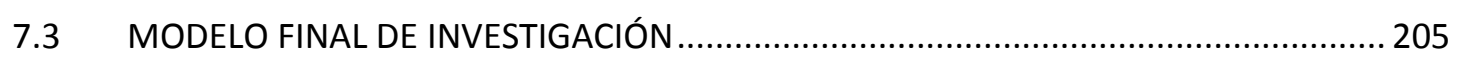

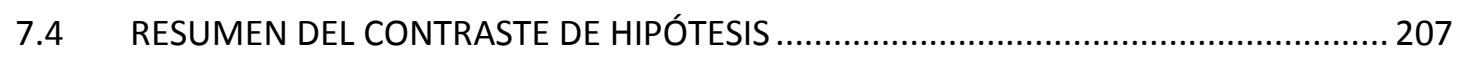

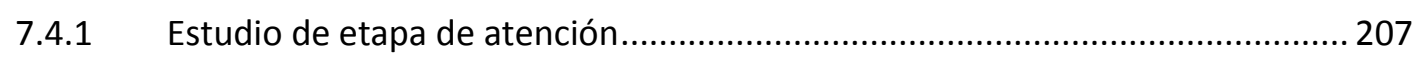

7.4.2 Estudio de la etapa de interés......................................................................... 208

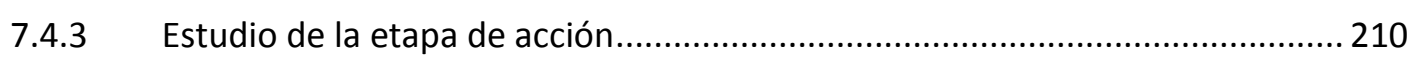

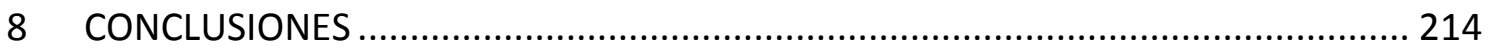

8.1 VALORACIÓN DEL CUMPLIMIENTO DE LOS OBJETIVOS DE INVESTIGACIÓN

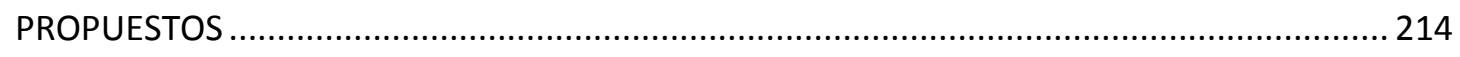

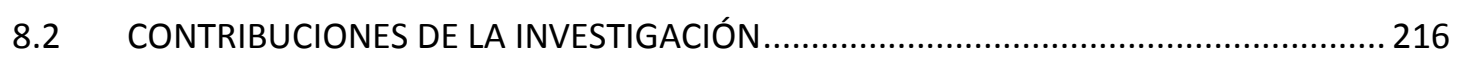

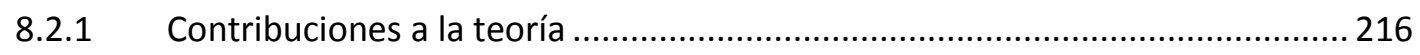

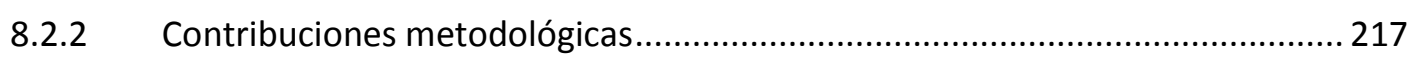

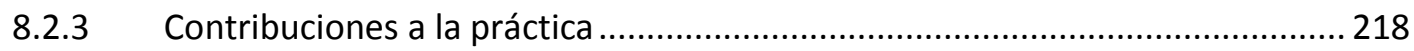

8.3 CONCLUSIONES Y DISCUSIÓN DE RESULTADOS ..................................................... 218 


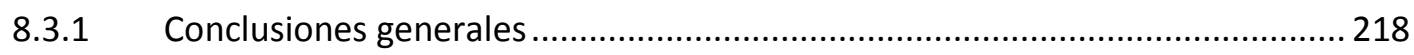

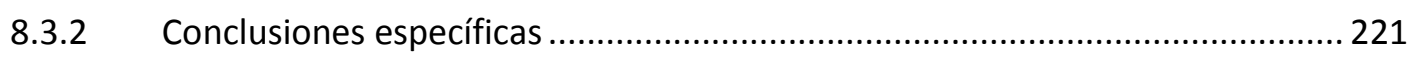

8.3.2.1 Variables de contenido visible ….............................................................. 222

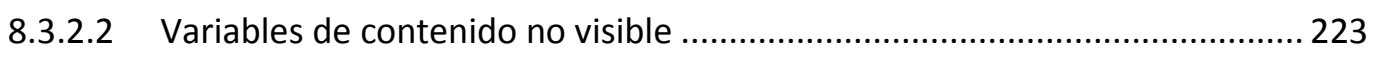

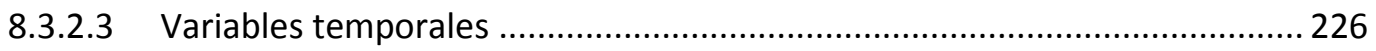

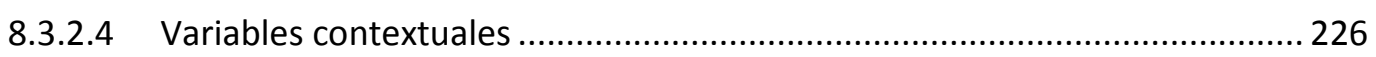

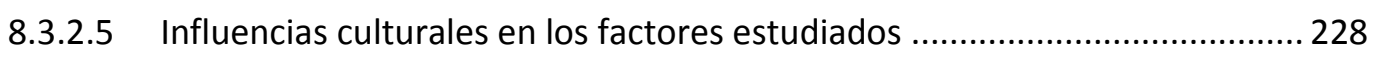

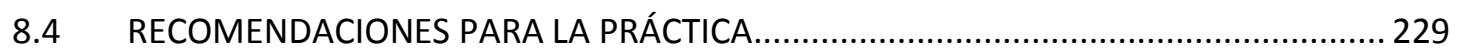

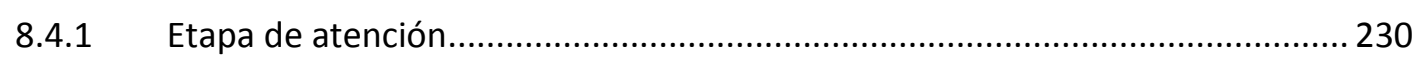

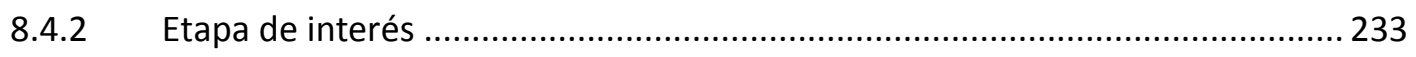

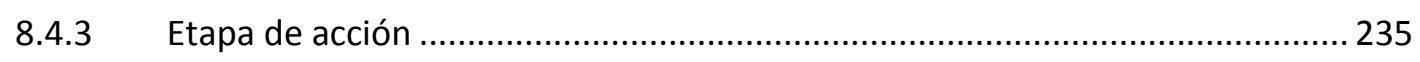

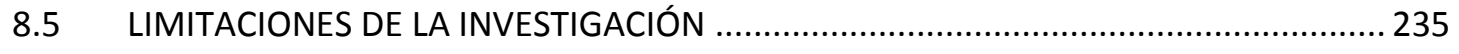

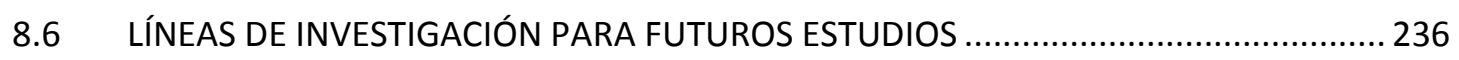

8.7 DIFUSIÓN DE RESULTADOS RELACIONADOS CON LA INVESTIGACIÓN ....................... 237

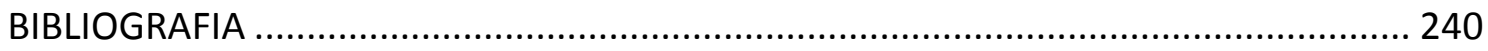

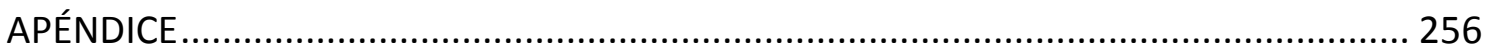

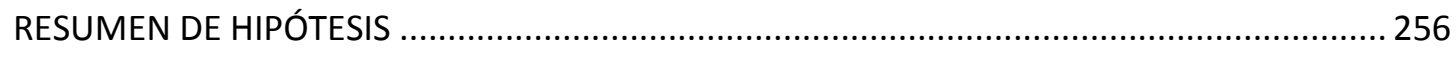

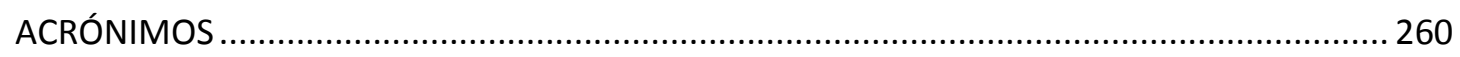


Figura 1 - Modelo de efectividad en el e-mail marketing (Rettie \& Chinttenden, 2003) ............ 4

Figura 2 - Programa de trabajo ................................................................................ 15

Figura 3 - Cronograma de trabajo ......................................................................... 18

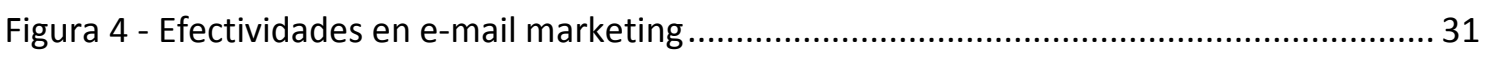

Figura 5 - Bandeja de entrada del cliente GMail............................................................ 33

Figura 6 - Relación entre etapas de AIDA y acciones realizadas en el entorno del e-mail marketing.

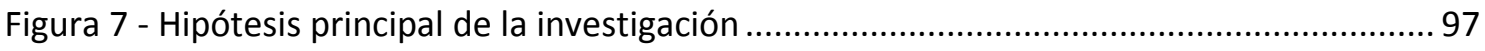

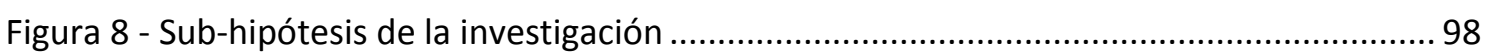

Figura 9 - Resumen de hipótesis de variables de influencia (independientes) en la atención. 101 Figura 10 - Resumen de hipótesis de variables de influencia (independientes) y moderadoras en la atención 104

Figura 11 - Resumen de hipótesis de variables de influencia (independientes) en el interés.. 107 Figura 12 - Resumen de hipótesis de variables de influencia (independientes) y moderadoras en el interés.

Figura 13 - Resumen de hipótesis de variables de influencia (independientes) en la acción... 114 Figura 14 - Resumen de hipótesis de variables de influencia (independientes) y moderadoras en la acción. 116

Figura 15 - Resumen del modelo teórico .............................................................. 117

Figura 16 - Histograma de la tasa de apertura........................................................... 141

Figura 17 - Histograma de la tasa de retención de suscriptores........................................ 141

Figura 18 - Distribución de los valores de contenido del asunto - Muestra atención (OR) ..... 143

Figura 19 - Distribución de los valores de día de la semana - Muestra atención (OR)............. 145

Figura 20 - Distribución de los valores de hora de envío - Muestra atención (OR) ................. 145

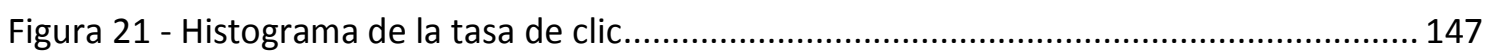

Figura 22 - Histograma de la tasa de conversión ...................................................... 148

Figura 23 - Falta de normalidad y heterocedasticidad de residuos en el análisis de la efectividad de retención de suscriptores (variable sin transformar) .............................................. 166

Figura 24 - Histograma y curva P-P de residuos estandarizados en la etapa de atención del modelo que incluye sólo las variables significativas 188

Figura 25 - Relación entre valores predichos estandarizados y residuos estandarizados en la etapa de atención del modelo que incluye sólo las variables significativas..... 188

Figura 26 - Histograma y curva P-P de residuos estandarizados en la etapa de interés submuestra efectividad de clic del modelo que incluye sólo las variables significativas 189 Figura 27 - Relación entre valores predichos estandarizados y residuos estandarizados en la etapa de interés - submuestra efectividad de clic del modelo que incluye sólo las variables significativas 190

Figura 28 - Histograma y curva P-P de residuos estandarizados en la etapa de interés submuestra efectividad de retención de suscriptores del modelo que incluye sólo las variables significativas 191 
Figura 29 - Relación entre valores predichos estandarizados y residuos estandarizados en la etapa de interés - submuestra efectividad de retención de suscriptores del modelo que incluye sólo las variables significativas. 191

Figura 30 - Histograma y curva P-P de residuos estandarizados en la etapa de acción del modelo que incluye sólo las variables significativas. 192

Figura 31 - Relación entre valores predichos estandarizados y residuos estandarizados en la etapa de acción del modelo que incluye sólo las variables significativas 193

Figura 32 - Representación gráfica de la interacción ALONC_MASCC en la etapa de atención del modelo que incluye sólo las variables significativas 195

Figura 33 - Representación gráfica de la interacción ATEM_DISTC en la etapa de atención del modelo que incluye sólo las variables significativas

Figura 34 - Representación gráfica de la interacción ADES_MASCC en la etapa de atención del modelo que incluye sólo las variables significativas .

Figura 35 - Representación gráfica de las interacciones SEGM_AVERC y SEGM_INDIC en la etapa de atención del modelo que incluye sólo las variables significativas.

Figura 36 - Representación gráfica de la interacción FRECC_INDIC en la etapa de atención del modelo que incluye sólo las variables significativas..... 200 Figura 37 - Representación gráfica de la interacción EESC_DISTC en la etapa de interés submuestra efectividad de clic del modelo que incluye sólo las variables significativas 202 Figura 38 - Representación gráfica de la interacción EIMAC_MASCC en la etapa de interés submuestra efectividad de clic del modelo que incluye sólo las variables significativas 203 Figura 39 - Representación gráfica de la interacción EESC_ORIEC en la etapa de acción del modelo que incluye sólo las variables significativas 205

Figura 40 - Modelo final de efectividad en el e-mail marketing 206 Figura 41 - Plantilla de correo electrónico con historia principal y secundarias. Fuente: simplyWorkz.... 231 
Tabla 1 - Localización geográfica de las muestras de estudios de e-mail marketing.................... 12

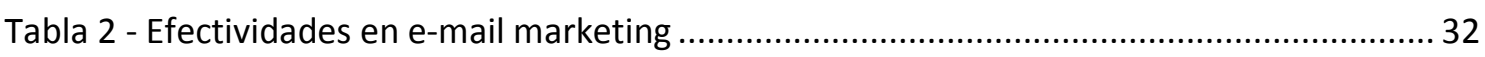

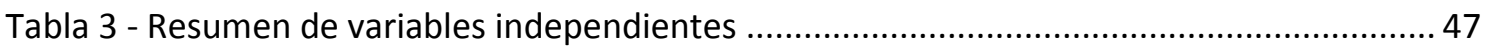

Tabla 4 - Relación entre investigaciones anteriores y variables independientes ........................ 48

Tabla 5 - Principales modelos de jerarquía de efectos. Adaptada de Belch \& Belch, 2003 y

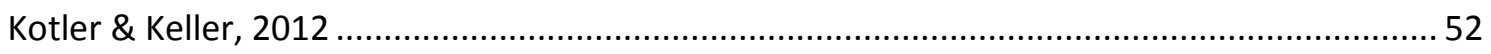

Tabla 6 - Resumen de principales modelos de jerarquía de efectos propuestos a lo largo del siglo XX. Adaptado de Wijaya (2015) y Barry \& Howard (1990) .................................................. 54

Tabla 7 - Resumen de dimensiones culturales de los principales modelos, adaptada de

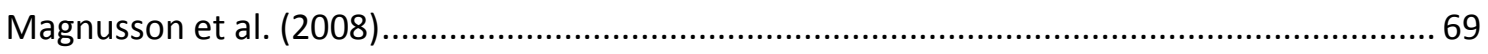

Tabla 8 - Factores de influencia potencialmente moderados por la dimensión distancia al poder

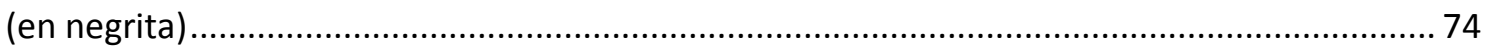

Tabla 9 - Factores de influencia potencialmente moderados por la dimensión individualismocolectivismo (en negrita).

Tabla 10 - Factores de influencia potencialmente moderados por la dimensión masculinidadfeminidad (en negrita) .80

Tabla 11 - Factores de influencia potencialmente moderados por la dimensión aversión a la incertidumbre (en negrita)

Tabla 12 - Factores de influencia potencialmente moderados por la dimensión orientación al largo plazo (en negrita)

Tabla 13 - Resumen de la relación entre elementos de influencia en el e-mail marketing y

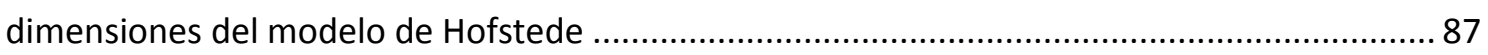

Tabla 14 - Resumen de variables independientes que serán incorporadas al modelo teórico .. 96

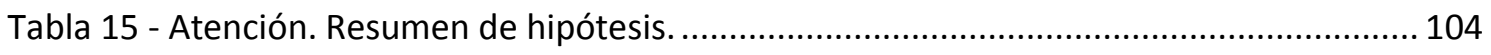

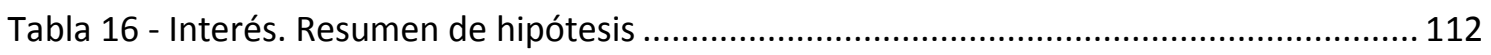

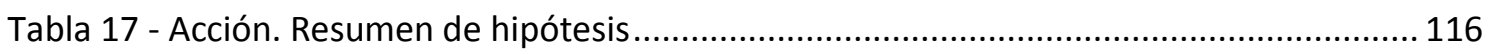

Tabla 18 - Atención. Operacionalización de variables dependientes. ....................................... 125

Tabla 19 - Interés. Operacionalización de variables dependientes. .......................................... 126

Tabla 20 - Acción. Operacionalización de variables dependientes. ............................................. 126

Tabla 21 - Longitud del asunto. Operacionalización de variables independientes.................... 127

Tabla 22 - Presencia de números en el asunto. Operacionalización de variables independientes.

Tabla 23 - Caracteres especiales en el asunto. Operacionalización de variables independientes.

Tabla 24 - Contenido del asunto. Descripción de categorías..................................................... 128

Tabla 25 - Contenido del asunto. Operacionalización de variables independientes.................. 129

Tabla 26 - Longitud del texto. Operacionalización de variables independientes ...................... 131

Tabla 27 - Número de enlaces. Operacionalización de variables independientes. .................... 132

Tabla 28 - Número de imágenes. Operacionalización de variables independientes................. 132

Tabla 29 - Incentivos económicos. Operacionalización de variables independientes............... 132 
Tabla 30 - Elementos que generan sensación de escasez. Operacionalización de variables

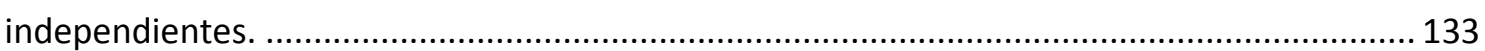

Tabla 31 - Frecuencia. Operacionalización de variables independientes. .................................. 134

Tabla 32 - Día y hora de envío. Operacionalización de variables independientes..................... 135

Tabla 33 - Segmentación. Operacionalización de variables independientes.............................. 135

Tabla 34 - Personalización. Operacionalización de variables independientes........................... 136

Tabla 35 - Dimensiones culturales. Operacionalización de variables moderadoras.................. 137

Tabla 36 - Resumen de operacionalización de variables independientes. .................................. 138

Tabla 37 - Resumen de operacionalización de variables dependientes y moderadoras........... 139

Tabla 38 - Descripción de las variables de contenido no visible - Muestra atención (OR) …... 142

Tabla 39 - Descripción de las variables temporales - Muestra atención (OR) e interés (UR) .. 144

Tabla 40 - Descripción de las variables contextuales - Muestra atención (OR) e interés (UR) 146

Tabla 41 - Descripción de las variables culturales - Muestra atención (OR) e interés (UR) ..... 146

Tabla 42 - Descripción de las variables de contenido visible - Muestra interés (CTOR) y acción (CR)

Tabla 43 - Descripción de las variables contextuales - Muestra interés (CTOR) y acción (CR) 149

Tabla 44 - Descripción de las variables culturales - Muestra interés (CTOR) y acción (CR) ..... 149

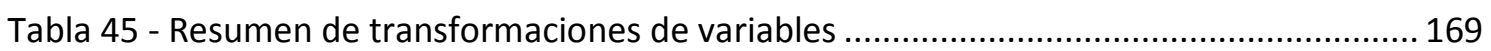

Tabla 46 - Varianza explicada en la etapa de atención del modelo que incluye todas las variables

Tabla 47 - Varianza explicada en la etapa de atención del modelo que incluye sólo las variables significativas

Tabla 48 - Varianza explicada en la etapa de interés - submuestra efectividad de clic del modelo que incluye todas las variables

Tabla 49 - Varianza explicada en la etapa de interés - submuestra efectividad de clic del modelo que incluye sólo las variables significativas

Tabla 50 - Varianza explicada en la etapa de interés - submuestra efectividad de retención de suscriptores de los modelos inicial y final

Tabla 51 - Varianza explicada en la etapa de acción del modelo que incluye todas las variables 173

Tabla 52 - Varianza explicada en la etapa de acción del modelo que incluye sólo las variables significativas

Tabla 53 - Tabla de coeficientes de correlación entre descuentos_individualismo-colectivismo, descuentos_distancia al poder, efectividad de apertura, distancia al poder e individualismocolectivismo.

Tabla 54 - Coeficientes en la etapa de atención del modelo que incluye todas las variables .. 177 Tabla 55 - Coeficientes en la etapa de atención del modelo que incluye sólo las variables significativas

Tabla 56 - Correlación entre número de enlaces, aversión a la incertidumbre y efectividad de clic 
Tabla 57 - Coeficientes en la etapa de interés - submuestra efectividad de clic del modelo que incluye todas las variables.

Tabla 58 - Coeficientes en la etapa de interés - submuestra efectividad de clic del modelo que incluye sólo las variables significativas

Tabla 59 - Coeficientes en la etapa de interés - submuestra efectividad de retención de

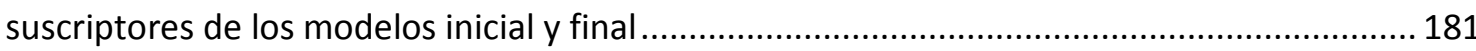

Tabla 60 - Coeficientes en la etapa de acción del modelo que incluye todas las variables....... 183

Tabla 61 - Coeficientes en la etapa de acción del modelo que incluye sólo las variables significativas

Tabla 62 - VIF de las variables en la etapa de atención del modelo que incluye sólo las variables significativas

Tabla 63 - Correlación entre variables independientes en la etapa de atención del modelo que incluye sólo las variables significativas - Parte 1

Tabla 64 - Correlación entre variables independientes en la etapa de atención del modelo que incluye sólo las variables significativas - Parte 2

Tabla 65 - VIF de las variables en la etapa de interés - submuestra efectividad de clic del modelo que incluye sólo las variables significativas

Tabla 66 - Correlación entre variables independientes en la etapa de interés - submuestra efectividad de clic del modelo que incluye sólo las variables significativas 186 Tabla 67 - VIF de las variables en la etapa de interés - submuestra efectividad de retención de suscriptores del modelo que incluye sólo las variables significativas. 186

Tabla 68 - Correlación entre variables independientes en la etapa de interés - submuestra efectividad de retención de suscriptores del modelo que incluye sólo las variables significativas

Tabla 69 - VIF de las variables en la etapa de acción del modelo que incluye sólo las variables significativas

Tabla 70 - Correlación entre variables independientes en la etapa de acción del modelo que incluye sólo las variables significativas

Tabla 71 - Relación de pendientes simples para la interacción ALONC_MASCC en la etapa de atención del modelo que incluye sólo las variables significativas - Procedimiento de JohnsonNeyman 194 Tabla 72 - Relación de pendientes simples para la interacción ATEM_DISTC en la etapa de atención del modelo que incluye sólo las variables significativas - Procedimiento de JohnsonNeyman 196

Tabla 73 - Relación de pendientes simples para la interacción ADES_MASCC en la etapa de atención del modelo que incluye sólo las variables significativas - Procedimiento de JohnsonNeyman 197

Tabla 74 - Relación de pendientes simples para las interacciones combinadas SEGM_AVERC y SEGM_INDIC en la etapa de atención del modelo que incluye sólo las variables significativas Procedimiento de pendientes simples para cuartiles 199 
Tabla 75 - Relación de pendientes simples para la interacción FRECC_INDIC en la etapa de atención del modelo que incluye sólo las variables significativas - Procedimiento de JohnsonNeyman 200

Tabla 76 - Relación de pendientes simples para la interacción EESC_DISTC en la etapa de interés - submuestra efectividad de clic del modelo que incluye sólo las variables significativas - Procedimiento de Johnson-Neyman 201

Tabla 77 - Relación de pendientes simples para la interacción EIMAC_MASCC en la etapa de interés - submuestra efectividad de clic del modelo que incluye sólo las variables significativas - Procedimiento de Johnson-Neyman 203

Tabla 78 - Relación de pendientes simples para la interacción EESC_ORIEC en la etapa de acción del modelo que incluye sólo las variables significativas - Procedimiento de JohnsonNeyman 204

Tabla 79 - Resumen del contraste de hipótesis para la etapa de atención 208

Tabla 80 - Resumen del contraste de hipótesis para la etapa de interés 210

Tabla 81 - Resumen del contraste de hipótesis para la etapa de acción 211 


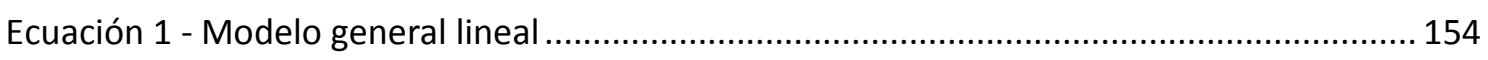

Ecuación 2 - Varianza explicada en regresión múltiple ordinaria ............................................ 158

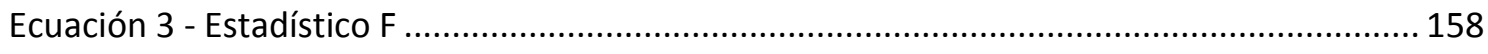

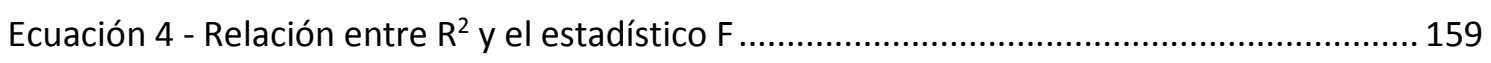

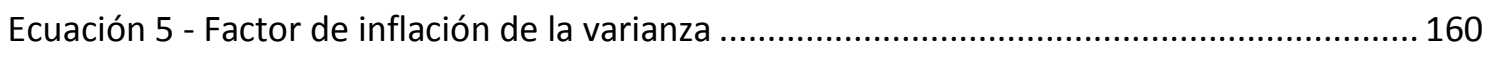

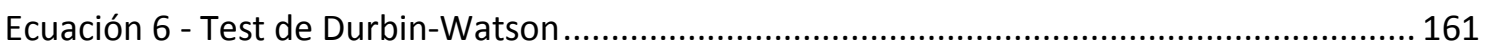

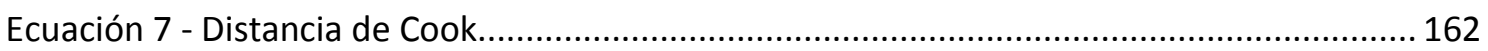




\section{Capítulo 1 - Introducción}

1.1 IMPORTANCIA DEL E-MAIL MARKETING

1.2 ANTECEDENTES

1.2.1 Introducción al e-mail marketing

1.2.2 La efectividad en el e-mail marketing

1.2.3 Introducción a la teoría de la jerarquía de efectos

1.2.4 Introducción a las influencias culturales en el comportamiento del consumidor

1.3 FORMULACIÓN DE LA INVESTIGACIÓN

1.3.1 Definición del problema de investigación

1.3.2 Contribuciones esperadas

1.3.3 Objetivos de la investigación

1.3.4 Tesis general

1.4 PROGRAMA, METODOLOGÍA, MEDIOS Y CRONOGRAMA DE TRABAJO

1.4.1 Programa de trabajo

1.4.2 Metodología a utilizar

1.4.3 Cronograma de trabajo 


\section{INTRODUCCIÓN}

\subsection{IMPORTANCIA DEL E-MAIL MARKETING}

La expansión de Internet durante los últimos 15 años ha ido acompañada de la adopción del correo electrónico (e-mail) como medio de comunicación. Progresivamente, los emails han sustituido al correo tradicional, tanto en el entorno personal como en el comercial. Se estima que en 2019 más de la mitad de la población mundial usa correo electrónico (Radicati, 2019).

Además del evidente ahorro en costes e incremento de eficiencia asociados al e-mail, la popularización del correo electrónico ha creado un nuevo medio de comunicación entre empresas y consumidores que contribuye al empoderamiento de estos últimos (Hartemo, 2016). En Estados Unidos, donde un 91\% de los usuarios lo consulta al menos una vez al día, el e-mail es el canal preferido para comunicaciones comerciales, alertas financieras, confirmaciones de compra y alertas de viaje (ExactTarget, 2012). Así, un $45 \%$ de las 200 franquicias comerciales más grandes de Estados Unidos utiliza el e-mail como canal de distribución de contenido promocional (Abrahams \& Deane, 2010).

En 2013, las empresas estadounidenses invirtieron en marketing digital el equivalente al $3.1 \%$ de sus ventas (Gartner, 2015). En este ámbito, la mayoría de la inversión publicitaria suele tener asociada un coste variable. Este es el caso de los banners (coste por impresión), motores de búsqueda (coste por clic) o marketing de afiliados (coste por conversión) (Florès, 2014). Sin embargo, el e-mail marketing opera con una estructura de costes fija o semifija, fundamentalmente asociada al mantenimiento del sistema de envío. Esto hace que los incrementos de suscriptores o de frecuencia de envío necesarios para conseguir crecimientos significativos de ventas no se conviertan en un incremento proporcional de los costes, lo que lo convierte en el canal más barato de los disponibles para la comunicación promocional (Baggott, 2011). Por tanto, el e-mail marketing se considera un canal clave en el entorno digital, ya que es enormemente efectivo desde un punto de vista de retorno de la inversión (Bawm \& Nath, 2014; Gopal, Tripathi, \& Walter, 2006). De hecho, las empresas estadounidenses lo consideran el canal de mayor ROI (eMarketer, 2018) e invirtieron en 2013 un 8.8\% de su presupuesto de marketing digital en e-mail marketing (Gartner, 2015).

Otro de los atributos que hacen del e-mail marketing una herramienta popular a la hora de lograr una comunicación efectiva es la posibilidad de alcanzar a múltiples consumidores a partir de un solo contacto, generando reenvíos voluntarios de los mensajes por parte de los propios usuarios (Fariborzi \& Zahedifard, 2012). 
De acuerdo a la legislación vigente en la mayoría de estados, el correo electrónico es un dato personal sujeto a las leyes de protección de datos. Por ende, las empresas están obligadas a obtener un consentimiento previo por parte del usuario para poder entablar comunicación comercial. Este hecho motiva que las compañías realicen importantes inversiones en campañas de captación de e-mails, ofreciendo descuentos u otro tipo de incentivos. Los consumidores se subscriben a listas de correo comerciales para mantenerse al corriente de eventos, concursos, nuevos productos y programas de fidelización (Carmen \& Nicolae, 2010).

En resumen, el e-mail marketing es actualmente un elemento clave en las campañas de comunicación corporativas y seguirá ocupando una posición importante durante los próximos años debido a su eficiencia y al progresivo incremento del número de usuarios de correo electrónico. Por tanto, resulta crucial entender los factores que afectan a su efectividad, de forma que las empresas puedan continuar optimizando la utilización de este canal. El presente trabajo de investigación doctoral se engloba en éste ámbito y, más concretamente, pretende: 1) proponer y validar un marco teórico que permita el estudio de la efectividad del e-mail marketing; 2) verificar la importancia absoluta de los factores identificados hasta la fecha utilizando una muestra diversa geográfica y culturalmente, así como evaluar su importancia relativa en función de variables culturales; y 3) estudiar y descubrir nuevos factores que contribuyan a la mejora de la efectividad de las campañas de e-mail marketing.

\subsection{ANTECEDENTES}

En los últimos años, la adopción por parte de las empresas de técnicas de e-mail marketing ha sido casi generalizada. De igual manera, la comunidad científica ha comenzado a estudiar este nuevo canal y su impacto en las actitudes y comportamientos de los consumidores. Las investigaciones iniciales sobre esta temática se apoyan en literatura sobre marketing directo y marketing de bases de datos. En particular, ciertos estudios sobre segmentación de bases de datos utilizan aproximaciones transferibles al dominio del e-mail marketing, como la minería de datos (data mining) sobre datos históricos de compra (Reutterer, Mild, Natter, \& Taudes, 2006). Resulta particularmente destacable el análisis de Rettie y Chittenden (2003) (Figura 1), que adapta el modelo desarrollado para comunicaciones a través de correo tradicional por Vriens, Scheer, Hoekstra y Bult (1998) al área del correo electrónico. Pese a ello, sólo contempla como posible respuesta por parte del consumidor el clic (obviando la conversión); además, el trabajo empírico, cuyas variables dependientes se limitan a la tasa de clic (Click-thru rate o CTR) y porcentaje de cancelación de subscripciones, no logra soportar las hipótesis relacionadas con la fase de apertura del correo. 


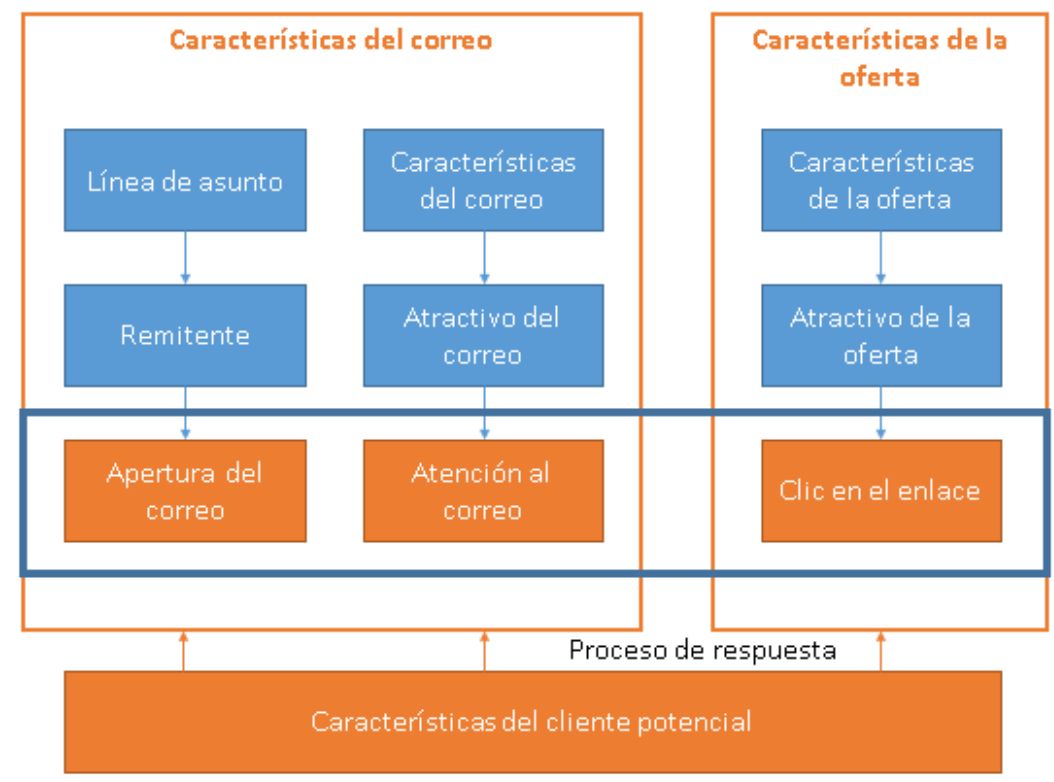

Figura 1 - Modelo de efectividad en el e-mail marketing (Rettie \& Chinttenden, 2003)

Otras aproximaciones han estudiado la influencia de este canal en variables más tradicionales del entorno publicitario. Así, diferentes estudios han demostrado los efectos positivos del e-mail marketing en la lealtad de los consumidores hacia la marca (Dufrene, Engelland, Lehman, \& Pearson, 2005; Merisavo \& Raulas, 2004), la retención de clientes (Jolley, Lee, Mizerski, \& Sadeque, 2013; Ting, 2012) o la confianza y la intención de compra (Dufrene et al., 2005).

\subsubsection{Introducción al e-mail marketing}

La llegada de los medios de comunicación digitales y el progresivo crecimiento de la penetración de internet en los hogares ha incrementado el número de posibilidades al alcance de las empresas para hacer llegar sus mensajes a los consumidores. Este hecho, junto con la paralela atomización de la audiencia de televisión -el medio por excelencia en la comunicación publicitaria- y los nuevos hábitos de consumo de medios por parte de las generaciones más jóvenes, han motivado que los departamentos de marketing hayan tenido que incrementar de manera significativa la complejidad de sus planes de medios para poder mantener el alcance y frecuencia de impacto de sus campañas.

En este entorno de experimentación cuasi forzosa, una de las herramientas que se ha consolidado en el marketing mix ha sido el e-mail marketing. Inicialmente al amparo de los departamentos de marketing directo como una extensión del equipo de base de datos para envíos de correo tradicional, los responsables de e-mail marketing han ido ganando peso específico hasta convertirse una pieza clave de la estrategia de marketing directo (Marinova, Murphy, \& Massey, 2002). Progresivos desafíos de índole fundamentalmente técnica, como la coordinación con el equipo responsable de la web, 
la captura de nuevos suscriptores a través de formularios online o el enriquecimiento visual de las comunicaciones a través de plantillas HTML (hypertext markup language; lenguaje de marcas de hipertexto), les han acercado a los departamentos de tecnología de la información y comercio electrónico. Así, actualmente el ejercicio del e-mail marketing requiere el dominio tanto de campos tradicionales del marketing -como el comportamiento del consumidor o la comunicación- como de áreas puramente técnicas, como la programación web o la gestión de bases de datos.

El paulatino aumento de complejidad y medios técnicos en el campo del e-mail marketing ha tenido como resultado un incremento exponencial de su utilidad. Inicialmente considerado un canal unidireccional, cuyos resultados sólo eran visibles a través de medidas indirectas como la notoriedad o los atributos de la marca, las inversiones en infraestructura tecnológica y la progresiva involucración de los departamentos de IT y comercio electrónico han dotado al e-mail marketing de una relativa bidireccionalidad, transformándolo profundamente (Mullen \& Daniels, 2009). La posibilidad de capturar cierto número de acciones de los consumidores y acceder de manera granular a los resultados de cada iniciativa ha creado la posibilidad de definir objetivos específicos para el canal -además de los objetivos genéricos de la campaña de la que cada envío forma parte- y de evaluar la efectividad de las diversas tácticas a la hora de conseguir dichos objetivos.

\subsubsection{La efectividad en el e-mail marketing}

Entendiendo el marketing como el desarrollo de una relación con el cliente que eventualmente favorezca la venta del producto o servicio (Baggott, 2011), los anunciantes evalúan cada medio de comunicación empleado para determinar tanto su efectividad en la comunicación del mensaje deseado como en el fomento de las actitudes y comportamientos que la marca desea incentivar en el consumidor. En medios de comunicación unidireccionales es habitual utilizar muestras de la población objetivo para este fin, si bien es muy difícil determinar la influencia concreta de cada medio (Lodish et al., 1995). Los medios bidireccionales permiten determinar una serie de objetivos intermedios directamente medibles con relativa precisión, y que posibilitan determinar la calidad de interacción del consumidor con la comunicación.

En el caso del e-mail marketing, los objetivos intermedios más estudiados han sido la apertura del correo (p.ej. Andersson et al., 2014; Balakrishnan \& Parekh, 2015; Bonfrer \& Drèze, 2009; San-José-Cabezudo \& Camarero-Izquierdo, 2012), la utilización de algún enlace del mismo para acceder a la web corporativa (p.ej. Bonfrer \& Drèze, 2009; Rettie \& Chittenden, 2003; White, Zahay, Thorbjornsen, \& Shavitt, 2008) y la realización del objetivo final perseguido por el anunciante en la comunicación -como una compra online- (p.ej. Reichhart, Pescher, \& Spann, 2013; Sigurdsson et al., 2013; $\mathrm{Wu}, \mathrm{Li}, \& \mathrm{Liu}, 2016)$. Así, la industria ha seleccionado variables clave que permiten 
evaluarlos, como la tasa de apertura - porcentaje de correos abiertos del total de correos enviados-, la tasa de clic o $C T R$-porcentaje de correos en los que el receptor ha seguido un enlace sobre el total de correos enviados- o la tasa de conversión porcentaje de suscriptores que realizaron la acción perseguida tras recibir el correo.

\subsubsection{Factores de influencia en el e-mail marketing}

Con el objetivo de determinar los factores que pueden tener influencia en cada una de estas variables se han realizado investigaciones tanto a nivel académico como corporativo. Algunas de las variables con mayor impacto, de acuerdo a los ejecutivos de marketing, son: la línea de asunto, la frecuencia de envío, la longitud del e-mail, la presencia de ilustraciones, el titular, el texto, la presencia del logo de la compañía, enlaces, elementos interactivos -como botones para cancelar la subscripción-, animaciones y elementos personalizados -por ejemplo, la inclusión del nombre del receptor- (Ellis-Chadwick \& Doherty, 2012), elementos específicos del contenido como el tipo de incentivo ofrecido al cliente, o la segmentación de la base de datos utilizada para incrementar la relevancia de la comunicación (Chittenden \& Rettie, 2003). Dada la elevada cantidad de potenciales factores de influencia, resulta necesario agruparlos en categorías que permitan sistematizar su análisis.

En primer lugar, se considera el momento en el que el consumidor se enfrenta a su bandeja de entrada de correo. En este escenario podemos encontrar algunas de las variables mencionadas anteriormente; en concreto, los elementos directamente visibles del correo, esto es, la información que en ese momento es accesible sin realizar ninguna acción adicional. Estos elementos son relevantes puesto que son los únicos disponibles para efectuar un primer juicio sobre la pertinencia de interactuar con el correo (Micheaux, 2011). En la mayoría de clientes de e-mail, estos elementos se limitan al remitente y la línea de asunto.

Una vez el consumidor ha decidido abrir el correo, se le revela el contenido del e-mail en sí; esto es, el cuerpo del correo que contiene el texto, las imágenes, los enlaces, etc. Estos componentes no apreciables hasta que el correo ha sido abierto se consideran elementos no directamente visibles en el contexto de esta investigación, y han sido tradicionalmente el conjunto más estudiado en los análisis de efectividad (p.ej. Carmen \& Nicolae, 2010; Chang, Rizal, \& Amin, 2013; Mogoș \& Acatrinei, 2015; San-JoséCabezudo \& Camarero-Izquierdo, 2012).

El momento en el que un correo ha sido enviado puede influir en su efectividad (Barnes, 2002; Ellis-Chadwick \& Doherty, 2012), puesto que influye la disposición anímica o la cantidad de tiempo disponible del usuario cuando evalúa su relevancia. Así, éste puede decidir ignorarlo si lo consulta a primera hora de un día laborable junto con muchos otros correos enviados durante la noche, o prestarle atención si lo consulta durante la 
tarde del fin de semana. Además de variables temporales básicas como el día y la hora de envío, el número de e-mails enviados por el mismo remitente en los días anteriores también pueden inclinar la actitud del usuario en una u otra dirección, y contribuir a que éste decida ignorar las comunicaciones de una determinada compañía cuando considere que son demasiado persistentes (Haq, 2009). Estos elementos compondrán el conjunto de variables temporales de esta tesis doctoral.

Finalmente, consideraciones contextuales como la personalización de la comunicación o la creación de determinados segmentos - a los que se envían comunicaciones diferentes adaptadas a sus características particulares- tienden a incrementar la relevancia del contenido $y$, por tanto, a aumentar las probabilidades de que el consumidor interactúe con los e-mails (Bawm \& Nath, 2014). Un ejemplo de esto sería la creación de segmentos en la base de datos de un banco en función de la edad de los suscriptores: se logra una comunicación más relevante si las hipotecas protagonizan las comunicaciones para el segmento más joven, y los productos de ahorro y planes de pensiones los envíos al segmento más senior.

Por tanto, la presente investigación utilizará estas cuatro categorías a la hora de clasificar los diferentes factores de influencia en la efectividad del e-mail marketing: elementos directamente visibles, no directamente visibles, temporales y contextuales.

\subsubsection{Introducción a la teoría de la jerarquía de efectos}

Desde la creación del marketing y el comienzo de la inversión en publicidad como método para dar a conocer los beneficios de un determinado producto, una de las principales prioridades de los anunciantes ha sido encontrar maneras de evaluar los resultados de las campañas de medios. Múltiples aproximaciones han tratado de dar respuesta a este problema, si bien no existe un consenso en la comunidad científica respecto a manera más adecuada de medir la efectividad publicitaria (Moriarty, 1983).

El objetivo final de las campañas de publicidad es generar ventas para la compañía (Kotler \& Keller, 2012). Las acciones de marketing no alcanzan este fin de manera inmediata, sino que logran objetivos intermedios como incrementar la notoriedad de una marca entre consumidores que la desconocen, o la difusión de sus beneficios específicos entre los que ya la conocen, objetivos que eventualmente acercan al consumidor al momento de la compra y, por tanto, generan un incremento de ventas (Lavidge \& Steiner, 1961).

Utilizando como base el mismo principio, las teorías de jerarquía de efectos postulan que las diferentes interacciones entre el consumidor y la marca hacen atravesar a éste a través de una serie de estadios cada vez más cercanos al objetivo final del anunciante, generalmente la venta del producto (Rehman, Javed, Nawaz, Ahmed, \& Hyder, 2014). Es por ello que los modelos de jerarquía de efectos han sido utilizados recurrentemente 
por la industria y la comunidad investigadora para abordar el análisis de la efectividad de la publicidad (Bauman et al., 2008; Jagpal, 1981; Smith, Chen, \& Yang, 2008).

\subsubsection{El modelo AIDA}

El modelo AIDA (Atención, Interés, Deseo, Acción), tal vez el más popular de los modelos que emplean la teoría de jerarquía de efectos, se remonta a finales de siglo XIX, momento en el que Elias St. Elmo Lewis desarrolla una guía para vendedores en la que identifica atención, interés y deseo como las sucesivas etapas que atraviesa un potencial comprador conforme se acerca a la adquisición de un producto (Strong, 1925). Posteriormente, el mismo Lewis añade una fase final -acción- que pretende reflejar el momento de la compra (Strong, 1925).

A lo largo de las siguientes décadas, múltiples autores añaden y eliminan etapas en un intento de explicar de manera más precisa el comportamiento del consumidor o incorporar los sucesivos adelantos tecnológicos, generando variaciones como AICA, AIDAS, AICCA o IADCA (Barry \& Howard, 1990; Wijaya, 2015). Pese a su aparente simplicidad, AIDA ha sobrevivido a las sucesivas transformaciones que los medios de comunicación han experimentado durante los siglos XX y XXI, y resulta una herramienta adecuada para abordar el estudio de la efectividad en el marketing digital (Ashcroft \& Hoey, 2001).

\subsection{AIDA en el e-mail marketing}

Existe un notable paralelismo entre las fases que atraviesa un consumidor en sus interacciones con el e-mail marketing -identificables a través de las acciones de apertura del correo, utilización de los enlaces incluidos en el texto y realización de la acción perseguida, y medibles a través de las tasas de apertura, clic y conversión- y las diferentes etapas del modelo AIDA. De hecho, los modelos propuestos hasta la fecha para el estudio del e-mail marketing (Bawm \& Nath, 2014; Rettie \& Chittenden, 2003) tienen un carácter procesal similar a AIDA, debido a la naturaleza fundamentalmente lineal inherente a las interacciones con este canal.

AIDA puede aplicarse al estudio del marketing digital sin modificaciones (Ashcroft \& Hoey, 2001) y de hecho grandes compañías de la industria digital como Google lo integran en la estructuración de sus productos (Florès, 2014). Por tanto, resulta pertinente utilizar el modelo AIDA como un soporte sobre el que articular el estudio de la efectividad del e-mail marketing.

\subsubsection{Introducción a las influencias culturales en el comportamiento del consumidor}

La progresiva globalización y el crecimiento exponencial del número de mercados a las que las empresas pueden acceder gracias al comercio electrónico han incrementado las 
oportunidades de negocio, pero también la complejidad a la hora de comprender los hábitos y preferencias de los consumidores. Así, la expansión geográfica que la venta online posibilita ha tenido como consecuencia un aumento de la variedad de perfiles de comprador. Si bien medidas socioeconómicas tradicionales como el PIB y renta per cápita han permitido realizar segmentaciones por países, la paulatina convergencia de la riqueza en mercados desarrollados no permite utilizarlas a la hora de explicar diferencias de comportamiento. En este punto, las diferencias culturales son la única variable disponible (De Mooij, 2003).

La cultura, entendida como la programación mental que diferencia a individuos de diferentes grupos o categorías (Hofstede, Hofstede, \& Minkov, 2010), se refleja en las comunicaciones de marketing (Baack \& Singh, 2007). La integración de las diferentes culturas nacionales en la comunicación promocional trasciende la mera traducción y adaptación del contenido al estándar social, y puede llegar a afectar a la forma de definir el carácter de la marca, o a la elección de los beneficios del producto que resulta más adecuado comunicar. Por ejemplo, en las culturas con un enfoque más individualista la comunicación promocional va encaminada a persuadir, mientras que en las tienen una componente más colectivista el objetivo es crear una relación de confianza (De Mooij \& Hofstede, 2010). Esta influencia también se extiende al ámbito digital, en el que pese a la globalización del comercio electrónico, los hábitos de compra y factores que determinan el atractivo de una página web también se ven influidos por la cultura (Jin, 2010), así como la percepción del consumidor de los elementos visibles de la publicidad online (Liu, Sinkovics, Pezderka, \& Haghirian, 2012).

Si bien las grandes compañías transnacionales obtienen un volumen de ventas suficiente en cada mercado como para justificar un estudio detallado de sus consumidores, las pequeñas empresas que abastecen a múltiples mercados no pueden financiar este tipo de estudios. Así, resulta necesario acudir a modelos simplificados que permitan integrar de manera eficiente las complejidades culturales en el estudio del comportamiento del consumidor. Durante el período 2000-2014, las teorías más utilizadas para este propósito por los investigadores han estado dominadas por los modelos de dimensiones culturales (Timokhina, Wagner, \& Urkmez, 2015).

\subsubsection{Dimensiones culturales de Hofstede}

De los múltiples modelos de dimensiones culturales, el de Hofstede (2001) es el más utilizado por la comunidad científica a la hora de estudiar el impacto de las culturas nacionales en el comportamiento del consumidor (Engelen \& Brettel, 2011; Steenkamp, 2001; Timokhina et al., 2015; Zhang, Beatty, \& Walsh, 2008) y, más específicamente, en la investigación sobre comercio y negocios (Baack \& Singh, 2007). Basado en entrevistas realizadas a empleados de IBM en múltiples países en los años sesenta y setenta, el modelo original de Hofstede postula que las culturas de las diferentes 
naciones varían a lo largo de cuatro dimensiones (Hofstede, 1980): distancia al poder, individualismo/colectivismo, masculinidad/femineidad, y aversión a la incertidumbre. Posteriores publicaciones añaden dos nuevas dimensiones al modelo -orientación al largo plazo e indulgencia/restricción (Hofstede et al., 2010).

La efectividad del modelo de Hofstede es notable, puesto que las diferentes puntuaciones de los países a lo largo de estas dimensiones explican la mayoría de las variaciones de consumo y comportamiento del consumidor entre naciones (De Mooij, 2003). Su vigencia también está demostrada, pues pese al tiempo transcurrido desde el estudio inicial, múltiples reproducciones modernas demuestran que, si bien los valores absolutos de los países han experimentado modificaciones, sus posiciones relativas en las escalas permanecen vigentes (De Mooij \& Hofstede, 2011).

El modelo de Hofstede resulta apropiado para teorizar sobre los diferentes comportamientos entre naciones (Baack \& Singh, 2007; Steenkamp, 2001) y las diferencias en la utilización de medios de comunicación online (Hermeking, 2006). Por tanto, resulta pertinente incorporarlo al estudio de la efectividad en el e-mail marketing, puesto que posibilita el análisis de la presencia de patrones culturales en el estudio de la importancia relativa de cada uno de los factores de influencia.

\subsection{FORMULACIÓN DE LA INVESTIGACIÓN}

\subsubsection{Definición del problema de investigación}

La planificación y ejecución adecuada de las campañas de e-mail marketing es fundamental a la hora de conseguir resultados óptimos. Las empresas invierten importantes recursos en medir y analizar los resultados de sus iniciativas, tratando de encontrar patrones que les permitan identificar elementos para mejorar las tasas de apertura o de conversión. Con este fin, los departamentos de marketing también realizan experimentos, como los test $\mathrm{A} / \mathrm{B} / \mathrm{n}$, en los que previamente al envío del e-mail objetivo a una base de datos, se evalúa la efectividad de varias versiones con pequeñas muestras de suscriptores, para posteriormente enviar la versión con mejores resultados al resto de usuarios (Bonfrer \& Drèze, 2009).

Por tanto, existe un notable interés en el ámbito corporativo en acumular conocimiento en relación a la efectividad del e-mail marketing. Sin embargo, la literatura académica existente sobre e-mail marketing es muy limitada, y se ha centrado en dos líneas de estudio fundamentales: la primera analiza el fenómeno del spam, entendido como correo electrónico enviado sin la obtención previa de permiso por parte del receptor (Cranor \& LaMacchia, 1998), mientras que la segunda estudia los factores que afectan a la efectividad de los e-mails consentidos -e-mails promocionales que el receptor ha consentido recibir de un remitente específico (Tezinde, Smith, \& Murphy, 2002). El 
alcance de esta investigación se centra en esta segunda categoría. De este modo, además del spam, también quedan excluidas de este análisis aquellas comunicaciones que no tienen una vocación promocional pese a ser consentidas, como por ejemplo los e-mails transaccionales (como la confirmación de una compra o el envío de los detalles de entrega del producto) o los e-mails relacionados con el servicio al cliente (gestión de quejas, cancelación del servicio, encuestas, etc.).

Gran cantidad de los estudios existentes evalúan en su mayor parte la correlación entre variables independientes y dependientes sin utilizar un soporte teórico específico, mientras que otros utilizan modelos que se limitan a conectar un número reducido de factores (Bawm \& Nath, 2014; Rettie \& Chittenden, 2003). Por tanto, se aprecia la ausencia de un marco teórico unificado de los factores de influencia en el e-mail marketing, dada la carencia de análisis con sólida base teórica (Sigurdsson et al., 2013).

Además de estas limitaciones, la mayoría de los estudios realizados en el ámbito de la efectividad del e-mail marketing utilizan una muestra con una componente geográfica muy localizada que dificulta la extrapolación de resultados (Tabla 1). Por ejemplo, en un contexto de comercio electrónico entre empresas y consumidores finales (Businessto-consumer, o $B 2 C$ ), se identifica la capacidad de divertir e informar como un elemento influyente en la actitud hacia el e-mail marketing en países como India (Haq, 2009) o Irán (Jamalzadeh, Behravan, \& Masoudi, 2012). Estos estudios se complementan con los resultados en Rumanía, donde se identifican los elementos puramente informativos como los preferidos por los usuarios en el contenido de los e-mails enviados por las compañías (Carmen \& Nicolae, 2010). Sin embargo, en contextos de comercio electrónico entre empresas (Business-to-business, o B2B), en países como Suecia se demuestra que las actitudes hacia el e-mail marketing son negativas (Andersson, Fredriksson, \& Berndt, 2014). Este patrón de estudios sobre elementos aislados y con muestras más o menos homogéneas y geográficamente concentradas también se reproduce en los enfoques puramente cuantitativos, como el de Balakrishnan y Parekh, (2015), que crean un método predictivo de tasas de apertura (open rates, OR) basado en los datos históricos de esta variable en función de diversos parámetros de la línea de asunto, utilizando para verificarlo una muestra de usuarios de Norteamérica.

De todas las investigaciones que exploran la efectividad en el e-mail marketing, solamente cuatro utilizan una muestra con múltiples entornos geográficos que permiten generalizar las conclusiones, como se aprecia en la tabla 1. No obstante, el alcance de éstas se limita al estudio de la influencia en la efectividad del e-mail marketing del color de fondo de las newsletters (Zviran, Te'eni \& Gross, 2006), la posición de los enlaces (Kumar \& Salo, 2018) y la inclusión del nombre del suscriptor en la línea de asunto (Sahni \& Wheeler 2016), así como al estudio de la efectividad del e-mail marketing en la retención de jugadores de un casino online (Jolley et al., 2013). 


\begin{tabular}{|l|l|}
\hline \multicolumn{1}{|c|}{ Estudio } & Muestra \\
\hline Andersson, Fredriksson, y Berndt, 2014 & Suecia \\
\hline Balakrishnan y Parekh, 2015 & EEUU \\
\hline Bawm y Nath, 2014 & Desconocida \\
\hline Carmen y Nicolae, 2010 & Rumania \\
\hline Chang, Rizal, y Amin, 2013 & Taiwan \\
\hline Chen, Wang, Herath, y Rao, 2011 & EEUU \\
\hline Chittenden y Rettie, 2003 & Reino Unido \\
\hline Dufrene, Engelland, Lehman, y Pearson, 2005 & Desconocido (máximo 2) \\
\hline Ellis-Chadwick y Doherty, 2012 & Reino Unido \\
\hline Haq, 2009 & India \\
\hline Jackson y DeCormier, 1999 & Desconocida \\
\hline Jamalzadeh, Behravan, y Masoudi, 2012 & Irán \\
\hline Jolley, Lee, Mizerski, y Sadeque, 2013 & Global \\
\hline Kumar y Salo, 2018 & Global \\
\hline Lu, Fu, y Yen, 2007 & Taiwan \\
\hline Marinova, Murphy, y Massey, 2002 & Australia \\
\hline Micheaux, 2011 & Francia \\
\hline Mogos y Acatrinei, 2015 & Desconocido \\
\hline Reichhart, Pescher, y Spann, 2013 & Alemania \\
\hline Sahni y Wheeler, 2016 & Global \\
\hline San-José-Cabezudo y Camarero-Izquierdo, 2012 & Un pais \\
\hline Shuey, 2014 & EEUU \\
\hline Sigurdsson, Hinriksson, y Menon, 2016 & Islandia \\
\hline Sigurdsson, Menon, Sigurdarson, Kristjansson y Foxall, 2013 & Islandia \\
\hline Smart y Cappel, 2003 & EEUU \\
\hline Theerthaana y Sharad, 2014 & EEUU, Reino Unido e India \\
\hline White, Zahay, Thorbjornsen, y Shavitt, 2008 & \\
\hline Zviran, Te'eni y Gross, 2006 & \\
\hline
\end{tabular}

Tabla 1 - Localización geográfica de las muestras de estudios de e-mail marketing

En otros casos, debido a que la muestra está extraída de entornos sociodemográficos muy reducidos (p.ej. Dufrene, Engelland, Lehman, \& Pearson, 2005; Mogoș \& Acatrinei, 2015), existe el riesgo de incurrir en errores muestrales. De esta forma, un aspecto común de estos estudios es señalar como una potencial limitación a sus conclusiones el tamaño de su muestra, y proponer como nuevas líneas de investigación la repetición de experimentos con muestras más amplias, heterogéneas y dispersas 
geográficamente. Este problema es común a múltiples teorías de marketing, que han sido desarrolladas y validadas sólo en mercados occidentales y que, por tanto, necesitan ser evaluadas a la luz de diferentes contextos culturales para identificar su capacidad de generalización (Steenkamp, 2001).

\subsubsection{Contribuciones esperadas}

Teniendo en cuenta lo anterior, esta investigación contribuye desde un punto de vista teórico con la creación de un marco conceptual capaz de unificar los diversos factores de influencia en el e-mail marketing basado en fundamentos teóricos, en concreto, un sistema de análisis de efectividad de la publicidad utilizado en otros canales y un modelo de evaluación de las diferencias de comportamiento entre consumidores en función de las influencias culturales. Por otro lado, la validación empírica de este marco conceptual con una muestra heterogénea y global permitirá contrastar y extender las conclusiones alcanzadas, pudiendo añadir nuevos factores de influencia que sirvan como base a futuras investigaciones en otros ámbitos.

Además, se ha de notar que, si bien existen algunos estudios del efecto moderador de elementos demográficos como el género, la edad o el poder adquisitivo en la efectividad del e-mail marketing, no existen investigaciones que evalúen la importancia relativa de los factores culturales de las diferentes regiones geográficas. A la vista de la progresiva tendencia del mundo digital a la personalización, esta investigación resultaría relevante desde un punto de vista práctico, puesto que permitiría a las empresas multinacionales con programas de e-mail marketing globales ofrecer una personalización más efectiva a través del potenciamiento de los factores más relevantes en cada mercado.

Asimismo, la evaluación simultánea de múltiples variables posibilitará determinar la importancia relativa de cada uno de ellas. Esta contribución también será relevante desde un punto de vista práctico, puesto que mejorará los resultados de aquellas empresas con recursos limitados en la ejecución de campañas de e-mail marketing y les permitirá priorizar la optimización de factores de influencia en función de su contribución potencial a la efectividad general.

\subsubsection{Objetivos de la investigación}

El objetivo principal de esta investigación es identificar los factores que afectan a la efectividad del e-mail marketing, verificar las conclusiones obtenidas por estudios existentes utilizando una muestra más amplia y diversa, identificar variables relevantes no incluidas en estudios previos en este campo, así como determinar la influencia de éstas en la efectividad de este canal. Finalmente, se evaluará la importancia relativa de todos estos factores en función de la cultura nacional de los consumidores.

Para alcanzar este propósito, se proponen los siguientes objetivos secundarios: 
- Realizar una revisión de la literatura existente acerca de la efectividad de las campañas de e-mail marketing y los factores de influencia, así como la relativa a comportamiento del consumidor en el entorno de la publicidad online.

- Desarrollar un modelo que integre los factores que determinan el comportamiento del consumidor online, así como los que inciden en la efectividad del correo electrónico como herramienta promocional, articulándolo a través de las variables utilizadas para evaluar dicha efectividad.

- Crear un instrumento de medida y determinar una metodología de investigación que permita validar empíricamente el modelo teórico desarrollado.

- Realizar una recogida de datos fundamentada en instrumento de medida desarrollado utilizando una muestra global.

- Contrastar las conclusiones obtenidas con las extraídas por investigaciones anteriores.

- Establecer y describir las diferencias desde un punto de vista geográfico y cultural, de forma que sea posible determinar una segmentación de consumidores en función de su región.

\subsubsection{Tesis general}

Uno de los objetivos principales de esta investigación es desarrollar un modelo teórico que permita evaluar la efectividad del e-mail marketing. Para ello se pretende utilizar como base el modelo AIDA, determinando efectividades parciales que se vinculen a cada una de las etapas de dicho modelo. Asimismo, se integrarán las variables que la existente literatura ha identificado como influyentes, y se utilizará el modelo de dimensiones culturales de Hofstede para evaluar el efecto moderador de las diferentes culturas nacionales.

La forma más efectiva para validar este modelo sería utilizar resultados de campañas reales de e-mail marketing que permitan contrastar las diferentes hipótesis. Una de las principales dificultades a las que se enfrenta la comunidad científica es la dificultad para conseguir datos que permitan explorar con suficiente profundidad este campo, tal y como se ha detallado anteriormente. Por este motivo, la mayoría de investigaciones hasta la fecha ha utilizado muestras limitadas desde un punto de vista geográfico o demográfico. Puesto que esta investigación pretende salvar este escollo, se enfrentará a la dificultad añadida de lograr que dichos datos estén integrados por una muestra de diversos países. A la vista de este hecho, existe la posibilidad de que sea necesario utilizar diferentes métodos de recogida de datos para validar el modelo en su totalidad.

A la luz de lo explicado en los apartados anteriores, se puede formular la hipótesis principal (HP) de investigación de la siguiente forma: 
Hipótesis Principal

"Existe una serie de variables temporales, contextuales y de contenido visible y no visible que influyen en la efectividad del e-mail marketing, moderadas por una serie de dimensiones culturales".

\subsection{PROGRAMA, METODOLOGÍA, MEDIOS Y CRONOGRAMA DE TRABAJO}

\subsubsection{Programa de trabajo}

Se propone el siguiente programa (Figura 2) para alcanzar los objetivos a los que aspira la presente investigación:

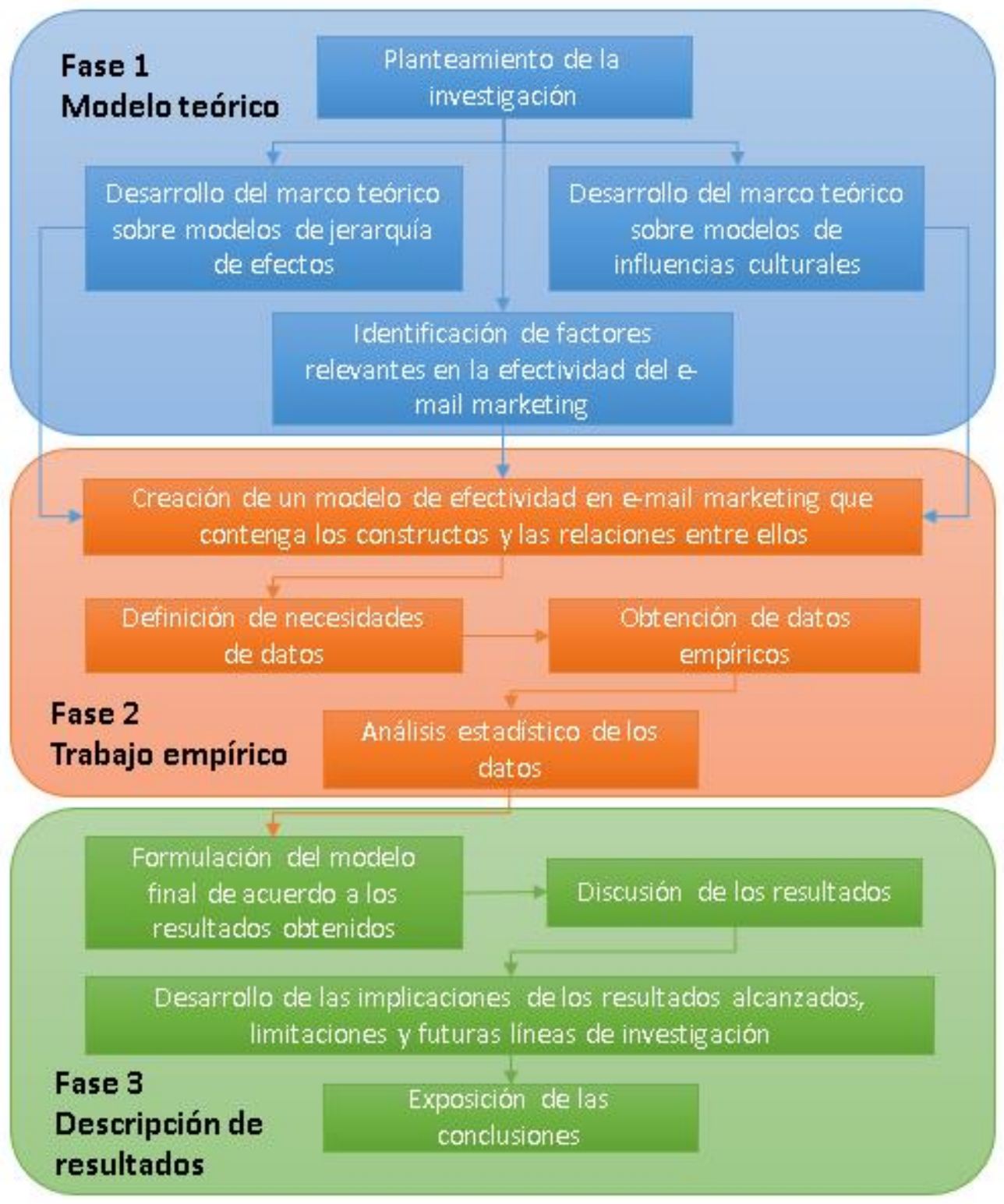

Figura 2 - Programa de trabajo 


\subsubsection{Metodología a utilizar}

La metodología que se utilizará en el curso de esta investigación, tal y como se resume en el programa de trabajo, contará con las siguientes fases:

\subsubsection{Fase I: estudio teórico}

\subsection{Marco teórico}

Se revisará la literatura en los campos de modelos de jerarquía de efectos -con especial énfasis en el modelo AIDA- e influencias culturales en el comportamiento del consumidor -con especial énfasis en el modelo de Hofstede. A continuación, se desarrollarán los marcos teóricos en éstas dos áreas, vinculando el modelo AIDA con las diferentes etapas que atraviesa el consumidor en sus interacciones con los correos electrónicos promocionales.

\subsection{Identificación de factores relevantes}

Se realizará una revisión de la literatura enfocada en el e-mail marketing, prestando especial atención a los rasgos comunes y diferenciadores de las metodologías utilizadas y a la composición de las muestras. Utilizando como base esta revisión, se identificarán aquellos factores que tienen relevancia en el estudio de la efectividad del e-mail marketing.

\subsubsection{Fase II: trabajo empírico}

\subsection{Propuesta de un modelo de efectividad en el e-mail marketing}

Partiendo de los marcos teóricos desarrollados, se procederá a la proposición de un modelo que integre los factores de influencia en la efectividad del e-mail marketing, mostrando las relaciones entre variables y constructos. Asimismo, se identificarán los indicadores que permitan realizar las medidas de los constructos.

\subsection{Definición de necesidades de datos}

Se establecerán las variables independientes y dependientes que permitirán medir los constructos integrantes del modelo propuesto y las relaciones entre ellos, utilizando como base la literatura existente. Para aquellos que no hayan sido estudiados anteriormente, se propondrán nuevas medidas.

\subsection{Obtención de datos empíricos}

Se abordará la negociación con varias empresas para la cesión de datos empíricos de email marketing que permitan contrastar las hipótesis de investigación. El objetivo será completar los requerimientos detallados en las necesidades de datos con una muestra tan geográficamente diversa como sea posible. En el caso de que esto no sea viable, se 
evaluará la posibilidad de crear un instrumento de medida alternativo que permita la recogida de datos.

\subsection{Análisis estadístico de datos}

Una vez determinada la metodología de análisis, se seleccionará el software más adecuado para el estudio de los datos, y se emprenderá un análisis de los mismos. Éste constará de varias fases; en concreto, su tratamiento para adaptarlos a los requerimientos del software, la exclusión de aquellas mediciones que sean erróneas o no resulten válidas y el estudio de su influencia en los resultados. Asimismo, se verificará el cumplimiento de todos aquellos requisitos necesarios para la validez de los resultados en función de la metodología escogida (por ejemplo, normalidad de residuos, ausencia de multicolinealidad, etc.).

\subsubsection{Descripción de los resultados de la investigación}

\subsection{Formulación del modelo final}

Los resultados arrojados por el análisis de los datos permitirán contrastar las hipótesis de investigación y, a partir de las relaciones identificadas, determinar el modelo final de efectividad en el e-mail marketing.

\subsection{Discusión de resultados}

Se plantearán posibles explicaciones a los resultados obtenidos y se compararán éstos con resultados de investigaciones anteriores, poniendo un especial énfasis en la discusión de las hipótesis soportadas y no soportadas.

\subsection{Descripción de las implicaciones de la investigación}

Se detallarán las limitaciones de la investigación y potenciales líneas futuras de estudio, así como las consecuencias fundamentales de la investigación y su impacto en futuros estudios.

\subsection{Exposición de las conclusiones}

Las conclusiones finales y los hallazgos esenciales de la investigación se presentarán de manera detallada.

\subsubsection{Medios que utilizará la investigación}

- Bibliografía relevante (artículos de revistas científicas, libros, ponencias en congresos) sobre e-mail marketing, modelos de jerarquía de efectos e influencias culturales en el comportamiento del consumidor.

- Entrevistas con expertos en comercio electrónico, e-mail marketing y comportamiento del consumidor.

- Datos empíricos cedidos por empresas. 
- Software de análisis estadístico.

- Orientaciones de los directores de tesis.

\subsubsection{Cronograma de trabajo}

A continuación, en la figura 3 se detalla el calendario de trabajo previsto para la presente investigación:

\begin{tabular}{|c|c|c|c|c|c|c|c|c|c|c|c|c|c|c|c|c|c|c|c|c|c|c|c|c|c|c|c|c|c|c|c|c|}
\hline \multirow{2}{*}{ Fase } & \multirow{2}{*}{ Etapa } & \multirow{2}{*}{ Descripción } & \multicolumn{6}{|c|}{2017} & \multicolumn{11}{|c|}{2018} & \multicolumn{11}{|c|}{2019} & \multicolumn{2}{|c|}{2020} \\
\hline & & & 1 & \begin{tabular}{l|l}
$\mathrm{J}$ & $\mathrm{A}$ \\
\end{tabular} & $\mathrm{A} \cdot \mathrm{S}$ & 0 & $\mathrm{~N}$ & $D$ & $\mathrm{E}$ & \begin{tabular}{|l|l}
$F$ & 1 \\
\end{tabular} & ML & $\mathrm{A} \mid \mathrm{M}$ & 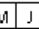 & 1 & $\mathrm{~A}$ & \begin{tabular}{l|l}
$s$ & 0 \\
\end{tabular} & \begin{tabular}{l|l}
0 & 1 \\
0
\end{tabular} & 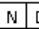 & 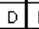 & E & \begin{tabular}{l|l}
$\mathrm{N}$ & $\mathrm{N}$ \\
\end{tabular} & a & \begin{tabular}{l|l}
$\mathrm{M}$ \\
$\mathrm{M}$
\end{tabular} & $\mathrm{M} J$ & 1 & A & 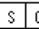 & \begin{tabular}{l|l}
0 & 1 \\
\end{tabular} & $\mathrm{~N}$ & D & \begin{tabular}{l|l}
$E$ & $F$ \\
$F$
\end{tabular} & \begin{tabular}{l|l}
$F$ & $M$ \\
\end{tabular} \\
\hline \multirow{2}{*}{1} & 1.1 & Marco teórico & & & & & & & & & & & & & & & & & & $\square$ & & & & & & & & & & & & \\
\hline & 1.2 & Identificación de factores & & & & & & & & & & & & & & & & & & & & & & & & & & & & & & \\
\hline \multirow{4}{*}{2} & 2.1 & Creación de modelo de efectividad & & & & & & & & & & & & & & & & & & & & & & & & & & & & & & \\
\hline & 2.2 & Definición de necesidades de datos & & & & & & & & & & & & & & & & & & & & & & & & & & & & & & \\
\hline & 2.3 & Obtención de datos empíricos & & & & & & & & & & & & & & & & & & & & & & & & & & & & & & \\
\hline & 2.4 & Análisis estadístico de datos & & & & & & & & & & & & & & & & & & & & & & & & & & & & & & \\
\hline \multirow{4}{*}{3} & 3.1 & Formulación del modelo final & & & & & & & & & & & & & & & & & & & & & & & & & & & & & & \\
\hline & 3.2 & Discusión de resultados & & & & & & & & & & & & & & & & & & & & & & & & & & & & & & \\
\hline & 3.3 & Implicaciones de la investigación & & & & & & & & & & & & & & & & & & & & & & & & & & & & & & \\
\hline & 3.4 & Conclusiones & & & & & & & & & & & & & & & & & & & & & & & & & & & & & & \\
\hline \multicolumn{3}{|c|}{ Redacción de la memoria de la tesis } & & & & & & & & & & & & & & & & & & & & & & & & & & & & & & \\
\hline
\end{tabular}

Figura 3 - Cronograma de trabajo 


\section{Capítulo 2 - E-mail marketing}

\subsection{ANTECEDENTES: EL CORREO ELECTRÓNICO}

2.1.1 El e-mail marketing

2.2 LA EFECTIVIDAD EN EL E-MAIL MARKETING

2.2.1 Efectividad de entrega

2.2.2 Efectividad de apertura

2.2.3 Efectividad de clic

2.2.4 Efectividad de conversión

2.2.5 Efectividad de retención de suscriptores

2.2.6 Efectividad en el e-mail marketing

2.3 FACTORES DE INFLUENCIA

2.3.1 Categorización de factores de influencia

2.3.2 Variables de contenido visible

2.3.3 Variables de contenido no visible

2.3.4 Variables temporales

2.3.5 Variables contextuales

2.3.6 Resumen de factores de influencia

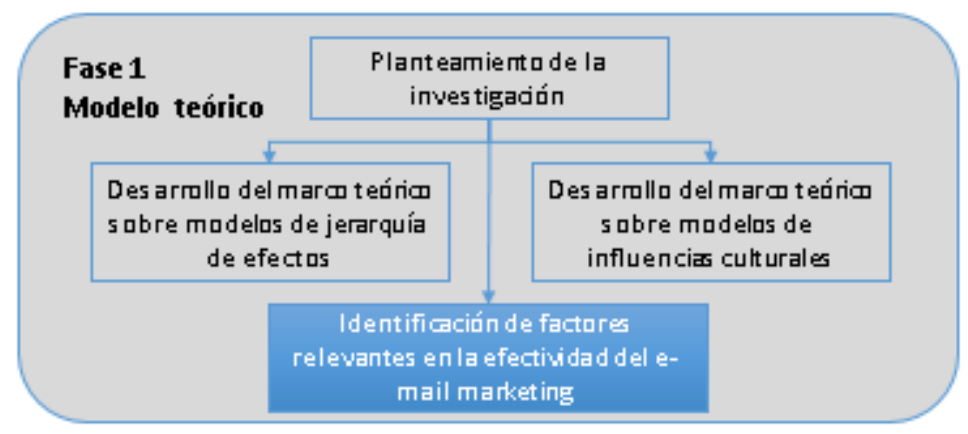




\section{E-MAIL MARKETING}

\subsection{ANTECEDENTES: EL CORREO ELECTRÓNICO}

Los orígenes del e-mail se remontan a 1972, año en el que Ray Tomlinson consiguió enviar un correo entre usuarios de diferentes servidores de la red ARPANET (Mullen \& Daniels, 2009). Si bien durante las primeras décadas el contenido de estas comunicaciones estaba limitado a texto simple, los desarrollos tecnológicos posteriores han posibilitado la utilización de diferentes formatos de maquetación, así como la integración de imágenes, videos y elementos dinámicos que cambian en función del usuario (Arnold, 2008).

Dichas funcionalidades convierten los correos electrónicos en entidades muy similares a páginas web y, de hecho, la mayoría utilizan como soporte archivos HTML, el formato predominante de internet (Arnold, 2008). Los archivos HTML son intercambiados y almacenados a través servidores corporativos o compartidos, y gestionados a través de programas informáticos ad hoc. Los usuarios pueden utilizar software específico, como por ejemplo Microsoft Outlook o Lotus Notes, o herramientas online de gestión del correo. La mayoría de ellos optan por esta segunda modalidad, subscribiéndose a servicios de correo gratuitos ofrecidos por compañías de servicios de internet -Internet Service Provider o ISP - como Yahoo, Google o Microsoft, accesibles a través de los navegadores (Litmus, 2017). Debido a su mayor preponderancia, esta tesis utilizará el término ISP para referirse a los clientes y servidores utilizados por los destinatarios de e-mail marketing.

Una de las herramientas que los ISPs facilitan al usuario es la interfaz de la bandeja de entrada, que recoge los remitentes y líneas de asunto de todos aquellos correos que han sido recibidos. Tradicionalmente, cada cuenta de correo disponía de una sola bandeja de entrada por motivos de simplicidad. Sin embargo, en 2013 el cliente de correo Gmail actualizó su interfaz con tres bandejas de correo diferentes - una principal, una social y una de promociones- y un sistema de clasificación automático que situaba los correos en cada una de ellas. Pese a la preponderancia de Gmail, en el contexto de esta investigación se asume la existencia de una única bandeja de entrada por motivos de simplicidad.

Los ISPs más populares son adecuados para el envío y gestión de un número limitado de correos con baja complejidad en su diseño, esto es, la utilización habitual realizada por un usuario privado, pero resultan insuficientes para satisfacer necesidades más complejas, como la gestión de una base de datos de direcciones de e-mail o la utilización de un diseño complejo que requiera maquetación avanzada e integración de elementos creativos. Estos requerimientos, en su mayoría establecidos por empresas que necesitan relacionarse con un gran número de usuarios, son satisfechos por proveedores 
de servicios de e-mail -E-mail Service Provider o ESP-como ExactTarget, Responsys o MailChimp (Arnold, 2008). Así, en el contexto de esta tesis se utilizará el término ESP para referirse a los clientes y servidores utilizados por los remitentes de e-mail marketing.

\subsubsection{El e-mail marketing}

El e-mail marketing, entendido como el envío de comunicación comercial a un grupo de usuarios utilizando el correo electrónico (Bawm \& Nath, 2014), comenzó en 1979 con un mensaje comercial enviado por Gary Thuerk a 400 usuarios de ARPANET (Hedley, 2006). Con el paso del tiempo esta actividad se ha vuelto más sofisticada, y actualmente requiere de la realización de manera armónica y coordinada una serie de acciones para aprovechar todo el potencial de una base de datos. A este conjunto de tareas se le suele denominar programa de e-mail marketing (Mullen \& Daniels, 2009).

El primer elemento fundamental de un programa de e-mail marketing es la captación de suscriptores, que se puede realizar a través de fuentes online, pero también en eventos offline como ferias o eventos en tienda (Bawm \& Nath, 2014; Groves, 2009). Debido a la existencia de regulación en la mayoría de mercados en relación al e-mail marketing, una parte crucial del proceso de adquisición de suscriptores implica que éstos acepten unos términos y condiciones del programa y que autoricen de manera explícita a la compañía a enviarles comunicación comercial (Arnold, 2008).

Esto es así porque la dirección de e-mail está considerada por múltiples legislaciones como un dato personal, lo cual implica que su adquisición y manipulación está sujeta a una regulación restrictiva, y que tanto los ESPs como las empresas que gestionan bases de datos han de ser especialmente cuidadosos para evitar la filtración indebida y los usos no autorizados. En España, la Agencia Española de Protección de Datos (AEPD) es la encargada de registrar las bases de datos comerciales, operación obligatoria para todas aquellas entidades que deseen realizar actividades de e-mail marketing. La LOPD o Ley Orgánica de Protección de Datos (Ley 15/1999) y la LSSI o Ley de Servicios de la Sociedad de la Información y de Comercio Electrónico (Ley 34/2012) componen el cuerpo regulatorio que gobierna este tipo de actividades. A nivel europeo, la GDPR o Regulación General de Protección de Datos (Regulation 2016/679) es la normativa con mayor relevancia para la gestión de bases de datos de correo electrónico.

El valor de cada dirección de e-mail capturada es diferente, y normalmente se calcula utilizando el valor medio histórico de cada suscriptor para un determinado segmento, o recurriendo a métodos de puntuación como RFM -Recency, Frequency, Monetary value- (Mullen \& Daniels, 2009). Así, la inversión en estas de actividades se realiza teniendo en cuenta el retorno de generado por el valor potencial de cada nuevo 
suscriptor, consideración en la que de manera indirecta influye la capacidad del programa de e-mail marketing de lograr ventas.

Una vez incorporado un nuevo usuario a la base de datos llega el momento de construir y desarrollar la relación a través de sucesivos e-mails, que tendrán como objetivo dar a conocer la marca y el surtido de productos (Groves, 2009), así como recoger información de las interacciones del consumidor con las comunicaciones. En esta etapa se suele integrar la dirección de e-mail en un segmento determinado de la base de datos de acuerdo a su situación geográfica, socioeconómica o a ciertos patrones de comportamiento.

Finalmente, una vez se ha logrado que el consumidor adquiera un producto de la compañía, los programas de e-mail suelen enfocarse en generar lealtad (Groves, 2009), esto es, en tratar que las futuras necesidades del usuario en las categorías que la compañía comercializa se satisfagan con productos de la misma. En este caso, de nuevo la relación se gestionará a través de e-mails, pero ahora existirá la posibilidad de incluir elementos personalizados cuyo contenido variará en función de las interacciones realizadas (Arnold, 2008).

Si bien todas estas fases pertenecen al desarrollo de un programa de e-mail marketing, esta tesis se centrará en el estudio de la efectividad de las comunicaciones de e-mail y, por tanto, excluirá las actividades relacionadas con la adquisición de suscriptores.

\subsection{LA EFECTIVIDAD EN EL E-MAIL MARKETING}

Uno de los principales retos a los que los responsables de e-mail marketing se enfrentan de manera recurrente es la manera de realizar de forma más efectiva su trabajo, esto es, conseguir que sus campañas tengan mejores resultados (Cases, Fournier, Dubois, \& Tanner, 2010; Theerthaana \& Sharad, 2014). El envío de un correo persigue crear notoriedad, lograr que un usuario considere la compra un producto determinado, incentivar una transacción o el uso de un producto y generar lealtad (Mullen \& Daniels, 2009), para lo cual se recurre a la utilización de un medio -el e-mail- para comunicar un mensaje (Fariborzi \& Zahedifard, 2012).

La RAE define efectividad como la "capacidad de lograr el efecto que se desea o se espera" (Real Academia Española, 2014). Por tanto, la efectividad de las campañas de correo electrónico estará ligada al objetivo que el remitente se haya propuesto. En general, el objetivo fundamental de una campaña de marketing es contribuir a potenciar la comercialización de un producto que satisfaga de las necesidades de un perfil de consumidor generando un beneficio para la compañía (Kotler \& Keller, 2012). En el contexto del e-mail marketing, es necesario articular este objetivo a lo largo de etapas, cuya superación estará ligada al cumplimiento de ciertos objetivos secundarios que se caracterizarán a lo largo de los siguientes apartados. 


\subsubsection{Efectividad de entrega}

La primera misión de todo correo electrónico es alcanzar la bandeja de entrada de su remitente. Si bien a primera vista esta consideración puede resultar peregrina, la aparición del spam tuvo como consecuencia un aumento descontrolado del número de correos que los usuarios recibían (Cranor \& LaMacchia, 1998). Esto a su vez motivó que los ISPs comenzarán a incorporar a sus servicios de correo herramientas que filtran de manera automática los correos no deseados (Fariborzi \& Zahedifard, 2012). Pese a la evolución de dichas herramientas, en la actualidad los filtros anti-spam también bloquean envíos legítimos que el consumidor ha consentido, lo cual supone un riesgo que los responsables de bases de datos han de prever y gestionar (Groves, 2009).

En el entorno del e-mail marketing, la "efectividad de entrega" se define como la capacidad de lograr que los e-mails lleguen a la bandeja de entrada de los suscriptores. La medida que nos permite evaluar esta variable es el porcentaje de e-mails enviados que alcanzan la bandeja de entrada de la base de datos objetivos. Esta tasa se conoce como deliverability (Abrahams \& Deane, 2010; Chittenden \& Rettie, 2003).

Excluyendo aquellos factores directamente atribuibles al usuario -como una bandeja de entrada llena o la cancelación de la cuenta de correo- el estudio de la efectividad de entrega es muy complejo, puesto que depende de variables poco transparentes y difíciles de medir (Arnold, 2008). Algunas de las principales son la reputación de la dirección IP del remitente, el número de usuarios que han denunciado una comunicación como spam o la presencia en la lista de destinatarios de direcciones de correo creadas ad hoc por los ISPs para detectar envíos no consentidos, conocidas como trampas de spam spamtraps- o tarros de miel -honeypots- (Arnold, 2008; Baggott, 2011). Los ISPs no comunican el deliverability a los remitentes, sino que simplemente les informan una vez deciden bloquear todos sus envíos, así que actualmente la única manera de estimar esta ratio es a través de compañías como ReturnPath, que utilizan paneles de direcciones email para calcular esta variable (Mullen \& Daniels, 2009).

Pese a que esta investigación reconoce la importancia de la efectividad de entrega en el estudio general de la efectividad del e-mail marketing, dada la enorme dificultad de acceder a datos empíricos y la limitada capacidad de las compañías para actuar sobre las variables de influencia, este elemento ha sido excluido del alcance de la presente tesis.

\subsubsection{Efectividad de apertura}

Una vez un e-mail ha alcanzado la bandeja de entrada, el siguiente objetivo natural que se plantea el remitente es lograr que el destinatario lo abra. En un contexto en el que cada usuario de EEUU recibe 41 e-mails cada día, de los cuales 10 son correos 
promocionales (Mullen \& Daniels, 2009), es natural que muchos de estos correos sean ignorados o directamente eliminados.

Asumiendo que los usuarios revisan todos sus correos en la bandeja de entrada para determinar si estos ameritan su atención, en el caso de que un consumidor decida no abrir un e-mail la comunicación entre el remitente y el destinatario será muy limitada. Por tanto, resulta importante para los remitentes determinar el número de usuarios que ha sido expuesto a su comunicación completa y el de aquellos que tan sólo han accedido a la parte de la línea de asunto que se muestra en la bandeja de entrada.

Cobra sentido, por tanto, definir la "efectividad de apertura" como la capacidad de lograr que los suscriptores abran los e-mails promocionales. Esta métrica permite determinar el éxito de una comunicación a la hora de generar una primera acción por parte de los usuarios - la apertura del correo-, especialmente importante puesto que representa una primera interacción entre el remitente y el destinatario que permite inferir que el correo ha captado la atención del destinatario (Arnold, 2008).

\subsubsection{Medida de la efectividad de apertura}

La variable más utilizada a la hora de analizar la efectividad de apertura se conoce como tasa de apertura u open-rate $(O R)$, definida como el porcentaje de e-mails abiertos en relación a los e-mails enviados. Esta variable es utilizada por múltiples estudios como un indicador clave de eficiencia (p.ej. Andersson et al., 2014; Balakrishnan \& Parekh, 2015; Bonfrer \& Drèze, 2009; San-José-Cabezudo \& Camarero-Izquierdo, 2012).

La mayoría de ESPs tiende a proporcionar el OR de un e-mail de manera automática y directa. Puesto que es este propio sistema el que realiza el envío de cada correo, el denominador de la tasa de apertura -esto es, el número de correos enviados- es directamente accesible (Arnold, 2008). Sin embargo, puesto la apertura de un correo se realiza en la bandeja de entrada de los ISPs -sistemas ajenos a los ESPs-, es necesario determinar el número de correos abiertos de manera indirecta. El procedimiento más común para realizar dicho conteo se basa en la inserción de un vínculo a un elemento alojado en el servidor del ESP en el código HTML del propio correo electrónico (Micheaux, 2011). Este elemento puede pertenecer al contenido del correo -como, por ejemplo, una imagen o un video- o crearse ad hoc -en este caso, se le denomina pixel(Baggott, 2011).

De esta manera, cada vez que un usuario abre un correo, su ISP se conecta al servidor del ESP en el que está alojado dicho elemento para descargarlo e incorporarlo al correo (Lim, Lim, Jiang, \& Achananuparp, 2016). El conteo del número de conexiones al servidor permite estimar la cantidad de destinatarios que han abierto el e-mail. Esta medida no es absolutamente precisa; por una parte, existen algunos clientes de correo que no cargan las imágenes o pixels (Baggott, 2011), infraestimando la cantidad de 
aperturas totales; por otro lado, si un mismo usuario abre el correo varias veces, las capacidades técnicas del ESP así como la configuración de la memoria de acceso rápida -o cache- determinarán si es posible identificar esas nuevas aperturas como pertenecientes al mismo usuario o si estas se contabilizarán como nuevas aperturas.

Finalmente, es relevante mencionar que a la hora de calcular la efectividad de apertura resultaría más adecuado el referenciar la tasa de apertura al número de correos que alcanzan la bandeja de entrada, y no al número de correos enviados. Esto es así porque tradicionalmente esta variable se utilizar para determinar cómo de exitoso es un correo a la hora de conseguir que los usuarios lo abran. Sin embargo, y debido a las dificultades anteriormente mencionadas respecto al estudio de la efectividad de entrega, el estándar de la industria referencia esta tasa al número de e-mails enviados, con el consiguiente riesgo de que la efectividad de entrega distorsione la medición de la efectividad de apertura real.

\subsubsection{Efectividad de clic}

En la mayoría de las situaciones, el espacio ocupado por el correo electrónico resultará insuficiente para conseguir el objetivo de la campaña, ya sea éste informacional o transaccional. Por tanto, lo más habitual es que los remitentes utilicen el e-mail marketing como una manera de lograr suscitar el interés de los usuarios, para posteriormente exhortarles a que visiten la página web corporativa, en la que se reforzará la comunicación inicial, se proporcionarán más detalles y se facilitará la realización de la acción perseguida en el envío.

Esto es así porque las limitaciones inherentes al e-mail marketing impiden completar la acción perseguida en el ISP del usuario, ya sea ésta la compra de un producto o el consumo de determinado contenido. Así, pese a que como se ha mencionado en apartados anteriores los correos electrónicos pueden tratar de alcanzar una gran variedad de objetivos generales, la mayoría de ellos comparte el objetivo parcial de conseguir que el usuario continúe la interacción con el remitente en alguna de las propiedades online del mismo, ya sea su página web, sus redes sociales, su aplicación móvil, etc. (Dufrene et al., 2005).

En este contexto, la "efectividad de clic" se define como la capacidad de lograr que los suscriptores hagan clic en los e-mails promocionales que están leyendo. Es obvio que para que esta métrica tenga sentido, el correo ha de contener algún enlace, requerimiento que la inmensa mayoría de correos promocionales cumple en la actualidad (Ellis-Chadwick \& Doherty, 2012). 


\subsubsection{Medida de la efectividad de clic}

El seguimiento de enlaces es un objetivo común a otros canales de la publicidad online, como los banners o la publicidad en motores de búsqueda. En el análisis de la efectividad de clic, el e-mail marketing utiliza la misma variable que éstos: la tasa conocida como click-thru rate (CTR) o tasa de clic, utilizada por múltiples estudios de efectividad (Bonfrer \& Drèze, 2009; Rettie \& Chittenden, 2003; White et al., 2008). Tradicionalmente esta métrica refleja la proporción de clics en relación al número de impresiones de un anuncio. Puesto que en el contexto del e-mail marketing el concepto impresión no es relevante, la efectividad de clic se referenciará al número de usuarios alcanzados por el correo.

De esta manera, existen dos posibles versiones del CTR: porcentaje de clics en relación a los e-mails enviados y porcentaje de clics en relación a los e-mails abiertos, a veces conocido como CTOR (Mullen \& Daniels, 2009). Pese a que la más popular es la primera de ellas, por definición se verá influida por la efectividad de apertura. Puesto que en el estudio que desarrolla esta tesis se pretende identificar los factores de influencia relativos a cada etapa de manera independiente, en el contexto de esta investigación se utilizará la segunda definición.

De manera similar a lo que sucede con la efectividad de apertura, el seguimiento de un enlace se realiza en un sistema ajeno al ESP, con lo que es necesaria una mecánica que permita a esta herramienta recoger el número de clics que los usuarios realizan en los correos. Existen varios métodos para ello, como el uso de JavaScript o AJAX (Asynchronous JavaScript And XML; JavaScript asíncrono y XML) (Bawm \& Nath, 2014), o la redirección, esto es, en la inserción de un enlace a una dirección del servidor controlado por el ESP, que a su vez redirigirá de manera automática el tráfico a la dirección web que a la que el anunciante pretendía enviar al usuario. En este último caso, el servidor del ESP podrá realizar un conteo del número de redirecciones y, de esta manera, determinar el numerador de la tasa de clic. De nuevo, las capacidades técnicas del ESP determinarán si será posible identificar las situaciones en las que el mismo usuario ha hecho clic varias veces en un correo, para lo cual será necesaria la creación de links con un identificador único para cada destinatario (Arnold, 2008; Lim et al., 2016).

\subsubsection{Efectividad de conversión}

En el entorno digital, el concepto "conversión" está asociado al cumplimiento del objetivo que una determinada campaña o interacción promocional persigue (Smart \& Cappel, 2003). Así, dependiendo de dicho objetivo, se utilizarán diferentes mecanismos para verificar la conversión. Podemos distinguir tres casos generales: 
- En las campañas que persiguen una acción específica y computable, el método más usual es el conteo de la misma, por ejemplo, si se persigue que un usuario complete un formulario con sus datos, el número de conversiones será el número de formularios válidos recibidos (Arnold, 2008).

- En el caso de acciones más genéricas, se suelen utilizar métricas intermedias. Como ejemplo de esto último, en el caso de que un e-mail persiga que el usuario consuma la información de la web, se utilizarán variables como el tiempo invertido por el usuario en cada visita o el número de páginas del sitio visitadas para determinar si el usuario ha alcanzado un umbral objetivo que permita dilucidar si se ha realizado la conversión (Florès, 2014).

- Finalmente, las situaciones en las que se persigue una acción no directamente observable en el entorno online, como pueda ser la asistencia a un evento en tienda o el incremento de la notoriedad, resultan más complejas de evaluar. Normalmente se recurrirá a encuestas o entrevistas directas entre el segmento de población estudiado (Arnold, 2008).

En cualquiera de estos tres casos, se puede definir la "efectividad de conversión" como la capacidad de lograr que los usuarios realicen la acción perseguida por la campaña. Esta métrica suele ser la más importante a la hora de determinar el éxito general de la promoción, al estar íntimamente ligada al objetivo perseguido, pero presenta particularidades en su medida que la someten a cierta controversia. A efectos de simplificar el análisis, y puesto que la mayor parte de la muestra que se utilizará en esta investigación tiene estas características, se asumirá que la acción perseguida por el anunciante es la venta online de un determinado producto o servicio en la web corporativa.

\subsubsection{Medida de la efectividad de conversión}

La variable tradicional que permite medir la efectividad de conversión se conoce como tasa de conversión, o conversion rate (CR), estimada como el porcentaje de usuarios que completa la acción objetivo (Smart \& Cappel, 2003). Cuando hay varios objetivos simultáneos, se suele utilizar una media ponderada (Bawm \& Nath, 2014). Este porcentaje se mide tradicionalmente en relación al número de visitas generado por la campaña hacia la plataforma objetivo -normalmente, la web corporativa-, que en la mayoría de los casos suele ser muy cercano al número de clics (Arnold, 2008). El CR ha sido usado como medida de efectividad en múltiples estudios de e-mail marketing (p.ej. Reichhart, Pescher, \& Spann, 2013; Sigurdsson et al., 2013; Wu, Li, \& Liu, 2016).

El cálculo de esta tasa requiere tanto la estimación de las visitas enviadas a la web como el número de transacciones realizadas. Las herramientas de análisis web como Google Analytics o Webtrends permiten determinar el número de visitas a una página concreta (Baggott, 2011). Para ello, todas las páginas que se deseen monitorizar deberán 
incorporar ciertas de líneas de código definidas por el desarrollador de la herramienta de análisis. Este código posibilitará la captura de una serie de variables en cada visita entre otras, tiempo que usuario permanece en la página, dirección IP, etc.- que serán transmitidas en tiempo real a la herramienta de análisis web para integrarse en una base de datos que los anunciantes podrán analizar a posteriori (Florès, 2014).

Puesto que cada página puede recibir visitas de muy variadas fuentes -por ejemplo, múltiples e-mails enviados en diferentes días de la semana pueden enlazar a la homepage-, resulta necesaria la creación de códigos unívocos que identifiquen cada campaña publicitaria. Estos códigos se incluirán en los enlaces del elemento publicitario que origina el tráfico a la página, de forma que cuando el consumidor descargue la página objetivo, la herramienta de análisis pueda identificar la fuente de la visita (Bawm \& Nath, 2014). Los códigos unívocos se categorizarán en una base de metadatos de forma que a posteriori resulte más fácil realizar un análisis agregado de diferentes tipos de campañas. (Bawm \& Nath, 2014).

El cálculo de transacciones completadas se determina computando el número de visitas a una página que sólo se muestre tras haber completado el pago, conocida comúnmente como página de confirmación de compra. El usuario alcanzará esta página posteriormente a la navegación por múltiples apartados del sitio (selección del producto, introducción de datos personales, pasarela de pago, entre otros) cuyos enlaces serán genéricos y no contendrán el código unívoco de la campaña. Para solventar esta dificultad, el código unívoco se almacena en un archivo temporal del ordenador del usuario conocido como cookie (Zikmund, Babin, Carr, \& Griffin, 2013), de forma que cada página posterior a la primera pueda identificar que el origen de la visita es la campaña cuyo código unívoco aparecía en el enlace de la comunicación promocional.

El proceso descrito resuelve la obtención del $\mathrm{CR}$ en un entorno simplificado. Sin embargo, el cálculo de la efectividad de conversión se enfrenta a una compleja problemática: determinar la influencia concreta de una campaña de e-mail marketing en comparación con los otros medios publicitarios utilizados por la compañía. El origen de este problema lo causa el hecho de que el consumidor utiliza múltiples fuentes de información para determinar la conveniencia de adquirir un producto (Solomon, Bamossy, Askegaard, \& Hogg, 2013), navegando por decenas de sitios webs y redes sociales e interactuando en este proceso con todo tipo de canales publicitarios.

Acotando dicha problemática al entorno de la publicidad online, en el caso de que un consumidor haya hecho clic en un banner, un correo electrónico, un anuncio en motores de búsqueda y otro en redes sociales previamente a la compra online, resultará complejo determinar la contribución específica de cada una de estas interacciones en la conversión final. En el momento de alcanzar la página de confirmación de la 
transacción, la cookie habrá almenado varios códigos unívocos, y será necesario determinar cómo atribuir la conversión entre todos ellos.

Los modelos de atribución son un conjunto de reglas que posibilitan la resolución de este problema (Florès, 2014). Algunos de los más populares son el de último clic -la última interacción se atribuye el $100 \%$ de la conversión-, todos los clics -la conversión se reparte a partes iguales entre todas las interacciones- o algorítmica - un modelo calcula la contribución de cada interacción en base a datos históricos- (Shao \& Li, 2011). De todos ellos, el más habitual es el de último clic (Berman, 2017) y, pese a que este modelo ignora las interacciones que existen entre los diferentes canales (Kireyev, Pauwels, \& Gupta, 2016), es utilizado por el $76 \%$ de las compañías y el $60 \%$ de las agencias de la región Asia-Pacífico (Econsultancy, 2015). Con el objetivo de solventar esta limitación, un reducido pero creciente número de anunciantes definen modelos de atribución multicanal -multi-touch-, que les permite definir de manera más precisa la contribución de cada una de las interacciones (Xu, Duan, \& Whinston, 2014).

El estudio de la efectividad de conversión se verá influido por el modelo de atribución utilizado en el cálculo de conversiones, y será necesario verificar que todos los datos de la muestra utilizan el mismo modelo para evitar alcanzar conclusiones erróneas.

\subsubsection{Efectividad de retención de suscriptores}

El tamaño de una base de datos es una de las variables determinantes de su valor y utilidad. A la vista de la estructura de costes semifijos del e-mail marketing y la relativa automatización de su operativa, y asumiendo que la efectividad de las campañas permanezca constante, el incremento de destinatarios resulta en un aumento de las ventas que no lleva aparejando un aumento proporcional de costes o recursos. Asimismo, la disminución de suscriptores acarrea consecuencias opuestas.

La LSSI y la LOEPD determinan que los usuarios han tener acceso de manera fácil y automática a un mecanismo que les permita corregir sus datos y cancelar su subscripción. Esta directriz es normalmente interpretada como una obligación por parte de los anunciantes de incluir un enlace que permita la cancelación de la subscripción a la base de datos en todos los e-mails promocionales y, de hecho, el $98 \%$ de los e-mails la incorporan a su contenido (Ellis-Chadwick \& Doherty, 2012). Así, un objetivo implícito de las campañas de e-mail marketing es conseguir retener al mayor porcentaje de suscriptores con el envío de cada correo.

La "efectividad de retención de suscriptores" se define como la capacidad de lograr que los usuarios permanezcan en la base de datos de la compañía. Si bien esta variable no influye de manera inmediata en el éxito de la campaña analizada, sí que puede tener influencia en los resultados de futuras campañas. Además, existe un número finito de potenciales suscriptores dispuesto a otorgar el consentimiento a recibir e-mails 
promocionales (Baggott, 2011), por lo que resulta fundamental controlar esta variable para no saturar el crecimiento potencial del canal.

\subsubsection{Medida de la efectividad de retención de suscriptores}

Las variaciones en la retención de suscriptores permiten valorar la relevancia de la comunicación, o la voluntad de los usuarios de continuar recibiendo comunicaciones promocionales. La variable tradicional empleada para su medida se denomina tasa de cancelación de suscripciones o retention rate, que relaciona el número que usuarios que abandonaron la base de datos con el número total de destinatarios. Así, estudios que evalúan factores como la presión promocional o la privacidad utilizan esta medida para detectar el grado de irritación del consumidor (Micheaux, 2011; Sahni et al., 2016).

El cálculo de esta tasa se realiza directamente en el ESP. Por una parte, requiere conocer el número de usuarios que recibió una determinada comunicación, dato directamente accesible por este sistema; por otro, el número de usuarios que utilizó el enlace de cancelación de la suscripción y la completó con éxito. Esta cancelación normalmente se realiza a través de un formulario alojado en el servidor del ESP o de la web corporativa. En este segundo caso, el formulario está directamente conectado con el ESP, puesto que es en ese sistema en el que se encuentra alojada la base de datos de usuarios. Así, en cualquiera de estos dos escenarios, y utilizando un proceso de códigos unívocos automáticamente generados similar al descrito en la medida de la efectividad de clic, el ESP determinará el número de usuarios que cancelaron la subscripción asociados a un envío determinado.

Sin embargo, es necesario puntualizar que la medida del retention rate no es completamente precisa, puesto que el usuario puede utilizar otros medios para evitar recibir más e-mails promocionales. Por una parte, puede cancelar su suscripción sin utilizar el enlace incluido en un correo, por ejemplo, accediendo al sitio web corporativo. Por otra, algunos ISP incluyen herramientas para facilitar la gestión de estas necesidades, como un editor de reglas de procesado de e-mails que permite borrar automáticamente correos de ciertos remitentes o accesos directos que posibilitan identificar a una determinada dirección en envío como spam (Arnold, 2008). En cualquiera de estos dos casos, será imposible atribuir la cancelación a un determinado envío, aunque haya sido el causante del abandono de la base de datos por parte del usuario. De esta manera, la efectividad de retención de suscriptores tiende a estar infraestimada.

\subsubsection{Efectividad en el e-mail marketing}

A la vista de lo detallado en los anteriores apartados, el estudio de la efectividad en el email marketing permite establecer efectividades parciales que se acomodan a su naturaleza procesal. Asimismo, estas efectividades son medibles a través de métricas 
razonablemente precisas y con gran aceptación dentro de la comunidad científica. De hecho, el deliverability, open rate, click-through rate, conversión rate y retention rate, son las métricas más estudiadas en este dominio (Baggott, 2011), ocupando generalmente el lugar de variables dependientes en la literatura.

La Figura 4 representa el cálculo de las efectividades parciales en relación a las diferentes métricas estudiadas. El inicio de la flecha indica el denominador de la tasa correspondiente, y el final de la flecha el numerador de la misma.

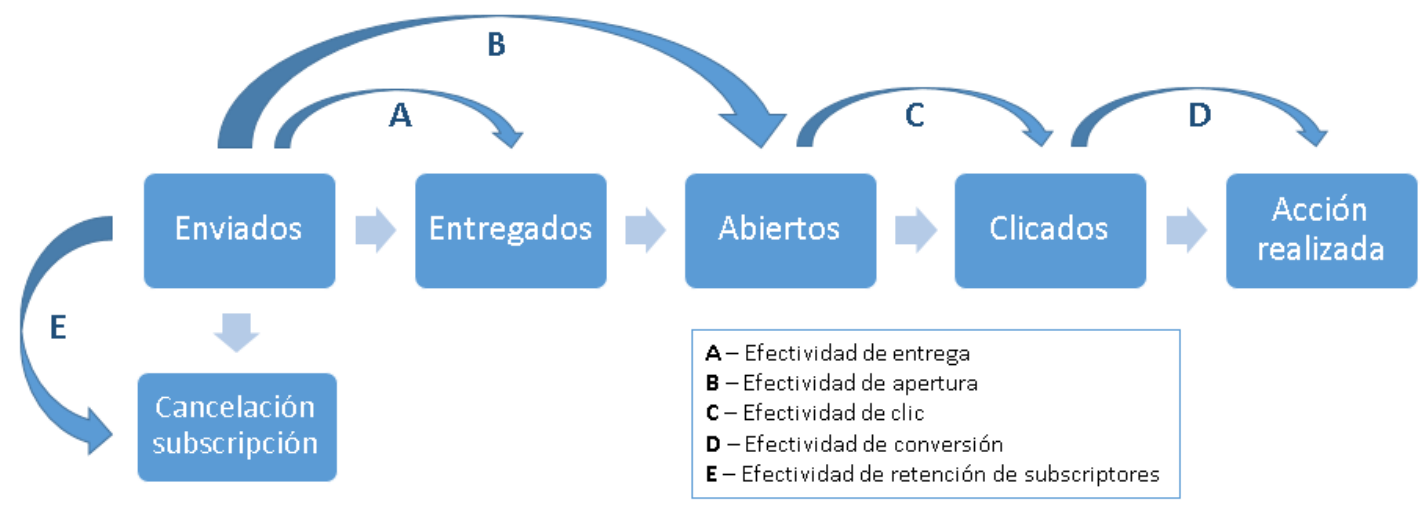

Figura 4 - Efectividades en e-mail marketing

En resumen, en el contexto del e-mail marketing, la mayoría de e-mails promocionales tienen como objetivo final generar una acción por parte del usuario en la web corporativa, y para ello han de lograr que el suscriptor atraviese sucesivas fases. Cada una de ellas tiene un objetivo asociado y, por tanto, una variable concreta que evalúa la efectividad de la comunicación en cada etapa (tabla 2). Asimismo, el anunciante pretende conservar el mayor número posible de usuarios en su base de datos tras cada envío.

Por tanto, se puede entender la efectividad en el e-mail marketing como la "capacidad de lograr que los suscriptores permanezcan en la base de datos y realicen una acción concreta en la web corporativa". Esta definición incorpora los cinco elementos estudiados, dado el carácter lineal y acumulativo de entrega, apertura, clic y conversión, y será utilizada en esta tesis como referencia en el estudio de los diversos factores de influencia.

\begin{tabular}{|c|c|c|c|}
\hline Efectividad & Definición & Variable & $\begin{array}{c}\text { Explicación del } \\
\text { ratio }\end{array}$ \\
\hline $\begin{array}{l}\text { Efectividad de } \\
\text { entrega }\end{array}$ & $\begin{array}{l}\text { Capacidad de lograr que los } \\
\text { e-mails lleguen a la bandeja } \\
\text { de entrada de los suscriptores }\end{array}$ & Deliverability & $\frac{\text { B-mails antrggados }}{\text { B- maiks atviados }}$ \\
\hline $\begin{array}{l}\text { Efectividad de } \\
\text { apertura }\end{array}$ & $\begin{array}{l}\text { Capacidad de lograr que los } \\
\text { suscriptores abran los e-mails } \\
\text { promocionales }\end{array}$ & $\begin{array}{l}\text { Tasa de apertura }(\mathrm{OR}, \text { open } \\
\text { rate })\end{array}$ & $\frac{a-\text { maiks abiartos }}{\text { B- maiks anviados }}$ \\
\hline
\end{tabular}




\begin{tabular}{|c|c|c|c|}
\hline $\begin{array}{l}\text { Efectividad de } \\
\text { clic }\end{array}$ & $\begin{array}{l}\text { Capacidad de lograr que los } \\
\text { suscriptores cliquen en los e- } \\
\text { mails promocionales }\end{array}$ & Click-thru rate (CTR) & $\begin{array}{l}\frac{\text { clics }}{\text { B- maiks anviados }} \\
\frac{\text { clics }}{\text { a- maiks abiartos }}\end{array}$ \\
\hline $\begin{array}{l}\text { Efectividad de } \\
\text { conversión }\end{array}$ & $\begin{array}{l}\text { Capacidad de lograr que los } \\
\text { usuarios realicen la acción } \\
\text { perseguida por la campaña } \\
\text { en la web corporativa }\end{array}$ & $\begin{array}{l}\text { Tasa de conversión }(\mathrm{CR}, \\
\text { conversion rate) }\end{array}$ & $\begin{array}{c}\frac{\text { conversiones }}{\text { clics }} \\
\text { convarsiones } \\
\text { B-mails gnviados }\end{array}$ \\
\hline $\begin{array}{l}\text { Efectividad de } \\
\text { retención de } \\
\text { suscriptores }\end{array}$ & $\begin{array}{l}\text { Capacidad de lograr que los } \\
\text { usuarios permanezcan en la } \\
\text { base de datos de la compañía }\end{array}$ & $\begin{array}{l}\text { Tasa de cancelación de } \\
\text { suscripciones }\end{array}$ & $\frac{\text { suscripotones cathe. }}{\text { s- mails anviados }}$ \\
\hline
\end{tabular}

Tabla 2 - Efectividades en e-mail marketing

\subsection{FACTORES DE INFLUENCIA}

\subsubsection{Categorización de factores de influencia}

Una gran parte de la literatura existente sobre e-mail marketing tiene como objetivo la identificación de elementos o variables de influencia en la efectividad de las campañas. Haq (2009) describe dos enfoques diferenciados. El primero tiene un carácter cuantitativo, y se centra en evaluar la influencia de diversos atributos de los correos electrónicos en su efectividad. En estos casos, los datos analizados suelen provenir de experimentos o ser proporcionados por empresas, y revelan el comportamiento del consumidor de manera implícita (Nichols, 1997). El segundo enfoque, por el contrario, se centra en evaluar las percepciones y comportamientos del consumidor ante correos promocionales, aplicando teorías psicológicas o modelos de comportamiento al espacio del e-mail marketing y validando los resultados con encuestas y -en algunos casos- con datos basados en campañas reales. En este segundo tipo de estudios, los datos recogidos son explícitos, puesto que el consumidor los proporciona de manera directa (Nichols, 1997).

Estos elementos nos permiten articular los diferentes constructos que se identifican en los estudios de comportamiento del consumidor en el contexto del e-mail marketing, y serán utilizados en esta investigación como variables independientes a la hora de estudiar la efectividad. A la vista del número y diversidad de los mismos, resulta conveniente agruparlos en categorías que permitan un análisis más sistemático. De este modo, la presente investigación distinguirá entre variables de contenido directamente visible, variables de contenido no directamente visible, variables temporales y variables contextuales.

Los elementos directamente visibles se particularizan por ser perceptibles sin que el consumidor realice ninguna acción. Por tanto, se limitarán a aquellos que se presentan cuando el usuario se enfrenta a su bandeja de entrada de correo. Una vez el e-mail ha sido abierto y el propio correo electrónico se revela en su totalidad, aparecerán los 
elementos no directamente visibles, es decir, aquellos que sólo pueden ser consultados tras abrir el correo.

Las variables temporales serán aquellas asociadas al momento de envío, tanto desde el punto de vista de un e-mail concreto como desde el que permite evaluar la relación entre varios correos enviados a la misma base de datos. Finalmente, las consideraciones contextuales se referirán a la introducción de elementos personalizados en los correos nombre, dirección, etc.- y a la segmentación.

\subsubsection{Variables de contenido visible}

Este tipo de variables se caracterizan por ser aparentes para el consumidor a la recepción del correo promocional antes de que éste realice ninguna acción. Su número y riqueza dependerá de la configuración de la bandeja de entrada y las capacidades del ISP del usuario. Las principales y más frecuentemente estudiadas son el asunto y el remitente (Balakrishnan \& Parekh, 2015). A pesar de ello, es común que algunos clientes de correo electrónico también muestren el pre-titular -preheader-, el tamaño del e-mail, la presencia de archivos adjuntos o la importancia del e-mail. Ninguno de estos elementos se menciona en la literatura de e-mail marketing, y por tanto el estudio inicial se reducirá a las dos principales.

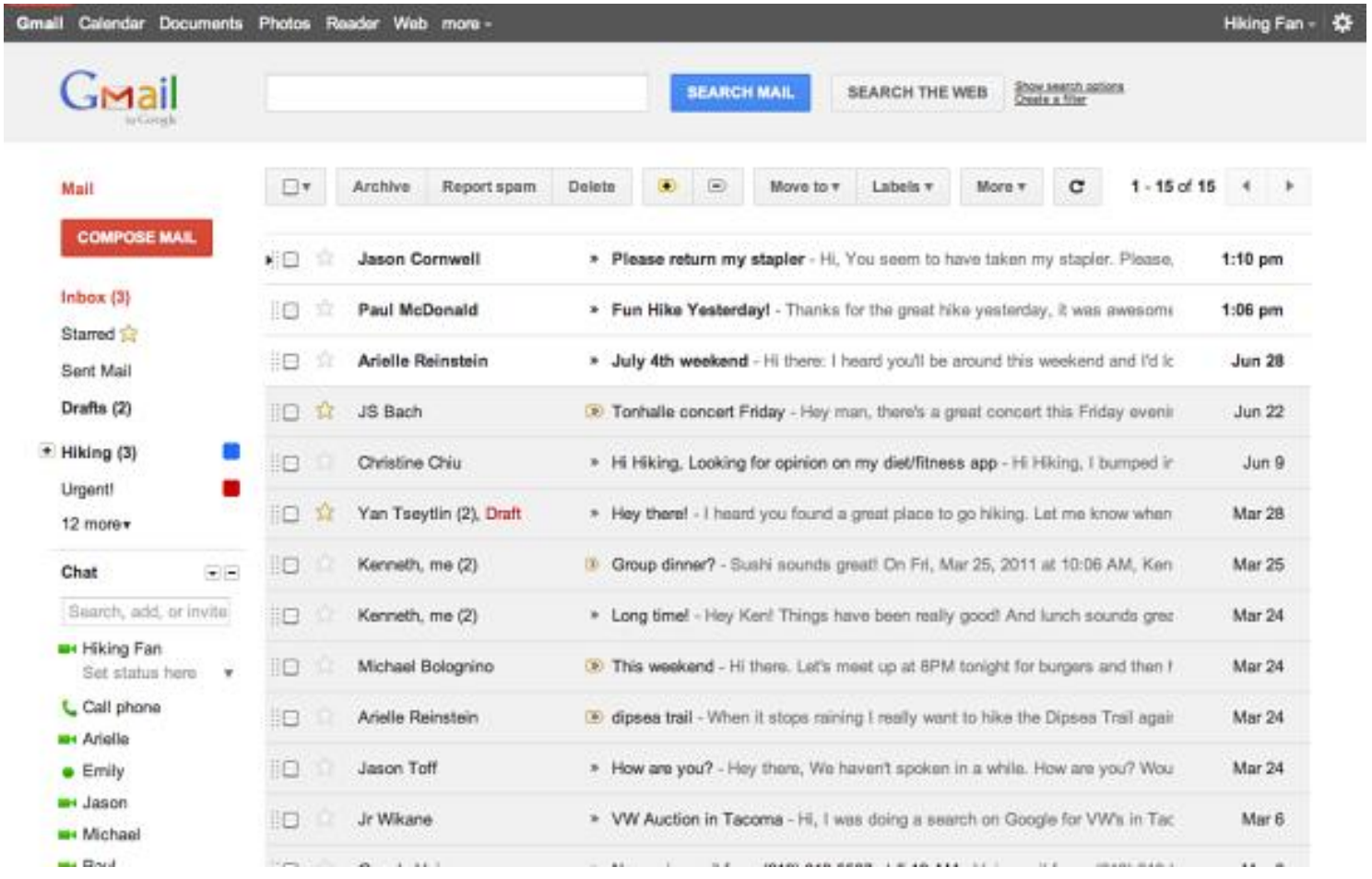

Figura 5 - Bandeja de entrada del cliente GMail

Pese a ciertas evidencias en contra de la relación entre remitente y asunto y la efectividad de apertura (San-José-Cabezudo \& Camarero-Izquierdo, 2012), ambos elementos son determinantes en la decisión de abrir un correo electrónico (Mogoș \& 
Acatrinei, 2015; Theerthaana \& Sharad, 2014). Se procederá por tanto a realizar un análisis detallado de los mismos.

\subsubsection{Asunto}

Comúnmente el asunto tiene como objetivo resumir el objetivo del correo de forma que el usuario pueda anticipar su contenido, permitiéndole determinar su pertinencia y el interés que tiene su lectura (Baggott, 2011). Asimismo, cumple funciones de referencia, puesto que ayuda a localizar un correo determinado cuando se realiza una búsqueda entre múltiples e-mails. Así, es un elemento fundamental, puesto que además de servir como primer soporte para el mensaje que pretende transmitir el anunciante, influencia en gran medida la posibilidad de que existan futuras interacciones con el e-mail. Un asunto poco claro o considerado irrelevante interrumpirá la comunicación con el usuario, mientras que un asunto que despierte interés o curiosidad tendrá más posibilidades de continuarla (Arnold, 2008).

La línea de asunto tiene 3.8 veces más efectividad a la hora de incidir en la efectividad de apertura que el remitente (Micheaux, 2011). Además, resulta mucho más fácil de manipular por parte de los responsables de e-mail marketing, puesto que un cambio de remitente requiere actuar sobre la configuración del ESP y la cuenta de correo asociada a los envíos, mientras que la edición del asunto es fácilmente ejecutable en la creación de cada nuevo correo. Es posible por tanto actuar sobre esta variable como medio para mejorar la efectividad de retención de suscripciones, la efectividad de apertura y la actitud del usuario ante el e-mail recibido. En este sentido, puede ser preferible alterar la línea de asunto antes que actuar sobre variables menos accionables como la frecuencia de envío, incluyendo por ejemplo elementos que identifiquen la comunicación como promocional (Micheaux, 2011) o añadiendo elementos informativos o entretenidos (Lu, $\mathrm{Fu}, \&$ Yen, 2007).

El estudio de la línea de asunto tiene diversas vertientes. Por un lado, puede abordarse desde una óptica puramente formal, analizando factores como su longitud o la presencia de determinados caracteres especiales; por otra parte, se puede afrontar desde un punto de vista semántico, evaluando el mensaje que pretende transmitir.

\subsection{Aspectos formales}

El aspecto formal se refiere al estudio del asunto como soporte de comunicación, y es relevante porque la presencia de números y ciertos caracteres especiales que no son habituales incrementan las posibilidades de que el consumidor preste atención al mensaje. Esto es así debido a que estos elementos permiten identificar una determinada comunicación publicitaria como promocional o relativa a un descuento, facilitando la captura de interés en el caso de que el consumidor esté contemplando la posibilidad de realizar una compra (Solomon et al., 2013). Por otra parte, un exceso de caracteres 
especiales puede incrementar las posibilidades de que el correo sea catalogado como spam (Arnold, 2008).

Asimismo, el estudio de su longitud es también pertinente, puesto que los textos extensos requieren un mayor intervalo de atención para ser procesados y obtienen una efectividad menor porque existen más posibilidades de que el consumidor decida ignorarlos (Solomon et al., 2013). Estas proposiciones generales sobre el proceso de percepción del consumidor son relevantes en el ámbito del e-mail marketing, puesto que pueden modular los comportamientos a la hora de evaluar la bandeja de entrada.

Además, existen consideraciones de índole práctica que también justifican el estudio de la longitud del asunto. En la mayoría de ISPs este elemento se trunca a partir del carácter número 50 (Groves, 2009), con lo que comunicaciones en las que se incluya información relevante a partir de ese punto se verán afectadas por esta situación. Este problema se exacerba debido a la difusión de los dispositivos móviles, en los que la anchura de pantalla es reducida y la necesidad de limitar la información es aún más acuciante.

En resumen, elementos como la longitud, la presencia de números y de ciertos caracteres especiales en el asunto pueden influir en la selección perceptual del usuario y, de hecho, permiten elaborar modelos de predicción de la tasa de apertura utilizando técnicas como el attribution scoring (Balakrishnan \& Parekh, 2015). Por este motivo, se incluirán estas tres variables en el estudio de la efectividad de apertura.

\subsection{Aspectos semánticos}

Desde un prisma semántico, la línea de asunto tiene como objetivo transmitir un determinado mensaje que capture la atención del consumidor y le incentive a abrir el correo electrónico. En la mayoría de casos, resume el contenido del e-mail y resalta sus aspectos fundamentales, si bien determinadas comunicaciones utilizan un enfoque disruptivo con el objeto crear diferenciación, utilizando juegos de palabras o creando suspense respecto al contenido del correo.

En general, y aunque se puede incrementar su relevancia incluyendo elementos que identifiquen la comunicación como contenido promocional (Micheaux, 2011), informativo o entretenido ( $\mathrm{Lu}$ et al., 2007), el mensaje comunicado no debe ser simplemente relevante, sino también interesante para lograr capturar la atención del consumidor (Kumar \& Salo, 2018). Puesto que los consumidores se subscriben a listas de correo comerciales para mantenerse al corriente de eventos, concursos, nuevos productos y programas de fidelización, pero muestran diferentes niveles de interés en cada una de estas temáticas (Carmen \& Nicolae, 2010), es de esperar que también presenten diferentes niveles de atención en función del contenido del asunto. 
La influencia del asunto está tradicionalmente asociada con la efectividad de apertura (Micheaux, 2011; Mogoș \& Acatrinei, 2015). Sin embargo, algunos estudios han analizado su influencia en la efectividad de clic, retención de suscriptores y conversión (Janke, 2014; Marinova et al., 2002; Micheaux, 2011; Theerthaana \& Sharad, 2014), obteniendo resultados contradictorios. Puesto que normalmente el asunto y el contenido del correo tienden a coincidir desde el punto de vista semántico, resulta complejo dilucidar la contribución individual de cada uno de estos elementos, puesto que ambos transmiten el mismo mensaje. Esto no sucede en el caso de la efectividad de apertura, ya que el usuario sólo ha sido expuesto a uno de ellos. Por este motivo, la presente investigación restringirá el estudio del asunto a su influencia sobre la efectividad de apertura.

Así, se pueden clasificar las líneas de asunto atendiendo su contenido o propósito (EllisChadwick \& Doherty, 2012). De esta forma, es posible establecer las siguientes categorías: promoción de ventas, información de producto, newsletter (noticias periódicas), requerimiento de acción, promoción de temporada e invitación a eventos. Esta categorización es consistente con la definición propuesta de efectividad y el contexto de esta investigación, ya que se encuentra orientada a objetivos particulares.

\subsubsection{Remitente}

El remitente de un e-mail identifica a la entidad que origina la comunicación y, por tanto, resulta una información importante a la hora de evaluar la relevancia de un correo. Normalmente esta variable se presenta como texto, en concreto, un nombre propio o el nombre de una empresa o departamento. Sin embargo, en algunos casos puede aparecer como una dirección de e-mail, lo que puede dificultar la identificación por parte del consumidor, situación poco deseable, ya que es fundamental que el remitente sea relevante, reconocible y estable (Groves, 2009)

Una adecuada gestión de esta variable puede mejorar la efectividad de apertura (Micheaux, 2011; San-José-Cabezudo \& Camarero-Izquierdo, 2012) y retención de suscriptores (Micheaux, 2011). Esto es así porque el remitente está asociado a la confianza que el consumidor deposita en el mensaje, lo cual influye en la intención de éste de realizar la acción que el anunciante persigue (Wilson, Hall-Phillips, \& Djamasbi, 2015). Además, esta variable permite identificar la autoridad del originador del correo, lo cual también influye en la efectividad del correo (Lim et al., 2016).

Las compañías experimentan con este elemento para mejorar los resultados de sus correos; por ejemplo, en los e-mails orientados a identificar potenciales compradores, la utilización del nombre de un agente en vez de una compañía incrementa la efectividad (Baggott, 2011). Sin embargo, esta variable resulta más compleja de manipular por 
parte de los responsables de e-mail marketing, puesto que su modificación implica la involucración de otros departamentos.

En general, el remitente de una base de datos comercial es estable, lo cual dificulta la experimentación. Así, pese a reconocer su importancia, esta investigación condicionará el análisis de esta variable a las características de la muestra estudiada.

\subsubsection{Variables de contenido no visible}

Tradicionalmente, las variables de contenido no directamente visible son las que más atención han recibido por parte de las empresas y comunidad científica, hecho probablemente causado por la errónea creencia de que el diseño y contenido del correo electrónico es la parte más influyente en el e-mail marketing (Baggott, 2011).

En esta categoría se encuadran aquellos elementos que sólo se revelan al usuario una vez ha abierto el correo electrónico. De manera similar al estudio realizado en el apartado anterior, en el análisis de los elementos de contenido no visible es pertinente diferenciar entre el aspecto formal, que se refiere al estudio del soporte del mensaje, y el aspecto semántico, que se refiere al significado del propio mensaje.

Puesto que el soporte general de los correos electrónicos son los ficheros HTML, en la evaluación de los aspectos formales del e-mail marketing resulta fundamental referirse a la morfología de este tipo de archivos. Los componentes fundamentales de un correo electrónico en formato HTML son el texto, las imágenes y los enlaces (Arnold, 2008) y, por tanto, es relevante efectuar un análisis detallado de cada uno de estos factores.

Es conveniente puntualizar que una vez abierto el correo, el dispositivo y el navegador que el usuario utilice para acceder al ISP pueden influir en la disposición de estos tres elementos (eMarketer, 2012). Por ejemplo, la reducida anchura de pantalla de los móviles implica que, a menos que se haya utilizado una técnica conocida como responsive design en el desarrollo del código HTML, los enlaces, imágenes y texto pueden aparezcer ilegibles o inutilizables (Gardner, 2011). Este hecho puede afectar a la efectividad de las variables de contenido no visible (bluehornet, 2013), e introducir ruido en la evaluación de su importancia relativa respecto a otras categorías de variables. En base a las cacterística de la muestra, esta investigación determinará si es posible incorporar este factor en la evaluación de la efectividad de las variables de contenido no visible.

\subsubsection{Aspectos formales}

\subsection{Texto}

El texto es el soporte fundamental del mensaje que el remitente pretende comunicar a través del correo electrónico. Una vez liberado de las estrictas limitaciones de longitud y 
formato que impone la línea de asunto, en el cuerpo del correo los responsables de las campañas publicitarias tienen la libertad de explayarse y construir un discurso que transmita los valores de la marca a la vez que incentive al consumidor a realizar la acción objetivo.

En este sentido, resulta especialmente importante la zona del correo que resulta visible sin realizar ningún movimiento de ratón -conocida como above the fold o por encima del pliegue (Mullen \& Daniels, 2009)-, puesto que será perceptible por todos los usuarios incluso si deciden no continuar interactuando con la comunicación (Groves, 2009). Esto es así porque los usuarios tienden a interactuar con un correo prestando mayor atención a la primera y última parte del mismo (Kumar \& Salo, 2018) y, por tanto, el contenido situado en estas áreas es especialmente crítico.

La variable fundamental que ha protagonizado los análisis del texto desde una óptica formal en la literatura es la longitud. Como se ha señalado en el análisis de la longitud del asunto, los textos extensos están asociadas a un esfuerzo superior por parte del consumidor en relación a los textos breves, lo que implica que los primeros son menos efectivos (Solomon \& Rabolt, 2009).

Así, la recomendación general en el ámbito del e-mail marketing es utilizar contenidos lo más cortos posibles (Arnold, 2008; Dufrene et al., 2005; Groves, 2009; Ting, 2012) aunque en determinadas ocasiones los textos más extensos demuestren una mayor efectividad (Baggott, 2011). Para poder aplicar con éxito esta recomendación es necesario determinar a partir de qué extensión se considera que un texto es largo. En este sentido, puede servir como referencia el hecho de que la longitud media de un correo electrónico es de 2.4 páginas (Ellis-Chadwick \& Doherty, 2012).

La influencia de la extensión del correo en algunas de las efectividades parciales que se han definido en esta investigación ha sido contrastada con experimentos específicos. En el estudio de la efectividad de clic, se han obtenido resultados contradictorios, en los que se ha demostrado que el incremento de esta variable puede afectar tanto de manera positiva (Kumar \& Salo, 2018) como negativa (Chittenden \& Rettie, 2003) al CTR. En el estudio de la efectividad de retención de suscriptores, se cree que la longitud incrementa el número de cancelación de subscripciones (Groves, 2009).

A la vista de estos resultados, parece razonable suponer que la extensión óptima de un correo puede venir determinada por el objetivo que persigue, y que por tanto es necesario experimentar con esta variable para determinar su valor adecuado (EllisChadwick \& Doherty, 2012).

\subsection{Imágenes}

Pese a que inicialmente los correos electrónicos no posibilitaban la utilización de componentes gráficos, tan pronto como la introducción de nuevos estándares permitió 
esta funcionalidad los responsables de bases de datos comerciales incorporaron rápidamente este formato a sus comunicaciones. Hoy la presencia de imágenes en emails promocionales es casi generalizada y, de hecho, el $90 \%$ de los e-mails contiene imágenes (Ellis-Chadwick \& Doherty, 2012).

La adición de este elemento ha permitido a los anunciantes nuevas posibilidades a la hora de comunicar su mensaje de manera más efectiva (Arnold, 2008). Así, mediante la adecuada integración de texto e imágenes, es posible transmitir una historia que permita al destinatario comprender la información mediante la interactuación con los diversos elementos (Tufte, 1995). Esto es así porque las imágenes incrementan la riqueza de la comunicación, y en el entorno online los soportes HTML con mayor riqueza son más efectivos (Simon \& Peppas, 2004).

Pese a que estudios preliminares afirman que los e-mails que contienen sólo texto pueden tener mayor eficiencia que los que contienen imágenes (Smart \& Cappel, 2003), que éstas no influyen en la efectividad de conversión (Theerthaana \& Sharad, 2014) y que el color de fondo tampoco parece influir en la efectividad de clic (Zviran et al., 2006), la presencia de imágenes contribuye significativamente a la mejora del CTR y, de hecho, esta variable mejora con el incremento del número de elementos gráficos (Chittenden \& Rettie, 2003).

Sin embargo, no es recomendable que las imágenes dominen la comunicación (Groves, 2009), y en ningún caso, que traten de paliar la ausencia de contenido (Tufte, 1995). Así, la determinación del número adecuado de imágenes en un correo promocional es un ejercicio delicado, puesto que resulta contraproducente incrementarlo a partir de un punto, ya que aumenta la complejidad del e-mail y puede dificultar la comprensión por parte del consumidor (Ellis-Chadwick \& Doherty, 2012). Esta investigación tratará de aportar mayor claridad sobre esta situación estudiando la incidencia del número de imágenes en la efectividad del e-mail marketing.

\subsection{Enlaces}

Debido a la limitación de funcionalidades inherente al entorno del correo electrónico, los remitentes de e-mail marketing necesitan en la mayoría de casos dirigir a los destinatarios a un sitio web que les permita completar la acción objetivo de la campaña. Un enlace es un componente web que genera una acción - en la mayoría de casos, la apertura de una página- cuando recibe un clic por parte del usuario (Arnold, 2008).

Los enlaces se incluyen en el cuerpo del correo, ya sea en el texto o directamente vinculados a elementos gráficos como botones o imágenes (Theerthaana \& Sharad, 2014). El 99\% de los correos electrónicos contienen enlaces (Ellis-Chadwick \& Doherty, 2012), y su presencia es absolutamente necesaria para justificar el sentido de la efectividad de clic. Sin embargo, la inclusión de enlaces en un correo no tiene influencia 
en la tasa de conversión (Theerthaana \& Sharad, 2014), puesto que ésta tiene lugar fuera del dominio del correo electrónico.

El posicionamiento de los enlaces en el e-mail también es relevante, siendo el lado izquierdo, y en concreto la parte superior izquierda, la más efectiva a la hora de lograr clics (Kumar \& Salo, 2018). Este resultado es consistente con los factores de selección de estímulos por parte del consumidor (Solomon \& Rabolt, 2009).

Si bien la necesidad de incluir este elemento en los correos electrónicos se considera casi incuestionable y no amerita ningún tipo de estudio, el número óptimo de enlaces es un tema de recurrente controversia. En primer lugar, cabe destacar el amplio rango de valores que puede tomar esta variable, puesto que existen correos tanto con un solo enlace como con cincuenta (Ellis-Chadwick \& Doherty, 2012).

Aunque el número de enlaces incrementa la efectividad de clic (Chittenden \& Rettie, 2003), se considera recomendable no abusar de este elemento, puesto que puede disminuir la atención prestada al mensaje (Ellis-Chadwick \& Doherty, 2012). Así, y puesto que todavía no se ha determinado el número óptimo de enlaces en una comunicación de e-mail (Ellis-Chadwick \& Doherty, 2012), esta investigación estudiará la influencia de esta variable en la efectividad del e-mail marketing.

\subsubsection{Aspectos semánticos}

La evaluación de la semántica de un correo electrónico se refiere al estudio del mensaje que el remitente pretende transmitir. Como se ha mencionado en apartados anteriores, el e-mail marketing suele tener como meta general el fomento del consumo de los productos del anunciante (Kotler \& Keller, 2012). Para la consecución de esta meta es común la utilización de diversas tácticas para influir en las percepciones del consumidor.

Una de las técnicas más recurrentes es la inclusión de razonamientos persuasivos que mejoren la actitud hacia el producto y justifiquen la compra (Kotler \& Keller, 2012). La componente cognitiva de las actitudes, que tiene en cuenta las creencias y pensamientos que el sujeto tiene hacia un determinado objeto, es más vulnerable que las componentes afectiva y de comportamiento a mensajes lógicos (Solomon et al., 2013). Además, la efectividad de mensajes persuasivos apoyados en argumentos lógicos es más elevada en aquellos consumidores involucrados en la categoría de productos que protagoniza la comunicación (Petty \& Cacioppo, 1986; Petty, Cacioppo, \& Goldman, 1981).

El hecho de que para convertirse en suscriptor de una base de datos los consumidores tengan que proporcionar su consentimiento y una serie de datos personales al anunciante implica una cierta involucración en la categoría. Por tanto, se puede inferir que en el entorno del e-mail marketing se espera que la utilización de mensajes que tratan de 
justificar la toma de una decisión de compra desde un punto de vista racional tenga una influencia positiva en la efectividad, puesto que la presencia de elementos que comuniquen claramente un beneficio mejora la eficiencia (Baggott, 2011). Algunos ejemplos de argumentos persuasivos son la existencia de un incentivo económico como un descuento o la disponibilidad limitada del producto anunciado, bien causada por un stock reducido o por la existencia de una fecha límite para realizar la compra (Arnold, 2008).

La presencia de incentivos económicos en los correos electrónicos promocionales aumenta la efectividad de clic (Chittenden \& Rettie, 2003; Sigurdsson et al., 2016) y conversión (Sigurdsson et al., 2013; Theerthaana \& Sharad, 2014), además de reducir la percepción de intrusión por parte del usuario causada por el envío (Chang et al., 2013; Lu et al., 2007). Existe por tanto un razonable consenso en cuanto a la efectividad de este tipo de mensaje, matizable en aquellos casos en los que el usuario no está interesado en la categoría de productos anunciada, puesto que en estas situaciones los incentivos económicos empeoran la efectividad (Sigurdsson et al., 2016).

Asimismo, la mención de una fecha límite para efectuar la acción requerida en un correo, u otro tipo de tácticas que persigan incrementar la sensación de urgencia y escasez mejoran la calidad de la comunicación (Baggott, 2011). Así, la presencia de este tipo de mensajes incrementa la efectividad de conversión (Shuey, 2014) y de clic (Groves, 2009) y, por tanto, contribuye de manera general a la eficiencia del canal.

Por todo lo anterior, en la evaluación de variables de contenido no visible desde un punto de vista semántico, esta investigación estudiará la influencia en la efectividad del e-mail marketing de los incentivos económicos y de las señales orientadas a crear sensación de escasez.

\subsubsection{Variables temporales}

Una vez finalizado del estudio de los componentes particulares de un correo electrónico y de su contenido, es necesario atender a variables externas a este medio con influencia demostrada en otros ámbitos de la comunicación promocional. Este es el caso de las variables temporales, puesto que el momento en el que ésta llega al consumidor puede influir en su efectividad (Barnes, 2002).

Es fácil imaginar que la relevancia para el usuario de una oferta de ocio nocturno será diferente un lunes respecto a un viernes, así como esperar que su voluntad de interactuar con contenido publicitario será superior cuando está desocupado -por ejemplo, mientras se encuentra en el transporte público- que en momentos del día en los que tiene que atender a otras labores. Asimismo, el número de ocasiones que el usuario ha sido expuesto a la comunicación promocional anteriormente es otra consideración de índole temporal que puede afectar a su predisposición respecto a la misma (Broussard, 2000). 
El estudio de variables temporales en el e-mail marketing es pertinente porque el momento en el que se envía un correo electrónico puede condicionar su efectividad (Barnes, 2002; Ellis-Chadwick \& Doherty, 2012). Además de variables temporales básicas como el día y la hora de envío, el número de e-mails enviados por el mismo remitente en los días anteriores también pueden inclinar la actitud del usuario en una $\mathrm{u}$ otra dirección, y contribuir a que éste decida ignorar las comunicaciones de una determinada compañía cuando considere que son demasiado persistentes (Haq, 2009). Por tanto, en este apartado se analizará tanto la influencia de la frecuencia como la del momento de envío.

\subsubsection{Frecuencia}

El estudio de la frecuencia de contacto publicitaria ha sido abordado de manera recurrente en el estudio de canales de comunicación tradicionales. En general, el objetivo de los anunciantes al analizar esta variable es determinar la frecuencia efectiva; esto es, el número de contactos necesario para que el mensaje transmitido sea asimilado y conduzca eventualmente a la acción perseguida por el anunciante (Broussard, 2000). Además de las características demográficas del segmento objetivo, en el cálculo de la frecuencia efectiva, es necesario considerar la notoriedad de la marca, la complejidad del mensaje y su novedad (Tellis, 1997).

En el entorno del e-mail marketing, el estudio de la frecuencia adopta otro enfoque, puesto que en vez de orientarse en determinar el número de veces que un mensaje ha de repetirse, se centra en el número de e-mails enviados a un consumidor durante un período determinado de tiempo (Micheaux, 2011). Esta variable se considera uno de los principales elementos de influencia en e-mail marketing (Baggott, 2011), puesto que afecta al proceso de percepción del consumidor. Cuando la frecuencia es muy elevada, desencadena la adaptación del usuario al estímulo perceptual -esto es, el consumidor determina que los últimos impactos no contienen ninguna información nueva, y que por tanto no merecen su interés-, reduciendo la efectividad de la comunicación (Solomon \& Rabolt, 2009).

Así, a los responsables de e-mail marketing se les plantea un dilema. Por una parte, una mayor cantidad de envíos genera mayores probabilidades de que el usuario preste atención a alguno de ellos, pero un exceso de frecuencia reduce el valor de la comunicación (Haq, 2009), y puede conducir a que el usuario decida cancelar su subscripción a la base de datos si considera que una compañía está "inundando" su bandeja de entrada de e-mails irrelevantes (Groves, 2009).

Se considera que el incremento de frecuencia no influye negativamente en la actitud del consumidor hacia el e-mail marketing (Haq, 2009). Es la percepción de presión promocional -definida desde un punto de vista del consumidor como un estado de 
irritación producido por el envío excesivo de e-mails por parte de una compañía- la que influye en esta variable y, de hecho, esta percepción no está relacionada con los mails que los suscriptores reciben realmente, sino con los que creen recibir (Micheaux, 2011).

Así, no existe una frecuencia adecuada para toda la base de datos, sino que varía por individuo y segmento (Baggott, 2011), y lo ideal es evaluar el potencial beneficio de cada nuevo e-mail en relación a la molestia que puede causar al consumidor (Dufrene et al., 2005). Asimismo, la frecuencia de contacto debería ajustarse en función de la frecuencia de compra del producto o servicio (Groves, 2009). Por ejemplo, para un producto de gran consumo debería ser superior que para un producto de consumo esporádico, como un coche.

En relación a la efectividad en el e-mail marketing, la frecuencia de envío influye en la tasa de apertura (Theerthaana \& Sharad, 2014), y en algunos casos, también en la efectividad de retención de suscriptores (Micheaux, 2011). Por tanto, esta investigación incorporará esta variable para poder determinar su importancia relativa respecto a los otros factores evaluados.

\subsubsection{Momento de envío}

El día de la semana y la hora de exposición han sido tradicionalmente elementos importantes en la optimización de campañas publicitarias, puesto que influyen en el comportamiento de los consumidores y su receptividad a los anuncios (Barnes, 2002). Por ejemplo, el momento de emisión afecta a la efectividad de los spots de televisión (Tellis, Chandy, \& MacInnis, 2005; Tellis, Chandy, \& Thaivanich, 2000) o de la publicidad de pago en buscadores (Kumar \& Tomkins, 2009; Rutz \& Bucklin, 2011).

Los responsables de e-mail marketing de algunas compañías consideran que estos dos factores también influyen en la efectividad de apertura (Ellis-Chadwick \& Doherty, 2012). Su estudio es, pues, relevante, dado que las campañas de e-mail marketing pueden ver su efectividad reducida independientemente de la calidad de su contenido si no se atiende a estas variables (Baggott, 2011; Groves, 2009). Un usuario puede decidir ignorar cierto e-mail si lo consulta a primera hora de un día laborable junto con muchos otros correos enviados durante la noche, o prestarle atención si lo consulta durante la tarde del fin de semana.

Existe sin embargo una importante puntualización: pese a que en el e-mail marketing la transmisión del mensaje es inmediata, el instante en el que se emite la comunicación publicitaria no coincide necesariamente con el momento en el que el destinatario la recibe. Los responsables de campañas de e-mail pueden determinar el instante en el que un suscriptor de una base de datos abre un correo electrónico, pero sin embargo resulta imposible establecer el momento en el que un usuario consulta la bandeja de entrada y 
decide abrir o no un correo. Así, el único dato disponible para la totalidad de una base de datos es el momento de envío.

Afortunadamente, y puesto que consultar la bandeja de entrada es la primera actividad que realizan los usuarios al conectarse al internet y la mayoría de ellos la visita varias veces al día (Faught, Whitten, \& Green, 2004), hecho facilitado por la accesibilidad del correo electrónico en los dispositivos móviles, resulta razonable suponer que habrá una ligera diferencia entre el momento de envío del correo y el momento en el que el usuario determina si ésta amerita su atención.

Por todo lo anterior, dada la importancia del día de la semana en otros canales publicitarios, y puesto que la comunidad científica todavía no ha determinado la hora óptima para enviar un correo electrónico (Ellis-Chadwick \& Doherty, 2012), esta investigación incorporará estas dos variables al estudio de la efectividad en el e-mail marketing.

\subsubsection{Variables contextuales}

Este apartado se centra en la evaluación de aquellos factores situacionales que no tienen una dimensión temporal, pero que pueden influir en la efectividad del e-mail marketing. Más concretamente, aborda aquellas técnicas que permiten al remitente adaptar la comunicación a las características de cada destinatario.

A la hora de diseñar contenido publicitario, los anunciantes se enfrentan al reto de crear una campaña que sea lo más relevante posible para el grupo heterogéneo de individuos que compone el universo de potenciales compradores. Así, pese a que diversos subgrupos de este conjunto pueden presentar barreras a la compra diferentes -que, por tanto, requieran argumentos de persuasión diferentes- resulta complejo mostrar a cada consumidor el anuncio adecuado.

Los medios de comunicación tradicionales permiten un elevado alcance en la difusión de publicidad, pero presentan limitaciones a la hora de personalizar del contenido de la misma (Barnes, 2002). Un spot situado en un determinado bloque de anuncios de un programa televisivo permite llegar a los espectadores de una manera muy simple, pero es casi inevitable que la comunicación promocional sea exactamente igual para todos ellos. Conscientes de la amenaza que esta limitación supone para sus futuros ingresos, las principales cadenas televisivas estadounidenses han empezado a trabajar conjuntamente con plataformas de venta de publicidad personalizada ( $\mathrm{Ng}, 2015)$, aunque estos esfuerzos son minoritarios hasta la fecha.

Algunos canales tradicionales permiten cierta flexibilidad geográfica -por ejemplo, el espacio publicitario disponible en las marquesinas de paradas de autobús- pero la utilización de atributos sociodemográficos para adaptar el mensaje al receptor resulta 
imposible en el entorno offline. Así, los anunciantes ejecutan sus campañas de compra de medios seleccionando aquellos espacios cuyas audiencias son más similares al público objetivo de su producto, utilizando por ejemplo las características generales de los habitantes de cada barrio para determinar en qué zonas de la ciudad posicionar publicidad exterior (Yancey et al., 2009). A pesar de esto, es inevitable que un número elevado de impactos publicitarios resulten irrelevantes.

La posibilidad de personalizar la publicidad ya sea a nivel de grupo -segmento- o de individuo en función de diferentes factores es una de las ventajas de los medios de comunicación digitales. El e-mail marketing es uno de los que mayor flexibilidad proporciona en este sentido, puesto que en el momento de la suscripción a la lista de correo las empresas suelen solicitar al consumidor diversos datos sociodemográficos. Asimismo, sus interacciones con las sucesivas comunicaciones y sus transacciones electrónicas permiten acumular información sobre sus intereses y períodos de actividad. Dichos registros posibilitan el diseño e-mails que se adapten mejor a sus inclinaciones y que, por tanto, obtengan mejores resultados (Bawm \& Nath, 2014; Jackson \& DeCormier, 1999). Por lo anterior, esta investigación abordará el estudio de la influencia de la personalización y la utilización de segmentos en la efectividad del email marketing.

\subsubsection{Personalización}

En el contexto del correo electrónico, la personalización se define como la utilización de contenido directamente asociado al receptor, como su nombre o su localización geográfica (Sahni et al., 2016). La inclusión de elementos personalizados se da en un tercio de los correos electrónicos promocionales (Ellis-Chadwick \& Doherty, 2012), y recuerda al consumidor que hay una relación preexistente entre él y el remitente (Ting, 2012).

La personalización hace a los correos más distintivos, lo que puede incrementar su eficiencia (Ansari \& Mela, 2003). Además, puede aumentar el grado de involucración del consumidor (Sahni et al., 2016), hecho que según la teoría del modelo de la probabilidad de elaboración de la persuasión (ELM) permite que los argumentos persuasivos sean más efectivos (Petty \& Cacioppo, 1986; Petty et al., 1981). Sin embargo, existe el riesgo de que el suscriptor reaccione de forma negativa ante lo que considera una invasión de su privacidad, un excesivo conocimiento de sus datos por parte de las empresas con las que se relaciona o incluso una amenaza hacia su libertad (White et al., 2008).

Existe controversia en el estudio de la influencia de la personalización en la efectividad del e-mail marketing. Ciertos autores lo consideran como un elemento importante a la hora de lograr de mejorar la efectividad de clic (Ansari \& Mela, 2003; Dufrene et al., 
2005; Postma \& Brokke, 2002), mientras otros defienden que puede influir negativamente tanto en la efectividad de clic como en la de retención de suscriptores para ciertos perfiles de consumidores (Marinova et al., 2002; White et al., 2008). Esto sugiere que existe un nivel adecuado de personalización en función de la etapa en la que la relación entre remitente y suscriptor se encuentre (Ellis-Chadwick \& Doherty, 2012).

Por ejemplo, es posible obtener una mejora significativa de efectividad de apertura, retención de suscriptores y conversión al incluir el nombre del receptor en el asunto, lo que causa un incremento de atención al mensaje y, por tanto, de la consideración de compra (Sahni et al., 2016). Pese a esto, es necesario minimizar el riesgo de rechazo por parte del consumidor. Para evitar reacciones negativas se debe justificar el motivo del uso de datos personales - por ejemplo, informando al usuario de que la comunicación se debe al lanzamiento de un servicio en su zona de residencia- puesto que, de no hacerlo, se incurre en el riesgo de disminuir la efectividad de clic (Marinova et al., 2002; White et al., 2008). Además, el CTR en e-mails con baja o ninguna personalización no es inferior a la de e-mails con alta personalización justificada (White et al., 2008). Por tanto, esta investigación analizará el impacto de la presencia de elementos personalizados en la efectividad del e-mail marketing con el objetivo de aportar una nueva perspectiva a la controversia existente en torno a este factor.

\subsubsection{Segmentación}

La segmentación de una base de datos se puede asimilar a un ejercicio de personalización que, en lugar de realizarse a nivel de usuario, se efectúa sobre un grupo de suscriptores. Sin llegar al nivel de precisión de la personalización, pretende hacer más interesante la comunicación para los destinatarios adaptándola a los intereses comunes del segmento (Baggott, 2011). Un ejemplo de esto sería la creación de segmentos en la base de datos de un banco en función de la edad de los suscriptores: se logra una comunicación más relevante si las hipotecas protagonizan los e-mails para el segmento más joven, y los productos de ahorro y planes de pensiones los envíos al segmento más senior.

Los datos más frecuentemente utilizados como base en la creación de segmentos son demográficos, de preferencia, de opinión y de comportamiento (Baggott, 2011), si bien el uso de interacciones del usuario con anteriores correos u otros elementos digitales resulta particularmente efectivo (Bawm \& Nath, 2014). Además de segmentaciones simples como la mencionada en el ejemplo anterior, es común la utilización de técnicas de puntuación como RFM -Recency, Frequency, Monetary value- (Mullen \& Daniels, 2009), en las que se evalúa a cada usuario en cada uno de estos tres aspectos, y se agrupa a los suscriptores en función de su puntuación total (Miglautsch, 2000). 
Así, determinando características e intereses comunes, es posible diseñar e-mails que se adapten mejor a las necesidades de grupos de usuarios y que, por tanto, produzcan mejores resultados, obteniéndose una efectividad de conversión superior al aplicar segmentaciones básicas (Jackson \& DeCormier, 1999). Métodos más complejos, como la agrupación de suscriptores utilizando datos históricos de tasas de apertura, CTR, interés dedicado a cada producto en la web y compras o emails enviados influyen positivamente en la efectividad de apertura, clic y conversión (Bawm \& Nath, 2014). Por tanto, la utilización de segmentos es una técnica adecuada para mejorar la efectividad del e-mail marketing, y es coherente introducir utilizar esta variable en esta investigación para determinar su importancia relativa respecto a otros factores.

\subsubsection{Resumen de factores de influencia}

A tenor de lo expuesto en los anteriores apartados, existen una serie de variables contextuales, temporales y de contenido directamente y no directamente visible que pueden influir en la efectividad del e-mail marketing. La tabla 3 resume los factores que formarán parte de la presente investigación según la literatura revisada, y la tabla 4 relaciona cada uno de ellos con los artículos en los que han sido estudiados.

Estos elementos ocuparán el lugar de variables independientes en el análisis posterior y, en función de las características de la muestra, será necesario determinar la manera más adecuada de operacionalizarlos para facilitar su estudio.

\begin{tabular}{|c|c|c|c|c|c|}
\hline \multicolumn{2}{|c|}{$\begin{array}{l}\text { Variables de contenido } \\
\text { directamente visible }\end{array}$} & \multicolumn{2}{|c|}{$\begin{array}{l}\text { Variables de contenido no } \\
\text { directamente visible }\end{array}$} & \multirow{2}{*}{$\begin{array}{l}\text { Variables } \\
\text { temporales }\end{array}$} & \multirow{2}{*}{$\begin{array}{c}\text { Variables } \\
\text { contextuales }\end{array}$} \\
\hline Formales & Mensaje & Formales & Mensaje & & \\
\hline $\begin{array}{l}\text { - Longitud } \\
\text { asunto } \\
\text { - Caracteres } \\
\text { especiales } \\
\text { asunto } \\
\text { - Presencia } \\
\text { de } \\
\text { números } \\
\text { asunto }\end{array}$ & $\begin{array}{l}\text { - Contenido } \\
\text { de la línea } \\
\text { de asunto } \\
\text { - Contenido } \\
\text { del } \\
\text { remitente }\end{array}$ & $\begin{array}{l}\text { - Longitud } \\
\text { texto } \\
\text { - Número de } \\
\text { imágenes } \\
\text { - Número de } \\
\text { enlaces }\end{array}$ & $\begin{array}{l}\text { - Incentivos } \\
\text { económico } \\
\text { s } \\
\text { - Sensación } \\
\text { de escasez }\end{array}$ & $\begin{array}{l}\text { - Frecuencia } \\
\text { - Día de la } \\
\text { semana } \\
\text { - Hora }\end{array}$ & $\begin{array}{l}\text { - Personalización } \\
\text { - Segmentación }\end{array}$ \\
\hline
\end{tabular}

Tabla 3 - Resumen de variables independientes 


\begin{tabular}{|c|c|c|c|c|c|c|c|c|c|}
\hline \multirow[b]{2}{*}{ Estudio } & \multicolumn{5}{|c|}{ Variables dependientes } & \multicolumn{4}{|c|}{ Variables independientes } \\
\hline & & שֶ. & Uี & 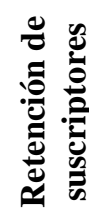 & 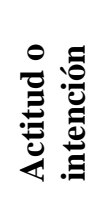 & 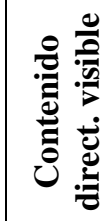 & 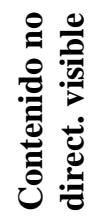 & 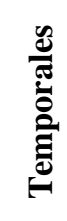 & 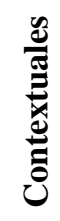 \\
\hline $\begin{array}{l}\text { Andersson, Fredriksson, y Berndt, } \\
2014\end{array}$ & & & & & $\mathrm{X}$ & & & & \\
\hline Balakrishnan y Parekh, 2015 & $\mathrm{X}$ & & & & & $\mathrm{X}$ & & & \\
\hline Bawm y Nath, 2014 & $\mathrm{X}$ & $\mathrm{X}$ & $\mathrm{X}$ & & & & & & $\mathrm{X}$ \\
\hline Carmen y Nicolae, 2010 & & & & & & & $\mathrm{X}$ & & \\
\hline Chang, Rizal, y Amin, 2013 & & & & & $X$ & & $\mathrm{X}$ & & \\
\hline Chen, Wang, Herath, y Rao, 2011 & & & & & $\mathrm{X}$ & & & & \\
\hline Chittenden y Rettie, 2003 & & $\mathrm{X}$ & & $\mathrm{X}$ & & $\mathrm{X}$ & $\mathrm{X}$ & & \\
\hline $\begin{array}{l}\text { Dufrene, Engelland, Lehman, y } \\
\text { Pearson, } 2005\end{array}$ & & & & & $\mathrm{X}$ & & & & \\
\hline Ellis-Chadwick y Doherty, 2012 & & & & & & $\mathrm{X}$ & $\mathrm{X}$ & $\mathrm{X}$ & \\
\hline Haq, 2009 & & & & & $\mathrm{X}$ & & $\mathrm{X}$ & $\mathrm{X}$ & \\
\hline Jackson y DeCormier, 1999 & & & $\mathrm{X}$ & & & & & & $\mathrm{X}$ \\
\hline $\begin{array}{l}\text { Jamalzadeh, Behravan, y Masoudi, } \\
2012\end{array}$ & & & & & $\mathrm{X}$ & & $\mathrm{X}$ & & \\
\hline $\begin{array}{l}\text { Jolley, Lee, Mizerski, y Sadeque, } \\
2013\end{array}$ & & & $\mathrm{X}$ & & & & & & \\
\hline Kumar y Salo, 2018 & $\mathrm{X}$ & $\mathrm{X}$ & $\mathrm{X}$ & & & $\mathrm{X}$ & $\mathrm{X}$ & & \\
\hline Lu, Fu, y Yen, 2007 & & & & & $\mathrm{X}$ & & $\mathrm{X}$ & & \\
\hline Marinova, Murphy, y Massey, 2002 & & $\mathrm{X}$ & & $\mathrm{X}$ & & $\mathrm{X}$ & $\mathrm{X}$ & & \\
\hline Micheaux, 2011 & $\mathrm{X}$ & $\mathrm{X}$ & & $\mathrm{X}$ & & & & $\mathrm{X}$ & \\
\hline Mogoș y Acatrinei, 2015 & & & & & $\mathrm{X}$ & $\mathrm{X}$ & $\mathrm{X}$ & & $\mathrm{X}$ \\
\hline Reichhart, Pescher, y Spann, 2013 & & $\mathrm{X}$ & $\mathrm{X}$ & & & & & & \\
\hline Sahni y Wheeler, 2016 & $\mathrm{X}$ & $\mathrm{X}$ & $\mathrm{X}$ & $\mathrm{X}$ & & & & & $X$ \\
\hline $\begin{array}{l}\text { San-José-Cabezudo y Camarero- } \\
\text { Izquierdo, } 2012\end{array}$ & & & & & $\mathrm{X}$ & $\mathrm{X}$ & $X$ & $X$ & \\
\hline Shuey, 2014 & & & & & $\mathrm{X}$ & & $\mathrm{X}$ & & \\
\hline $\begin{array}{l}\text { Sigurdsson, Hinriksson, y Menon, } \\
2016\end{array}$ & $\mathrm{X}$ & $\mathrm{X}$ & $\mathrm{X}$ & $\mathrm{X}$ & & & $\mathrm{X}$ & & $X$ \\
\hline $\begin{array}{l}\text { Sigurdsson, Menon, Sigurdarson, } \\
\text { Kristjansson y Foxall, } 2013\end{array}$ & $X$ & $\mathrm{X}$ & $\mathrm{X}$ & $\mathrm{X}$ & & & $\mathrm{X}$ & & \\
\hline Smart y Cappel, 2003 & & $\mathrm{X}$ & $\mathrm{X}$ & & & & $\mathrm{X}$ & & \\
\hline Theerthaana y Sharad, 2014 & & & & & $\mathrm{X}$ & $\mathrm{X}$ & $\mathrm{X}$ & $\mathrm{X}$ & $\mathrm{X}$ \\
\hline $\begin{array}{l}\text { White, Zahay, Thorbjornsen, y } \\
\text { Shavitt, } 2008\end{array}$ & & & & & $\mathrm{X}$ & & $\mathrm{X}$ & & $\mathrm{X}$ \\
\hline Zviran, Te’eni y Gross, 2006 & & $\mathrm{X}$ & & & & & $\mathrm{X}$ & & \\
\hline
\end{tabular}

Tabla 4 - Relación entre investigaciones anteriores y variables independientes 


\section{Capítulo 3 - Modelos de jerarquía de efectos. El modelo AIDA.}

3.1 EL ESTUDIO DE LA EFECTIVIDAD PUBLICITARIA

3.1.1 Teorías de jerarquía de efectos

3.2 EL MODELO AIDA

3.2.1 Atención

3.2.2 Interés

3.2.3 Deseo

3.2.4 Acción

3.3 APLICACIÓN DEL MODELO AIDA EN EL E-MAIL MARKETING

3.3.1 Crítica de AIDA: Debilidades y fortalezas

3.3.2 Aplicación de AIDA al e-mail marketing

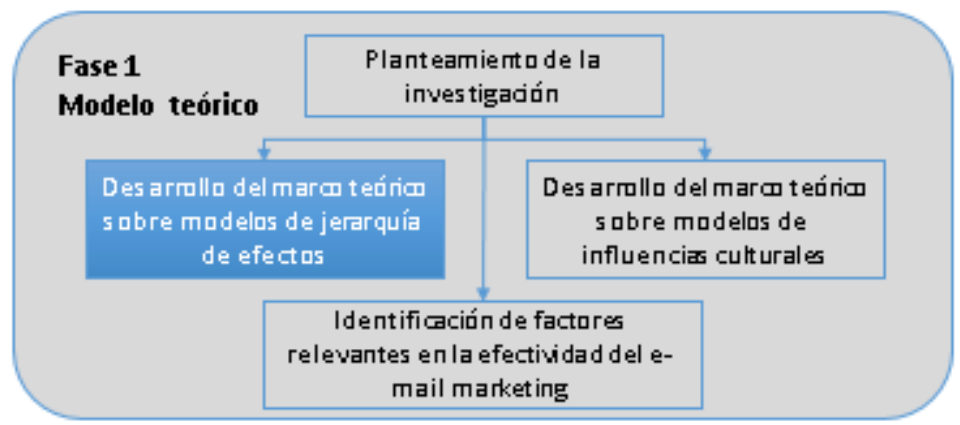




\section{MODELOS DE JERARQUÍA DE EFECTOS. EL MODELO AIDA}

\subsection{EL ESTUDIO DE LA EFECTIVIDAD PUBLICITARIA}

Desde la creación del marketing y el comienzo de la inversión publicitaria, una de las principales prioridades de los anunciantes ha sido encontrar maneras de evaluar los resultados de las campañas de medios. Múltiples aproximaciones han tratado de dar respuesta a este problema, si bien no existe un consenso en la comunidad científica respecto a manera más adecuada de medir la efectividad publicitaria (Moriarty, 1983). Sin embargo, se ha logrado alcanzar un razonable acuerdo sobre el sujeto de estudio: los anunciantes no deben enfocarse en el producto, sino en el consumidor (Kotler \& Keller, 2012).

La publicidad se puede definir como una comunicación persuasiva a través de medios masivos orientada a influir a una audiencia objetivo a la vez que informa de los productos y servicios de la compañía (Moriarty et al., 2012). Estos productos y servicios estarán orientados a satisfacer una necesidad del consumidor (Kotler \& Keller, 2012), ya sea esta de tipo utilitario - orientada a solventar problemas o necesidades- o expresivo - orientada a un uso social o estético- (Maclnnis \& Jaworski, 1989). Por tanto, se puede concluir que el objeto final de la publicidad es generar ventas (Lavidge \& Steiner, 1961) o, al menos, un aumento de la cuota de mercado de la compañía (Rehman, Nawaz, Ilyas, \& Hyder, 2014).

Los tres dominios básicos de la publicidad son la percepción, la educación y la persuasión (Moriarty, 1983). Así, los anuncios buscan fomentar respuestas cognitivas, emocionales (Maclnnis \& Jaworski, 1989) y conativas (Smith et al., 2008) a través de un proceso persuasivo que se puede interpretar como educacional (Moriarty, 1983; Wijaya, 2015).

La literatura recoge múltiples aproximaciones al estudio de la efectividad de la publicidad, pero según Scholten (1996) hay tres enfoques que dominan sobre todos los demás: los modelos de jerarquía de efectos (Lavidge \& Steiner, 1961; Strong, 1925), el modelo de probabilidad de elaboración (Petty \& Cacioppo, 1986; Petty et al., 1981; Petty, Cacioppo, \& Schumann, 1983) y el modelo de procesado de la información (McGuire, 1978) -que presenta una estructura hasta cierto punto similar a los modelos de jerarquía de efectos (Belch \& Belch, 2003).

Los modelos de jerarquía de efectos proponen una serie de estadios sucesivos que acercan al consumidor a la compra del producto (Kotler \& Keller, 2012), y serán analizados con más detalle en el apartado siguiente. El modelo de probabilidad de elaboración -ELM o Elaboration Likelihood Model- (Petty \& Cacioppo, 1986; Petty et 
al., 1981, 1983) propone la existencia de dos rutas alternativas para modificar la actitud del consumidor: la central, basada en la reflexión sobre argumentos lógicos, y que el consumidor adopta cuando está motivado y capacitado para ello, y la periférica, adoptada en caso contrario y basada en otros procesos como inferencias o asociaciones de ideas. Por su parte, el modelo de procesado de la información -IPM o Information Processing Model- (McGuire, 1978) propone la existencia de seis etapas en la interacción del consumidor con la comunicación publicitaria -presentación, atención, compresión, conclusión, retención y comportamiento- que determinan la actitud que éste adopta hacia el producto objetivo.

Tanto el modelo ELM como el modelo IPM presentan a primera vista ciertas incompatibilidades con el alcance y enfoque que esta investigación ha planteado en el estudio de la efectividad en el e-mail marketing. ELM requiere valorar la capacitación y motivación del consumidor a la hora de abordar la interacción con el correo electrónico, tarea que implicaría la recogida de datos explícitos -posiblemente a través de entrevistas- y que limitaría la muestra a un número de sujetos con los que resultaría imposible desarrollar un análisis estadístico robusto, dada la gran cantidad de factores de influencia identificados. IPM presenta una problemática similar, puesto que resultaría sumamente arriesgado aventurar un vínculo entre las etapas de comprensión, conclusión y retención y los datos implícitos de campañas reales en los que pretende basarse esta tesis.

A la vista de lo anterior, se procederá a realizar un análisis detallado de las teorías de jerarquía de efectos con el objetivo de identificar un modelo simplificado que se adecúe a la definición de eficiencia en el e-mail marketing propuesta en los anteriores capítulos.

\subsubsection{Teorías de jerarquía de efectos}

Como se ha mencionado anteriormente, el objetivo final de las campañas de publicidad es generar ventas para la compañía (Kotler \& Keller, 2012). Las acciones de marketing no alcanzan este fin de manera inmediata, sino que logran objetivos intermedios como incrementar la notoriedad de una marca entre consumidores que la desconocen o contribuir a la difusión de sus beneficios específicos entre los que ya la conocen, objetivos que eventualmente acercan al consumidor al momento de la compra y, por tanto, generan un incremento de ventas (Lavidge \& Steiner, 1961). Utilizando como base el mismo principio, las teorías de jerarquía de efectos postulan que las diferentes interacciones entre el consumidor y anunciante hacen atravesar a éste a través de una serie de estadios cada vez más cercanos al objetivo final de la marca, esto es, la venta del producto (Rehman et al., 2014a).

Estos modelos proponen una respuesta sistemática en la que cada una de las etapas secuenciales es claramente identificable y analizable de manera independiente (Smith et 
al., 2008), creando un marco de medida adecuado para evaluar su efectividad (Cramphorn, 2006). Así, presentan una cadena de vínculos causales entre fases con el objetivo de caracterizar el comportamiento del consumidor en ciertos instantes (Bauman et al., 2008). Estas etapas no tienen por qué ser equidistantes (Lavidge \& Steiner, 1961), pero se desarrollan de forma ordenada en el tiempo (Barry \& Howard, 1990).

La popularidad de los modelos de jerarquía de efectos no se restringe al estudio de la publicidad y, de hecho, otros ámbitos de la investigación psicológica y de comportamiento han utilizado con éxito modelos similares (Belch \& Belch, 2003). Este es el caso de la teoría de adopción de innovaciones, que define las diferentes etapas que atraviesa una innovación tecnológica desde que comienza a ser adoptada por una pequeña comunidad de usuarios hasta que se generaliza (Rogers, 1962).

A lo largo del último siglo se han propuesto múltiples modelos de jerarquía de efectos con el objetivo de identificar estrategias para incrementar la demanda (Scholten, 1996). El modelo AIDA -atención, interés, deseo y acción- (Strong, 1925) es el más popular de ellos, y se detallará en el siguiente apartado. Además de AIDA, cabe destacar dos modelos clásicos con gran influencia en el marco teórico de algunas variaciones modernas (Kotler \& Keller, 2012), resumidos en la tabla 5.

\begin{tabular}{|c|l|l|l|l|}
\cline { 2 - 5 } \multicolumn{1}{c|}{ Etapa } & \multicolumn{1}{|c|}{ AIDA } & \multicolumn{1}{c|}{$\begin{array}{c}\text { Jerarquía de } \\
\text { efectos }\end{array}$} & $\begin{array}{c}\text { Adopción de } \\
\text { innovaciones }\end{array}$ & $\begin{array}{c}\text { Procesamiento } \\
\text { de la } \\
\text { información }\end{array}$ \\
\hline Cognitiva & Atención & $\begin{array}{l}\text { Notoriedad } \\
\text { Conocimiento }\end{array}$ & Notoriedad & $\begin{array}{l}\text { Presentación } \\
\text { Atención } \\
\text { Comprensión }\end{array}$ \\
\hline Afectiva & $\begin{array}{l}\text { Interés } \\
\text { Deseo }\end{array}$ & $\begin{array}{l}\text { Afecto } \\
\text { Preferencia } \\
\text { Convicción }\end{array}$ & $\begin{array}{l}\text { Interés } \\
\text { Evaluación }\end{array}$ & $\begin{array}{l}\text { Aprovechamiento } \\
\text { Retención }\end{array}$ \\
\hline Comportamiento & Acción & Compra & $\begin{array}{l}\text { Prueba } \\
\text { Adopción }\end{array}$ & Comportamiento \\
\hline
\end{tabular}

Tabla 5 - Principales modelos de jerarquía de efectos. Adaptada de Belch \& Belch, 2003 y Kotler \& Keller, 2012

La propuesta de Lavidge y Steiner (1961) fue especialmente innovadora, puesto que observó por primera vez las diferentes fases de los modelos de jerarquía de efectos bajo un prisma psicológico, interpretando la interacción anuncio-sujeto como una secuencia primero cognitiva, posteriormente emocional y finalmente conductual (Rehman et al., 2014a), estructuración que fue aceptada e incorporado por varias modelos posteriores (Barry \& Howard, 1990; Smith et al., 2008). Por su parte, el modelo DAGMAR Defining Advertising Goals for Measured Advertising Results, o definición de los objetivos de la publicidad para obtener resultados medibles- (Colley, 1961) fue particularmente novedoso porque propuso que los efectos de la comunicación eran la 
base lógica de los objetivos de la publicidad (Belch \& Belch, 2003). Así, articulando esta interacción en las etapas de notoriedad, comprensión, convicción y acción, tuvo una popularidad superior a la de cualquier otro modelo en los años posteriores a su publicación (Ghirvu, 2013).

A lo largo de los siglos XX y XXI los modelos de jerarquía de efectos han sido utilizados recurrentemente por la industria y la comunidad investigadora para abordar el análisis de la efectividad de la publicidad (Bauman et al., 2008; Jagpal, 1981; Smith et al., 2008). Asimismo, pueden aplicarse al estudio de la comunicación online (Bruner \& Kumar, 2000; Florès, 2014) y, de hecho, varios estudios proponen aproximaciones basadas en jerarquía de efectos para el análisis de la efectividad en motores de búsqueda (Gauzente, 2009) o banners (Goodrich, 2011). Por consiguiente, y a la vista de que los modelos de jerarquía de efectos resultan un punto de partida adecuado para estudiar de efectividad de e-mail marketing, a lo largo del siguiente apartado se procederá a la evaluación en detalle del modelo AIDA, considerado como la propuesta primigenia y más representativa de esta tipología de modelos (Florès, 2014; Huey, 1999; Rehman et al., 2014a).

\subsection{EL MODELO AIDA}

El modelo AIDA, tal vez el más popular de los modelos que emplean la teoría de jerarquía de efectos, se remonta a finales de siglo XIX, momento en el que E. St. Elmo Lewis desarrolla una guía para vendedores en la que identifica atención, interés y deseo como las sucesivas etapas cognitivas que atraviesa un potencial comprador conforme se acerca a la adquisición de un producto (Strong, 1925). Posteriormente, el mismo Lewis añade una fase final -acción- que pretende reflejar el momento de la compra (Strong, 1925). A lo largo de las siguientes décadas, múltiples autores añaden y eliminan etapas (tabla 6) en un intento de explicar de manera más precisa el comportamiento del consumidor o incorporar los sucesivos adelantos tecnológicos, generando variaciones como AICA, AIDAS, AICCA o IADCA (Barry \& Howard, 1990; Wijaya, 2015) que, en algunos casos, simplemente suponen cambios de nomenclatura (Barry \& Howard, 1990).

Pese a su aparente simplicidad y a ciertas evidencias en contra de la relación causal entre sus tres primeras etapas (Cramphorn, 2006), AIDA ha sobrevivido a las diversas transformaciones que los medios de comunicación han experimentado durante las últimas décadas, y resulta una herramienta adecuada para abordar el estudio de la efectividad en el marketing digital (Ashcroft \& Hoey, 2001).

A lo largo de los siguientes apartados, se desarrollarán en detalle cada una de las etapas de AIDA desde un punto de vista teórico, con el objetivo de tratar de vincularlas a 
posteriori con las diferentes medidas de efectividad parcial del e-mail marketing definidas en el capítulo 2 .

\begin{tabular}{|l|l|l|}
\hline Año & \multicolumn{1}{|c|}{ Modelo } & \multicolumn{1}{|c|}{ Autor } \\
\hline 1898 & AID: Atención, Interés, Deseo & E. St Elmo Lewis \\
\hline 1900 & AIDA: Atención, Interés, Deseo, Acción & E St Elmo Lewis \\
\hline 1910 & AICA: Atención, Interés, Convicción, Acción & Printers Ink Editorial \\
\hline 1911 & AIDAS: Atención, Interés, Deseo, Acción, Satisfacción & Arthur F. Sheldon \\
\hline 1915 & $\begin{array}{l}\text { AICCA: Atención, Interés, Confianza, Convicción, } \\
\text { Acción }\end{array}$ & Samuel R . Hall \\
\hline 1921 & AIDCA: Atención, Interés, Deseo, Precaución, Acción & Robert E. Ramsay \\
\hline 1921 & AIDCA: Atención, Interés, Deseo, Convicción, Acción & Harry D. Kitson \\
\hline 1922 & AUA: Atención, Interés, Juicio, Acción & Alexander Osbom \\
\hline 1940 & AIDCA: Atención, Interés, Deseo, Convicción, Acción & Clyde Bedell \\
\hline 1956 & AIDMA: Atención, Interés, Deseo, Memoria, Acción & Merrill Devoe \\
\hline 1961 & ACCA Conciencia, Comprensión, Convicción. Acción & Russell H. Colley \\
\hline
\end{tabular}

Tabla 6 - Resumen de principales modelos de jerarquía de efectos propuestos a lo largo del siglo XX. Adaptado de Wijaya (2015) y Barry \& Howard (1990)

\subsubsection{Atención}

La atención es un campo de la psicología perceptual clave en la efectividad de la publicidad (Moriarty, 1983), y forma parte de la mayoría de modelos de jerarquía de efectos (Wijaya, 2015; Yoo, Kim, \& Stout, 2004) e incluso de teorías con estructuras alternativas que utilizan este factor para definir diferentes estadios de sensibilidad del consumidor (Maclnnis \& Jaworski, 1989). En un entorno saturado de mensajes publicitarios, en el que cada persona recibe entre 1000 y 5000 impactos promocionales diarios (Martí Parreño, Cabrera García-Ochoa, \& Aldás Manzano, 2013), la popularidad de este constructo en los modelos resulta natural, ya que el primer objetivo que toda campaña de marketing persigue es fijar la atención del consumidor. En este contexto, la RAE define la atención como la "acción de aplicar voluntariamente el entendimiento a un objeto espiritual o sensible" (Real Academia Española, 2014). Desde un punto de vista psicológico, la atención se considera un recurso cognitivo limitado (Kahneman, 1973) que puede aplicarse en diversos grados a un objeto (Maclnnis \& Jaworski, 1989). Pese a que existe una componente de la atención que es involuntaria, en general los individuos deciden de manera consciente los estímulos a los que atienden -lo que se conoce como atención selectiva- tras haber registrado, almacenado y reconocido la información perceptual (Kahneman, 1973). 
A la vista de lo anterior, resulta necesario que los anunciantes presenten a los consumidores un estímulo inicial que, tras ser procesado inicialmente, les lleve a concluir que un anuncio amerita su atención. Para lograr este objetivo, suele ser habitual la incorporación en la publicidad de elementos novedosos que se aparten de lo normal y generen diferenciación (Yoo et al., 2004). Manejando variables como el tamaño del anuncio, su color, la posición que ocupa en el medio de comunicación o su potencial de ser percibido como una información novedosa, las empresas tratan de influir en el proceso de selección perceptual para asegurar que sus comunicaciones no se pierden en el sinnúmero de estímulos que el consumidor ha de procesar (Solomon et al., 2013). En aquellos casos en los que el nivel de involucración del consumidor en el anuncio es elevado, aumentará la intensidad con la que percibe las señales que tratan de capturar su atención (Maclnnis \& Jaworski, 1989). De esta manera, el estudio de la atención en el contexto de la publicidad se centra en los primeros momentos en los que en el consumidor interactúa con el contenido promocional. En el caso de que dicha interacción no sea positiva, la comunicación se truncará y el mensaje publicitario no será percibido en su totalidad.

\subsubsection{Atención en el e-mail marketing}

En el contexto del e-mail marketing, el momento tradicional en el que el consumidor decide si otorgar atención a un correo tiene lugar cuando consulta la bandeja de entrada. Pese a que la progresiva expansión de los teléfonos móviles inteligentes y la popularidad de las aplicaciones de correo ha conseguido que un abundante número de usuarios pueda tomar esta decisión cuando recibe una notificación en la pantalla inicial de su teléfono móvil, a efectos de esta investigación nos referiremos exclusivamente a la bandeja de entrada como el lugar en el que sucede la primera interacción con un correo.

Es llamativa la mención de la existencia de un desorden de déficit de atención en el email marketing -basada en el hecho de que sólo una de cada tres palabras es leída(Mullen \& Daniels, 2009), afirmación tal vez exagerada pero hasta cierto punto justificable a la vista del elevado número de correos que cada usuario recibe, tanto legítimos como no deseados. En general, es más difícil que el spam logre captar la atención, puesto que los impactos promocionales no solicitados reducen el nivel de involucración del consumidor (San-José-Cabezudo \& Camarero-Izquierdo, 2012). En cuanto a los envíos legítimos, y pese a que en ellos no se da esta problemática, es necesario que contengan información no sólo relevante, sino también interesante para captar la atención del usuario (Kumar \& Salo, 2018). Algunas técnicas para capturar la atención en este entorno son el uso de elementos disruptivos (San-José-Cabezudo \& Camarero-Izquierdo, 2012), útiles porque producen un contraste en relación a los otros impactos publicitarios (Smith et al., 2008), y la utilización de elementos pictóricos correctamente localizados en el soporte publicitario (Goodrich, 2011). 
Pese a que la atención ha sido tradicionalmente una variable compleja de medir en la mayoría de canales de comunicación (Florès, 2014), una de las características del e-mail marketing es que el que el consumidor debe efectuar una acción -abrir el e-mail- para consumir el mensaje promocional. Esta particularidad permite detectar de manera fehaciente el número de consumidores que ha prestado atención a un correo. Se establece así un paralelismo entre lo que anteriormente se ha definido como eficiencia de apertura y la capacidad de conseguir situar al consumidor en el primer estadio del modelo AIDA (Arnold, 2008). Esta aproximación también es consistente con otras aplicaciones del marco AIDA al estudio de la eficiencia de banners, en las que la primera interacción con el soporte publicitario se consideraba perteneciente a la fase de atención (Goodrich, 2011). Por ello, a efectos del modelo que se planteará en el capítulo cinco, la captura de la atención estará vinculada a la tasa de apertura de un determinado envío, y a la hora de interpretar las variables independientes que pueden influir en esta etapa se tomarán en cuenta las consideraciones que se han detallado en los anteriores párrafos.

\subsubsection{Interés}

La segunda etapa que según AIDA atraviesan los consumidores en su interacción con la publicidad es la del interés, definido por la RAE como "inclinación del ánimo hacia un objeto, persona, narración, etc.” (Real Academia Española, 2014). Desde un punto de vista psicológico, este estado presenta componentes tanto cognitivos (Wijaya, 2015) como afectivos (Hassan, Zaleha, Nadzim, \& Shiratuddin, 2015; Wijaya, 2015), lo que permite situarlo en el punto en el que las percepciones sensoriales comienzan a operar en el plano de las actitudes, opiniones y juicios.

Capturar la atención del usuario asegura que la comunicación entre anunciante y consumidor no se interrumpa nada más comenzar, pero para conseguir que dicha interacción se mantenga es necesario avanzar hasta la fase de interés. Para que un usuario alcance esta etapa es fundamental que disponga de un cierto conocimiento de los beneficios del producto (Hassan et al., 2015), lo que implica la necesidad de que se le transmita información básica sobre la campaña que le permita crearse un juicio ( $\mathrm{Su}$, Huang, Chen, \& Li, 2016). En consecuencia, el interés no tiene una dimensión temporal tan inmediata como la atención, sino que exige una interacción de cierta duración que asegure la correcta comunicación de los trazos generales del mensaje.

Para el estimular el interés es fundamental que la comunicación contenga un contenido novedoso (Hassan et al., 2015), lo que evita que el consumidor ignore el mensaje porque considere que ya ha sido expuesto a él y no va a obtener información nueva efecto conocido como adaptación perceptual (Solomon et al., 2013). Asimismo, la manera de presentar la información también tiene influencia en las probabilidades de alcanzar esta fase. En general es recomendable que los datos que se muestran al 
consumidor no parezcan obvios pero que tampoco resulten excesivamente complejos (Bruner \& Kumar, 2000), pues esto asegurará un correcto equilibrio entre sensación novedosa y facilidad de procesar la información expuesta.

Una de las consecuencias de la aparición de interés es su expresión activa (Ghirvu, 2013), que puede manifestarse a través del deseo de obtener más información acerca del objeto que suscita ese interés (Ashcroft \& Hoey, 2001). De esta manera, y en línea con lo esperado en un modelo de jerarquía de efectos, así como la atención actúa como puerta de entrada hacia el interés, el interés también actúa como fase introductoria hacia una relación más profunda entre usuario y marca en la que, en algunos casos, éste puede asumir la iniciativa de la comunicación.

En resumen, alcanzar la etapa de interés supone el mantenimiento de la comunicación entre anunciante y consumidor que se ha establecido en la fase de la atención, objetivo que las marcas tratan de alcanzar suscitando la curiosidad de éste con información adicional novedosa y fácilmente procesable.

\subsubsection{Interés en el e-mail marketing}

En línea con lo expuesto en los anteriores párrafos, el fomento del interés en el entorno online está asociado a estrategias informativas utilizando soportes interactivos que incluyen texto, imágenes, videos, etc. (Hassan et al., 2015). En general las páginas web son el lugar más efectivo a la hora de fomentar la aparición del interés (Lagrosen, 2005), hecho motivado por la mayor flexibilidad que ofrece este tipo de soporte en relación a todos los demás del entorno online. Así, pese a que tanto el e-mail marketing como las páginas web se desarrollan en formato HTML, el consumidor percibe una clara diferencia entre ambos (Cases et al., 2010).

En el entorno concreto del e-mail marketing, y a la vista de la necesidad de presentar una cantidad abundante de información que conduzca al usuario hasta la fase de interés, es razonable concluir que no será posible alcanzar esta etapa a menos que el receptor del correo lo haya abierto, puesto que los datos disponibles antes de la apertura del correo se reducen al remitente y a la línea de asunto, elementos que resultan insuficientes para el correcto establecimiento de un juicio. Así, la apertura del correo representa una frontera clara entre la atención y el interés, y por tanto este último sólo podrá aparecer una vez el usuario tenga acceso al correo completo.

Asumiendo la tesis de que el interés está asociado con una expresión activa que puede manifestarse como una búsqueda de información adicional (Ashcroft \& Hoey, 2001), es posible vincular esta etapa a la acción más natural para obtener más información en un e-mail; esto es, a hacer clic en alguno de los enlaces de la comunicación. Así, se puede establecer una relación entre la capacidad de suscitar interés en el consumidor y lo que anteriormente se ha definido como efectividad de clic (Florès, 2014), puesto que a 
través de esta acción el consumidor declara de manera implícita su intención de obtener más información. Asimismo, y bajo la premisa de que si una comunicación de e-mail no suscita interés en el consumidor éste reaccionará tratando de evitar futuros contactos (Micheaux, 2011), resulta también lógico establecer una relación entre la capacidad de despertar interés en el potencial comprador y lo que anteriormente se ha como efectividad de retención de suscriptores. En conclusión, esta investigación vinculará la etapa de interés según el modelo AIDA a las tasas de clic -relación positiva- y de retención de suscriptores -relación negativa-, y examinará los factores de influencia estas variables a la luz de las consideraciones detalladas en los anteriores párrafos.

\subsection{3 $\underline{\text { Deseo }}$}

En la siguiente etapa de AIDA aparece el deseo, entendido por la RAE como "el acto de aspirar con vehemencia al conocimiento, posesión o disfrute de algo" (Real Academia Española, 2014) y que, aplicado al contexto publicitario, podemos reducir a la aspiración a la posesión del producto o servicio publicitado (Hassan et al., 2015).

El deseo implica un estado emocional en el que el consumidor cree en la veracidad del mensaje publicitario (Wijaya, 2015), aspira e incluso sueña con el producto objetivo (Lin \& Huang, 2006) y se inclina a tomar la acción perseguida por la compañía, generalmente la compra del producto (Rehman et al., 2014a). Cuanto más fuerte sea este sentimiento de deseo, mayor será su intención de compra y, por tanto, mayores las posibilidades de que alcance el siguiente estadio (Mihart, 2012).

En este sentido, cabe destacar que el estado de deseo está asociado a los sentimientos hacia la marca (Cramphorn, 2006) y que, por tanto, la facilidad de alcanzar esta etapa variará en función de las interacciones previas entre el consumidor y la compañía. Así, a la hora de conseguir mejorar la efectividad de la comunicación, es especialmente relevante la adecuada definición del público objetivo al que alcanza la campaña ( $\mathrm{Su}$ et al., 2016), pues esto permitirá adaptar los mensajes a las necesidades específicas de cada segmento en función de su percepción de la marca.

A diferencia de la atención y el interés, la fase de deseo ha sido desde el origen de AIDA una de las que más controversia ha despertado, y múltiples autores la reemplazaron a principios del siglo XX por convicción, confianza o juicio (Strong, 1925). La evolución del estadio de interés al de deseo es sumamente difícil de medir (Ghirvu, 2013), puesto que la frontera entre la mera inclinación y la aspiración resulta difusa. Es además previsible que el consumidor, una vez haya desarrollado interés por el producto, comience a interactuar con múltiples fuentes y canales para adquirir más información. Estos mensajes, de los cuales sólo algunos son moderados por el anunciante, ayudarán a configurar su posición, y será complejo determinar la contribución individual de cada uno de ellos a la creación de deseo. 


\subsubsection{Deseo en el e-mail marketing}

En el entorno de la publicidad online las herramientas para provocar tanto interés como deseo coinciden, y se centran en la presentación de información, explicaciones sobre los productos (Hassan et al., 2015) y contenido elaborado e interactivo (Lagrosen, 2005). La inclusión en estos soportes de elementos persuasivos de carácter utilitario, como estímulos económicos para completar la compra, también juega un rol particularmente importante en esta fase (Hassan et al., 2015).

En el caso de la presente investigación, y aceptando la premisa de que una vez el consumidor ha alcanzado la etapa de interés ya ha abandonado el ISP y se encuentra en la web a la que dirigen los enlaces del e-mail promocional, es posible concluir que la aparición del deseo no sucede en el contexto de plataformas y herramientas asociadas al e-mail marketing. Así, identificar esta etapa implicará la utilización de métricas que nos permitan evaluar la interacción del consumidor con el contenido de la web.

En un contexto limitado a las plataformas controladas por el anunciante, el número de páginas visitadas por sesión o el número de visitas por visitante único resultan medidas adecuadas para evaluar la aparición del estado de deseo según AIDA (Florès, 2014). Sin embargo, y de manera similar a lo expuesto en el segundo capítulo, existe la posibilidad de que el usuario consulte páginas similares no controladas por la marca, evalúe opiniones de otros usuarios, visite los perfiles corporativos en las redes sociales y, en resumen, acceda a información de muy variadas fuentes fuera del alcance de la compañía.

En este escenario, la evaluación exclusiva de la página web a la que apuntan los enlaces resultaría en una percepción sesgada del verdadero comportamiento del consumidor. Desafortunadamente, y a diferencia de lo detallado en el estudio de la efectividad de conversión en el capítulo 2, resulta imposible urdir un sistema de códigos unívocos y cookies que solucionen esta problemática, puesto que implicaría la cooperación de múltiples fuentes ajenas al anunciante. Por todo ello, esta investigación no vinculará la fase de deseo a ninguna etapa concreta del estudio de la efectividad en el e-mail marketing, y se limitará a asumir su aparición en plataformas tanto externas como controladas por el anunciante.

\subsubsection{Acción}

Finalmente, la última etapa de AIDA es la acción, definida por la RAE como el "resultado de hacer" (Real Academia Española, 2014), y que a la vista de los objetivos comerciales inherentes a cualquier campaña se asociará en la mayoría de casos a la compra del producto objetivo (Rehman et al., 2014a). Por este motivo, y de manera similar a la atención, este estadio forma parte de la mayoría de modelos de jerarquía de efectos (Wijaya, 2015). 
Desde un prisma psicológico, la acción se enmarca en un plano eminentemente conductual (Wijaya, 2015), y señala la exitosa finalización del proceso cognitivo diseñado por el anunciante (Ghirvu, 2013). Además, resulta la fase más fácilmente constatable de AIDA, debido a su carácter binario y la relativa simplicidad con la que puede medirse a través de herramientas ya existentes.

Para favorecer la etapa de acción, lo ideal es que el producto presente un beneficio claro para el consumidor y no exija un excesivo esfuerzo (Wilson et al., 2015). Esto es así porque esta fase es la más compleja de alcanzar del modelo debido a que el esfuerzo que supone alcanzar niveles sucesivos para el receptor del mensaje aumenta a medida que se avanza en cada etapa del proceso (Bauman et al., 2008). Además, esta circunstancia se verá influida por el hecho de que cuanto mayor sea el compromiso psicológico o económico que requiera una compra resultará más difícil persuadir al consumidor de que alcance la siguiente fase del modelo (Lavidge \& Steiner, 1961). A tenor de esto, resulta de especial relevancia que el análisis de este estadio se aborde con una muestra de productos con características similares.

\subsubsection{Acción en e-mail marketing}

Dadas las posibilidades que ofrece el comercio electrónico, el entorno online resulta un marco adecuado en el que alcanzar la última fase de AIDA (Hassan et al., 2015). En el entorno del e-mail marketing, y a la vista de la definición expuesta en el capítulo segundo, existe una equivalencia exacta entre la efectividad de conversión y la capacidad de lograr que los receptores del correo alcancen esta fase. Sin embargo, y debido de nuevo a la posibilidad de que el consumidor interactúe con otros elementos adicionales al correo, es complejo determinar la influencia de cada uno de ellos en la consecución de la acción perseguida (Jordan, Mahdian, Vassilvitskii, \& Vee, 2011). Por consiguiente, en la evaluación del número de suscriptores que alcanzan esta última etapa de AIDA el modelo de atribución utilizado tendrá una importancia capital, y por ello esta investigación vinculará la etapa de acción a la efectividad de conversión, y evaluará su aparición a través de la tasa de conversión.

\subsection{APLICACIÓN DEL MODELO AIDA EN EL E-MAIL MARKETING}

\subsubsection{Crítica de AIDA: Debilidades y fortalezas}

Una vez desarrolladas las diferentes fases de AIDA y determinada su vinculación a las etapas del e-mail marketing, resulta adecuado establecer sus carencias y fortalezas para evaluar la pertinencia de su uso. En primer lugar, AIDA se puede considerar un modelo excesivamente simple (Moriarty, 1983) y que, por ello, presenta ciertas limitaciones a la vista de los resultados de investigación más recientes. Entre las más importantes, 
destacan el asumir que cada etapa está conectada con la anterior (Moriarty, 1983), que las decisiones del consumidor son racionales (Barnham, 2008; Moriarty, 1983) y que éste atraviesa un proceso lineal y ordenado de interacciones discretas que obvia la interrelación entre fases cognitivas y emocionales (Barry \& Howard, 1990; Huey, 1999).

Asimismo, no incorpora elementos con probada influencia en el comportamiento del consumidor, como su capacidad de procesar información (Maclnnis \& Jaworski, 1989), su lealtad a la marca (Kotler \& Keller, 2012) o su nivel de elaboración (Petty \& Cacioppo, 1986; Petty et al., 1981), situándole en una posición reactiva frente a la información que recibe, en lugar de percibirlo como una entidad proactiva que se sirve de la información disponible para tomar decisiones (Huey, 1999).

Por otra parte, AIDA resulta un método especialmente simple de aplicar (Huey, 1999), presentando cierta similitud con los árboles de decisión utilizados para modelar el procesamiento de la información del consumidor en el contexto de la compra de un producto (Bettman, 1970).

No obstante, y pese a las múltiples modificaciones que se han propuesto, el principio básico del modelo permanece intacto y todavía es relevante (Hassan et al., 2015), y sus sucesivas etapas ofrecen la ventaja de permitir identificar las contribuciones de contactos independientes (Kojima, Kimura, Yamaji, \& Amasaka, 2010). Además, permite aislar claramente las variables más importantes para comprender la respuesta del consumidor (Strong, 1925), y por este motivo resulta una herramienta valiosa desde un punto de vista de planificación empresarial, ya que permite acotar actividades y acciones específicas (Barry \& Howard, 1990).

En vista de lo anterior, es posible concluir que la principal ventaja e inconveniente de AIDA es su simplicidad. Por una parte, esta característica implica que es un modelo limitado apoyado en supuestos hasta cierto punto cuestionables, pero por otra lo convierte en especialmente práctico y operacional.

\subsubsection{Aplicación de AIDA al e-mail marketing}

Una vez estudiadas las diferentes fases de AIDA y analizadas sus debilidades y fortalezas, resulta necesario preguntarse si su uso en esta investigación es pertinente. Considerando en primer lugar el e-mail marketing como un canal perteneciente al entorno digital, se puede evaluar la idoneidad de AIDA en este dominio.

El consenso general es que AIDA es adecuado para modelar el objetivo de la comunicación online, que es estimular el consumo a través de contenido atractivo (Lagrosen, 2005), y puede aplicarse al estudio del marketing digital sin modificaciones (Ashcroft \& Hoey, 2001). De hecho, grandes compañías de la industria digital como 
Google lo integran en la estructuración de sus productos (Florès, 2014). Así, existen múltiples estudios que utilizan AIDA de manera satisfactoria para evaluar la efectividad de canales de comunicación online, como es el caso de publicidad en móviles (Rehman et al., 2014b; Su et al., 2016), redes sociales (Hassan et al., 2015; Lukka \& James, 2014; Wood \& Burkhalter, 2014), posicionamiento de producto en juegos online (Ghirvu, 2013), eficiencia de páginas web (Lagrosen, 2005) y blogs (Lin \& Huang, 2006).

Restringiendo el análisis al área específica del e-mail marketing, la utilización de AIDA parece una aproximación adecuada. En primer lugar, las tres etapas fundamentales en este canal -lograr que el receptor abra el e-mail, mantener su interés y persuadirle para que realice la opción objetivo (Theerthaana \& Sharad, 2014) - coinciden con las fases de atención, interés y acción de AIDA. Además, todos los modelos propuestos hasta la fecha tienen un carácter procesal muy similar a AIDA (Bawm \& Nath, 2014; Chittenden \& Rettie, 2003; Lim et al., 2016), y de hecho AIDA se ha utilizado con éxito en un estudio de eficiencia (Rehman et al., 2014b).

Como se ha detallado en los anteriores párrafos, existe un notable paralelismo entre las diferentes efectividades parciales que se han definido para el e-mail marketing y las etapas del modelo AIDA. Este hecho permite superar una de las dificultades más recurrentes de los modelos de jerarquía de efectos: la medida de la evolución del consumidor a lo largo de las diferentes etapas, y la forma de identificar el momento en el que se encuentra en cada una de ellas (Lavidge \& Steiner, 1961).

A la vista de que AIDA ha sido utilizado con éxito en el estudio de tanto el marketing digital como el e-mail marketing y de que existe un notable encaje entre este modelo y la manera de estructurar el análisis de la efectividad propuesta en anteriores capítulos, esta investigación utilizará AIDA para articular las etapas que el consumidor atraviesa en su interacción con el e-mail marketing.

Se introducirá sin embargo una ligera modificación en AIDA. Tal y como se ha mencionado anteriormente, la fase de deseo no será incluida en esta tesis, lo que simplificará el modelo en tres etapas asociadas a diferentes efectividades parciales. Esta aproximación es consistente con la estructuración de modelos de jerarquía de efectos en etapas cognitivas, afectivas y conativas propuesta por Lavidge \& Steiner (1963). A continuación, la figura 6 resume las diferentes fases de AIDA y su relación con las variables dependientes detalladas en este estudio. 


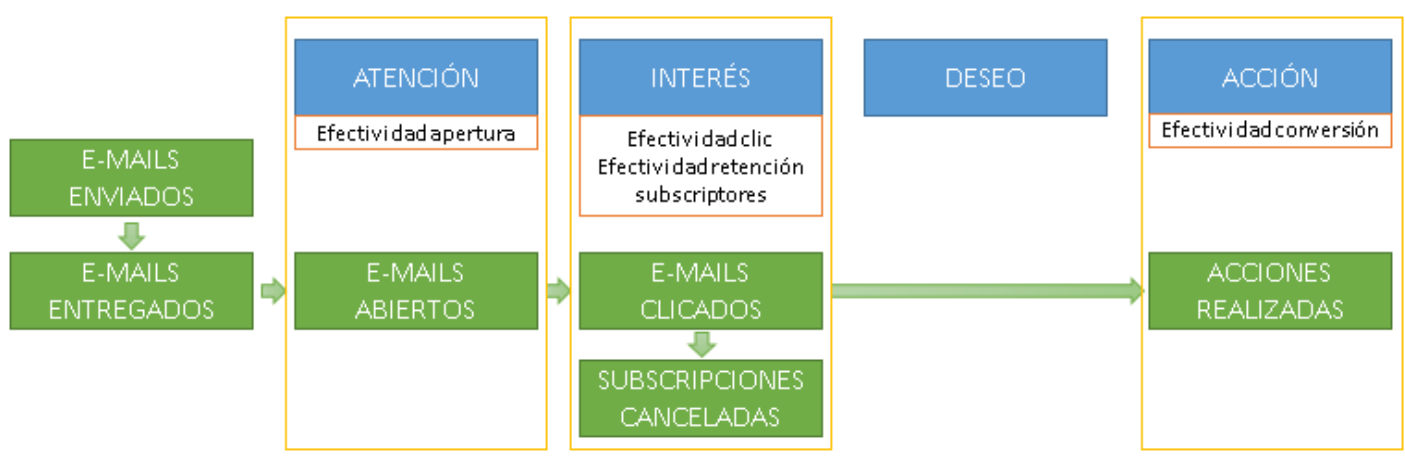

Figura 6 - Relación entre etapas de AIDA y acciones realizadas en el entorno del e-mail marketing. 


\section{Capítulo 4 - Modelos de dimensiones culturales. El modelo de Hofstede}

4.1 LA INFLUENCIA DE LA CULTURA EN EL COMPORTAMIENTO DEL CONSUMIDOR

4.1.1 Perfiles de consumidor en el entorno digital

4.1.2 La cultura y su influencia en el comportamiento del consumidor

4.1.3 Los modelos de dimensiones culturales

4.2 DIMENSIONES CULTURALES DE HOFSTEDE

4.2.1 Origen del modelo de Hofstede

4.2.2 Dimensiones culturales: modelo original

4.2.3 Dimensiones culturales: extensiones al modelo original

4.3 DIMENSIONES CULTURALES DE HOFSTEDE EN EL E-MAIL MARKETING

4.3.1 Critica del modelo de Hofstede

4.3.2 Aplicación del modelo de Hofstede al e-mail marketing

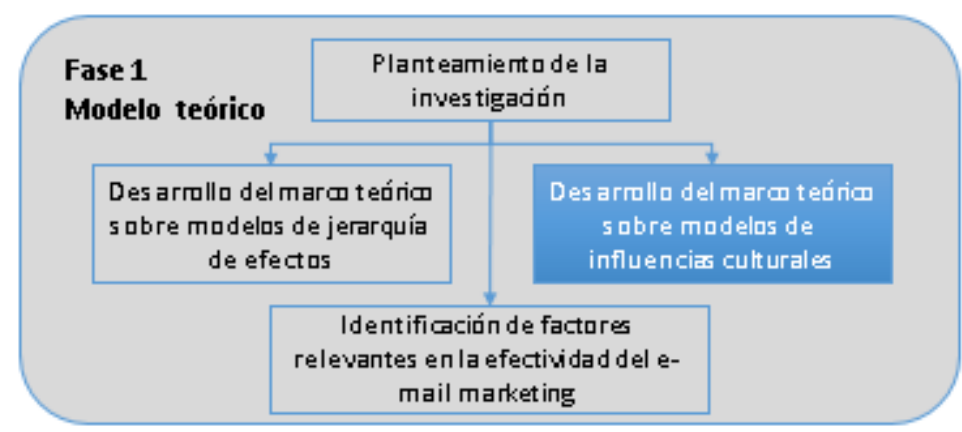




\section{MODELOS DE DIMENSIONES CULTURALES. EL MODELO DE HOFSTEDE}

\subsection{LA INFLUENCIA DE LA CULTURA EN EL COMPORTAMIENTO DEL CONSUMIDOR}

\subsubsection{Perfiles de consumidor en el entorno digital}

El capítulo anterior ha vinculado la estructura de efectividad en el e-mail marketing propuesta en el segundo capítulo con AIDA, un modelo general de comportamiento de consumidor. En la realización de este ejercicio se ha asumido implícitamente que el comportamiento de los destinatarios de correos electrónicos comerciales es razonablemente homogéneo. Esta premisa resulta aceptable en un entorno restringido, en el que los clientes de una empresa se limitan a un grupo acotado y recurrente.

Sin embargo, la idiosincrasia del entorno digital implica la automática ampliación del universo de usuarios potenciales de cualquier negocio tradicional que decida digitalizarse. Las limitaciones físicas y geográficas se disipan, y sólo permanecen aquellas que pueden representar una barrera al establecimiento de comunicación entre emisor y receptor: el acceso al canal -en 2016 un 47\% de la población mundial usaba internet (International Telecommunication Union, 2016)- y el uso de un lenguaje común.

La progresiva globalización y el crecimiento exponencial del número de mercados a los que las empresas pueden acceder gracias al comercio electrónico han incrementado las oportunidades de negocio, pero también la complejidad a la hora de comprender los hábitos y preferencias de los consumidores. La expansión geográfica que la venta online posibilita ha tenido como consecuencia un aumento de la variedad de perfiles de comprador. Por ejemplo, el sitio web en castellano de una empresa española será inmediatamente accesible y comprensible por usuarios con acceso a internet basados en Latinoamérica. Sin embargo, existe la posibilidad de que su contenido y productos no sean relevantes para este nuevo mercado, ya que las preferencias, hábitos de consumo, renta disponible y barreras de compra pueden ser sustancialmente diferentes a las de los usuarios españoles. De esta manera, y aunque la utilización de una estrategia común para todos los mercados resulta más cómoda desde un punto de vista de ejecución, la conquista de nuevos mercados requiere la adaptación de la misma a las particularidades locales (Nair \& Ramakrishnan, 2016).

Es necesario por tanto identificar un método efectivo para incorporar la diversidad global de perfiles de consumidor a la estrategia de marketing. A la hora de afrontar este problema variable socioeconómicas tradicionales como el PIB, riesgo país y renta per cápita han permitido realizar segmentaciones por países (Karande, Almurshidee, \& Al- 
Olayan, 2006), si bien la paulatina convergencia de la riqueza en mercados desarrollados las ha despojado de su utilidad a la hora de explicar diferencias de comportamiento, siendo en este punto las diferencias culturales la única variable disponible (DeMooij, 2003). Por este motivo la mayoría de estudios internacionales en el ámbito de negocios y comercio incorporan la cultura como un factor fundamental (Sivakumar \& Nakata, 2001).

De esta manera, la cultura (nacional) adquiere una gran relevancia en esta tesis doctoral, puesto que permitirá formular hipótesis explicativas sobre posibles diferencias en la efectividad de los factores identificados y por tanto incrementará la profundidad del análisis. Consecuentemente, resulta no sólo relevante sino también pertinente realizar un análisis detallado de este constructo.

\subsubsection{La cultura y su influencia en el comportamiento del consumidor}

La RAE define cultura como un "conjunto de conocimientos que permite a alguien desarrollar su juicio crítico" (Real Academia Española, 2014), conjunto que puede ser interpretado desde un punto de vista social como una "programación mental que permite diferenciar a individuos de diferentes grupos o categorías" (Hofstede et al., 2010). Esta programación se sitúa en un nivel intermedio, entre la naturaleza humana -común a todos los individuos de la raza humana- y la personalidad -de carácter estrictamente individual- (Hofstede et al., 2010).

La cultura no se considera un factor ambiental, sino que es inherente al propio individuo (DeMooij \& Hofstede, 2010), y su origen se deriva de una compleja mezcla que incluye principios religiosos, exigencias económicas y políticas, etc. (Sekaran, 1983), cuya influencia individual es difícil diferenciar, pero cuya riqueza la convierte en el elemento con mayor influencia en un amplio dominio de comportamientos humanos (Soares, Farhangmehr, \& Shoham, 2007; Steenkamp, 2001).

Las diferencias culturales se manifiestan a través de valores -o tendencias a preferir un estado de las cosas sobre otro-, rituales -actividades colectivas socialmente esenciales-, héroes - personas que representan un modelo de comportamiento- y símbolos -gestos, palabras, dibujos, etc. con un significado compartido por miembros de una cultura(Hofstede et al., 2010). Existen múltiples niveles a los que se puede manifestar la cultura -regional, étnico, religioso, generacional, entre otros--, pero el nacional es el más práctico (Hofstede et al., 2010).

Una de las áreas de influencia de la cultura es la comunicación entre empresas y consumidores (Baack \& Singh, 2007). La integración de las diferentes culturas nacionales en la estrategia de marketing trasciende la mera traducción y adaptación del contenido al estándar social, y puede llegar a afectar a la forma de definir el carácter de la marca o a la elección de los beneficios de un producto que resultan más relevantes. 
Por ejemplo, en las culturas con un enfoque más individualista la comunicación promocional va encaminada a persuadir, mientras que en las tienen una componente más colectivista el objetivo es crear una relación de confianza (DeMooij \& Hofstede, 2010). Esta necesidad se acentúa en el estudio del procesamiento de la información por parte del consumidor y los análisis de efectividad de la publicidad, puesto que no incorporar la influencia cultural conduce a una potencial interpretación incorrecta de los resultados (DeMooij \& Hofstede, 2010), así como a ignorar variaciones sistemáticas de creencias y comportamientos (Steenkamp, 2001).

La influencia de la cultura también se extiende a las interacciones entre individuos y ordenadores (Diaz, Rusu, \& Collazos, 2017) y, en particular, al uso de internet (DeMooij, 2013). Así, esta variable influye en los hábitos de compra y factores que determinan el atractivo de una página web (Jin, 2010) y la percepción del consumidor de los elementos visibles de la publicidad online (Liu et al., 2012). El contenido culturalmente relevante es fundamental para mejorar la efectividad de las webs orientadas a la venta online, puesto que la mayor facilidad de uso y mejora en la actitud hacia el sitio web derivada de actividades de adaptación cultural incrementan la intención de compra (Singh, Fassott, Chao, \& Hoffmann, 2006).

Si bien las grandes compañías transnacionales obtienen un volumen de ventas suficiente en cada mercado como para justificar un estudio detallado de las características culturales de sus consumidores, las pequeñas empresas que abastecen a varios mercados no pueden financiar este tipo de actividad. Así, resulta necesario acudir a modelos simplificados que permitan integrar de manera eficiente las complejidades culturales en el estudio del comportamiento del consumidor.

Existen numerosas aproximaciones a la operacionalización de la cultura, siendo las más comunes la caracterización etnológica -de carácter puramente descriptivo-, la utilización de equivalencias como la nacionalidad y la inferencia de valores -o dimensiones culturales- a través del uso de datos empíricos tanto directos como indirectos (Soares et al., 2007). Durante el período 2000-2014, las teorías más utilizadas para el estudio del comportamiento del consumidor han estado dominadas por los modelos de dimensiones culturales (Timokhina et al., 2015). Por consiguiente, resulta adecuado que en el marco de esta tesis se investigue la idoneidad de este tipo de teorías en el estudio de la efectividad del e-mail marketing.

\subsubsection{Los modelos de dimensiones culturales}

Los modelos de dimensiones culturales son adecuados para el estudio de las implicaciones de la cultura en los procesos mentales y sociales de los individuos, y su influencia en las estrategias publicitarias (DeMooij \& Hofstede, 2010). Pese a la complejidad inherente al concepto "cultura", resultan una manera sencilla de 
operacionalizarlo e incorporarlo de manera efectiva en las investigaciones en las que esta variable es relevante. Su diseño se basa en la elección de una serie de dimensiones - definidas como aspectos de una cultura que pueden ser medidos en relación a otras culturas (Hofstede et al., 2010) - vinculadas a la manera en que los individuos de entornos culturales diferentes se relacionan con la autoridad, entienden su propia concepción o resuelven dilemas habituales (DeMooij \& Hofstede, 2010). Esta metodología se basa en el convencimiento de que todas las sociedades se enfrentan a problemas similares (Hofstede et al., 2010) y, a través de cuestionarios, recogen las puntuaciones que permiten determinar las posiciones relativas de cada cultura para cada una de las dimensiones propuestas.

Los modelos de dimensiones culturales de Hofstede (1980), Schwartz (1994) y el estudio GLOBE (House, Hanges, Javidan, Dorfman, \& Gupta, 2004) son los más conocidos y utilizados (Blodgett, Bakir, \& Rose, 2008; DeMooij \& Hofstede, 2010; Engelen \& Brettel, 2011; Kirkman, Lowe, \& Gibson, 2006; Magnusson, Wilson, Zdravkovic, Zhou, \& Westjohn, 2008). Por tanto, resulta pertinente presentarlos brevemente para tratar de determinar sus diferencias y puntos en común. Sus principales componentes se resumen en la tabla 7.

\begin{tabular}{|l|l|l|}
\hline \multicolumn{1}{|c|}{ Hofstede (1980) } & \multicolumn{1}{c|}{ Schwartz (1994) } & \multicolumn{1}{c|}{ GLOBE (House et al., 2004) } \\
\hline Individualismo-Colectivismo & Conservadurismo & Distancia al poder \\
\hline Distancia al poder & Autodirección & Aversión a la incertidumbre \\
\hline Aversión a la incertidumbre & Hedonismo & Colectivismo institucional \\
\hline Masculinidad-Feminidad & Jerarquía & Colectivismo individual \\
\hline Orientación al largo plazo & Control & Igualdad entre géneros \\
\hline Indulgencia-Restricción & Igualitarismo & Asertividad \\
\hline & Armonía/Estimulación & Orientación al futuro \\
\hline & & Orientación al desempeño \\
\hline & & Orientación humana \\
\hline
\end{tabular}

Tabla 7 - Resumen de dimensiones culturales de los principales modelos, adaptada de Magnusson et al. (2008)

El modelo de Hofstede postula que las culturas de las diferentes naciones varían a lo largo de cuatro dimensiones (Hofstede, 1980): distancia al poder, individualismo/colectivismo, masculinidad/femineidad, y aversión a la incertidumbre. Posteriores estudios (Hofstede et al., 2010) añaden dos nuevas dimensiones al modelo: orientación al largo plazo e indulgencia/restricción.

Schwartz (1994) identifica 45 valores comunes a todas las culturas nacionales y, a través de una encuesta realizada a profesores y estudiantes de más de 60 países, los reduce a 7 dominios nacionales-culturales, expresados a lo largo de tres dimensiones culturales. Estas dimensiones evalúan la relación entre individuo y grupo, los comportamientos socialmente responsables y el rol de la humanidad en relación con el 
medio ambiente y el entorno social. Cada una de ellas define la situación de los individuos relativa a dos valores que se contraponen como, por ejemplo, preferencia por la organización jerárquica en contraposición a la igualitaria.

El programa GLOBE (House et al., 2004) tiene como objetivo estudiar las relaciones entre la cultura y la efectividad en el liderazgo de organizaciones a través de entrevistas y focus groups con miembros de diversas culturas. Utilizando una técnica similar a la de Schwartz (1994), identifica nueve dimensiones culturales. Una aportación original de esta investigación es el estudio de la diferencia entre valores teóricos (declarados) y comportamientos reales, que revela correlaciones negativas entre valores $\mathrm{y}$ comportamientos en varias dimensiones.

Existe cierta controversia en la literatura respecto a la selección del modelo más relevante para evaluar el impacto de la cultura en una investigación científica, habiendo cierto acuerdo sobre el hecho de que el país utilizado como referencia tiene cierta influencia en esta decisión (Magnusson et al., 2008). Múltiples meta-análisis y estudios comparativos concluyen que existe una notable convergencia entre todos ellos (DeMooij, 2015; Magnusson et al., 2008; Soares et al., 2007; Taras, Kirkman, \& Steel, 2010), lo que induce a creer que la aportación de los modelos posteriores a Hofstede es limitada (Baack \& Singh, 2007; Magnusson et al., 2008).

Resulta también pertinente evaluar la potencial aplicación de estos modelos en el marco general de esta investigación; esto es, el estudio del comportamiento del consumidor en el entorno digital. Pese a que ninguno de ellos se diseñó específicamente para evaluar el impacto de las culturas nacionales en el comportamiento del consumidor (DeMooij, 2015; DeMooij \& Hofstede, 2010), el de Hofstede (2001) es el más influyente (Kirkman et al., 2006; Sivakumar \& Nakata, 2001; Soares et al., 2007), el más utilizado por la comunidad científica para este propósito (DeMooij, 2015; Engelen \& Brettel, 2011; Steenkamp, 2001; Timokhina et al., 2015; Zhang et al., 2008) y resultas especialmente relevante en las áreas de psicología y administración de empresas (Baskerville, 2003), y en la investigación sobre comercio y negocios (Baack \& Singh, 2007).

Por lo anterior, el modelo de Hofstede se considera el punto de partida más adecuado para el estudio de la cultura en esta investigación doctoral, a la vista de su utilización mayoritaria por otras investigaciones similares, su popularidad -es el que más citas acumula en el Social Sciences Citation Index (Kirkman et al., 2006)-, su simplicidad de uso (DeMooij \& Hofstede, 2010) y la limitada aportación adicional que suponen modelos posteriores. Por ello las siguientes secciones presentan y evalúan en detalle el modelo de Hofstede y su potencial aplicación en el estudio de la efectividad en el e-mail marketing. 


\subsection{DIMENSIONES CULTURALES DE HOFSTEDE}

\subsubsection{Origen del modelo de Hofstede}

De manera similar a los demás modelos de dimensiones culturales, el de Hofstede está basado en cuestionarios administrados a una muestra global. Su primera versión se basó en entrevistas realizadas a empleados de IBM en cuarenta países en los años sesenta y setenta, y reveló divergencias culturales en las áreas de desigualdad social, relación entre individuos y el grupo, los roles de género y la manera de gestionar la incertidumbre (Hofstede, 1980).

Una de las principales diferencias en relación a otros modelos de dimensiones culturales es que, durante la investigación, Hofstede adoptó un enfoque puramente empírico para extraer resultados de una base de datos sin ningún condicionamiento teórico anterior (DeMooij, 2015). La restricción de la muestra a empleados de IBM tuvo como consecuencia que los perfiles de los individuos estudiados fueran muy parecidos en todos los aspectos menos en la nacionalidad, hecho que permitió atribuir las divergencias de respuesta a las diferencias entre culturas nacionales (Hofstede et al., 2010).

Posteriormente, el estudio fue replicado múltiples veces utilizando diferentes perfiles de individuos (Hoppe, 1990; Merritt, 2000; Mouritzen \& Svara, 2002; Shane, 1995; van Nimwegen, 2002), lo que permitió aumentar el número de países y corroborar los resultados alcanzados. Una revisión ulterior realizada con el objetivo de corregir el potencial sesgo de los investigadores causado por su propio condicionamiento cultural permitió incorporar la dimensión "orientación al largo plazo" (Hofstede et al., 2010). Finalmente, un análisis de datos secundarios que estudiaban los valores globales permitió la identificación de una sexta dimensión definida como "indulgenciarestricción" (Hofstede et al., 2010). El modelo de Hofstede utiliza por tanto seis dimensiones culturales para determinar las diferencias entre las diferentes culturas nacionales. La puntuación los países en cada de una de estas dimensiones ha sido estandarizada utilizando un valor del 1 al 100 que permite una fácil comparación fácil entre estados.

La efectividad del modelo de Hofstede es notable, puesto que las diferentes puntuaciones a lo largo de estas dimensiones explican la mayoría de las diferencias de consumo y comportamiento del consumidor entre naciones (DeMooij, 2003). Su vigencia también está demostrada, pues pese a que el tiempo transcurrido desde el estudio inicial genera dudas a la vista del dinamismo étnico y de valores experimentado por ciertos países (Baskerville, 2003), la cultura tiende a cambiar muy lentamente (Sivakumar \& Nakata, 2001) y, de hecho, múltiples reproducciones modernas demuestran que, si bien los valores absolutos de los estados han experimentado 
modificaciones, sus posiciones relativas en las escalas permanecen vigentes (DeMooij \& Hofstede, 2010).

Así, a lo largo de los siguientes apartados se procederá al desarrollo de las diferentes dimensiones culturales del modelo de Hofstede, primero desde un punto de vista general y de comportamiento de consumidor, y posteriormente en el contexto de esta investigación; es decir, en el ámbito digital y más concretamente en el del e-mail marketing. En esta segunda fase se tratará de establecer vínculos con el modelo de efectividad de e-mail marketing propuesto en los anteriores capítulos, con el objetivo de encontrar indicios que permitan detectar situaciones en las que las dimensiones de Hofstede ejerzan una influencia moderadora sobre las variables independientes.

\subsubsection{Dimensiones culturales: modelo original}

\subsubsection{Distancia al poder}

La primera dimensión del modelo, conocida como distancia al poder, se define como el grado de aceptación del hecho de que el poder está desigualmente repartido en la sociedad por parte de los miembros menos poderosos de la misma (Hofstede, 2001a). Desde un punto de vista general, esta dimensión caracteriza aspectos de las interacciones entre los individuos como el grado de dependencia entre subordinados y empleados, o la importancia del respeto en las relaciones familiares y en los centros de enseñanza (Hofstede et al., 2010).

En el ámbito de la comunicación publicitaria y el marketing, su influencia se relaciona con la manera en que los consumidores proyectan sus propios valores en las marcas de productos, determinando de esta manera el posicionamiento al que éstas deben aspirar para establecer una conexión emocional con los mismos. Por ejemplo, en los países con puntuación elevada en esta dimensión es importante demostrar el estatus propio para que los demás cobren conciencia de la situación de cada individuo, siendo la utilización de determinadas marcas una de las maneras de alcanzar este fin (DeMooij, 2011). Así, en estas naciones, las marcas más deseadas han de estar asociadas al prestigio; por el contrario, en países situados en el otro extremo del espectro (y que además presentan valores altos de aversión a la incertidumbre) la característica más apreciada en una marca es su capacidad de innovación (DeMooij \& Hofstede, 2010).

Además, se cree que la efectividad de la publicidad es superior en sociedades con alta distancia al poder, dado que uno de los fines que persigue la mayoría de impactos publicitarios es construir una imagen de marca a la que el individuo desee asociarse, estableciendo dicho vínculo a través de su consumo (Möller \& Eisend, 2010). Esta creencia se refuerza por el hecho de que una elevada distancia al poder está asociada a una falta de voluntad para cuestionar la autoridad establecida, lo que puede conducir a una más fácil aceptación del contenido de los anuncios (Wang \& Sun, 2010). En esta 
misma línea, la distancia al poder también se vincula a la manera en que los individuos adquieren información para la compra, siendo una puntuación baja en esta dimensión síntoma de una preferencia por criterios basados en el sentimiento hacia la marca, mientras que una componente alta acompañada de un carácter individualista favorecerá el uso de medios de comunicación (DeMooij \& Hofstede, 2010).

En resumen, la distancia al poder está vinculada a la influencia en las relaciones sociales de factores como la posición jerárquica o la clase social. Dicha influencia se articula en el entorno publicitario a través de diferentes niveles de receptividad a los mensajes promocionales y, también, de la utilización de diferentes estrategias de posicionamiento de las marcas. Todos estos indicios apuntan a que la distancia al poder puede ser una dimensión relevante en el estudio de la efectividad del e-mail marketing.

\subsection{Distancia al poder en el e-mail marketing}

A la vista de los anteriores párrafos, y puesto que el e-mail marketing se considera un vehículo publicitario, se espera de manera general una efectividad superior de este canal en sociedades con elevada distancia al poder. Además, esta dimensión influye en el porcentaje de renta invertido en ciertas categorías - por ejemplo, ocio-(DeMooij, 2013), lo que reforzará la necesidad de mantener la categoría de producto constante en cualquier muestra de múltiples naciones a efectos de evaluar la efectividad de conversión.

En relación a las variables de influencia detalladas en el capítulo segundo, es relevante destacar que esta dimensión se vincula a la percepción de exclusividad de un producto por parte del consumidor - característica vinculada a su escasez-, así como a la caracterización de un producto como promocional o barato (Albers-Miller \& Gelb, 1996). Esto supone la existencia de indicios que permiten teorizar sobre un vínculo entre la distancia al poder y variables de contenido desde un punto de vista semántico, tanto visible -temática de la línea de asunto- como no visible - presencia de incentivos y sensación de escasez. Por tanto, resultará de interés estudiar la efectividad de estas variables en función de la posición de cada país en esta dimensión, puesto que puede existir una influencia moderadora de la distancia al poder en la efectividad de estos elementos. 


\begin{tabular}{|c|c|c|c|c|c|}
\hline \multicolumn{2}{|c|}{$\begin{array}{l}\text { Variables de contenido } \\
\text { directamente visible }\end{array}$} & \multicolumn{2}{|c|}{$\begin{array}{l}\text { Variables de contenido no } \\
\text { directamente visible }\end{array}$} & \multirow{2}{*}{$\begin{array}{l}\text { Variables } \\
\text { temporales }\end{array}$} & \multirow{2}{*}{$\begin{array}{c}\text { Variables } \\
\text { contextuales }\end{array}$} \\
\hline Formales & Mensaje & Formales & Mensaje & & \\
\hline $\begin{array}{l}\text { Longitud } \\
\text { asunto }\end{array}$ & $\begin{array}{c}\text { Contenido de } \\
\text { la línea de } \\
\text { asunto } \\
\end{array}$ & $\begin{array}{l}\text { Longitud } \\
\text { texto }\end{array}$ & $\begin{array}{l}\text { Incentivos } \\
\text { económicos }\end{array}$ & Frecuencia & Personalización \\
\hline $\begin{array}{c}\text { Caracteres } \\
\text { especiales } \\
\text { asunto } \\
\end{array}$ & $\begin{array}{l}\text { Contenido del } \\
\text { remitente }\end{array}$ & $\begin{array}{l}\text { Número de } \\
\text { imágenes }\end{array}$ & $\begin{array}{l}\text { Sensación de } \\
\text { escasez }\end{array}$ & $\begin{array}{l}\text { Día de la } \\
\text { semana }\end{array}$ & Segmentación \\
\hline $\begin{array}{l}\text { Presencia de } \\
\text { números } \\
\text { asunto }\end{array}$ & & $\begin{array}{l}\text { Número de } \\
\text { enlaces }\end{array}$ & & Hora & \\
\hline
\end{tabular}

Tabla 8 - Factores de influencia potencialmente moderados por la dimensión distancia al poder (en negrita)

\subsubsection{Individualismo-colectivismo}

El binomio individualismo-colectivismo es la segunda dimensión del modelo de Hofstede, y evalúa la importancia relativa de los intereses del individuo y su núcleo cercano en relación a los intereses del grupo (Hofstede, 2001a). Su influencia determina la manera de caracterizar la propia identidad de las personas; así, en países con alta componente individualista, la identidad se limita al propio individuo -en contraposición al individuo más su grupo cercano de los colectivistas-, y se tiende a asumir que los valores propios son universales (DeMooij, 2011). De manera general se considera que la situación de un país en esta dimensión es relevante en el estudio de aspectos de las relaciones sociales como la comunicación explícita de desacuerdo, la importancia de la armonía en las relaciones de grupo, la independencia o los vínculos afectivos con la familia (Hofstede et al., 2010).

Pese a tener un poder predictivo similar a las demás (Taras et al., 2010), esta dimensión del modelo de Hofstede es la más utilizada en las investigaciones científicas (Kirkman et al., 2006; Timokhina et al., 2015), lo que implica la existencia de prolija bibliografía que permitirá detectar potenciales indicios de su influencia en las variables independientes de esta investigación. En concreto, y desde una óptica de comportamiento del consumidor, se considera que el binomio individualismocolectivismo influye en la manera en que se realizan las decisiones de compra, siendo característica de culturas individualistas la adopción de criterios puramente personales (DeMooij, 2014). Utilizando esta premisa como criterio general, en el siguiente apartado se detallarán las conclusiones alcanzadas que son relevantes para esta investigación tanto desde un punto de vista de entorno digital como de e-mail marketing. 


\subsection{Individualismo-colectivismo en el e-mail marketing}

En general, existe cierta controversia en la influencia de esta dimensión en la efectividad de la publicidad digital. Por una parte, el marketing digital se considera más manipulador en las culturas individualistas, lo que puede afectar a su efectividad al ser considerados los intentos de manipulación como una forma de influencia en las decisiones individuales (Möller \& Eisend, 2010). Por otra, en las culturas individualistas y con una puntuación baja en la dimensión distancia al poder los medios de comunicación y las opiniones de amigos tienen gran influencia a la hora de definir las decisiones de compra, mientras que en las colectivistas, estas decisiones se basan en el sentimiento hacia la marca (DeMooij \& Hofstede, 2010), lo que implica que en general la comunicación digital sea menos efectiva en las culturas colectivistas con baja distancia al poder. La existencia de argumentos en una y otra dirección no permite determinar claramente una relación general entre esta segunda dimensión y el entorno digital.

Sin embargo, un enfoque reducido únicamente a la efectividad de conversión permite mayor discernimiento. La mayor propensión de las culturas individualistas a adoptar nuevas tecnologías como internet (Hermeking, 2006) o el comercio electrónico (Hofstede et al., 2010) es relevante en el estudio de dicha efectividad en el e-mail marketing, y debe ser considerado a la hora de interpretar los resultados de estudios con muestras localizadas en países con alta componente individualista (Reichhart et al., 2013), puesto que puede introducir un sesgo en los resultados.

Una vez delimitado someramente el entorno general, resulta adecuado vincular los estudios existentes a los factores de influencia en el e-mail marketing detallados en el capítulo segundo. Se procederá a realizar este ejercicio por orden, utilizando la categorización determinada en ese apartado, con la salvedad de que, en este caso, y para mayor claridad de la exposición, se agruparán las variables de contenido tanto visibles como no visibles en dos categorías: formales y semánticas.

El estudio de las variables de contenido desde un punto de vista formal presenta múltiples perspectivas. Como punto de partida, es relevante destacar que en las culturas individualistas, los consumidores quieren llegar al mensaje principal de los anuncios rápidamente (DeMooij \& Hofstede, 2010) y en general prefieren un diseño web minimalista (Diaz et al., 2017). Por tanto, es de esperar que esta dimensión sea relevante a la hora de evaluar la influencia de factores relativos a la complejidad de la comunicación; por ejemplo, que la teórica menor efectividad de apertura motivada por una excesiva longitud de la línea de asunto sea más acentuada en culturas individualistas.

Asimismo, la preferencia por el texto de culturas individualistas en contraposición a la preferencia por las imágenes de las culturas colectivistas (DeMooij, 2014; Hermeking, 
2006) señala una potencial influencia moderadora de esta dimensión en el número de imágenes. En concreto, la teórica mejora en la efectividad de clic causada por el mayor número de imágenes debería más significativa en culturas colectivistas. El estudio de esta influencia puede arrojar luz sobre la mayor efectividad de clic y conversión en determinadas circunstancias de e-mails puramente textuales en contraposición a los que contienen imágenes (Smart \& Cappel, 2003), conclusión poco intuitiva pero que puede estar influida por el hecho de que el estudio reseñado utiliza una muestra limitada a Estados Unidos, un país con una puntuación elevada en esta dimensión.

El diseño del soporte a la navegación del contenido en webs -que en el caso del correo electrónico se puede interpretar como la presencia de elementos que contienen enlacesestá influido por la preferencia de una cultura por la comunicación con mucho o poco contexto, preferencia vinculada a la dimensión individualismo-colectivismo (Hermeking, 2006). Esto justificará el estudio de una potencial relación entre la dimensión que nos ocupa y la efectividad del número de enlaces en la efectividad de clic, puesto que se espera que la mejora de efectividad causada por el incremento del número de enlaces sea más notable en culturas colectivistas. Asimismo, la preferencia de culturas individualistas de un diseño web más minimalista (Diaz et al., 2017), refuerza esta suposición.

Finalmente, las culturas colectivistas muestran una mayor preferencia por signos y símbolos en la comunicación (DeMooij, 2011), hecho que sumado de nuevo a la preferencia de las culturas individualistas por el diseño minimalista (Diaz et al., 2017), permite suponer que la presencia de caracteres especiales en la línea de asunto mejorará más la efectividad de apertura en las culturas colectivistas.

En cuanto a las variables de contenido desde un punto de vista semántico, hay que destacar que la posición relativa en esta segunda dimensión determina el enfoque utilizado para transmitir los beneficios del producto por parte de la comunicación online, dada la tendencia de los países con culturas individualistas a caracterizar el éxito a través de objetos materiales, utilizar un estilo argumentativo, dar preeminencia a la acción y la juventud, y enfatizar la novedad y el cambio en contraposición a la tradición e historia (Marcus \& Gould, 2000), así como a percibir de manera positiva la caracterización de un producto como distintivo -característica asociada a la escasez(Albers-Miller \& Gelb, 1996). Además, los consumidores de estas culturas son más receptivos a un proceso persuasivo de venta (DeMooij \& Hofstede, 2010) o con incentivos orientados a una necesidad individual (Kale, De, \& Kreider, 2007). Todo esto apunta a la relevancia de evaluar la influencia de esta dimensión en el contenido del asunto y la utilización de incentivos económicos o de elementos que señalan escasez, puesto que la teórica mejora de efectividad que producen será más acentuada en las culturas individualistas. 
El estudio de las variables temporales, y de la frecuencia en particular, está asociado a la intrusión (Micheaux, 2011). Un aspecto relevante de las culturas individualistas es la importancia que atribuyen a preservar la privacidad del individuo (Marcus \& Gould, 2000). Este hecho arroja cierta luz sobre la controversia existente en el entorno del email marketing respecto a la influencia de esta variable en la efectividad del canal, ya que en estudios que realizados en países individualistas (Marinova et al., 2002) se concluye de manera tajante que la invasión de la privacidad empeora la efectividad, mientras que en los realizados en países con una componente claramente colectivista (Chang et al., 2013), elementos como el valor asociado al e-mail moderan dicha influencia. Esto permite teorizar sobre una potencial influencia moderadora de esta dimensión el estudio de la influencia de la frecuencia en la efectividad del e-mail marketing, hipótesis reforzada por resultados obtenidos en otros canales digitales, como los banners, campo en el que existen indicios de que los individuos de culturas individualistas tienen una mayor sensibilidad a la sensación de intrusión (Möller \& Eisend, 2010).

Finalmente, y en el caso de las variables contextuales, es reseñable el hecho de que las culturas individualistas son más propensas al uso de información personal (Marcus \& Gould, 2000) y que sus individuos esperan una experiencia más personalizada en la interacción digital (Kale et al., 2007; Kale, 2003). Esto permite aventurar que cualquier técnica orientada a hacer los mensajes promocionales más personalizados, como es el caso de la segmentación o personalización, será más efectiva en culturas individualistas.

En resumen, la abundancia de bibliografía ha permitido a lo largo de los anteriores párrafos relacionar todos los factores de influencia detallados en el capítulo segundo con la excepción de presencia de números en el asunto, hora de envío y día de envíocon el binomio individualismo-colectivismo. Por este motivo, la segunda dimensión de Hofstede será posiblemente la más relevante en el contexto de esta investigación y, dada la fortaleza de alguno de los indicios expuestos, es de suponer que ejerza una influencia moderadora en al menos cierto número de variables. La tabla 9 presenta el resumen de las relaciones detectadas.

\begin{tabular}{|c|c|c|c|c|c|}
\hline \multicolumn{2}{|c|}{$\begin{array}{l}\text { Variables de contenido } \\
\text { directamente visible }\end{array}$} & \multicolumn{2}{|c|}{$\begin{array}{c}\text { Variables de contenido no } \\
\text { directamente visible }\end{array}$} & \multirow{2}{*}{$\begin{array}{l}\text { Variables } \\
\text { temporales }\end{array}$} & \multirow{2}{*}{$\begin{array}{l}\text { Variables } \\
\text { contextuales }\end{array}$} \\
\hline Formales & Mensaje & Formales & Mensaje & & \\
\hline $\begin{array}{l}\text { Longitud } \\
\text { asunto }\end{array}$ & $\begin{array}{l}\text { Contenido de la } \\
\text { línea de asunto }\end{array}$ & $\begin{array}{l}\text { Longitud } \\
\text { texto }\end{array}$ & $\begin{array}{l}\text { Incentivos } \\
\text { económicos }\end{array}$ & Frecuencia & Personalización \\
\hline $\begin{array}{c}\text { Caracteres } \\
\text { especiales } \\
\text { asunto } \\
\end{array}$ & $\begin{array}{l}\text { Contenido del } \\
\text { remitente }\end{array}$ & $\begin{array}{c}\text { Número } \\
\text { de } \\
\text { imágenes }\end{array}$ & $\begin{array}{l}\text { Sensación } \\
\text { de escasez }\end{array}$ & $\begin{array}{l}\text { Día de la } \\
\text { semana }\end{array}$ & Segmentación \\
\hline $\begin{array}{c}\text { Presencia de } \\
\text { números asunto }\end{array}$ & & $\begin{array}{c}\text { Número } \\
\text { de enlaces }\end{array}$ & & Hora & \\
\hline
\end{tabular}

Tabla 9 - Factores de influencia potencialmente moderados por la dimensión individualismo-colectivismo (en negrita) 


\subsubsection{Masculinidad-feminidad}

La tercera dimensión del modelo tiene también formato de binomio -en este caso, masculinidad-feminidad-, y permite clasificar a las sociedades de acuerdo a su afinidad con uno de estos dos paradigmas: el de las culturas masculinas, en las que los roles están definidos por géneros, y se espera que los hombres sean asertivos, duros y enfocados en el éxito material y las mujeres modestas, tiernas y enfocadas en la calidad de vida, y el de las culturas femeninas, en las que se espera que tanto hombres como mujeres sean modestos, tiernos y enfocados en la calidad de vida (Hofstede, 2001a). La diferente situación de las sociedades en este eje determina la prioridad e importancia de valores como el reconocimiento, la cooperación, el poder adquisitivo o las relaciones personales (Hofstede et al., 2010). De esta manera, las sociedades masculinas valoran sobre todo el éxito, mientras que las femeninas se enfocan en la calidad de vida (DeMooij \& Hofstede, 2010).

Estos paradigmas tienen influencia en los hábitos de compra, por ejemplo, a través de una mayor importancia de los objetos de lujo y marcas como medio para mostrar el éxito en las sociedades masculinas, o de un superior nivel de gasto en productos para el hogar o artesanía en las sociedades femeninas (DeMooij \& Hofstede, 2010). Es importante reseñar que en el estudio inicial de Hofstede (1980), los hombres de todas las sociedades mostraban mayor preferencia por valores masculinos y las mujeres por valores femeninos, pero que los resultados agregados de todos los individuos de una cultura nacional permitían delinear un posicionamiento claro en esta escala. Este hecho es relevante porque refuerza el concepto de que la aplicación de las dimensiones de Hofstede sólo tiene sentido a nivel nacional (Hofstede, 2001a), y que cualquier segmentación de estas sociedades (por ejemplo, en géneros) puede conducir a resultados erróneos.

En resumen, el nivel de preferencia de las sociedades por determinados valores asociados a roles de género explica ciertos hábitos de consumo, por lo que tiene sentido profundizar en la dimensión masculinidad-feminidad para determinar si existen indicios de influencia en la efectividad del e-mail marketing.

\subsection{Masculinidad-feminidad en el e-mail marketing}

En general, existe una falta de literatura que vincule de manera directa esta dimensión a la comunicación digital o el e-mail marketing, y es difícil encontrar resultados relevantes aparte de menciones generales acerca de un escepticismo superior de las culturas femeninas hacia la publicidad (DeMooij \& Hofstede, 2010). Sin embargo, utilizando estudios vinculados a otros ámbitos, es posible detectar ciertos indicios que conecten la masculinidad-feminidad con las variables de influencia determinadas en el capítulo segundo de esta tesis. 
Así, en el entorno de la comunicación se puede esperar un mayor énfasis y efectividad de los mensajes promocionales centrados en las relaciones y calidad de vida en culturas femeninas (en comparación con el bienestar material o el desafío), así como un uso de mensajes promocionales orientados a la construcción de una conexión emocional en las femeninas en comparación con los enfocados tanto en la recolección de datos (Hofstede et al., 2010) como en juegos y desafíos (Diaz et al., 2017) de las masculinas.

Esta predilección por los datos y por un consumo de contenido basado puramente en el intercambio de información objetiva permite sugerir cierta vinculación entre esta dimensión y la efectividad de variables de contenido desde un punto de vista semántico, como la presencia de descuentos o sensación de escasez. Así, es relevante contrastar los resultados que indican la influencia positiva en la intención de compra de la presencia de datos concretos como precios o porcentajes de descuento en e-mails promocionales utilizando una muestra de un país con un alto índice de masculinidad como Estados Unidos (Shuey, 2014), puesto que puede existir cierta influencia cultural en los resultados.

Por otra parte, en las culturas masculinas se da una preferencia por los juegos y desafíos, lo que puede influir a la hora de seleccionar ciertas temáticas de asunto como preferidas (Singh et al., 2006). Así, esta dimensión puede tener cierta influencia en el análisis semántico del asunto, a la vista de la utilización del e-mail marketing en la promoción de concursos.

Finalmente, ciertos análisis vinculan esta dimensión a la preferencia por la simplicidad en la navegación a través de contenidos HTML por parte de las culturas masculinas (Diaz et al., 2017). Este hecho permite relacionar la posición en el eje masculinidadfeminidad con variables de contenido formales que determinan la extensión y complejidad de un correo electrónico, como es el caso de las longitudes de asunto y texto, o del número de enlaces e imágenes.

En resumen, pese a la escasez de literatura que vincule la tercera dimensión de Hofstede al e-mail marketing, es posible utilizar la investigación en otros ámbitos para proponer ciertos indicios que justifiquen el estudio de la influencia de esta dimensión en variables de contenido tanto formales como semánticas, tal y como se aprecia en la tabla 10. 


\begin{tabular}{|c|c|c|c|c|c|}
\hline \multicolumn{2}{|c|}{$\begin{array}{l}\text { Variables de contenido } \\
\text { directamente visible }\end{array}$} & \multicolumn{2}{|c|}{$\begin{array}{l}\text { Variables de contenido no } \\
\text { directamente visible }\end{array}$} & \multirow{2}{*}{$\begin{array}{l}\text { Variables } \\
\text { temporales }\end{array}$} & \multirow{2}{*}{$\begin{array}{l}\text { Variables } \\
\text { contextuales }\end{array}$} \\
\hline Formales & Mensaje & Formales & Mensaje & & \\
\hline $\begin{array}{l}\text { Longitud } \\
\text { asunto }\end{array}$ & $\begin{array}{c}\begin{array}{c}\text { Contenido de } \\
\text { la línea de } \\
\text { asunto }\end{array} \\
\end{array}$ & $\begin{array}{l}\text { Longitud } \\
\text { texto }\end{array}$ & $\begin{array}{l}\text { Incentivos } \\
\text { económicos }\end{array}$ & Frecuencia & Personalización \\
\hline $\begin{array}{l}\text { Caracteres } \\
\text { especiales } \\
\text { asunto }\end{array}$ & $\begin{array}{l}\text { Contenido del } \\
\text { remitente }\end{array}$ & $\begin{array}{l}\text { Número de } \\
\text { imágenes }\end{array}$ & $\begin{array}{l}\text { Sensación de } \\
\quad \text { escasez }\end{array}$ & $\begin{array}{c}\text { Día de la } \\
\text { semana }\end{array}$ & Segmentación \\
\hline $\begin{array}{l}\text { Presencia de } \\
\text { números } \\
\text { asunto }\end{array}$ & & $\begin{array}{l}\text { Número de } \\
\text { enlaces }\end{array}$ & & Hora & \\
\hline
\end{tabular}

Tabla 10 - Factores de influencia potencialmente moderados por la dimensión masculinidad-feminidad (en negrita)

\subsubsection{Aversión a la incertidumbre}

La aversión a la incertidumbre, entendiendo incertidumbre como el nivel de amenaza que suponen para los miembros de una determinada cultura las situaciones ambiguas o desconocidas (Hofstede, 2001), es la cuarta dimensión del modelo de Hofstede. Este constructo está relacionado con la ambigüedad relativa al propio futuro inherente a la condición humana. Pese a que en el desarrollo de cualquier vida normal es imposible escapar a un cierto grado de incertidumbre, dado el carácter esencialmente subjetivo de lo que cada individuo considera como una amenaza, la ambigüedad ante el futuro puede ser intolerable para ciertos individuos e indiferente o incluso positiva para otros (Kramer, 1999; Marcus \& Gould, 2000). La amalgama de estos diferentes niveles de sensibilidad que se manifiestan a nivel individual conforma la posición de una cultura nacional en esta dimensión.

Las naciones utilizan diferentes enfoques en los campos de la tecnología, la ley y la religión a la hora de gestionar la incertidumbre (Hofstede et al., 2010). Estos tres dominios se relacionan respectivamente con la ambigüedad que aparece en la interacción de los individuos con la naturaleza, otros individuos y su propio futuro (Hofstede et al., 2010). De este modo, las sociedades con una puntuación muy alta en esta dimensión tienen un mayor respecto por las reglas y leyes (Hofstede et al., 2010), son menos abiertas a la adopción de innovaciones y tienden a confiar en expertos a la hora de determinar sus preferencias de compra (DeMooij, 2011; DeMooij \& Hofstede, 2010). Además, la posición en esta dimensión determina el nivel de inversión en ciertas categorías (DeMooij, 2003), lo que hace necesario que los estudios en que los que sea utilizada como variable independiente o moderadora se restrinjan a una tipología de producto homogénea.

En resumen, esta dimensión está relacionada con la manera de gestionar la ambigüedad por parte de las diversas sociedades $y$, puesto que existen indicios de que puede tener influencia en el comportamiento del consumidor, resulta pertinente examinarla más en detalle en el contexto de esta tesis. 


\subsection{Aversión a la incertidumbre en el e-mail marketing}

A la vista de la relativa novedad del marketing digital y comercio electrónico y, por consiguiente, de la incertidumbre que genera en ciertos sectores de la población (Hofstede et al., 2010), se espera una efectividad inferior de la publicidad online en aquellas sociedades con una elevada puntuación en esta dimensión. Asimismo, esta ambigüedad asociada al comercio electrónico se puede traducir en una menor efectividad de conversión de cualquier medio digital y, por extrapolación, del e-mail marketing.

En relación a las variables independientes que utiliza esta investigación, resulta razonable establecer un nexo entre esta dimensión y la inclusión de elementos de contenido visible enfocados en generar sensación de escasez (Hofstede et al., 2010), a la vista de la usual asociación de estas tácticas con plazos limitados de tiempo para tomar la decisión de compra. Por tanto, en el contexto de esta investigación esta dimensión es relevante para contrastar la incidencia positiva en la intención de compra de la presencia de elementos que indican una duración limitada de la oferta en e-mails promocionales, como demuestra un estudio con una muestra limitada a un país con aversión a la incertidumbre relativamente baja (Shuey, 2014). También es razonable cuestionar la influencia de la percepción de riesgo en la efectividad de apertura, según el experimento realizado con una muestra limitada a ese mismo país (Chen, Wang, Herath, \& Rao, 2011).

Por otra parte, la cuarta dimensión de Hofstede tiene influencia en la efectividad de la comunicación online en función de los elementos utilizados, esto es, la presencia de texto o la inclusión de imágenes adicionales (Vishwanath, 2003). Las culturas con elevada aversión a la incertidumbre prefieren la comunicación simple y con una cantidad limitada de datos y opciones (Marcus \& Gould, 2000), hechos que permiten proponer una potencial función moderadora de esta dimensión en la influencia del número de imágenes, enlaces y las longitudes de texto y asunto en la efectividad del email marketing.

En cuanto a las variables contextuales, las posibilidades de segmentación que ofrecen los medios digitales posibilitan que la comunicación se adapte a las barreras de compra del consumidor y le permita conocer nuevos productos, lo cual contribuye a disipar su incertidumbre sobre innovaciones (Möller \& Eisend, 2010). Así, aquellos e-mails que incorporan una comunicación más adaptada a las reticencias del consumidor pueden tener un mayor éxito a la hora de mitigar la incertidumbre de éste respecto a su compra, lo que permite teorizar sobre la potencial influencia de esta dimensión sobre la variable segmentación.

En resumen, y a la vista de lo expuesto en los anteriores párrafos, es posible relacionar esta dimensión con las variables de influencia señaladas en la tabla 11. 


\begin{tabular}{|c|c|c|c|c|c|}
\hline \multicolumn{2}{|c|}{$\begin{array}{l}\text { Variables de contenido } \\
\text { directamente visible }\end{array}$} & \multicolumn{2}{|c|}{$\begin{array}{c}\text { Variables de contenido no } \\
\text { directamente visible }\end{array}$} & \multirow{2}{*}{$\begin{array}{l}\text { Variables } \\
\text { temporales }\end{array}$} & \multirow{2}{*}{$\begin{array}{c}\text { Variables } \\
\text { contextuales }\end{array}$} \\
\hline Formales & Mensaje & Formales & Mensaje & & \\
\hline $\begin{array}{l}\text { Longitud } \\
\text { asunto }\end{array}$ & $\begin{array}{l}\text { Contenido de } \\
\text { la línea de } \\
\text { asunto }\end{array}$ & $\begin{array}{l}\text { Longitud } \\
\text { texto }\end{array}$ & $\begin{array}{l}\text { Incentivos } \\
\text { económicos }\end{array}$ & Frecuencia & Personalización \\
\hline $\begin{array}{c}\text { Caracteres } \\
\text { especiales } \\
\text { asunto }\end{array}$ & $\begin{array}{l}\text { Contenido del } \\
\text { remitente }\end{array}$ & $\begin{array}{l}\text { Número de } \\
\text { imágenes }\end{array}$ & $\begin{array}{l}\text { Sensación de } \\
\text { escasez }\end{array}$ & $\begin{array}{l}\text { Día de la } \\
\text { semana }\end{array}$ & Segmentación \\
\hline $\begin{array}{l}\text { Presencia de } \\
\text { números } \\
\text { asunto }\end{array}$ & & $\begin{array}{l}\text { Número de } \\
\text { enlaces }\end{array}$ & & Hora & \\
\hline
\end{tabular}

Tabla 11 - Factores de influencia potencialmente moderados por la dimensión aversión a la incertidumbre (en negrita)

\subsubsection{Dimensiones culturales: extensiones al modelo original}

\subsubsection{Orientación al largo plazo}

La quinta dimensión del modelo de Hofstede es la orientación al largo plazo, entendida como la predilección de una sociedad por virtudes como la perseverancia y el ahorro, orientadas al futuro, en contraposición a virtudes como el respeto por la tradición, las obligaciones sociales y la imagen pública, radicadas en el pasado y el presente (Hofstede, 2001). Las preguntas que dieron origen a esta dimensión no formaron parte de la encuesta a empleados de IBM en la que se basó el modelo inicial de Hofstede, sino que se extrajeron de la Encuesta de Valores Chinos (Hofstede \& Bond, 1988). Pese a que desde un punto de vista estadístico la mejora obtenida por la adición de esta dimensión al modelo es limitada (Magnusson et al., 2008), se considera que enriquece el modelo para los países asiáticos (Diaz et al., 2017) y, por tanto, debe ser tenida en cuenta en el contexto de esta tesis.

La posición de una cultura nacional en esta dimensión influye en aspectos como la capacidad de adoptar estrategias que requieran una gran inversión inicial (DeMooij \& Hofstede, 2010) -superior en las culturas orientadas al largo plazo- o la influencia social a favor de un mayor porcentaje de gasto de la renta disponible -superior en países cortoplacistas- (Hofstede et al., 2010). Si bien no ha sido posible hallar literatura que relacione esta dimensión con hábitos y tendencias de consumo desde un punto de vista empírico, existe un limitado corpus que la ha vinculado teóricamente a determinadas variables que pueden resultar relevantes en esta investigación. Se procederá, por tanto, a describir dichos estudios y su potencial vinculación con el análisis de la efectividad del e-mail marketing.

\subsection{Orientación al largo plazo en el e-mail marketing}

Desde un punto de vista general, y a la vista de que una de las características de las sociedades con baja orientación al largo plazo es su preferencia por la satisfacción inmediata de los deseos de consumo (Hofstede et al., 2010), esta dimensión puede 
resultar relevante a la hora de evaluar la efectividad de conversión, a la vista de la rapidez y comodidad con la que el comercio electrónico permite completar una compra.

En línea con esta idea, las sociedades con baja orientación al largo plazo tienen una preferencia por la acción inmediata (Marcus \& Gould, 2000), lo que permite suponer un potencial efecto moderador de esta dimensión en la efectividad de la utilización de técnicas para crear sensación de escasez, puesto que el objetivo de éstas es acelerar el proceso de compra.

Por otro lado, los clientes de sociedades más orientadas al largo plazo tienen mayores expectativas acerca de la cantidad de información proporcionada por una comunicación promocional, así como de su utilidad (Mazaheri, Richard, \& Laroche, 2011). Esto nos permite relacionar esta dimensión con aquellas variables de contenido que cuantifican la cantidad de información presentada -longitud del asunto y del texto, número de imágenes y enlaces-.

Por tanto, y pese a la ausencia de estudios en el ámbito del marketing digital, existen indicios de una potencial relación de la orientación al largo plazo con las variables de influencia en el e-mail marketing -resumida en la tabla 12- y, por tanto, resulta adecuado incorporar la quinta dimensión de Hofstede a esta tesis.

\begin{tabular}{|c|c|c|c|c|c|}
\hline \multicolumn{2}{|c|}{$\begin{array}{l}\text { Variables de contenido } \\
\text { directamente visible }\end{array}$} & \multicolumn{2}{|c|}{$\begin{array}{c}\text { Variables de contenido no } \\
\text { directamente visible }\end{array}$} & \multirow{2}{*}{$\begin{array}{l}\text { Variables } \\
\text { temporales }\end{array}$} & \multirow{2}{*}{$\begin{array}{l}\text { Variables } \\
\text { contextuales }\end{array}$} \\
\hline Formales & Mensaje & Formales & Mensaje & & \\
\hline $\begin{array}{l}\text { Longitud } \\
\text { asunto }\end{array}$ & $\begin{array}{l}\text { Contenido de } \\
\text { la línea de } \\
\text { asunto }\end{array}$ & $\begin{array}{l}\text { Longitud } \\
\text { texto }\end{array}$ & $\begin{array}{l}\text { Incentivos } \\
\text { económicos }\end{array}$ & Frecuencia & Personalización \\
\hline $\begin{array}{c}\text { Caracteres } \\
\text { especiales } \\
\text { asunto } \\
\end{array}$ & $\begin{array}{l}\text { Contenido del } \\
\text { remitente }\end{array}$ & $\begin{array}{l}\text { Número de } \\
\text { imágenes }\end{array}$ & $\begin{array}{l}\text { Sensación de } \\
\text { escasez }\end{array}$ & $\begin{array}{l}\text { Día de la } \\
\text { semana }\end{array}$ & Segmentación \\
\hline $\begin{array}{l}\text { Presencia de } \\
\text { números } \\
\text { asunto }\end{array}$ & & $\begin{array}{l}\text { Número de } \\
\text { enlaces }\end{array}$ & & Hora & \\
\hline
\end{tabular}

Tabla 12 - Factores de influencia potencialmente moderados por la dimensión orientación al largo plazo (en negrita)

\subsubsection{Indulgencia-restricción}

Finalmente, el binomio indulgencia-restricción es la sexta dimensión del modelo, y estudia la tendencia por parte de una sociedad a regular y limitar los deseos naturales de divertirse y disfrutar la vida (Hofstede et al., 2010). Desarrollada a partir de un estudio de los resultados de la Encuesta mundial de valores (Minkov, 2007), resulta una adición reciente al modelo de Hofstede, y está vinculada a la percepción de felicidad -tanto racional como emocional- de las diferentes culturas.

Esta dimensión define la importancia de la calidad de vida en contraposición a la seguridad para una sociedad, así como el nivel de importancia y recursos que se 
destinan al ocio. Debido a su limitada adopción por parte de la comunidad científica (Diaz et al., 2017), su presencia es casi inexistente en literatura, con lo que no resulta posible vincularla a ninguna de las variables en las que se enfoca esta tesis. Por este motivo, la sexta dimensión del modelo de Hofstede quedará fuera del alcance de esta investigación, y de aquí en adelante cualquier referencia al modelo de Hofstede se entenderá como relativa a las cinco primeras dimensiones.

\subsection{DIMENSIONES CULTURALES DE HOFSTEDE EN EL E- MAIL MARKETING}

Tras haber emprendido un análisis descriptivo detallado del modelo de Hofstede y haber vinculado cada una de sus dimensiones a diferentes variables de influencia en el e-mail marketing, resulta oportuno como siguiente paso el realizar un análisis crítico de las fortalezas y limitaciones del propio modelo con el objeto de determinar la pertinencia de su utilización en la presente investigación. A estos efectos, se procede a lo largo de los siguientes párrafos a detallar algunas de las limitaciones identificadas por la comunidad científica, que posteriormente serán juzgadas a la luz de su importancia en el contexto del estudio de la efectividad del e-mail marketing.

\subsubsection{Critica del modelo de Hofstede}

A pesar de su aceptación generalizada y de su cuasi universal reconocimiento, el modelo de Hofstede presenta algunas limitaciones. Desde un punto de vista teórico, las más importantes son las suposiciones implícitas de que en cada país sólo existe una cultura nacional (Baskerville, 2003; Marcus \& Gould, 2000), o que ésta está delimitada por el territorio, y funciona como un valor compartido, implícito y sistemáticamente causal (Mcsweeney, 2002). Puesto que el concepto cultura vertebra el modelo y actúa como única variable independiente, estas suposiciones son especialmente relevantes porque, de ser incorrectas, el modelo en su totalidad resultaría invalidado. A este respecto, Hofstede (2010) menciona que, aunque es necesaria cierta cautela en su utilización, el concepto cultura nacional es razonable a la vista de que, aunque las naciones no equivalen a sociedades, existen en ellas fuerzas que las impulsan a mayor integración (como la presencia de un lenguaje, medios de comunicación o sistema educativo y político común). También es destacable que en posteriores versiones de su modelo, tal vez para mitigar esta objeción en los casos más evidentes, Hofstede realiza segmentaciones que van más allá de la nación, como es el caso de la presencia de valores diferenciados para la Suiza germánica y la Suiza francesa, o la Bélgica francesa y la Bélgica neerlandesa.

Además, y pese a que desde un punto de vista antropológico y sociológico resulta controvertido asumir la equivalencia entre nación y cultura, la fácil operacionalización y medida de la nacionalidad, así como la complejidad inherente a cualquier otra 
alternativa, compensa esta limitación en determinadas áreas de investigación (Baskerville, 2003; Soares et al., 2007). Resulta razonable además suponer que, pese a la existencia de cierta heterogeneidad en las sociedades -representadas por diferentes "subculturas"-, una de ellas será la más común, y por tanto la más representativa del país (Sivakumar \& Nakata, 2001). Las aproximaciones que tratan de utilizar un nivel inferior -microculturas pertenecientes a un mismo país (Recabarren, Nussbaum, \& Leiva, 2008)- o superior -clusters de países (Magnusson et al., 2008)- no terminan de resolver el problema, puesto que se enfrentan a una problemática similar en una escala diferente.

Desde un punto de vista metodológico, una de las principales limitaciones del modelo es la utilización en sus primeras versiones de una muestra reducida (Kirkman et al., 2006) y particularmente pequeña para algunos países como Pakistán, Hong Kong y Singapur (Mcsweeney, 2002), hecho que introdujo cierta incertidumbre inicial en relación a los resultados. Asimismo, existe cierta controversia acerca de la vinculación entre las preguntas de la encuesta y la dimensión cultural a la que están asociadas, a la vista de las dificultades presentadas para obtener validez convergente y discriminante si se aplican ligeras modificaciones al instrumento de medida (Blodgett et al., 2008). A pesar de estas críticas, posteriores reediciones del estudio de Hofstede realizadas por investigadores independientes con muestras más amplias han confirmado los resultados iniciales (Hoppe, 1990; Merritt, 2000; Mouritzen \& Svara, 2002; Shane, 1995; van Nimwegen, 2002).

También desde un punto de vista metodológico, el hecho de que la muestra del estudio inicial se componga en su totalidad de empleados de una misma compañía (IBM), en su mayoría del departamento de ventas y marketing, genera dudas respecto a la pertinencia de extrapolar las conclusiones al resto de la población nacional, dada la ausencia de trabajadores manuales, estudiantes, desempleados, jubilados, etc. (Mcsweeney, 2002). Hofstede (2001) considera que esa consistencia representa una ventaja más que un inconveniente, pues la comparación de individuos que comparten unos valores organizacionales y funcionales permite concluir que las diferencias que afloran son de índole exclusivamente cultural. Sin embargo, esta explicación también requiere asumir la existencia una cultura organizacional única y compartida para todos los empleados de IBM (Mcsweeney, 2002).

A la vista de estas limitaciones, una potencial alternativa es utilizar el modelo de Hofstede en combinación con el modelo de Schwartz (1994) -descrito en el primer apartado de este capítulo- (Baack \& Singh, 2007; Steenkamp, 2001). En el contexto de esta tesis esta opción no resulta razonable, puesto que el modelo de Schwartz ha sido muy poco utilizado en el campo del marketing (Baack \& Singh, 2007) y, además, existen evidencias de un elevado grado de equivalencia entre ambos, con altas correlaciones entre las dimensiones de los dos modelos (Steenkamp, 2001). 
En cuanto a las fortalezas del modelo de Hofstede, posiblemente la más valorada sea su simplicidad y claridad (Kirkman et al., 2006). Además, las dimensiones de Hofstede son el conjunto disponible de variables que miden la cultura más amplio que existe (Sivakumar \& Nakata, 2001) y, pese a sus limitaciones, este modelo resulta el método más adecuado para evaluar la influencia de la cultura en investigaciones en las áreas del marketing (Soares et al., 2007), especialmente para el desarrollo de teorías que comparan comportamientos y actitudes en diferentes países (Steenkamp, 2001).

\subsubsection{Aplicación del modelo de Hofstede al e-mail marketing}

A la vista de lo desarrollado en el anterior apartado, se puede concluir que el modelo de Hofstede es el más utilizado por la comunidad científica para evaluar la influencias culturales en el comportamiento del consumidor (Engelen \& Brettel, 2011; Steenkamp, 2001; Timokhina et al., 2015; Zhang et al., 2008), resulta apropiado para teorizar sobre los diferentes comportamientos entre naciones (Baack \& Singh, 2007; Steenkamp, 2001) y las diferencias en la utilización de medios de comunicación online (Hermeking, 2006). Además, este modelo ya ha sido aplicado en la investigación sobre efectividad de otros medios de comunicación online, como los banners (Möller \& Eisend, 2010) o la publicidad en teléfonos móviles (Liu et al., 2012).

Dada esta información, resulta razonable incorporar las dimensiones culturales de Hofstede al modelo unificado de efectividad del e-mail marketing. Por ello, esta investigación utilizará el modelo de Hofstede para evaluar la existencia de potenciales efectos moderadores de la cultura en los factores de influencia en la efectividad del email marketing.

Esta decisión implica que será necesario tener en cuenta las limitaciones de su aplicación para asegurar que la investigación resulta robusta desde un punto de vista metodológico. Dichas limitaciones serán desarrolladas en detalle en el capítulo seis, en el que se tratará la operacionalización de las culturas nacionales.

A continuación, la tabla 13 resume las vinculaciones entre las diferentes dimensiones de Hofstede y las variables de influencia recogidas en el capítulo segundo. 


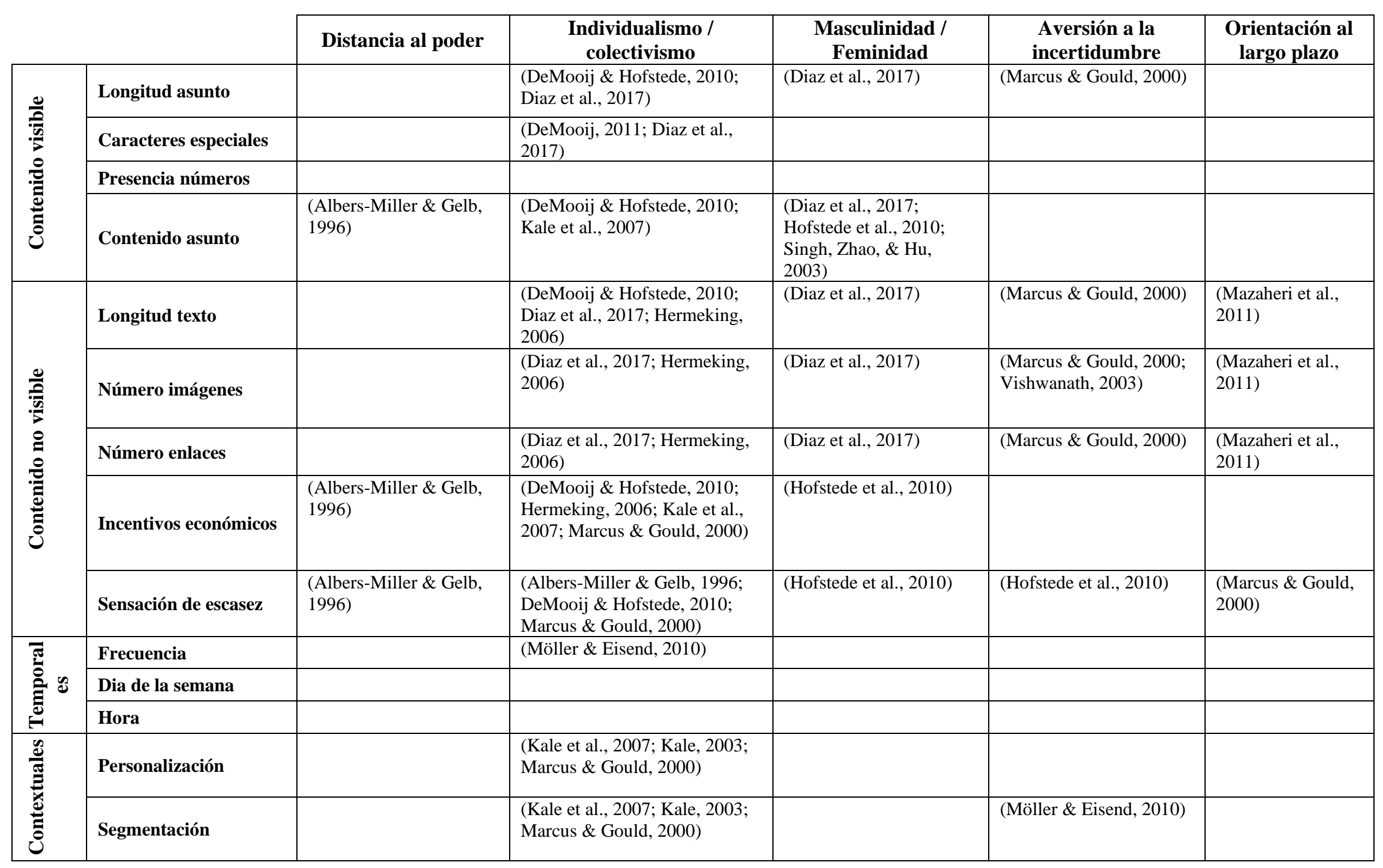

Tabla 13 - Resumen de la relación entre elementos de influencia en el e-mail marketing y dimensiones del modelo de Hofstede 


\title{
Capítulo 5 - Modelo e hipótesis de investigación
}

\author{
5.1 INTRODUCCIÓN \\ 5.2 LA EFECTIVIDAD EN EL E-MAIL MARKETING - VARIABLES DE MEDIDA \\ 5.2.1 Atención \\ 5.2.2 Interés \\ 5.2.3 Acción \\ 5.3 FACTORES DE INFLUENCIA EN LA EFECTIVIDAD DEL E-MAIL MARKETING \\ 5.3.1 Factores de contenido visible \\ 5.3.2 Factores de contenido no visible \\ 5.3.3 Factores temporales \\ 5.3.4 Factores contextuales \\ 5.3.5 Factores culturales \\ 5.3.6 Resumen de factores \\ 5.4 MODELO TEÓRICO DE INVESTIGACIÓN \\ 5.4.1 Atención \\ 5.4.2 Interés \\ 5.4.3 Acción \\ 5.5 RESUMEN DEL MODELO
}

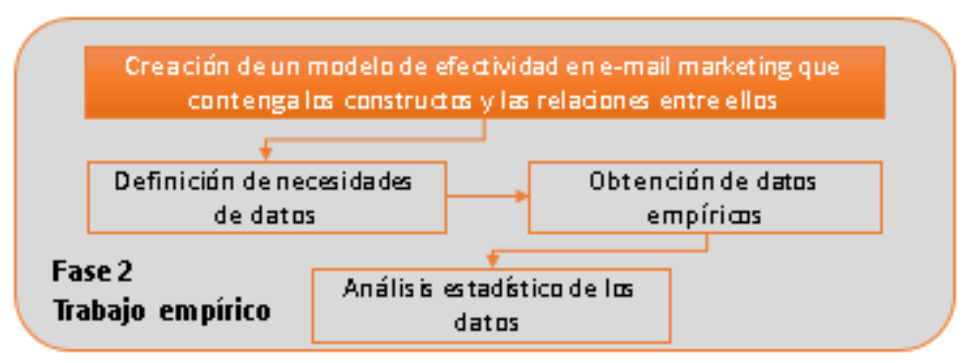




\section{MODELO E HIPÓTESIS DE INVESTIGACIÓN}

\subsection{INTRODUCCIÓN}

Tras concluir la exposición teórica acerca de la efectividad en el e-mail marketing, los modelos generales de comportamiento del consumidor y las influencias culturales en su relación con este canal, el siguiente paso de esta investigación es la proposición de un modelo que articule estas teorías de una forma ordenada y coherente, para posteriormente proceder a su comprobación empírica. De cara a conseguir este propósito, resulta pertinente desglosar el objetivo principal de este capítulo -la proposición de un modelo de efectividad en el e-mail marketing- en objetivos parciales que permitan desarrollar un plan de acción progresivo. Así, se pueden identificar las siguientes fases:

Identificación de la manera más adecuada de definir y medir la efectividad en el email marketing. Esta primera etapa utilizará como soporte teórico las definiciones recogidas en el capítulo tercero, así como las efectividades parciales detalladas en el capítulo segundo.

Establecimiento de los factores de influencia generales en el e-mail marketing. Esta fase se basará en el desarrollo expuesto en el capítulo segundo, en el que se identifican diversos factores de influencia agrupados en varias categorías según la literatura existente. Se realizará un análisis crítico de cada uno de ellos para determinar la pertinencia de su inclusión en el modelo.

Determinación de los factores culturales que pueden moderar las relaciones de influencia en el e-mail marketing. Para alcanzar este tercer objetivo, se tomará como base el desarrollo del capítulo cuarto y se determinarán las dimensiones de Hofstede que serán añadidas al modelo.

Establecimiento de hipótesis sobre las relaciones entre variables. Esta última fase tomará todas las variables identificadas en las tres anteriores y propondrá hipótesis soportadas en el marco teórico detallado en los capítulos segundo, tercero y cuarto para conformar la propuesta de modelo teórico de efectividad.

\subsection{LA EFECTIVIDAD EN EL E-MAIL MARKETING - VARIABLES DE MEDIDA}

\subsubsection{Atención}

Según lo detallado en el tercer capítulo, la atención, como primera fase del modelo AIDA, se vinculará en el e-mail marketing al momento en el que el consumidor consulta su bandeja de entrada. Esta etapa está relacionada con lo que se ha definido en 
el capítulo segundo como efectividad de apertura, que relaciona el número de correos abiertos con el de correos enviados a través de la variable tasa de apertura.

De esta manera, el modelo teórico de esta tesis utilizará la atención, entendida como la "acción de aplicar voluntariamente el entendimiento a un objeto espiritual o sensible" (Real Academia Española, 2014), como una de las vías de parametrización de la efectividad en el e-mail marketing, a la vista de la existencia de abundante literatura que incorpora este constructo (Arnold, 2008; Kumar \& Salo, 2018; Mullen \& Daniels, 2009; San-José-Cabezudo \& Camarero-Izquierdo, 2012).

\subsubsection{Interés}

El interés, definido como "inclinación del ánimo hacia un objeto, persona, narración, etc.” (Real Academia Española, 2014), es la segunda fase del modelo AIDA. Este concepto resulta una etapa relevante en el estudio de la efectividad del correo electrónico como canal de comunicación, puesto que su aparición condiciona que la comunicación trascienda este soporte y continúe por otros medios, acercando al consumidor al objetivo final del anunciante.

De acuerdo con lo desarrollado en el marco teórico, el interés está vinculado a la efectividad de clic y de retención de suscriptores. Esta relación se justifica porque una de las consecuencias de la aparición de interés es su expresión activa (Ghirvu, 2013), que puede manifestarse a través del deseo de obtener más información acerca del objeto que suscita ese interés (Ashcroft \& Hoey, 2001). En el entorno del correo electrónico, la acción más natural para obtener más detalles es el clic en uno de los enlaces del texto, y la acción más natural para dejar de recibir información es la cancelación de la subscripción.

Así, el interés se incluirá en el modelo teórico puesto que es otro de los constructos que permiten determinar la efectividad de un correo electrónico, hecho consistente con la frecuente utilización de esta variable en la literatura (Florès, 2014; Hassan et al., 2015; Lagrosen, 2005; Micheaux, 2011).

\subsubsection{Acción}

Finalmente, la acción o "resultado de hacer" (Real Academia Española, 2014), es el último constructo que se empleará en esta investigación para evaluar la efectividad del e-mail marketing. Esta última etapa de AIDA resulta sumamente intuitiva, pues refleja de manera transparente la consecución del objetivo que persigue el anunciante. Asociada a la efectividad de conversión, según la definición del capítulo segundo, la acción aparece en múltiples estudios de efectividad en el e-mail marketing (Bawm \& Nath, 2014; Jackson \& DeCormier, 1999; Jolley et al., 2013; Kumar \& Salo, 2018; Reichhart et al., 2013; Sahni et al., 2016; Sigurdsson et al., 2013, 2016; Smart \& 
Cappel, 2003), y resulta por tanto una variable clave a tener en cuenta en el modelo de efectividad.

\subsection{FACTORES DE INFLUENCIA EN LA EFECTIVIDAD DEL E- MAIL MARKETING}

\subsubsection{Factores de contenido visible}

Siguiendo la clasificación detallada en el capítulo segundo, estas variables son aparentes a la recepción del correo electrónico, y se pueden clasificar como formales o semánticas. Las fundamentales están relacionadas con la línea de asunto y el remitente, puesto que estos dos campos son los únicos generalmente accesibles en esta etapa.

La longitud del asunto es la primera variable formal que se recoge en el marco teórico, y su importancia está relacionada con el esfuerzo requerido por parte del destinatario para procesar información (Solomon et al., 2013), así como con la posibilidad de que se trunque debido a la configuración del ISP (Groves, 2009). A la vista de esto, será agregada al modelo teórico.

La presencia de caracteres especiales en el asunto es la segunda variable formal detallada en el capítulo segundo, y también será añadida al modelo teórico puesto que resulta pertinente comprobar si el efecto esperado -que gracias a su presencia el consumidor sea capaz de identificar una promoción como promocional (Solomon et al., 2013)- mejora la eficiencia.

En esta misma línea, la presencia de números en el asunto también será incorporada al modelo, puesto que tradicionalmente los dígitos se han asociado a la presencia de descuentos o promociones en el ámbito publicitario (Solomon et al., 2013) y, por tanto, pueden ayudar al destinatario a interpretar más fácilmente el contenido del correo.

La inclusión de estas tres variables formales de manera separada es una propuesta innovadora de esta tesis, puesto que hasta la fecha sólo han sido utilizadas de manera conjunta en los análisis de efectividad (Balakrishnan \& Parekh, 2015).

Enfocando ahora el análisis en el plano semántico, el contenido del asunto se considera la variable más importante de esta categoría (Micheaux, 2011), puesto que codifica el tipo de mensaje que el correo pretende transmitir (Baggott, 2011) y, por tanto, permite dilucidar qué temáticas son más relevantes y efectivas. Por tanto, su presencia es imperativa en el modelo.

Finalmente, el marco teórico también recoge el contenido del remitente como una potencial variable de influencia, puesto que está asociada a la confianza que el destinatario deposita en el mensaje (Wilson et al., 2015). Sin embargo, su importancia relativa en relación al asunto es limitada (Micheaux, 2011), presenta poca variabilidad 
(Baggott, 2011) y resulta muy difícil de codificar de manera consistente. Además, la muestra que utilizará esta tesis no permite un análisis de esta variable. Por todos estos motivos, esta investigación no incluirá el remitente en el modelo de efectividad del email marketing.

\subsubsection{Factores de contenido no visible}

Esta segunda categoría de variables recoge aquellos elementos que sólo son aparentes una vez el consumidor ha abierto el correo electrónico. Como se detalla en el segundo capítulo, tradicionalmente éste es el campo más estudiado por la literatura enfocada en la efectividad del e-mail marketing, puesto que existe la creencia generalizada de que el diseño y contenido del correo es la parte más influyente en los resultados obtenidos por este canal (Baggott, 2011). De nuevo es pertinente diferenciar entre aspectos formales y semánticos a la hora de abordar estas variables.

Desde un punto de vista formal, y de forma similar a la longitud del asunto, la longitud del texto influye en el esfuerzo necesario por parte del destinatario para procesar el correo (Solomon et al., 2013) y resulta, por ende, un factor relevante en el estudio de la efectividad. La abundante literatura que utiliza esta variable (Arnold, 2008; Baggott, 2011; Dufrene et al., 2005; Ellis-Chadwick \& Doherty, 2012; Groves, 2009) no ha determinado de manera tajante cuál es la longitud óptima de un correo, con lo que esta investigación añadirá este factor al modelo y tratará de arrojar luz sobre la controversia actual.

El número de imágenes que incluye un correo permite valorar la riqueza de la comunicación, pues los contenidos gráficos mejoran la efectividad en el entorno online (Simon \& Peppas, 2004) al transmitir el mensaje de manera que resulta más comprensible para el consumidor (Tufte, 1995). Así, esta variable se agregará al modelo teórico propuesto.

La última variable de contenido no visible formal es el número de enlaces que presenta la comunicación, elemento relevante en el estudio de la efectividad puesto que, pese a su presencia casi generalizada en todos los correos electrónicos, todavía no se ha determinado la cantidad óptima de links para maximizar la efectividad (Ellis-Chadwick \& Doherty, 2012). Así, el modelo de esta tesis incluirá esta variable y tratará de arrojar más luz sobre este aspecto.

Desde un punto de vista semántico, el capítulo segundo identifica como primera variable la utilización de incentivos económicos en el contenido, elemento enormemente popular en la literatura (Chang et al., 2013; Rettie \& Chittenden, 2003; Sigurdsson et al., 2013, 2016; Theerthaana \& Sharad, 2014), y con influencia en la efectividad de este canal, por lo que se procederá a añadir esta variable al modelo. 
Finalmente, la presencia de elementos que crean sensación de escasez y, por tanto, incrementan la sensación de urgencia en el consumidor animándole a completar el objetivo perseguido por el anunciante, tiene influencia en la efectividad del canal (Groves, 2009; Shuey, 2014), resultando de esta manera pertinente incluir este constructo en el modelo teórico.

\subsubsection{Factores temporales}

Los elementos temporales también son relevantes en el estudio de la efectividad puesto que pueden determinar la receptividad del consumidor a la comunicación promocional, condicionando así su efectividad independientemente del contenido de la misma (Barnes, 2002). Este tipo de variables aportan riqueza al análisis porque trascienden el entorno del canal y contextualizan al consumidor. Por este motivo, se incorporarán a esta propuesta de modelo teórico.

El primer factor, ampliamente estudiado en el entorno del e-mail marketing es la frecuencia de contacto (Ellis-Chadwick \& Doherty, 2012; Haq, 2009; Micheaux, 2011; Theerthaana \& Sharad, 2014), una de las variables fundamentales en este medio (Baggott, 2011) a la vista de su influencia en el proceso perceptual del consumidor (Solomon et al., 2013). Por ello resulta fundamental su inclusión en este estudio para garantizar la robustez del modelo.

El siguiente factor temporal es el momento de envío, elemento que tradicionalmente se codifica como día de la semana y hora de envío. La razón de ser de estas variables radica en su capacidad de medir la situación más adecuada para realizar un determinado contacto publicitario, y su potencial es muy elevado puesto que ajustarlas requiere un esfuerzo pequeño por parte de los anunciantes. Su influencia en el e-mail marketing es conocida (Ellis-Chadwick \& Doherty, 2012), si bien no existe casi literatura de carácter empírico al respecto, con lo que resulta pertinente incluirlas en esta tesis.

\subsubsection{Factores contextuales}

Finalmente, los factores contextuales están relacionados con la capacidad del remitente de adaptar el contenido del correo a las características particulares del receptor. Cuanto más relevante resulte una comunicación para el consumidor, más probabilidades tendrá de conseguir su objetivo, con lo que la inclusión de este tipo de parámetros en el modelo resulta pertinente.

La primera variable de esta categoría es la personalización, entendida como la inclusión en el correo de elementos directamente vinculados al receptor-como su nombre o dirección- con el objetivo de recordar la relación preexistente entre remitente y destinatario (Sahni et al., 2016). Su influencia en la efectividad ha sido estudiada de manera recurrente (Ansari \& Mela, 2003; Dufrene et al., 2005; Marinova et al., 2002; 
Postma \& Brokke, 2002; White et al., 2008), si bien las conclusiones al respecto son contradictorias, de acuerdo a lo expuesto en el capítulo segundo. De nuevo, resulta pertinente añadirla al modelo teórico de esta tesis con el objetivo proporcionar un nuevo punto de vista en la existente controversia.

En segundo lugar, la segmentación es el otro tipo de variable contextual de aplicación en el e-mail marketing. La creación de particiones en la base de datos de e-mails para adaptar la comunicación a cada uno de los segmentos es una técnica con efectos positivos en la efectividad (Bawm \& Nath, 2014; Jackson \& DeCormier, 1999) y, por tanto, su inclusión en el modelo es relevante dados los objetivos que persigue esta tesis.

\subsubsection{Factores culturales}

A la vista de lo detallado en el capítulo cuarto, el modelo de dimensiones culturales de Hofstede (1980) será la herramienta utilizada por esta investigación para incorporar la influencia cultural al modelo de efectividad del e-mail marketing. A continuación, se repasarán brevemente las dimensiones culturales que se utilizarán en esta tesis.

En primer lugar, la distancia al poder es relevante en esta investigación a la vista de su vinculación con la manera en los que los consumidores utilizan las marcas como herramienta de posicionamiento social (DeMooij, 2011) y con la utilización de técnicas promocionales para incentivar el consumo (Albers-Miller \& Gelb, 1996). Así, la distancia al poder se incluirá en el modelo teórico.

La segunda dimensión de Hofstede, el binomio individualismo-colectivismo, también es relevante, puesto que su popularidad entre la comunidad científica tiene como consecuencia la existencia de un gran número de estudios que la vinculan a factores similares a los identificados en esta investigación de acuerdo a lo detallado en el apartado pertinente del capítulo cuarto (DeMooij, 2014; Diaz et al., 2017; Hermeking, 2006; Kale et al., 2007; Marcus \& Gould, 2000). Por tanto, esta dimensión también formará parte del modelo teórico.

El binomio masculinidad-feminidad influye en la efectividad de ciertos mensajes promocionales en diversos canales de comunicación (Hofstede et al., 2010), así como en la preferencia por determinadas actividades como desafíos o concursos, hechos que justifican la inclusión de esta variable en el análisis de efectividad que ocupa a esta tesis.

Hofstede propone como cuarta dimensión la aversión a la incertidumbre, tradicionalmente vinculada a la preferencia por entornos reglados y conocidos. A la vista de la naturaleza intrínsecamente innovadora del medio digital, resulta relevante en el estudio de cualquier fenómeno en este ámbito. Además, este constructo puede determinar la preferencia por la utilización de ciertas variables de contenido desde un 
punto de vista formal en ciertas culturas (Marcus \& Gould, 2000), con lo que su inclusión en el modelo resulta justificada a la vista del nexo que es posible establecer con algunos de sus componentes.

La quinta dimensión del modelo, conocida como orientación a largo plazo, se relaciona con las expectativas de información que los consumidores tienen en relación a las comunicaciones promocionales (Mazaheri et al., 2011), así como a la facilidad con la que se verán impulsados a atender a estímulos que les urjan a realizar una compra (Marcus \& Gould, 2000), hechos que justifican su incorporación al modelo.

Finalmente, la última dimensión del modelo -el binomio indulgencia-restricción- no será incorporada a esta investigación puesto que, siguiendo el razonamiento expuesto en el capítulo cuarto, no existe literatura que permita asociarla a ninguno de los constructos identificados a lo largo de las anteriores páginas, hecho posiblemente causado por su reciente incorporación al modelo de Hofstede.

\subsubsection{Resumen de factores}

A la vista de lo desarrollado en los anteriores apartados, se han excluido dos de las variables identificadas inicialmente en el marco teórico, en concreto, el contenido del remitente y la dimensión de Hofstede indulgencia-restricción. La tabla 14 muestra un resumen de las variables que serán utilizadas para plantear las hipótesis de investigación.

\begin{tabular}{|c|c|c|c|c|c|c|}
\hline \multicolumn{2}{|c|}{$\begin{array}{c}\text { Variables de } \\
\text { contenido } \\
\text { directamente visible }\end{array}$} & \multicolumn{2}{|c|}{$\begin{array}{c}\text { Variables de } \\
\text { contenido no } \\
\text { directamente visible }\end{array}$} & \multirow{2}{*}{$\begin{array}{c}\text { Variables } \\
\text { temporales }\end{array}$} & \multirow{2}{*}{$\begin{array}{c}\text { Variables } \\
\text { contextuales }\end{array}$} & \multirow{2}{*}{$\begin{array}{l}\text { Variables } \\
\text { culturales }\end{array}$} \\
\hline Formales & Mensaje & Formales & Mensaje & & & \\
\hline $\begin{array}{l}\text { Longitud } \\
\text { asunto } \\
\text { Caracteres } \\
\text { especiales } \\
\text { asunto } \\
\text { Presencia de } \\
\text { números } \\
\text { asunto }\end{array}$ & $\begin{array}{l}\text { Contenido } \\
\text { de la línea } \\
\text { de asunto }\end{array}$ & $\begin{array}{l}\text { Longitud } \\
\text { texto } \\
\text { Número de } \\
\text { imágenes } \\
\text { Número de } \\
\text { enlaces }\end{array}$ & $\begin{array}{l}\text { Incentivos } \\
\text { económicos } \\
\text { Sensación de } \\
\text { escasez }\end{array}$ & $\begin{array}{l}\text { Frecuencia } \\
\text { Día de la } \\
\text { semana } \\
\text { Hora }\end{array}$ & $\begin{array}{l}\text { Personalización } \\
\text { Segmentación }\end{array}$ & $\begin{array}{l}\text { Distancia al poder } \\
\text { Individualismo- } \\
\text { Colectivismo } \\
\text { Masculinidad- } \\
\text { Feminidad } \\
\text { Aversión a la } \\
\text { incertidumbre } \\
\text { Orientación al largo } \\
\text { plazo }\end{array}$ \\
\hline
\end{tabular}

Tabla 14 - Resumen de variables independientes que serán incorporadas al modelo teórico

\subsection{MODELO TEÓRICO DE INVESTIGACIÓN}

Una vez identificadas las variables relevantes para esta tesis, el siguiente paso lógico es plantear las hipótesis relativas a las relaciones entre ellas que permitan completar el modelo teórico de efectividad del e-mail marketing. Para ello, se utilizarán como variables dependientes las detalladas en el primer apartado de este capítulo, y como 
variables independientes, los factores de influencia que se desarrollan en el segundo. Siguiendo lo propuesto en el planteamiento de esta investigación, la hipótesis principal de esta tesis, planteada de forma general, es la siguiente:

Hipótesis Principal

"Existe una serie de variables temporales, contextuales y de contenido visible y no visible que inciden en la efectividad del e-mail marketing, moderadas por una serie de dimensiones culturales".

La figura 7 muestra de forma resumida esta hipótesis

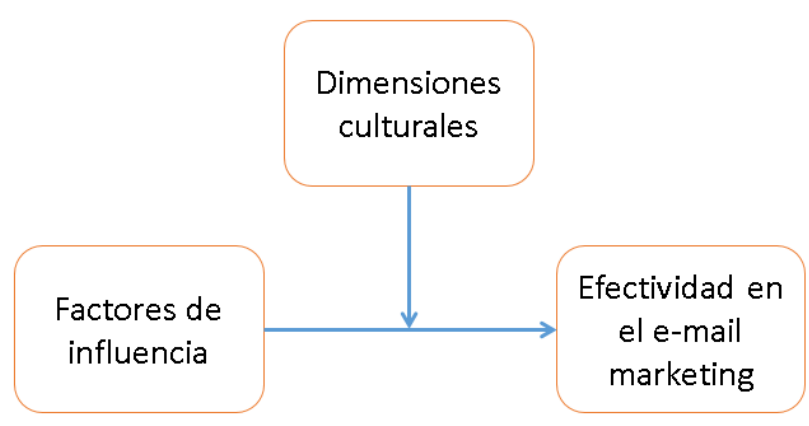

Figura 7 - Hipótesis principal de la investigación

Como se ha detallado en el apartado anterior, los constructos que se utilizarán para evaluar la efectividad de la comunicación serán:

- Atención

- Interés

- Acción

A partir de estos conceptos, la hipótesis general se descompone en las siguientes subhipótesis generales:

\section{Hipótesis 1}

Existe una serie de variables temporales, contextuales y de contenido visible y no visible que inciden en la atención en el e-mail marketing.

\section{Hipótesis 1A}

La incidencia de las variables temporales, contextuales y de contenido visible y no visible en la atención en el e-mail marketing está moderada por una serie de dimensiones culturales. 


\section{Hipótesis 2}

Existe una serie de variables temporales, contextuales y de contenido visible y no visible que inciden en el interés en el e-mail marketing.

\section{Hipótesis 2A}

La incidencia de las variables temporales, contextuales y de contenido visible y no visible en el interés en el e-mail marketing está moderada por una serie de dimensiones culturales.

\section{$\underline{\text { Hipótesis } 3}$}

Existe una serie de variables temporales, contextuales y de contenido visible y no visible que inciden en la acción en el e-mail marketing.

\section{Hipótesis 3A}

La incidencia de las variables temporales, contextuales y de contenido visible y no visible en la acción en el e-mail marketing está moderada por una serie de dimensiones culturales.

Este conjunto de sub-hipótesis se representa gráficamente en la figura 8.

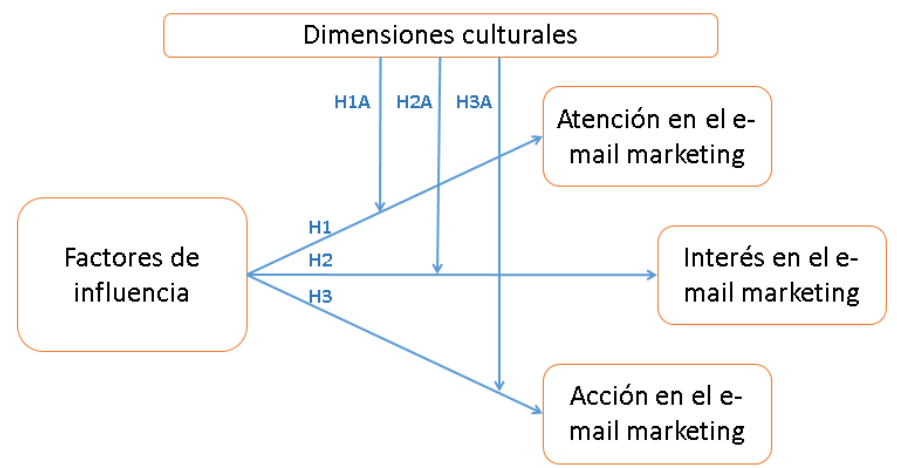

Figura 8 - Sub-hipótesis de la investigación

A continuación, se procederá a realizar una revisión de las relaciones entre los factores de influencia y cada una de las etapas de AIDA. Como paso previo al desarrollo teórico, y de cara a facilitar la identificación de hipótesis, es pertinente fijar una metodología de nomenclatura. Así, todas aquellas hipótesis cuya variable dependiente sea la atención tendrán como primera cifra el número 1, aquellas cuya variable dependiente sea el interés tendrán como primera cifra el número 2 y aquellas cuya variable dependiente sea la acción tendrán como primera cifra el número 3. En cuanto a las hipótesis que relacionen variables moderadoras, se asignará una letra determinada para cada dimensión de Hofstede, que será añadida a continuación del número identificador de la hipótesis que vincula la variable independiente con la dependiente. Así, las hipótesis 
moderadas por la distancia al poder terminarán en A, las moderadas por individualismocolectivismo terminarán en $\mathrm{B}$, las moderadas por masculinidad-feminidad terminarán en C, las moderadas por aversión a la incertidumbre terminarán en D y las moderadas por orientación al largo plazo terminarán en E. En el apéndice se presenta una relación completa todas las hipótesis utilizadas a lo largo de este documento, así como de los acrónimos utilizados para identificar las variables.

\subsubsection{Atención}

\subsubsection{Relaciones de las variables de contenido visible}

De acuerdo a lo detallado en las anteriores líneas, el asunto, elemento fundamental en análisis de la efectividad del e-mail marketing (Chittenden \& Rettie, 2003; Micheaux, 2011; Mogoș \& Acatrinei, 2015; Theerthaana \& Sharad, 2014), será el único componente de esta categoría incluido en el alcance de esta investigación. El aspecto formal de esta variable es relevante porque la presencia de números y ciertos caracteres especiales que no son habituales en la comunicación incrementan las posibilidades de que el consumidor preste atención al mensaje (Solomon et al., 2013). Por otra parte, los textos largos requieren un mayor intervalo de atención para ser procesados y obtienen una efectividad menor porque existen más posibilidades de que el consumidor decida ignorarlos (Solomon et al., 2013). Desde un punto de vista semántico, el mensaje comunicado por el asunto debe ser interesante para lograr capturar la atención del consumidor (Kumar \& Salo, 2018), resultado que dependerá en gran medida de la temática del mismo (Carmen \& Nicolae, 2010). Por tanto se proponen las siguientes hipótesis:

$\mathrm{H}_{11}$ : El incremento del número de caracteres de la línea de asunto disminuye la atención prestada por el usuario al e-mail marketing.

$\mathrm{H}_{12}$ : La presencia de caracteres numéricos en la línea de asunto aumenta la atención prestada por el usuario al e-mail marketing.

$\mathrm{H}_{13}$ : La presencia de caracteres especiales y signos de puntuación en la línea de asunto aumenta la atención prestada por el usuario al e-mail marketing.

$\mathrm{H}_{14}$ : El contenido de la línea de asunto influye en la atención prestada por el usuario al e-mail marketing.

\subsubsection{Relaciones de las variables temporales}

La relevancia de las variables temporales está asociada a su capacidad de medir elementos vinculados a la situación del consumidor e independientes del contenido promocional. El día de la semana y la hora de exposición han sido tradicionalmente elementos importantes en la optimización de campañas publicitarias, puesto que 
influyen en el comportamiento de los consumidores y su receptividad a los anuncios (Barnes, 2002), y pueden influir en la atención prestada a los correos electrónicos promocionales (Ellis-Chadwick \& Doherty, 2012). La frecuencia de envío también es relevante porque cuando es muy elevada desencadena la adaptación del usuario al estímulo perceptual -esto es, el consumidor determina que los últimos impactos no contienen ninguna información nueva y que, por tanto, no merecen su interés-, reduciendo la efectividad de la comunicación (Solomon et al., 2013). Por tanto:

$\mathrm{H}_{15}$ : El incremento de frecuencia de envío de correos electrónicos de e-mail marketing disminuye la atención prestada por el usuario al e-mail marketing.

$\mathrm{H}_{16}$ : El día de la semana de envío de correos electrónicos de e-mail marketing influye en la atención prestada por el usuario al e-mail marketing.

$\mathrm{H}_{17}$ : La hora de envío de correos electrónicos de e-mail marketing influye en la atención prestada por el usuario al e-mail marketing.

\subsubsection{Relaciones de las variables contextuales}

El valor de las variables contextuales reside en su capacidad de adaptar la comunicación

a las características particulares del consumidor, ya sea a nivel individual personalización- o de segmento - segmentación-. Dichas técnicas posibilitarán diseñar e-mails que se adapten mejor a los intereses de cada grupo de usuarios y que, por tanto, obtengan mejores resultados, tanto en el caso de la segmentación (Bawm \& Nath, 2014; Jackson \& DeCormier, 1999) como en el de la personalización (Sahni, Wheeler, \& Chintagunta, 2018). De lo anterior se proponen las siguientes hipótesis:

$\mathrm{H}_{18}$ : El uso de técnicas de personalización aumenta la atención prestada los usuarios al e-mail marketing.

$\mathrm{H}_{19}$ : El uso de técnicas de segmentación aumenta la atención prestada los usuarios al e-mail marketing.

La figura 9 presenta un resumen de las hipótesis detalladas anteriormente. 


\begin{tabular}{|c|c|c|c|}
\hline \multirow{5}{*}{$\begin{array}{l}\text { Variables de } \\
\text { Contenido } \\
\text { Visible }\end{array}$} & Longitud asunto & $\mathrm{H} 11$ & \multirow{12}{*}{$\begin{array}{l}\text { Atención en el e- } \\
\text { mail marketing }\end{array}$} \\
\hline & Caracteres especiales & $\mathrm{H} 12$ & \\
\hline & Números asunto & $\mathrm{H} 13$ & \\
\hline & & $\mathrm{H} 14$ & \\
\hline & Contenido asunto & & \\
\hline \multirow{4}{*}{$\begin{array}{l}\text { Variables } \\
\text { Temporales }\end{array}$} & Frecuencia & H15 & \\
\hline & Dia de la semana & H16 & \\
\hline & & $\mathrm{H} 17$ & \\
\hline & Hora & \multirow[b]{2}{*}{$\mathrm{H} 18$} & \\
\hline \multirow{3}{*}{$\begin{array}{l}\text { Variables } \\
\text { Contextuales }\end{array}$} & Personalización & & \\
\hline & & \multirow[t]{2}{*}{$\mathrm{H} 19$} & \\
\hline & Segmentación & & \\
\hline
\end{tabular}

Figura 9 - Resumen de hipótesis de variables de influencia (independientes) en la atención.

\subsubsection{Relaciones de las variables culturales}

La cultura nacional tiene influencia en el comportamiento del consumidor, según lo desarrollado en el capítulo cuarto y, por tanto, resulta pertinente evaluar si las dimensiones culturales pueden moderar las hipótesis que se han propuesto en los anteriores párrafos. Se procederá a realizar un análisis de cada variable de influencia para posteriormente, proponer hipótesis basadas en las relaciones determinadas en el marco teórico.

En relación a la longitud del asunto, es posible vincular esta variable al deseo de los consumidores en los países con alta componente individualista de llegar al mensaje principal de los anuncios rápidamente (DeMooij \& Hofstede, 2010). Asimismo, las culturas masculinas, las individualistas, las poco orientadas al largo plazo y las que tienen elevada aversión a la incertidumbre prefieren un diseño web minimalista y una comunicación simple (Diaz et al., 2017; Marcus \& Gould, 2000; Mazaheri et al., 2011), lo cual permite sugerir una relación con esta variable. Así pues, se postulan las siguientes hipótesis:

$\mathrm{H}_{11 \mathrm{~B}}$ : $\mathrm{El}$ incremento del número de caracteres de la línea de asunto disminuye más la atención prestada por el usuario al e-mail marketing en países con elevada puntuación en la dimensión Individualismo-Colectivismo.

$\mathrm{H}_{11 \mathrm{C}}$ : El incremento del número de caracteres de la línea de asunto disminuye más la atención prestada por el usuario al e-mail marketing en países con elevada puntuación en la dimensión Masculinidad-Feminidad.

$\mathrm{H}_{11 \mathrm{D}}$ : El incremento del número de caracteres de la línea de asunto disminuye más la atención prestada por el usuario al e-mail marketing en países con elevada puntuación en la dimensión Aversión a la incertidumbre. 
$\mathrm{H}_{11 \mathrm{E}}$ : El incremento del número de caracteres de la línea de asunto disminuye más la atención prestada por el usuario al e-mail marketing en países con baja puntuación en la dimensión Orientación al largo plazo.

La presencia de caracteres especiales en el asunto se relaciona con el hecho de que las culturas colectivistas muestran una mayor preferencia que las individualistas por signos y símbolos en la comunicación (DeMooij, 2011), lo cual, sumado de nuevo a la preferencia de éstas últimas por el diseño minimalista (Diaz et al., 2017), permite suponer la influencia de la segunda dimensión de Hofstede en esta variable. Así, se plantea la siguiente hipótesis:

$\mathrm{H}_{12 \mathrm{~B}}$ : La presencia de caracteres especiales en la línea de asunto aumenta más la atención prestada por el usuario al e-mail marketing en países con baja puntuación en la dimensión Individualismo-Colectivismo.

La efectividad del contenido del asunto en el e-mail marketing puede verse influida por la distancia al poder, a la vista de la aversión de países con una alta puntuación en esta dimensión por la caracterización de un producto como promocional o barato (Albers-Miller \& Gelb, 1996), hecho que permite teorizar sobre su potencial influencia en aquellos e-mails en los que su asunto destaque una promoción. Asimismo, y puesto que las culturas individualistas son más receptivas a un proceso persuasivo de venta (DeMooij \& Hofstede, 2010) o con incentivos orientados a una necesidad individual (Kale et al., 2007), es de esperar que las temáticas promocionales obtengan mejores resultados. Por otra parte, las culturas masculinas muestran una preferencia por los juegos y desafíos (Diaz et al., 2017; Singh et al., 2006) así como por los datos objetivos (Hofstede et al., 2010) -por ejemplo, la presencia de descuentos-, hecho que de nuevo se puede vincular a una mayor efectividad de estas temáticas. Estos datos permiten proponer las siguientes hipótesis:

$\mathrm{H}_{14 \mathrm{~A}}$ : Los contenidos de temática promocional en la línea de asunto aumentan más la atención prestada por el usuario al e-mail marketing en países con baja puntuación en la dimensión Distancia al poder.

$\mathrm{H}_{14 \mathrm{~B}}$ : Los contenidos de temática promocional en la línea de asunto aumentan más la atención prestada por el usuario al e-mail marketing en países con alta puntuación en la dimensión Individualismo-Colectivismo.

$\mathrm{H}_{14 \mathrm{D}}$ : Los contenidos de temática promocional o de concursos en la línea de asunto aumentan más la atención prestada por el usuario al e-mail marketing en países con alta puntuación en la dimensión Masculinidad-Feminidad.

La frecuencia está relacionada con la intrusión de una comunicación (Micheaux, 2011), hecho que es relevante examinar a la vista de la importancia que las culturas 
individualistas atribuyen a preservar la privacidad del individuo (Marcus \& Gould, 2000) y a los resultados negativos obtenidos por otros medios de comunicación digitales -banners- en culturas individualistas cuando son considerados intrusivos (Möller \& Eisend, 2010). Así, se plantea:

$\mathrm{H}_{15 \mathrm{~B}}$ : La frecuencia disminuye más la atención prestada por el usuario al e-mail marketing en países con alta puntuación en la dimensión IndividualismoColectivismo.

Finalmente, en cuanto a la personalización y la segmentación, y a la vista de que de que las culturas individualistas son más propensas al uso de información personal (Marcus \& Gould, 2000) y sus individuos esperan una experiencia más personalizada en la interacción digital (Kale et al., 2007; Kale, 2003), se espera cierta influencia de esta dimensión en la efectividad de cualquiera de estas dos técnicas. Asimismo, una información más personalizada puede ser más efectiva en las culturas con elevada aversión a la incertidumbre, puesto que contribuye a disipar las dudas particulares sobre las innovaciones (Möller \& Eisend, 2010). En esta línea, se plantean las siguientes hipótesis:

$\mathrm{H}_{18 \mathrm{~B}}$ : La personalización aumenta más la atención prestada por el usuario al email marketing en países con alta puntuación en la dimensión IndividualismoColectivismo.

$\mathrm{H}_{19 \mathrm{~B}}$ : La segmentación aumenta más la atención prestada por el usuario al e-mail marketing en países con alta puntuación en la dimensión IndividualismoColectivismo.

H19D: La segmentación aumenta más la atención prestada por el usuario al e-mail marketing en países con alta puntuación en la dimensión Aversión a la incertidumbre.

A continuación, la figura 10 y la tabla 15 resumen el conjunto de hipótesis relativas a la atención. 


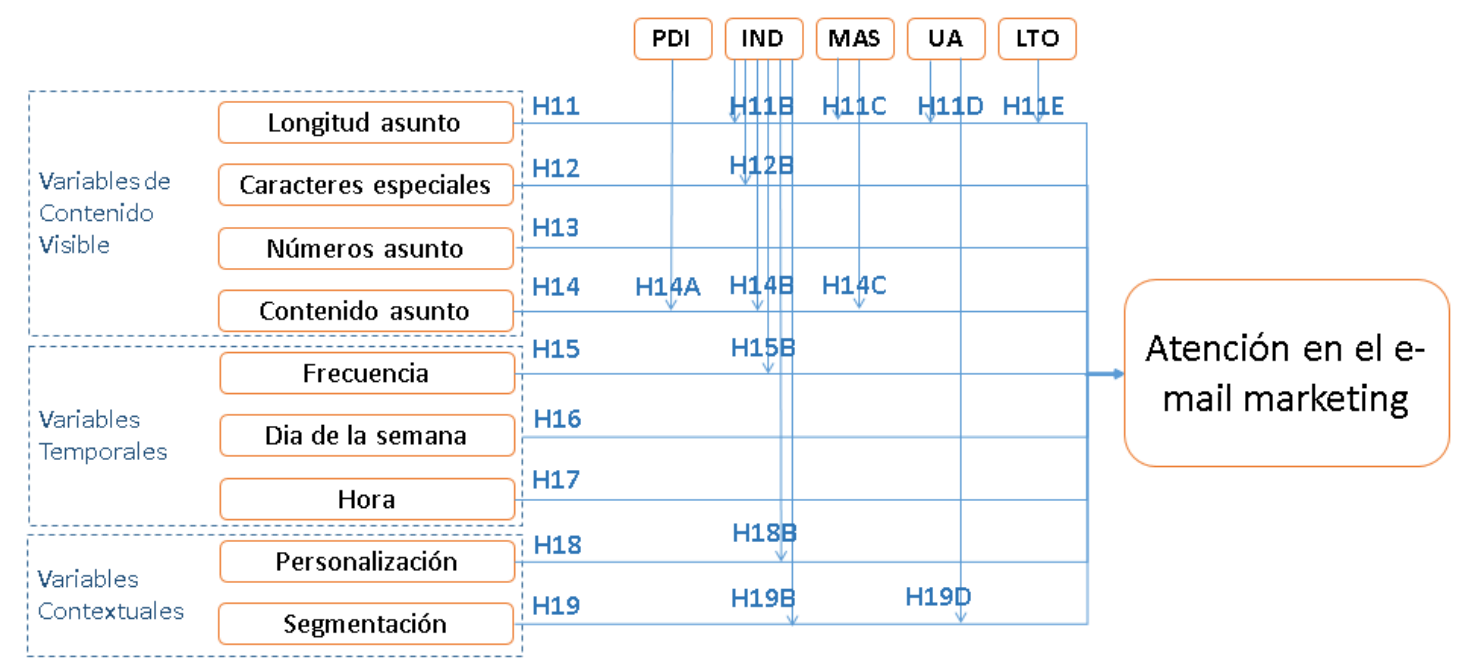

Figura 10 - Resumen de hipótesis de variables de influencia (independientes) y moderadoras en la atención

\begin{tabular}{|c|c|c|c|c|}
\hline $\begin{array}{c}\text { Categoría de } \\
\text { Variable }\end{array}$ & Antecedente & Naturaleza & $\begin{array}{c}\text { Variable } \\
\text { endógena }\end{array}$ & Hipótesis \\
\hline \multirow{4}{*}{$\begin{array}{l}\text { Contenido } \\
\text { visible }\end{array}$} & Longitud Asunto & - & \multirow{9}{*}{ Atención } & $\mathrm{H}_{11}$ \\
\hline & Caracteres Especiales & + & & $\mathrm{H}_{12}$ \\
\hline & Números Asunto & + & & $\mathrm{H}_{13}$ \\
\hline & Contenido Asunto & $<>$ & & $\mathrm{H}_{14}$ \\
\hline \multirow{3}{*}{ Temporal } & Frecuencia & - & & $\mathrm{H}_{15}$ \\
\hline & Día de la semana & $<>$ & & $\mathrm{H}_{16}$ \\
\hline & Hora de envío & $<>$ & & $\mathrm{H}_{17}$ \\
\hline \multirow{2}{*}{ Contextual } & Personalización & + & & $\mathrm{H}_{18}$ \\
\hline & Segmentación & + & & $\mathrm{H}_{19}$ \\
\hline \multirow{12}{*}{ Cultural } & Individualismo-Colectivismo & + & \multirow{4}{*}{$\begin{array}{l}\text { Moderadora de } \\
\text { hipótesis } \mathrm{H}_{11}\end{array}$} & $\mathrm{H}_{11 \mathrm{~B}}$ \\
\hline & Masculinidad-Feminidad & + & & $\mathrm{H}_{11 \mathrm{C}}$ \\
\hline & Aversión a la incertidumbre & + & & $\mathrm{H}_{11 \mathrm{D}}$ \\
\hline & Orientación al largo plazo & - & & $\mathrm{H}_{11 \mathrm{E}}$ \\
\hline & Individualismo-Colectivismo & - & $\begin{array}{l}\text { Moderadora de } \\
\text { hipótesis } \mathrm{H}_{12}\end{array}$ & $\mathrm{H}_{12 \mathrm{~B}}$ \\
\hline & Distancia al poder & - & \multirow{3}{*}{$\begin{array}{l}\text { Moderadora de } \\
\text { hipótesis } \mathrm{H}_{14}\end{array}$} & $\mathrm{H}_{14 \mathrm{~A}}$ \\
\hline & Individualismo-Colectivismo & + & & $\mathrm{H}_{14 \mathrm{~B}}$ \\
\hline & Masculinidad-Feminidad & + & & $\mathrm{H}_{14 \mathrm{C}}$ \\
\hline & Individualismo-Colectivismo & + & $\begin{array}{l}\text { Moderadora de } \\
\text { hipótesis } \mathrm{H}_{15}\end{array}$ & $\mathrm{H}_{15 \mathrm{~B}}$ \\
\hline & Individualismo-Colectivismo & + & $\begin{array}{c}\text { Moderadora de } \\
\text { hipótesis } \mathrm{H}_{18}\end{array}$ & $\mathrm{H}_{18 \mathrm{~B}}$ \\
\hline & Individualismo-Colectivismo & + & \multirow{2}{*}{$\begin{array}{l}\text { Moderadora de } \\
\text { hipótesis } \mathrm{H}_{19}\end{array}$} & $\mathrm{H}_{19 \mathrm{~B}}$ \\
\hline & Aversión a la incertidumbre & + & & $\mathrm{H}_{19 \mathrm{D}}$ \\
\hline
\end{tabular}

Tabla 15 - Atención. Resumen de hipótesis. 


\subsection{2 $\underline{\text { Interés }}$}

\subsubsection{Relaciones de las variables de contenido visible}

De esta categoría de variables, tan solo el contenido del asunto se ha relacionado con la aparición del interés en el e-mail marketing (Marinova et al., 2002; Micheaux, 2011). Sin embargo, puesto que el asunto y el contenido del correo tienden a coincidir desde el punto de vista semántico, resulta complejo dilucidar la contribución individual de cada uno de estos elementos, puesto que cumplen una función análoga.

Ninguno de los estudios citados en el anterior párrafo incluía variables de contenido no visible desde un punto de vista semántico, por lo que cabe concluir que se trataba de modelos simplificados que concentraban la carga semántica de la comunicación en el asunto. Puesto que el enfoque de esta tesis es más detallado y el modelo propuesto contará con variables de contenido no visible de carácter semántico, esta variable de contenido visible se excluirá del alcance con vistas a evitar problemas de colinealidad en el análisis.

\subsubsection{Relaciones de las variables de contenido no visible}

Tal y como se ha detallado en el capítulo segundo, esta categoría de variables es la más estudiada en relación con la aparición del interés, por lo que existe abundante literatura que justifica su inclusión en esta tesis. A continuación, se presentará brevemente el soporte teórico que justifica las hipótesis que propondrá esta investigación.

En general, la relevancia de la longitud del texto del correo viene determinada por el hecho de que los textos extensos están asociadas a un esfuerzo superior por parte del consumidor comparado con el exigido por los textos breves, lo que implica que los primeros son menos efectivos (Solomon \& Rabolt, 2009). Así, son preferibles los textos cortos (Arnold, 2008; Dufrene et al., 2005; Groves, 2009; Ting, 2012), puesto que benefician la aparición del interés (Groves, 2009; Rettie \& Chittenden, 2003).

La presencia de imágenes enriquece la comunicación y hace más fácil que el consumidor comprenda el mensaje que el anunciante pretende transmitir (Simon \& Peppas, 2004; Tufte, 1995). Si bien éstas no deben paliar la ausencia de contenido (Tufte, 1995) ni ser completamente dominantes (Groves, 2009), existen indicios que señalan que el interés crece con el número de imágenes (Rettie \& Chittenden, 2003).

En cuanto a los enlaces, su presencia se considera fundamental en cualquier correo electrónico para asegurar que el consumidor puede alcanzar otros dominios digitales del anunciante una vez ha terminado de leer el e-mail y, en general, pese a que no es recomendable abusar de este elemento (Ellis-Chadwick \& Doherty, 2012), se considera que el interés crece con el número de vínculos de un correo (Chittenden \& Rettie, 2003; Kumar \& Salo, 2018). 
Desde un punto de vista semántico, la presencia de incentivos en el correo es una variable extremadamente relevante en el análisis de la efectividad, a la vista del abundante soporte teórico que recomienda la utilización de argumentos lógicos para incentivar el interés del consumidor (Kotler \& Keller, 2012; Petty et al., 1983; Solomon et al., 2013), tal y como se ha detallado en el capítulo segundo. Así, estos elementos son efectivos en el ámbito del e-mail marketing (Baggott, 2011), y están vinculados a una mejora del interés en las comunicaciones. Este estudio propone dos tipologías de argumentos con contrastada eficiencia en el e-mail marketing: los incentivos económicos (Chang et al., 2013; Chittenden \& Rettie, 2003; Lu et al., 2007; Theerthaana \& Sharad, 2014) y los asociados a la urgencia y la escasez (Arnold, 2008; Baggott, 2011; Groves, 2009). Por todo lo anterior, se proponen las siguientes hipótesis:

$\mathrm{H}_{21}$ : El incremento de la longitud del texto del correo disminuye el interés del usuario en el e-mail marketing.

$\mathrm{H}_{22}$ : El incremento del número de imágenes del correo aumenta el interés del usuario en el e-mail marketing.

$\mathrm{H}_{23}$ : El incremento del número de enlaces del correo aumenta el interés del usuario en el e-mail marketing.

$\mathrm{H}_{24}$ : La presencia de incentivos económicos incrementa el interés del usuario en el e-mail marketing.

$\mathrm{H}_{25}$ : La presencia de elementos que generan sensación de escasez incrementa el interés del usuario en el e-mail marketing.

\subsubsection{Relaciones de las variables temporales}

De manera análoga a lo expuesto en el estudio de la atención en el e-mail marketing, la frecuencia se considera relacionada con la percepción de intrusión que causa un correo electrónico (Micheaux, 2011). Así, una frecuencia demasiado elevada puede constituir una amenaza para la aparición del interés por parte del consumidor (Groves, 2009; Micheaux, 2011), por lo que se plantea:

$\mathrm{H}_{26}$ : El incremento de frecuencia de envío disminuye el interés del usuario en el e-mail marketing.

\subsubsection{Relaciones de las variables contextuales}

También de manera similar a lo detallado en el estudio de la atención, las técnicas de personalización y segmentación permiten adaptar el contenido del correo a las necesidades del usuario y, por tanto, mejorar la eficiencia a través de unos elementos de contenido más relevantes para el consumidor. Esto tiene como consecuencia un mayor interés del usuario en la comunicación promocional siempre que, en el caso de la 
personalización, ésta esté justificada (Bawm \& Nath, 2014; Sahni et al., 2016; White et al., 2008). Por tanto, se plantean las siguientes hipótesis:

$\mathrm{H}_{27}$ : La personalización incrementa el interés del usuario en el e-mail marketing.

$\mathrm{H}_{28}$ : La segmentación incrementa el interés del usuario en el e-mail marketing.

La figura 11 resume las hipótesis expuestas en las anteriores líneas.

\begin{tabular}{|c|c|c|c|}
\hline & Longitud texto & $\mathrm{H} 21$ & \\
\hline & Número de imágenes & $\mathrm{H} 22$ & \\
\hline Variables de & & $\mathrm{H} 23$ & \\
\hline Contenido & Número de enlaces & & \\
\hline No Visible & & $\mathrm{H} 24$ & \\
\hline & Incentivos & $\mathrm{H} 25$ & Interés en el e. \\
\hline & Escasez & & iliteles eil te \\
\hline 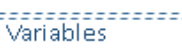 & 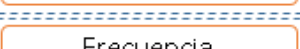 & $\mathrm{H} 26$ & mail marketing \\
\hline Temporales $=:$ & 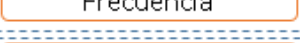 & & \\
\hline Variables & Personalización & $\mathrm{H} 27$ & \\
\hline Contextuales & Segmentación & $\mathrm{H} 28$ & \\
\hline
\end{tabular}

Figura 11 - Resumen de hipótesis de variables de influencia (independientes) en el interés

\subsubsection{Relaciones de las variables culturales}

De nuevo, en este caso se utilizará una nomenclatura que asignará una letra determinada para cada dimensión de Hofstede, que será añadida a continuación del número identificador de la hipótesis que vincula la variable independiente con la dependiente, según lo descrito en el apartado anterior. El apéndice permite consultar la relación completa de hipótesis.

En el caso de la longitud del texto, número de imágenes y número de enlaces, y de manera similar a lo desarrollado en el estudio de la longitud del asunto, es posible vincular estas variables al deseo de los consumidores en los países con alta componente individualista de llegar al mensaje principal de los anuncios rápidamente (DeMooij \& Hofstede, 2010). Asimismo, las culturas masculinas, las individualistas, las poco orientadas al largo plazo y las que tienen elevada aversión a la incertidumbre prefieren un diseño web minimalista y una comunicación simple (Diaz et al., 2017; Hermeking, 2006; Marcus \& Gould, 2000; Mazaheri et al., 2011), lo cual soporta la proposición de las siguientes hipótesis:

$\mathrm{H}_{21 \mathrm{~B}}$ : El incremento de la longitud del texto del correo disminuye más el interés del usuario en el e-mail marketing en países con elevada puntuación en la dimensión Individualismo-Colectivismo. 
$\mathrm{H}_{21 \mathrm{C}}$ : El incremento de la longitud del texto del correo disminuye más el interés del usuario en el e-mail marketing en países con elevada puntuación en la dimensión Masculinidad-Feminidad.

$\mathrm{H}_{21 D}$ : El incremento de la longitud del texto del correo disminuye más el interés del usuario en el e-mail marketing en países con elevada puntuación en la dimensión Aversión a la incertidumbre.

$\mathrm{H}_{21 \mathrm{E}}$ : $\mathrm{El}$ incremento de la longitud del texto del correo disminuye más el interés del usuario en el e-mail marketing en países con baja puntuación en la dimensión Orientación al largo plazo.

$\mathrm{H}_{22 \mathrm{~B}}$ : El incremento del número de imágenes aumenta más el interés del usuario en el e-mail marketing en países con baja puntuación en la dimensión Individualismo-Colectivismo.

$\mathrm{H}_{22 \mathrm{C}}$ : El incremento del número de imágenes aumenta más el interés del usuario en el e-mail marketing en países con baja puntuación en la dimensión Masculinidad-Feminidad.

$\mathrm{H}_{22 \mathrm{D}}$ : El incremento del número de imágenes aumenta más el interés del usuario en el e-mail marketing en países con baja puntuación en la dimensión Aversión a la incertidumbre.

$\mathrm{H}_{22 \mathrm{E}}$ : $\mathrm{El}$ incremento del número de imágenes aumenta más el interés del usuario en el e-mail marketing en países con alta puntuación en la dimensión Orientación al largo plazo.

$\mathrm{H}_{23 \mathrm{~B}}$ : $\mathrm{El}$ incremento del número de enlaces aumenta más el interés del usuario en el e-mail marketing en países con baja puntuación en la dimensión Individualismo-Colectivismo.

$\mathrm{H}_{23 \mathrm{C}}$ : El incremento del número de enlaces aumenta más el interés del usuario en el e-mail marketing en países con baja puntuación en la dimensión Masculinidad-Feminidad.

$\mathrm{H}_{23 D}$ : $\mathrm{El}$ incremento del número de enlaces aumenta más el interés del usuario en el e-mail marketing en países con baja puntuación en la dimensión Aversión a la incertidumbre.

$\mathrm{H}_{23 \mathrm{E}}$ : El incremento del número de enlaces aumenta más el interés del usuario en el e-mail marketing en países con alta puntuación en la dimensión Orientación al largo plazo. 
En cuanto a las variables semánticas de contenido no visible - esto es, la presencia de incentivos económicos y de elementos que crean sensación de escasez-, es posible vincularlas a la distancia al poder a través de la mayor relevancia que las culturas con elevada puntuación en esta dimensión conceden a la exclusividad de un producto, hecho potenciado por la sensación de escasez y reducido por la utilización de ofertas promocionales (Albers-Miller \& Gelb, 1996). Además, dada la preferencia de las culturas individualistas por un proceso persuasivo de venta (DeMooij \& Hofstede, 2010; Kale et al., 2007) y la de las masculinas por los datos (Hofstede et al., 2010), es posible teorizar sobre una posible influencia de estas dos dimensiones de Hofstede en el estudio de la efectividad de las variables que nos ocupan. Finalmente, el vínculo existente entre aversión a la incertidumbre y la reducción en el plazo de compra incentivado por los elementos crean urgencia (Hofstede et al., 2010), así como la preferencia de culturas con baja orientación al largo plazo por la acción inmediata (Marcus \& Gould, 2000) permiten asociar la cuarta y quinta dimensión de Hofstede con los elementos que general escasez. Por tanto, se plantean las siguientes hipótesis:

$\mathrm{H}_{24 \mathrm{~A}}$ : La presencia de incentivos económicos incrementa más el interés del usuario en el e-mail marketing en países con baja puntuación en la dimensión Distancia al poder.

$\mathrm{H}_{24 \mathrm{~B}}$ : La presencia de incentivos económicos incrementa más el interés del usuario en el e-mail marketing en países con alta puntuación en la dimensión Individualismo-Colectivismo.

$\mathrm{H}_{24 \mathrm{C}}$ : La presencia de incentivos económicos incrementa más el interés del usuario en el e-mail marketing en países con alta puntuación en la dimensión Masculinidad-Feminidad.

$\mathrm{H}_{25 \mathrm{~A}}$ : La presencia de elementos que generan sensación de escasez incrementa más el interés del usuario en el e-mail marketing en países con alta puntuación en la dimensión Distancia al poder.

$\mathrm{H}_{25 \mathrm{~B}}$ : La presencia de elementos que generan sensación de escasez incrementa más el interés del usuario en el e-mail marketing en países con alta puntuación en la dimensión Individualismo-Colectivismo.

$\mathrm{H}_{25 \mathrm{C}}$ : La presencia de elementos que generan sensación de escasez incrementa más el interés del usuario en el e-mail marketing en países con alta puntuación en la dimensión Masculinidad-Feminidad.

$\mathrm{H}_{25 \mathrm{D}}$ : La presencia de elementos que generan sensación de escasez incrementa más el interés del usuario en el e-mail marketing en países con alta puntuación en la dimensión Aversión a la incertidumbre. 
$\mathrm{H}_{25 \mathrm{E}}$ : La presencia de elementos que generan sensación de escasez incrementa más el interés del usuario en el e-mail marketing en países con baja puntuación en la dimensión Orientación al largo plazo.

De nuevo, la relación de la frecuencia con la intrusión (Micheaux, 2011) y su asociación a la importancia de la privacidad en las culturas individualistas (Marcus \& Gould, 2000), así como resultados negativos obtenidos por otros medios de comunicación digitales -banners- en culturas individualistas cuando son considerados intrusivos (Möller \& Eisend, 2010), sustentan la siguiente hipótesis:

$\mathrm{H}_{26 \mathrm{~B}}$ : El incremento de frecuencia de envío disminuye más el interés del usuario en el e-mail marketing en países con alta puntuación en la dimensión Individualismo-Colectivismo.

Finalmente, en cuanto a la personalización y la segmentación, se señalará de nuevo el vínculo entre culturas individualistas y mayor propensión al uso de información personal (Marcus \& Gould, 2000), así como mayores expectativas de experiencias personalizada en la interacción digital (Kale et al., 2007; Kale, 2003). Además, y puesto que la segmentación contribuye a despejar de manera más concreta las dudas específicas de un grupo de individuos similares respecto a un producto, se puede vincular esta variable con la aversión a la incertidumbre (Möller \& Eisend, 2010). En esta línea, se plantean:

н27B: La personalización aumenta más el interés prestado por el usuario al e-mail marketing en países con alta puntuación en la dimensión IndividualismoColectivismo.

н28в: La segmentación aumenta más el interés prestado por el usuario al e-mail marketing en países con alta puntuación en la dimensión IndividualismoColectivismo.

H28D: La segmentación aumenta más el interés prestado por el usuario al e-mail marketing en países con alta puntuación en la dimensión Aversión a la incertidumbre.

La figura 12 y la tabla 16 resumen las hipótesis relacionadas con la etapa de interés. 


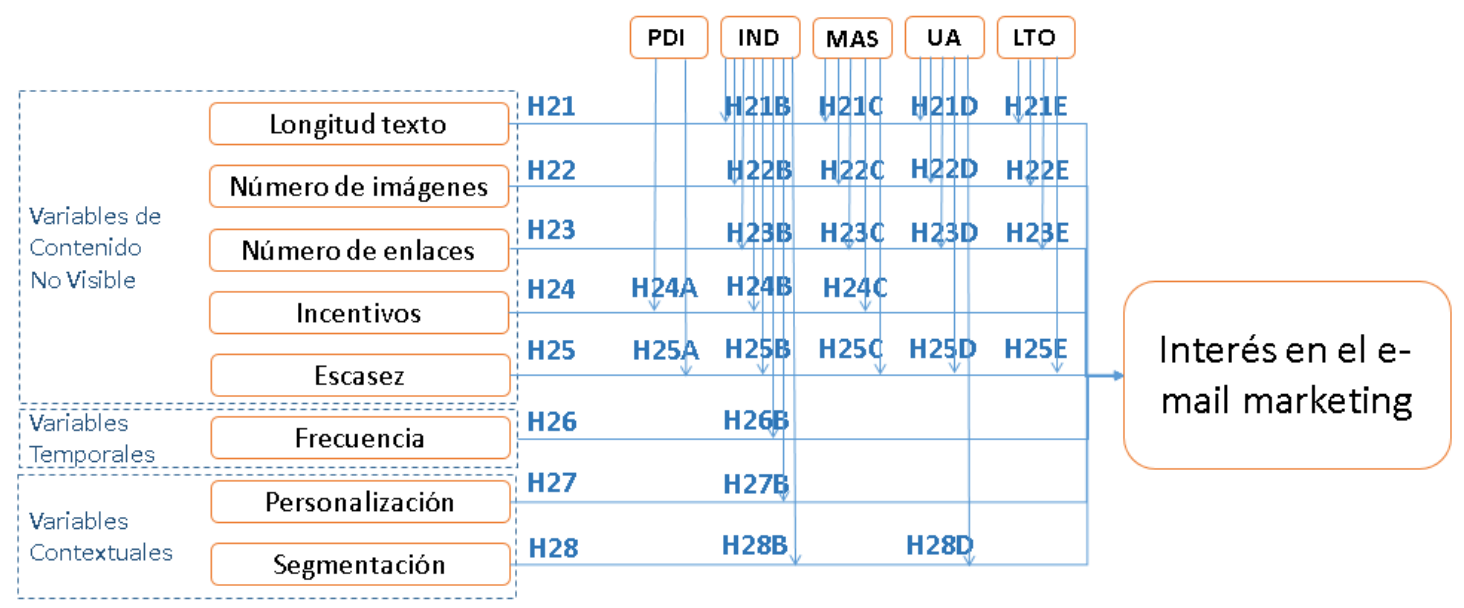

Figura 12 - Resumen de hipótesis de variables de influencia (independientes) y moderadoras en el interés 


\begin{tabular}{|c|c|c|c|c|}
\hline $\begin{array}{c}\text { Categoría de } \\
\text { Variable }\end{array}$ & Antecedente & Naturaleza & $\begin{array}{c}\text { Variable } \\
\text { endógena }\end{array}$ & Hipótesis \\
\hline \multirow{5}{*}{$\begin{array}{l}\text { Contenido no } \\
\text { visible }\end{array}$} & Longitud Texto & - & \multirow{8}{*}{ Interés } & $\mathrm{H}_{21}$ \\
\hline & Número de imágenes & + & & $\mathrm{H}_{22}$ \\
\hline & Numero de enlaces & + & & $\mathrm{H}_{23}$ \\
\hline & Incentivos económicos & + & & $\mathrm{H}_{24}$ \\
\hline & Sensación de escasez & + & & $\mathrm{H}_{25}$ \\
\hline Temporal & Frecuencia & - & & $\mathrm{H}_{26}$ \\
\hline \multirow{2}{*}{ Contextual } & Personalización & + & & $\mathrm{H}_{27}$ \\
\hline & Segmentación & + & & $\mathrm{H}_{28}$ \\
\hline \multirow{24}{*}{ Cultural } & Individualismo-Colectivismo & + & \multirow{4}{*}{$\begin{array}{l}\text { Moderadora de } \\
\text { hipótesis } \mathrm{H}_{2} 1\end{array}$} & $\mathrm{H}_{21 \mathrm{~B}}$ \\
\hline & Masculinidad-Feminidad & + & & $\mathrm{H}_{21 \mathrm{C}}$ \\
\hline & Aversión a la incertidumbre & + & & $\mathrm{H}_{21 \mathrm{D}}$ \\
\hline & Orientación al largo plazo & - & & $\mathrm{H}_{21 \mathrm{E}}$ \\
\hline & Individualismo-Colectivismo & - & \multirow{4}{*}{$\begin{array}{l}\text { Moderadora de } \\
\text { hipótesis } \mathrm{H}_{22}\end{array}$} & $\mathrm{H}_{22 \mathrm{~B}}$ \\
\hline & Masculinidad-Feminidad & - & & $\mathrm{H}_{22 \mathrm{C}}$ \\
\hline & Aversión a la incertidumbre & - & & $\mathrm{H}_{22 \mathrm{D}}$ \\
\hline & Orientación al largo plazo & + & & $\mathrm{H}_{22 \mathrm{E}}$ \\
\hline & Individualismo-Colectivismo & - & \multirow{4}{*}{$\begin{array}{l}\text { Moderadora de } \\
\text { hipótesis } \mathrm{H}_{23}\end{array}$} & $\mathrm{H}_{23 \mathrm{~B}}$ \\
\hline & Masculinidad-Feminidad & - & & $\mathrm{H}_{23 \mathrm{C}}$ \\
\hline & Aversión a la incertidumbre & - & & $\mathrm{H}_{23 \mathrm{D}}$ \\
\hline & Orientación al largo plazo & + & & $\mathrm{H}_{23 \mathrm{E}}$ \\
\hline & Distancia al poder & - & \multirow{3}{*}{$\begin{array}{l}\text { Moderadora de } \\
\text { hipótesis } \mathrm{H}_{24}\end{array}$} & $\mathrm{H}_{24 \mathrm{~A}}$ \\
\hline & Individualismo-Colectivismo & + & & $\mathrm{H}_{24 \mathrm{~B}}$ \\
\hline & Masculinidad-Feminidad & + & & $\mathrm{H}_{24 \mathrm{C}}$ \\
\hline & Distancia al poder & + & \multirow{5}{*}{$\begin{array}{l}\text { Moderadora de } \\
\text { hipótesis } \mathrm{H}_{25}\end{array}$} & $\mathrm{H}_{25 \mathrm{~A}}$ \\
\hline & Individualismo-Colectivismo & + & & $\mathrm{H}_{25 \mathrm{~B}}$ \\
\hline & Masculinidad-Feminidad & + & & $\mathrm{H}_{25 \mathrm{C}}$ \\
\hline & Aversión a la incertidumbre & + & & $\mathrm{H}_{25 \mathrm{D}}$ \\
\hline & Orientación al largo plazo & - & & $\mathrm{H}_{25 \mathrm{E}}$ \\
\hline & Individualismo-Colectivismo & + & $\begin{array}{l}\text { Moderadora de } \\
\text { hipótesis } \mathrm{H}_{26}\end{array}$ & $\mathrm{H}_{26 \mathrm{~B}}$ \\
\hline & Individualismo-Colectivismo & + & $\begin{array}{c}\text { Moderadora de } \\
\text { hipótesis } \mathrm{H}_{27}\end{array}$ & $\mathrm{H}_{27 \mathrm{~B}}$ \\
\hline & Individualismo-Colectivismo & + & \multirow{2}{*}{$\begin{array}{l}\text { Moderadora de } \\
\text { hipótesis } \mathrm{H}_{28}\end{array}$} & $\mathrm{H}_{28 \mathrm{~B}}$ \\
\hline & Aversión a la incertidumbre & + & & $\mathrm{H}_{28 \mathrm{D}}$ \\
\hline
\end{tabular}

Tabla 16 - Interés. Resumen de hipótesis

\subsubsection{Acción}

\subsubsection{Relaciones de las variables de contenido visible}

De manera similar a lo expuesto en el apartado relativo al interés, de esta categoría de variables tan solo el contenido del asunto se ha relacionado con la acción en el e-mail 
marketing (Janke, 2014; Theerthaana \& Sharad, 2014). Sin embargo, puesto que el asunto y el contenido del correo tienden a coincidir desde el punto de vista semántico y resulta complejo determinarla contribución individual de cada uno de estos elementos, se excluirán estas variables del estudio de la acción.

\subsubsection{Relaciones de las variables de contenido no visible}

La justificación del uso de elementos como incentivos económicos y elementos que generan urgencia y escasez en la fase de acción es la misma -si cabe, más evidente- que la recogida en el apartado del interés. Estos argumentos persuasivos están totalmente enfocados en conseguir que el usuario complete la acción perseguida por el remitente compra del producto, en el caso del comercio electrónico-, y su utilización en el ámbito del e-mail marketing está vinculada a incrementos de efectividad en el área de la acción (Shuey, 2014; Sigurdsson et al., 2013; Theerthaana \& Sharad, 2014). Así, se proponen las siguientes hipótesis:

$\mathrm{H}_{31}$ : La presencia de incentivos económicos incrementa las posibilidades de que el usuario realice la acción perseguida por el remitente en el e-mail marketing.

$\mathrm{H}_{32}$ : La presencia de elementos que generan sensación de escasez incrementa las posibilidades de que el usuario realice la acción perseguida por el remitente en el e-mail marketing.

\subsubsection{Relaciones de las variables contextuales}

Tal y como se ha desarrollado en el estudio de las etapas anteriores del modelo AIDA, las técnicas de personalización y segmentación mejoran la efectividad del e-mail marketing a través de contenidos adaptados a las particularidades de cada usuario. La utilización de estas técnicas mejora los resultados en la fase de acción (Jackson \& DeCormier, 1999; Sahni et al., 2016; Theerthaana \& Sharad, 2014), hecho que posibilita el planteamiento de las siguientes hipótesis:

$\mathrm{H}_{33}$ : La utilización de técnicas de personalización incrementa las posibilidades de que el usuario realice la acción perseguida por el remitente en el e-mail marketing.

$\mathrm{H}_{34}$ : La utilización de técnicas de segmentación incrementa las posibilidades de que el usuario realice la acción perseguida por el remitente en el e-mail marketing.

La figura 13 resume las hipótesis detalladas en las anteriores líneas. 


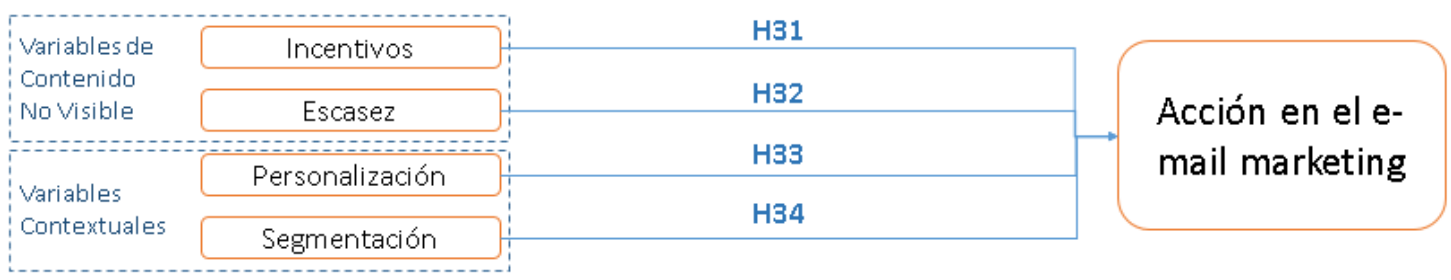

Figura 13 - Resumen de hipótesis de variables de influencia (independientes) en la acción

\subsubsection{Relaciones de las variables culturales}

La relación de las dimensiones culturales con las variables de influencia en la etapa de acción es idéntica a la planteada para estas mismas variables en la etapa de interés. Así, en las siguientes líneas se plantearán someramente las relaciones estudiadas para proponer hipótesis moderadoras.

En cuanto a la presencia de incentivos económicos y de elementos que crean sensación de escasez, se vincularán a la distancia al poder a través de la mayor relevancia que las culturas con elevada puntuación en esta dimensión conceden a la exclusividad de un producto, hecho que se potencia si se crea una sensación de escasez, y que se disminuye a través de ofertas promocionales (Albers-Miller \& Gelb, 1996); al individualismocolectivismo a través de la preferencia de las culturas individualistas por un proceso persuasivo de venta (DeMooij \& Hofstede, 2010; Kale et al., 2007); a la masculinidadfeminidad a través de la preferencia de las culturas masculinas por los datos (Hofstede et al., 2010); a la aversión a la incertidumbre a través de la reducción en el plazo de compra estimulado por los elementos que aumentan la urgencia en la compra (Hofstede et al., 2010); y, finalmente, a la orientación al largo plazo a través de la preferencia de culturas con baja puntuación en esta dimensión por la acción inmediata (Marcus \& Gould, 2000). De esta manera, se plantea la siguiente serie de hipótesis:

$\mathrm{H}_{31 \mathrm{~A}}$ : La presencia de incentivos económicos incrementa más la acción del usuario en el e-mail marketing en países con baja puntuación en la dimensión Distancia al poder.

$\mathrm{H}_{31 \mathrm{~B}}$ : La presencia de incentivos económicos incrementa más la acción del usuario en el e-mail marketing en países con alta puntuación en la dimensión Individualismo-Colectivismo.

$\mathrm{H}_{31 \mathrm{C}}$ : La presencia de incentivos económicos incrementa más la acción del usuario en el e-mail marketing en países con alta puntuación en la dimensión Masculinidad-Feminidad.

$\mathrm{H}_{32 \mathrm{~A}}$ : La presencia de elementos que generan sensación de escasez incrementa más la acción del usuario en el e-mail marketing en países con alta puntuación en la dimensión Distancia al poder. 
$\mathrm{H}_{32 \mathrm{~B}}$ : La presencia de elementos que generan sensación de escasez incrementa más la acción del usuario en el e-mail marketing en países con alta puntuación en la dimensión Individualismo-Colectivismo.

$\mathrm{H}_{32 \mathrm{C}}$ : La presencia de elementos que generan sensación de escasez incrementa más la acción del usuario en el e-mail marketing en países con alta puntuación en la dimensión Masculinidad-Feminidad.

$\mathrm{H}_{32 \mathrm{D}}$ : La presencia de elementos que generan sensación de escasez incrementa más la acción del usuario en el e-mail marketing en países con alta puntuación en la dimensión Aversión a la incertidumbre.

$\mathrm{H}_{32 \mathrm{E}}$ : La presencia de elementos que generan sensación de escasez incrementa más la acción del usuario en el e-mail marketing en países con baja puntuación en la dimensión Orientación al largo plazo.

Como conclusión, y en cuanto a la personalización y la segmentación, estas variables se vincularán al individualismo-colectivismo a través de la mayor propensión de culturas individualistas al uso de información personal (Marcus \& Gould, 2000) y a esperar experiencias personalizada en la interacción digital (Kale et al., 2007; Kale, 2003). Además, en el caso exclusivo de la segmentación, se vinculará esta variable a la aversión a la incertidumbre ya que contribuye a atacar de manera más efectiva las barreras de compra de un grupo de individuos similares respecto a un producto (Möller $\&$ Eisend, 2010). De lo anterior, se plantean:

$\mathrm{H}_{33 \mathrm{~B}}$ : La personalización aumenta más la acción del usuario en el e-mail marketing en países con alta puntuación en la dimensión IndividualismoColectivismo.

$\mathrm{H}_{34 \mathrm{~B}}$ : La segmentación aumenta más la acción del usuario en el e-mail marketing en países con alta puntuación en la dimensión Individualismo-Colectivismo.

$\mathrm{H}_{34 \mathrm{D}}$ : La segmentación aumenta más la acción del usuario en el e-mail marketing en países con alta puntuación en la dimensión Aversión a la incertidumbre.

La figura 14 y la tabla 17 resumen las hipótesis enunciadas para la etapa de acción. 


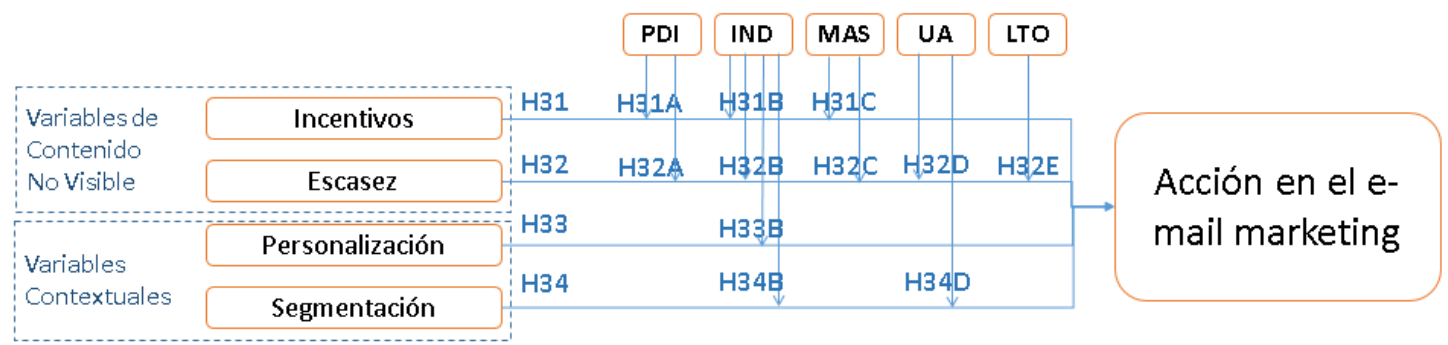

Figura 14 - Resumen de hipótesis de variables de influencia (independientes) y moderadoras en la acción.

\begin{tabular}{|c|c|c|c|c|}
\hline $\begin{array}{c}\text { Categoría de } \\
\text { Variable }\end{array}$ & Antecedente & Naturaleza & $\begin{array}{c}\text { Variable } \\
\text { endógena }\end{array}$ & Hipótesis \\
\hline \multirow{2}{*}{$\begin{array}{l}\text { Contenido no } \\
\text { visible }\end{array}$} & Incentivos económicos & + & \multirow{4}{*}{ Acción } & $\mathrm{H}_{31}$ \\
\hline & Sensación de escasez & + & & $\mathrm{H}_{32}$ \\
\hline \multirow{2}{*}{ Contextual } & Personalización & + & & $\mathrm{H}_{33}$ \\
\hline & Segmentación & + & & $\mathrm{H}_{34}$ \\
\hline \multirow{11}{*}{ Cultural } & Distancia al poder & - & \multirow{3}{*}{$\begin{array}{l}\text { Moderadora de } \\
\text { hipótesis } \mathrm{H}_{31}\end{array}$} & $\mathrm{H}_{31 \mathrm{~A}}$ \\
\hline & Individualismo-Colectivismo & + & & $\mathrm{H}_{31 \mathrm{~B}}$ \\
\hline & Masculinidad-Feminidad & + & & $\mathrm{H}_{31 \mathrm{C}}$ \\
\hline & Distancia al poder & + & \multirow{5}{*}{$\begin{array}{l}\text { Moderadora de } \\
\text { hipótesis } \mathrm{H}_{32}\end{array}$} & $\mathrm{H}_{32 \mathrm{~A}}$ \\
\hline & Individualismo-Colectivismo & + & & $\mathrm{H}_{32 \mathrm{~B}}$ \\
\hline & Masculinidad-Feminidad & + & & $\mathrm{H}_{32 \mathrm{C}}$ \\
\hline & Aversión a la incertidumbre & + & & $\mathrm{H}_{32 \mathrm{D}}$ \\
\hline & Orientación al largo plazo & - & & $\mathrm{H}_{32 \mathrm{E}}$ \\
\hline & Individualismo-Colectivismo & + & $\begin{array}{l}\text { Moderadora de } \\
\text { hipótesis } \mathrm{H}_{33}\end{array}$ & $\mathrm{H}_{33 \mathrm{~B}}$ \\
\hline & Individualismo-Colectivismo & + & \multirow{2}{*}{$\begin{array}{l}\text { Moderadora de } \\
\text { hipótesis } \mathrm{H}_{34}\end{array}$} & $\mathrm{H}_{34 \mathrm{~B}}$ \\
\hline & Aversión a la incertidumbre & + & & $\mathrm{H}_{34 \mathrm{D}}$ \\
\hline
\end{tabular}

Tabla 17 - Acción. Resumen de hipótesis

\subsection{RESUMEN DEL MODELO}

A continuación, la figura 15 presenta un resumen de la propuesta teórica del modelo de efectividad en el e-mail marketing. Son destacables las ligeras variaciones respecto al modelo inicial propuesto en el capítulo primero - por ejemplo, con la eliminación de hipótesis que relacionan las variables de contenido visible con el interés-, resultado de las decisiones detalladas en los anteriores párrafos que han sido tomadas con el objetivo de reducir la complejidad del modelo. 


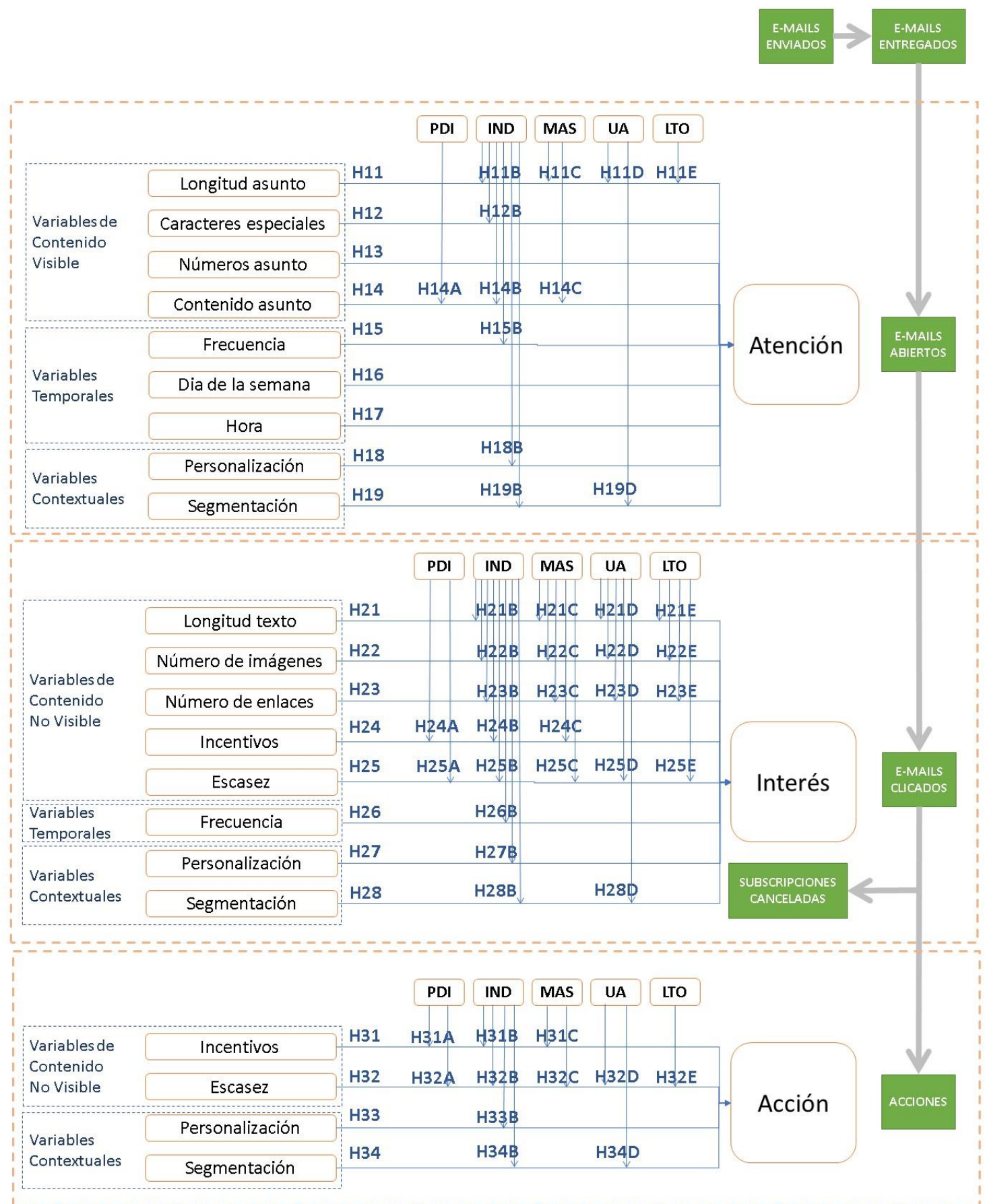

Figura 15 - Resumen del modelo teórico 


\title{
Capítulo 6 - Diseño del trabajo empírico
}

\author{
6.1 CARACTERÍSTICAS DE LA INVESTIGACIÓN \\ 6.2 ALCANCE DEL ESTUDIO \\ 6.3 NECESIDADES DE DATOS \\ 6.4 OPERACIONALIZACIÓN DE LAS VARIABLES \\ 6.4.1 Variables dependientes \\ 6.4.2 Variables de contenido visible \\ 6.4.3 Variables de contenido no visible \\ 6.4.4 Variables temporales \\ 6.4.5 Variables contextuales \\ 6.4.6 Dimensiones culturales \\ 6.4.7 Resumen de la operacionalización
}

6.5 DESCRIPCIÓN DE LA MUESTRA

6.5.1 Muestra para el estudio de la etapa de atención (OR) e interés (UR)

6.5.2 Muestra para el estudio de la etapa de interés (CTOR) y conversión (CR)

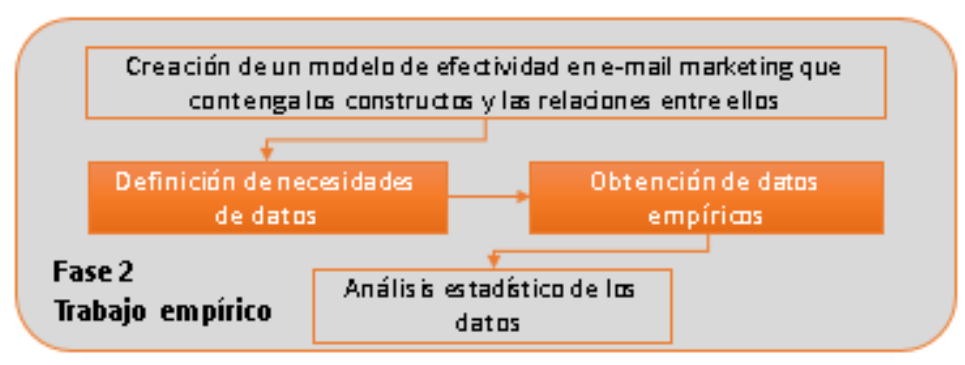




\section{DISEÑO DEL TRABAJO EMPÍRICO}

\subsection{CARACTERÍSTICAS DE LA INVESTIGACIÓN}

Una vez finalizada la propuesta de modelo teórico, resulta pertinente como siguiente paso el proporcionar más detalles del procedimiento empírico que se utilizará para su validación. A tal efecto, se procederá a describir desde una óptica práctica el objeto de esta tesis, de manera que sea posible definir a posteriori las características adecuadas de la muestra y las técnicas más apropiadas para la operacionalización de variables.

Tal y como se ha expresado en anteriores apartados, el objetivo fundamental de esta tesis es la proposición y validación de un modelo teórico de efectividad en el e-mail marketing. Dicho modelo incorporará variables que permitan operacionalizar la efectividad, factores de influencia inherentes al entorno del correo electrónico - de contenido visible y no visible, temporales y contextuales- y factores más generales que pueden tener influencia en el consumidor-dimensiones culturales. El desarrollo de acciones de e-mail marketing tiene como objetivo general influir en el comportamiento humano (Baggott, 2011). Así, la presente tesis se encuadra en el ámbito de las ciencias sociales, puesto que el objetivo genérico de éstas es el estudio de la sociedad humana (Kuper, 2004).

Atendiendo ahora a la metodología utilizada, es posible clasificar las investigaciones en tres ramas fundamentales en función de su propósito último: exploratorias -orientadas a clarificar ambigüedades o descubrir oportunidades, investigan relaciones entre conceptos de manera general-, descriptivas - orientadas a identificar características de objetos, personas, grupos, etc.- y causales -enfocadas en el establecimiento de relaciones causa-efecto previamente propuestas- (Zikmund et al., 2013). A la vista de esta categorización, las características de esta investigación permiten considerarla como exploratoria, puesto que el objetivo fundamental es la identificación de qué factores son relevantes en la materia y cuál es su importancia relativa.

En esta misma línea, y atendiendo ahora a los medios utilizados, se pueden clasificar de manera general las investigaciones como teóricas -enfocadas en la discusión de conceptos generales e ideas- y empíricas - la discusión teórica se apoya en la experiencia y los procedimientos prácticos- (Zikmund et al., 2013). Por ello, resulta razonable clasificar este estudio como empírico, a la vista de que utilizará datos reales de campañas de e-mail marketing para validar el modelo teórico propuesto. En concreto, la investigación se considerará un estudio de campo, puesto que se basa en datos obtenidos en un entorno no controlado por el investigador -en contraste con las investigaciones de laboratorio- (Zikmund et al., 2013). 
En cuanto al tipo de razonamiento que se empleará en este análisis, y partiendo de la base de que en general se considera una investigación como deductiva cuando infiere conclusiones sobre una situación concreta utilizando como base premisas generales, y como inductiva cuando basada en hechos particulares infiere una relación general (Zikmund et al., 2013), este trabajo de investigación tiene una naturaleza deductiva.

Por otra parte, y puesto que para el estudio propuesto será posible la utilización de evidencias medibles y cuantificables a través de cifras, la investigación tendrá un carácter cuantitativo, en oposición a los estudios cualitativos, que utilizan otra serie de métodos como la observación directa (Field, 2013).

Finalmente, esta tesis utilizará una técnica estadística conocida como regresión múltiple que se sitúa en el campo del análisis multivariante (Field, 2013), si bien los aspectos relativos a la técnica de análisis serán detallados con más profundidad en el capítulo siguiente.

\subsection{ALCANCE DEL ESTUDIO}

A la hora de determinar el alcance, conviene de nuevo tomar como punto de partida el objetivo de esta investigación; esto es, la propuesta y validación de un modelo unificado de efectividad en el e-mail marketing. Una de las principales limitaciones identificadas en la revisión de la literatura ha sido la limitación geográfica presente en la mayoría de investigaciones realizadas hasta la fecha -en el capítulo primero se han proporcionado más detalles a este respecto. Entre otras, una de las aportaciones originales de esta investigación será la utilización una muestra global, por lo que, desde un punto de vista geográfico, su alcance se considera mundial.

Pese a que debido a la confidencialidad de los datos no se pueden proporcionar resultados desglosados, es posible mencionar que la muestra incluye datos de cincuenta y dos culturas nacionales situadas en los cinco continentes. Este hecho permite confiar en una diversidad suficiente como para permitir extraer conclusiones globales, así como cumplir con los requerimientos metodológicos de aplicación del modelo de Hofstede, que exigen al menos 5 países presentes en la muestra para poder garantizar unos resultados relevantes (DeMooij \& Hofstede, 2010).

En cuanto al alcance temporal, los datos utilizados se han extraído de campañas enviadas entre 2011 y 2017, con lo que su vigencia y diversidad resulta suficiente para asegurar la relevancia de las conclusiones.

Finalmente, a lo largo del marco teórico se han puntualizado en diversas ocasiones circunstancias de tipo práctico, teórico y metodológico que influían en el alcance de la investigación. Resulta pertinente resumirlas de nuevo para ofrecer una visión global del dicho alcance. En concreto, se ha mencionado: 
Capítulo 1

- El e-mail marketing puede ser consentido -el usuario ha autorizado la comunicación previa- o no consentido -spam. Esta investigación se limita a la primera de estas categorías, si bien la literatura ha estudiado ambas.

- Algunas comunicaciones consentidas no tienen un carácter promocional, como son aquellas puramente transaccionales (confirmación de compra) o de servicio (entrega de un pedido). Esta investigación se enfoca únicamente en las comunicaciones promocionales.

Capítulo 2

- Pese a reconocer la importancia de la efectividad de entrega en el estudio del email marketing, la imposibilidad de acceder a datos empíricos y la limitada capacidad de los anunciantes de actuar sobre sus variables de influencia ha conducido a su exclusión del alcance.

- Pese a que el e-mail marketing no incluye solamente el envío de comunicaciones, sino que también abarca la captación y gestión de suscriptores de la base de datos, esta tesis se restringe a la parte relativa al estudio de efectividad en el envío de comunicaciones.

Capítulo 3

- La etapa de deseo del modelo AIDA se excluirá del alcance debido a la imposibilidad de aislarla de manera fiable con el enfoque que adopta esta investigación.

Capítulo 4

- Pese a haber sido incorporada recientemente al modelo, la sexta dimensión de Hofstede (Indulgencia-restricción) quedará fuera del alcance del estudio debido a la falta de soporte teórico para su inclusión en el estudio.

\subsection{NECESIDADES DE DATOS}

Una vez caracterizada la investigación y delimitado el alcance, y como paso posterior a la propuesta del modelo teórico de efectividad, se plantea la necesidad de definir las características de los datos necesarios para validarlo -o refutarlo- y determinar la manera más adecuada de obtenerlos. Una cuidadosa revisión de lo expuesto hasta la fecha pone de relieve cinco condiciones fundamentales.

- El primer requisito resulta obvio: es necesario que todos los factores de influencia y variables dependientes propuestos en el modelo teórico estén 
disponibles o puedan ser deducidos, puesto que en caso contrario no sería posible la validación del modelo completo.

- El segundo requerimiento, mencionado en las líneas anteriores, está asociado a la vocación global del estudio: es necesario que los datos provengan de múltiples países -al menos 5 son necesarios para poder utilizar el modelo de Hofstede (DeMooij \& Hofstede, 2010)-, de forma que se pueda valorar la influencia de la cultura y asegurar la validez de las conclusiones generales.

- El tercer requisito viene asociado al producto o servicio anunciado: toda la muestra deberá ser homogénea en cuanto a categoría de producto para evitar que la influencia de algunas dimensiones culturales en el nivel de inversión en diferentes categorías impida una lectura clara de los resultados (DeMooij, 2014).

- La cuarta condición es de índole metodológica, y resulta clave en el estudio de la efectividad de conversión: es necesario que el modelo de atribución utilizado sea consistente a lo largo de toda la muestra, puesto que de otra manera los resultados no serían fiables.

- El quinto requerimiento, también de índole metodológica, es relativo al tamaño de la muestra. En un análisis de regresión múltiple, el mínimo de registros necesario para poder conducir el análisis depende del número de variables independientes y del tamaño del efecto a medir (Field, 2013). En el caso más desfavorable - detectar efectos pequeños $\left(\mathrm{f}^{2}=0.02\right)$ en la etapa de atención, para la que existen 46 predictores incluyendo las variables de interacción-, es necesaria una muestra de 1444 muestras con un nivel de significación $\alpha=0.05 \mathrm{y}$ una potencia estadística $\beta=0.8$ (Faul et al., 2009). Así, es necesario que la muestra de cada etapa cuente con un número suficiente de registros para poder ser utilizada.

Estos cinco requerimientos resultan innegociables para garantizar un punto de partida que permita aspirar a alcanzar los objetivos del proyecto $\mathrm{y}$, por tanto, han de ser incorporados en el proceso de obtención y filtrado de datos. A la hora de preguntarse cuál es la mejor manera de abordar dicho proceso, como primera opción cabe plantearse si es factible la realización de un estudio de laboratorio -esto es, en condiciones controladas por el investigador (Field, 2013). Sin embargo, y dado el alcance delimitado anteriormente, la ejecución de dicho estudio resultaría sumamente dificultosa. Esto es así porque para alcanzar tal fin sería necesario construir una base de datos suficientemente grande y diversa vinculada a la venta online de un producto concreto tarea titánica que podría llevar años-, o bien el investigador necesitaría encontrar una organización con una base de datos de las características definidas que la pusiera a su servicio durante un notable número de envíos - posibilidad harto improbable a la vista del enorme coste de oportunidad para dicha organización. 
Descartada esta opción, parece necesario acudir a resultados de campañas ya realizadas que cumplan con los requisitos anteriormente definidos. Esta vía resulta mucho más factible y, además, a la vista del carácter empírico de esta investigación y su vocación eminentemente práctica -orientada a servir a las empresas y entidades que utilizan el email marketing de forma regular-, la utilización de este tipo de datos incrementa las posibilidades de que cualquier conclusión alcanzada tenga utilidad práctica para los ejecutivos de marketing.

Por este motivo, se ha procedido a abordar tanto a compañías como a ESPs y gestores de bases de datos comerciales para solicitar su colaboración. De aquellos que han accedido a participar, se han seleccionado aquellos registros que cumplían los requisitos definidos anteriormente, para posteriormente dividirlos en tres muestras en función de las diferentes etapas del modelo -atención, interés, acción. Dichas muestras serán descritas en mayor detalle en el último apartado de este capítulo.

\subsection{OPERACIONALIZACIÓN DE LAS VARIABLES}

Una vez caracterizados los requisitos de los datos y determinado el cauce para su obtención, el siguiente paso en el desarrollo del trabajo empírico consiste en determinar la manera más adecuada de traducir los constructos integrados en el modelo teórico en variables medibles y aptas para su tratamiento en un programa estadístico. Si bien a lo largo del marco teórico se ha especificado la manera de abordar este ejercicio para constructos concretos, se presenta a continuación la metodología utilizada para todos ellos.

\subsubsection{Variables dependientes}

En el desarrollo del marco teórico se ha expuesto la necesidad de desglosar la efectividad del e-mail marketing -objeto de estudio principal de esta tesis- en efectividades parciales que permitan un análisis pormenorizado que recoja la complejidad del comportamiento del consumidor en su interacción con este canal. Asimismo, se han vinculado dichas efectividades con diversas etapas del modelo AIDA. A continuación, se presenta cada una de ellas y la metodología utilizada en su operacionalización.

\subsubsection{Atención}

La atención se ha vinculado a la apertura del correo por parte del usuario y, por tanto, a la efectividad de apertura. Tal y como muestra la tabla 18, esta variable se operacionaliza a través de la tasa de apertura -open rate $(O R)_{-}$, definida como el porcentaje de e-mails abiertos en relación a los enviados (Balakrishnan \& Parekh, 2015; Bawm \& Nath, 2014; Kumar \& Salo, 2018; Micheaux, 2011; Sahni et al., 2016; Sigurdsson et al., 2013, 2016). De todas las opciones detalladas para la obtención de la 
efectividad de apertura en el apartado correspondiente del capítulo segundo, esta investigación se basa en datos proporcionados por los ESPs a través de la inserción de un pixel en el código del correo.

\begin{tabular}{|c|c|c|c|c|}
\hline Constructo & Efectividad & Código & Variable & Fuente \\
\hline Atención & $\begin{array}{l}\text { Efectividad } \\
\text { de apertura }\end{array}$ & OR & $\begin{array}{l}\text { Tasa de } \\
\text { apertura }\end{array}$ & $\begin{array}{l}\text { Balakrishnan \& Parekh (2015), Bawm \& Nath } \\
\text { (2014), Kumar \& Salo (2018), Micheaux (2011), } \\
\text { Sahni \& Wheeler (2016), Sigurdsson et al. (2013, } \\
\text { 2016). }\end{array}$ \\
\hline
\end{tabular}

Tabla 18 - Atención. Operacionalización de variables dependientes.

\subsubsection{Interés}

El interés está vinculado tanto a la efectividad de clic como a la de retención de suscriptores. Como muestra la tabla 19, la efectividad de clic se operacionaliza habitualmente a través de la tasa de clic -conocida como CTR o click-thru rate-, que relaciona los e-mails clicados con los enviados (Bawm \& Nath, 2014; Bonfrer \& Drèze, 2009; Kumar \& Salo, 2018; Marinova et al., 2002; Micheaux, 2011; Reichhart et al., 2013; Rettie \& Chittenden, 2003; Sahni et al., 2016; Sigurdsson et al., 2013, 2016; Smart \& Cappel, 2003). Sin embargo, esta medida se verá influida por le efectividad de apertura, ya que sólo aquellos usuarios que han abierto el correo podrán acceder a sus enlaces. Puesto que el modelo teórico es de carácter procesal y está planteado de forma que cada etapa se analice de forma independiente, esta investigación operacionalizará la efectividad de clic utilizando el CTOR -click-to-open-rate- que calcula el porcentaje de e-mails en los que el usuario ha seguido un enlace en relación al número de e-mails abiertos (Mullen \& Daniels, 2009). De las técnicas disponibles para el conteo de clics detalladas en el capítulo segundo, los datos han sido obtenidos directamente de los ESPs a través de redireccionamiento.

En cuanto a la efectividad de retención de suscriptores, se operacionalizará esta variable a través de la tasa de cancelación de suscriptores $-U R$ o unsubscribe rate-, que mide el porcentaje de usuarios que utilizó el enlace del correo para la cancelación de la suscripción a la base de datos en relación al número total de correos enviados (Marinova et al., 2002; Micheaux, 2011; Rettie \& Chittenden, 2003; Sahni et al., 2016; Sigurdsson et al., 2013, 2016). Dicha medida estará sujeta a las consideraciones relativas a su exactitud detalladas en el apartado correspondiente del capítulo segundo. 


\begin{tabular}{|c|l|l|l|l|}
\hline Constructo & \multicolumn{1}{|c|}{ Efectividad } & Código & \multicolumn{1}{c|}{ Variable } & \multicolumn{1}{c|}{ Fuente } \\
\hline & $\begin{array}{l}\text { Efectividad de } \\
\text { clic }\end{array}$ & CTOR & Tasa de clic & Mullen \& Daniels (2011) \\
\cline { 2 - 5 } Interés & $\begin{array}{l}\text { Efectividad de } \\
\text { retención de } \\
\text { suscriptores }\end{array}$ & UR & $\begin{array}{l}\text { Tasa de } \\
\text { cancelación de } \\
\text { subscripciones }\end{array}$ & $\begin{array}{l}\text { Bawm \& Nath (2014), Jackson } \\
\text { \& DeCormier (1999), Jolley } \\
\text { et al. (2013), Kumar \& Salo } \\
\text { (2018), Reichhart et al. (2013), } \\
\text { Sahni \& Wheeler (2016), } \\
\text { Sigurdsson et al. (2013, 2016), } \\
\text { Smart \& Cappel (2003) }\end{array}$ \\
\hline
\end{tabular}

Tabla 19 - Interés. Operacionalización de variables dependientes.

\subsubsection{Acción}

Finalmente, la etapa de acción se vincula a la efectividad de conversión, que a su vez se operacionaliza a través de la tasa de conversión $-C R$ o conversión rate-, tal y como se aprecia en la tabla 20. El cálculo de esta tasa relaciona el número de conversiones alcanzadas con las visitas enviadas a la web (Bawm \& Nath, 2014; Jackson \& DeCormier, 1999; Jolley et al., 2013; Kumar \& Salo, 2018; Reichhart et al., 2013; Sahni et al., 2016; Sigurdsson et al., 2013, 2016; Smart \& Cappel, 2003). En el caso de la muestra utilizada por esta tesis, las visitas se estimarán a través del conteo del número de clics generados por el correo. Puesto que la muestra esta extraída de un entorno de comercio electrónico, en el cálculo de las conversiones se considerará que una conversión equivale a una transacción. Así, se considerará una sola conversión tanto a la situación en la que el usuario añade varios artículos al carrito de la compra online para posteriormente realizar el pago como a la adquisición de un solo artículo.

Atendiendo las consideraciones detalladas en el capítulo segundo respecto al cálculo de las conversiones, esta investigación utilizará datos obtenidos a través de una herramienta de análisis web con códigos unívocos bajo el modelo de atribución de último clic.

\begin{tabular}{|l|l|l|l|l|}
\hline Constructo & \multicolumn{1}{|c|}{ Efectividad } & Código & \multicolumn{1}{c|}{ Variable } & \multicolumn{1}{c|}{ Fuente } \\
\hline Acción & Efectividad de & CR & Tasa de & Bawm \& Nath (2014), \\
& conversión & & conversión & Jackson \& DeCormier (1999), \\
& & & & Jolley et al. (2013), Kumar \& \\
& & & Salo (2018), Reichhart et al. \\
& & & (2013), Sahni \& Wheeler \\
& & & & \\
& & & & \\
& & & & \\
& & & & \\
& & & & \\
& & & & \\
\hline
\end{tabular}

Tabla 20 - Acción. Operacionalización de variables dependientes.

\subsubsection{Variables de contenido visible}

En la codificación de las variables de contenido visible es necesario un único componente del correo: el asunto. Este elemento ha sido extraído directamente de los ESPs. En la codificación de las variables formales se ha utilizado la herramienta de 
filtrado de Microsoft Excel en el caso de la presencia de números y caracteres especiales, y el comando LEN para el conteo de la longitud.

En la codificación desde un punto de vista semántico ha sido necesario como primer paso traducir todos los registros a un lenguaje común -se ha seleccionado el inglés porque éste era el idioma más frecuente de la muestra- desde los diversos idiomas utilizados. Para esto, se ha utilizado la herramienta integrada en Google Sheets a través de la instrucción GOOGLETRANSLATE vinculada al traductor online de Google.

\subsubsection{Longitud del asunto}

El cálculo de la longitud del asunto se ha realizado efectuando un conteo de los caracteres que forman este elemento, incluyendo también los espacios y signos de puntuación, de manera similar a lo efectuado por Balakrishnan y Parekh (2015), tal y como muestra la tabla 21.

\begin{tabular}{|c|l|l|l|}
\hline Constructo & Código & Variable & Fuente \\
\hline Longitud de asunto & ALON & Ratio & Balakrishnan \& Parekh (2015) \\
\hline
\end{tabular}

Tabla 21 - Longitud del asunto. Operacionalización de variables independientes.

\subsubsection{Presencia de números en el asunto}

Esta variable dicotómica toma el valor de 1 si existe algún número en el asunto, y de 0 si este no es el caso, de manera similar a lo desarrollado por Balakrishnan y Parekh (2015), tal y como muestra la tabla 22.

\begin{tabular}{|c|c|c|c|}
\hline Constructo & Código & Variable & Fuente \\
\hline Números en asunto & ANUM & Dicotómica & Balakrishnan \& Parekh (2015) \\
\hline
\end{tabular}

Tabla 22 - Presencia de números en el asunto. Operacionalización de variables independientes.

\subsubsection{Presencia de caracteres especiales en el asunto}

El estudio utilizado como fuente de esta variable (Balakrishnan \& Parekh, 2015) no determina en detalle qué caracteres se consideran especiales. Dado que el objetivo de esta variable es capturar elementos distintivos en el asunto (Solomon et al., 2013), no se han considerado como caracteres especiales los acentos, apóstrofes y signos de puntuación más comunes -coma, punto, punto y coma y dos puntos-, puesto que en algunos lenguajes éstos están presentes en la mayoría de frases. Durante la codificación de este constructo, se han encontrado los siguientes caracteres especiales:

$$
! " \cdot \$ € \% \& /() ?: i^{\wedge}+{ }^{* * \cdot{ }_{-}}<>\ldots+\cdots !
$$

Esta variable dicotómica toma el valor de 1 si existe alguno de los caracteres anteriormente citados en el asunto, y de 0 si este no es el caso, tal y como resume la tabla 23. 


\begin{tabular}{|l|l|l|l|}
\hline \multicolumn{1}{|c|}{ Constructo } & Código & Variable & Fuente \\
\hline $\begin{array}{l}\text { Caracteres especiales en } \\
\text { asunto }\end{array}$ & ACAR & Dicotómica & Balakrishnan \& Parekh (2015) \\
\hline
\end{tabular}

Tabla 23 - Caracteres especiales en el asunto. Operacionalización de variables independientes.

\subsubsection{Contenido del asunto}

La clasificación de líneas de asunto en función de su contenido se ha realizado a partir de las siguientes categorías (tabla 24): oferta de descuento, información de producto, boletín de noticias, promoción de temporada, teaser (prelanzamiento), requerimiento de acción, promoción general, concurso, invitación a evento en tienda, regalo gratuito, oferta de bonus y otros (Ellis-Chadwick \& Doherty, 2012).

Tras la primera evaluación de la muestra, se han añadido dos categorías adicionales, cada una de las cuales combina dos de las enumeradas anteriormente: descuentos de temporada y promoción general con concurso. Aparte de estos dos casos concretos justificados por el elevado número de registros pertenecientes a estas categorías, aquellos registros que pertenecían simultáneamente a otras dos categorías han sido excluidos de la muestra para evitar crear un exceso de complejidad.

\begin{tabular}{|l|l|}
\hline \multicolumn{1}{|c|}{ Categoría } & \multicolumn{1}{c|}{ Criterio de clasificación } \\
\hline Oferta de descuento & $\begin{array}{l}\text { Promoción que comunique explícitamente una reducción del precio } \\
\text { habitual (por ejemplo, "20\% de descuento" o "10€ menos") }\end{array}$ \\
\hline Promoción de temporada & $\begin{array}{l}\text { Promoción que no se englobe en la categoría anterior con temática } \\
\text { estacional (otoño, invierno...), días señalados (Black Friday, San } \\
\text { Valentín...) o festividades religiosas o nacionales (Navidad, } \\
\text { Hanukkah, Día de la Independencia) }\end{array}$ \\
\hline Descuento de temporada & $\begin{array}{l}\text { Promoción que cumpla los parámetros de las dos categorías } \\
\text { anteriores. }\end{array}$ \\
\hline Regalo gratuito & Oferta de un regalo gratuito \\
\hline Oferta de bonus & $\begin{array}{l}\text { Oferta de puntos adicionales en la tarjeta de fidelidad o de fondos } \\
\text { adicionales para una compra futura. }\end{array}$ \\
\hline Promoción general & $\begin{array}{l}\text { Promoción no incluida en ninguna de las cuatro categorías } \\
\text { anteriores. }\end{array}$ \\
\hline Teaser (prelanzamiento) & Anticipo de una campaña futura \\
\hline Requerimiento de acción & $\begin{array}{l}\text { Solicitud de una acción por parte del usuario diferente a la compra y } \\
\text { a la participación en un concurso }\end{array}$ \\
\hline Información de producto & Comunicación informativa en relación con el producto \\
\hline Boletín de noticias & Comunicación informativa no relacionada con el producto \\
\hline Concurso & Invitación a participar en un concurso o anuncio de ganadores. \\
\hline Promoción general con concurso & $\begin{array}{l}\text { Invitación a participar en un concurso que también comunica una } \\
\text { promoción general }\end{array}$ \\
\hline Invitación a evento en tienda & Invitación a acudir a una tienda \\
\hline Otros & E-mails no incluidos en ninguna de las trece categorías anteriores \\
\hline
\end{tabular}

Tabla 24 - Contenido del asunto. Descripción de categorías.

Puesto que la técnica estadística seleccionada no permite la utilización de variables nominales, será necesario acudir a la codificación a través de variables dummy de variables nominales. Esta técnica consiste en la creación de un número de variables 
dicotómicas igual al de valores puede adoptar la variable nominal menos una unidad (Keith, 2015). Esta unidad representa el escenario base del modelo lineal, y suele ser el valor más frecuente en la distribución (Field, 2013). Así, las variables dicotómicas toman un valor de 1 cuando existe una diferencia respecto al escenario base, y de 0 si no es así. En el caso de la muestra de esta investigación, el valor más frecuente será el de 'Promoción General', y por tanto se procederá a codificar las otras posiciones de esta variable de acuerdo al criterio expuesto (tabla 25).

\begin{tabular}{|l|l|l|l|}
\hline \multicolumn{1}{|c|}{ Constructo } & \multicolumn{1}{c|}{ Código } & \multicolumn{1}{c|}{ Variable } & \multicolumn{1}{c|}{ Fuente } \\
\hline Contenido asunto - Descuento & ADES & Dicotómica & Ellis-Chadwick \& Doherty (2012) \\
\hline Contenido asunto - Temporada & ATEM & Dicotómica & Ellis-Chadwick \& Doherty (2012) \\
\hline $\begin{array}{l}\text { Contenido asunto - Descuento de } \\
\text { temporada }\end{array}$ & ADTE & Dicotómica & Ellis-Chadwick \& Doherty (2012) \\
\hline Contenido asunto - Regalo & AREG & Dicotómica & Ellis-Chadwick \& Doherty (2012) \\
\hline Contenido asunto - Bonus & ABON & Dicotómica & Ellis-Chadwick \& Doherty (2012) \\
\hline Contenido asunto - Teaser & ATEA & Dicotómica & Ellis-Chadwick \& Doherty (2012) \\
\hline Contenido asunto - Acción & AACC & Dicotómica & Ellis-Chadwick \& Doherty (2012) \\
\hline Contenido asunto - Producto & APRO & Dicotómica & Ellis-Chadwick \& Doherty (2012) \\
\hline Contenido asunto - Noticias & ANOT & Dicotómica & Ellis-Chadwick \& Doherty (2012) \\
\hline Contenido asunto - Concurso & ACON & Dicotómica & Ellis-Chadwick \& Doherty (2012) \\
\hline $\begin{array}{l}\text { Contenido asunto - Concurso y } \\
\text { Promoción }\end{array}$ & ACPR & Dicotómica & Ellis-Chadwick \& Doherty (2012) \\
\hline Contenido asunto - Evento & AEVE & Dicotómica & Ellis-Chadwick \& Doherty (2012) \\
\hline Contenido asunto - Otro & AOTR & Dicotómica & Ellis-Chadwick \& Doherty (2012) \\
\hline
\end{tabular}

Tabla 25 - Contenido del asunto. Operacionalización de variables independientes.

\subsubsection{Variables de contenido no visible}

La codificación de las variables de contenido no visible requiere de acceso al correo electrónico enviado a los consumidores. Tal y como se ha detallado en el marco teórico, los correos electrónicos son ficheros HTML con una estructura similar a una página web. Para la extracción de los datos requeridos ha sido necesario el desarrollo de una aplicación VBA (Visual Basic for Applications), cuyo código comentado se reproduce a continuación.

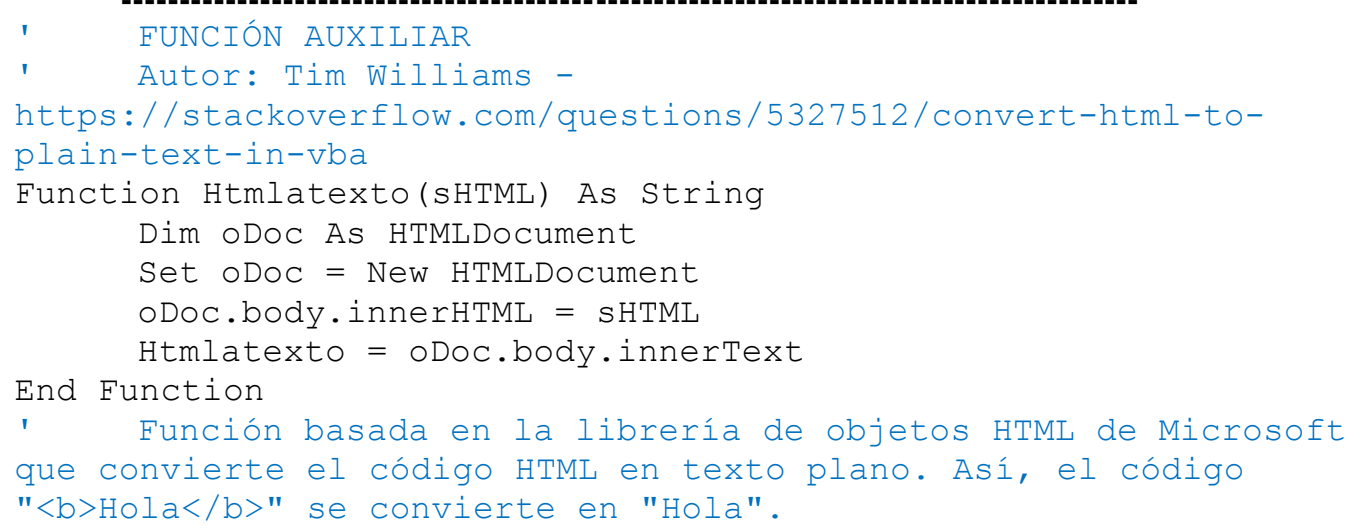




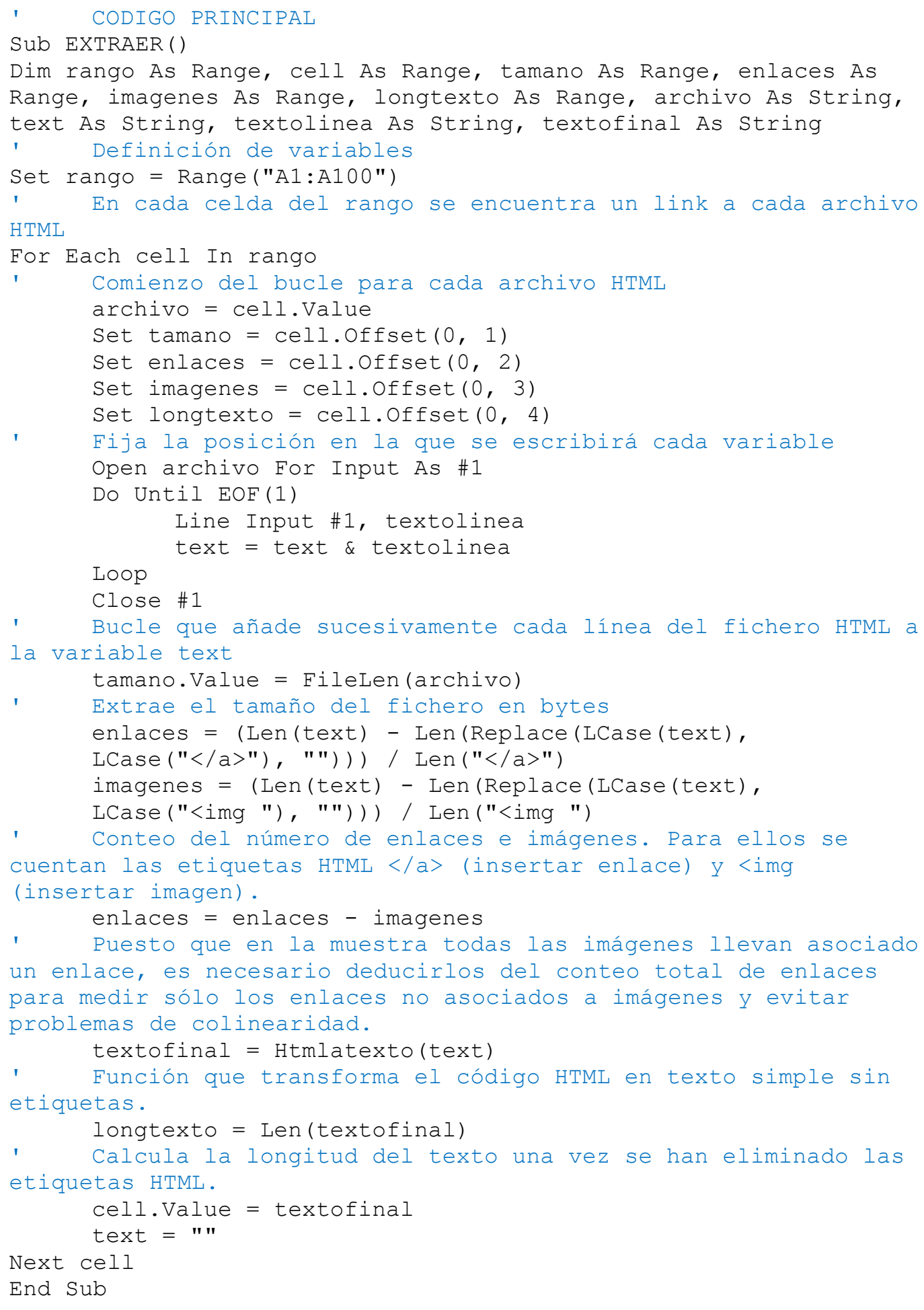

\subsubsection{Longitud del texto del e-mail}

La comunidad científica no ha adoptado un método consistente en el cálculo de esta variable, puesto que se han utilizado como unidades de medida el número de palabras (Kumar \& Salo, 2018), el número de veces que es necesario avanzar la página -scrolls(Chittenden \& Rettie, 2003) y el número de páginas (Ellis-Chadwick \& Doherty, 2012). 
Las dos últimas opciones han sido descartadas en esta investigación puesto que su valor varía en función de la resolución de la pantalla del usuario, métrica razonablemente estable en el momento de realización de los estudios que la utilizan -dado que el acceso al correo electrónico se realizaba casi en exclusiva a través de ordenadores-, pero poco reveladora en el entorno actual, en el que es habitual interactuar con dispositivos de todos los tamaños. En relación al conteo de palabras, su uso puede ser razonable para muestras de un solo idioma pero, debido a la diferente longitud media de las palabras en cada idioma (Smith, 2012), puede resultar poco certera en las muestra de múltiples idiomas. Por ejemplo, su utilización produciría un valor inferior para el texto "extraordinaria promoción" que para "hot Xmas sale". Dado que esta variable pretende evaluar la complejidad del texto y su influencia en el proceso perceptual (Solomon et al., 2013), esta técnica parece poco adecuada. Por estos motivos, se ha decidido utilizar una metodología similar a la elegida para el estudio de la longitud del asunto; esto es, un conteo de los caracteres que forman este elemento, incluyendo también los espacios y signos de puntuación. La tabla 26 resume las características de esta variable.

\begin{tabular}{|c|l|l|l|}
\hline \multicolumn{1}{|c|}{ Constructo } & Código & \multicolumn{1}{c|}{ Variable } & Fuente \\
\hline Longitud texto e-mail & ELON & Ratio & Adaptado de Balakrishnan \& Parekh (2015) \\
\hline
\end{tabular}

Tabla 26 - Longitud del texto. Operacionalización de variables independientes

\subsubsection{Número de enlaces del e-mail}

El conteo del número de enlaces es una variable utilizada con relativa frecuencia en el estudio del e-mail marketing (Ellis-Chadwick \& Doherty, 2012; Kumar \& Salo, 2018; Rettie \& Chittenden, 2003; Theerthaana \& Sharad, 2014). Para la obtención de este dato se ha efectuado el conteo de veces que aparece en el código HTML la estructura $\langle/ a\rangle$, tal y como se ha detallado en el código expuesto anteriormente. Esta medida resulta precisa puesto que la inserción de enlaces en HTML utiliza la siguiente sintaxis:

$$
<\text { a href="www.direccionwebenlazada.com" }>\text { texto o imagen que ve el usuario }\langle/ a\rangle
$$

Así, la estructura $</ a>$ aparece necesariamente una vez por enlace. Sin embargo, resulta una práctica común asociar un enlace a todas las imágenes del texto (Arnold, 2008), como de hecho ocurre en la muestra objeto de esta investigación. Por tanto es necesario sustraer el número de imágenes del número de enlaces calculado con el método anterior, con el objetivo de que ambas variables midan fenómenos diferentes. Además, si ambas variables se introducen tal cual han sido calculadas en el modelo, existe el riesgo de colinealidad entre variables, lo cual entorpece el análisis estadístico. De esta manera, el conteo de enlaces se restringirá a aquellos no asociados a imágenes, de forma que esta variable proporcione más riqueza al modelo. La tabla 27 detalla las características de esta variable. 


\begin{tabular}{|l|l|l|l|}
\hline Constructo & Código & Variable & \multicolumn{1}{c|}{ Fuente } \\
\hline Número de enlaces e-mail & EENL & Ratio & $\begin{array}{l}\text { Ellis-Chadwick \& Doherty (2012), Kumar } \\
\text { \& Salo (2018), Rettie \& Chittenden (2003), } \\
\text { Theerthaana \& Sharad (2014) }\end{array}$ \\
\hline
\end{tabular}

Tabla 27 - Número de enlaces. Operacionalización de variables independientes.

\subsubsection{Número de imágenes del e-mail}

El número de imágenes es también una variable frecuente en la literatura (EllisChadwick \& Doherty, 2012; Kumar \& Salo, 2018; Rettie \& Chittenden, 2003; Smart \& Cappel, 2003; Theerthaana \& Sharad, 2014). De manera análoga al caso anterior, su obtención se ha efectuado a través del conteo de veces que aparece en el código HTML la estructura <img, tal y como se ha detallado en el código. Esta medida resulta precisa puesto que la inserción de imágenes en HTML utiliza la siguiente sintaxis:

$$
\text { <img src="imagen.jpg"> }
$$

Así, la estructura <img aparece necesariamente una vez por imagen. La tabla 28 detalla las características de esta variable.

\begin{tabular}{|l|l|l|l|}
\hline \multicolumn{1}{|c|}{ Constructo } & Código & \multicolumn{1}{c|}{ Variable } & \multicolumn{1}{c|}{ Fuente } \\
\hline $\begin{array}{l}\text { Número de imágenes e- } \\
\text { mail }\end{array}$ & EIMA & Ratio & $\begin{array}{l}\text { Ellis-Chadwick \& Doherty (2012), Kumar } \\
\text { \& Salo (2018), Rettie \& Chittenden (2003), } \\
\text { Smart \& Cappel (2003), Theerthaana \& } \\
\text { Sharad (2014) }\end{array}$ \\
\hline
\end{tabular}

Tabla 28 - Número de imágenes. Operacionalización de variables independientes.

\subsubsection{Presencia de incentivos económicos en el e-mail}

En el estudio del efecto de los incentivos económicos en la efectividad del e-mail marketing, la comunidad científica ha considerado como tales los cupones (Rettie \& Chittenden, 2003), los descuentos (Baltas, 2003; Chang et al., 2013; Rettie \& Chittenden, 2003; Sahni et al., 2016; Shuey, 2014; Sigurdsson et al., 2013, 2016) y los premios (Rettie \& Chittenden, 2003). Así, en la codificación de esta variable dicotómica -con valor 1 si existen incentivos y 0 si no existen-se han tenido en cuenta la presencia de estas tres variedades en el texto. De manera similar al estudio del contenido del asunto, ha sido necesaria la traducción del texto extraído por el código detallado anteriormente, para lo cual se ha utilizado el acceso automático a Google Translate disponible en Google Sheets. La tabla 29 detalla las características de esta variable.

\begin{tabular}{|l|l|l|l|}
\hline \multicolumn{1}{|c|}{ Constructo } & Código & \multicolumn{1}{c|}{ Variable } & \multicolumn{1}{c|}{ Fuente } \\
\hline $\begin{array}{l}\text { Incentivos económicos e- } \\
\text { mail }\end{array}$ & EINC & Dicotómica & $\begin{array}{l}\text { Baltas (2003), Ellis-Chadwick \& Doherty } \\
(2012), \text { Kumar \& Salo (2018), Rettie \& } \\
\end{array}$ \\
& & $\begin{array}{l}\text { Chittenden (2003), Smart \& Cappel (2003), } \\
\text { Theerthaana \& Sharad (2014) }\end{array}$ \\
\hline
\end{tabular}

Tabla 29 - Incentivos económicos. Operacionalización de variables independientes. 


\subsubsection{Presencia de elementos que crean sensación de escasez en el e-mail}

A la hora de generar sensación de escasez, las dos técnicas identificadas por la literatura son la mención explícita de la existencia de un número limitado de unidades (Arnold, 2008) y la existencia de una fecha límite próxima en el tiempo a partir de la cual ya no es posible acceder a la promoción comunicada (Arnold, 2008; Shuey, 2014). Así, en la codificación de esta variable dicotómica -con valor 1 si existen elementos que generen sensación de escasez y 0 si no existen-, se han tenido en cuenta la presencia de estas dos variedades en la comunicación. Cabe puntualizar que, de manera general, todas las promociones tienen una duración limitada, con lo que es habitual que la comunicación incluya una mención al período durante el cual la oferta está disponible. Debido a esto, la simple mención de la fecha no se ha considerado como un elemento que genere sensación de escasez salvo que fuera acompañada de expresiones que persiguieran este fin, como por ejemplo "Apresúrese: sólo disponible hasta el 1 de enero". De nuevo se ha recurrido a las traducciones efectuadas con Google Translate para la codificación. La tabla 30 detalla las características de esta variable.

\begin{tabular}{|c|c|c|c|}
\hline Constructo & Código & Variable & Fuente \\
\hline Sensación escasez e-mail & EESC & Dicotómica & Arnold (2008), Shuey (2014) \\
\hline
\end{tabular}

Tabla 30 - Elementos que generan sensación de escasez. Operacionalización de variables independientes.

\subsubsection{Variables temporales}

Este tipo de variables tienen como origen el momento concreto en el que se ha enviado la comunicación. Este dato se encuentra normalmente alojado en los ESPs junto con otras variables generales de la campaña. Así, en la muestra utilizada por esta investigación, el momento de envío se ha obtenido a través de una consulta a este sistema.

\subsubsection{Frecuencia de envío}

Tal y como se menciona en el capítulo quinto, la operacionalización habitual de la frecuencia en TV o banners -número de veces que se ha emitido un anuncio determinado (Broussard, 2000; Tellis et al., 2000)- no es aplicable al entorno del correo electrónico, puesto que el usuario espera recibir e-mails periódicamente, pero con diferente contenido. Los estudios de e-mail marketing asocian la frecuencia a un conteo de comunicaciones enviadas durante un rango de tiempo (Ellis-Chadwick \& Doherty, 2012; Micheaux, 2011), si bien esta variable es calculada durante un período concreto por ejemplo, la frecuencia es igual al número de e-mails enviados durante las tres semanas en las que se desarrolla el experimento- y no para un período continuo - esto es, el valor de dicha variable para cada envío a una base de datos durante un período de varios años. 
Para solventar esta dificultad, se ha propuesto una aproximación similar a la utilizada en las investigaciones basadas en modelos RFM (Chen, Kuo, Wu, \& Tang, 2009; Miglautsch, 2000), en las que se establece un conteo de todas las comunicaciones enviadas por un remitente durante un período previo a cada registro estudiado -en este caso, de 30 días. Se han eliminado del conteo aquellos e-mails que, debido a que han sido segmentados, no han alcanzado la totalidad de la base de datos objetivo. La tabla 31 resume las características de la operacionalización de esta variable.

\begin{tabular}{|l|l|l|l|}
\hline \multicolumn{1}{|c|}{ Constructo } & Código & \multicolumn{1}{|c|}{ Variable } & \multicolumn{1}{c|}{ Fuente } \\
\hline Frecuencia & FREC & Ratio & $\begin{array}{l}\text { Chen, Kuo, Wu, \& Tang (2009), Miglautsch } \\
(2000)\end{array}$ \\
\hline
\end{tabular}

Tabla 31 - Frecuencia. Operacionalización de variables independientes.

\subsubsection{Día y hora de envío}

Pese a que, como se ha mencionado anteriormente, el día de la semana y la hora de envío son datos proporcionados directamente por los ESPs, ha sido necesario realizar un ajuste sobre ambas variables para adaptarlas al horario local. Puesto que dos envíos realizados en el mismo momento a San Francisco y Berlín llegarán en diferentes etapas de la jornada - a un lugar de día y a otro de noche-, y dado que estas variables pretenden contextualizar la interacción con el e-mail marketing en relación con el consumidor, resulta necesario adaptarlas al horario local para proceder a su análisis (mailermailer, 2016).

En este ejercicio de transformación también se han tenido en cuenta los horarios de verano e invierno de las diferentes naciones. Asimismo, en aquellos países que abarcan varias zonas horarias, se ha seleccionado como referencia aquella en la que se encuentran la mayoría de suscriptores en el momento del envío. De manera similar al escenario del contenido del asunto, es necesaria la codificación a través de variables dummy para poder incorporar estos constructos al modelo. Los valores más frecuentes para cada variable, y que por tanto serán utilizados como escenarios base, son el martes para el día de la semana y las 9h para la hora de envío (tabla 32).

\begin{tabular}{|l|l|l|l|}
\hline \multicolumn{1}{|c|}{ Constructo } & Código & \multicolumn{1}{c|}{ Variable } & \multicolumn{1}{c|}{ Fuente } \\
\hline Día de la semana - lunes & DIAL & Dicotómica & mailermailer (2016) \\
\hline Día de la semana - miércoles & DIAM & Dicotómica & mailermailer (2016) \\
\hline Día de la semana - jueves & DIAJ & Dicotómica & mailermailer (2016) \\
\hline Día de la semana - viernes & DIAV & Dicotómica & mailermailer (2016) \\
\hline Día de la semana - sábado & DIAS & Dicotómica & mailermailer (2016) \\
\hline Día de la semana - domingo & DIAD & Dicotómica & mailermailer (2016) \\
\hline Hora de envío - 00 & HO00 & Dicotómica & mailermailer (2016) \\
\hline Hora de envío - 01 & HO01 & Dicotómica & mailermailer (2016) \\
\hline Hora de envío - 02 & HO02 & Dicotómica & mailermailer (2016) \\
\hline Hora de envío - 03 & HO03 & Dicotómica & mailermailer (2016) \\
\hline
\end{tabular}




\begin{tabular}{|l|l|l|l|}
\hline Hora de envío - 04 & HO04 & Dicotómica & mailermailer (2016) \\
\hline Hora de envío - 05 & HO05 & Dicotómica & mailermailer (2016) \\
\hline Hora de envío - 06 & HO06 & Dicotómica & mailermailer (2016) \\
\hline Hora de envío - 07 & HO07 & Dicotómica & mailermailer (2016) \\
\hline Hora de envío - 08 & HO08 & Dicotómica & mailermailer (2016) \\
\hline Hora de envío - 10 & HO10 & Dicotómica & mailermailer (2016) \\
\hline Hora de envío - 11 & HO11 & Dicotómica & mailermailer (2016) \\
\hline Hora de envío - 12 & HO12 & Dicotómica & mailermailer (2016) \\
\hline Hora de envío - 13 & HO13 & Dicotómica & mailermailer (2016) \\
\hline Hora de envío - 14 & HO14 & Dicotómica & mailermailer (2016) \\
\hline Hora de envío - 15 & HO15 & Dicotómica & mailermailer (2016) \\
\hline Hora de envío - 16 & HO16 & Dicotómica & mailermailer (2016) \\
\hline Hora de envío - 17 & HO17 & Dicotómica & mailermailer (2016) \\
\hline Hora de envío - 18 & HO18 & Dicotómica & mailermailer (2016) \\
\hline Hora de envío - 19 & HO19 & Dicotómica & mailermailer (2016) \\
\hline Hora de envío - 20 & HO20 & Dicotómica & mailermailer (2016) \\
\hline Hora de envío - 21 & HO21 & Dicotómica & mailermailer (2016) \\
\hline Hora de envío - 22 & HO22 & Dicotómica & mailermailer (2016) \\
\hline Hora de envío - 23 & HO23 & Dicotómica & mailermailer (2016) \\
\hline
\end{tabular}

Tabla 32 - Día y hora de envío. Operacionalización de variables independientes.

\subsubsection{Variables contextuales}

\subsubsection{Segmentación}

La literatura identifica diferentes variables como base para la creación de segmentos en las bases de datos: número de transacciones anteriores (Bawm \& Nath, 2014), efectividad de campañas anteriores (Bawm \& Nath, 2014) o interés en determinados productos (Jackson \& DeCormier, 1999). En la codificación de esta variable dicotómica -con valor 1 si existe segmentación y 0 si no existe- se han considerado estos tres escenarios. El origen de los datos han sido los ESPs, puesto que normalmente son estas herramientas las que contienen las tablas a partir de las cuales se realiza la segmentación. La tabla 33 resume las características de esta variable.

\begin{tabular}{|l|l|l|l|}
\hline \multicolumn{1}{|c|}{ Constructo } & Código & Variable & \multicolumn{1}{c|}{ Fuente } \\
\hline Segmentación & SEGM & Dicotómica & $\begin{array}{l}\text { Bawm \& Nath (2014), Jackson \& } \\
\text { DeCormier (1999) }\end{array}$ \\
\hline
\end{tabular}

Tabla 33 - Segmentación. Operacionalización de variables independientes.

\subsubsection{Personalización}

La personalización se refiere a la inclusión de elementos en el correo electrónico basados en las características particulares de cada usuario. Algunos de ellos son el nombre (Marinova et al., 2002; Sahni et al., 2016; White et al., 2008), la dirección (White et al., 2008) o referencias a los gustos personales (White et al., 2008). La 
inserción de estos elementos se realiza a través de un componente dinámico en el código HTML que extrae de una base de datos (generalmente alojada en el ESP) el valor adecuado para cada suscriptor. Así, la identificación de los correos que contienen estos elementos puede realizarse o bien a través del análisis del código HTML con una técnica similar a la utilizada para el conteo del número de enlaces, o bien acudiendo directamente a los ESPs.

Esta variable dicotómica -con valor 1 si existen elementos de personalización y 0 si no existen- también se ha codificado teniendo en cuenta los escenarios descritos en el primer párrafo de este apartado. De acuerdo con el modelo, esta variable aparece en hipótesis relativas a las fases de atención, interés y acción. Sin embargo, puesto que en la fase de atención el lector no ha accedido al contenido no visible, será necesario valorar si existe personalización sólo en los elementos a los que tiene acceso en esta etapa; es decir, en el asunto.

Por ello parece razonable disgregarla en dos variables: personalización en el asunto que será utilizada en el estudio de la efectividad de apertura- y personalización en el correo -que será utilizada en el estudio del resto de fases. Sin embargo, tras proceder a la evaluación de la muestra, se ha observado que todos los elementos contienen algún elemento de personalización en el texto, con lo que la segunda variable no resulta relevante. Así, en lo sucesivo, la variable personalización hace referencia exclusivamente al asunto. La tabla 34 resume las características de esta variable.

\begin{tabular}{|l|l|l|l|}
\hline \multicolumn{1}{|c|}{ Constructo } & Código & \multicolumn{1}{c|}{ Variable } & \multicolumn{1}{c|}{ Fuente } \\
\hline Personalización & SEGM & Dicotómica & $\begin{array}{l}\text { Marinova et al., (2002) Sahni \& Wheeler } \\
\text { (2016), White, Zahay, Thorbjornsen, \& } \\
\text { Shavitt (2008) }\end{array}$ \\
\hline
\end{tabular}

Tabla 34 - Personalización. Operacionalización de variables independientes.

\subsubsection{Dimensiones culturales}

Finalmente, los valores de las dimensiones culturales han sido obtenidos de la web personal de Geert Hofstede (Hofstede, 2016), en la que pone a disposición de la comunidad científica versiones actualizadas de los mismos en función de las últimas investigaciones. En el caso de los utilizados en esta investigación la última actualización se realizó en diciembre de 2015.

Antes de proceder a añadir dichos valores a cada registro de la muestra, es necesario detenerse en algunas consideraciones metodológicas para cerciorarse de que la aplicación del modelo de Hofstede garantice la obtención de resultados coherentes.

En primer lugar, y como ya se ha mencionado en el comienzo de este capítulo, son necesarios al menos 5 países en la muestra, requisito al que se adecúa la muestra de esta tesis (DeMooij \& Hofstede, 2010). Asimismo, es recomendable la utilización de 
constructos y variables universales que puedan ser replicadas en todos los países de estudio (DeMooij \& Hofstede, 2010). A la vista de la universalidad de las acciones relacionadas con el correo electrónico -apertura, clic, cancelación de la subscripción, compra- y de la estandarización global tanto del canal como de los dispositivos de acceso al mismo, este requerimiento no supone obstáculo en el desarrollo de esta investigación.

Finalmente, es necesario mencionar el riesgo de incurrir en una falacia ecológica cuando el modelo de Hofstede se aplica a nivel individual (DeMooij, 2013; DeMooij \& Hofstede, 2010; Hofstede, 2001b). Pese a que algunos estudios utilizan este enfoque (Kirkman et al., 2006), dado que el modelo está desarrollado a nivel nacional el autor confirma que es necesario asignar los valores a este nivel, asumiendo que se cuenta con una muestra suficientemente heterogénea (DeMooij \& Hofstede, 2010). Puesto que esta investigación cuenta con datos agregados y no pretende trabajar a nivel individual, salvar este escollo será relativamente fácil, y se procederá, por tanto, a asignar valores a cada registro según la cultura nacional de origen. A continuación, la tabla 35 resume los detalles para estas cinco variables.

\begin{tabular}{|l|l|l|l|}
\hline \multicolumn{1}{|c|}{ Constructo } & \multicolumn{1}{c|}{ Código } & \multicolumn{1}{c|}{ Variable } & \multicolumn{1}{c|}{ Fuente } \\
\hline Distancia al poder & DIST & Ratio & Hofstede, Hofstede, \& Minkov (2010) \\
\hline Individualismo-Colectivismo & INDI & Ratio & Hofstede, Hofstede, \& Minkov (2010) \\
\hline Masculinidad-Feminidad & MASC & Ratio & Hofstede, Hofstede, \& Minkov (2010) \\
\hline Aversión a la incertidumbre & AVER & Ratio & Hofstede, Hofstede, \& Minkov (2010) \\
\hline Orientación al largo plazo & ORIE & Ratio & Hofstede, Hofstede, \& Minkov (2010) \\
\hline
\end{tabular}

Tabla 35 - Dimensiones culturales. Operacionalización de variables moderadoras.

\subsubsection{Resumen de la operacionalización}

A continuación, se presentan las tablas 36 y 37, que resumen las características de las variables detalladas en los anteriores apartados

\begin{tabular}{|c|c|c|c|c|}
\hline Constructo & Efectividad & Código & Variable & Fuente \\
\hline Atención & $\begin{array}{l}\text { Efectividad de } \\
\text { apertura }\end{array}$ & OR & $\begin{array}{l}\text { Tasa de } \\
\text { apertura }\end{array}$ & $\begin{array}{l}\text { Balakrishnan \& Parekh (2015), Bawm } \\
\text { \& Nath (2014), Kumar \& Salo (2018), } \\
\text { Micheaux (2011), Sahni \& Wheeler } \\
\text { (2018), Sigurdsson et al. (2013, 2016). }\end{array}$ \\
\hline \multirow[b]{2}{*}{ Interés } & $\begin{array}{l}\text { Efectividad de } \\
\text { clic }\end{array}$ & CTOR & Tasa de clic & Mullen \& Daniels (2011). \\
\hline & $\begin{array}{l}\text { Efectividad de } \\
\text { retención de } \\
\text { suscriptores }\end{array}$ & UR & $\begin{array}{l}\text { Tasa de } \\
\text { cancelación de } \\
\text { subscripciones }\end{array}$ & $\begin{array}{l}\text { Marinova et al. (2002), Micheaux } \\
\text { (2011), Rettie \& Chittenden (2003), } \\
\text { Sahni \& Wheeler (2016), Sigurdsson et } \\
\text { al. (2013, 2016) }\end{array}$ \\
\hline
\end{tabular}




\begin{tabular}{|l|l|l|l|l|}
\hline & & & $\begin{array}{l}\text { Bawm \& Nath (2014), Jackson \& } \\
\text { DeCormier (1999), Jolley et al. (2013), } \\
\text { Kumar \& Salo (2018), Reichhart et al. } \\
\text { Acción }\end{array}$ & $\begin{array}{l}\text { Efectividad de } \\
\text { conversión }\end{array}$ \\
& CR & $\begin{array}{l}\text { Tasa de } \\
\text { conversión } \\
\text { Sigurdsson et al. (2013, 2016), Smart \& } \\
\text { Cappel (2003) }\end{array}$ \\
\hline
\end{tabular}

Tabla 36 - Resumen de operacionalización de variables independientes.

\begin{tabular}{|c|c|c|c|}
\hline Constructo & Código & Variable & Fuente \\
\hline Longitud de asunto & ALON & Ratio & Balakrishnan \& Parekh (2015) \\
\hline Números en asunto & ANUM & Dicotómica & Balakrishnan \& Parekh (2015) \\
\hline $\begin{array}{l}\text { Caracteres especiales en } \\
\text { asunto }\end{array}$ & ACAR & Dicotómica & Balakrishnan \& Parekh (2015) \\
\hline $\begin{array}{l}\text { Contenido asunto - } \\
\text { Descuento }\end{array}$ & ADES & Dicotómica & Ellis-Chadwick \& Doherty (2012) \\
\hline $\begin{array}{l}\text { Contenido asunto - } \\
\text { Temporada }\end{array}$ & ATEM & Dicotómica & Ellis-Chadwick \& Doherty (2012) \\
\hline $\begin{array}{l}\text { Contenido asunto - } \\
\text { Descuento de temporada }\end{array}$ & ADTE & Dicotómica & Ellis-Chadwick \& Doherty (2012) \\
\hline Contenido asunto - Regalo & AREG & Dicotómica & Ellis-Chadwick \& Doherty (2012) \\
\hline Contenido asunto - Bonus & $\mathrm{ABON}$ & Dicotómica & Ellis-Chadwick \& Doherty (2012) \\
\hline Contenido asunto - Teaser & ATEA & Dicotómica & Ellis-Chadwick \& Doherty (2012) \\
\hline Contenido asunto - Acción & AACC & Dicotómica & Ellis-Chadwick \& Doherty (2012) \\
\hline Contenido asunto - Producto & APRO & Dicotómica & Ellis-Chadwick \& Doherty (2012) \\
\hline Contenido asunto - Noticias & ANOT & Dicotómica & Ellis-Chadwick \& Doherty (2012) \\
\hline Contenido asunto - Concurso & $\mathrm{ACON}$ & Dicotómica & Ellis-Chadwick \& Doherty (2012) \\
\hline $\begin{array}{l}\text { Contenido asunto - Concurso } \\
\text { y Promoción }\end{array}$ & ACPR & Dicotómica & Ellis-Chadwick \& Doherty (2012) \\
\hline Contenido asunto - Evento & AEVE & Dicotómica & Ellis-Chadwick \& Doherty (2012) \\
\hline Contenido asunto - Otro & AOTR & Dicotómica & Ellis-Chadwick \& Doherty (2012) \\
\hline Longitud texto e-mail & ELON & Ratio & $\begin{array}{l}\text { Adaptado de Balakrishnan \& Parekh } \\
(2015)\end{array}$ \\
\hline Número de imágenes e-mail & EIMA & Ratio & $\begin{array}{l}\text { Ellis-Chadwick \& Doherty (2012), Kumar } \\
\text { \& Salo (2018), Rettie \& Chittenden (2003), } \\
\text { Theerthaana \& Sharad (2014) }\end{array}$ \\
\hline Número de enlaces e-mail & EENL & Ratio & $\begin{array}{l}\text { Ellis-Chadwick \& Doherty (2012), Kumar } \\
\& \text { Salo (2018), Rettie \& Chittenden (2003), } \\
\text { Smart \& Cappel (2003), Theerthaana \& } \\
\text { Sharad (2014) }\end{array}$ \\
\hline $\begin{array}{l}\text { Incentivos económicos e- } \\
\text { mail }\end{array}$ & EINC & Dicotómica & $\begin{array}{l}\text { Baltas (2003), Ellis-Chadwick \& Doherty } \\
\text { (2012), Kumar \& Salo (2018), Rettie \& } \\
\text { Chittenden (2003), Smart \& Cappel (2003), } \\
\text { Theerthaana \& Sharad (2014) }\end{array}$ \\
\hline Sensación de escasez e-mail & EESC & Dicotómica & Arnold (2008), Shuey (2014) \\
\hline Frecuencia & FREC & Ratio & $\begin{array}{l}\text { Chen, Kuo, Wu, \& Tang (2009), } \\
\text { Miglautsch (2000) }\end{array}$ \\
\hline Día de la semana - lunes & DIAL & Dicotómica & mailermailer (2016) \\
\hline Día de la semana - miércoles & DIAM & Dicotómica & mailermailer (2016) \\
\hline Día de la semana - jueves & DIAJ & Dicotómica & mailermailer (2016) \\
\hline Día de la semana - viernes & DIAV & Dicotómica & mailermailer (2016) \\
\hline Día de la semana - sábado & DIAS & Dicotómica & mailermailer (2016) \\
\hline Día de la semana - domingo & DIAD & Dicotómica & mailermailer (2016) \\
\hline Hora de envío - 00 & $\mathrm{HO} 00$ & Dicotómica & mailermailer (2016) \\
\hline
\end{tabular}




\begin{tabular}{|c|c|c|c|}
\hline Hora de envío - 01 & $\mathrm{HO} 01$ & Dicotómica & mailermailer (2016) \\
\hline Hora de envío - 02 & $\mathrm{HO} 02$ & Dicotómica & mailermailer (2016) \\
\hline Hora de envío - 03 & $\mathrm{HO} 03$ & Dicotómica & mailermailer (2016) \\
\hline Hora de envío - 04 & $\mathrm{HO} 04$ & Dicotómica & mailermailer (2016) \\
\hline Hora de envío - 05 & $\mathrm{HO} 05$ & Dicotómica & mailermailer (2016) \\
\hline Hora de envío - 06 & HO06 & Dicotómica & mailermailer (2016) \\
\hline Hora de envío - 07 & $\mathrm{HO} 07$ & Dicotómica & mailermailer (2016) \\
\hline Hora de envío - 08 & $\mathrm{HO} 08$ & Dicotómica & mailermailer (2016) \\
\hline Hora de envío - 10 & HO10 & Dicotómica & mailermailer (2016) \\
\hline Hora de envío - 11 & HO11 & Dicotómica & mailermailer (2016) \\
\hline Hora de envío - 12 & HO12 & Dicotómica & mailermailer (2016) \\
\hline Hora de envío - 13 & HO13 & Dicotómica & mailermailer (2016) \\
\hline Hora de envío - 14 & HO14 & Dicotómica & mailermailer (2016) \\
\hline Hora de envío - 15 & HO15 & Dicotómica & mailermailer (2016) \\
\hline Hora de envío - 16 & HO16 & Dicotómica & mailermailer (2016) \\
\hline Hora de envío - 17 & HO17 & Dicotómica & mailermailer (2016) \\
\hline Hora de envío - 18 & HO18 & Dicotómica & mailermailer (2016) \\
\hline Hora de envío - 19 & HO19 & Dicotómica & mailermailer (2016) \\
\hline Hora de envío - 20 & $\mathrm{HO} 20$ & Dicotómica & mailermailer (2016) \\
\hline Hora de envío - 21 & $\mathrm{HO} 21$ & Dicotómica & mailermailer (2016) \\
\hline Hora de envío - 22 & $\mathrm{HO} 22$ & Dicotómica & mailermailer (2016) \\
\hline Hora de envío - 23 & $\mathrm{HO} 23$ & Dicotómica & mailermailer (2016) \\
\hline Segmentación & SEGM & Dicotómica & $\begin{array}{l}\text { Bawm \& Nath (2014), Jackson \& } \\
\text { DeCormier (1999) }\end{array}$ \\
\hline Personalización & PERS & Dicotómica & $\begin{array}{l}\text { Marinova et al., (2002) Sahni \& Wheeler } \\
\text { (2016), White, Zahay, Thorbjornsen, \& } \\
\text { Shavitt (2008) }\end{array}$ \\
\hline Distancia al poder & DIST & Ratio & Hofstede, Hofstede, \& Minkov (2010) \\
\hline Individualismo-Colectivismo & INDI & Ratio & Hofstede, Hofstede, \& Minkov (2010) \\
\hline Masculinidad-Feminidad & MASC & Ratio & Hofstede, Hofstede, \& Minkov (2010) \\
\hline Aversión a la incertidumbre & AVER & Ratio & Hofstede, Hofstede, \& Minkov (2010) \\
\hline Orientación al largo plazo & ORIE & Ratio & Hofstede, Hofstede, \& Minkov (2010) \\
\hline
\end{tabular}

Tabla 37 - Resumen de operacionalización de variables dependientes y moderadoras.

\subsection{DESCRIPCIÓN DE LA MUESTRA}

Este apartado recoge información tanto sobre las características particulares de cada una de las submuestras -atención, interés, acción- utilizadas en este estudio como de la muestra general -que agrupa a todas las anteriores. Inicialmente, se exponen detalles relativos a la muestra general, para pasar a continuación a detallar las muestras específicas de cada etapa.

Como se ha mencionado en el tercer apartado de este capítulo, los datos tienen su origen en campañas realizadas por compañías del entorno del comercio electrónico entre 2011 y 2017 en múltiples países. Las fuentes han sido el ESP Get Response y diversas 
compañías de dicho sector que han proporcionado datos de variables dependientes enmascarados a través de la aplicación de un factor -constante para toda la muestra.

La muestra general cumple con los requisitos expuestos en el apartado tercero de este capítulo, en concreto:

- Primer requisito - factores de influencia: la muestra general recoge todos los factores de influencia y variables dependientes.

- Segundo requisito - presencia de al menos 5 países: la muestra general está integrada por campañas efectuadas en 52 países de los cinco continentes.

- Tercer requisito - categoría de producto homogénea: la muestra general es homogénea.

- Cuarto requisito - un solo modelo de atribución: la muestra general utilizará en todos los casos el modelo de último clic.

- Quinto requisito - al menos 1.000 registros: la muestra general cuenta con 4.483 registros que representan aproximadamente 400 millones de correos enviados.

Estas características generales aseguran un punto de partida válido para el comienzo de la investigación. Sin embargo, la ausencia en algunos registros de los valores de ciertas variables - motivada por la utilización de varias fuentes- implica que el tamaño y características de las muestras de las diferentes etapas de efectividad sean diferentes. Así, existirán dos submuestras diferentes: una será válida para el estudio de la efectividad de apertura (OR) y de la retención de suscriptores (UR) y otra, para el estudio de la efectividad de clic (CTOR) y de conversión (CR). A continuación, se procederá a detallar las características de estas dos muestras.

\subsubsection{Muestra para el estudio de la etapa de atención (OR) e interés (UR)}

Las características de esta primera muestra coinciden casi completamente con las de la muestra general, esto es, 4.467 entradas provenientes de 52 países que representan 400 millones de correos enviados (la potencia estadística resultante es de $\beta=0.999$ para un efecto de tamaño $\mathrm{f}^{2}=0.02$ ). A continuación, se detallan las características de las variables que componen la muestra y que serán utilizadas en el análisis.

\subsubsection{Variables dependientes - tasa de apertura y tasa de retención de suscriptores}

En las figuras 16 y 17 se presentan los histogramas de las variables dependientes OR y UR. Nótese que no se incluyen valores de la variable, por carecer estos de sentido al haberse aplicado un factor de corrección constante sobre los datos originales. En cuanto a la tasa de apertura, se aprecia cierta normalidad en la distribución, pero es muy destacable la falta de simetría de la variable, producida por algunos valores extremos elevados, hecho motivado por la presencia de comunicaciones muy segmentadas en las que las tasas de apertura han sido muy elevadas. 
La tasa de retención de suscriptores presenta una distribución con razonable parecido a la de la distribución de Pearson con 1-2 grados de libertad, en el que la mayoría de registros se concentran en los valores iniciales para posteriormente ir disminuyendo de manera exponencial.

Con relación a estas dos distribuciones, y dada la potencial influencia de esta falta de normalidad en los resultados, en el capítulo siguiente serán evaluadas posibles acciones correctivas.

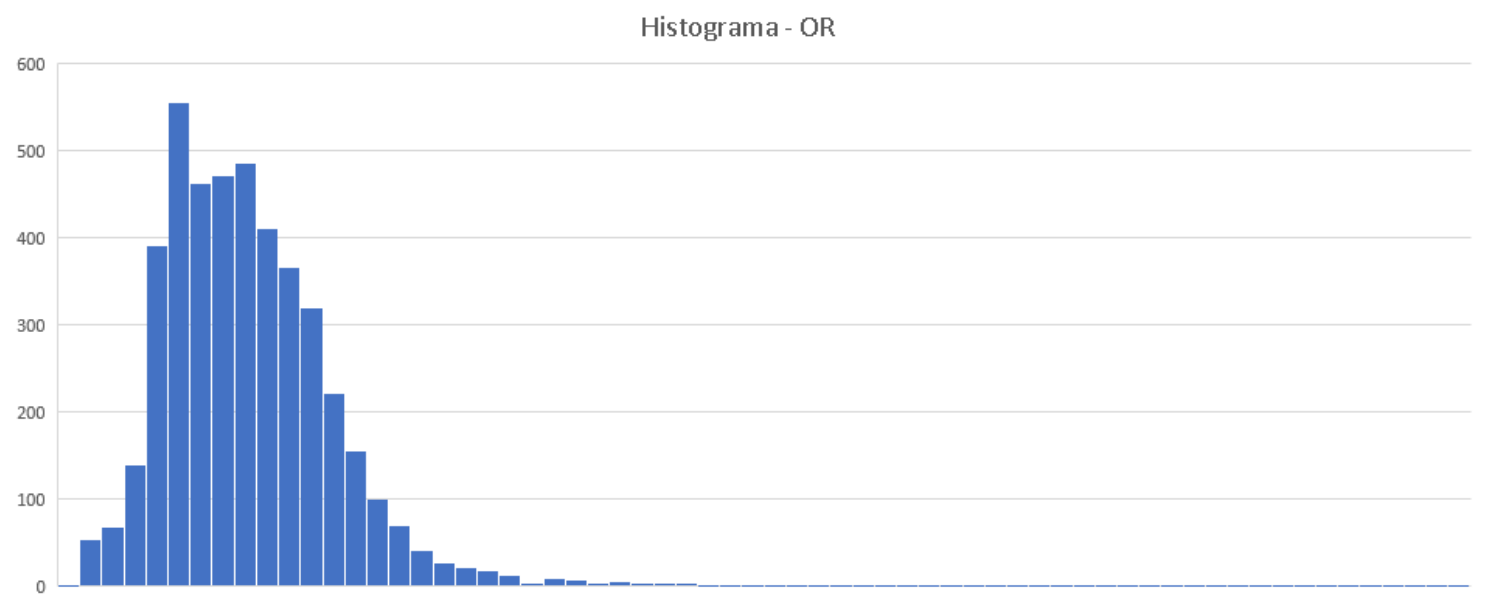

Figura 16 - Histograma de la tasa de apertura

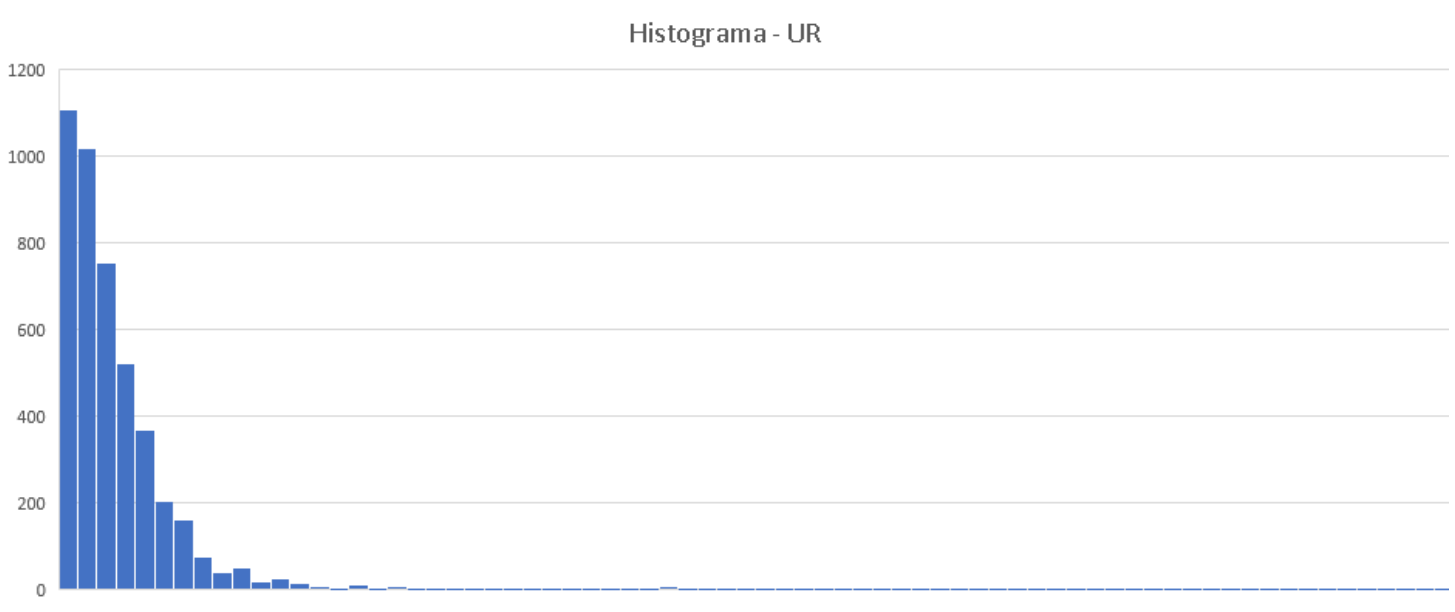

Figura 17 - Histograma de la tasa de retención de suscriptores

\subsubsection{Factores de contenido no visible}

En la tabla 38 y figura 18 se presentan las características de las variables de contenido no visible, así como un diagrama que muestra de manera gráfica la distribución de los diferentes valores de la variable contenido del asunto. Las variables numéricas han sido descritas a través de su media y la desviación estándar, mientras que las categóricas se describen a través del conteo de casos para los que adoptan el valor 1 . 
A la vista de la existencia de algunas temáticas para las que no existe ningún registro en la variable contenido del asunto -en concreto, las categorías de Teaser, Acción y Evento-, se procederá a partir de este punto a eliminarlas de esta investigación con el objeto de reducir la complejidad del análisis.

Los resultados indican una presencia abrumadora de temáticas promocionales -el $85.2 \%$ de los envíos incluía algún tipo de promoción-, lo que resulta razonable a la vista de que el objetivo final perseguido por las compañías suele ser la venta del producto. La ausencia de envíos orientados a incrementar el tráfico de clientes a tiendas u otros emplazamientos físicos puede estar motivada por la ausencia de los mismos -la empresa vende exclusivamente online- o por la ejecución de una estrategia de distribución en las que los canales offline y online están totalmente separados. Asimismo, la ausencia de envíos con temática Teaser y Evento permite suponer una mecánica promocional sencilla y poco integrada con otros canales de marketing.

\begin{tabular}{|l|c|c|c|c|c|c|}
\hline \multirow{2}{*}{\multicolumn{1}{|c|}{ Variable }} & \multicolumn{3}{c|}{ Variables Categóricas } & \multicolumn{2}{c|}{$\begin{array}{c}\text { Variables } \\
\text { numéricas }\end{array}$} \\
\cline { 2 - 7 } & Var=1 & $\%$ & Var=0 & $\%$ & Media & $\begin{array}{c}\text { Desv. } \\
\text { Estándar }\end{array}$ \\
\hline Longitud de asunto & & & & & 55.80 & 19.47 \\
\hline Números en asunto & 1477 & $33.1 \%$ & 2990 & $66.9 \%$ & & \\
\hline Caracteres especiales en asunto & 1314 & $29.4 \%$ & 3153 & $70.6 \%$ & & \\
\hline Contenido asunto - Descuento & 1382 & $30.9 \%$ & 3085 & $69.1 \%$ & & \\
\hline Contenido asunto - Temporada & 273 & $6.1 \%$ & 4194 & $93.9 \%$ & & \\
\hline $\begin{array}{l}\text { Contenido asunto - Descuento de } \\
\text { temporada }\end{array}$ & 39 & $0.9 \%$ & 4428 & $99.1 \%$ & & \\
\hline Contenido asunto - Regalo & 10 & $0.2 \%$ & 4457 & $99.8 \%$ & & \\
\hline Contenido asunto - Bonus & 20 & $0.4 \%$ & 4447 & $99.6 \%$ & & \\
\hline Contenido asunto - Promoción Gral. & 2069 & $46.3 \%$ & 2398 & $53.7 \%$ & & \\
\hline Contenido asunto - Teaser & 0 & $0.0 \%$ & 4467 & $100.0 \%$ & & \\
\hline Contenido asunto - Acción & 0 & $0.0 \%$ & 4467 & $100.0 \%$ & & \\
\hline Contenido asunto - Producto & 240 & $5.4 \%$ & 4227 & $94.6 \%$ & & \\
\hline Contenido asunto - Noticias & 76 & $1.7 \%$ & 4391 & $98.3 \%$ & & \\
\hline Contenido asunto - Concurso & 99 & $2.2 \%$ & 4368 & $97.8 \%$ & & \\
\hline $\begin{array}{l}\text { Contenido asunto - Concurso y } \\
\text { Promoción }\end{array}$ & 15 & $0.3 \%$ & 4452 & $99.7 \%$ & & \\
\hline Contenido asunto - Evento & 0 & $0.0 \%$ & 4467 & $100.0 \%$ & & \\
\hline Contenido asunto - Otro & 244 & $5.5 \%$ & 4223 & $94.5 \%$ & & \\
\hline
\end{tabular}

Tabla 38 - Descripción de las variables de contenido no visible - Muestra atención (OR) 


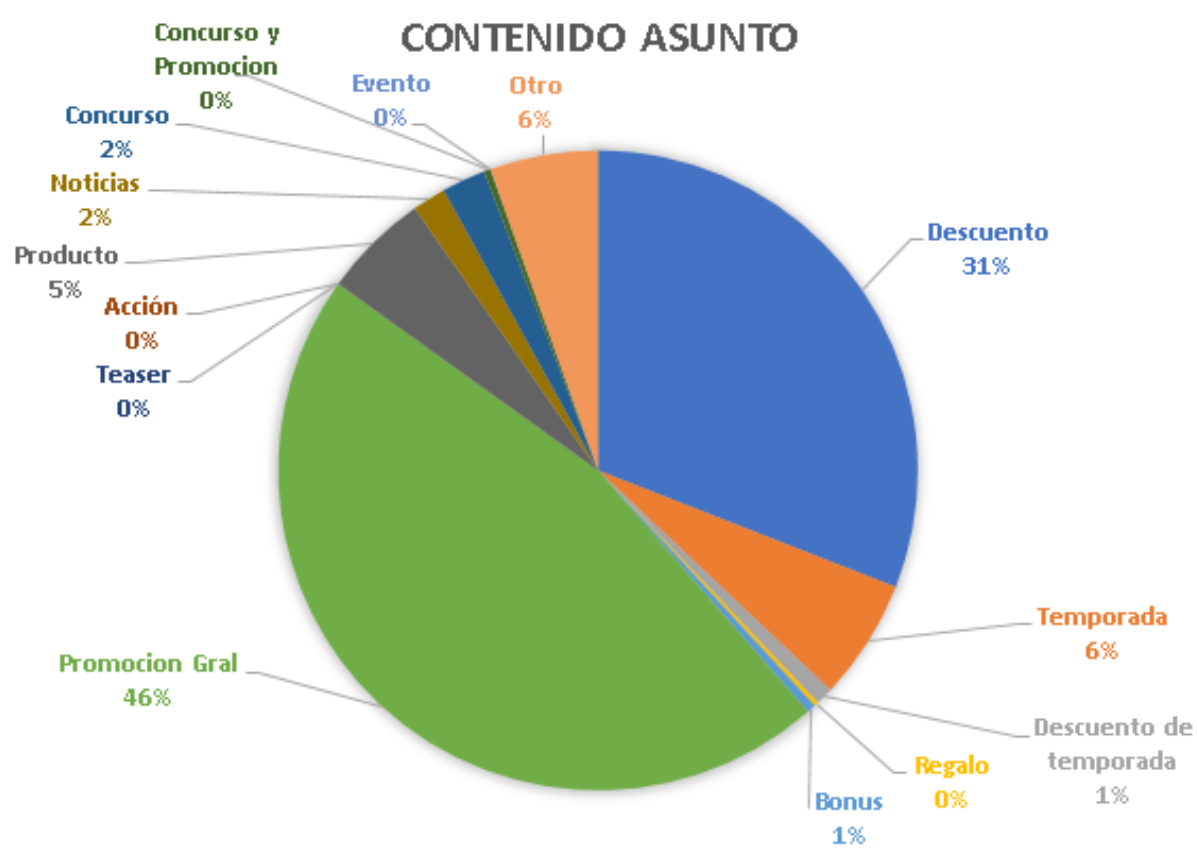

Figura 18 - Distribución de los valores de contenido del asunto - Muestra atención (OR)

\subsubsection{Factores temporales}

A continuación, en la tabla 39 y figuras 19 y 20 se detallan los valores de las variables temporales empleadas en la muestra. Resulta particularmente destacable el hecho de que la frecuencia de contacto para el $95 \%$ de los casos oscile entre cero y cinco e-mails cada treinta días, lo que lleva a pensar que los remitentes tienen mecánicas promocionales semanales o han fijado como frecuencia máxima un e-mail a la semana. Teniendo en cuenta que la frecuencia de envío debería ajustarse a la frecuencia de compra (Groves, 2009), esto resulta razonable en un entorno B2C de comercio electrónico.

En cuanto a los días de la semana, resulta relevante la concentración en los días de mitad de semana - martes, miércoles y jueves acaparan el $61.4 \%$ de los envíos- en contraposición a los fines de semana -sábado y domingo acumulan el 13.2\% de envíos, lo que puede deberse a motivos operativos -es más difícil movilizar recursos en fin de semana. Tal y como se ha mencionado en la codificación de variables dummy, el martes se tomará como escenario base dado que es el valor más frecuente.

Finalmente, la tabla de frecuencias de horas de envío permite ver que éstos se concentran en el horario de mañana -el $40.9 \%$ se realizan de $9 \mathrm{~h}$. a $13 \mathrm{~h} .-$, mientras que el horario nocturno es mucho menos utilizado -de $21 \mathrm{~h}$. a $8 \mathrm{~h}$. tan solo se envía el $3.4 \%$ de correos. Esto es consistente con las razones operativas mencionadas anteriormente. De nuevo, el valor más frecuente -las 9 h.- será utilizado como escenario base en la variable dummy. 


\begin{tabular}{|c|c|c|c|c|c|c|}
\hline \multirow[b]{2}{*}{ Variable } & \multicolumn{4}{|c|}{ Variables Categóricas } & \multicolumn{2}{|c|}{ Variables numéricas } \\
\hline & Var $=1$ & $\%$ & Var $=0$ & $\%$ & Media & $\begin{array}{c}\text { Desv. } \\
\text { Estándar }\end{array}$ \\
\hline Frecuencia & & & & & 2.60 & 1.51 \\
\hline Día de la semana - lunes & 339 & $7.6 \%$ & 4128 & $92.4 \%$ & & \\
\hline Día de la semana - martes & 1263 & $28.3 \%$ & 3204 & $71.7 \%$ & & \\
\hline Día de la semana - miércoles & 810 & $18.1 \%$ & 3657 & $81.9 \%$ & & \\
\hline Día de la semana - jueves & 671 & $15.0 \%$ & 3796 & $85.0 \%$ & & \\
\hline Día de la semana - viernes & 795 & $17.8 \%$ & 3672 & $82.2 \%$ & & \\
\hline Día de la semana - sábado & 562 & $12.6 \%$ & 3905 & $87.4 \%$ & & \\
\hline Día de la semana - domingo & 27 & $0.6 \%$ & 4440 & $99.4 \%$ & & \\
\hline Hora de envío - 00 & 1 & $0.0 \%$ & 4466 & $100.0 \%$ & & \\
\hline Hora de envío - 01 & 2 & $0.0 \%$ & 4465 & $100.0 \%$ & & \\
\hline Hora de envío - 02 & 0 & $0.0 \%$ & 4467 & $100.0 \%$ & & \\
\hline Hora de envío - 03 & 1 & $0.0 \%$ & 4466 & $100.0 \%$ & & \\
\hline Hora de envío - 04 & 0 & $0.0 \%$ & 4467 & $100.0 \%$ & & \\
\hline Hora de envío - 05 & 2 & $0.0 \%$ & 4465 & $100.0 \%$ & & \\
\hline Hora de envío - 06 & 16 & $0.4 \%$ & 4451 & $99.6 \%$ & & \\
\hline Hora de envío - 07 & 18 & $0.4 \%$ & 4449 & $99.6 \%$ & & \\
\hline Hora de envío - 08 & 97 & $2.2 \%$ & 4370 & $97.8 \%$ & & \\
\hline Hora de envío - 09 & 575 & $12.9 \%$ & 3892 & $87.1 \%$ & & \\
\hline Hora de envío - 10 & 504 & $11.3 \%$ & 3963 & $88.7 \%$ & & \\
\hline Hora de envío - 11 & 328 & $7.3 \%$ & 4139 & $92.7 \%$ & & \\
\hline Hora de envío - 12 & 223 & $5.0 \%$ & 4244 & $95.0 \%$ & & \\
\hline Hora de envío - 13 & 198 & $4.4 \%$ & 4269 & $95.6 \%$ & & \\
\hline Hora de envío - 14 & 155 & $3.5 \%$ & 4312 & $96.5 \%$ & & \\
\hline Hora de envío - 15 & 204 & $4.6 \%$ & 4263 & $95.4 \%$ & & \\
\hline Hora de envío - 16 & 96 & $2.1 \%$ & 4371 & $97.9 \%$ & & \\
\hline Hora de envío - 17 & 56 & $1.3 \%$ & 4411 & $98.7 \%$ & & \\
\hline Hora de envío - 18 & 39 & $0.9 \%$ & 4428 & $99.1 \%$ & & \\
\hline Hora de envío - 19 & 15 & $0.3 \%$ & 4452 & $99.7 \%$ & & \\
\hline Hora de envío - 20 & 16 & $0.4 \%$ & 4451 & $99.6 \%$ & & \\
\hline Hora de envío - 21 & 6 & $0.1 \%$ & 4461 & $99.9 \%$ & & \\
\hline Hora de envío - 22 & 6 & $0.1 \%$ & 4461 & $99.9 \%$ & & \\
\hline Hora de envío - 23 & 2 & $0.0 \%$ & 4465 & $100.0 \%$ & & \\
\hline
\end{tabular}

Tabla 39 - Descripción de las variables temporales - Muestra atención (OR) e interés (UR) 


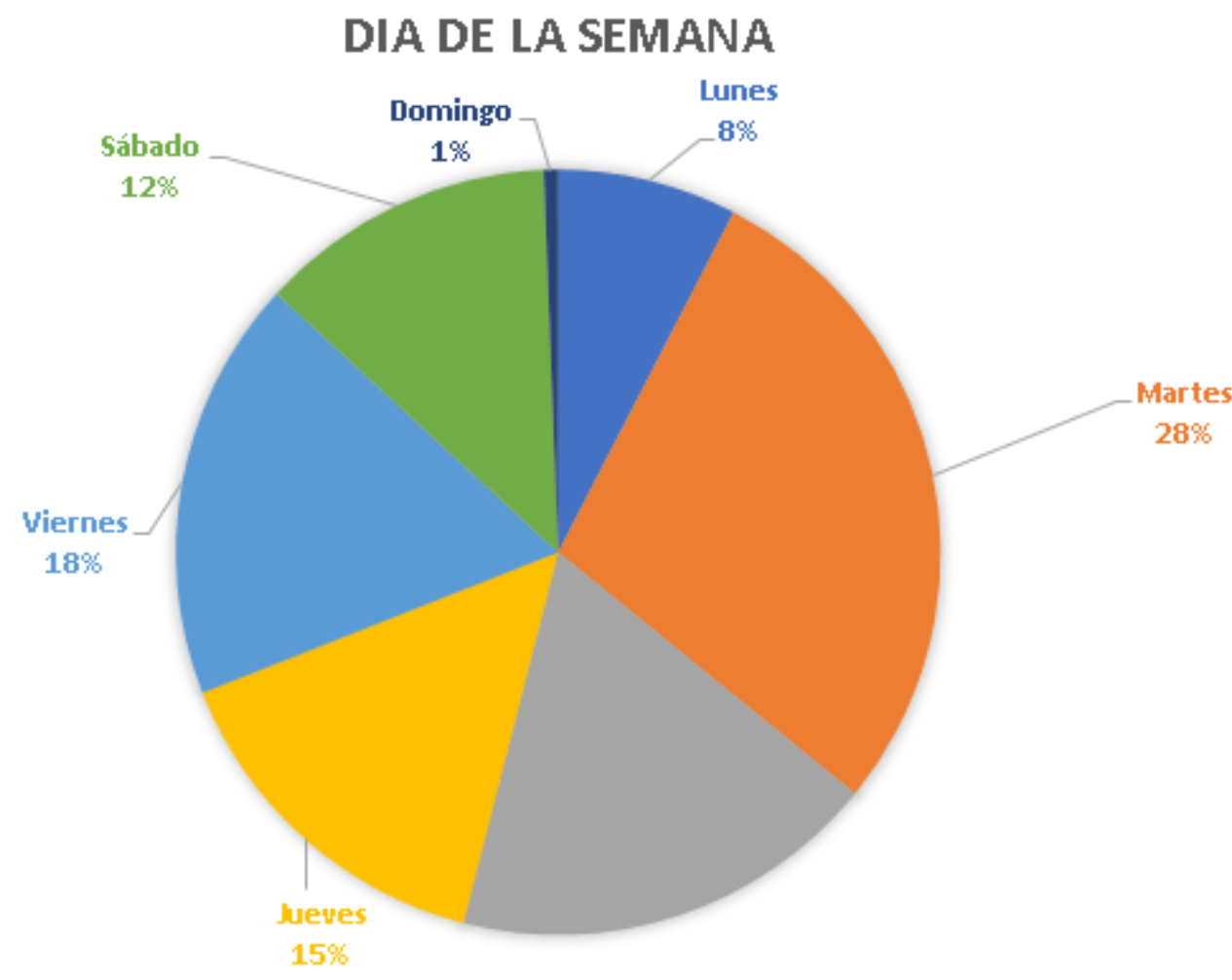

Figura 19 - Distribución de los valores de día de la semana - Muestra atención (OR)

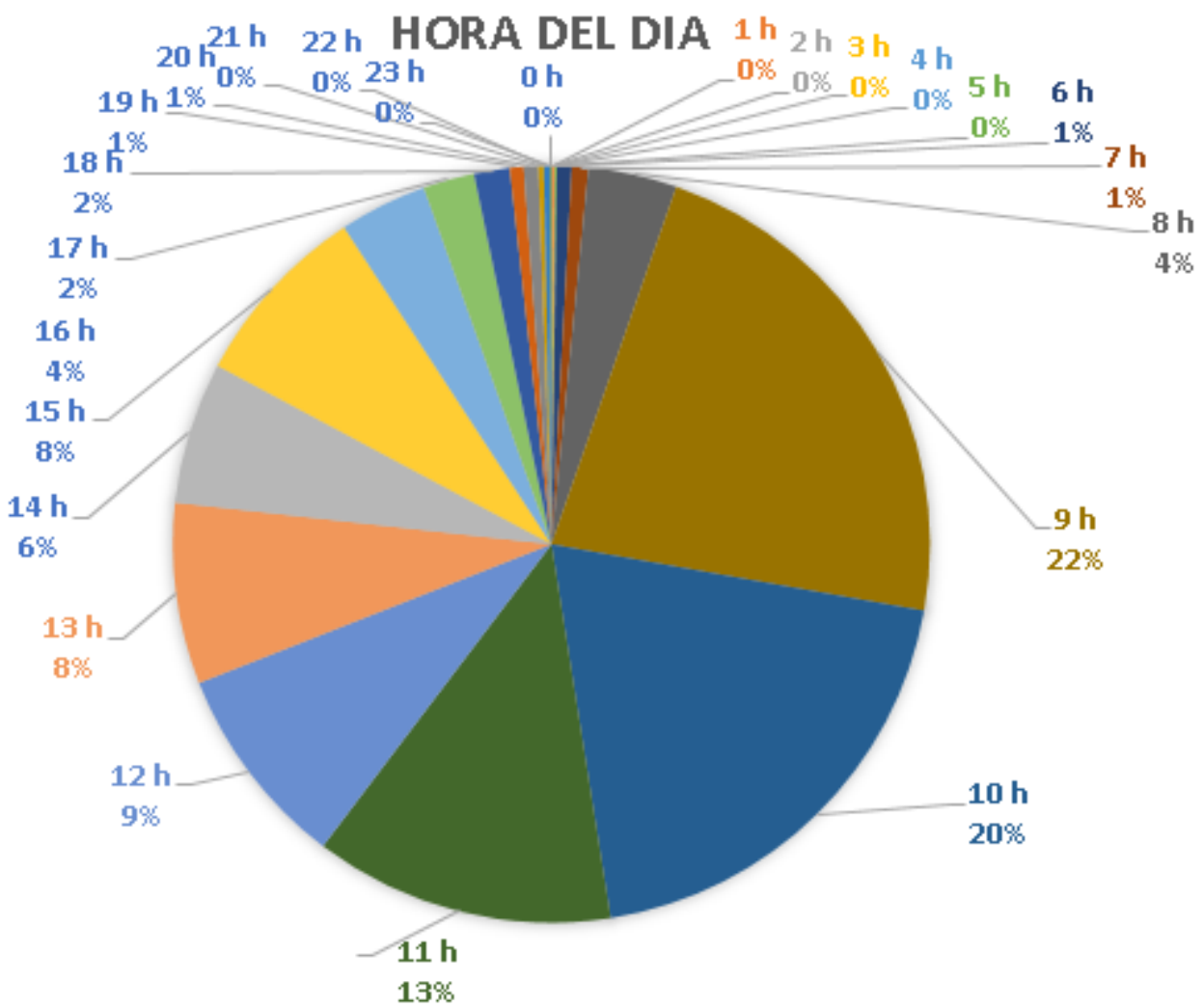

Figura 20 - Distribución de los valores de hora de envío - Muestra atención (OR) 


\subsubsection{Factores contextuales}

En relación con las variables contextuales, y de acuerdo a la tabla 40, se aprecia un escaso uso de las técnicas de segmentación, lo que puede apuntar a una estrategia consciente de segmentación por países o a limitaciones técnicas del ESP: o bien la herramienta no permite la utilización de esta técnica de manera intuitiva por parte del usuario, o no se encuentra integrada con otros sistemas y, por tanto, no puede utilizar datos externos para la creación de segmentos.

En cuanto a la personalización en el asunto, su utilización es incluso más limitada, alcanzando tan sólo el $0.5 \%$ de envíos realizados. Esto permite aventurar que los remitentes han comprobado que esta técnica no les reporta beneficios y la utilizan muy infrecuentemente o que, debido a que existan muy pocos perfiles de la base de datos con información personal relevante, sólo sea posible utilizarla en un número limitado de ocasiones.

\begin{tabular}{|l|c|c|c|c|}
\hline \multirow{2}{*}{\multicolumn{1}{|c|}{ Variable }} & \multicolumn{4}{|c|}{ Variables Categóricas } \\
\cline { 2 - 5 } & Var=1 & \% & Var=0 & $\%$ \\
\hline Segmentación & 154 & $3.4 \%$ & 4313 & $96.6 \%$ \\
\hline Personalización & 23 & $0.5 \%$ & 4444 & $99.5 \%$ \\
\hline
\end{tabular}

Tabla 40 - Descripción de las variables contextuales - Muestra atención (OR) e interés (UR)

\subsubsection{Dimensiones culturales}

Finalmente, en la tabla 41 se presentan los valores de las dimensiones culturales de Hofstede. A la vista de las medias y las desviaciones estándar, se puede apreciar que la muestra está razonablemente centrada y que existen valores para el rango completo de cada dimensión en la misma. Si bien es necesario mencionar que las dimensiones distancia al poder y aversión a la incertidumbre aparecen desplazadas hacia valores ligeramente elevados, la presencia de un número razonables de casos con valores bajos en estas dos dimensiones permite suponer que la muestra es suficientemente diversa como para poder detectar efectos de moderación a lo largo de cada una de ellas.

\begin{tabular}{|l|c|c|}
\hline \multirow{2}{*}{\multicolumn{1}{c|}{ Variable }} & \multicolumn{2}{c|}{ Variables numéricas } \\
\cline { 2 - 3 } & Media & $\begin{array}{c}\text { Desv. } \\
\text { Estándar }\end{array}$ \\
\hline Distancia al poder & 58.36 & 21.58 \\
\hline Individualismo-Colectivismo & 50.81 & 23.42 \\
\hline Masculinidad-Feminidad & 51.06 & 17.12 \\
\hline Aversión a la incertidumbre & 59.46 & 21.12 \\
\hline Orientación al largo plazo & 46.82 & 19.51 \\
\hline
\end{tabular}

Tabla 41 - Descripción de las variables culturales - Muestra atención (OR) e interés (UR) 


\subsubsection{Muestra para el estudio de la etapa de interés (CTOR) y conversión (CR)}

Esta muestra se compone de una porción de la muestra general, y está formada por 1.679 entradas de campañas realizadas en 50 países que representan 140 millones de correos enviados. Su tamaño es notablemente inferior a la anterior por la imposibilidad de codificar las variables semánticas de contenido visible para un bloque de campañas proporcionadas por parte de las fuentes. A continuación, se analizarán en detalle cada una de las variables que la componen.

\subsubsection{Variables dependientes - tasa de clic y tasa de conversión}

En las figuras 21 y 22 se presentan los histogramas de las variables dependientes CTOR y CR, de nuevo sin valores debido a la aplicación de un factor de corrección para la ofuscación de datos. La tasa de clic presenta cierta normalidad, si bien, de manera similar al caso de la efectividad de apertura, se percibe una asimetría positiva producida por valores extremos elevados. De nuevo, estos valores están asociados a comunicaciones segmentadas. Esta distribución es similar, aunque menos extrema, que las obtenidas por otras investigaciones que estudian la tasa de clic basadas en valores empíricos (Robinson, Wysocka, \& Hand, 2007).

También de manera similar al caso de la tasa de retención de suscriptores, la tasa de conversión se asemeja a la de la distribución de Pearson, en este caso con 3-4 grados de libertad, concentrándose la mayoría de registros en los valores más bajos. De nuevo la segmentación aparece en alguno de los valores elevados.

Tal y como sucede con la muestra anterior, dada la falta de normalidad en los resultados, en el capítulo siguiente serán evaluadas posibles acciones correctivas en relación con estas variables dependientes.

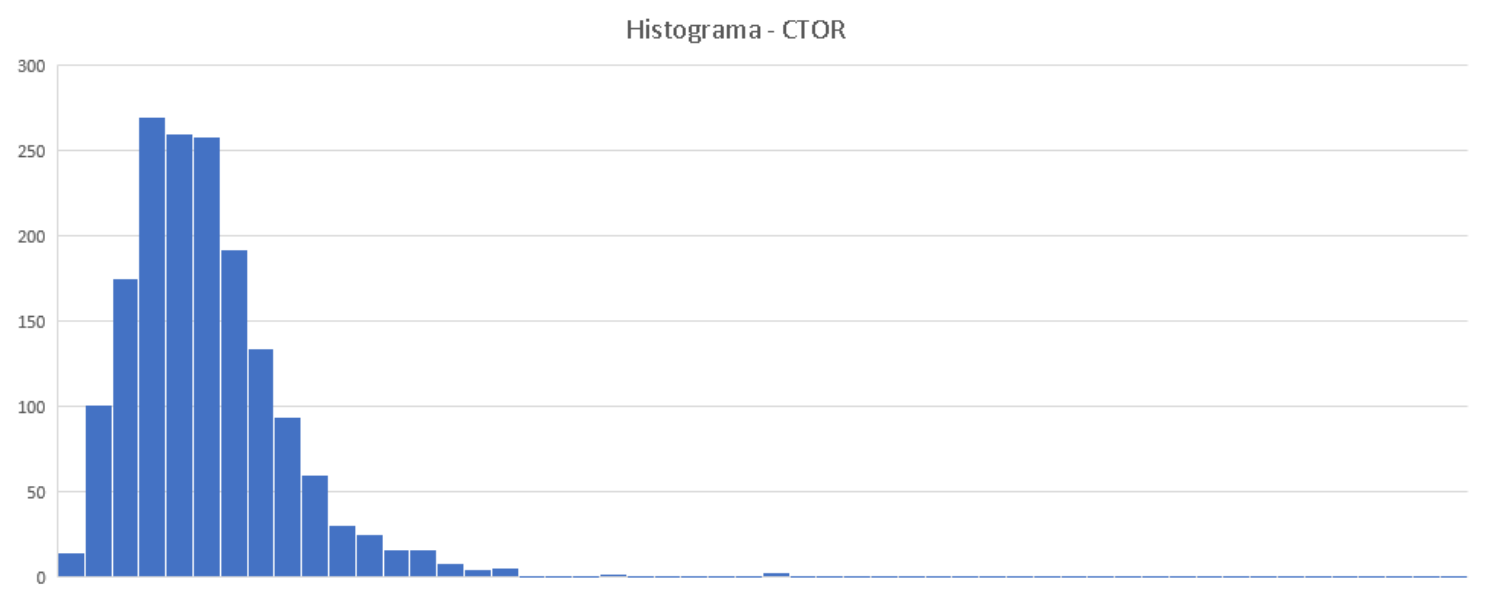

Figura 21 - Histograma de la tasa de clic 


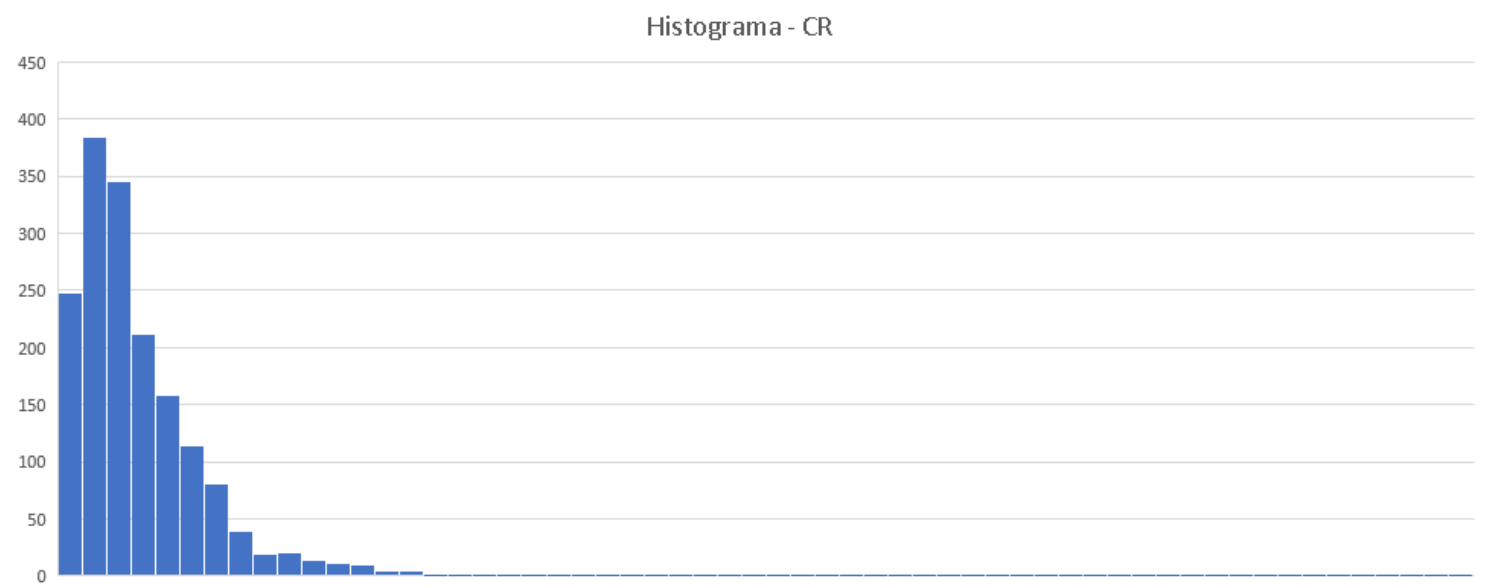

Figura 22 - Histograma de la tasa de conversión

\subsubsection{Factores de contenido visible}

La tabla 42 recoge el resumen de los valores de contenido visible tanto formales como semánticos. Es especialmente reseñable el hecho de que la muestra presente un elevado número de enlaces en relación con estudios anteriores en los que el $90 \%$ de los envíos tenía menos de 31 enlaces (Ellis-Chadwick \& Doherty, 2012), mientras que en el caso estudiado este número se reduce al 59\%. Los datos son también notablemente superiores a otras investigaciones que mencionan una media de 3.4 enlaces (Rettie \& Chittenden, 2003) o de 9.24 en estudios recientes (Kumar \& Salo, 2018). Este hecho puede señalar diferentes comportamientos en función de categorías de producto o simplemente diferentes diseños de plantilla estándar de e-mail.

El número de imágenes es inferior al de otras investigaciones recientes -18.52 de media en Kumar \& Salo (2018)- y notablemente superior al de investigaciones anteriores -1.7 de media en Rettie \& Chittenden (2003)-, pero es necesario señalar que ciertos elementos integrados en el correo para facilitar el análisis de datos -píxeles-, elementos de reducido tamaño como el logo de la compañía o enlaces a redes sociales a través de su logo también aparecen codificados como imágenes.

Por su parte, la presencia de incentivos económicos es consecuente con los valores obtenidos en la clasificación de líneas de asunto en clave semántica, dada la definición asumida de menciones explícitas de un descuento o rebaja de precio. 


\begin{tabular}{|l|c|c|c|c|c|c|}
\hline \multirow{2}{*}{\multicolumn{1}{c|}{ Variable }} & \multicolumn{3}{c|}{ Variables Categóricas } & \multicolumn{2}{c|}{ Variables numéricas } \\
\cline { 2 - 7 } & Var=1 & $\mathbf{\%}$ & Var=0 & $\mathbf{\%}$ & Media & $\begin{array}{c}\text { Desv. } \\
\text { Estándar }\end{array}$ \\
\hline Longitud texto e-mail & & & & & 2121.95 & 719.1 \\
\hline Número de imágenes e-mail & & & & & 11.79 & 7.75 \\
\hline Número de enlaces e-mail & & & & & 27.65 & 9.66 \\
\hline Incentivos económicos e-mail & 552 & $32.9 \%$ & 1127 & $67.1 \%$ & & \\
\hline Sensación de escasez e-mail & 657 & $39.1 \%$ & 1022 & $60.9 \%$ & & \\
\hline
\end{tabular}

Tabla 42 - Descripción de las variables de contenido visible - Muestra interés (CTOR) y acción (CR)

\subsubsection{Factores contextuales}

Los factores contextuales, cuyos valores se describen en la tabla 43, representan de nuevo una parte limitada de la muestra. La explicación aventurada en el apartado 5.1.4 descripción de factores contextuales para la muestra de OR y UR- relativas a estas variables es también de aplicación en este caso, y simplemente es reseñable que, dada la presencia de sólo diez casos con personalización, es altamente improbable que la herramienta estadística sea capaz de detectar efectos significativos.

\begin{tabular}{|l|c|c|c|c|}
\hline \multirow{2}{*}{\multicolumn{1}{|c|}{ Variable }} & \multicolumn{4}{|c|}{ Variables Categóricas } \\
\cline { 2 - 5 } & Var=1 & $\mathbf{\%}$ & Var=0 & \% \\
\hline Segmentación & 38 & $2.3 \%$ & 1641 & $97.7 \%$ \\
\hline Personalización & 10 & $0.6 \%$ & 1669 & $99.4 \%$ \\
\hline
\end{tabular}

Tabla 43 - Descripción de las variables contextuales - Muestra interés (CTOR) y acción (CR)

\subsubsection{Dimensiones culturales}

Finalmente, la distribución de las variables culturales presentada en la tabla 44, de nuevo con valores razonablemente centrados y que abarcan la mayoría del rango de las dimensiones de Hofstede, resulta razonable y permiten asumir que será posible detectar efectos de moderación a lo largo de todo el espectro de valores.

\begin{tabular}{|l|c|c|}
\hline \multirow{2}{*}{\multicolumn{1}{|c|}{ Variable }} & \multicolumn{2}{c|}{ Variables numéricas } \\
\cline { 2 - 3 } & Media & $\begin{array}{c}\text { Desv. } \\
\text { Estándar }\end{array}$ \\
\hline Distancia al poder & 59.51 & 22.86 \\
\hline Individualismo-Colectivismo & 50.15 & 24.00 \\
\hline Masculinidad-Feminidad & 52.12 & 16.72 \\
\hline Aversión a la incertidumbre & 58.78 & 21.90 \\
\hline Orientación al largo plazo & 46.39 & 18.78 \\
\hline
\end{tabular}

Tabla 44 - Descripción de las variables culturales - Muestra interés (CTOR) y acción (CR) 


\section{Capítulo 7 - Análisis de datos y resultados}

\subsection{TÉCNICA ESTADÍSTICA APLICADA}

7.1.1 Justificación de la técnica seleccionada

7.1.2 Especificación de un modelo de regresión múltiple

7.1.3 Análisis e interpretación de regresión múltiple

\subsection{ANÁLISIS DE DATOS}

7.2.1 Transformación de variables

7.2.2 Análisis del modelo

7.3 MODELO FINAL DE INVESTIGACIÓN

7.4 RESUMEN DEL CONTRASTE DE HIPÓTESIS

7.4.1 Estudio de etapa de atención

7.4.2 Estudio de la etapa de interés

7.4.3 Estudio de la etapa de acción

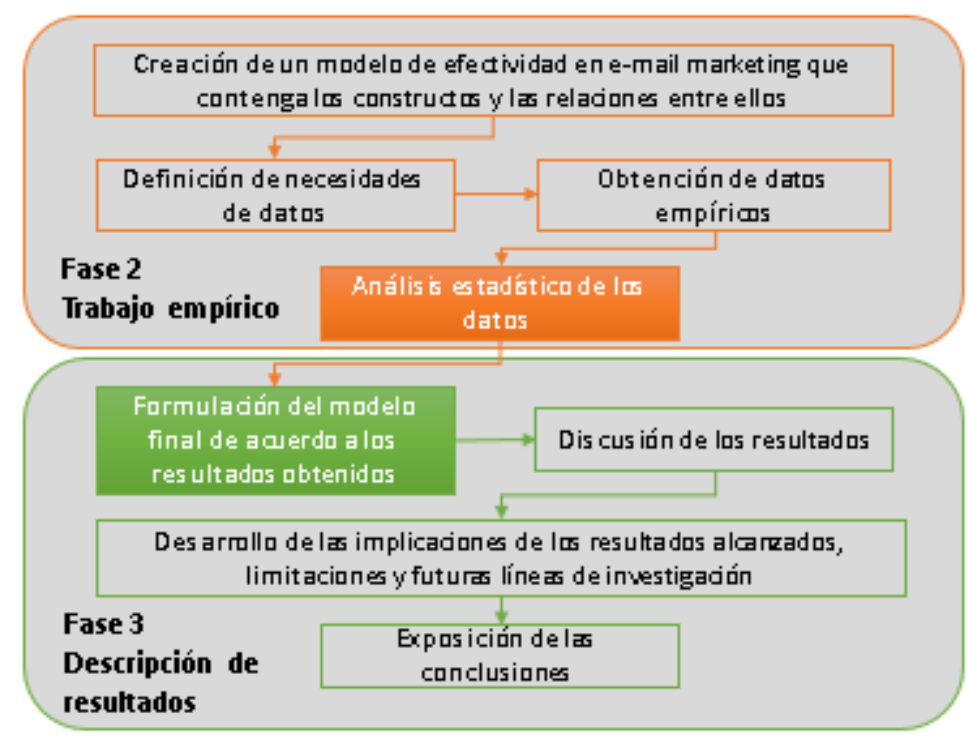




\section{ANÁLISIS DE DATOS Y RESULTADOS}

\subsection{TÉCNICA ESTADÍSTICA APLICADA}

Una vez determinado el modelo teórico que se quiere validar en base a la revisión de la literatura, fijado un criterio coherente de operacionalización de variables y obtenida una muestra de características adecuadas, es necesario determinar la mejor manera de conducir un análisis estadístico que permita validar empíricamente las hipótesis presentadas.

Este capítulo aspira a tal fin. Inicialmente se presentará la técnica estadística seleccionada, justificando su elección y determinando desde un punto de vista teórico las consideraciones necesarias para su correcta utilización. A posteriori, se procederá al análisis de las muestras obtenidas teniendo en cuenta los criterios fijados con anterioridad, y realizando previamente aquellas transformaciones de variables necesarias para ello. Finalmente, se presentarán los resultados obtenidos y se contrastarán con las hipótesis previamente postuladas.

\subsubsection{Justificación de la técnica seleccionada}

La selección de una técnica estadística determinada viene condicionada por las particularidades de la investigación y de las variables utilizadas, siendo tres parámetros de notable importancia: las características de la distribución de valores para cada una de las variables (Field, 2013) y la tipología de las variables utilizadas y su número especialmente, el número de variables dependientes (Zikmund et al., 2013). Utilizando este criterio como base, se procederá a evaluar las muestras para cada uno de estos tres parámetros.

En primer lugar, es necesario mencionar que la distribución de las variables es relevante porque está relacionada con la existencia de una serie de supuestos necesarios para la aplicación de técnicas paramétricas -en concreto, aditividad, linealidad, normalidad e independencia de ciertos parámetros y homocedasticidad (Cohen, Cohen, West, \& Aiken, 2003). Los gráficos de distribución mostrados en el capítulo anterior permiten intuir cierta normalidad en las variables, lo cual supone un punto de partida adecuado para que sea posible la utilización de una técnica paramétrica (Field, 2013).

Atendiendo al segundo parámetro - características de las variables-, la tipología de las variables de la muestra empleada es particularmente variada, dada la existencia de variables nominales, ordinales, categóricas y de razón (ratio). Sin embargo, tal y como se ha desarrollado en el capítulo anterior, se han adoptado técnicas de transformación como la creación de variables dummy que han permitido cuantificarlas. 
Finalmente, y en relación con el número de variables utilizado, podemos clasificar los métodos estadísticos en univariables, bivariables y multivariables (Zikmund et al., 2013). A estos efectos, y desde un punto de vista de variables independientes, resulta lógico que el método seleccionado para la presente investigación haya de ser multivariable teniendo en cuenta el número de factores de influencia que se pretenden evaluar.

Con respecto a las variables dependientes, y dado que el modelo teórico propuesto pretende analizar cada etapa de interacción con el e-mail marketing de manera independiente $-\mathrm{y}$, por tanto, presenta hipótesis diferentes para cada una de las efectividades parciales definidas-, el análisis de cada variable dependiente se realizará de manera aislada. Así, se puede concluir que existe sólo una variable dependiente en cada uno de los modelos. En la evaluación de hipótesis con técnicas paramétricas para modelos multivariable con una sola variable dependiente existen dos técnicas recomendadas: si las variables son cuantitativas, el método adecuado es la regresión múltiple y, si no lo son, el análisis discriminante múltiple (Zikmund et al., 2013). Dado que tras las transformaciones todas las variables son cuantitativas, la técnica recomendada es la regresión múltiple.

Este razonamiento fundamentalmente teórico está refrendado también por la práctica, puesto que esta técnica se considera habitual en el análisis de problemas relativos al mundo del marketing y los negocios (Richardson, 2015), y además resulta adecuada en estudios de campo en los que el investigador tiene una capacidad de manipulación muy limitada (Keith, 2015). De hecho, existen investigaciones de efectividad de canales publicitarios digitales con una estructura similar a la que propone esta tesis que utilizan la regresión múltiple como técnica estadística. Este es el caso un estudio de la efectividad de clic en banners en función de factores que incluyen la longitud del texto y el uso de incentivos económicos (Robinson et al., 2007), o de otro estudio de la misma variable dependiente que, además de los anteriores, incluye factores relacionados con el coste de la compra de medios (Baltas, 2003). Por tanto, parece razonable considerar la regresión múltiple como punto de partida para el análisis estadístico del modelo de efectividad de e-mail marketing.

En los siguientes párrafos se desglosarán en mayor detalle las características de esta técnica y los requisitos para su adecuada aplicación.

\subsubsection{Especificación de un modelo de regresión múltiple}

La regresión múltiple es una técnica correspondiente al modelo general lineal que utiliza más de una variable independiente para estimar coeficientes que, asociados a dichas variables, minimicen el error del modelo a través del método de mínimos cuadrados (Cohen et al., 2003). Así, tal y como muestra la ecuación 1, cada variable independiente 
$y_{i}$ se expresa como una relación lineal de coeficientes $b_{i}$ multiplicados por variables independientes $X_{i}$, a los que se suman una constante $b_{0} \mathrm{y}$ un error $\varepsilon$ que mide la diferencia entre el modelo y el valor real de la variable independiente.

$$
y_{i}=b_{0}+\sum_{i=1}^{n} b_{i} x_{i}+\varepsilon
$$

Ecuación 1 - Modelo general lineal

En su vertiente ordinaria, esta técnica estima los parámetros asociados a cada una de las variables independientes que minimizan la suma de cuadrados de los errores o residuos $-\mathrm{SS}_{\mathrm{R}}-\mathrm{y}$ requiere de la utilización de variables cuantitativas o binarias. Otra vertiente popular en aquellos casos en los que existe heteroscedasticidad utiliza una técnica similar pero, en este caso, minimiza la suma ponderada de cuadrados de los residuos (Pedhazur, 1997). Esta tesis utilizará la primera de estas técnicas, conocida como regresión múltiple ordinaria.

En la regresión múltiple se pueden ignorar aquellos registros para los que no existen valores de una variable exclusivamente en los cálculos para el coeficiente de dicha variable, o en los cálculos de los coeficientes de todas las variables, siendo esta última opción la más recomendable para evitar resultados difíciles de interpretar (Field, 2013). A la vista de esto, esta tesis incluirá sólo registros para los que se disponga de valores en todas las variables independientes.

Una de las limitaciones de la regresión múltiple es su incapacidad de identificar efectos que no sean directos, como por ejemplo, los de mediación (Keith, 2015). Sin embargo, y puesto que en la revisión de la literatura no se han identificado este tipo de relaciones entre variables, se presupone que esta limitación no afectará a la validez del presente análisis.

\subsubsection{Requerimientos en el uso de regresión múltiple}

La regresión múltiple, al igual que el resto de técnicas basadas en el modelo lineal general, está sujeta a una serie de requisitos de índole metodológica debido a que está fundamentada en test paramétricos basados en la distribución normal (Field, 2013). Estos requerimientos, ordenados en función de su importancia, son:

- Aditividad y linealidad: implica que la variable dependiente está linealmente relacionada con las independientes, y que la mejor manera de combinar estas últimas para determinar su relación con la variable dependiente es a través de la suma (Richardson, 2015). Este requisito es clave: si no se cumple, todos los parámetros que aporta el modelo son incorrectos (Keith, 2015). Como se desarrollará más adelante, el gráfico de residuos estandarizados versus valores 
predichos por el modelo estandarizados puede ayudar a identificar situaciones de falta de linealidad (Field, 2013).

- Independencia de residuos: este requisito implica que los errores de cada uno de los casos de la muestra no estén relacionados entre sí (Pedhazur, 1997). La manera más habitual de identificar problemas con este requisito es través del test Durbin-Watson, que busca correlaciones de primer grado en los errores (Field, 2013).

- Homocedasticidad: esta cualidad se define como la estabilidad de la varianza a diferentes valores de la variable independiente. En el caso de no cumplirse, puede tener un efecto importante en los test de significación de los parámetros (Richardson, 2015). Tradicionalmente se utiliza el test de Levene para identificar esta situación, pero en muestras grandes -como las de esta investigación- puede resultar significativo incluso para efectos poco importantes, por lo que se recomienda acudir al gráfico de residuos estandarizados versus valores predichos por el modelo estandarizados (Field, 2013).

- Ausencia de multicolinealidad: este requisito impone que entre cualquier par de variables independientes no existan altos niveles de correlación (Richardson, 2015), y para su análisis existen una serie de estadísticas como el factor VIF que se detallarán en posteriores párrafos.

- Normalidad de residuos: la existencia de curtosis, asimetría o valores extremos en los residuos puede incrementar el error del modelo, por lo que es necesario verificar el aspecto de esta distribución (Field, 2013). La normalidad de la distribución muestral también es importante y se alcanza a través de una muestra suficientemente grande (Richardson, 2015). Tradicionalmente, los test de Kolmogorov-Smirnoff y Shapiro-Wilk ayudan a detectar falta de normalidad de residuos pero, de nuevo, en muestras muy grandes pueden resultar significativos incluso para efectos poco importantes (Field, 2013) y, de hecho, la violación de este requisito sólo se considera seria en muestras pequeñas (Keith, 2015).

Dado que para poder dar por válidos los resultados de un análisis de regresión múltiple será necesario verificar el cumplimiento de estos requisitos, a lo largo del apartado 7.1.3 se propondrán técnicas a tal efecto.

\subsubsection{Metodologías de regresión múltiple}

Las diversas metodologías de regresión múltiple ordinaria se diferencian en su proceso para añadir variables independientes al modelo. El análisis de las diversas técnicas es relevante cuando existe cierta correlación entre las variables independientes, hecho casi inevitable en una propuesta como la de esta tesis, en el que algunas muestras cuentan con un número elevado de variables independientes. 
En la variante conocida como jerárquica, el investigador determina el orden en el que las variables se introducen en el modelo, utilizando como criterio la importancia esperada de cada una de ellas (Pedhazur, 1997). Así, utilizando como base investigaciones previas, es necesario introducir primero aquellas variables con mayores probabilidades de resultar relevantes, para a continuación añadir aquellas en los que las posibilidades son menores. Este proceso puede realizarse en tantas etapas como sea necesario.

La variante denominada de entrada forzada introduce todas las variables del modelo a la vez sin permitir al investigador influir en el orden, lo cual elimina cierta componente de aleatoriedad, si bien no permite incorporar al análisis los resultados obtenidos previamente (Pedhazur, 1997).

Finalmente, la variante de introducción por etapas utiliza una técnica de decisión matemática que determina la capacidad predictora de cada variable para seleccionar el orden en el que se añaden -en la versión hacia adelante o forward-o eliminan -en la versión hacia atrás o backward- del modelo (Pedhazur, 1997). Pese a parecer a priori más recomendable debido a la automatización de decisiones metodológicas, este método no es adecuado puesto que la relevancia de añadir o eliminar cada nueva variable es determinada en función de las que ya existen en el modelo, lo que puede conducir a situaciones de exceso o carencia de variables (Field, 2013).

Dada la existencia de literatura que permite evaluar la importancia relativa de cada variable, y a efectos de diferenciar hipótesis moderadoras de hipótesis directas, esta investigación utilizará la introducción por etapas según el siguiente proceso secuencial:

- Etapa 1: introducción inicial de todas las variables independientes con influencia directa en la variable dependiente.

- Etapa 2: introducción posterior de todas las variables moderadoras de las relaciones entre las variables independientes de la etapa 1 y la variable dependiente.

- Etapa 3: eliminación de las variables no significativas.

El apartado 7.2.2.2 presenta los resultados de los diversos coeficientes para cada una de estas etapas.

\subsubsection{Operacionalización de variables moderadoras en regresión múltiple}

Tal y como se ha definido en el planteamiento del modelo teórico, las variables moderadoras modifican las relaciones entre otras variables (Cohen et al., 2003). La evaluación de efectos de moderación en la regresión múltiple se realiza a través de la introducción en el modelo de dos variables independientes adicionales para cada hipótesis: la variable moderadora y la variable de interacción, calculada como el 
producto de la variable moderadora y la moderada (Keith, 2015). Si bien será esta última la que determine si existe efecto moderador, es necesaria la introducción de la variable moderadora para que el modelo sea válido (Hayes, 2013).

De cara a facilitar la interpretación de los coeficientes $b_{i}$, se recomienda realizar un proceso de centrado en las variables continuas -esto es, transformar una variable en desviaciones alrededor de un punto fijo- utilizando como base la media (Field, 2013). Este proceso no afecta al coeficiente $b_{i}$ relativo a la variable de interacción, pero sí a los de la independiente y moderadora, representando en este caso la relación con la variable dependiente cuando el valor del resto de variables independientes y moderadoras está en su media (Hayes, 2013). Asimismo, contribuye a disminuir las posibilidades de que exista multicolinealidad entre las nuevas variables añadidas al modelo (Cohen et al., 2003).

En el caso de que existan interacciones, los coeficientes de las variables independientes no serán relevantes -aunque sean estadísticamente significativos- (Field, 2013). Para determinar en detalle el efecto de la variable moderadora, será necesario realizar un análisis de pendientes simples, que consistirá en evaluar la relación entre la variable independiente y la dependiente a valores altos y bajos de la moderadora (Aiken, West, \& Reno, 1991). Esto puede conducir a la selección de una zona de significación; esto es, la selección de un rango de valores de la variable moderadora en los que existe interacción (Field, 2013). La técnica de Johnson-Neyman, detallada en profundidad en las siguientes páginas, es la más adecuada para determinar la zona de significación (Hayes, 2013).

Para valorar si el efecto de interacción es relevante en el modelo, es recomendable introducir en una primera etapa la variable independiente y en una segunda la moderadora y la de interacción, para posteriormente evaluar si el incremento de $\mathrm{R}^{2}$ en el modelo es significativo (Keith, 2015). En el caso de que el término de interacción sea estadísticamente significativo, se asume que existe un cambio de pendiente a medida que los valores de la variable moderadora cambian (Hayes, 2013).

Finalmente, es necesario tener en cuenta que la capacidad del modelo de revelar múltiples relaciones de moderación es limitada, puesto que debido a la naturaleza de la operacionalización estos efectos son más difíciles de detectar (Keith, 2015).

\subsubsection{Análisis e interpretación de regresión múltiple}

Una vez definidas las características de la regresión múltiple ordinaria en su versión de introducción jerárquica, los requisitos para su uso y los fundamentos teóricos que gobiernan su aplicación, se procederá en los siguientes apartados a exponer de manera más concreta la metodología que se utilizará en su aplicación a las muestras de esta 
investigación. Para ello, se detallará la selección de determinadas estadísticas y técnicas para comprobar el cumplimiento de requisitos, y se señalarán los valores críticos que permitirán suponer o descartar la ausencia de problemas.

\subsubsection{Varianza explicada y relevancia predictiva}

En la aplicación de técnicas estadísticas para análisis de datos, el parámetro que permite evaluar cómo de exitoso es el modelo a la hora de replicar las observaciones reales es una de las variables fundamentales en el análisis de resultados. En el análisis de regresión múltiple, el encaje del modelo con los datos determina a través de la ratio $\mathrm{R}^{2}$, cuyo valor se obtiene de acuerdo con la ecuación 2.

$$
R^{2}=\frac{S S_{M}}{S S_{T}}
$$

Ecuación 2 - Varianza explicada en regresión múltiple ordinaria

En este cociente, $\mathrm{SS}_{\mathrm{M}}$ es la suma de cuadrados de la diferencia entre la media y el modelo, y $\mathrm{SS}_{\mathrm{T}}$ es la suma de cuadrados de la diferencia entre la media y los valores observados. De esta manera, $\mathrm{R}^{2}$ resulta un indicador del porcentaje de varianza que consigue explicar el modelo relativo a la media.

Una vez determinada la capacidad explicativa del modelo, es necesario verificar si dicha capacidad es estadísticamente significativa o no, para lo cual es necesario estimar las probabilidades de estar incurriendo en un error de tipo I -falso positivo- y, posteriormente, delimitar un valor crítico a partir del cual se considerará el análisis como válido. El factor F, definido según la ecuación 3, es el test que se utiliza con estos propósitos (Field, 2013). Esta ratio se define como la relación entre varianza sistemática -explicada por el modelo- en relación a la varianza no sistemática -los residuos(Pedhazur, 1997)

$$
F=\frac{M S_{M}}{M S_{R}}
$$

\section{Ecuación 3 - Estadístico F}

En este caso, se realiza una media de la suma de cuadrados para estimar $M S_{M}$ y $M S_{R}$, utilizando como denominador en el cálculo los grados de libertad, que en el caso de $M S_{M}$ serán el número de variables del modelo y en el caso de $M S_{R}$, el número de observaciones menos el número de parámetros estimados -esto es, el número de variables dependientes más uno. De manera intuitiva, esta estadística compara la capacidad explicativa del modelo contra sus errores. La relación entre $\mathrm{F}$ y $\mathrm{R}^{2}$ se define según la ecuación 4 , siendo $\mathrm{N}$ el número de observaciones y k el número de variables dependientes. 


$$
F=\frac{(N-k-1) R^{2}}{k\left(1-R^{2}\right)}
$$

Ecuación 4 - Relación entre $R^{2}$ y el estadístico F

Una vez conocido el valor de $\mathrm{F}$, la utilización de una distribución $\mathrm{F}$ con $\mathrm{k}-1$ y N-k grados de libertad permitirá obtener un valor $p$, que a su vez se comparará con el valor crítico de este último estadístico -en el caso de esta investigación, 0.05- para determinar si la regresión es estadísticamente significativa. Estos cálculos serán realizados de manera automática por el paquete estadístico, con lo que en la interpretación de resultados simplemente será necesario determinar si el valor p resulta dentro del rango que permite aceptar el modelo.

\subsubsection{Evaluación de los coeficientes}

Los coeficientes asociados a las variables independientes -los valores $b_{i}$ del modelo lineal general- son el resultado principal de un análisis de regresión múltiple. Dichos coeficientes se pueden interpretar como los factores que ponderan una variable sintética compuesta por las variables independientes que predice la variable dependiente (Thompson, 1999).

Así, una vez aseverada la relevancia de los resultados desde un punto de vista del modelo en su totalidad, resulta relevante realizar un análisis de cada coeficiente en particular. Este punto es de vital importancia puesto que está asociado al objetivo de esta investigación doctoral de identificar qué factores de influencia son relevantes y la importancia relativa de cada uno de ellos. Su signo también permitirá determinar la dirección de la relación que les une con la variable dependiente.

Sin embargo, el uso de coeficientes $b_{i}$ no permitiría una comparación justa entre parámetros, al estar cada uno de ellos adaptado a las unidades de medida de su correspondiente variable independiente. Dicho ejercicio se puede efectuar a través de los valores beta estandarizados $-\beta i-$, que miden el número de unidades en desviaciones estándar que cambia la variable dependiente por cada cambio de una desviación estándar de la variable independiente (Pedhazur, 1997). Aquellos que resulten significativos estadísticamente -hecho que se comprobará a través del valor $\mathrm{p}$ asociado a su estadístico t- tendrán influencia en el modelo, y en función del valor de beta, se podrá obtener una indicación de su importancia relativa.

Como regla general -basada en la investigación sobre aprendizaje- para valorar la magnitud de la aportación de cada variable, se pueden considerar betas inferiores a 0.05 como demasiado pequeñas para ser consideradas influyentes en la variable dependiente, entre 0.05 y 0.1 pequeñas pero influyentes, entre 0.1 y 0.25 moderadas pero influyentes y superiores a 0.25 de gran influencia (Keith, 2015). 


\subsubsection{Multicolinealidad}

Como se ha mencionado previamente, la ausencia de multicolinealidad - de correlación entre variables independientes- es uno de los requisitos para la utilización de la regresión múltiple ordinaria. Su análisis resulta de especial relevancia, dado que la multicolinealidad es habitual en las investigaciones sobre el comportamiento humano que utilizan datos no experimentales, como es el caso de esta tesis (Pedhazur, 1997). La existencia de dichas correlaciones tiene múltiples efectos negativos. Su presencia afecta a los coeficientes $b_{i}$, limita el valor de $\mathrm{R}^{2}$ porque las nuevas variables no añaden capacidad explicativa de varianza adicional a la aportada por las variables ya existentes en el modelo con las que existe correlación, limita la capacidad del investigador de determinar la importancia relativa de las variables independientes (Field, 2013) y reduce la precisión de todos los cálculos debido a los errores de redondeo (Pedhazur, 1997).

A la hora de determinar correlaciones entre variables, resulta intuitivo como primer paso el análisis de la matriz de correlación entre variables. Sin embargo, este método puede no resultar siempre totalmente efectivo (Pedhazur, 1997); por ejemplo, con el caso de variables sintéticas formadas a través de operaciones con otras variables (Keith, 2015). Así, es habitual recurrir al estadístico VIF -variance inflation factor o factor de inflación de varianza-, un índice que evalúa el incremento de la cantidad de varianza de cada coeficiente en relación con una situación en la que no existe correlación entre ninguna de las variables independientes (Cohen et al., 2003). Su valor se calcula según la ecuación 5 , en la que $R_{i, 1,2 \ldots(i) \ldots, k}^{2}$ representa la correlación múltiple entre cada variable independiente $i$ y las otras variables independientes.

$$
V I F_{i}=\frac{1}{1-R_{i, 1,2 \ldots .(i) \ldots k}^{2}}
$$

Ecuación 5 - Factor de inflación de la varianza

La obtención del VIF se realiza de manera automática para cada parámetro por parte el paquete estadístico. Para su utilización, se considera que valores individuales superiores a 6-7 (Keith, 2015) o valores medios de VIF significativamente superiores a 1 indican potencial presencia de multicolinealidad (Bowerman \& O’Connell, 1990).

\subsubsection{Análisis de residuos}

El análisis de residuos tiene como objetivo el valorar el cumplimiento de alguno de los requisitos necesarios para dar por válidos los resultados de un análisis de regresión múltiple. En la comprobación del requisito de independencia de los residuos el test de Durbin-Watson (Durbin \& Watson, 1950; 1951) resulta el método más apropiado entre los utilizados habitualmente (Cohen et al., 2003; Cook \& Weisberg, 1982). Esta 
estadística evalúa la existencia de correlación de primer orden entre residuos, y su valor se calcula de acuerdo con la ecuación 6.

$$
D=\frac{\sum_{t=2}^{T}\left(e_{t}-e_{t-1}\right)^{2}}{\sum_{t=1}^{T} e_{t}^{2}}
$$

Ecuación 6 - Test de Durbin-Watson

De manera general, valores superiores a 3 e inferiores a 1 para cada etapa del modelo indican problemas de independencia (Field, 2013), si bien este método es relevante en análisis de series temporales en los que existe un orden establecido en las observaciones mientras que en otro tipo de muestras puede producir resultados no relevantes (Cohen et al., 2003).

En la comprobación del requisito de normalidad de residuos se pueden utilizar múltiples alternativas. Así, resultan válidos tanto un histograma o un gráfico P-P, acompañados de técnicas auxiliares para los valores de los extremos, como el conteo del número de casos en los que el valor del residuo normalizado es superior a 1.96 o inferior a -1.96 para verificar si representa menos del 5\% de la muestra (Field, 2013).

Finalmente, el análisis de cumplimiento de los requisitos de homocedasticidad y linealidad se realiza a través de la evaluación del gráfico que relaciona los residuos estandarizados con los valores estimados por el modelo estandarizados (Keith, 2015). En dicho gráfico, una distribución desordenada y arbitraria de puntos apunta a la validez del modelo, mientras que patrones con formas curvilíneas indican potencial falta de normalidad, y patrones con forma de embudo señalan heterocedasticidad (Field, 2013). Si sobre este conjunto de puntos se ajusta una línea no paramétrica que tiene un aspecto de "recta dibujada por un niño a mano alzada", se puede asumir que el modelo está ausente de problemas, mientras que líneas más curvas señalan la violación de los requisitos (Cohen et al., 2003).

\subsubsection{Valores extremos y casos influyentes}

Los valores extremos y casos con excesiva influencia pueden tener un efecto superior a otros casos de la muestra en los coeficientes e intervalos de confianza, y por este motivo es necesario evaluar la pertinencia de mantenerlos en el modelo. Los valores extremos se detectan casi exclusivamente a través de la identificación de residuos elevados, siendo la estadística de residuos estandarizados la más habitual (Pedhazur, 1997). Una vez determinadas las observaciones problemáticas, es recomendable su evaluación concreta para determinar si son el resultado de errores de codificación, si son casos excepcionales pero válidos o si existe algún patrón que los agrupe y permita identificar una potencial variable de influencia que no forma parte del modelo (Keith, 2015). En 
general, se considera que valores superiores a 3 desviaciones típicas merecen un análisis detenido (Field, 2013).

En cuanto a los casos con excesiva influencia, las metodologías fundamentales para su identificación se basan en la evaluación de los cambios que supondrían para el modelo la exclusión de cada uno de los casos (Cohen et al., 2003). La distancia de Cook evalúa el cambio total que se produce en los valores del modelo al eliminar cada uno de los casos (Cook \& Weisberg, 1982). Esta estadística es especialmente recomendable en muestras grandes con normalidad de residuos (Cohen et al., 2003), motivo por el cual será utilizado en esta tesis. Su valor se define de acuerdo con la ecuación 7 , siendo $\tilde{y}$ el valor predicho con todos los casos en el modelo, $\tilde{y}_{(i)}$ el valor predicho con la observación $i$ eliminada de la muestra y $M S_{\text {residuo(i) }}$ el residuo medio cuadrado con la observación i eliminada de la muestra.

$$
D_{i}=\frac{\sum\left(\tilde{y}-\tilde{y}_{(i)}\right)^{2}}{(k+1) M S_{\text {rasiduo }(i)}}
$$

Ecuación 7 - Distancia de Cook

La distancia de Cook se obtiene automáticamente por parte del software estadístico y, en general, se considera que valores superiores a 1 indican excesiva influencia y merecen una observación detallada (Cook \& Weisberg, 1982).

\subsubsection{Análisis de pendientes simples para variables de interacción}

Finalmente, en el caso de que existan hipótesis moderadoras estadísticamente significativas, será necesario determinar la dirección del efecto, así como el intervalo de valores de la variable moderadora para el cuál el efecto de interacción es significativo. La utilización del método de pendientes simples resulta apropiado a estos efectos (Aiken et al., 1991), siendo particularmente útil la adopción de la técnica de JohnsonNeyman (Johnson \& Neyman, 1936), que consiste en la ejecución de la regresión múltiple para múltiples valores de la variable moderadora para obtener múltiples puntos de pendiente y significación - $p$-valores- (Field, 2013). Esta técnica, aplicable cuando la variable moderadora es continua, tiene la ventaja de evitar la arbitrariedad inherente a la selección de un número limitado de puntos -cuartiles, valores enteros de desviaciones estándar, etc.-, puesto que determina los puntos de corte de manera que entre ellos se encuentren aquellos cuyos valores del estadístico $p$ coinciden con el valor crítico que determina la significación (Hayes, 2013). Así, se procederá a aplicar este método automatizado en el software estadístico SPSS a través de una rutina adicional desarrollada por Hayes (2013)-, para posteriormente representar gráficamente los resultados. 


\subsubsection{Definición del modelo final}

Una vez concluida la exposición de los múltiples test y estadísticos que permiten validar un análisis de regresión múltiple, es necesario determinar la metodología de definición del modelo final. Como punto de partida, se puede recurrir al objetivo de esta tesis: definir un modelo de eficiencia en el e-mail marketing. En general, todo modelo teórico obtenido con regresión múltiple ordinaria tendrá que cumplir tres requisitos: que sus variables independientes tengan sentido desde un punto de vista teórico, que el modelo en general sea estadísticamente significativo y que cada variable independiente sea estadísticamente significativa (Richardson, 2015).

Para cumplir esta última condición es necesario eliminar del modelo inicial aquellas variables que no explican varianza adicional. Este requisito tiene su explicación en el hecho de que una variable adicional en el modelo sin influencia sobre la variable dependiente incrementará los errores de las otras variables independientes (Cohen et al., 2003). Así, será necesario encontrar una manera de dilucidar si la adición de cada nueva variable al modelo mejora el encaje. Para ello, se utilizará la mejora de valores de $\mathrm{R}^{2}$ producidos como consecuencia de añadir parámetros, y un test de análisis de varianza ANOVA- que compruebe la mejora del modelo respecto a la media a través del coeficiente F -proceso conocido como construcción de modelos (Richardson, 2015) o análisis de sensibilidad (Cohen et al., 2003).

A efectos de ilustrar brevemente este proceso, en el análisis de resultados se presentarán para las dos primeras fases - varianza explicada y análisis de coeficientes- resultados del modelo inicial, coincidente con el teórico y con presencia de todas las variables, y del modelo final, que será aquel en el que sólo aparecen las variables estadísticamente significativas. En posteriores etapas se analizará solamente el modelo final.

A lo largo del análisis de sensibilidad, es posible encontrar situaciones en las que las variables independientes estén relacionadas entre sí y con la variable dependiente, hecho que puede conducir a que variables que no eran significativas pasen a serlo -0 a la inversa- tras la adición de una nueva variable (Cohen et al., 2003). De hecho, en el desarrollo del análisis de sensibilidad para las dos primeras muestras se han identificado en algunos casos variables independientes cuyo $p$-valor varía notablemente en función de la presencia de otras variables independientes en el modelo. Si bien cambios ligeros son razonables a medida que el modelo evoluciona y se añade capacidad explicativa por parte de otras variables, variaciones que en algunos casos determinen que la variable es significativa y en otros no deben ser objeto de análisis detallado.

En este tipo de situaciones, el criterio general en el estudio del marketing es evitar a toda costa la aparición de errores tipo I -falsos positivos-, para lo cual se asume cierta flexibilidad en relación a los errores tipo II -falsos negativos- (Zikmund et al., 2013). 
La técnica utilizada en el análisis de regresión múltiple ordinaria para determinar cómo de fiable es el efecto de una variable independiente en la dependiente es la evaluación de la consistencia de sus resultados en múltiples modelos en los que se añadan o eliminen variables; esto es, la realización de un análisis de sensibilidad (Cohen et al., 2003).

Una posible causa establecida por la literatura para las situaciones de falta de consistencia en el valor del estadístico $p$ es que una de las variables tenga un efecto supresor sobre otra - esto es, que la presencia una variable independiente en el modelo altere la relación entre la otra variable independiente y la variable dependiente(Pedhazur, 1997). Esta definición es objeto de controversia (Pedhazur, 1997), y de hecho algunos autores la limitan a aquellos escenarios en los que la nueva variable independiente anule la relación entre una variable independiente y la dependiente (Cohen et al., 2003). La supresión está asociada a las correlaciones parciales entre variables independientes y resulta un fenómeno complejo de interpretar (Cohen et al., 2003; Pedhazur, 1997).

Existen dos supuestos teóricos que pueden dar lugar a la existencia de supresión: el primero es que el producto de la correlación variable dependiente-variable independiente A, multiplicado por la correlación entre variables independientes, sea superior al coeficiente de correlación entre la variable dependiente y la variable independiente B; el segundo, que la correlación entre variables independientes sea negativa, y la correlación entre cada variable independiente y la dependiente sea positiva (Cohen et al., 2003).

Así, para cada variable independiente para la que se presenten dudas con relación a su significación, se valorará la estabilidad del estadístico $p$ en función de diferentes escenarios -diferentes grupos de variables independientes-, para evaluar posteriormente si existe alguna variable particular vinculada a las variaciones de dicho estadístico. En el caso de que sea así, se procederá a valorar si existe relación de supresión soportada desde un punto de vista teórico, para determinar si tiene sentido mantener dicha variable en el modelo final.

En resumen, y atendiendo al criterio general de minimizar errores tipo I, salvo que existan evidencias sólidas desde un punto de vista cuantitativo de relación de supresión acompañadas de una explicación teórica razonable que vincule ambas variables independientes, esta investigación excluirá del modelo aquellas variables independientes cuya significación no resulte estable.

\subsubsection{Resumen de la metodología de evaluación}

Terminadas tanto la exposición teórica general sobre el método de regresión múltiple por mínimos cuadrados ordinarios como el desarrollo práctico del proceso de 
evaluación de los resultados, se ofrece un breve resumen de la metodología que será utilizada en el análisis de las diversas muestras de esta tesis:

- Se identificarán las variables independientes que añaden capacidad explicativa al modelo (es decir, que incrementan $\mathrm{R}^{2}$ ) y las que no lo hacen, a través de varias regresiones por etapas, para llegar a determinar el modelo inicial y final.

- Se registrará qué variables independientes son relevantes y su importancia relativa a través de los coeficientes beta y los valores asociados al estadístico t.

- Se establecerán potenciales situaciones de multicolinealidad a través del coeficiente VIF -valores medios muy superiores a 1 y máximos superiores a 6y la matriz de correlación entre variables.

- Se identificarán situaciones de falta de independencia de errores a través del test Durbin-Watson-valores superiores a 3 e inferiores a 1.

- Se evaluará la normalidad de los residuos a través de histogramas, gráficos P-P y el conteo de casos con valores normalizados superiores a dos desviaciones estándar.

- Se valorará la linealidad y homocedasticidad a través del gráfico de valores predichos normalizados versus residuos normalizados.

- Se determinará la existencia de casos de excesiva influencia-especialmente en aquellos con residuos elevados- a través de la distancia de Cook -valores superiores a 1.

- Se establecerá el rango de valores para los que los efectos de interacción son relevantes para las hipótesis moderadoras estadísticamente significativas a través de la técnica de análisis de pendientes simples y el procedimiento JohnsonNeyman.

\subsection{ANÁLISIS DE DATOS}

\subsubsection{Transformación de variables}

Como paso previo a la realización del análisis, es necesario incurrir en una serie de consideraciones metodológicas que facilitarán la obtención de resultados. En concreto, debido a las necesidades específicas de alguna de las técnicas que se van a utilizar, será necesario transformar ciertas variables como paso previo a su introducción en el modelo. A lo largo de los siguientes párrafos se procederá a detallar los motivos que sustentan la necesidad de realizar de cada transformación y la mecánica operativa de la misma.

\subsubsection{Transformación de variables dependientes}

La distribución de las variables dependientes ha sido detallada en el apartado de descripción de las muestras del capítulo quinto. Pese a que, tal y como se mencionó en 
ese análisis, los histogramas presentan indicios de normalidad, dicha normalidad no es perfecta debido a la existencia de cierta asimetría positiva. Aunque la anormalidad de variables no tiene por qué afectar a los requisitos de la regresión múltiple si la muestra es grande (Field, 2013), algunos test iniciales sobre las muestras de esta investigación confirman potenciales problemas de normalidad de residuos y heterocedasticidad (figura 23) que pueden estar causados por la distribución de las variables independientes.
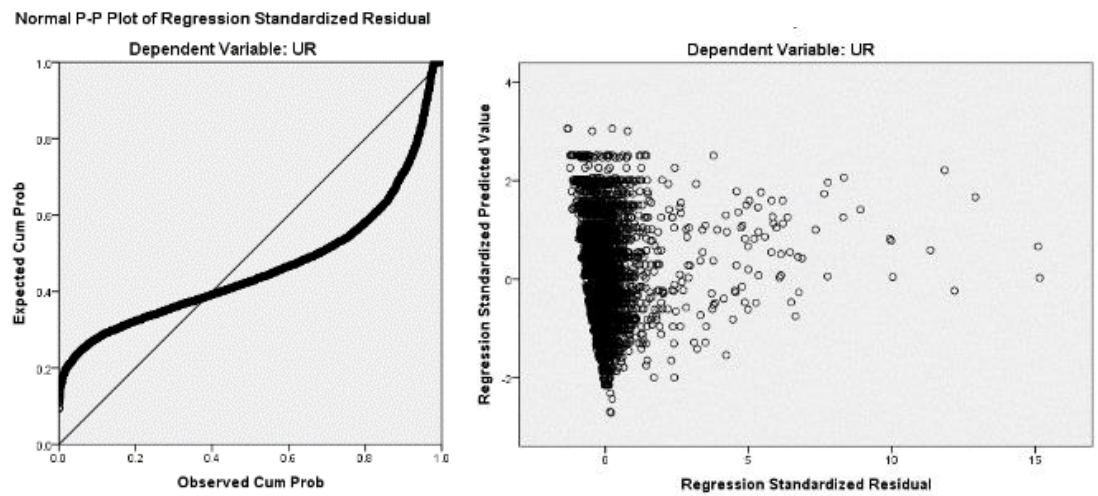

Figura 23 - Falta de normalidad y heterocedasticidad de residuos en el análisis de la efectividad de retención de suscriptores (variable sin transformar)

Las transformaciones de variables ayudan en situaciones de excesiva heteroscedasticidad y falta de normalidad de residuos (Keith, 2015), siendo la transformación logarítmica una de las medidas más habituales para reducir asimetría positiva (Cohen et al., 2003; Field, 2013). Esta asimetría es habitual en las variables dependientes que utiliza esta investigación, de forma similar a otras investigaciones de la misma naturaleza (Robinson et al., 2007), y la solución adoptada en estos casos ha sido también la transformación logarítmica -en concreto, empleando el logaritmo neperiano. A la vista de esto, se utilizará dicha transformación con todas las variables dependientes de esta tesis.

Su aplicación a las tasas OR, CTOR y CR no presenta dificultades, pero en el caso de UR, la existencia de 34 casos con valores de cero no permite asignar un valor para estos registros. La exclusión de estos casos restaría capacidad explicativa al modelo, al ser casos relevantes puesto que han obtenido un resultado extremo, pero válido. En estas situaciones, se recomienda añadir una constante de valor pequeño a los valores como paso previo a su transformación (Cohen et al., 2003). Así, se ha seleccionado como constante el valor de $0.05 \%$, que es el valor mínimo de UR en la muestra, como paso previo a la transformación logarítmica. A efectos de nomenclatura, se añadirá al comienzo de los códigos asignados a las variables previamente los caracteres LN, pasando OR a ser LNOR, CTOR a ser LNCTOR, y así sucesivamente. 


\subsubsection{Transformación de variables independientes}

Tal y como se ha detallado anteriormente en este capítulo, el método para evaluar la existencia de efectos moderadores requerirá realizar un centrado previo de las variables independientes continuas -longitud de asunto, longitud de texto, número de imágenes, número de enlaces y frecuencia- y moderadoras - dimensiones culturales- para realizar correctamente el análisis de interacción. El centrado se realizará alrededor de la media de cada variable para cada muestra. Como paso posterior, será necesario crear una variable de interacción definida como el producto de cada par de variable independiente y variable moderadora para cada hipótesis de moderación. Así, se calcularán las variables de interacción para las relaciones de moderación utilizando el producto de la variable independiente - centrada si es continua- y la variable moderadora -centrada en todos los casos, dado que las dimensiones de Hofstede son variables cuantitativas continuas. El cálculo de dichos productos sólo requiere un breve comentario en el caso de la variable contenido del asunto -codificada a través de variables dummy.

Dado el carácter nominal de esta variable y el hecho de que las hipótesis de moderación para la misma sólo aparecen soportadas desde un punto de vista teórico para un número limitado de temáticas, se calcularán variables de interacción solamente para las variables dummy relevantes. En concreto, puesto que la relación moderadora de la distancia al poder viene asociada a temáticas promocionales, se relacionará esta dimensión únicamente con las variables dummy ADES, ATEM y ADTE; por otro lado, la relación moderadora de individualismo-colectivismo está asociada a la presencia de incentivos concretos como descuentos, así que se crearán variables de interacción sólo para ADES y ADTE; finalmente, dado que la relación moderadora de masculinidadfeminidad está asociada a temáticas de concursos y descuentos, se crearán productos de interacción para ADES, ADTE, ACON y ACPR.

A efectos de nomenclatura, y de cara a distinguir las variables centradas de las originales, se añadirá a los códigos asignados a las variables previamente una $\mathrm{C}$ al final en el caso de que hayan sido centradas. La nomenclatura de las variables de interacción se establecerá utilizando el código de la variable independiente seguido de un guion bajo y posteriormente, del código de la variable moderadora -por ejemplo, ALONC_MASCC será el producto de longitud de asunto centrada y masculinidadfeminidad centrada.

\subsubsection{Resumen de transformación de variables}

A continuación, se muestra una tabla resumen de todas las transformaciones realizadas. 


\begin{tabular}{|c|c|c|c|}
\hline Variable & $\begin{array}{c}\text { Código } \\
\text { original }\end{array}$ & Operación & Código final \\
\hline Efectividad de apertura & OR & $\begin{array}{l}\text { Transformación } \\
\text { Log. Nep. }\end{array}$ & LNOR \\
\hline Efectividad de clic & CTOR & $\begin{array}{l}\text { Transformación } \\
\text { Log. Nep. }\end{array}$ & LNCTOR \\
\hline Efectividad de retención de suscriptores & UR & $\begin{array}{l}\text { Transformación } \\
\text { Log. Nep. }\end{array}$ & LNUR \\
\hline Efectividad de conversión & $\mathrm{CR}$ & $\begin{array}{l}\text { Transformación } \\
\text { Log. Nep. }\end{array}$ & LNCR \\
\hline Longitud de asunto & ALON & Centrado & ALONC \\
\hline Longitud texto e-mail & ELON & Centrado & ELONC \\
\hline Número de imágenes e-mail & EIMA & Centrado & EIMAC \\
\hline Número de enlaces e-mail & EENL & Centrado & EENLC \\
\hline Frecuencia & $\overline{\text { FREC }}$ & Centrado & FRECC \\
\hline Distancia al poder & DIST & Centrado & DISTC \\
\hline Individualismo-Colectivismo & INDI & Centrado & INDIC \\
\hline Masculinidad-Feminidad & MASC & Centrado & MASCC \\
\hline Aversión a la incertidumbre & AVER & Centrado & AVERC \\
\hline Orientación al largo plazo & ORIE & Centrado & ORIEC \\
\hline $\begin{array}{l}\text { Interacción entre Longitud de asunto y } \\
\text { Masculinidad-Feminidad }\end{array}$ & Ninguno & $\begin{array}{l}\text { Producto } \\
\text { interacción }\end{array}$ & ALONC_MASCC \\
\hline $\begin{array}{l}\text { Interacción entre Promoción de temporada y } \\
\text { Distancia al poder }\end{array}$ & Ninguno & $\begin{array}{l}\text { Producto } \\
\text { interacción }\end{array}$ & ATEM_DISTC \\
\hline $\begin{array}{l}\text { Interacción entre Descuentos y Masculinidad- } \\
\text { Feminidad }\end{array}$ & Ninguno & $\begin{array}{l}\text { Producto } \\
\text { interacción }\end{array}$ & ADES_MASCC \\
\hline $\begin{array}{l}\text { Interacción entre Segmentación e Individualismo- } \\
\text { Colectivismo }\end{array}$ & Ninguno & $\begin{array}{l}\text { Producto } \\
\text { interacción }\end{array}$ & SEGM_INDIC \\
\hline $\begin{array}{l}\text { Interacción entre Segmentación y Aversión a la } \\
\text { incertidumbre }\end{array}$ & Ninguno & $\begin{array}{l}\text { Producto } \\
\text { interacción }\end{array}$ & SEGM_AVERC \\
\hline $\begin{array}{l}\text { Interacción entre Frecuencia e Individualismo- } \\
\text { Colectivismo }\end{array}$ & Ninguno & $\begin{array}{l}\text { Producto } \\
\text { interacción }\end{array}$ & FRECC_INDIC \\
\hline $\begin{array}{l}\text { Interacción entre Longitud de asunto e } \\
\text { Individualismo-Colectivismo }\end{array}$ & Ninguno & $\begin{array}{l}\text { Producto } \\
\text { interacción }\end{array}$ & ALONC_INDIC \\
\hline $\begin{array}{l}\text { Interacción entre Longitud de asunto y Aversión a } \\
\text { la incertidumbre }\end{array}$ & Ninguno & $\begin{array}{l}\text { Producto } \\
\text { interacción }\end{array}$ & ALONC_AVERC \\
\hline $\begin{array}{l}\text { Interacción entre Longitud de asunto y } \\
\text { Orientación al largo plazo }\end{array}$ & Ninguno & $\begin{array}{l}\text { Producto } \\
\text { interacción }\end{array}$ & ALONC_ORIEC \\
\hline $\begin{array}{l}\text { Interacción entre Caracteres especiales en asunto e } \\
\text { Individualismo-Colectivismo }\end{array}$ & Ninguno & $\begin{array}{l}\text { Producto } \\
\text { interacción }\end{array}$ & ACAR_INDIC \\
\hline Interacción entre Descuentos y Distancia al poder & Ninguno & $\begin{array}{l}\text { Producto } \\
\text { interacción }\end{array}$ & ADES_DISTC \\
\hline $\begin{array}{l}\text { Interacción entre Descuentos de temporada y } \\
\text { Distancia al poder }\end{array}$ & Ninguno & $\begin{array}{l}\text { Producto } \\
\text { interacción }\end{array}$ & ADTE_DISTC \\
\hline $\begin{array}{l}\text { Interacción entre Descuentos e Individualismo- } \\
\text { Colectivismo }\end{array}$ & Ninguno & $\begin{array}{l}\text { Producto } \\
\text { interacción }\end{array}$ & ADES_INDIC \\
\hline $\begin{array}{l}\text { Interacción entre Descuentos de temporada e } \\
\text { Individualismo-Colectivismo }\end{array}$ & Ninguno & $\begin{array}{l}\text { Producto } \\
\text { interacción }\end{array}$ & ADTE_INDIC \\
\hline $\begin{array}{l}\text { Interacción entre Descuentos de temporada y } \\
\text { Masculinidad-Feminidad }\end{array}$ & Ninguno & $\begin{array}{l}\text { Producto } \\
\text { interacción }\end{array}$ & ADTE_MASCC \\
\hline $\begin{array}{l}\text { Interacción entre Concursos y Masculinidad- } \\
\text { Feminidad }\end{array}$ & Ninguno & $\begin{array}{l}\text { Producto } \\
\text { interacción }\end{array}$ & ACON_MASCC \\
\hline $\begin{array}{l}\text { Interacción entre Promoción y concursos y } \\
\text { Masculinidad-Feminidad }\end{array}$ & Ninguno & $\begin{array}{l}\text { Producto } \\
\text { interacción }\end{array}$ & ACPR_MASCC \\
\hline
\end{tabular}




\begin{tabular}{|c|c|c|c|}
\hline $\begin{array}{l}\text { Interacción entre Personalización e } \\
\text { Individualismo-Colectivismo }\end{array}$ & Ninguno & $\begin{array}{l}\text { Producto } \\
\text { interacción }\end{array}$ & PERS_INDIC \\
\hline $\begin{array}{l}\text { Interacción entre Longitud texto e-mail e } \\
\text { Individualismo-Colectivismo }\end{array}$ & Ninguno & $\begin{array}{l}\text { Producto } \\
\text { interacción }\end{array}$ & ELONC_INDIC \\
\hline $\begin{array}{l}\text { Interacción entre Longitud texto e-mail y } \\
\text { Masculinidad-Feminidad }\end{array}$ & Ninguno & $\begin{array}{l}\text { Producto } \\
\text { interacción }\end{array}$ & ELONC_MASCC \\
\hline $\begin{array}{l}\text { Interacción entre Longitud texto e-mail y } \\
\text { Aversión a la incertidumbre }\end{array}$ & Ninguno & $\begin{array}{l}\text { Producto } \\
\text { interacción }\end{array}$ & ELONC_AVERC \\
\hline $\begin{array}{l}\text { Interacción entre Longitud texto e-mail y } \\
\text { Orientación al largo plazo }\end{array}$ & Ninguno & $\begin{array}{l}\text { Producto } \\
\text { interacción }\end{array}$ & ELONC_ORIEC \\
\hline $\begin{array}{l}\text { Interacción entre Número de imágenes e-mail e } \\
\text { Individualismo-Colectivismo }\end{array}$ & Ninguno & $\begin{array}{l}\text { Producto } \\
\text { interacción }\end{array}$ & EIMAC_INDIC \\
\hline $\begin{array}{l}\text { Interacción entre Número de imágenes e-mail y } \\
\text { Masculinidad-Feminidad }\end{array}$ & Ninguno & $\begin{array}{l}\text { Producto } \\
\text { interacción }\end{array}$ & EIMAC_MASCC \\
\hline $\begin{array}{l}\text { Interacción entre Número de imágenes e-mail y } \\
\text { Aversión a la incertidumbre }\end{array}$ & Ninguno & $\begin{array}{l}\text { Producto } \\
\text { interacción }\end{array}$ & EIMAC_AVERC \\
\hline $\begin{array}{l}\text { Interacción entre Número de imágenes e-mail y } \\
\text { Orientación al largo plazo }\end{array}$ & Ninguno & $\begin{array}{l}\text { Producto } \\
\text { interacción }\end{array}$ & EIMAC_ORIEC \\
\hline $\begin{array}{l}\text { Interacción entre Número de enlaces e-mail e } \\
\text { Individualismo-Colectivismo }\end{array}$ & Ninguno & $\begin{array}{l}\text { Producto } \\
\text { interacción }\end{array}$ & EENLC_INDIC \\
\hline $\begin{array}{l}\text { Interacción entre Número de enlaces e-mail y } \\
\text { Masculinidad-Feminidad }\end{array}$ & Ninguno & $\begin{array}{l}\text { Producto } \\
\text { interacción }\end{array}$ & EENLC_MASCC \\
\hline $\begin{array}{l}\text { Interacción entre Número de enlaces e-mail y } \\
\text { Aversión a la incertidumbre }\end{array}$ & Ninguno & $\begin{array}{l}\text { Producto } \\
\text { interacción }\end{array}$ & EENLC_AVERC \\
\hline $\begin{array}{l}\text { Interacción entre Número de enlaces e-mail y } \\
\text { Orientación al largo plazo }\end{array}$ & Ninguno & $\begin{array}{l}\text { Producto } \\
\text { interacción }\end{array}$ & EENLC_ORIEC \\
\hline $\begin{array}{l}\text { Interacción entre Incentivos económicos y } \\
\text { Distancia al poder }\end{array}$ & Ninguno & $\begin{array}{l}\text { Producto } \\
\text { interacción }\end{array}$ & EINC_DISTC \\
\hline $\begin{array}{l}\text { Interacción entre Incentivos económicos e } \\
\text { Individualismo-Colectivismo }\end{array}$ & Ninguno & $\begin{array}{l}\text { Producto } \\
\text { interacción }\end{array}$ & EINC_INDIC \\
\hline $\begin{array}{l}\text { Interacción entre Incentivos económicos y } \\
\text { Masculinidad-Feminidad }\end{array}$ & Ninguno & $\begin{array}{l}\text { Producto } \\
\text { interacción }\end{array}$ & EINC_MASCC \\
\hline $\begin{array}{l}\text { Interacción entre sensación de escasez y Distancia } \\
\text { al poder }\end{array}$ & Ninguno & $\begin{array}{l}\text { Producto } \\
\text { interacción }\end{array}$ & EESC_DISTC \\
\hline $\begin{array}{l}\text { Interacción entre sensación de escasez e } \\
\text { Individualismo-Colectivismo }\end{array}$ & Ninguno & $\begin{array}{l}\text { Producto } \\
\text { interacción }\end{array}$ & EESC_INDIC \\
\hline $\begin{array}{l}\text { Interacción entre sensación de escasez y } \\
\text { Masculinidad-Feminidad }\end{array}$ & Ninguno & $\begin{array}{l}\text { Producto } \\
\text { interacción }\end{array}$ & EESC_MASCC \\
\hline $\begin{array}{l}\text { Interacción entre sensación de escasez y Aversión } \\
\text { a la incertidumbre }\end{array}$ & Ninguno & $\begin{array}{l}\text { Producto } \\
\text { interacción }\end{array}$ & EESC_AVERC \\
\hline $\begin{array}{l}\text { Interacción entre sensación de escasez y } \\
\text { Orientación al largo plazo }\end{array}$ & Ninguno & $\begin{array}{l}\text { Producto } \\
\text { interacción }\end{array}$ & EESC_ORIEC \\
\hline
\end{tabular}

Tabla 45 - Resumen de transformaciones de variables

\subsubsection{Análisis del modelo}

Una vez detalladas las diferentes etapas en el análisis de un modelo de regresión lineal, y tras haber realizado las transformaciones necesarias en las variables para asegurar una correcta aplicación de la técnica, se procederá a utilizar la misma sobre las diferentes muestras empleadas en esta investigación. A continuación, se realizará una breve exposición de los resultados de cada muestra para cada una de las etapas del análisis. Así, tal y como se ha mencionado en el apartado de construcción del modelo final, en la exposición de resultados se procederá a presentar para cada muestra la varianza explicada y los coeficientes beta del modelo inicial -con todas las variables- y final - 
sólo con las variables estadísticamente significativas-, para posteriormente pasar a analizar la validez del modelo final a través del cumplimiento de los requisitos metodológicos.

\subsubsection{Varianza explicada y relevancia predictiva}

\subsection{Estudio de la etapa de atención}

Dado el elevado número de variables independientes propuestas en el modelo teórico, se ha procedido a realizar un análisis de sensibilidad detallado para determinar los factores de influencia relevantes. Este proceso ha consistido en la eliminación en cada etapa del modelo de cada una de las variables independientes de manera individual para evaluar su influencia en la capacidad predictiva y si su presencia generaba efectos de supresión. Tras el análisis preliminar, se han identificado como estadísticamente significativas la longitud del asunto, el contenido del asunto -en concreto, las temáticas de descuento, promoción de temporada, regalo, bonus y otros-, la segmentación, la frecuencia y el día de la semana -en concreto, los días lunes, martes, viernes y sábado-. La variable hora de envío ha sido excluida del modelo debido a problemas de multicolinealidad. Se han detectado también seis efectos moderadores que serán desarrollados en los apartados siguientes.

Las tablas 46 y 47 recogen el resumen del modelo, tanto para la versión en la que se han introducido todas las variables como para aquella en la que sólo aparecen las variables representativas. Cada una de las tablas presenta dos modelos: el 1 contiene sólo las variables asociadas a hipótesis generales, y el 2, aquellas asociadas tanto a hipótesis generales como a hipótesis moderadoras. Esta aproximación permite valorar la capacidad explicativa aportada por las relaciones de moderación, y será utilizada en el análisis de las muestras posteriores.

\begin{tabular}{|c|c|c|c|c|c|c|c|c|c|c|}
\hline \multirow[b]{2}{*}{ Modelo } & \multirow[b]{2}{*}{$\mathbf{R}$} & \multirow[b]{2}{*}{$\mathbf{R}^{2}$} & \multirow[b]{2}{*}{$\begin{array}{l}\text { Adj. } \\
\mathbf{R}^{2}\end{array}$} & \multirow{2}{*}{$\begin{array}{l}\text { Error } \\
\text { Estd. } \\
\text { Est. }\end{array}$} & \multicolumn{5}{|c|}{ Estadísticas incremento varianza } & \multirow[b]{2}{*}{$\begin{array}{l}\text { Durbin- } \\
\text { Watson }\end{array}$} \\
\hline & & & & & $\begin{array}{c}\text { Cambio } \\
\mathbf{R}^{2}\end{array}$ & $\begin{array}{c}\text { Cambio } \\
\text { F }\end{array}$ & df1 & df2 & $\begin{array}{c}\text { Cambio } \\
\text { Sig. F }\end{array}$ & \\
\hline 1 & $.390^{\mathrm{a}}$ & .152 & .148 & .3610 & .152 & 36.339 & 22 & 4444 & .000 & \\
\hline 2 & $.531^{\mathrm{b}}$ & .282 & .275 & .3331 & .130 & 34.714 & 23 & 4421 & .000 & 1.256 \\
\hline
\end{tabular}

a. Predictores: (Constante), DIAD, AREG, ACPR, ABON, ADTE, ANOT, ACON, PERS, DIAV, APRO, AOTR, FRECC, ATEM, DIAL, ALONC, SEGM, DIAS, DIAJ, ACAR, ADES, DIAM, ANUM

b. Predictores: (Constante), DIAD, AREG, ACPR, ABON, ADTE, ANOT, ACON, PERS, DIAV, APRO, AOTR, FRECC, ATEM, DIAL, ALONC, SEGM, DIAS, DIAJ, ACAR, ADES, DIAM, ANUM, ALONC_MASCC, ACON_MASCC, ADTE_INDIC, SEGM_AVERC, ACPR_MASCC, ADES_MASCC, PERS_INDIC, ALONC_INDIC, FRECC_INDIC, ORIEC, ALONC_AVERC, ALONC_ORIEC, ATEM_DISTC, ADES_DISTC, AVERC, ADTE_MASCC, INDIC, MASCC, SEGM_INDIC, ADTE_DISTC, ADES_INDIC, DISTC, ACAR_INDIC

Tabla 46 - Varianza explicada en la etapa de atención del modelo que incluye todas las variables 


\begin{tabular}{|c|c|c|c|c|c|c|c|c|c|c|}
\hline \multirow[b]{2}{*}{ Modelo } & \multirow[b]{2}{*}{$\mathbf{R}$} & \multirow[b]{2}{*}{$\mathbf{R}^{2}$} & \multirow[b]{2}{*}{$\begin{array}{l}\text { Adj. } \\
\mathbf{R}^{2}\end{array}$} & \multirow{2}{*}{$\begin{array}{l}\text { Error } \\
\text { Estd. } \\
\text { Est. }\end{array}$} & \multicolumn{5}{|c|}{ Estadísticas incremento varianza } & \multirow{2}{*}{$\begin{array}{l}\text { Durbin- } \\
\text { Watson }\end{array}$} \\
\hline & & & & & $\begin{array}{c}\text { Cambio } \\
\mathbf{R}^{2}\end{array}$ & $\begin{array}{c}\text { Cambio } \\
\text { F }\end{array}$ & df1 & df2 & $\begin{array}{c}\text { Cambio } \\
\text { Sig. F }\end{array}$ & \\
\hline 1 & $.383^{\mathrm{a}}$ & .147 & .145 & 3618 & 147 & 69.731 & 11 & 4455 & .000 & \\
\hline 2 & $.514^{\mathrm{b}}$ & .264 & .260 & .3365 & .117 & 64.114 & 11 & 4444 & .000 & 1.241 \\
\hline
\end{tabular}

a. Predictores: (Constante), DIAS, SEGM, ATEM, ABON, AOTR, AREG, DIAL, FRECC, DIAV, ADES, DIAM

b. Predictores: (Constante), DIAS, SEGM, ATEM, ABON, AOTR, AREG, DIAL, FRECC, DIAV, ADES, DIAM, ALONC_MASCC, SEGM_AVERC, ADES_MASCC, FRECC_INDIC, ALONC, ATEM_DISTC, AVERC, INDIC, MASCC, SEGM_INDIC, DISTC

Tabla 47 - Varianza explicada en la etapa de atención del modelo que incluye sólo las variables significativas

Nótese que el coeficiente $\mathrm{R}^{2}$ final del modelo con todas las variables es superior al del modelo sólo con las variables estadísticamente significativas.

El modelo final explica el $26.4 \%$ de la varianza, con lo que se puede considerar como representativo de efectos medios, hecho razonable puesto que existe un número significativo de externalidades con influencia en la tasa de apertura que no es posible incorporar - por ejemplo, qué otros correos hay presentes en la bandeja de entrada del usuario. La varianza explicada ajustada proporciona una estimación no sesgada de la varianza explicada de la población que tiene en cuenta la complejidad del modelo y permite realizar una validación cruzada del mismo; en este caso, la varianza explicada ajustada se reduce sólo en $0.4 \%$ respecto a la del modelo, y por tanto se puede confirmar una buena validación cruzada del modelo.

\subsection{Estudio de la etapa de interés}

Tal y como se ha desarrollado en el marco teórico, el interés será operacionalizado a través de la efectividad de clic y la de retención de suscriptores. Se procederá a analizar cada una de estas submuestras de manera independiente.

\subsection{Efectividad de clic}

Tras realizar de nuevo un ejercicio de introducción progresiva de variables independientes, se presentan a continuación los resultados obtenidos. Los factores estadísticamente significativos que ha identificado el análisis son la longitud del correo, el número de imágenes y la presencia de elementos que generan sensación de escasez. A su vez, se han detectado efectos moderadores de las dimensiones culturales: en el caso del número de imágenes, por la dimensión masculinidad-feminidad; en el caso de los elementos que generan escasez, por la dimensión distancia al poder.

Las tablas 48 y 49 recogen el resumen del modelo, tanto para la versión en la que se han introducido todas las variables como para aquella en la que sólo aparecen las variables representativas. 
El modelo explica un $13.4 \%$ de la varianza, lo cual puede ser considerado como referente a un efecto medio. En este caso, la varianza explicada ajustada se reduce ligeramente hasta un $13 \%$.

\begin{tabular}{|c|c|c|c|c|c|c|c|c|c|c|}
\hline \multirow[b]{2}{*}{ Modelo } & \multirow[b]{2}{*}{$\mathbf{R}$} & \multirow[b]{2}{*}{$\mathbf{R}^{2}$} & \multirow[b]{2}{*}{$\begin{array}{c}\text { Adj. } \\
\mathbf{R}^{2}\end{array}$} & \multirow{2}{*}{$\begin{array}{c}\text { Error } \\
\text { Estd. } \\
\text { Est. }\end{array}$} & \multicolumn{5}{|c|}{ Estadísticas incremento varianza } & \multirow[b]{2}{*}{$\begin{array}{l}\text { Durbin- } \\
\text { Watson }\end{array}$} \\
\hline & & & & & Cambio $\mathbf{R}^{2}$ & $\begin{array}{c}F \\
\text { Change }\end{array}$ & df1 & df2 & $\begin{array}{l}\text { Sig. F } \\
\text { Change }\end{array}$ & \\
\hline 1 & $.338^{\mathrm{a}}$ & .114 & .111 & 4288 & .114 & 30.780 & 7 & 1671 & .000 & \\
\hline 2 & $.449^{\mathrm{b}}$ & .202 & .185 & .4106 & .087 & 6.424 & 28 & 1643 & .000 & 1.520 \\
\hline
\end{tabular}

a. Predictores: (Constante), PERS, EINC, SEGM, EENLC, EESC, ELONC, EIMAC

b. Predictores: (Constante), PERS, EINC, SEGM, EENLC, EESC, ELONC, EIMAC, EENLC_AVERC, EENLC_ORIEC, EINC_MASCC, SEGM_AVERC, EESC_ORIEC, EIMAC_INDIC, EESC_AVERC, EESC_DISTC, EENLC_MASCC, ELONC_ORIEC, ELONC_AVERC, EENLC_INDIC, EESC_MASCC, EINC_INDIC, PERS_INDIC, ELONC_MASCC, ORIEC, AVERC, INDIC, MASCC, EINC_DISTC, EIMAC_ORIEC, ELONC_INDIC, SEGM_INDIC, EIMAC_AVERC, EESC_INDIC, EIMAC_MASCC, DISTC

Tabla 48 - Varianza explicada en la etapa de interés - submuestra efectividad de clic del modelo que incluye todas las variables

\begin{tabular}{|c|c|c|c|c|c|c|c|c|c|c|}
\hline \multirow[b]{2}{*}{ Modelo } & \multirow[b]{2}{*}{$\mathbf{R}$} & \multirow[b]{2}{*}{$\mathbf{R}^{2}$} & \multirow{2}{*}{$\begin{array}{c}\text { Adj. } \\
\mathbf{R}^{2}\end{array}$} & \multirow{2}{*}{$\begin{array}{c}\text { Error } \\
\text { Estd. } \\
\text { Est. }\end{array}$} & \multicolumn{5}{|c|}{ Estadísticas incremento varianza } & \multirow[b]{2}{*}{$\begin{array}{l}\text { Durbin- } \\
\text { Watson }\end{array}$} \\
\hline & & & & & Cambio $\mathbf{R}^{2}$ & $\begin{array}{c}\text { F } \\
\text { Change }\end{array}$ & df1 & df2 & $\begin{array}{c}\text { Sig. F } \\
\text { Change }\end{array}$ & \\
\hline 1 & $.336^{\mathrm{a}}$ & .113 & .111 & .42872 & .113 & 70.962 & 3 & 1675 & .000 & \\
\hline 2 & $.366^{\mathrm{b}}$ & .134 & .130 & .4241 & .021 & 10.167 & 4 & 1671 & .000 & 1.445 \\
\hline
\end{tabular}

a. Predictores: (Constante), EESC, EIMAC, ELONC

b. Predictores: (Constante), EESC, EIMAC, ELONC, EIMAC_MASCC, EESC_DISTC, MASCC, DISTC

Tabla 49 - Varianza explicada en la etapa de interés - submuestra efectividad de clic del modelo que incluye sólo las variables significativas

\subsection{Efectividad de retención de suscriptores}

Dado el limitado número de variables de esta muestra, no ha sido necesario realizar un análisis de sensibilidad. Los resultados detallados en la tabla 50 implican la existencia de influencia por parte tanto de la frecuencia como de la personalización en la retención de suscriptores, si bien ninguna de las hipótesis moderadoras ha resultado soportada.

Así, puesto que las hipótesis no moderadoras han resultado todas significativas y las hipótesis moderadoras han resultado todas no significativas, la siguiente tabla recoge tanto el modelo inicial (2) como final (1). La capacidad predictiva del modelo final es muy limitada $-1.8 \%-$, lo que implica limitada eficiencia por parte de estas dos variables para predecir la retención de suscriptores. Este hecho será discutido en más detalle en el capítulo de conclusiones.

\begin{tabular}{|c|c|c|c|c|c|c|c|c|c|c|}
\hline \multirow[b]{2}{*}{ Modelo } & \multirow[b]{2}{*}{$\mathbf{R}$} & \multirow[b]{2}{*}{$\mathbf{R}^{2}$} & \multirow{2}{*}{$\begin{array}{c}\text { Adj. } \\
\mathbf{R}^{2}\end{array}$} & \multirow{2}{*}{$\begin{array}{c}\text { Error } \\
\text { Estd. } \\
\text { Est. }\end{array}$} & \multicolumn{5}{|c|}{ Estadísticas incremento varianza } & \multirow{2}{*}{$\begin{array}{l}\text { Durbin- } \\
\text { Watson }\end{array}$} \\
\hline & & & & & Cambio $\mathbf{R}^{2}$ & $\begin{array}{c}\text { F } \\
\text { Change }\end{array}$ & df1 & df2 & $\begin{array}{c}\text { Sig. F } \\
\text { Change }\end{array}$ & \\
\hline 1 & $.135^{\mathrm{a}}$ & .018 & .018 & .9551 & .018 & 41.690 & 2 & 4464 & .000 & \\
\hline
\end{tabular}




\begin{tabular}{l|l|l|l|l|l|l|l|l|l|l|}
\hline 2 & $.483^{\mathrm{b}}$ & .233 & .232 & .8443 & .215 & 416.943 & 3 & 4461 & .000 & 1.773 \\
\hline
\end{tabular}
a. Predictores: (Constante), FRECC, PERS
b. Predictores: (Constante), FRECC, PERS, PERS_INDIC, FRECC_INDIC, INDIC

Tabla 50 - Varianza explicada en la etapa de interés - submuestra efectividad de retención de suscriptores de los modelos inicial y final

\subsection{Estudio de la etapa de acción}

La progresiva introducción de factores de influencia en el modelo arroja el resultado mostrado en la tabla 51: los incentivos económicos, la sensación de escasez y la segmentación son estadísticamente significativas; sin embargo, la personalización no resulta significativa. Como siguiente paso, y tras añadir las variables independientes en la primera etapa, se procede a definir el modelo con las variables moderadoras y los variables de interacción, como muestra la tabla 52. En este caso, sólo una de estas últimas resulta estadísticamente significativa: la moderación de la sensación de escasez por la orientación al largo plazo.

La varianza explicada es pequeña - de un 5.3\%-, lo cual confirma la dificultad a la hora de explicar un fenómeno que tiene lugar fuera del entorno del e-mail marketing. La varianza ajustada se reduce ligeramente hasta un 5.0\%.

\begin{tabular}{|c|c|c|c|c|c|c|c|c|c|c|}
\hline \multirow[b]{2}{*}{ Modelo } & \multirow[b]{2}{*}{$\mathbf{R}$} & \multirow[b]{2}{*}{$\mathbf{R}^{2}$} & \multirow[b]{2}{*}{$\begin{array}{c}\text { Adj. } \\
\mathbf{R}^{2}\end{array}$} & \multirow[b]{2}{*}{$\begin{array}{c}\text { Error } \\
\text { Estd. } \\
\text { Est. }\end{array}$} & \multicolumn{5}{|c|}{ Estadísticas incremento varianza } & \multirow[b]{2}{*}{$\begin{array}{c}\text { Durbin } \\
- \\
\text { Watson }\end{array}$} \\
\hline & & & & & $\begin{array}{c}\text { Cam } \\
\text { bio } \\
\mathbf{R}^{2}\end{array}$ & F Change & df1 & df 2 & $\begin{array}{c}\text { Sig. F } \\
\text { Change }\end{array}$ & \\
\hline 1 & $.213^{\mathrm{a}}$ & .046 & .043 & .8409 & .046 & 19.986 & 4 & 1674 & .000 & \\
\hline 2 & $.278^{\mathrm{b}}$ & .077 & .066 & .8308 & .032 & 3.543 & 16 & 1658 & .000 & 1.436 \\
\hline
\end{tabular}

a. Predictores: (Constante), PERS, EINC, SEGM, EESC

b. Predictores: (Constante), PERS, EINC, SEGM, EESC, MASCC, EESC_ORIEC, EESC_AVERC, SEGM_AVERC, EESC_DISTC, EINC_INDIC, EINC_MASCC, PERS_INDIC, ORIEC, EESC_MASCC, AVERC, INDIC, EINC_DISTC, SEGM_INDIC, DISTC, EESC_INDIC

Tabla 51 - Varianza explicada en la etapa de acción del modelo que incluye todas las variables

\begin{tabular}{|c|c|c|c|c|c|c|c|c|c|c|}
\hline \multirow[b]{2}{*}{ Modelo } & \multirow[b]{2}{*}{$\mathbf{R}$} & \multirow[b]{2}{*}{$\mathbf{R}^{2}$} & \multirow{2}{*}{$\begin{array}{c}\text { Adj. } \\
\mathbf{R}^{\mathbf{2}}\end{array}$} & \multirow{2}{*}{$\begin{array}{c}\text { Error } \\
\text { Estd. } \\
\text { Est. }\end{array}$} & \multicolumn{5}{|c|}{ Estadísticas incremento varianza } & \multirow{2}{*}{$\begin{array}{l}\text { Durbin- } \\
\text { Watson }\end{array}$} \\
\hline & & & & & $\begin{array}{c}\text { Cambio } \\
\mathbf{R}^{2}\end{array}$ & $\begin{array}{c}\text { F } \\
\text { Change }\end{array}$ & df1 & df2 & $\begin{array}{c}\text { Sig. F } \\
\text { Change }\end{array}$ & \\
\hline 1 & $.213^{\mathrm{a}}$ & .045 & .044 & .8407 & .045 & 26.600 & 3 & 1675 & .000 & \\
\hline 2 & $.230^{\mathrm{b}}$ & .053 & .050 & .8380 & .007 & 6.508 & 2 & 1673 & .002 & 1.391 \\
\hline
\end{tabular}

a. Predictores: (Constante), EINC, SEGM, EESC

b. Predictores: (Constante), EINC, SEGM, EESC, EESC_ORIEC, ORIEC

Tabla 52 - Varianza explicada en la etapa de acción del modelo que incluye sólo las variables significativas 


\subsubsection{Evaluación de los coeficientes}

\subsection{Estudio de etapa de atención}

Como paso previo a la exposición de valores de los coeficientes, es necesario mencionar que en esta muestra se presenta la situación de inestabilidad del $p$-valor asociada a ciertos coeficientes en función de la presencia de otras variables independientes detallada en el apartado 7.1.3.7 (Definición del modelo final). Así, la variable caracteres especiales en el asunto -ACARC- y las interacciones de longitud de asunto con individualismo-colectivismo -ALONC_INDIC-, descuentos con distancia al poder ADES_DISTC- y descuentos con individualismo-colectivismo -ADES_INDIC-, resultan significativas en el modelo inicial, pero han sido excluidas del modelo final porque su significación estaba vinculada a la presencia de otras variables en el modelo.

En el caso de ACARC y ALONC_INDIC, no ha sido posible establecer qué variable concreta condicionaba los valores de su significación, pues su valor $p$ cambia significativamente asociado a varias de ellas. En concreto, en el caso de ACARC, la presencia de las dimensiones de Hofstede en el modelo eleva su $p$-valor por encima de 0.05 , la posterior adición de los factores de interacción para las variables independientes de contenido visible lo reduce por debajo de este umbral, y la adición final de los factores de interacción de las variables temporales y contextuales vuelve a elevarlo por encima. En el caso de ALONC_INDIC, la presencia en el modelo de las otras cuatro dimensiones de Hofstede reducía su $p$-valor hasta hacerlo significativo, contribuyendo cada una de ellas a lograrlo.

En el caso de ADES_DISTC y ADES_INDIC., su significación está asociada a su presencia conjunta en el modelo. Tal y como muestra la tabla 53, en el caso de estas dos variables no se cumplen las condiciones teóricas de supresión expuestas en el apartado 7.1.3.7 -la correlación entre LNOR y ADES_DISTC, -.151, es superior (en valor absoluto) al producto de la correlación entre LNOR y ADES_INDIC por la correlación entre ADES_INDIC y ADES_DISTC $(0.141 *-0.698=-0.098)$ -

\begin{tabular}{|l|l|c|c|c|c|c|}
\hline \multicolumn{2}{|c|}{} & $\begin{array}{c}\text { ADES_ } \\
\text { INDIC }\end{array}$ & $\begin{array}{c}\text { ADES_ } \\
\text { DISTC }\end{array}$ & LNOR & DISTC & INDIC \\
\hline \multirow{3}{*}{ Corr. Pearson } & ADES_INDIC & $\mathbf{1 . 0 0 0}$ & $\mathbf{- . 6 9 8}$ & $\mathbf{. 1 4 1}$ & $\mathbf{- . 3 7 5}$ & $\mathbf{. 5 4 6}$ \\
\cline { 2 - 7 } & ADES_DISTC & $\mathbf{- . 6 9 8}$ & $\mathbf{1 . 0 0 0}$ & $\mathbf{- . 1 5 1}$ & $\mathbf{. 5 2 8}$ & $\mathbf{- . 3 8 5}$ \\
\cline { 2 - 7 } & LNOR &. .141 & -.151 & $\mathbf{1 . 0 0 0}$ & -.270 & .196 \\
\cline { 2 - 7 } & DISTC & $\mathbf{- . 3 7 5}$ & $\mathbf{. 5 2 8}$ & $\mathbf{- . 2 7 0}$ & $\mathbf{1 . 0 0 0}$ & $\mathbf{- . 7 2 3}$ \\
\cline { 2 - 7 } & INDIC & $\mathbf{. 5 4 6}$ & $\mathbf{- . 3 8 5}$ & $\mathbf{. 1 9 6}$ & $\mathbf{- . 7 2 3}$ & $\mathbf{1 . 0 0 0}$ \\
\hline
\end{tabular}

Tabla 53 - Tabla de coeficientes de correlación entre descuentos_individualismo-colectivismo, descuentos_distancia al poder, efectividad de apertura, distancia al poder e individualismo-colectivismo

De hecho, la existencia de un elevado factor de correlación entre ambas (-.698), motivado por el hecho de que han sido computadas como el producto de las misma 
variable dicotómica -ADES- por dos dimensiones culturales con una alta correlación INDIC y DISTC, cuyo coeficiente $r$ es de -0.723-, sugiere una explicación más fácil: la existencia de elevada colinealidad entre estas dos dimensiones culturales conduce a variaciones del $p$-valor, hecho consistente con los fundamentos teóricos expuestos en el apartado 7.1.3.3 dedicado a la multicolinealidad.

Así, cabe acudir para todos los casos al criterio general expuesto en el apartado 7.1.3.7 (Definición del modelo final), según el cual es recomendable ignorar aquellas variables que en un análisis de sensibilidad cambien bruscamente sus coeficientes. Por este motivo, se han eliminado del modelo final todas estas variables y efectos de interacción.

Por tanto, los coeficientes beta sugieren que la segmentación y la frecuencia son las variables más relevantes, seguidas de efectos más pequeños debidos al contenido del asunto y el día de la semana de envío, si bien debido a la existencia de relaciones de moderación, esta aseveración es sólo válida para valores medios de las dimensiones de Hofstede (Hayes, 2013). Asimismo, la variable longitud del asunto se mantendrá en el modelo porque, pese a que la relación de influencia directa no ha resultado significativa (el p-valor es superior a 0.05), existe un efecto de moderación -el producido por la dimensión masculinidad-feminidad-que sí ha resultado significativo.

A continuación, las tablas 54 y 55 muestran los coeficientes asociadas a las variables independientes. 


\begin{tabular}{|c|c|c|c|c|c|c|}
\hline \multirow{2}{*}{\multicolumn{2}{|c|}{ Modelo }} & \multicolumn{2}{|c|}{$\begin{array}{l}\text { Coeficientes no } \\
\text { estandarizados }\end{array}$} & \multirow{2}{*}{$\begin{array}{c}\begin{array}{c}\text { Coeficientes } \\
\text { estandarizados }\end{array} \\
\text { Beta } \\
\end{array}$} & \multirow[t]{2}{*}{$\mathbf{t}$} & \multirow{2}{*}{ Sig. } \\
\hline & & B & Error Est. & & & \\
\hline \multirow[t]{23}{*}{1} & (Constante) & 3.503 & .017 & & 210.327 & .000 \\
\hline & ALONC & $8.611 \mathrm{E}-05$ & .000 & .004 & .292 & .770 \\
\hline & ANUM & .018 & .014 & .022 & 1.315 & .188 \\
\hline & ACAR & .049 & .014 & .058 & 3.596 & .000 \\
\hline & ADES & -.120 & .014 & -.142 & -8.837 & .000 \\
\hline & ATEM & .086 & .023 & .052 & 3.652 & .000 \\
\hline & ADTE & -.093 & .059 & -.022 & -1.577 & .115 \\
\hline & AREG & .320 & .116 & .039 & 2.767 & .006 \\
\hline & ABON & -.178 & .081 & -.030 & -2.186 & .029 \\
\hline & APRO & .010 & .025 & .006 & .403 & .687 \\
\hline & ANOT & .050 & .043 & .016 & 1.146 & .252 \\
\hline & ACON & -.049 & .037 & -.019 & -1.319 & .187 \\
\hline & ACPR & -.115 & .094 & -.017 & -1.226 & .220 \\
\hline & AOTR & .136 & .025 & .079 & 5.390 & .000 \\
\hline & SEGM & .482 & .031 & .225 & 15.769 & .000 \\
\hline & PERS & -.127 & .076 & -.023 & -1.669 & .095 \\
\hline & FRECC & -.069 & .004 & -.267 & -18.808 & .000 \\
\hline & DIAL & .060 & .022 & .040 & 2.679 & .007 \\
\hline & DIAM & -.048 & .017 & -.047 & -2.871 & .004 \\
\hline & DIAJ & .018 & .018 & .016 & .996 & .319 \\
\hline & DIAV & -.048 & .017 & -.047 & -2.881 & .004 \\
\hline & DIAS & -.036 & .019 & -.031 & -1.920 & .055 \\
\hline & DIAD & -.017 & .070 & -.003 & -.242 & .809 \\
\hline \multirow[t]{17}{*}{2} & (Constante) & 3.506 & .016 & & 225.007 & .000 \\
\hline & ALONC & .000 & .000 & -.022 & -1.564 & .118 \\
\hline & ANUM & .017 & .013 & .020 & 1.306 & .192 \\
\hline & ACAR & .020 & .013 & .023 & 1.516 & .129 \\
\hline & ADES & -.047 & .013 & -.056 & -3.542 & .000 \\
\hline & ATEM & .063 & .023 & .039 & 2.804 & .005 \\
\hline & ADTE & -.003 & .060 & -.001 & -.055 & .956 \\
\hline & AREG & .418 & .107 & .050 & 3.886 & .000 \\
\hline & ABON & -.170 & .076 & -.029 & -2.250 & .024 \\
\hline & APRO & .008 & .023 & .005 & .339 & .735 \\
\hline & ANOT & .036 & .040 & .012 & .899 & .368 \\
\hline & $\mathrm{ACON}$ & -.012 & .035 & -.005 & -.346 & .729 \\
\hline & ACPR & .006 & .088 & .001 & .065 & .948 \\
\hline & AOTR & .110 & .023 & .064 & 4.674 & .000 \\
\hline & SEGM & .600 & .035 & .280 & 17.048 & .000 \\
\hline & PERS & -.009 & .071 & -.002 & -.125 & .900 \\
\hline & FRECC & -.085 & .004 & -.325 & -23.830 & .000 \\
\hline
\end{tabular}




\begin{tabular}{|l|c|c|c|c|c|}
\hline DIAL & .062 & .021 & .042 & 2.970 & $\mathbf{. 0 0 3}$ \\
\hline DIAM & -.047 & .016 & -.046 & -3.029 & $\mathbf{. 0 0 2}$ \\
\hline DIAJ & .026 & .016 & .023 & 1.570 & .116 \\
\hline DIAV & -.030 & .015 & -.030 & -1.957 & $\mathbf{. 0 5 0}$ \\
\hline DIAS & -.094 & .018 & -.080 & -5.354 & $\mathbf{. 0 0 0}$ \\
\hline DIAD & -.066 & .065 & -.013 & -1.008 & .314 \\
\hline DISTC & -.005 & .000 & -.297 & -12.623 & $\mathbf{. 0 0 0}$ \\
\hline INDIC & .001 & .001 & .076 & 2.503 & $\mathbf{. 0 1 2}$ \\
\hline MASCC & -.001 & .000 & -.064 & -3.897 & $\mathbf{. 0 0 0}$ \\
\hline AVERC & .001 & .000 & .065 & 4.521 & $\mathbf{. 0 0 0}$ \\
\hline ALONC_MASCC & $-4.214 \mathrm{E}-05$ & .000 & -.037 & -2.628 & $\mathbf{. 0 0 9}$ \\
\hline ATEM_DISTC & .002 & .001 & .031 & 2.192 & $\mathbf{. 0 2 8}$ \\
\hline ADES_MASCC & -.002 & .001 & -.048 & -3.031 & $\mathbf{. 0 0 2}$ \\
\hline SEGM_INDIC & -.014 & .001 & -.158 & -9.574 & $\mathbf{. 0 0 0}$ \\
\hline SEGM_AVERC & -.010 & .001 & -.100 & -7.323 & $\mathbf{. 0 0 0}$ \\
\hline FRECC_INDIC & .001 & .000 & .052 & 3.899 & $\mathbf{. 0 0 0}$ \\
\hline ORIEC & .003 & .000 & .127 & 9.071 & $\mathbf{. 0 0 0}$ \\
\hline ALONC_INDIC & $-2.531 E-05$ & .000 & -.028 & -2.001 & $\mathbf{. 0 4 5}$ \\
\hline ALONC_AVERC & $3.088 \mathrm{E}-06$ & .000 & .003 & .234 & .815 \\
\hline ALONC_ORIEC & $1.095 \mathrm{E}-05$ & .000 & .012 & .869 & .385 \\
\hline ACAR_INDIC & -.001 & .001 & -.039 & -1.464 & .143 \\
\hline ADES_DISTC & .003 & .001 & .085 & 3.869 & $\mathbf{. 0 0 0}$ \\
\hline ADTE_DISTC & -.001 & .003 & -.007 & -.355 & .722 \\
\hline ADES_INDIC & .003 & .001 & .089 & 3.794 & $\mathbf{. 0 0 0}$ \\
\hline ADTE_INDIC & -.002 & .004 & -.008 & -.431 & .667 \\
\hline ADTE_MASCC & $8.748 \mathrm{E}-05$ & .004 & .000 & .025 & .980 \\
\hline ACON_MASCC & .000 & .002 & -.002 & -.188 & .851 \\
\hline ACPR_MASCC & .000 & .010 & .000 & -.019 & .985 \\
\hline PERS_INDIC & -.001 & .003 & -.004 & -.281 & .778 \\
\hline
\end{tabular}

Tabla 54 - Coeficientes en la etapa de atención del modelo que incluye todas las variables 


\begin{tabular}{|c|c|c|c|c|c|c|}
\hline & Modelo & $\begin{array}{l}\text { Coeficie } \\
\text { estanda }\end{array}$ & $\begin{array}{l}\text { es no } \\
\text { ados }\end{array}$ & $\begin{array}{c}\text { Coeficientes } \\
\text { estandarizados }\end{array}$ & $t$ & Sig. \\
\hline & & B & $\begin{array}{c}\text { Error } \\
\text { Est. }\end{array}$ & Beta & & B \\
\hline 1 & (Constante) & 3.549 & .010 & & 360.305 & .000 \\
\hline & ADES & -.098 & .012 & -.115 & -7.979 & .000 \\
\hline & ATEM & .087 & .023 & .053 & 3.765 & .000 \\
\hline & AREG & .302 & .116 & .036 & 2.613 & .009 \\
\hline & ABON & -.176 & .082 & -.030 & -2.164 & .031 \\
\hline & AOTR & .128 & .024 & .075 & 5.266 & .000 \\
\hline & SEGM & .480 & .030 & .224 & 15.849 & .000 \\
\hline & FRECC & -.067 & .004 & -.260 & -18.554 & .000 \\
\hline & DIAL & .050 & .021 & .034 & 2.343 & .019 \\
\hline & DIAM & -.056 & .015 & -.055 & -3.638 & .000 \\
\hline & DIAV & -.059 & .015 & -.058 & -3.875 & .000 \\
\hline & DIAS & -.043 & .017 & -.036 & -2.448 & .014 \\
\hline 2 & (Constante) & 3.535 & .009 & & 379.907 & .000 \\
\hline & ADES & -.044 & .012 & -.052 & -3.747 & .000 \\
\hline & ATEM & .068 & .022 & .042 & 3.060 & .002 \\
\hline & AREG & .405 & .108 & .049 & 3.745 & .000 \\
\hline & ABON & -.200 & .076 & -.034 & -2.625 & .009 \\
\hline & AOTR & .108 & .023 & .063 & 4.679 & .000 \\
\hline & SEGM & .620 & .035 & .289 & 17.670 & .000 \\
\hline & FRECC & -.084 & .004 & -.322 & -23.659 & .000 \\
\hline & DIAL & .048 & .020 & .032 & 2.393 & .017 \\
\hline & DIAM & -.058 & .014 & -.057 & -4.062 & .000 \\
\hline & DIAV & -.044 & .014 & -.043 & -3.061 & .002 \\
\hline & DIAS & -.098 & .016 & -.083 & -5.932 & .000 \\
\hline & MASCC & -.001 & .000 & -.042 & -2.645 & .008 \\
\hline & DISTC & -.005 & .000 & -.284 & -14.349 & .000 \\
\hline & INDIC & .001 & .000 & .079 & 3.937 & .000 \\
\hline & AVERC & .002 & .000 & .084 & 5.920 & .000 \\
\hline & ALONC & .000 & .000 & -.017 & -1.279 & $.201^{\dagger}$ \\
\hline & ALONC_MASCC & $-4.452 \mathrm{E}-05$ & .000 & -.039 & -2.978 & .003 \\
\hline & ATEM_DISTC & .002 & .001 & .028 & 2.013 & .044 \\
\hline & ADES_MASCC & -.002 & .001 & -.035 & -2.304 & .021 \\
\hline & SEGM_INDIC & -.014 & .001 & -.156 & -9.381 & .000 \\
\hline & SEGM_AVERC & -.009 & .001 & -.090 & -6.591 & .000 \\
\hline & FRECC_INDIC & .001 & .000 & .066 & 4.976 & .000 \\
\hline
\end{tabular}

${ }^{\dagger}$ La variable ALONC no ha resultado significativa, pero se mantiene en el modelo porque la relación de moderación ALONC-MASCC sí ha resultado significativa

Tabla 55 - Coeficientes en la etapa de atención del modelo que incluye sólo las variables significativas 


\subsection{Estudio de la etapa de interés}

\subsection{Efectividad de clic}

En las siguientes páginas se presentan las tablas tanto para el modelo que incluye todas las variables como para el que incluye solamente las variables estadísticamente significativas. En este caso también existe inestabilidad de $p$-valores para ciertas variables. En concreto, pese a que la variable número de enlaces -EENLC- y las interacciones de elementos que generan sensación de escasez con la dimensión aversión a la incertidumbre -EESC_AVERC -, longitud del correo y masculinidad-feminidad ELONC_MASCC - y longitud del correo y orientación al largo plazo ELONC_ORIEC- son significativas en el modelo general, dejan de resultar significativas al eliminar ciertas variables del modelo.

Se ha realizado un análisis de sensibilidad en cada etapa del modelo, eliminando cada una de las variables independientes de manera individual para evaluar su influencia en la capacidad predictiva y si su presencia generaba efectos de supresión. Los resultados obtenidos apuntan a que EENLC está vinculada con AVERC -cuando AVERC está en el modelo, EENLC es significativa, y cuando no está, no lo es-, EESC_AVERC con IMAC_AVERC y ELONC_MASCC con ELONC_ORIEC. Todos los pares de variables producen resultados significativos de correlación entre sí.

Ninguna de estas cuatro variables cumple las condiciones teóricas para que exista supresión. A efectos ilustrativos, se reproducirá el cálculo realizado para la variable EENLC: el producto de la correlación entre esta variable dependiente y aversión al poder multiplicado por la correlación entre ambas variables independientes es inferior (en valor absoluto) a la correlación entre la variable dependiente y número de enlaces. Así, utilizando los valores de la tabla 56, en este caso $|-0.076|>|-0.189 * 0.166|=\mid-$ $0.031 \mid$, de acuerdo con los coeficientes mostrados en la tabla 56.

De nuevo, se utilizará el criterio de ignorar aquellas variables que en el análisis de sensibilidad cambian bruscamente sus coeficientes, con los que estas cuatro variables serán eliminadas del modelo final. Así, tal y como muestran las tablas 57 y 58, el estudio de los coeficientes beta revela que la longitud del correo es la variable más relevante en el estudio de la efectividad de clic, seguido del número de imágenes y de los incentivos que generan escasez, y que estas dos últimas variables se encuentran moderadas por una de las dimensiones de Hofstede.

\begin{tabular}{|l|l|c|c|c|}
\hline \multicolumn{5}{|c|}{ Correlaciones } \\
\hline \multirow{3}{*}{ Corr. Pearson } & EENLC & EENLC & LNCTOR & AVERC \\
\cline { 2 - 5 } & LNCTOR & $\mathbf{1 . 0 0 0}$ & $\mathbf{- . 0 7 6}$ & $\mathbf{- . 1 8 9}$ \\
\cline { 2 - 5 } & AVERC & $\mathbf{- . 0 7 6}$ & $\mathbf{1 . 0 0 0}$ &. $\mathbf{. 1 6 6}$ \\
\hline
\end{tabular}

Tabla 56 - Correlación entre número de enlaces, aversión a la incertidumbre y efectividad de clic 


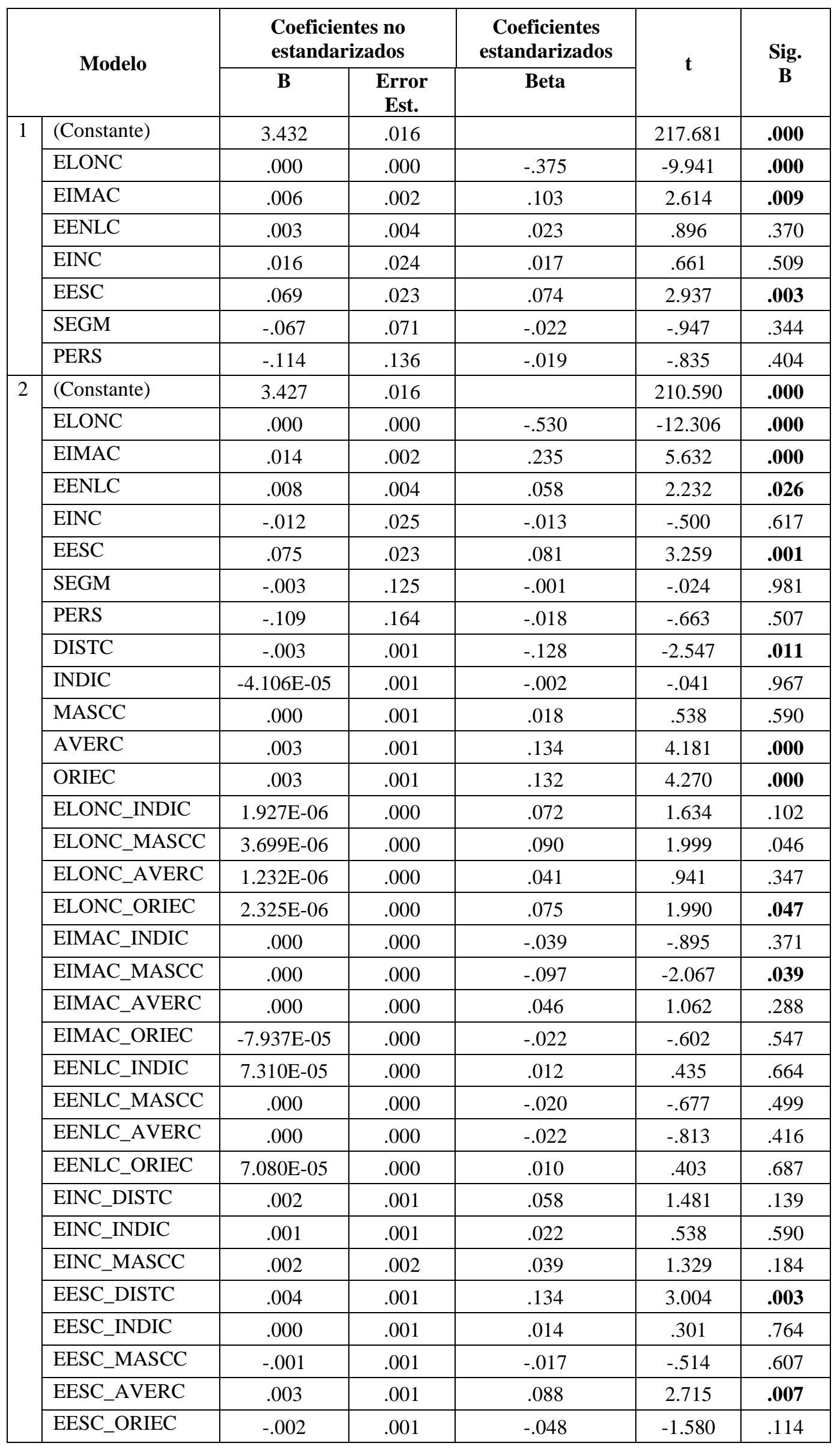




\begin{tabular}{|l|l|c|c|c|c|c|}
\hline & PERS_INDIC & -.011 & .011 & -.028 & -1.027 & .305 \\
\cline { 2 - 7 } & SEGM_INDIC & -.008 & .006 & -.059 & -1.404 & .161 \\
\cline { 2 - 7 } & SEGM_AVERC & .000 & .004 & .002 & .091 & .927 \\
\hline
\end{tabular}

Tabla 57 - Coeficientes en la etapa de interés - submuestra efectividad de clic del modelo que incluye todas las variables

\begin{tabular}{|c|c|c|c|c|c|c|}
\hline \multirow{2}{*}{\multicolumn{2}{|c|}{ Modelo }} & \multicolumn{2}{|c|}{$\begin{array}{l}\text { Coeficientes no } \\
\text { estandarizados }\end{array}$} & \multirow{2}{*}{$\begin{array}{c}\begin{array}{c}\text { Coeficientes } \\
\text { estandarizados }\end{array} \\
\text { Beta }\end{array}$} & \multirow{2}{*}{$\mathbf{t}$} & \multirow{2}{*}{ Sig. } \\
\hline & & B & $\begin{array}{c}\text { Error } \\
\text { Est. }\end{array}$ & & & \\
\hline \multirow[t]{4}{*}{1} & (Constante) & 3.434 & .014 & & 247.769 & 0.000 \\
\hline & ELONC & .000 & .000 & -.384 & -10.296 & .000 \\
\hline & EIMAC & .007 & .002 & .113 & 3.042 & .002 \\
\hline & EESC & .069 & .023 & .074 & 2.984 & .003 \\
\hline \multirow[t]{8}{*}{2} & (Constante) & 3.434 & .014 & & 249.850 & 0.000 \\
\hline & ELONC & .000 & .000 & -.410 & -10.688 & .000 \\
\hline & EIMAC & .009 & .002 & .147 & 3.914 & .000 \\
\hline & EESC & .071 & .023 & .076 & 3.061 & .002 \\
\hline & DISTC & -.002 & .001 & -.102 & -3.392 & .001 \\
\hline & MASCC & .002 & .001 & .061 & 2.577 & .010 \\
\hline & EIMAC_MASCC & .000 & .000 & -.053 & -2.267 & .024 \\
\hline & EESC_DISTC & .005 & .001 & .154 & 5.206 & .000 \\
\hline
\end{tabular}

Tabla 58 - Coeficientes en la etapa de interés - submuestra efectividad de clic del modelo que incluye sólo las variables significativas

\subsection{Efectividad de retención de suscriptores}

La tabla 59 muestra los coeficientes para la segunda muestra de la etapa de interés, siendo de nuevo el modelo 1 el final y el modelo 2 el inicial. En relación con la importancia relativa de las variables, a través del coeficiente beta se aprecia que la frecuencia resulta más influyente que la personalización.

\begin{tabular}{|c|c|c|c|c|c|c|}
\hline & \multirow{2}{*}{ Modelo } & \multicolumn{2}{|c|}{$\begin{array}{l}\text { Coeficientes no } \\
\text { estandarizados }\end{array}$} & \multirow{2}{*}{$\begin{array}{c}\begin{array}{c}\text { Coeficientes } \\
\text { estandarizados }\end{array} \\
\text { Beta }\end{array}$} & \multirow{2}{*}{$\mathbf{t}$} & \multirow{2}{*}{$\begin{array}{l}\text { Sig. } \\
\text { B }\end{array}$} \\
\hline & & B & $\begin{array}{c}\text { Error } \\
\text { Est. }\end{array}$ & & & \\
\hline \multirow[t]{3}{*}{1} & (Constante) & -1.985 & .014 & & -138.561 & .000 \\
\hline & PERS & -.762 & .200 & -.057 & -3.813 & .000 \\
\hline & FRECC & -.077 & .009 & -.121 & -8.131 & .000 \\
\hline \multirow[t]{6}{*}{2} & (Constante) & -1.990 & .013 & & -153.010 & .000 \\
\hline & PERS & -.603 & .179 & -.045 & -3.375 & .001 \\
\hline & FRECC & -.153 & .009 & -.239 & -17.506 & .000 \\
\hline & INDIC & .020 & .001 & .475 & 35.110 & .000 \\
\hline & FRECC_INDIC & .001 & .000 & .020 & 1.531 & .126 \\
\hline & PERS_INDIC & .011 & .009 & .017 & 1.244 & .213 \\
\hline
\end{tabular}

Tabla 59 - Coeficientes en la etapa de interés - submuestra efectividad de retención de suscriptores de los modelos inicial y final 


\subsection{Estudio de la etapa de acción}

El análisis de los coeficientes para esta última etapa del modelo confirma las conclusiones alcanzadas en el análisis de varianza: todas las variables independientes excepto la personalización- resultan significativas, y sólo una de las hipótesis moderadoras resulta sustentada, tal y como muestran las tablas 60 y 61. Las tres variables independientes significativas tienen coeficientes beta en el mismo rango, con lo que no es posible determinar que exista una de mayor importancia que las demás. Además, dada la existencia de una relación de moderación para elementos que generan sensación de escasez, los coeficientes de esta variable variarán en función de la cultura nacional de los suscriptores. Asimismo, la constante no ha resultado estadísticamente significativa, lo cual implica que la efectividad de conversión de un correo electrónico sin incentivos, sensación de escasez, segmentación o personalización no difiere de 0 , lo cual parece lógico puesto que un e-mail de estas características tendría muy posiblemente un carácter fundamentalmente informativo (newsletter, invitación a evento, etc.).

\begin{tabular}{|c|c|c|c|c|c|c|}
\hline & \multirow[t]{2}{*}{ Modelo } & \multicolumn{2}{|c|}{$\begin{array}{l}\text { Coeficientes no } \\
\text { estandarizados }\end{array}$} & \multirow{2}{*}{$\begin{array}{c}\begin{array}{c}\text { Coeficientes } \\
\text { estandarizados }\end{array} \\
\text { Beta }\end{array}$} & \multirow[t]{2}{*}{$\mathbf{t}$} & \multirow{2}{*}{$\underset{\text { B }}{\text { Sig. }}$} \\
\hline & & B & Error Est. & & & \\
\hline \multirow[t]{5}{*}{1} & (Constante) & -.023 & .029 & & -.788 & .431 \\
\hline & EINC & .256 & .045 & .140 & 5.698 & .000 \\
\hline & EESC & .163 & .043 & .093 & 3.769 & .000 \\
\hline & SEGM & .650 & .138 & .112 & 4.703 & .000 \\
\hline & PERS & -.114 & .267 & -.010 & -.427 & .670 \\
\hline \multirow[t]{19}{*}{2} & (Constante) & -.032 & .029 & & -1.118 & .264 \\
\hline & EINC & .299 & .047 & .163 & 6.396 & .000 \\
\hline & EESC & .161 & .043 & .091 & 3.699 & .000 \\
\hline & SEGM & .781 & .252 & .135 & 3.104 & .002 \\
\hline & PERS & -.026 & .329 & -.002 & -.079 & .937 \\
\hline & DISTC & -.002 & .002 & -.060 & -1.236 & .217 \\
\hline & INDIC & -.002 & .002 & -.057 & -1.106 & .269 \\
\hline & MASCC & -.004 & .002 & -.083 & -2.467 & .014 \\
\hline & AVERC & -.004 & .001 & -.095 & -3.022 & .003 \\
\hline & ORIEC & .000 & .001 & -.005 & -.159 & .873 \\
\hline & EINC_DISTC & .003 & .003 & .037 & .904 & .366 \\
\hline & EINC_INDIC & .003 & .003 & .050 & 1.206 & .228 \\
\hline & EINC_MASCC & .004 & .003 & .037 & 1.230 & .219 \\
\hline & EESC_DISTC & .004 & .003 & .062 & 1.323 & .186 \\
\hline & EESC_INDIC & .004 & .003 & .069 & 1.411 & .158 \\
\hline & EESC_MASCC & .001 & .003 & .010 & .319 & .750 \\
\hline & EESC_AVERC & -.002 & .002 & -.035 & -1.126 & .260 \\
\hline & EESC_ORIEC & .008 & .002 & .104 & 3.362 & .001 \\
\hline & PERS_INDIC & .011 & .022 & .015 & .517 & .605 \\
\hline
\end{tabular}




\begin{tabular}{|l|l|c|c|c|c|c|}
\hline & SEGM_INDIC & -.009 & .011 & -.034 & -.773 & .439 \\
\cline { 2 - 7 } & SEGM_AVERC & .006 & .008 & .022 & .750 & .453 \\
\hline
\end{tabular}

Tabla 60 - Coeficientes en la etapa de acción del modelo que incluye todas las variables

\begin{tabular}{|c|c|c|c|c|c|c|}
\hline & \multirow[t]{2}{*}{ Modelo } & \multicolumn{2}{|c|}{$\begin{array}{l}\text { Coeficientes no } \\
\text { estandarizados }\end{array}$} & \multirow{2}{*}{$\begin{array}{c}\begin{array}{c}\text { Coeficientes } \\
\text { estandarizados }\end{array} \\
\text { Beta }\end{array}$} & \multirow[t]{2}{*}{$\mathbf{t}$} & \multirow[t]{2}{*}{ Sig. } \\
\hline & & B & Error Est. & & & \\
\hline \multirow[t]{4}{*}{1} & (Constante) & -.023 & .029 & & -.807 & .420 \\
\hline & EINC & .256 & .045 & .140 & 5.705 & .000 \\
\hline & EESC & .163 & .043 & .092 & 3.758 & .000 \\
\hline & SEGM & .651 & .138 & .113 & 4.709 & .000 \\
\hline \multirow[t]{6}{*}{2} & (Constante) & -.023 & .029 & & -.815 & .415 \\
\hline & EINC & .258 & .045 & .141 & 5.765 & .000 \\
\hline & EESC & .161 & .043 & .091 & 3.728 & .000 \\
\hline & SEGM & .637 & .138 & .110 & 4.600 & .000 \\
\hline & ORIEC & -.001 & .001 & -.016 & -.526 & .599 \\
\hline & EESC_ORIEC & .007 & .002 & .094 & 3.190 & .001 \\
\hline
\end{tabular}

Tabla 61 - Coeficientes en la etapa de acción del modelo que incluye sólo las variables significativas

\subsubsection{Multicolinealidad}

\subsection{Estudio de etapa de atención}

El estudio de la multicolinealidad se abordará a través de los coeficientes de correlación entre variables independientes y el análisis del coeficiente VIF, detallado en el desarrollo teórico de los anteriores apartados. En el caso de esta primera muestra, los valores del coeficiente VIF se mantienen por debajo de 3 para todas las variables que han resultado significativas en el estudio, con lo que a priori se pueden descartar problemas de multicolinealidad en la muestra, pese a la existencia de algunas relaciones significativas de correlación entre variables independientes. A continuación, se presentan en la tabla 62 los valores de VIF y en las tablas 63 y 64 las correlaciones de Pearson para las variables independientes del modelo final.

\begin{tabular}{|l|l|}
\hline \multicolumn{1}{|c|}{ Variable } & VIF \\
\hline ADES & 1.165 \\
\hline ATEM & 1.132 \\
\hline AREG & 1.029 \\
\hline ABON & 1.022 \\
\hline AOTR & 1.089 \\
\hline SEGM & 1.616 \\
\hline FRECC & 1.117 \\
\hline DIAL & 1.104 \\
\hline DIAM & 1.190 \\
\hline DIAV & 1.177 \\
\hline DIAS & 1.180 \\
\hline
\end{tabular}




\begin{tabular}{|l|l|}
\hline MASCC & 1.499 \\
\hline DISTC & 2.365 \\
\hline INDIC & 2.412 \\
\hline AVERC & 1.210 \\
\hline ALONC & 1.066 \\
\hline ALONC_MASCC & 1.038 \\
\hline ATEM_DISTC & 1.176 \\
\hline ADES_MASCC & 1.400 \\
\hline SEGM_INDIC & 1.660 \\
\hline SEGM_AVERC & 1.114 \\
\hline FRECC_INDIC & 1.071 \\
\hline
\end{tabular}

Tabla 62 - VIF de las variables en la etapa de atención del modelo que incluye sólo las variables significativas

\begin{tabular}{|c|c|c|c|c|c|c|c|c|c|c|c|c|c|}
\hline & & 音 & $\underset{8}{8}$ & 疍 & 苗 & $\begin{array}{l}Z \\
\stackrel{Z}{Z} \\
\mathbf{Z}\end{array}$ & $\stackrel{8}{\stackrel{8}{0}}$ & $\frac{\pi}{3}$ & 20 & 晃 & 量 & $\frac{\theta}{2}$ & $\underset{⿱ 乛}{D}$ \\
\hline \multirow{23}{*}{$\begin{array}{l}\text { Corr. } \\
\text { Pearson }\end{array}$} & LNOR & 1.000 & -.137 & .076 & .060 & -.004 & .105 & .216 & -.238 & .060 & -.025 & -.035 & -.038 \\
\hline & ADES & -.137 & 1.000 & -.171 & -.032 & -.045 & -.161 & -.057 & -.003 & .033 & -.123 & -.042 & -.030 \\
\hline & ATEM & .076 & -.171 & 1.000 & -.012 & -.017 & -.061 & .003 & -.045 & -.041 & .001 & .052 & .010 \\
\hline & AREG & .060 & -.032 & -.012 & 1.000 & -.003 & -.011 & .121 & .019 & -.014 & -.010 & .003 & .039 \\
\hline & ABON & -.004 & -.045 & -.017 & -.003 & 1.000 & -.016 & .061 & -.034 & -.019 & -.005 & -.014 & -.015 \\
\hline & AOTR & .105 & -.161 & -.061 & -.011 & -.016 & 1.000 & .095 & .029 & .046 & .043 & -.014 & -.032 \\
\hline & SEGM & .216 & -.057 & .003 & .121 & .061 & .095 & 1.000 & .102 & .043 & -.003 & .005 & -.009 \\
\hline & FRECC & -.238 & -.003 & -.045 & .019 & -.034 & .029 & .102 & 1.000 & -.001 & .007 & -.002 & .076 \\
\hline & DIAL & .060 & .033 & -.041 & -.014 & -.019 & .046 & .043 & -.001 & 1.000 & -.135 & -.133 & -.109 \\
\hline & DIAM & -.025 & -.123 & .001 & -.010 & -.005 & .043 & -.003 & .007 & -.135 & 1.000 & -.219 & -.179 \\
\hline & DIAV & -.035 & -.042 & .052 & .003 & -.014 & -.014 & .005 & -.002 & -.133 & -.219 & 1.000 & -.177 \\
\hline & DIAS & -.038 & -.030 & .010 & .039 & -.015 & -.032 & -.009 & .076 & -.109 & -.179 & -.177 & 1.000 \\
\hline & MASCC & -.033 & -.042 & -.065 & .008 & .010 & .014 & .019 & .059 & -.025 & .029 & .015 & -.032 \\
\hline & DISTC & -.270 & .197 & -.075 & .004 & .010 & -.006 & -.091 & -.184 & .055 & -.023 & .035 & -.171 \\
\hline & INDIC & .196 & -.225 & .065 & .006 & .010 & .038 & .111 & .241 & -.038 & .036 & -.033 & .140 \\
\hline & AVERC & .020 & .054 & -.041 & -.003 & -.023 & .056 & .013 & -.105 & .010 & -.014 & -.038 & -.034 \\
\hline & ALONC & -.028 & .069 & -.021 & -.010 & -.013 & -.147 & -.033 & .058 & .018 & .000 & .005 & .095 \\
\hline & ALONC_MASCC & -.064 & .004 & -.034 & -.007 & .005 & .006 & .021 & .004 & -.028 & .017 & .000 & .003 \\
\hline & ATEM_DISTC & -.048 & .046 & -.267 & .003 & .005 & .016 & -.001 & -.054 & .018 & .030 & -.014 & -.054 \\
\hline & ADES_MASCC & -.046 & -.057 & .010 & .002 & .003 & .009 & -.037 & -.024 & .000 & .002 & .031 & -.042 \\
\hline & SEGM_INDIC & .052 & -.007 & .009 & .135 & -.031 & -.013 & .569 & .087 & -.049 & .012 & .032 & .020 \\
\hline & SEGM_AVERC & -.048 & -.024 & .015 & -.046 & -.009 & -.042 & .066 & -.042 & -.017 & .006 & -.027 & -.025 \\
\hline & FRECC_INDIC & .035 & -.036 & .019 & .029 & -.020 & -.017 & .043 & .158 & -.005 & .020 & -.015 & -.002 \\
\hline
\end{tabular}

Tabla 63 - Correlación entre variables independientes en la etapa de atención del modelo que incluye sólo las variables significativas - Parte 1 


\begin{tabular}{|c|c|c|c|c|c|c|c|c|c|c|c|c|}
\hline & & $\frac{0}{0}$ & $\stackrel{U}{\mathscr{n}}$ & 㐋 & 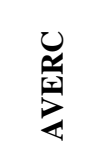 & \begin{tabular}{l}
0 \\
$Z$ \\
0 \\
\multirow{2}{*}{}
\end{tabular} & 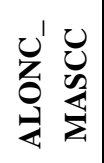 & $\sum_{i}^{\sum_{i}^{\prime}}$ & 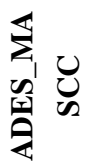 & 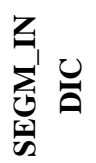 & 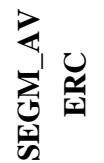 & ِّ \\
\hline & LNOR & \begin{tabular}{|l|}
-.033 \\
\end{tabular} & -.270 & .196 & .020 & -.028 & \begin{tabular}{|c|}
-.064 \\
\end{tabular} & \begin{tabular}{|c|}
-.048 \\
\end{tabular} & -.046 & .052 & \begin{tabular}{|c|}
-.048 \\
\end{tabular} & .035 \\
\hline Pears & ADES & -.042 & .197 & -.225 & .054 & .069 & .004 & .046 & -.057 & -.007 & -.024 & -.036 \\
\hline & ATEM & -.065 & -.075 & .065 & -.041 & -.021 & -.034 & -.267 & .010 & .009 & .015 & .019 \\
\hline & AREG & .008 & .004 & .006 & -.003 & -.010 & $\begin{array}{l}-007 \\
\end{array}$ & .003 & .002 & .135 & $\begin{array}{l}-.046 \\
\end{array}$ & .029 \\
\hline & ABON & .010 & .010 & .010 & -.023 & -.013 & .005 & .005 & .003 & $\begin{array}{l}.031 \\
\end{array}$ & -.009 & -.020 \\
\hline & AOTR & .014 & -.006 & .038 & .056 & -.147 & .006 & .016 & .009 & -.013 & -.042 & -.017 \\
\hline & SEGM & .019 & -.091 & .111 & .013 & -.033 & .021 & -.001 & $\begin{array}{l}-.037 \\
\end{array}$ & .569 & .066 & .043 \\
\hline & FRECC & .059 & $\begin{array}{l}-184 \\
-.184\end{array}$ & .241 & $\begin{array}{l}.105 \\
\end{array}$ & .058 & .004 & $\begin{array}{l}-.054 \\
\end{array}$ & -.024 & .087 & $\begin{array}{l}-.042 \\
\end{array}$ & .158 \\
\hline & DIAL & -.025 & .055 & -.038 & .010 & .018 & -.028 & .018 & .000 & -.049 & -.017 & -.005 \\
\hline & DIAM & .029 & -.023 & .036 & -.014 & .000 & .017 & .030 & .002 & .012 & .006 & .020 \\
\hline & DIAV & .015 & .035 & $\begin{array}{l}.033 \\
\end{array}$ & $\begin{array}{l}.038 \\
\end{array}$ & .005 & .000 & -.014 & .031 & .032 & -.027 & -.015 \\
\hline & DIAS & -.032 & -.171 & .140 & -.034 & .095 & .003 & -.054 & -.042 & .020 & -.025 & -.002 \\
\hline & MASCC & 1.000 & -047 & .190 & .214 & -.028 & .128 & .056 & .514 & .022 & .040 & .070 \\
\hline & DISTC & -.047 & 1.000 & -.723 & .226 & -.103 & .072 & .266 & .022 & -.133 & .065 & -.077 \\
\hline & INDIC & .190 & -.723 & 1.000 & -.068 & .113 & $\begin{array}{l}-.038 \\
\end{array}$ & -.210 & .109 & .190 & -.027 & .071 \\
\hline & AVERC & .214 & .226 & $\begin{array}{l}.068 \\
-.06\end{array}$ & 1.000 & -.001 & .087 & .106 & .132 & \begin{tabular}{|l|}
-.027 \\
\end{tabular} & .187 & -.153 \\
\hline & ALONC & -.028 & -.103 & .113 & -.001 & 1.000 & .035 & -.062 & -.013 & .011 & -.020 & .022 \\
\hline & ALONC_MASCC & .128 & .072 & -.038 & .087 & .035 & 1.000 & .091 & .109 & .000 & .024 & -.010 \\
\hline & ATEM_DISTC & .056 & .266 & -.210 & .106 & -.062 & .091 & 1.000 & -.003 & -.025 & .027 & .021 \\
\hline & ADES_MASCC & .514 & .022 & .109 & .132 & -.013 & .109 & -.003 & 1.000 & -.032 & .067 & .000 \\
\hline & SEGM_INDIC & .022 & -.133 & .190 & -.027 & .011 & .000 & -.025 & -.032 & 1.000 & -.146 & .095 \\
\hline & SEGM_AVERC & .040 & .065 & -.027 & .187 & -.020 & .024 & .027 & .067 & -.146 & 1.000 & -.072 \\
\hline & FRECC_INDIC & .070 & -.077 & .071 & -.153 & .022 & -.010 & .021 & .000 & .095 & $\begin{array}{l}.072 \\
\end{array}$ & 1.000 \\
\hline
\end{tabular}

Tabla 64 - Correlación entre variables independientes en la etapa de atención del modelo que incluye sólo las variables significativas - Parte 2

\subsection{Estudio de la etapa de interés}

\subsection{Efectividad de clic}

En este segundo caso, y tal y como muestra la tabla 65, los valores del VIF también permiten descartar problemas de colinealidad, puesto que todos se encuentran por debajo de 3, si bien es relevante mencionar la existencia de una correlación elevada y significativa entre la longitud del correo y el número de imágenes $(r=0.781)$, hecho razonable puesto que ambas variables están relacionadas con la complejidad del correo. Así, a mayor número de imágenes, existe más texto que las acompañe y explique, y a la inversa. Pese a que el valor de esta correlación resulta elevado, el VIF y las comprobaciones posteriores que se han realizado permiten asumir los resultados como válidos. La tabla 66 presenta los coeficientes de Pearson para esta etapa.

\begin{tabular}{|l|c|}
\hline \multicolumn{1}{|c|}{ Variable } & VIF \\
\hline ELONC & 2.838 \\
\hline
\end{tabular}




\begin{tabular}{|l|l|}
\hline EIMAC & 2.732 \\
\hline EESC & 1.193 \\
\hline DISTC & 1.734 \\
\hline MASCC & 1.093 \\
\hline EIMAC_MASCC & 1.051 \\
\hline EESC_DISTC & 1.681 \\
\hline
\end{tabular}

Tabla 65 - VIF de las variables en la etapa de interés - submuestra efectividad de clic del modelo que incluye sólo las variables significativas

\begin{tabular}{|c|c|c|c|c|c|c|c|c|c|}
\hline & & 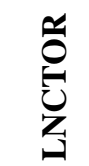 & 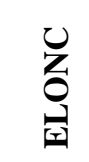 & 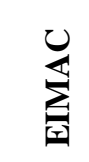 & 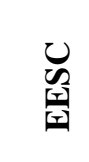 & $\frac{U}{0}$ & U & 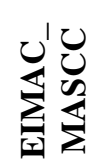 & 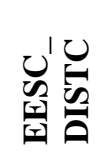 \\
\hline Corr. & LNCTOR & 1.000 & -.323 & -.213 & .175 & .042 & .007 & -.067 & .130 \\
\hline Pearson & ELONC & -.323 & 1.000 & .781 & -.368 & -.105 & .174 & .040 & -.124 \\
\hline & EIMAC & -.213 & .781 & 1.000 & -.359 & .020 & .059 & .060 & -.076 \\
\hline & EESC & .175 & -.368 & -.359 & 1.000 & .020 & .032 & .038 & .020 \\
\hline & DISTC & .042 & -105 & .020 & .020 & 1.000 & -.095 & -.102 & .629 \\
\hline & MASCC & .007 & .174 & .059 & .032 & -.095 & 1.000 & -.153 & -.077 \\
\hline & $\begin{array}{l}\text { EIMAC_- } \\
\text { MASCC }\end{array}$ & -.067 & .040 & .060 & .038 & -.102 & -.153 & 1.000 & -.066 \\
\hline & $\begin{array}{l}\text { EESC__ } \\
\text { DISTC }\end{array}$ & .130 & -1.124 & -.076 & .020 & .629 & -.077 & -.066 & 1.000 \\
\hline
\end{tabular}

Tabla 66 - Correlación entre variables independientes en la etapa de interés - submuestra efectividad de clic del modelo que incluye sólo las variables significativas

\subsection{Efectividad de retención de suscriptores}

En esta segunda muestra de la etapa de interés, y dado el limitado número de variables que han resultado significativas para esta etapa del modelo, resulta fácil comprobar la existencia de ausencia de multicolinealidad, tanto a través del VIF de la tabla 67 como de los coeficientes de correlación de Pearson en la tabla 68.

\begin{tabular}{|l|c|}
\hline \multicolumn{1}{|c|}{ Variable } & VIF \\
\hline PERS & 1.002 \\
\hline FRECC & 1.002 \\
\hline
\end{tabular}

Tabla 67 - VIF de las variables en la etapa de interés - submuestra efectividad de retención de suscriptores del modelo que incluye sólo las variables significativas

\begin{tabular}{|l|l|c|c|c|}
\hline & & LNUR & PERS & FRECC \\
\hline \multirow{2}{*}{$\begin{array}{l}\text { Correlación } \\
\text { Pearson }\end{array}$} & LNUR & $\mathbf{1 . 0 0 0}$ & $\mathbf{- . 0 6 2}$ & $\mathbf{- . 1 2 3}$ \\
\cline { 2 - 5 } & PERS & $\mathbf{- . 0 6 2}$ & $\mathbf{1 . 0 0 0}$ & $\mathbf{. 0 4 2}$ \\
\cline { 2 - 5 } & FRECC & $\mathbf{- . 1 2 3}$ & $\mathbf{. 0 4 2}$ & $\mathbf{1 . 0 0 0}$ \\
\hline
\end{tabular}

Tabla 68 - Correlación entre variables independientes en la etapa de interés - submuestra efectividad de retención de suscriptores del modelo que incluye sólo las variables significativas 


\subsection{Estudio de la etapa de acción}

Finalmente, en el caso de la etapa de acción los valores del VIF también resultan cercanos a 1, siendo el máximo 1.553 (tabla 69), lo que permite descartar problemas de multicolinealidad. En este apartado de nuevo sólo se incluyen los resultados de las variables que resultan representativas. La matriz de correlaciones presentada en la tabla 70 es consistente con este resultado, puesto que sólo existen indicios de correlación entre la variable moderadora y el factor de interacción.

\begin{tabular}{|l|c|c|}
\hline \multirow{2}{*}{ Variable } & \multicolumn{2}{c|}{$\begin{array}{c}\text { Estadísticas de } \\
\text { Colinealidad }\end{array}$} \\
\cline { 2 - 3 } & Tolerancia & VIF \\
\hline (Constante) & & \\
\hline EINC & .946 & 1.057 \\
\hline EESC & .943 & 1.060 \\
\hline SEGM & .997 & 1.003 \\
\hline (Constante) & & \\
\hline EINC & .946 & 1.057 \\
\hline EESC & .943 & 1.060 \\
\hline SEGM & .987 & 1.013 \\
\hline ORIEC & .644 & 1.553 \\
\hline EESC_ORIEC & .649 & 1.540 \\
\hline
\end{tabular}

Tabla 69 - VIF de las variables en la etapa de acción del modelo que incluye sólo las variables significativas

\begin{tabular}{|l|l|c|c|c|c|c|c|}
\hline \multicolumn{2}{|c|}{} & LNCR & EINC & EESC & SEGM & ORIEC & EESC_ORIE \\
\hline \multirow{3}{*}{$\begin{array}{l}\text { Correlación } \\
\text { de Pearson }\end{array}$} & LNCR & $\mathbf{1 . 0 0 0}$ & $\mathbf{. 1 6 1}$ & $\mathbf{. 1 1 8}$ & $\mathbf{. 1 0 7}$ & $\mathbf{. 0 4 8}$ & $\mathbf{. 0 8 8}$ \\
\cline { 2 - 8 } & EINC & $\mathbf{. 1 6 1}$ & $\mathbf{1 . 0 0 0}$ & $\mathbf{. 2 3 1}$ & -.004 & -.025 & -.013 \\
\cline { 2 - 8 } & EESC & $\mathbf{. 1 1 8}$ & $\mathbf{. 2 3 1}$ & $\mathbf{1 . 0 0 0}$ & $\mathbf{- . 0 5 6}$ & .008 & .008 \\
\cline { 2 - 8 } & SEGM & $\mathbf{. 1 0 7}$ & -.004 & -.056 & $\mathbf{1 . 0 0 0}$ & $\mathbf{. 0 9 7}$ & $\mathbf{. 0 4 1}$ \\
\cline { 2 - 8 } & ORIEC & $\mathbf{. 0 4 8}$ & -.025 & .008 & $\mathbf{. 0 9 7}$ & $\mathbf{1 . 0 0 0}$ & $\mathbf{. 5 9 2}$ \\
\cline { 2 - 8 } & EESC_ORIEC & $\mathbf{. 0 8 8}$ & -.013 & .008 & $\mathbf{. 0 4 1}$ & $\mathbf{. 5 9 2}$ & $\mathbf{1 . 0 0 0}$ \\
\hline
\end{tabular}

Tabla 70 - Correlación entre variables independientes en la etapa de acción del modelo que incluye sólo las variables significativas

\subsubsection{Análisis de residuos, valores extremos y casos influyentes}

A lo largo de este apartado, se verificará para todas las muestras el cumplimiento de algunos de los requisitos de la técnica de regresión múltiple por mínimos cuadrados ordinarios: ausencia de autocorrelación de residuos, normalidad de residuos, linealidad del modelo y ausencia de heterocedasticidad. Posteriormente, se realizará un análisis de aquellos casos extremos y con excesiva influencia en el modelo para tratar de detectar si existe algún tipo de singularidad que explique su presencia, y tratar de justificar la conveniencia de mantenerlos o excluirlos del modelo final. 


\subsection{Estudio de la etapa de atención}

En esta primera etapa, el valor de la estadística de Durbin-Watson es de 1.241, hecho que permite descartar la presencia de autocorrelación de residuos, al estar este valor dentro del rango situado entre los valores críticos 1 y 3 . El análisis de casos significativos ha detectado 226 valores -el 5.04\% de la muestra- con un residuo estandarizado no situado en el rango de dos desviaciones estándar alrededor de la media, y 83 casos -el $1.86 \%$ de la muestra- fuera del rango de tres desviaciones estándar. Estos valores, junto con la gráfica P-P y el histograma presentado en la figura 24 permiten asumir la normalidad de los residuos.
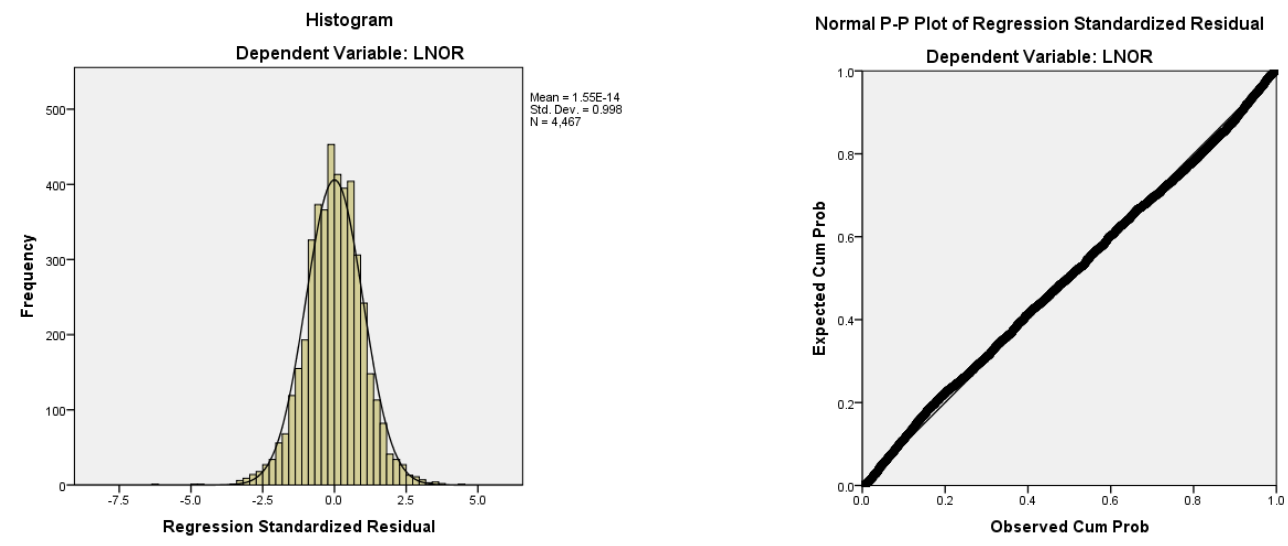

Figura 24 - Histograma y curva P-P de residuos estandarizados en la etapa de atención del modelo que incluye sólo las variables significativas

En cuanto a la linealidad y homocedasticidad, se asumen dichos requisitos como cumplidos a la vista de la figura 25 , dado que no existen una distribución con forma curva o de embudo y la línea no paramétrica de ajuste de los puntos no adopta forma curva.

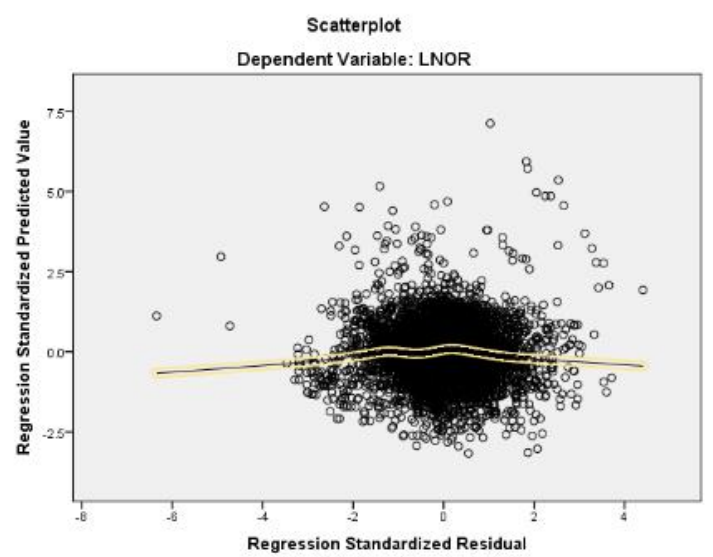

Figura 25 - Relación entre valores predichos estandarizados y residuos estandarizados en la etapa de atención del modelo que incluye sólo las variables significativas 
En el análisis de residuos se han encontrado 84 entradas situadas a más de tres desviaciones múltiples de la media, siendo este el valor crítico definido en los anteriores párrafos que señala la necesidad de un análisis detallado. Una revisión individualizada de estos registros permite descartar errores en la codificación, y una evaluación simultánea de los mismos permite observar que se trata en la mayoría de casos de envíos con tasas de apertura muy por encima de la media -en algunos casos, causadas por una segmentación muy precisa o una temática que ha resultado particularmente exitosa- o muy por debajo de la media. En el análisis conjunto de registros con el objetivo de encontrar un patrón concreto, destaca la concentración de casos en dos países concretos -41 de las 84 entradas-, hecho que puede obedecer a una particular baja calidad de la base de datos en estas dos naciones. Sin embargo, dada la presencia de residuos razonables en una significativa mayoría de registros del total de correos enviados en estos dos países, el hecho de la distancia de Cook para todos los casos de la muestra -incluidos estos- es inferior a 1 y el hecho de que la única potencial variable explicativa -el país de envío- ya se ha incorporado al modelo a través de las dimensiones de Hofstede, se ha decidido mantener todos los registros en la muestra y asumir que esta variabilidad es razonable para una distribución normal.

\subsection{Estudio de la etapa de interés}

\subsection{Submuestra efectividad de clic}

En esta segunda submuestra, el coeficiente de Durbin-Watson tiene un valor de 1.445, lo que permite también descartar autocorrelación de residuos. Existen casos 70 casos -el $4.17 \%$ de la muestra-, con un residuo estandarizado superior a 1.96 y 23 casos -el $1.37 \%$ de la muestra- con un residuo estandarizado superior a 2.58 , hecho indicador de razonable normalidad de residuos, y que asociado a las gráficas P-P e histograma de la figura 26 confirman el cumplimiento de este requisito.
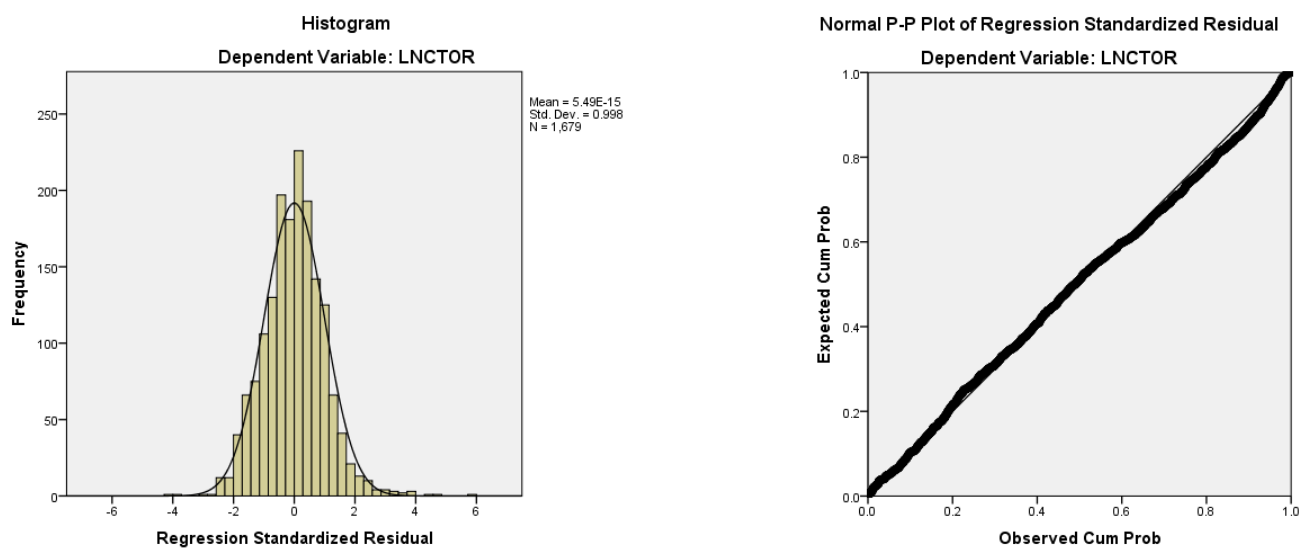

Figura 26 - Histograma y curva P-P de residuos estandarizados en la etapa de interés - submuestra efectividad de clic del modelo que incluye sólo las variables significativas 
Los requisitos de homocedasticidad y linealidad también se pueden considerar cumplidos a la vista del gráfico de la figura 27 que relaciona valores predichos estandarizados con residuos estandarizados, dada la ausencia de formas de embudo y curvilíneas.

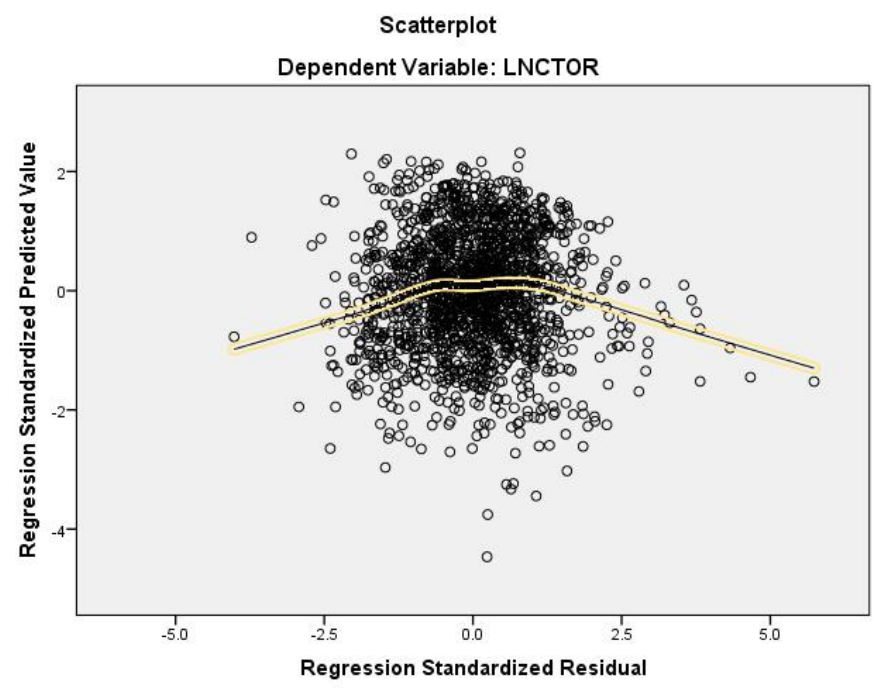

Figura 27 - Relación entre valores predichos estandarizados y residuos estandarizados en la etapa de interés - submuestra efectividad de clic del modelo que incluye sólo las variables significativas

La distancia de Cook para todos los casos del modelo no ha sido superior a 1, lo que permite descartar la existencia de casos con excesiva influencia. El análisis de casos extremos en el modelo se ha desarrollado en aquellos con residuos superiores a tres desviaciones estándar. Se han descartado errores de codificación en todos ellos, y su análisis conjunto permite detectar que 19 de los 23 casos de estas características obedecen a promociones concentradas a lo largo de un mes particular en varios países que obtuvieron resultados significativamente por encima de la media. Análogamente al caso anterior, se procede a mantener todos los registros en el modelo y se considera que la variabilidad observada entra dentro de la normalidad.

\subsection{Submuestra efectividad de retención de suscriptores}

En esta submuestra también es posible descartar la existencia de autocorrelación de primer orden entre residuos dado que el valor del coeficiente de Durbin-Watson es 1.773. Existen 205 casos -el 4.59\%- con un residuo estandarizado con valor absoluto superior a dos desviaciones estándar, y 108 casos -el 2.42\%- en los que dicho valor absoluto es superior a tres desviaciones estándar. Este último dato se aleja ligeramente de las expectativas de normalidad -sólo el $1 \%$ de los casos debería situarse en este rango. Sin embargo, el análisis del histograma y gráfico P-P de la figura 28 permite confirmar la existencia de normalidad de residuos, con lo que en principio se descarta la existencia de problemas con este requisito. 

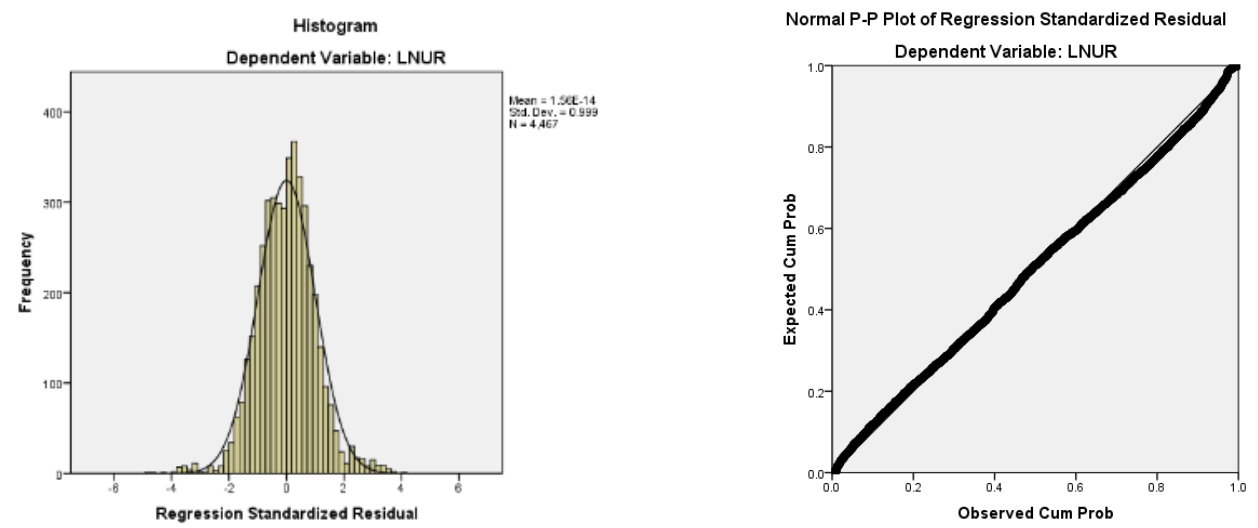

Figura 28 - Histograma y curva P-P de residuos estandarizados en la etapa de interés - submuestra efectividad de retención de suscriptores del modelo que incluye sólo las variables significativas

La observación del gráfico valores predichos estandarizados versus residuos estandarizados permite descartar problemas de heterocedasticidad y linealidad, si bien es necesario destacar la existencia de varios puntos alineados en una recta en su zona izquierda, que corresponden a aquellos registros cuya tasa de retención de suscriptores es cero, y que a través de la transformación $\ln (x+c)$ detallada en el apartado 7.2.1 han adquirido un valor constante. Pese a que su forma, mostrada en la figura 29, apunta a ligeros indicios de heterocedasticidad, dado su limitado número y la normalidad de los otros puntos, se descarta el incumplimiento de este requisito.

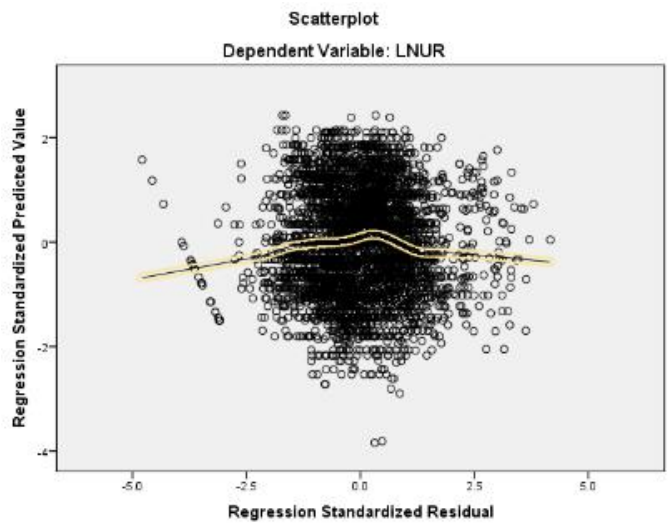

Figura 29 - Relación entre valores predichos estandarizados y residuos estandarizados en la etapa de interés - submuestra efectividad de retención de suscriptores del modelo que incluye sólo las variables significativas

En el análisis de casos con excesiva influencia, cabe destacar la ausencia de casos con una distancia de Cook superior a 1, lo que permite descartar a priori este tipo de problemas. El análisis individual de los casos cuyo residuo estandarizado es superior a tres permite descartar problemas de codificación. Su análisis conjunto permite identificar dos patrones significativos. Por un lado, aparecen los 34 casos identificados en el 7.2.1 debido a que su valor para la variable UR es 0 , y cuyo mantenimiento en el modelo ya se justificó en dicho apartado. Por otro lado, otro patrón que agrupa a un 
gran número de valores elevados -el 52\% de todos ellos- es su ocurrencia a lo largo de mayo, si bien no resulta posible encontrar una explicación razonable para este hecho. A la vista de que la media de la distancia de Cook de este $52 \%$ de casos resulta inferior que la del $48 \%$ de casos no situados en dicho mes, se puede concluir que este hecho no identifica casos con influencia superior a aquellos repartidos a lo largo de todo el período, con lo que se ha optado por mantener todos los casos en el modelo a falta de una explicación que permita justificar su eliminación.

\subsection{Estudio de la etapa de acción}

En primer lugar, se comprueba que el coeficiente de Durbin-Watson tiene un valor de 1.391, lo que de acuerdo con los criterios fijados en anteriores apartados, permite descartar autocorrelación de residuos. El análisis de casos proporciona 85 entradas con un residuo estandarizado superior a 2 , que suponen un $5.06 \%$ de los casos, valor ajustado a la distribución normal (5\%). Existen 27 casos con residuo estandarizado superior a 2.57 , que representa el $1.61 \%$ de la muestra, valor algo menos ajustado a la distribución normal (1\%), pero aun así aceptable.

El histograma y la gráfica P-P de la figura 30 también proporcionan indicios de la relativa normalidad de la distribución de residuos, si bien es posible detectar una ligera asimetría positiva que se traduce en una separación de la media de la curva P-P en sus valores medios. A la vista de que sólo situaciones muy evidentes han de ser tenidas en cuenta en muestras grandes (Field, 2013; Keith, 2015), se asume que la hipótesis de normalidad de errores se cumple.
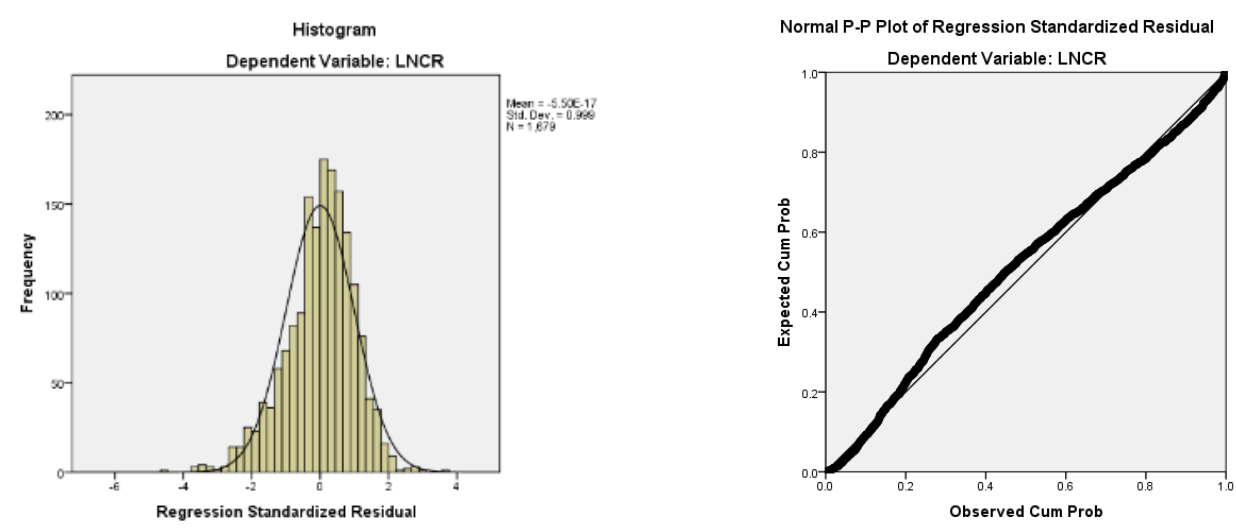

Figura 30 - Histograma y curva P-P de residuos estandarizados en la etapa de acción del modelo que incluye sólo las variables significativas

En cuanto a la linealidad y homocedasticidad, el gráfico de la figura 31 que relaciona valores predichos estandarizados con residuos estandarizados presenta una distribución razonablemente aleatoria, sin muestras de curvatura o formas de embudo, y la línea no paramétrica ajustada al mismo cumple las condiciones descritas en apartados anteriores, lo que permite establecer que ambos requisitos se cumplen. 


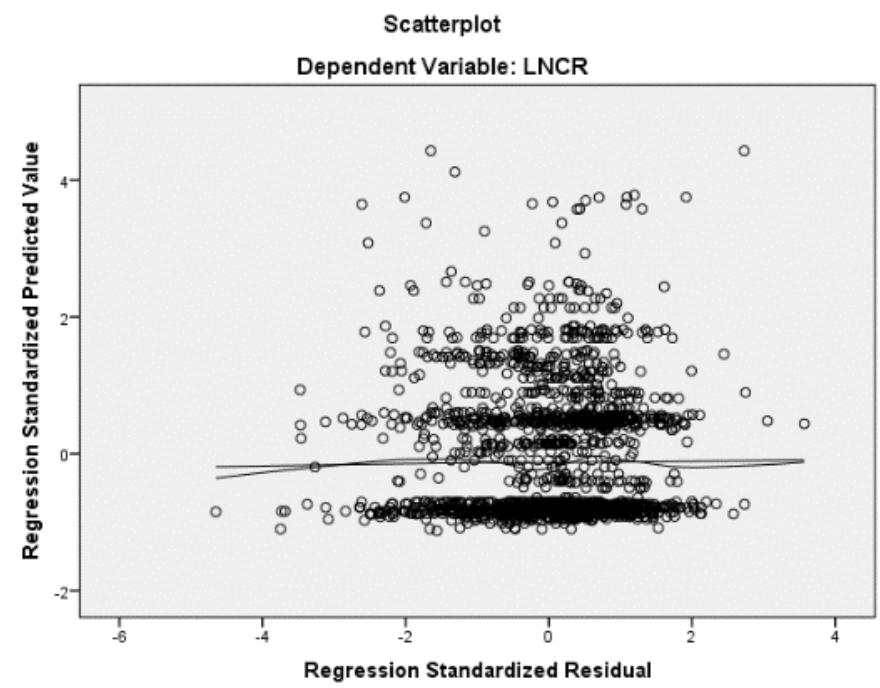

Figura 31 - Relación entre valores predichos estandarizados y residuos estandarizados en la etapa de acción del modelo que incluye sólo las variables significativas

Finalmente, se procede a la evaluación de casos con excesiva influencia y valores extremos, utilizando como base aquellos casos cuyos residuos son superiores a tres desviaciones estándar. Como primer indicio positivo, se puede mencionar que la distancia de Cook no es superior en ninguno de ellos al valor de referencia 1 -de hecho, no es superior a este valor para ningún caso de la muestra. Se han revisado individualmente estas 27 entradas para determinar si existe algún error de codificación, descartándose esta situación en todos los casos. Un análisis conjunto no ha permitido inferir ningún tipo de parámetro particular que permita agruparlos, más allá de la presencia de múltiples envíos con valores de CR muy por encima o muy por debajo de la media. De este modo, se procede a mantener todos los registros en la muestra

\subsubsection{Análisis de pendientes simples para variables de interacción}

\subsection{Estudio de etapa de atención}

A continuación, se procede a analizar los efectos de moderación detectados en el análisis de regresión múltiple para la primera etapa del modelo. Tal y como se aprecia en el resumen de coeficientes para el modelo final, existen seis interacciones en la muestra: ALONC_MASCC, ATEM_DISTC, ADES_MASCC, SEGM_INDIC, SEGM_AVERC y FRECC_INDIC. Se procederá a aplicar el procedimiento de Johnson-Neyman a cada una de las variables independientes con una sola variable moderadora, mientras que en el caso de SEGM, dado que existen dos relaciones de moderación para el mismo modelo, se procederá a realizar un estudio combinado a través de pendientes simples.

En el caso de la interacción entre longitud del asunto y masculinidad-feminidad ALONC_MASCC-, los resultados de la tabla 71 muestran que sólo existe un intervalo no significativo para los valores centrados de esta dimensión de Hofstede situados entre 
-2.21 y 15.70. A la vista de los valores dicha tabla 71 y de la figura 32, se establecerán dos zonas con comportamientos diferentes:

- Para valores muy bajos y medios-bajos en la dimensión masculinidad-feminidad, la relación entre la variable independiente y la dependiente tiene signo positivo a mayor longitud de asunto, mayor tasa de apertura- y la relación de interacción, negativo - a medida que disminuye el valor de masculinidad, el incremento de la longitud del asunto es más positivo en la tasa de apertura.

- Para valores altos de la dimensión masculinidad-feminidad, la relación entre la variable independiente y la dependiente tiene signo negativo -a mayor longitud de asunto, menos tasa de apertura-, y la relación de interacción, negativo -a medida que aumenta el valor de masculinidad, el aumento de la longitud del asunto en la efectividad de apertura es más negativo-.

A continuación, se muestran las tablas específicas del procedimiento Johnson-Neyman y su representación gráfica.

\begin{tabular}{|c|c|c|c|}
\hline $\begin{array}{c}\text { MASCC } \\
\text { (valores) }\end{array}$ & Efecto & $\mathbf{t}$ & p-valor \\
\hline-46.0645 & 0.0037 & 4.6661 & $\mathbf{0}$ \\
\hline-41.5645 & 0.0034 & 4.6476 & $\mathbf{0}$ \\
\hline-37.0645 & 0.0031 & 4.618 & $\mathbf{0}$ \\
\hline-32.5645 & 0.0027 & 4.5712 & $\mathbf{0}$ \\
\hline-28.0645 & 0.0024 & 4.4971 & $\mathbf{0}$ \\
\hline-23.5645 & 0.0021 & 4.3792 & $\mathbf{0}$ \\
\hline-19.0645 & 0.0018 & 4.1901 & $\mathbf{0}$ \\
\hline-14.5645 & 0.0014 & 3.8859 & $\mathbf{0 . 0 0 0 1}$ \\
\hline-10.0645 & 0.0011 & 3.4031 & $\mathbf{0 . 0 0 0 7}$ \\
\hline-5.5645 & 0.0008 & 2.6746 & $\mathbf{0 . 0 0 7 5}$ \\
\hline-2.2186 & 0.0006 & 1.9605 & $\mathbf{0 . 0 5}$ \\
\hline-1.0645 & 0.0005 & 1.6856 & 0.0919 \\
\hline 3.4355 & 0.0002 & 0.5458 & 0.5853 \\
\hline 7.9355 & -0.0002 & -0.5467 & 0.5846 \\
\hline 12.4355 & -0.0005 & -1.4467 & 0.1481 \\
\hline 15.7098 & -0.0007 & -1.9605 & $\mathbf{0 . 0 5}$ \\
\hline 16.9355 & -0.0008 & -2.1247 & $\mathbf{0 . 0 3 3 7}$ \\
\hline 21.4355 & -0.0011 & -2.6177 & $\mathbf{0 . 0 0 8 9}$ \\
\hline 25.9355 & -0.0015 & -2.9753 & $\mathbf{0 . 0 0 2 9}$ \\
\hline 30.4355 & -0.0018 & -3.2383 & $\mathbf{0 . 0 0 1 2}$ \\
\hline 34.9355 & -0.0021 & -3.4357 & $\mathbf{0 . 0 0 0 6}$ \\
\hline 39.4355 & -0.0024 & -3.5871 & $\mathbf{0 . 0 0 0 3}$ \\
\hline 43.9355 & -0.0028 & -3.7056 & $\mathbf{0 . 0 0 0 2}$ \\
\hline & & & \\
\hline
\end{tabular}

Tabla 71 - Relación de pendientes simples para la interacción ALONC_MASCC en la etapa de atención del modelo que incluye sólo las variables significativas - Procedimiento de Johnson-Neyman 


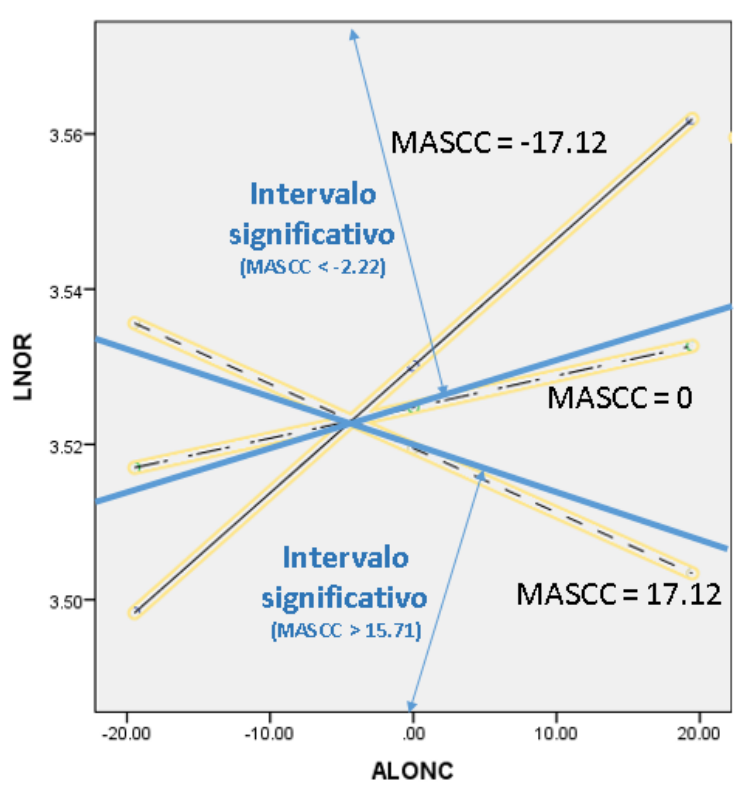

Figura 32 - Representación gráfica de la interacción ALONC_MASCC en la etapa de atención del modelo que incluye sólo las variables significativas

En cuanto a la interacción entre promociones de temporada y distancia al poder ATEM_DISTC-, se aprecia en la tabla 72 y figura 33 que esta interacción, significativa para valores medios y altos de DISTC, tiene carácter positivo -a mayor aumento de la distancia al poder, mayor incremento de la efectividad de apertura causado por la presencia de promociones de temporada. Esta relación se aprecia en el hecho de que a medida que aumenta DISTC, mayor es la distancia entre las líneas que señalan los valores 0 y 1 de ATEM de la gráfica inferior.

\begin{tabular}{|c|c|c|c|}
\hline $\begin{array}{c}\text { DISTC } \\
\text { (valores) }\end{array}$ & Efecto & $\mathbf{t}$ & p-valor \\
\hline-47.3638 & -0.0181 & -0.3978 & 0.6908 \\
\hline-42.7138 & -0.009 & -0.2149 & 0.8298 \\
\hline-38.0638 & 0.0002 & 0.0057 & 0.9955 \\
\hline-33.4138 & 0.0094 & 0.2732 & 0.7847 \\
\hline-28.7638 & 0.0185 & 0.5982 & 0.5497 \\
\hline-24.1138 & 0.0277 & 0.9896 & 0.3224 \\
\hline-19.4638 & 0.0369 & 1.4491 & 0.1474 \\
\hline-14.8138 & 0.046 & 1.9603 & $\mathbf{0 . 0 5}$ \\
\hline-14.8122 & 0.046 & 1.9605 & $\mathbf{0 . 0 5}$ \\
\hline-10.1638 & 0.0552 & 2.4785 & $\mathbf{0 . 0 1 3 2}$ \\
\hline-5.5138 & 0.0644 & 2.9347 & $\mathbf{0 . 0 0 3 4}$ \\
\hline-0.8638 & 0.0735 & 3.2671 & $\mathbf{0 . 0 0 1 1}$ \\
\hline 3.7862 & 0.0827 & 3.4561 & $\mathbf{0 . 0 0 0 6}$ \\
\hline 8.4362 & 0.0919 & 3.5253 & $\mathbf{0 . 0 0 0 4}$ \\
\hline 13.0862 & 0.101 & 3.5153 & $\mathbf{0 . 0 0 0 4}$ \\
\hline 17.7362 & 0.1102 & 3.4615 & $\mathbf{0 . 0 0 0 5}$ \\
\hline
\end{tabular}




\begin{tabular}{|l|c|c|c|}
\hline 22.3862 & 0.1194 & 3.3877 & $\mathbf{0 . 0 0 0 7}$ \\
\hline 27.0362 & 0.1285 & 3.3077 & $\mathbf{0 . 0 0 0 9}$ \\
\hline 31.6862 & 0.1377 & 3.2287 & $\mathbf{0 . 0 0 1 3}$ \\
\hline 36.3362 & 0.1469 & 3.1539 & $\mathbf{0 . 0 0 1 6}$ \\
\hline 40.9862 & 0.156 & 3.0848 & $\mathbf{0 . 0 0 2}$ \\
\hline 45.6362 & 0.1652 & 3.0217 & $\mathbf{0 . 0 0 2 5}$ \\
\hline
\end{tabular}

Tabla 72 - Relación de pendientes simples para la interacción ATEM_DISTC en la etapa de atención del modelo que incluye sólo las variables significativas - Procedimiento de Johnson-Neyman

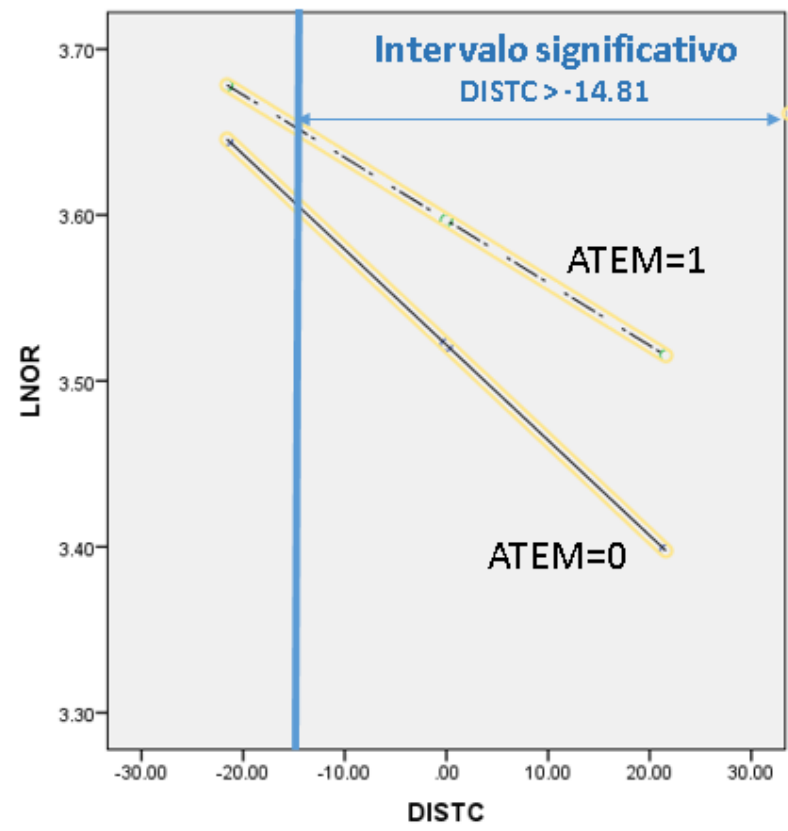

Figura 33 - Representación gráfica de la interacción ATEM_DISTC en la etapa de atención del modelo que incluye sólo las variables significativas

La relación de interacción entre MASCC y ADES resulta de carácter negativo, puesto que a medida que aumenta el valor de masculinidad, más negativo resulta el efecto de la presencia de esta temática en la efectividad de apertura. Dicha relación es sólo válida para valores medios y altos de la dimensión masculinidad-feminidad. A continuación, se presentan la tabla 73 y figura 34 con una representación gráfica que sustenta estas afirmaciones.

\begin{tabular}{|c|c|c|c|}
\hline $\begin{array}{c}\text { MASCC } \\
\text { (valores) }\end{array}$ & Efecto & $\mathbf{t}$ & p-valor \\
\hline-46.0645 & 0.0109 & 0.312 & 0.755 \\
\hline-41.5645 & 0.0001 & 0.0018 & 0.9985 \\
\hline-37.0645 & -0.0108 & -0.3724 & 0.7096 \\
\hline-32.5645 & -0.0217 & -0.8301 & 0.4065 \\
\hline-28.0645 & -0.0325 & -1.3971 & 0.1625 \\
\hline-24.4123 & -0.0413 & -1.9605 & $\mathbf{0 . 0 5}$ \\
\hline-23.5645 & -0.0434 & -2.107 & $\mathbf{0 . 0 3 5 2}$ \\
\hline
\end{tabular}




\begin{tabular}{|c|c|c|c|}
\hline-19.0645 & -0.0542 & -2.9994 & $\mathbf{0 . 0 0 2 7}$ \\
\hline-14.5645 & -0.0651 & -4.1074 & $\mathbf{0}$ \\
\hline-10.0645 & -0.0759 & -5.4192 & $\mathbf{0}$ \\
\hline-5.5645 & -0.0868 & -6.8041 & $\mathbf{0}$ \\
\hline-1.0645 & -0.0976 & -7.9692 & $\mathbf{0}$ \\
\hline 3.4355 & -0.1085 & -8.6148 & $\mathbf{0}$ \\
\hline 7.9355 & -0.1194 & -8.7007 & $\mathbf{0}$ \\
\hline 12.4355 & -0.1302 & -8.4261 & $\mathbf{0}$ \\
\hline 16.9355 & -0.1411 & -8.0058 & $\mathbf{0}$ \\
\hline 21.4355 & -0.1519 & -7.5656 & $\mathbf{0}$ \\
\hline 25.9355 & -0.1628 & -7.1587 & $\mathbf{0}$ \\
\hline 30.4355 & -0.1736 & -6.8005 & $\mathbf{0}$ \\
\hline 34.9355 & -0.1845 & -6.491 & $\mathbf{0}$ \\
\hline 39.4355 & -0.1953 & -6.2247 & $\mathbf{0}$ \\
\hline 43.9355 & -0.2062 & -5.9954 & $\mathbf{0}$ \\
\hline
\end{tabular}

Tabla 73 - Relación de pendientes simples para la interacción ADES_MASCC en la etapa de atención del modelo que incluye sólo las variables significativas - Procedimiento de Johnson-Neyman

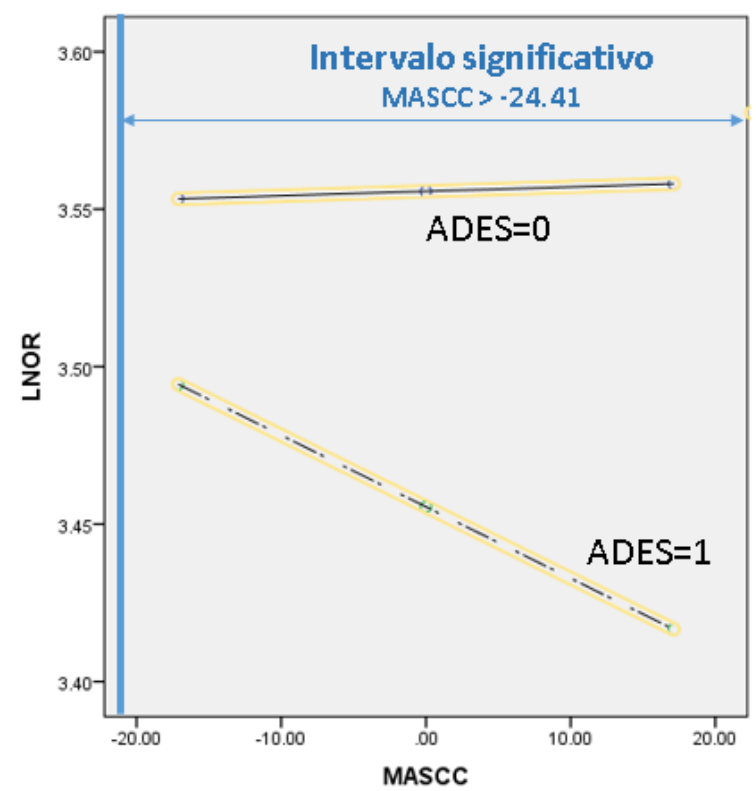

Figura 34 - Representación gráfica de la interacción ADES_MASCC en la etapa de atención del modelo que incluye sólo las variables significativas

En cuanto a las relaciones de interacción para la variable segmentación, dada la existencia de dos variables moderadoras, no resulta correcto analizarlas por separado, sino que es necesario delimitar los espacios geométricos para los que existe significación (Hayes, 2013). En esta situación, el procedimiento de Johnson-Neyman no es apropiado, por lo que no será posible delimitar con la precisión de anteriores variables la región de significación. Sin embargo, un análisis de pendientes simples 
permitirá determinar aproximadamente el área para los cuales las relaciones de moderación son válidas.

A estos efectos, la tabla 74 permite apreciar que el valor del p-valor es inferior a 0.05 para todo el rango de valores de la variable INDIC mientras el valor de AVERC se mantenga por debajo de la media (-0.4589), sin embargo, para el siguiente cuartil de AVERC (15.5411), el último punto de INDIC (29.1898) no resulta significativo. En el último punto de AVERC (26.5411), la relación ya no es significativa para los dos últimos puntos de INDIC (20.1898 y 19.1898). Esto permite representar una zona gráfica aproximada de validez de la relación de moderación como la de la figura 35. Nótese que esta zona no es precisa dado que este procedimiento no proporciona los puntos exactos en los que el p-valor alcanza el valor crítico.

El efecto de moderación causado por ambas dimensiones tiene sentido negativo: a medida que AVERC aumenta, para valores constantes de INDIC el efecto positivo de la segmentación en la efectividad de apertura es menor; asimismo, a medida que INDIC aumenta, para valores constantes de AVERC, el efecto positivo de la segmentación en la efectividad de apertura es menor.

\begin{tabular}{|c|c|c|c|c|}
\hline $\begin{array}{c}\text { AVERC } \\
\text { (valores) }\end{array}$ & $\begin{array}{c}\text { INDIC } \\
\text { (valores) }\end{array}$ & Efecto & t & p-valor \\
\hline-29.4589 & -30.8102 & 1.3677 & 8.8614 & $\mathbf{0}$ \\
\hline-29.4589 & -20.8102 & 1.2279 & 9.3388 & $\mathbf{0}$ \\
\hline-29.4589 & -2.8102 & 0.9763 & 10.2483 & $\mathbf{0}$ \\
\hline-29.4589 & 20.1898 & 0.6547 & 9.0642 & $\mathbf{0}$ \\
\hline-29.4589 & 29.1898 & 0.5289 & 6.9839 & $\mathbf{0}$ \\
\hline-13.4589 & -30.8102 & 1.21 & 8.5272 & $\mathbf{0}$ \\
\hline-13.4589 & -20.8102 & 1.0702 & 9.0948 & $\mathbf{0}$ \\
\hline-13.4589 & -2.8102 & 0.8186 & 10.5024 & $\mathbf{0}$ \\
\hline-13.4589 & 20.1898 & 0.497 & 9.4236 & $\mathbf{0}$ \\
\hline-13.4589 & 29.1898 & 0.3712 & 6.2561 & $\mathbf{0}$ \\
\hline-0.4589 & -30.8102 & 1.0819 & 7.9996 & $\mathbf{0}$ \\
\hline-0.4589 & -20.8102 & 0.9421 & 8.529 & $\mathbf{0}$ \\
\hline-0.4589 & -2.8102 & 0.6904 & 9.9789 & $\mathbf{0}$ \\
\hline-0.4589 & 20.1898 & 0.3689 & 8.3484 & $\mathbf{0}$ \\
\hline-0.4589 & 29.1898 & 0.243 & 4.5365 & $\mathbf{0}$ \\
\hline 15.5411 & -30.8102 & 0.9242 & 6.9993 & $\mathbf{0}$ \\
\hline 15.5411 & -20.8102 & 0.7843 & 7.286 & $\mathbf{0}$ \\
\hline 15.5411 & -2.8102 & 0.5327 & 7.8398 & $\mathbf{0}$ \\
\hline 15.5411 & 20.1898 & 0.2112 & 4.3589 & $\mathbf{0}$ \\
\hline 15.5411 & 29.1898 & 0.0853 & 1.4453 & 0.1484 \\
\hline 26.5411 & -30.8102 & 0.8157 & 6.1227 & $\mathbf{0}$ \\
\hline 26.5411 & -20.8102 & 0.6759 & 6.1513 & $\mathbf{0}$ \\
\hline 26.5411 & -2.8102 & 0.4243 & 5.7704 & $\mathbf{0}$ \\
\hline & & & & \\
\hline
\end{tabular}




\begin{tabular}{|l|l|l|l|l|}
\hline 26.5411 & 20.1898 & 0.1027 & 1.7305 & 0.0836 \\
\hline 26.5411 & 29.1898 & -0.0231 & -0.333 & 0.7392 \\
\hline
\end{tabular}

Tabla 74 - Relación de pendientes simples para las interacciones combinadas SEGM_AVERC y SEGM_INDIC en la etapa de atención del modelo que incluye sólo las variables significativas -

Procedimiento de pendientes simples para cuartiles

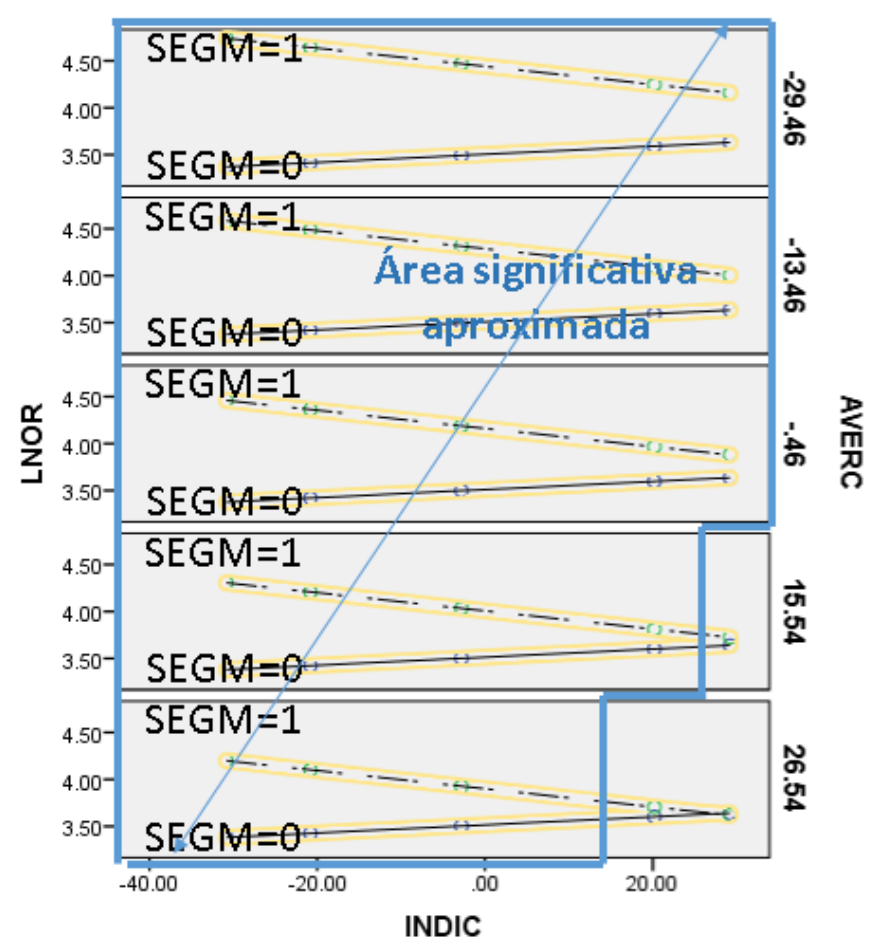

Figura 35 - Representación gráfica de las interacciones SEGM_AVERC y SEGM_INDIC en la etapa de atención del modelo que incluye sólo las variables significativas

Finalmente, la relación entre frecuencia e individualismo-colectivismo -interacción FRECC_INDIC- es de carácter positivo, puesto que a medida que aumenta el valor de esta dimensión, el efecto negativo del aumento de frecuencia en la efectividad de apertura es menos pronunciado. La ausencia de puntos de transición en el procedimiento Johnson-Neyman indica que la relación de interacción es válida para todos los valores de la variable moderadora (Hayes, 2013). A continuación, se presentan en la tabla 75 las pendientes simples para la media y los valores a una desviación estándar en los que se aprecia cómo la pendiente (la columna efecto) se convierte en menos negativa a medida que aumenta el valor de individualismo-colectivismo, efecto representado en la figura 36. 


\begin{tabular}{|c|c|c|c|}
\hline $\begin{array}{c}\text { INDIC } \\
\text { (valores) }\end{array}$ & Efecto & $\mathbf{t}$ & p-valor \\
\hline-23.4217 & -0.0979 & -18.3221 & $\mathbf{0}$ \\
\hline 0 & -0.0836 & -22.8597 & $\mathbf{0}$ \\
\hline 23.4217 & -0.0694 & -15.0303 & $\mathbf{0}$ \\
\hline
\end{tabular}

Tabla 75 - Relación de pendientes simples para la interacción FRECC_INDIC en la etapa de atención del modelo que incluye sólo las variables significativas - Procedimiento de Johnson-Neyman

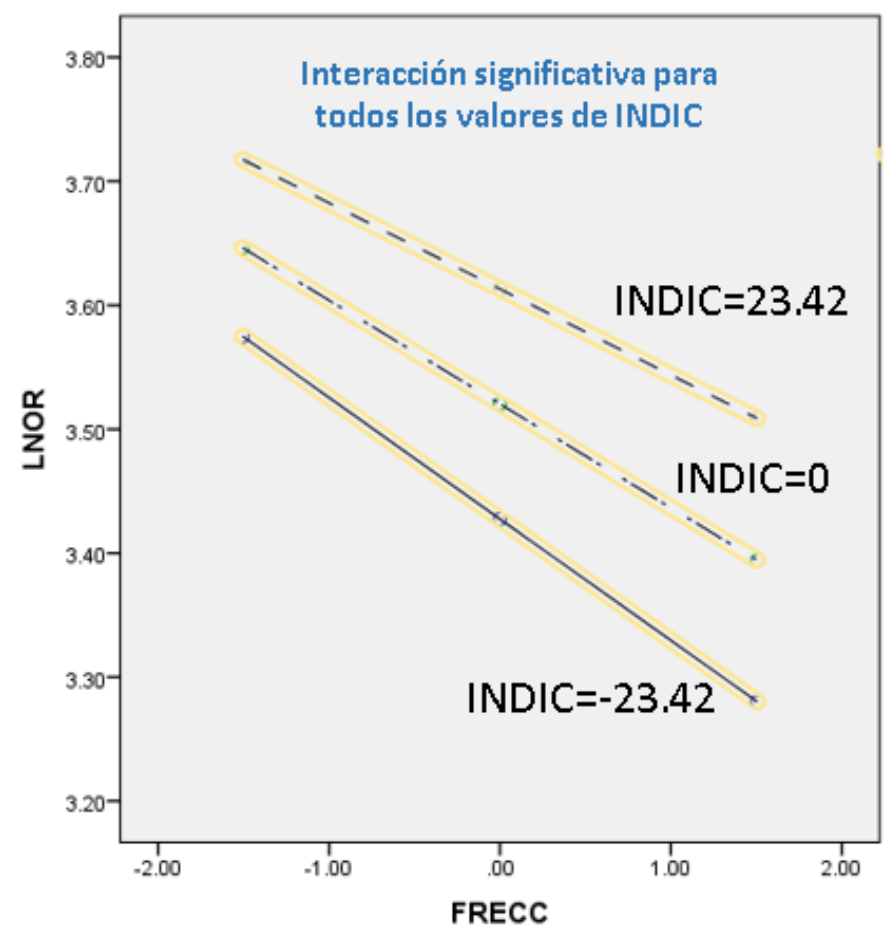

Figura 36 - Representación gráfica de la interacción FRECC_INDIC en la etapa de atención del modelo que incluye sólo las variables significativas

\subsection{Estudio de la etapa de interés}

\subsection{Submuestra efectividad de clic}

Se procederá a analizar los efectos de moderación detectados por la regresión, que en este caso se limitan a EESC_DISTC y EIMAC_MASCC. En el caso de la primera interacción, la aplicación del procedimiento de Johnson-Neyman produce valores significativos $(\mathrm{p}<0.05)$ para valores de la dimensión distancia al poder centrada superiores a -5.62 e inferiores a -29.82 en su efecto sobre los elementos que generan sensación de escasez

A la vista del análisis de pendientes de la tabla 76, existe una zona estadísticamente significativa con pendientes positivas y otra con pendientes negativas, tal y como muestra la figura 37. Así, para valores medios y elevados de la dimensión distancia al poder, a mayor distancia al poder, más se potencian los efectos positivos que tiene sobre 
la efectividad de clic la presencia de elementos que generan sensación de escasez. Sin embargo, para valores muy bajos de DISTC -inferiores a $-29.82-$, pese a que se mantiene el signo de la interacción - a mayor DISTC, más positiva es la presencia de elementos que general sensación de escasez-, el signo de la relación entre variable independiente y variable dependiente es negativo, esto es, se consigue una mayor efectividad de clic si no están presentes elementos que generan sensación de escasez.

\begin{tabular}{|c|c|c|c|}
\hline $\begin{array}{c}\text { DISTC } \\
\text { (valores) }\end{array}$ & Efecto & $\mathbf{t}$ & p-valor \\
\hline-48.5068 & -0.1596 & -3.1736 & $\mathbf{0 . 0 0 1 5}$ \\
\hline-43.8568 & -0.1373 & -2.9549 & $\mathbf{0 . 0 0 3 2}$ \\
\hline-39.2068 & -0.115 & -2.6905 & $\mathbf{0 . 0 0 7 2}$ \\
\hline-34.5568 & -0.0927 & -2.3678 & $\mathbf{0 . 0 1 8}$ \\
\hline-29.9068 & -0.0704 & -1.9705 & $\mathbf{0 . 0 4 8 9}$ \\
\hline-29.8112 & -0.0699 & -1.9614 & $\mathbf{0 . 0 5}$ \\
\hline-25.2568 & -0.0481 & -1.4786 & 0.1394 \\
\hline-20.6068 & -0.0258 & -0.8706 & 0.3841 \\
\hline-15.9568 & -0.0035 & -0.1283 & 0.8979 \\
\hline-11.3068 & 0.0188 & 0.7504 & 0.4531 \\
\hline-6.6568 & 0.0411 & 1.7341 & 0.0831 \\
\hline-5.6176 & 0.0461 & 1.9614 & $\mathbf{0 . 0 5}$ \\
\hline-2.0068 & 0.0634 & 2.7462 & $\mathbf{0 . 0 0 6 1}$ \\
\hline 2.6432 & 0.0857 & 3.6811 & $\mathbf{0 . 0 0 0 2}$ \\
\hline 7.2932 & 0.108 & 4.4506 & $\mathbf{0}$ \\
\hline 11.9432 & 0.1303 & 5.0206 & $\mathbf{0}$ \\
\hline 16.5932 & 0.1526 & 5.4083 & $\mathbf{0}$ \\
\hline 21.2432 & 0.1749 & 5.6548 & $\mathbf{0}$ \\
\hline 25.8932 & 0.1972 & 5.8026 & $\mathbf{0}$ \\
\hline 30.5432 & 0.2195 & 5.8849 & $\mathbf{0}$ \\
\hline 35.1932 & 0.2419 & 5.9252 & $\mathbf{0}$ \\
\hline 39.8432 & 0.2642 & 5.9392 & $\mathbf{0}$ \\
\hline 44.4932 & 0.2865 & 5.9368 & $\mathbf{0}$ \\
\hline & & & \\
\hline
\end{tabular}

Tabla 76 - Relación de pendientes simples para la interacción EESC_DISTC en la etapa de interés submuestra efectividad de clic del modelo que incluye sólo las variables significativas - Procedimiento de Johnson-Neyman 


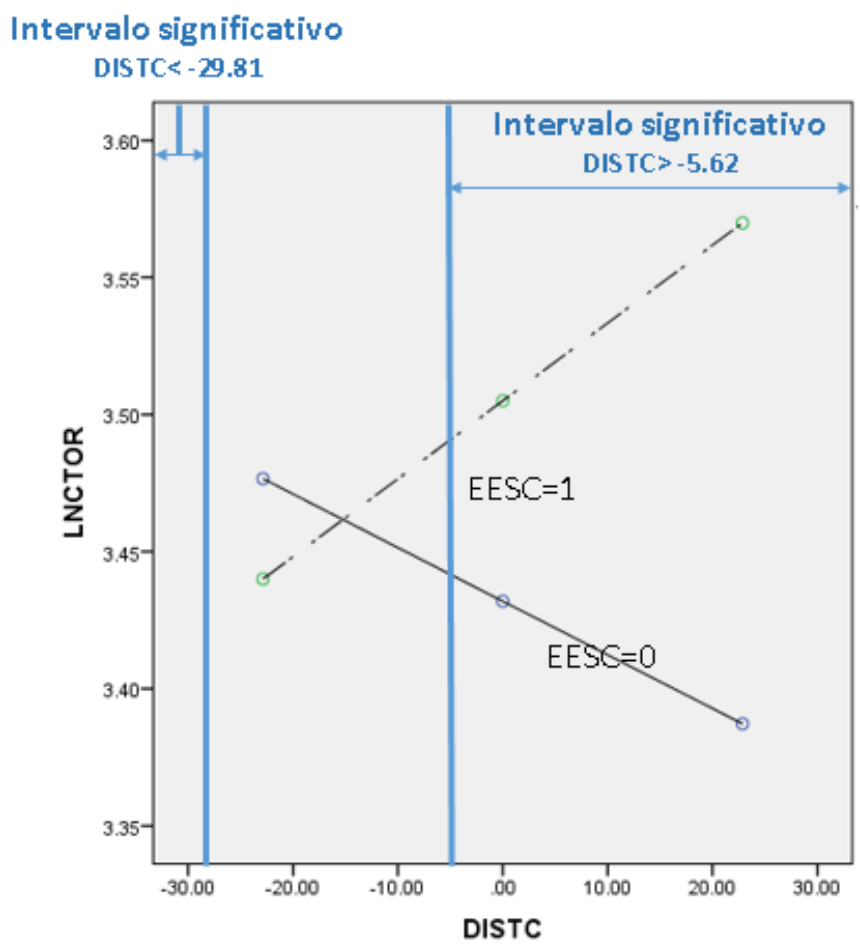

Figura 37 - Representación gráfica de la interacción EESC_DISTC en la etapa de interés - submuestra efectividad de clic del modelo que incluye sólo las variables significativas

En cuanto a la interacción entre número de imágenes y masculinidad-feminidad, el análisis obtiene efectos de moderación estadísticamente significativos para valores de MASCC inferiores a 13.14, tal y como recoge la tabla 77. A la vista de la representación de la figura 38, se puede concluir que la relación de interacción tiene un signo negativo, esto es, a menos masculinidad, más se potencian los efectos positivos que tiene sobre la efectividad de clic la inclusión de cada imagen adicional. Esto se aprecia en dicha figura en el hecho de que a medida que aumenta el valor de la dimensión moderadora, la pendiente de la recta de regresión entre la variable dependiente y la independiente se hace menos pronunciada.

\begin{tabular}{|c|c|c|c|}
\hline $\begin{array}{c}\text { MASCC } \\
\text { (valores) }\end{array}$ & Efecto & $\mathbf{t}$ & p-valor \\
\hline-47.1233 & 0.0171 & 3.4835 & $\mathbf{0 . 0 0 0 5}$ \\
\hline-42.6233 & 0.0162 & 3.5624 & $\mathbf{0 . 0 0 0 4}$ \\
\hline-38.1233 & 0.0153 & 3.6476 & $\mathbf{0 . 0 0 0 3}$ \\
\hline-33.6233 & 0.0144 & 3.7378 & $\mathbf{0 . 0 0 0 2}$ \\
\hline-29.1233 & 0.0135 & 3.83 & $\mathbf{0 . 0 0 0 1}$ \\
\hline-24.6233 & 0.0125 & 3.9183 & $\mathbf{0 . 0 0 0 1}$ \\
\hline-20.1233 & 0.0116 & 3.991 & $\mathbf{0 . 0 0 0 1}$ \\
\hline-15.6233 & 0.0107 & 4.0286 & $\mathbf{0 . 0 0 0 1}$ \\
\hline-11.1233 & 0.0098 & 4.0013 & $\mathbf{0 . 0 0 0 1}$ \\
\hline-6.6233 & 0.0089 & 3.872 & $\mathbf{0 . 0 0 0 1}$ \\
\hline-2.1233 & 0.0079 & 3.6091 & $\mathbf{0 . 0 0 0 3}$ \\
\hline
\end{tabular}




\begin{tabular}{|c|c|c|c|}
\hline 2.3767 & 0.007 & 3.209 & $\mathbf{0 . 0 0 1 4}$ \\
\hline 6.8767 & 0.0061 & 2.7085 & $\mathbf{0 . 0 0 6 8}$ \\
\hline 11.3767 & 0.0052 & 2.1699 & $\mathbf{0 . 0 3 0 2}$ \\
\hline 13.1422 & 0.0048 & 1.9614 & $\mathbf{0 . 0 5}$ \\
\hline 15.8767 & 0.0043 & 1.6504 & 0.0991 \\
\hline 20.3767 & 0.0033 & 1.1838 & 0.2367 \\
\hline 24.8767 & 0.0024 & 0.7818 & 0.4344 \\
\hline 29.3767 & 0.0015 & 0.4425 & 0.6582 \\
\hline 33.8767 & 0.0006 & 0.1583 & 0.8742 \\
\hline 38.3767 & -0.0003 & -0.0799 & 0.9363 \\
\hline 42.8767 & -0.0012 & -0.2804 & 0.7792 \\
\hline
\end{tabular}

Tabla 77 - Relación de pendientes simples para la interacción EIMAC_MASCC en la etapa de interés submuestra efectividad de clic del modelo que incluye sólo las variables significativas - Procedimiento de Johnson-Neyman

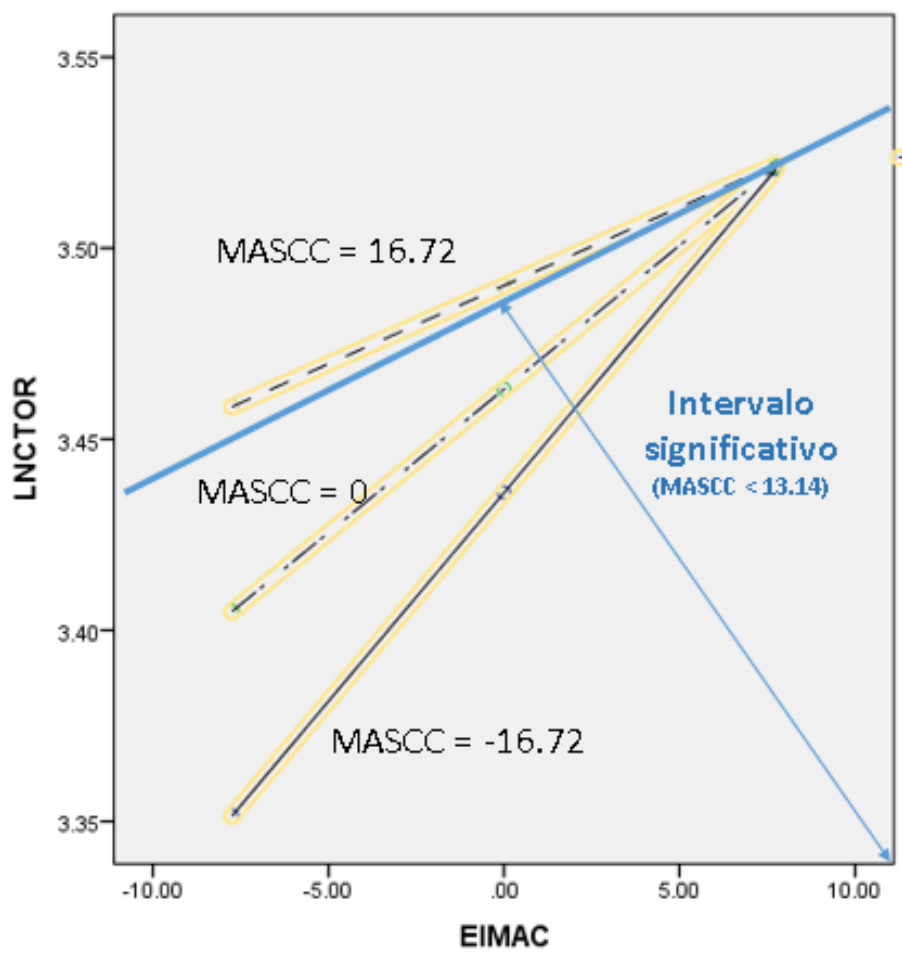

Figura 38 - Representación gráfica de la interacción EIMAC_MASCC en la etapa de interés - submuestra efectividad de clic del modelo que incluye sólo las variables significativas

\subsection{Submuestra efectividad de retención de suscriptores}

Dada la inexistencia de relaciones de moderación significativas detectadas en el análisis de esta submuestra, no se realizarán análisis de pendientes simples.

\subsection{Estudio de la etapa de acción}

En la única interacción de la última etapa -EESC_ORIEC-, la aplicación del procedimiento de Johnson-Neyman produce valores significativos $(\mathrm{p}<0.05)$ para valores 
de la dimensión orientación a largo plazo centrados superiores a -8.47. A partir de este punto, las pendientes son positivas y crecientes, lo que indica una moderación de signo positivo - a mayor orientación al largo plazo, más positivo es el efecto de los elementos que generan escasez en la efectividad de conversión- para valores medios y alto de esta dimensión.

En la tabla 78 se recogen los coeficientes para diferentes valores de la dimensión orientación a largo plazo, y en la figura 39 se aprecia el efecto de interacción para aquellos casos en los que se existen elementos que generan sensación de escasez en el email -esto es, aquellos para los que la variable EESC toma el valor de 1.

\begin{tabular}{|c|c|c|c|}
\hline $\begin{array}{c}\text { ORIEC } \\
\text { (valores) }\end{array}$ & Efecto & $\mathbf{t}$ & p-valor \\
\hline-33.543 & -0.0835 & -0.8417 & 0.4001 \\
\hline-29.1854 & -0.0517 & -0.5782 & 0.5632 \\
\hline-24.8277 & -0.02 & -0.2495 & 0.803 \\
\hline-20.47 & 0.0118 & 0.1656 & 0.8685 \\
\hline-16.1123 & 0.0435 & 0.6936 & 0.488 \\
\hline-11.7546 & 0.0753 & 1.3605 & 0.1739 \\
\hline-8.4693 & 0.0992 & 1.9614 & $\mathbf{0 . 0 5}$ \\
\hline-7.3969 & 0.107 & 2.1739 & $\mathbf{0 . 0 2 9 9}$ \\
\hline-3.0393 & 0.1387 & 3.0837 & $\mathbf{0 . 0 0 2 1}$ \\
\hline 1.3184 & 0.1705 & 3.9479 & $\mathbf{0 . 0 0 0 1}$ \\
\hline 5.6761 & 0.2022 & 4.5864 & $\mathbf{0}$ \\
\hline 10.0338 & 0.234 & 4.919 & $\mathbf{0}$ \\
\hline 14.3915 & 0.2657 & 5.004 & $\mathbf{0}$ \\
\hline 18.7492 & 0.2974 & 4.9469 & $\mathbf{0}$ \\
\hline 23.1068 & 0.3292 & 4.8273 & $\mathbf{0}$ \\
\hline 27.4645 & 0.3609 & 4.6894 & $\mathbf{0}$ \\
\hline 31.8222 & 0.3927 & 4.5534 & $\mathbf{0}$ \\
\hline 36.1799 & 0.4244 & 4.4277 & $\mathbf{0}$ \\
\hline 40.5376 & 0.4562 & 4.3144 & $\mathbf{0}$ \\
\hline 44.8952 & 0.4879 & 4.2136 & $\mathbf{0}$ \\
\hline 49.2529 & 0.5196 & 4.1241 & $\mathbf{0}$ \\
\hline 53.6106 & 0.5514 & 4.0448 & $\mathbf{0 . 0 0 0 1}$ \\
\hline
\end{tabular}

Tabla 78 - Relación de pendientes simples para la interacción EESC_ORIEC en la etapa de acción del modelo que incluye sólo las variables significativas - Procedimiento de Johnson-Neyman 


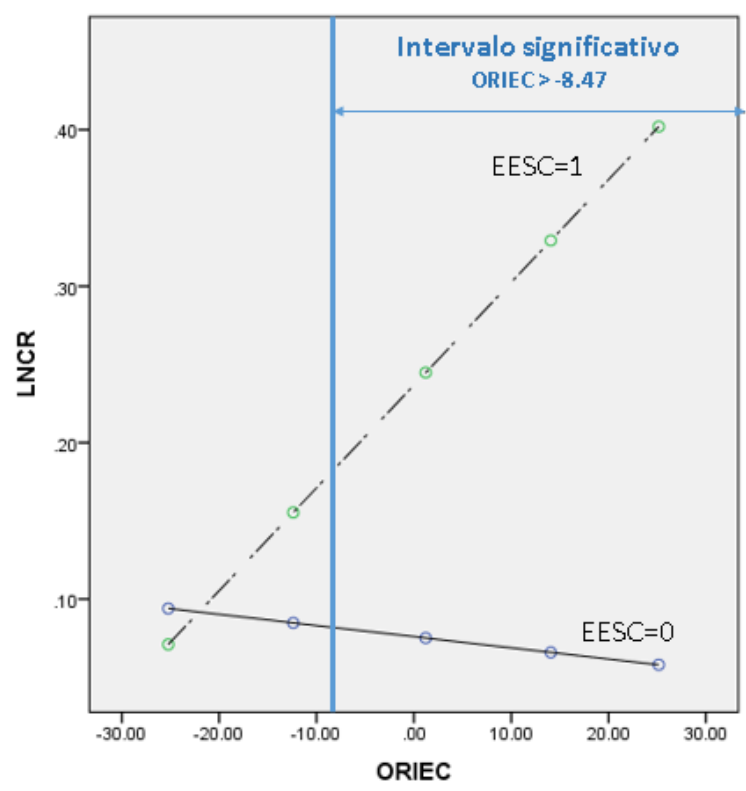

Figura 39 - Representación gráfica de la interacción EESC_ORIEC en la etapa de acción del modelo que incluye sólo las variables significativas

\subsection{MODELO FINAL DE INVESTIGACIÓN}

A continuación, en la figura 40 se presenta el modelo teórico final tras haber incorporado las hipótesis que se soportan y haber descartado aquellas para las que no ha sido posible rechazar la hipótesis nula. En el caso de las relaciones de moderación que han resultado estadísticamente significativas pero cuya dirección no se correspondía con la hipótesis propuesta, se han incorporado también al modelo. 


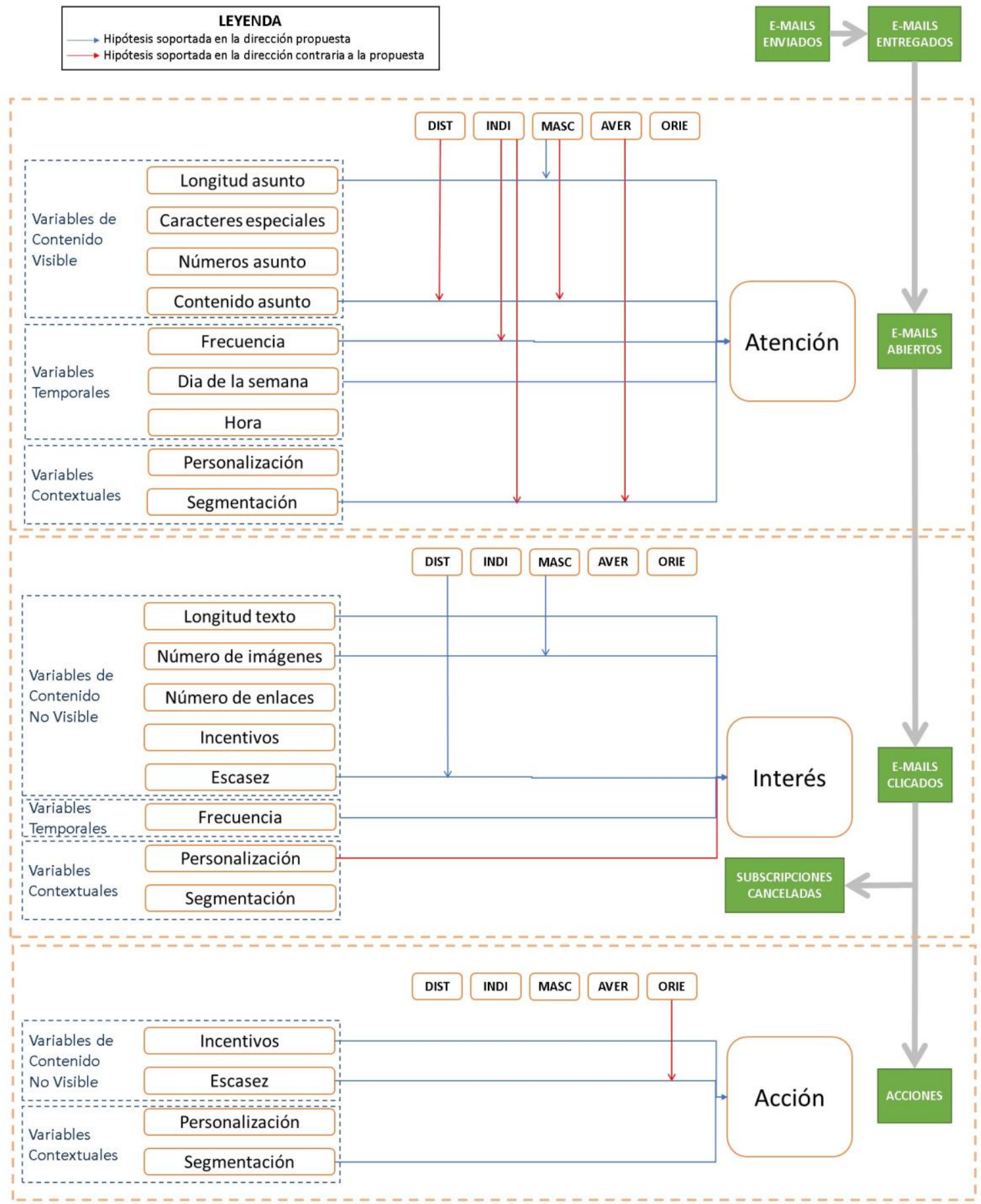

Figura 40 - Modelo final de efectividad en el e-mail marketing 


\subsection{RESUMEN DEL CONTRASTE DE HIPÓTESIS}

A continuación, se presenta un resumen de las hipótesis planteadas en el modelo final y los resultados expuestos en los apartados anteriores.

\subsubsection{Estudio de etapa de atención}

La tabla 79 recoge el resumen de los resultados alcanzados en la primera etapa del estudio.

\begin{tabular}{|c|c|c|}
\hline \multicolumn{2}{|r|}{ Hipótesis } & Soportada \\
\hline H11 & $\begin{array}{l}\text { El incremento del número de caracteres de la línea de asunto disminuye la atención } \\
\text { prestada por el usuario al e-mail marketing. }\end{array}$ & No \\
\hline H12 & $\begin{array}{l}\text { La presencia de caracteres numéricos en la línea de asunto aumenta la atención } \\
\text { prestada por el usuario al e-mail marketing. }\end{array}$ & No \\
\hline H13 & $\begin{array}{l}\text { La presencia de caracteres especiales y signos de puntuación en la línea de asunto } \\
\text { aumenta la atención prestada por el usuario al e-mail marketing. }\end{array}$ & No \\
\hline H14 & $\begin{array}{l}\text { El contenido de la línea de asunto influye en la atención prestada por el usuario } \\
\text { al e-mail marketing. }\end{array}$ & Sí \\
\hline H15 & $\begin{array}{l}\text { El incremento de frecuencia de envío de correos electrónicos de e-mail } \\
\text { marketing disminuye la atención prestada por el usuario al e-mail marketing. }\end{array}$ & Sí \\
\hline H16 & $\begin{array}{l}\text { El día de la semana de envío de correos electrónicos de e-mail marketing } \\
\text { influye en la atención prestada por el usuario al e-mail marketing. }\end{array}$ & Sí \\
\hline H17 & $\begin{array}{l}\text { La hora de envío de correos electrónicos de e-mail marketing influye en la atención } \\
\text { prestada por el usuario al e-mail marketing. }\end{array}$ & $\begin{array}{l}\text { No } \\
\text { contrastada }\end{array}$ \\
\hline $\mathrm{H} 18$ & $\begin{array}{l}\text { El uso de técnicas de personalización aumenta la atención prestada los usuarios al e- } \\
\text { mail marketing. }\end{array}$ & No \\
\hline H19 & $\begin{array}{l}\text { El uso de técnicas de segmentación aumenta la atención prestada los usuarios al } \\
\text { e-mail marketing. }\end{array}$ & Sí \\
\hline H11B & $\begin{array}{l}\text { El incremento del número de caracteres de la línea de asunto disminuye más la } \\
\text { atención prestada por el usuario al e-mail marketing en países con elevada } \\
\text { puntuación en la dimensión Individualismo-Colectivismo. }\end{array}$ & No \\
\hline H11C & $\begin{array}{l}\text { El incremento del número de caracteres de la línea de asunto disminuye más la } \\
\text { atención prestada por el usuario al e-mail marketing en países con elevada } \\
\text { puntuación en la dimensión Masculinidad-Feminidad. }\end{array}$ & Sí \\
\hline H11D & $\begin{array}{l}\text { El incremento del número de caracteres de la línea de asunto disminuye más la } \\
\text { atención prestada por el usuario al e-mail marketing en países con elevada } \\
\text { puntuación en la dimensión Aversión a la incertidumbre. }\end{array}$ & No \\
\hline H11E & $\begin{array}{l}\text { El incremento del número de caracteres de la línea de asunto disminuye más la } \\
\text { atención prestada por el usuario al e-mail marketing en países con baja puntuación } \\
\text { en la dimensión Orientación al largo plazo. }\end{array}$ & No \\
\hline
\end{tabular}




\begin{tabular}{|c|c|c|}
\hline H12B & $\begin{array}{l}\text { La presencia de caracteres especiales en la línea de asunto aumenta más la atención } \\
\text { prestada por el usuario al e-mail marketing en países con baja puntuación en la } \\
\text { dimensión Individualismo-Colectivismo. }\end{array}$ & No \\
\hline H14A & $\begin{array}{l}\text { Los contenidos de temática promocional en la línea de asunto aumentan más la } \\
\text { atención prestada por el usuario al e-mail marketing en países con baja puntuación } \\
\text { en la dimensión Distancia al poder. }\end{array}$ & No* \\
\hline H14B & $\begin{array}{l}\text { Los contenidos de temática promocional en la línea de asunto aumentan más la } \\
\text { atención prestada por el usuario al e-mail marketing en países con alta puntuación en } \\
\text { la dimensión Individualismo-Colectivismo. }\end{array}$ & No \\
\hline $\mathrm{H} 14 \mathrm{C}$ & $\begin{array}{l}\text { Los contenidos de temática promocional o de concursos en la línea de asunto } \\
\text { aumentan más la atención prestada por el usuario al e-mail marketing en países con } \\
\text { alta puntuación en la dimensión Masculinidad-Feminidad. }\end{array}$ & No* \\
\hline H15B & $\begin{array}{l}\text { La frecuencia disminuye más la atención prestada por el usuario al e-mail marketing } \\
\text { en países con alta puntuación en la dimensión Individualismo-Colectivismo. }\end{array}$ & $\mathrm{No}^{*}$ \\
\hline H18B & $\begin{array}{l}\text { La personalización aumenta más la atención prestada por el usuario al e-mail } \\
\text { marketing en países con alta puntuación en la dimensión Individualismo- } \\
\text { Colectivismo. }\end{array}$ & No \\
\hline H19B & $\begin{array}{l}\text { La segmentación aumenta más la atención prestada por el usuario al e-mail } \\
\text { marketing en países con alta puntuación en la dimensión Individualismo- } \\
\text { Colectivismo. }\end{array}$ & No* \\
\hline H19D & $\begin{array}{l}\text { La segmentación aumenta más la atención prestada por el usuario al e-mail } \\
\text { marketing en países con alta puntuación en la dimensión Aversión a la } \\
\text { incertidumbre. }\end{array}$ & No* \\
\hline
\end{tabular}

*Hipótesis soportada en la dirección contraria

Tabla 79 - Resumen del contraste de hipótesis para la etapa de atención

\subsubsection{Estudio de la etapa de interés}

La tabla 80 muestra el resumen de contraste de hipótesis para la segunda etapa del modelo.

\begin{tabular}{|l|l|c|}
\hline \multicolumn{1}{|c|}{ Hipótesis } & Soportada \\
\hline H21 & $\begin{array}{l}\text { El incremento de la longitud del texto del correo disminuye el interés del } \\
\text { usuario en el e-mail marketing. }\end{array}$ & Sí \\
\hline H22 & $\begin{array}{l}\text { El incremento del número de imágenes del correo aumenta el interés del } \\
\text { usuario en el e-mail marketing. }\end{array}$ & Sí \\
\hline H23 & $\begin{array}{l}\text { El incremento del número de enlaces del correo aumenta el interés del usuario en el } \\
\text { e-mail marketing. }\end{array}$ & No \\
\hline H24 & $\begin{array}{l}\text { La presencia de incentivos económicos incrementa el interés del usuario en el e- } \\
\text { mail marketing. }\end{array}$ & No \\
\hline H25 & $\begin{array}{l}\text { La presencia de elementos que generan sensación de escasez incrementa el } \\
\text { interés del usuario en el e-mail marketing. }\end{array}$ & Sí \\
\hline H26 & $\begin{array}{l}\text { El incremento de frecuencia de envío disminuye el interés del usuario en el e- } \\
\text { mail marketing. }\end{array}$ & Sí \\
\hline H27 & La personalización incrementa el interés del usuario en el e-mail marketing. & No* \\
\hline H28 & La segmentación incrementa el interés del usuario en el e-mail marketing. & No \\
\hline
\end{tabular}




\begin{tabular}{|c|c|c|}
\hline $\mathrm{H} 21 \mathrm{~B}$ & $\begin{array}{l}\text { El incremento de la longitud del texto del correo disminuye más el interés del } \\
\text { usuario en el e-mail marketing en países con elevada puntuación en la dimensión } \\
\text { Individualismo-Colectivismo. }\end{array}$ & No \\
\hline $\mathrm{H} 21 \mathrm{C}$ & $\begin{array}{l}\text { El incremento de la longitud del texto del correo disminuye más el interés del } \\
\text { usuario en el e-mail marketing en países con elevada puntuación en la dimensión } \\
\text { Masculinidad-Feminidad. }\end{array}$ & No \\
\hline H21D & $\begin{array}{l}\text { El incremento de la longitud del texto del correo disminuye más el interés del } \\
\text { usuario en el e-mail marketing en países con elevada puntuación en la dimensión } \\
\text { Aversión a la incertidumbre. }\end{array}$ & No \\
\hline $\mathrm{H} 21 \mathrm{E}$ & $\begin{array}{l}\text { El incremento de la longitud del texto del correo disminuye más el interés del } \\
\text { usuario en el e-mail marketing en países con baja puntuación en la dimensión } \\
\text { Orientación al largo plazo. }\end{array}$ & No \\
\hline $\mathrm{H} 22 \mathrm{~B}$ & $\begin{array}{l}\text { El incremento del número de imágenes aumenta más el interés del usuario en el e- } \\
\text { mail marketing en países con baja puntuación en la dimensión Individualismo- } \\
\text { Colectivismo. }\end{array}$ & No \\
\hline H22C & $\begin{array}{l}\text { El incremento del número de imágenes aumenta más el interés del usuario en } \\
\text { el e-mail marketing en países con baja puntuación en la dimensión } \\
\text { Masculinidad-Feminidad. }\end{array}$ & Sí \\
\hline $\mathrm{H} 22 \mathrm{D}$ & $\begin{array}{l}\text { El incremento del número de imágenes aumenta más el interés del usuario en el e- } \\
\text { mail marketing en países con baja puntuación en la dimensión Aversión a la } \\
\text { incertidumbre. }\end{array}$ & No \\
\hline $\mathrm{H} 22 \mathrm{E}$ & $\begin{array}{l}\text { El incremento del número de imágenes aumenta más el interés del usuario en el e- } \\
\text { mail marketing en países con alta puntuación en la dimensión Orientación al largo } \\
\text { plazo. }\end{array}$ & No \\
\hline $\mathrm{H} 23 \mathrm{~B}$ & $\begin{array}{l}\text { El incremento del número de enlaces aumenta más el interés del usuario en el e- } \\
\text { mail marketing en países con baja puntuación en la dimensión Individualismo- } \\
\text { Colectivismo. }\end{array}$ & No \\
\hline $\mathrm{H} 23 \mathrm{C}$ & $\begin{array}{l}\text { El incremento del número de enlaces aumenta más el interés del usuario en el e- } \\
\text { mail marketing en países con baja puntuación en la dimensión Masculinidad- } \\
\text { Feminidad. }\end{array}$ & No \\
\hline $\mathrm{H} 23 \mathrm{D}$ & $\begin{array}{l}\text { El incremento del número de enlaces aumenta más el interés del usuario en el e- } \\
\text { mail marketing en países con baja puntuación en la dimensión Aversión a la } \\
\text { incertidumbre. }\end{array}$ & No \\
\hline $\mathrm{H} 23 \mathrm{E}$ & $\begin{array}{l}\text { El incremento del número de enlaces aumenta más el interés del usuario en el e- } \\
\text { mail marketing en países con alta puntuación en la dimensión Orientación al largo } \\
\text { plazo. }\end{array}$ & No \\
\hline $\mathrm{H} 24 \mathrm{~A}$ & $\begin{array}{l}\text { La presencia de incentivos económicos incrementa más el interés del usuario en el } \\
\text { e-mail marketing en países con baja puntuación en la dimensión Distancia al poder. }\end{array}$ & No \\
\hline H24B & $\begin{array}{l}\text { La presencia de incentivos económicos incrementa más el interés del usuario en el } \\
\text { e-mail marketing en países con alta puntuación en la dimensión Individualismo- } \\
\text { Colectivismo. }\end{array}$ & No \\
\hline $\mathrm{H} 24 \mathrm{C}$ & $\begin{array}{l}\text { La presencia de incentivos económicos incrementa más el interés del usuario en el } \\
\text { e-mail marketing en países con alta puntuación en la dimensión Masculinidad- } \\
\text { Feminidad. }\end{array}$ & No \\
\hline H25A & $\begin{array}{l}\text { La presencia de elementos que generan sensación de escasez incrementa más el } \\
\text { interés del usuario en el e-mail marketing en países con alta puntuación en la } \\
\text { dimensión Distancia al poder. }\end{array}$ & Sí \\
\hline $\mathrm{H} 25 \mathrm{~B}$ & $\begin{array}{l}\text { La presencia de elementos que generan sensación de escasez incrementa más el } \\
\text { interés del usuario en el e-mail marketing en países con alta puntuación en la } \\
\text { dimensión Individualismo-Colectivismo. }\end{array}$ & No \\
\hline
\end{tabular}




\begin{tabular}{|c|c|c|}
\hline $\mathrm{H} 25 \mathrm{C}$ & $\begin{array}{l}\text { La presencia de elementos que generan sensación de escasez incrementa más el } \\
\text { interés del usuario en el e-mail marketing en países con alta puntuación en la } \\
\text { dimensión Masculinidad-Feminidad. }\end{array}$ & No \\
\hline $\mathrm{H} 25 \mathrm{D}$ & $\begin{array}{l}\text { La presencia de elementos que generan sensación de escasez incrementa más el } \\
\text { interés del usuario en el e-mail marketing en países con alta puntuación en la } \\
\text { dimensión Aversión a la incertidumbre. }\end{array}$ & No \\
\hline $\mathrm{H} 25 \mathrm{E}$ & $\begin{array}{l}\text { La presencia de elementos que generan sensación de escasez incrementa más el } \\
\text { interés del usuario en el e-mail marketing en países con baja puntuación en la } \\
\text { dimensión Orientación al largo plazo. }\end{array}$ & No \\
\hline H26B & $\begin{array}{l}\text { El incremento de frecuencia de envío disminuye más el interés del usuario en el e- } \\
\text { mail marketing en países con alta puntuación en la dimensión Individualismo- } \\
\text { Colectivismo. }\end{array}$ & No \\
\hline $\mathrm{H} 27 \mathrm{~B}$ & $\begin{array}{l}\text { La personalización aumenta más el interés prestado por el usuario al e-mail } \\
\text { marketing en países con alta puntuación en la dimensión Individualismo- } \\
\text { Colectivismo. }\end{array}$ & No \\
\hline $\mathrm{H} 28 \mathrm{~B}$ & $\begin{array}{l}\text { La segmentación aumenta más el interés prestado por el usuario al e-mail marketing } \\
\text { en países con alta puntuación en la dimensión Individualismo-Colectivismo. }\end{array}$ & No \\
\hline $\mathrm{H} 28 \mathrm{D}$ & $\begin{array}{l}\text { La segmentación aumenta más el interés prestado por el usuario al e-mail marketing } \\
\text { en países con alta puntuación en la dimensión Aversión a la incertidumbre. }\end{array}$ & No \\
\hline
\end{tabular}

*Hipótesis soportada en la dirección contraria

Tabla 80 - Resumen del contraste de hipótesis para la etapa de interés

\subsubsection{Estudio de la etapa de acción}

Finalmente, la tabla 81 muestra el resumen del contraste de hipótesis para la tercera etapa del modelo.

\begin{tabular}{|c|c|c|}
\hline \multicolumn{2}{|r|}{ Hipótesis } & \multirow{2}{*}{$\frac{\text { Soportada }}{\text { Sí }}$} \\
\hline H31 & $\begin{array}{l}\text { La presencia de incentivos económicos incrementa la acción del usuario en el e- } \\
\text { mail marketing. }\end{array}$ & \\
\hline H32 & $\begin{array}{l}\text { La presencia de elementos que generan sensación de escasez incrementa la } \\
\text { acción del usuario en el e-mail marketing. }\end{array}$ & Sí \\
\hline H33 & $\begin{array}{l}\text { La utilización de técnicas de personalización incrementa la acción del usuario en el } \\
\text { e-mail marketing. }\end{array}$ & No \\
\hline H34 & $\begin{array}{l}\text { La utilización de técnicas de segmentación incrementa la acción del usuario en } \\
\text { el e-mail marketing. }\end{array}$ & Sí \\
\hline $\mathrm{H} 31 \mathrm{~A}$ & $\begin{array}{l}\text { La presencia de incentivos económicos incrementa más la acción del usuario en el e- } \\
\text { mail marketing en países con baja puntuación en la dimensión Distancia al poder. }\end{array}$ & No \\
\hline H31B & $\begin{array}{l}\text { La presencia de incentivos económicos incrementa más la acción del usuario en el e- } \\
\text { mail marketing en países con alta puntuación en la dimensión Individualismo- } \\
\text { Colectivismo. }\end{array}$ & No \\
\hline $\mathrm{H} 31 \mathrm{C}$ & $\begin{array}{l}\text { La presencia de incentivos económicos incrementa más la acción del usuario en el } \\
\text { e-mail marketing en países con alta puntuación en la dimensión Masculinidad- } \\
\text { Feminidad. }\end{array}$ & No \\
\hline $\mathrm{H} 32 \mathrm{~A}$ & $\begin{array}{l}\text { La presencia de elementos que generan sensación de escasez incrementa más la } \\
\text { acción del usuario en el e-mail marketing en países con alta puntuación en la } \\
\text { dimensión Distancia al poder. }\end{array}$ & No \\
\hline
\end{tabular}




\begin{tabular}{|c|l|c|}
\hline H32B & $\begin{array}{l}\text { La presencia de elementos que generan sensación de escasez incrementa más la } \\
\text { acción del usuario en el e-mail marketing en países con alta puntuación en la } \\
\text { dimensión Individualismo-Colectivismo. }\end{array}$ & No \\
\hline H32C & $\begin{array}{l}\text { La presencia de elementos que generan sensación de escasez incrementa más la } \\
\text { acción del usuario en el e-mail marketing en países con alta puntuación en la } \\
\text { dimensión Masculinidad-Feminidad. }\end{array}$ & No \\
\hline H32D & $\begin{array}{l}\text { La presencia de elementos que generan sensación de escasez incrementa más la } \\
\text { acción del usuario en el e-mail marketing en países con alta puntuación en la } \\
\text { dimensión Aversión a la incertidumbre. }\end{array}$ & No \\
\hline H32E & $\begin{array}{l}\text { La presencia de elementos que generan sensación de escasez incrementa más la } \\
\text { acción del usuario en el e-mail marketing en países con baja puntuación en la } \\
\text { dimensión Orientación al largo plazo. }\end{array}$ & No* \\
\hline H33B & $\begin{array}{l}\text { La personalización aumenta más la acción del usuario en el e-mail marketing en } \\
\text { países con alta puntuación en la dimensión Individualismo-Colectivismo. }\end{array}$ & No \\
\hline H34B & $\begin{array}{l}\text { La segmentación aumenta más la acción del usuario en el e-mail marketing en países } \\
\text { con alta puntuación en la dimensión Individualismo-Colectivismo. }\end{array}$ & $\begin{array}{l}\text { La segmentación aumenta más la acción del usuario en el e-mail marketing en países } \\
\text { con alta puntuación en la dimensión Aversión a la incertidumbre. }\end{array}$ \\
\hline
\end{tabular}

* Hipótesis soportada en la dirección contraria

Tabla 81 - Resumen del contraste de hipótesis para la etapa de acción 


\section{Capítulo 8 - Conclusiones}

8.1 VALORACIÓN DEL CUMPLIMIENTO DE LOS OBJETIVOS DE INVESTIGACIÓN PROPUESTOS

8.2 CONTRIBUCIONES DE LA INVESTIGACIÓN

8.2.1 Contribuciones a la teoría

8.2.2 Contribuciones metodológicas

8.2.3 Contribuciones a la práctica

8.3 CONCLUSIONES Y DISCUSIÓN DE RESULTADOS.

8.3.1 Conclusiones generales

8.3.2 Conclusiones específicas

8.4 RECOMENDACIONES PARA LA PRÁCTICA.

8.4.1 Etapa de atención

8.4.2 Etapa de interés

8.4.3 Etapa de acción

8.5 LIMITACIONES DE LA INVESTIGACIÓN

8.6 LÍNEAS DE INVESTIGACIÓN PARA FUTUROS ESTUDIOS

8.7 DIFUSIÓN DE RESULTADOS RELACIONADOS CON LA INVESTIGACIÓN

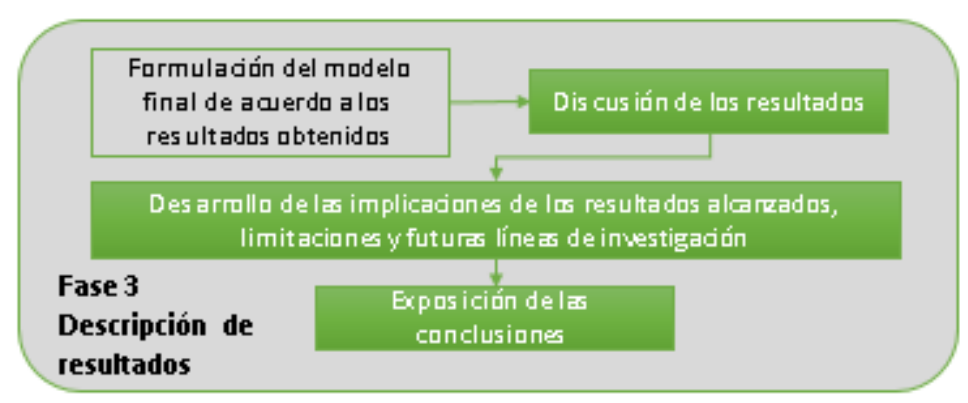




\section{CONCLUSIONES}

A lo largo de las siguientes líneas se exponen las principales conclusiones a las que ha llegado esta tesis doctoral. Dicho análisis no se limita a los resultados empíricos presentados en el anterior capítulo, sino que aspira a incorporar los aprendizajes teóricos y metodológicos que se han alcanzado. A continuación, se resumen las limitaciones de la investigación determinadas por el alcance propuesto y las particularidades de los datos recogidos, y se proponen diversas líneas de investigación con las que sería posible continuar ampliando el conocimiento de la efectividad en el e-mail marketing.

\subsection{VALORACIÓN DEL CUMPLIMIENTO DE LOS OBJETIVOS DE INVESTIGACIÓN PROPUESTOS}

En primer lugar, se analizará si el trabajo de investigación presentado a lo largo de los anteriores capítulos ha alcanzado los objetivos que se propusieron en el apartado 1.3.3 del primer capítulo.

Objetivo secundario 1

Realizar una revisión de la literatura existente acerca de la efectividad de las campañas de e-mail marketing y los factores de influencia, así como la relativa a comportamiento del consumidor en el entorno de la publicidad online.

A lo largo de los capítulos segundo a cuarto se han presentado las conclusiones extraídas de un profundo análisis de la literatura. Dicha revisión ha permitido por una parte resaltar aquellos factores de influencia en el e-mail marketing identificados en otras investigaciones y, por otra, seleccionar el modelo de jerarquía de efectos AIDA y el modelo de dimensiones culturales de Hofstede como las herramientas más adecuadas para abordar el estudio del comportamiento del consumidor desde un punto de vista general y de cultura nacional. Asimismo, ha permitido identificar las limitaciones del corpus existente -en particular, las relativas a la selección de muestras y factores estudiados-, lo que ha posibilitado que la presente investigación pueda realizar una contribución original y relevante. De esta forma, este objetivo se da por alcanzado.

Objetivo secundario 2

Desarrollar un modelo que integre los factores que determinan el comportamiento del consumidor online, así como los que inciden en la efectividad del correo electrónico como herramienta promocional, articulándolo a través de las variables utilizadas para evaluar dicha efectividad.

El análisis de la literatura realizado en el campo del estudio de la efectividad en el email marketing ha permitido recoger todos los factores que han formado parte de 
investigaciones anteriores, seleccionándose aquellos particularmente relevantes a partir de los resultados obtenidos. Dichos factores han sido agrupados de una manera coherente que ha posibilitado el estudio tanto de su influencia directa en la efectividad como de su importancia relativa en relación con otros factores.

A posteriori, y tras la incorporación de los modelos de Hofstede y AIDA como elementos vertebradores, en el capítulo quinto se ha planteado un modelo de efectividad basado en las conclusiones alcanzadas tanto por estudios concretos en el ámbito del email marketing como por aquellos realizados en entornos similares. Por tanto, este segundo objetivo también se da por cumplido.

Objetivo secundario 3

Crear un instrumento de medida y determinar una metodología de investigación que permita validar empíricamente el modelo teórico desarrollado.

En las primeras etapas de esta investigación se ha deconstruido el concepto genérico de "efectividad en el e-mail marketing", reduciéndolo a etapas progresivas y fácilmente delimitables que pueden ser parametrizadas a través de tasas utilizadas de manera habitual por la industria y la comunidad científica. Asimismo, se han expuesto aproximaciones contrastadas para la operacionalización de la mayoría de variables de influencia, utilizando en algunos casos estudios anteriores del entorno del e-mail marketing y en otros estudios del entorno digital. En aquellos casos específicos en los que este enfoque ha resultado infructuoso, se han realizado propuestas de operacionalización fundamentadas teóricamente que han permitido incorporar todos los factores de influencia identificados al estudio empírico. De esta manera, este objetivo se considera alcanzado.

Objetivo secundario 4

Realizar una recogida de datos fundamentada en los instrumentos de medida desarrollados utilizando una muestra global.

Una vez definidas las necesidades de datos en base al modelo propuesto y las directrices de operacionalización detalladas, se ha realizado un breve estudio de la manera más adecuada de abordar la recogida de datos, detallado en el capítulo sexto, seguido de la obtención de datos empíricos proporcionados por terceras partes. Dado que los datos obtenidos han posibilitado la realización de un análisis empírico robusto, se considera este cuarto objetivo como cumplido.

Objetivo secundario 5

Contrastar las conclusiones obtenidas con las extraídas por investigaciones anteriores. 
Objetivo secundario 6

Establecer y describir las diferencias desde un punto de vista geográfico y cultural, de forma que sea posible determinar una segmentación de consumidores en función de su región.

A lo largo de los siguientes apartados del presente capitulo se expondrá una discusión general de las conclusiones alcanzadas por el análisis empírico tanto a nivel general como geográfico-cultural, relacionando los resultados obtenidos con los expuestos en investigaciones anteriores, de forma que se alcancen el quinto y sexto objetivos secundarios.

\subsection{CONTRIBUCIONES DE LA INVESTIGACIÓN}

Se presentan a continuación las contribuciones originales de la presente tesis desde un punto de vista teórico, metodológico y práctico.

\subsubsection{Contribuciones a la teoría}

Desde el punto de vista teórico, una de las principales contribuciones de esta investigación doctoral es la propuesta y validación de un modelo de efectividad en el email marketing articulado en etapas sucesivas. Este modelo está basado tanto en la combinación de modelos existentes -teoría de la jerarquía de efectos y AIDA, dimensiones culturales de Hofstede- como en la incorporación de factores específicos de influencia en el e-mail marketing -frecuencia, segmentación-y en otros canales de marketing -día de la semana, extraído del estudio de efectividad de anuncios televisivos.

A lo largo de los anteriores capítulos se ha propuesto y demostrado la existencia de factores de influencia en el e-mail marketing a los que ha sido posible asignar diferentes niveles de relevancia. La elección de dichos factores está soportada por investigaciones anteriores, y su estructuración es consistente con teorías de reconocida utilidad y notable vigencia. Este sólido apoyo teórico-conceptual proporciona robustez al modelo planteado.

La investigación ha propuesto una categorización de factores en cinco grupos claramente diferenciados que permite la expansión del modelo sin necesidad de modificar la arquitectura planteada, y que puede resultar de utilidad en futuras investigaciones. Esto ha supuesto una diferencia fundamental en relación con anteriores estudios, que analizaban un número limitado de factores sin una taxonomía definida que aportara coherencia a los resultados.

Asimismo, otra aportación notable de esta tesis doctoral ha sido la demostración de que el contexto cultural es relevante en el estudio del e-mail marketing. De esto se deriva 
una implicación fundamental: anteriores investigaciones que han utilizado muestras limitadas a entornos culturales o socioeconómicos particulares han de ser interpretadas teniendo en cuenta esta limitación. En los resultados del análisis empírico se han hallado ocho relaciones moderadoras por parte de elementos culturales, hecho particularmente novedoso puesto que éste es el primer intento de incorporar la cultura nacional al estudio del e-mail marketing.

Además de estas contribuciones de carácter general, cabe mencionar -brevemente, puesto que serán desarrolladas en más detalle en los posteriores apartados de este capítulo- la identificación de frecuencia y segmentación como factores fundamentales de influencia en la atención, la longitud del correo en el interés y la existencia de incentivos económicos, sensación de escasez y segmentación en la acción. El estudio conjunto de múltiples variables y la obtención de los resultados mencionados permite priorizar futuras líneas de investigación para permitir el desarrollo de resultados más específicos.

\subsubsection{Contribuciones metodológicas}

Desde una perspectiva metodológica, destaca como principal aportación de esta investigación la propuesta de un modelo de efectividad del e-mail marketing que facilita la comprensión del comportamiento del consumidor en el entorno del marketing digital. El análisis empírico realizado confirma la validez de dicho modelo, así como la metodología seguida para obtenerlo -combinación de la identificación de variables de influencia obtenidas tras un análisis de la literatura de la efectividad de e-mail marketing, y su posterior articulación basada en la selección de modelos contrastados de comportamiento del consumidor.

Asimismo, la creación de categorías que agrupan a los factores de influencia de manera coherente con el proceso perceptual y conductual del consumidor es una aportación de especial relevancia, puesto que permite una aproximación más ordenada al estudio de la efectividad en el entorno del e-mail marketing y puede permitir articular de manera lógica y estructurada futuras investigaciones en este campo.

Por otra parte, la deconstrucción del concepto efectividad en efectividades parciales subconceptos coherentes con el desarrollo procesal de la interacción de los usuarios con el correo electrónico- resulta una contribución relevante, puesto que reduce la brecha existente entre el entorno empresarial, enfocado en indicadores de rendimiento (KPIs) y variables de medida, y el mundo académico, enfocado en constructos que pueden resultar de difícil aplicación desde un punto de vista práctico.

Adicionalmente, la definición y validación de escalas de medida de algunas variables de influencia también resulta una aportación importante que puede simplificar futuras investigaciones. En este sentido, resultan destacables la creación de una metodología 
específica basada en RFM para medir la frecuencia en estudios de campo con muestras segmentadas, así como la validación de la categorización de temáticas de asunto propuesta por Ellis-Chadwick \& Doherty (2012).

Finalmente, la creación de una subrutina VBA que posibilita la extracción de variables de contenido visible de archivos HTML es también una pequeña contribución de índole metodológica que puede simplificar futuras investigaciones.

\subsubsection{Contribuciones a la práctica}

La contribución práctica fundamental de esta tesis será desarrollada en los siguientes apartados, y engloba una serie de conclusiones relativas a la importancia relativa de las variables de influencia y las técnicas más adecuadas para incrementar la efectividad del e-mail marketing. La aplicación parcial o total de las recomendaciones presentadas resultaría beneficiosa para el ecosistema del correo electrónico en su conjunto: el consumidor recibirá correos más relevantes -desde un punto de vista cultural, temporal, contextual y de contenido-, hecho que repercutirá en su deseo de interactuar con el canal y que, eventualmente, conducirá al objetivo perseguido por los anunciantes.

De este modo, las recomendaciones de esta investigación contribuirán a reforzar el círculo virtuoso establecido entre publicidad relevante e interacción con contenido comercial que resulta beneficioso para todos los participantes del entorno del e-mail marketing. Las estrategias para la implementación de dichas conclusiones por parte de las empresas no requieren modificaciones costosas en su operativa ni conllevan desarrollos que resulten de difícil ejecución, sino que se limitan a la aplicación de ligeros ajustes en el cómo, cuándo y qué comunicar.

\subsection{CONCLUSIONES Y DISCUSIÓN DE RESULTADOS}

\subsubsection{Conclusiones generales}

El e-mail marketing es uno de los canales más eficientes del marketing mix a la hora de alcanzar los objetivos de comunicación de una compañía. La capacidad de personalización inherente al entorno digital alcanza su máximo exponente en un medio en el que el consumidor ha de autorizar el establecimiento de comunicación, proporcionar ciertos datos personales que posibilitarán el consumo de un contenido más relevante e interactuar en un entorno discreto que permitirá la codificación de su comportamiento, facilitando el ajuste de futuros envíos a sus preferencias implícitas. Conscientes de las ventajas de este canal, los anunciantes se han embarcado en programas para mejorar los resultados de sus envíos a través de experimentos que han facilitado identificar elementos relevantes en la efectividad del e-mail marketing. Sin embargo, la utilización de un enfoque restringido a factores individuales o a entornos 
geográficos limitados no ha permitido hasta la fecha la generalización de las conclusiones obtenidas.

El resultado de esta tesis doctoral es un modelo de efectividad del e-mail marketing compuesto por factores de influencia identificados a partir de la literatura científica existente y articulado a través de teorías generales de comportamiento del consumidor. Dicho modelo está estructurado en tres etapas -atención, interés y acción- asociadas a cuatro efectividades parciales - de apertura, de clic, de retención de suscriptores y de conversión-, e identifica cinco categorías de factores: de contenido visible, de contenido no visible, temporales, contextuales -categorías inherentes al entorno del e-mail marketing- y culturales -categoría relativa a un ámbito general.

Un primer análisis de la capacidad predictiva del modelo en las diferentes etapas resulta revelador de la complejidad inherente a la utilización de estudios de campo en la investigación de fenómenos complejos como el comportamiento de los usuarios. Si se evalúa la rama del principal desarrollo procesal propuesto -apertura, clic y conversión-, se observa que el modelo final explica un $26.4 \%$ de la varianza para la primera etapa, un $13.4 \%$ de la segunda y un $5.3 \%$ de la tercera. Esta disminución progresiva se produce a medida que las acciones del usuario le llevan desde un entorno restringido al ámbito del correo electrónico - la bandeja de entrada- y, por ende, más fácilmente modelable, hasta un ambiente totalmente exógeno al canal -la plataforma de comercio electrónico del anunciante- en la que infinidad de elementos pueden jugar un papel relevante. Esta situación resulta coherente con investigaciones anteriores que revelan una mayor complejidad en cada etapa sucesiva de los modelos de carácter procesal de comportamiento del consumidor (Bauman et al., 2008).

Los datos obtenidos permiten concluir que la utilidad de los factores de influencia tradicionales del canal es razonable en las etapas en las que el consumidor se encuentra directamente involucrado con el mismo, pero que estos factores contribuyen de manera marginal a predecir el comportamiento en entornos ajenos. En concreto, en el caso de la conversión, elementos tradicionales no capturados por el modelo como la estrategia de precio, los productos sustitutivos o incluso la posibilidad de realizar la compra en diferentes canales de distribución pueden tener un papel extremadamente relevante (Kotler \& Keller, 2012).

Resulta también reseñable la limitada capacidad de las variables propuestas a la hora de predecir la efectividad de retención de suscriptores, dado que el modelo explica tan sólo $1.8 \%$ de la varianza. Sin embargo, y tal y como muestra la tabla 50, la varianza explicada puede incrementarse notablemente si se considera el efecto directo de las dimensiones culturales, hecho apreciable dado el notable incremento de $\mathrm{R}^{2}$ (de $1.8 \%$ a $23.2 \%$ ) en el modelo que estudia el análisis de moderación a pesar de que las variables de interacción no han resultado significativas. El alcance de esta investigación se limita 
al investigar el rol moderador de las dimensiones culturales, con lo que este resultado no será analizado en detalle, si bien es necesario apuntar que los resultados obtenidos son coherentes con los de investigaciones que señalan la notable influencia directa de las dimensiones individualismo-colectivismo y orientación a largo plazo en la efectividad de retención de suscriptores (Lorente-Páramo, Hernández-García \& Chaparro-Peláez, 2020b).

Los resultados del estudio empírico realizado ofrecen indicios sobre las variables en las que los responsables de bases de datos han de centrar su atención para incrementar la atención que los usuarios prestan a sus e-mails. En este caso, el control de la frecuencia de envío y la utilización de técnicas de segmentación aparecen como los factores más relevantes a la hora de influir en la efectividad de apertura. En un orden de magnitud inferior, la temática del asunto -en concreto, el uso de descuentos, promociones de temporada, bonus o regalos, en contraposición a las promociones generales-, la longitud del asunto o el día de la semana también tienen efectos relevantes en esta métrica. La existencia de diversas relaciones de moderación por parte de dimensiones culturales para seis de estas variables independientes apunta a la relevancia de la cultura nacional en el estudio de esta etapa.

En lo referido la efectividad de clic, la longitud del correo aparece como el factor más importante de esta fase, seguido del número de imágenes y la presencia de elementos que generan sensación de escasez. Dado el protagonismo de factores ligados a los incentivos económicos en la anterior etapa, resulta destacable la irrelevancia de esta variable en la efectividad de clic. En contraposición, son variables de contenido vinculadas a la complejidad del correo y a la escasez del producto las que consiguen afectar a los resultados. Este hecho permite sugerir que el consumidor necesita información nueva para mantener la interacción con el correo y que dicha información ha de ser comunicada de manera simple, conclusiones ambas coherentes con la teoría de procesado de la información (Solomon \& Rabolt, 2009). De nuevo, la existencia de relaciones de moderación por parte de ciertas dimensiones de Hofstede revela la importancia de una contextualización cultural en el estudio de esta etapa.

Con relación a la efectividad de retención de suscriptores, tal y como se ha mencionado en las líneas anteriores, la limitada capacidad explicativa del modelo hace fútil el ejercicio de traducir los resultados matemáticos a conclusiones generales. Así, pese a que el software estadístico apunta a una mayor importancia de la frecuencia en relación con la personalización, se descartarán estos resultados para concluir que son necesarios esfuerzos adicionales a los que identifican el rol de las dimensiones culturales como variable de influencia directa para arrojar más luz sobre este fenómeno.

Finalmente, el estudio de la etapa de acción revela efectos equivalentes de las variables semánticas -incentivos económicos y sensación de escasez- y de las técnicas de 
segmentación, apareciendo también una relación de moderación que apunta a cierta relevancia de los factores culturales. En relación a ambas variables semánticas, y puesto que la capacidad explicativa del modelo es pequeña pero relevante, es necesario mencionar que su presumible vinculación a otros factores externos -por ejemplo, la posibilidad de que tanto los incentivos económicos como la escasez se hayan comunicado en otros soportes como la web del anunciante o canales de comunicación alternativos, o el hecho de que el precio sea competitivo en relación con otras alternativas, en el caso de los incentivos económicos- requiere una interpretación cautelosa. Esto no quiere decir que dichas variables deban de ser ignoradas por los responsables de bases de datos, puesto que efectos pequeños pueden tener un impacto muy significativo en el retorno de inversión de una campaña - por ejemplo, Lewis y Rao (2015) estiman que un $25 \%$ de retorno de inversión se corresponde con un tamaño del efecto de 0.0047 .

Así, un e-mail enviado durante una promoción que tuviera ambas características incentivos económicos y escasez-, pero que las comunicara en todos los canales excepto correo electrónico podría tener mejores resultados que uno en el que, ante la misma promoción, el anunciante eligiera comunicar exclusivamente ambas características en el correo electrónico. Si bien la anterior aseveración no deja de ser una hipótesis sin ningún soporte más allá de la incidental limitada capacidad explicativa del modelo, su exposición cumple una función ilustrativa del motivo por el que las conclusiones relativas a esta fase tendrán una naturaleza conservadora. De esta manera, es posible concluir que las tres variables mencionadas juegan un papel en la efectividad de conversión, pero que es altamente probable que variables exógenas tengan una influencia más relevante.

En resumen, los resultados de esta investigación permiten concluir que existen variables de contenido visibles, no visibles, temporales, contextuales y culturales que tienen influencia en la efectividad del e-mail marketing. Dichas variables tienen mejor capacidad predictiva en las etapas iniciales del desarrollo procesal que atraviesa el consumidor en su interacción con el canal, siendo especialmente relevantes la frecuencia y la segmentación en el caso de la efectividad de apertura, y la longitud del correo en el caso de la efectividad de clic. La existencia de relaciones moderadoras por parte de las dimensiones de Hofstede en todas las etapas permite también concluir la existencia de diferencias de comportamiento del consumidor en su interacción con este canal en función de su cultura nacional, siendo ésta una de las principales aportaciones originales de esta tesis doctoral.

\subsubsection{Conclusiones específicas}

Se procederá a continuación a realizar un desarrollo en profundidad de los resultados obtenidos en relación con las diversas tipologías de factores de influencia, 
contrastándolos con anteriores investigaciones y destacando aquellas aportaciones que resultan novedosas.

\subsubsection{Variables de contenido visible}

El estudio de las variables de contenido visible se encuentra acotado al campo de la efectividad de apertura, según el modelo propuesto. Desde un punto de vista formal, la presencia de caracteres especiales y números en el asunto no ha resultado significativa, mientras que la longitud del asunto sí que lo ha sido. Esto difiere de resultados obtenidos en otros análisis realizados dentro del marco de esta tesis (Lorente-Páramo, Hernández-García \& Chaparro-Peláez, 2020c), en los que sólo los caracteres especiales resultaban relevantes. Este hecho podría estar causado por la diferente contextualización del ejercicio, ya que en dicho estudio no se evalúa la influencia cultural, lo que permite utilizar una muestra un 30\% mayor a la de esta investigación, al no ser necesario excluir los registros correspondientes a países para los que no existen valores de las dimensiones culturales. La diferente relevancia de los caracteres especiales es, sin embargo, significativa, puesto que señala que la sensibilidad de este tipo de variables es elevada, y que su relevancia puede cambiar en función del contexto.

Así, es posible proponer que el carácter disruptivo que se atribuye a los números y caracteres especiales es limitado, a la vista de su abundancia en los correos, hecho por el que ambas variables no tienen una influencia significativa en la efectividad de apertura. La longitud del asunto resulta relevante en esta fase, teniendo una incidencia positiva en la efectividad de apertura en países con baja puntuación en la dimensión masculinidadfeminidad y negativa en países con elevada puntuación en la dimensión masculinidadfeminidad, hecho consistente con la preferencia de este último tipo de culturas por una comunicación más simple (Diaz et al., 2017). Por otra parte, el crecimiento del entorno móvil en el e-mail marketing y sus implicaciones en relación con las diferentes longitudes de truncamiento para las líneas de asunto sugieren la conveniencia de estudiar más en detalle esta variable en relación con el dispositivo utilizado por el usuario.

En relación al aspecto semántico, los resultados obtenidos son consistentes con anteriores estudios que señalan la importancia de la temática en la efectividad de apertura (Kumar \& Salo, 2018; Micheaux, 2011). En concreto, se puede concluir que las temáticas promocionales de índole cuantitativa, esto es, las centradas en descuentos o bonus, han perdido su tradicional efectividad con respecto a otras promociones generales, tal vez debido a su omnipresencia en el entorno publicitario. Por otra parte, la mayor efectividad de temáticas no tan habituales, como los regalos o las promociones de temporada, puede interpretarse de dos maneras: por una parte, se podría sugerir que incrementar el uso de estas temáticas, dentro de lo que permite su carácter estacional, es una vía adecuada para mejorar la efectividad de apertura; por otra, en el caso de las 
promociones de temporada, también es posible invertir la dirección de causalidad y señalar que su mayor efectividad está motivada por la planificación de compras que el consumidor realiza asociada a determinadas fechas (Black Friday, Navidad, entre otras) y que, sabiendo la importancia de este período, los anunciantes han de asegurarse en controlar el resto de variables de influencia para maximizar los resultados de estas campañas.

Este postulado general ha de ser ampliado en el caso de las promociones de descuento y de temporada, dada la existencia de relaciones de moderación por parte de dimensiones culturales. Así, con relación a estas últimas, su efectividad es siempre mayor que la de las promociones generales, si bien en aquellas culturas con puntuación elevada en la dimensión distancia al poder este efecto será más acusado. De manera similar, en el caso de las promociones de descuento, su pérdida de efectividad comparada con las promociones generales es superior en aquellas culturas con altas puntuaciones en la dimensión masculinidad-feminidad.

Ambas situaciones contrastan con los postulados generales que sostienen la existencia de aversión a la caracterización de un producto como promocional o barato en países con una alta puntuación en distancia al poder (Albers-Miller \& Gelb, 1996) o la preferencia de por datos objetivos como los descuentos en culturas con elevada puntuación en la dimensión masculinidad-feminidad (Hofstede et al., 2010), y revelan que el comportamiento del consumidor en el entorno del e-mail marketing difiere del que presenta en un contexto general. En el primer caso, los resultados pueden reconciliarse con el postulado general dado puesto que uno de los motivos para suscribirse a una base de datos es el interés en recibir promociones (Carmen \& Nicolae, 2010). Así, es posible que en países con elevada puntuación en la dimensión distancia al poder haya un menor número de personas con interés en promociones que en otras culturas, pero que aquellas que consientan en formar parte de la base de datos no presenten un mayor rechazo que los suscriptores de otros entornos culturales. Con respecto a la mayor pérdida de efectividad de las promociones de descuento en las culturas masculinas, es más complejo establecer una explicación robusta, pero resulta razonable suponer que el consumidor de estas culturas, en lugar de favorecer la presencia de elementos objetivos como los descuentos, se cuestione la objetividad de todo el contenido -incluido el descuento- dado el interés del remitente en que éste ejecute una acción determinada.

\subsubsection{Variables de contenido no visible}

El estudio de las variables de contenido no visible desde un punto de vista formal se ha limitado al campo de la efectividad de clic. Esto es así porque su relevancia se asocia a la complejidad del correo y, por tanto, su potencial influencia está acotada al entorno en el que el usuario interactúa con el mismo, esto es, el momento en el que lo lee. Así, la 
longitud del texto resulta el elemento más transcendente en esta etapa, teniendo los textos largos un efecto claramente disuasorio para el consumidor.

Este hecho resulta coherente tanto con la cultura de la inmediatez asociada al entorno digital como con el hecho de que la tipología de mensaje transmitido a través del e-mail marketing es relativamente simple, cuestión que asociada a la riqueza -en cuanto a capacidad comunicativa- de los elementos utilizados -imágenes, textos en diversas fuentes y formatos, etc.- resulta en que un exceso de longitud hace a los usuarios perder el interés.

En relación a la controversia existente respecto a esta variable, los resultados de esta tesis se alinean con la mayoría de autores que proponen la utilización de contenidos de extensión limitada (Arnold, 2008; Chittenden \& Rettie, 2003; Dufrene et al., 2005; Groves, 2009; Ting, 2012), en contraposición a los que sostienen que el incremento de longitud puede tener consecuencias positivas en la efectividad de clic (Baggott, 2011; Kumar \& Salo, 2018).

Por otra parte, los resultados empíricos de la variable número de imágenes implican que el incremento de este tipo de elemento en el correo mejora su efectividad de clic, conclusión coincidente con las alcanzadas por ciertos estudios anteriores (Rettie \& Chittenden, 2003; Simon \& Peppas, 2004) y con la tendencia de la industria digital a primar el contenido gráfico en contraposición al textual, evidenciada por las recientes alteraciones al newsfeed de Facebook o al auge de redes sociales centradas en contenido audiovisual como Instagram. El incremento de este efecto en países con baja puntuación en la dimensión masculinidad-feminidad es de nuevo consistente con la preferencia de las culturas con elevada puntuación en esta dimensión por la simplicidad (Diaz et al., 2017).

Los resultados no han encontrado una influencia significativa del número de enlaces en la efectividad de clic, conclusión relevante puesto que refuta las propuestas de estudios anteriores que afirman que este elemento afecta positiva (Chittenden \& Rettie, 2003) o negativamente (Ellis-Chadwick \& Doherty, 2012) al interés. Este resultado sugiere que la evolución de la configuración de los enlaces en el correo y, sobre todo, su necesaria asociación a los otros componentes formales -texto e imágenes-, han hecho que el consumidor ya no repare en su existencia, y se limite a valorar la complejidad de un correo a través de los elementos que puede apreciar a simple vista, sin evaluar las funcionalidades asociadas a los mismos.

En cuanto a las variables semánticas, y teniendo en cuenta las puntualizaciones expuestas en el apartado anterior relativos al estudio de la etapa de acción, los resultados obtenidos resultan interesantes, a la vista de los evidentes contrastes con la literatura existente que postula la influencia de la existencia de incentivos económicos 
en la efectividad de clic (Chittenden \& Rettie, 2003; Sigurdsson et al., 2016). Los resultados del análisis indican que este tipo de incentivos no tiene una influencia significativa en la etapa de interés, situación posiblemente motivada por el hecho de que su existencia ya se ha comunicado al consumidor en la línea de asunto en un elevado número de casos -se ha comprobado que existe una elevada correlación entre temáticas promocionales con descuentos en el asunto y esta variable de la muestra. Así, dado que este elemento no aporta información nueva, su influencia se puede considerar despreciable.

En cuanto a la etapa de acción, la existencia de incentivos económicos independientemente del canal utilizado para la comunicación- juega un papel importante en la conversión (Baggott, 2011; Solomon et al., 2013), resultando por tanto relevante en la consecución del objetivo perseguido por el remitente del correo.

Los elementos que generan sensación de escasez influyen tanto en la etapa de efectividad de clic como de conversión, si bien en ambos casos existen dimensiones culturales que moderan la relación entre variables dependientes e independientes. En el primero de ellos, la relevancia que las culturas con elevada puntuación en la dimensión distancia al poder conceden a la exclusividad de un producto (Albers-Miller \& Gelb, 1996) -hecho potenciado por la sensación de escasez- implica que este efecto se refuerza con el crecimiento de la puntuación en esta dimensión. Así, la existencia de comportamientos diferenciados en función de la dimensión distancia al poder -en culturas con baja puntuación estos elementos son contraproducentes puesto que disminuyen la efectividad de clic, mientras en aquellas con elevada puntuación mejoran dicha efectividad-, lo que sugiere que la aplicación indiscriminada de esta técnica es un error y que resulta fundamental contextualizar la comunicación desde un punto de vista cultural para evitar limitar el CTR.

En el caso de la efectividad de conversión, y de nuevo reiterando la interpretación cautelosa que ha de hacerse del análisis dada la limitada capacidad explicativa del modelo, los resultados empíricos rechazan la relación propuesta en el apartado de hipótesis de que la preferencia por la acción inmediata de países con baja orientación al largo plazo se traduce en una mayor efectividad de conversión en presencia de elementos que generan sensación de escasez. De hecho, los resultados apuntan hacia la relación opuesta -a mayor orientación al largo plazo, mayor efectividad de conversión causan los elementos que generan sensación de escasez-, si bien no se ha encontrado un soporte teórico que permita aventurar una explicación al respecto. Teniendo en cuenta lo anterior, resulta de especial interés la confirmación de este resultado por parte de futuros estudios. 


\subsubsection{Variables temporales}

El estudio de las variables temporales tiene como principal protagonista a la etapa de atención, pues la incidencia de éstas contextualiza al consumidor y determina su voluntad de iniciar la interacción con la comunicación.

La frecuencia es el factor más importante de esta categoría y, junto con la existencia de segmentación, resulta el más relevante en el estudio de la efectividad de apertura. Esta situación se hace más acusada a medida que disminuye la puntuación en la dimensión individualismo-colectivismo -hecho que contrasta con la hipótesis propuesta inicialmente, que proponía la relación opuesta-, dada la reactividad de naciones individualistas hacia la invasión de privacidad que puede suponer un aumento de frecuencia. Estos resultados concuerdan con los estudios que postulan que la frecuencia no está directamente relacionada con la percepción de intrusión (Micheaux, 2011) y refuerzan la teoría de que un aumento de frecuencia reduce el valor de la comunicación (Haq, 2009), implicando una disminución de la atención generada por la adaptación por parte del usuario al estímulo perceptual -esto es, al e-mail- (Solomon et al., 2013).

El efecto de la frecuencia en la tasa de apertura sugiere la existencia de un coste de oportunidad para cada envío que no puede ser soslayado con envíos ulteriores muy cercanos en el tiempo, dado que la efectividad de estos últimos se vería reducida. Esta variable es también la más relevante en el estudio de la efectividad de retención de suscriptores, actuando de manera negativa sobre la misma en línea con lo propuesto por Micheaux (2011), si bien, tal y como se ha mencionado, el hecho de que la capacidad explicativa de este modelo sea extremadamente limitada implica la necesidad de relativizar cualquier conclusión obtenida.

El estudio del día de la semana también arroja resultados relevantes en el análisis de la etapa de atención, si bien de menor magnitud que la frecuencia. Los lunes resultan el día más efectivo para el envío de comunicaciones, seguidos en segundo lugar por los miércoles, jueves y domingo, y a continuación por los martes, viernes y sábados. El protagonismo del lunes concuerda con los resultados obtenidos por estudios similares realizados por este investigador y sus directores, abordados en un marco más amplio de investigación, si bien los relacionados con el resto de días son diferentes. Esto apunta a una cierta sensibilidad por parte de esta variable, y permite concluir la necesidad de que sea estudiada por cada responsable de marketing en el contexto de su propia base de datos.

\subsubsection{Variables contextuales}

La segmentación y la personalización son las únicas variables que han sido analizadas a lo largo de las tres etapas del proceso, hecho que enriquecerá la interpretación de resultados puesto que permitirá señalar las diferencias entre las diversas etapas. Tal y 
como se mencionó en la descripción realizada en el capítulo quinto, las características de la muestra hacen que el estudio de la personalización resulte complejo dado el limitado número de entradas en las que aparece este factor. Por tanto, será necesaria cierta prudencia en la elaboración de conclusiones al respecto.

En la etapa de atención destaca de manera notable el papel de la segmentación, siendo muy relevante su influencia positiva en la tasa de apertura. Dicha influencia se ve aumentada a medida que disminuye la puntuación de una nación en las dimensiones individualismo-colectivismo y aversión a la incertidumbre, hecho contrario a lo propuesto en las hipótesis planteadas, puesto que en general los miembros de culturas más individualistas esperan una experiencia más personalizada en la interacción digital (Kale et al., 2007; Kale, 2003), mientras en aquellas naciones que tienen un elevado grado de aversión a la incertidumbre la información particularizada puede contribuir a disipar las dudas sobre las innovaciones (Möller \& Eisend, 2010).

Este resultado hace necesario interpretar los resultados bajo una nueva óptica, y proponer que es posible que en los países con elevada puntuación en individualismocolectivismo ya se dé por sentada cierta personalización en las comunicaciones, pero que en algunos casos el exceso de adaptación puede suponer rechazo al percibirse como una invasión de la intimidad, en línea con estudios en otros ámbitos del marketing digital (Möller \& Eisend, 2010). En cuanto a la moderación ejercida por la dimensión aversión a la incertidumbre, los resultados parecen apuntar a que la información más personalizada posibilitada por la segmentación no contribuye a disminuir la incertidumbre. En general, es prudente concluir que la segmentación incrementa la atención y que, de hecho, puede resultar una estrategia efectiva para combatir el coste de oportunidad generado por el exceso de frecuencia mencionado en el apartado anterior, puesto que además de incrementar la efectividad de apertura, una comunicación personalizada que se envía a una sección limitada de la base de datos contribuye a reducir la frecuencia total de envíos.

La segmentación no parece influir en la etapa de interés, resultado que contrasta con estudios anteriores (Bawm \& Nath, 2014). Sin embargo, a la vista de las múltiples metodologías de creación de segmentos existentes, no resultaría prudente concluir que este factor no es relevante para la etapa de interés, siendo más adecuado sostener que las técnicas utilizadas por las empresas que componen la muestra de esta investigación no han logrado mejorar el CTR, pero que no es posible descartar que otras aproximaciones puedan tener más éxito.

En cuanto a la efectividad de conversión, los resultados parecen confirmar la teoría de que la existencia de segmentación incrementa las posibilidades de que el usuario realice la acción objetivo del anunciante (Jackson \& DeCormier, 1999) y que, por tanto, pese al posible coste tanto en infraestructura como en medios humanos que puede tener el 
desarrollo de un programa de segmentación en una base de datos, es una técnica que puede ofrecer potenciales retornos de inversión.

La personalización no ha resultado relevante en las etapas de atención y acción del modelo de e-mail marketing, y sólo marginalmente en la etapa de interés -a través del estudio de la efectividad de retención de suscriptores. Este hecho contrasta vivamente con la abundancia de literatura que propone una influencia significativa - ya sea negativa o positiva- de esta variable (Marinova et al., 2002; Sahni et al., 2016; Theerthaana \& Sharad, 2014; White et al., 2008), lo que, a la vista de la vigencia de dos de los estudios y a los problemas de la muestra mencionados anteriormente, impide extraer conclusiones más allá de la recomendación de explorar más en detalle esta variable.

\subsubsection{Influencias culturales en los factores estudiados}

El estudio de las influencias culturales en la efectividad del e-mail marketing ha sido tal vez el aspecto más novedoso del enfoque de esta investigación. A la vista de la obtención de ocho situaciones en las que la cultura ejerce un papel relevante, se puede concluir que es razonable añadir el campo del e-mail marketing a la lista de disciplinas influidas por factores culturales, siendo ésta una aportación novedosa y de crucial relevancia en el contexto de esta tesis doctoral.

El análisis de las relaciones de moderación estadísticamente significativas ejercidas por las dimensiones de Hofstede en ciertos factores de influencia ha sido desarrollada en el estudio realizado para cada uno de ellos en los anteriores párrafos, con lo que este apartado no se detendrá en mencionarlas de nuevo. Sin embargo, será relevante puntualizar que la inexistencia de investigaciones previas con un enfoque similar en el estudio del e-mail marketing ha motivado que la mecánica de creación de hipótesis en cuanto a las relaciones de moderación haya sido más aventurada -se han utilizado como referencia estudios en áreas generales del marketing digital y el comportamiento del consumidor- y que, por tanto, resulte razonable que sólo 8 de las 47 hipótesis propuestas hayan resultado significativas.

Este enfoque de acusado carácter exploratorio ha permitido, sin embargo, alcanzar la conclusión de que la cultura es relevante en este ámbito, lo que abre la puerta a un significativo número de nuevas líneas de investigación. Por tanto, y pese a que algunos de los resultados obtenidos no resultan particularmente intuitivos, se puede considerar el objetivo principal en relación a esta parte de la investigación como cumplido. En línea con esto, una de las principales limitaciones mencionadas en la revisión de la literatura ha sido la utilización de muestras no globales para un número elevado de estudios. En el caso de que la cultura resultara un elemento moderador en el establecimiento de 
relaciones de influencia de ciertas variables, este hecho podría contribuir a explicar resultados contradictorios alcanzados en algunas situaciones.

Desafortunadamente, los resultados alcanzados no han contribuido a arrojar luz a este respecto. Por ejemplo, la ausencia de confirmación de hipótesis moderadoras con respecto a la personalización no permite dilucidar si su impacto es positivo (Sahni et al., 2016) o negativo (Marinova et al., 2002; White et al., 2008) en la efectividad de clic. Otro ejemplo si cabe más sorprendente es el que relaciona la dimensión masculinidadfeminidad con el número de imágenes. Dada la existencia de una relación significativa de moderación, cabría esperar que fuera posible explicar por qué una muestra en Reino Unido considera este factor como positivo en la efectividad de clic (Chittenden \& Rettie, 2003) mientras que una muestra global lo considera irrelevante (Kumar \& Salo, 2018). Sin embargo, el sentido de la relación obtenida por esta investigación es justo el contrario al esperado, lo que no permite resolver esta controversia.

Finalmente, en el desarrollo de la fase empírica esta investigación se ha topado con resultados inesperados en relación con las dimensiones culturales de Hofstede. Si bien el enfoque adoptado se limitaba a presumir relaciones de moderación en las variables de influencia, la necesaria introducción de las variables de Hofstede en el modelo requerida por la metodología de análisis de regresión múltiple- ha permitido comprobar que dichas dimensiones pueden jugar un papel muy relevante como variables independientes.

Así, tal y como se ha detallado en el capítulo séptimo, todas las dimensiones de Hofstede han resultado significativas en el estudio de la atención, siendo la distancia al poder particularmente relevante, en un escala similar a la frecuencia y segmentación; por su parte, la orientación al largo plazo y la aversión a la incertidumbre han resultado significativas en el estudio de la efectividad de clic, individualismo-colectivismo lo ha resultado en el estudio de la efectividad de retención de suscriptores -en una gran proporción, contribuyendo a incrementar la varianza explicada de $1.8 \%$ a $23.2 \%$ - y masculinidad-feminidad y orientación al largo plazo lo han resultado en el estudio de etapa de acción.

Como se ha mencionado en el apartado 8.3.1, estos resultados, si bien fuera del alcance que planteó inicialmente esta tesis, han permitido identificar una línea de investigación con razonables posibilidades de éxito: la incorporación al modelo de ciertas dimensiones culturales como factores directos de influencia, lo que ha derivado en dos publicaciones reseñadas en el apartado 8.7.

\subsection{RECOMENDACIONES PARA LA PRÁCTICA}

El carácter eminentemente práctico de esta tesis doctoral permite desarrollar con facilidad una serie de sugerencias que se derivan de las conclusiones expuestas en los 
anteriores párrafos. Como se mencionó en la propuesta de esta investigación, uno de los objetivos fundamentales de la misma era el desarrollo de recomendaciones que permitieran mejorar la efectividad de sus campañas a las pequeñas y medianas empresas que no pueden financiar estudios de mercado específicos para cada uno de los países en los que operan. A continuación, se presentan dichas recomendaciones, relacionándolas con cada una de las etapas en las que se articula el modelo, y se sugieren diversas técnicas para extraer el máximo valor posible de los recursos disponibles por parte de cada anunciante. Adicionalmente, se utilizará el caso de España como ejemplo a la hora de particularizar los resultados obtenidos desde un punto de vista cultural.

\subsubsection{Etapa de atención}

Las principales variables de influencia en esta fase han resultado ser la frecuencia y la segmentación. Por una parte, los resultados de efectividad decreciente con la frecuencia implican que, pese a la aparente gratuidad económica de cada comunicación, es necesario que las compañías sean selectivas, trasladando al e-mail marketing la mentalidad que impera en la compra de publicidad en otros canales, en los que la limitación de presupuesto actúa como catalizador de una selección cuidadosa de los mensajes. Actualmente, la percepción de gratuidad de este medio puede tener como consecuencia una utilización excesiva del mismo. Dada la relevancia de la frecuencia, parece razonable la creación tanto de un sistema de coste virtual que ponga de manifiesto el coste de oportunidad de cada envío como de un mecanismo de priorización que permita identificar las comunicaciones que ameritan ser enviadas. Otra potencial ruta para gestionar el exceso de frecuencia consiste en limitar el número de envíos mensuales a una cifra prefijada. En el caso de que existan de manera recurrente múltiples contenidos relevantes, puede ser recomendable la creación de una plantilla de correo electrónico que soporte múltiples mensajes, por ejemplo, a través de un formato que contenga una historia principal que protagonice el correo acompañada de un pequeño párrafo que introduzca una historia secundaria, tal y como muestra la figura 41. 

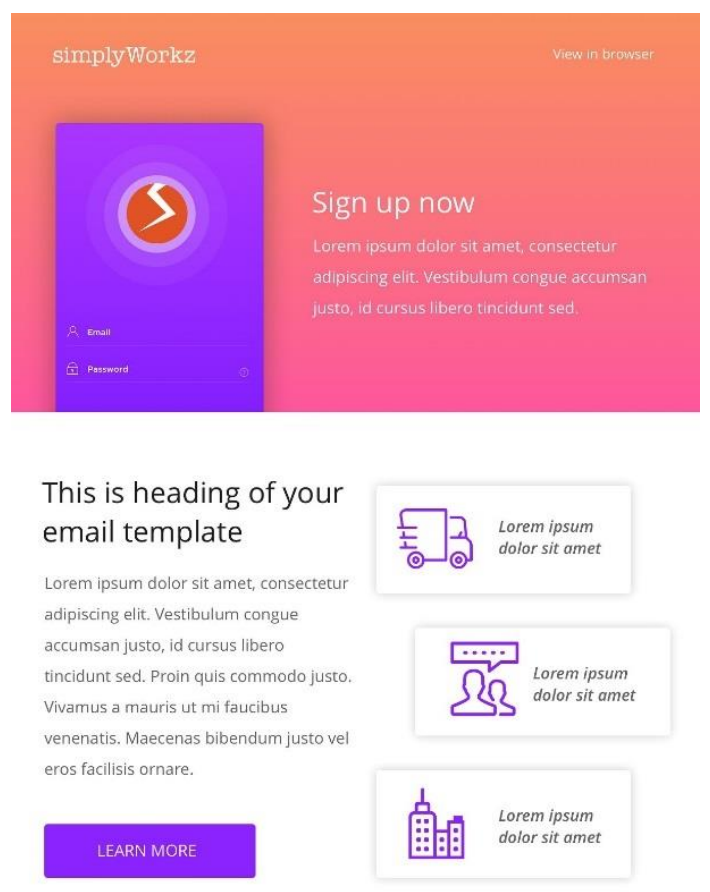

Figura 41 - Plantilla de correo electrónico con historia principal y secundarias. Fuente: simplyWorkz

En lo referido a la segmentación, los resultados demuestran la contribución de este factor al incremento de atención. Sin embargo, es necesario mencionar que el éxito de esta técnica está basado en la utilización de un criterio relevante para la construcción de segmentos y en la creación de contenido adaptado a cada segmento. Así, es recomendable la construcción de segmentos utilizando criterios como los desarrollados por los departamentos de marketing para identificar a los grupos de consumidores potenciales para cada producto -por ejemplo, sociodemográficos, geográficos, etc.-, e incorporar en la comunicación el producto más relevante para cada segmento (Baggott, 2011). La utilización de los datos del entorno de e-mail marketing, por ejemplo, los referentes a interacciones con correos anteriores, es también una técnica apropiada; una práctica popular consiste en identificar a aquellos suscriptores que llevan varios envíos sin interactuar con los correos y crear una promoción particular o comunicación específica para confirmar que siguen interesados en continuar recibiendo comunicaciones comerciales -técnica conocida como recuperación de suscriptores. Tras varios intentos infructuosos, es recomendable eliminar a los usuarios inactivos de la base de datos, lo que contribuirá a mejorar la reputación del remitente ante los ISPs e incrementará la efectividad de entrega (Baggott, 2011).

La extrapolación al e-mail marketing de los segmentos creados a través de otro tipo de herramientas internas, como por ejemplo los softwares de CRM o los programas de 
fidelidad, es otra técnica interesante que permite identificar el valor relativo de cada suscriptor y asegurarse de que aquellos que puedan suponer mayores ingresos reciban una comunicación lo más ajustada posible a sus necesidades. La utilización de segmentos mejora de manera intrínseca la frecuencia de envío, puesto que aumenta la relevancia de la comunicación para cada usuario y, por tanto, elimina aquellos emails irrelevantes que sin la utilización de esta metodología habrían alcanzado a toda la base de datos. Así, esta técnica incrementa por partida doble la efectividad de apertura y es, por tanto, una de las principales mejoras a introducir en un programa de e-mail marketing.

Además de la segmentación y la frecuencia, y en un nivel inferior de importancia, la temática del asunto, su longitud y el día de la semana de envío pueden contribuir a mejorar la efectividad de apertura. Una baja frecuencia proporciona cierta flexibilidad a la hora de seleccionar el día de envío, hecho que contribuye a aumentar la efectividad puesto que permite elegir el más adecuado. A este respecto, es recomendable experimentar con esta variable para identificar los días más relevantes en cada base de datos, puesto que a priori no es posible utilizar generalizaciones a la vista de los resultados obtenidos.

En cuanto al asunto, y dado que como se ha mencionado anteriormente las promociones habituales parecen haberse vuelto tan frecuentes que resultan invisibles a los ojos del consumidor, la experimentación con temáticas como los regalos o las promociones de temporada, así como los mensajes orientados a aspectos experienciales o sociales de la marca, son vías alternativas para mejorar la atención del usuario. En consonancia con esto, la presencia de números ya no supone un elemento disruptivo en la comunicación y, por tanto, no contribuye a incrementar la atención del usuario, hecho que también es aplicable a la utilización de caracteres especiales. De esta manera, no resultará necesario condicionar la redacción de la línea de asunto a la presencia de estos elementos formales, sino adecuar el asunto a la temática específica.

En lo que respecta a la longitud del asunto, es recomendable mantener actualizadas las longitudes máximas que muestran las bandejas de entrada en los dispositivos y sistemas operativos móviles más habituales para asegurar que no se pierda información relevante, así como tratar de mantenerla entre 50 y 55 caracteres, ya que tras realizar un análisis de sensibilidad -consistente en ordenar la serie ALON-OR en orden creciente de número de caracteres y estimar en qué intervalo de valores de ALON hay un número de casos elevado con un OR superior al OR medio- entre la efectividad de apertura y esta variable, se observa que este intervalo es el óptimo desde un punto de vista de efectividad.

Finalmente, las influencias culturales resultan relevantes en esta fase, lo que hace necesario calibrar la posición de las culturas nacionales en las dimensiones distancia al 
poder, individualismo-colectivismo, masculinidad-feminidad y aversión a la incertidumbre para valorar posibles modificaciones en la importancia relativa de cada factor que presente una relación de moderación -longitud y contenido de asunto, frecuencia y segmentación-, adaptando las recomendaciones generales a cada mercado, de acuerdo a las conclusiones específicas desarrolladas en el anterior apartado.

En el caso de España, sus puntuaciones en las dimensiones distancia al poder e individualismo-colectivismo resultan casi iguales a la media, lo que mantiene las recomendaciones generales relativas a la frecuencia, la segmentación y el contenido del asunto. Su posición inferior a la media en la dimensión masculinidad-feminidad -con un valor de 42, inferior al valor crítico de 49 mencionado en el capítulo anterior- sitúa a nuestro país en el grupo de aquellos en los que el incremento de longitud del asunto mejora la efectividad de apertura y en el de los que la utilización de temáticas de descuentos será menos negativa que para la media. Por otra parte, su posición notablemente más elevada a la media en la dimensión aversión a la incertidumbre superior a una desviación estándar- implica que, si bien la segmentación resulta una técnica efectiva, lo será menos que en la media de países, por lo que la frecuencia resultará el factor más importante en esta fase.

\subsubsection{Etapa de interés}

La recomendación fundamental asociada a la mejora de efectividad en esta etapa es sin duda la necesidad de reducir al máximo posible la longitud de los correos electrónicos, dado que esta variable ha resultado la más influyente en la fase asociada al interés. La inexistencia de un límite riguroso para la extensión de los emails -a diferencia de otros medios digitales como la publicidad en buscadores o los bannerspuede resultar contraproducente, puesto que será necesaria la creación de estrictos controles internos que aseguren que los correos no exceden una longitud determinada.

A este respecto, tras la realización de un análisis de sensibilidad análogo al realizado para la longitud del asunto, se constata el empeoramiento progresivo causado por el incremento de longitud a partir de los 1400 caracteres, con lo que la recomendación es mantenerse por debajo de esta cifra, puesto que a partir de ese punto la pérdida de efectividad causada por cada nuevo carácter se hace más patente. No hay que olvidar que la utilización de imágenes o la ampliación de la información en el sitio web al que dirijan los enlaces son alternativas razonables en el caso de que el mensaje que haya que comunicar sea particularmente complejo.

Existen varias técnicas para generar un interés suficiente en el consumidor con un texto de longitud reducida. En primer lugar, una buena disposición estética de la plantilla de correo y una adecuada priorización de los objetivos de comunicación -a través de los tamaños de fuente, imágenes, colores u otro tipo de los múltiples tratamientos posibles 
en el entorno HTML- pueden ser realmente determinantes a la hora de asegurar la adecuada transmisión del mensaje. De esta manera, se recomienda la utilización de los colores amarillo y el verde por su mayor efectividad (Zviran et al., 2006), el uso de dos columnas de diferente anchura cuando haya varios mensajes que comunicar (Arnold, 2008), y la inclusión del mensaje principal en la parte superior izquierda del correo, puesto que es la que recibe mayor atención por parte del usuario (Kumar \& Salo, 2018). Asimismo, es recomendable no reciclar textos desarrollados para otro tipo de canales con una limitación más extensa en cuanto a longitud -por ejemplo, publicidad en revistas, contenidos editoriales, relaciones públicas-, y contar con editores entrenados en la creación de textos específicos para el entorno del e-mail marketing.

Finalmente, es necesario mencionar que la recomendación ofrecida para la etapa de atención respecto a la reducción de la frecuencia de envío no debe entrar en conflicto con la expuesta en esta segunda etapa -por ejemplo, optando por concentrar el contenido de varios e-mails en un solo envío con para disminuir la frecuencia-, puesto que la mejora de efectividad de apertura lograda se vería compensada por una reducción de efectividad de clic. Como se ha mencionado, la utilización de técnicas de maquetación inteligente es una ruta más adecuada para mejorar los resultados de ambas etapas. Asimismo, y puesto que el número de imágenes incrementa la efectividad de clic, es recomendable su utilización como soporte para reducir la longitud del texto. Además de la habitual función ilustrativa de fotografías o dibujos, formatos como los iconos, las infografías o los textos integrados pueden aportar mayores posibilidades a la hora de comunicar mensajes de cierta complejidad.

Desde un punto de vista semántico, la ausencia de influencia de los incentivos económicos -en línea con los resultados obtenidos para la etapa de atención- reafirma la recomendación de utilizar temáticas no asociadas a descuentos en el e-mail marketing, o bien, limitar lo máximo posible su extensión en el cuerpo del correo. Los elementos que generan sensación de escasez, sin embargo, si parecen influir en la efectividad de clic. Por tanto, es necesario contextualizar culturalmente la base de datos para determinar la relevancia de este factor, siendo recomendable incluirlos en países con valores de distancia al poder superiores a 54, y siendo contraproducente hacerlo en naciones con puntuación inferior a 30 en esta dimensión. A este respecto, se recuerda que las técnicas más habituales son la mención de la existencia de un número de unidades limitadas o de una fecha límite a partir de la cual los productos o la promoción no estará disponible. En el caso concreto de España, y dado que su puntuación en la dimensión distancia al poder es de 57, la utilización de esta técnica es recomendable.

Finalmente, es necesario mencionar que el incremento de interés propiciado por las imágenes se hace más acusado en aquellos países con baja puntuación en la dimensión 
masculinidad-feminidad, lo que apunta a la importancia de dar relevancia a esta técnica en este grupo de naciones, en el que se encuentra incluido España.

\subsubsection{Etapa de acción}

Dado que en el caso de esta última etapa todos los factores de influencia detectados tienen un orden de magnitud similar, por lo que las recomendaciones que se presentan a continuación se espera que tengan efectos similares. En primer lugar, la utilización de técnicas de segmentación tiene una influencia positiva en la efectividad de conversión, con lo que se reiteran las sugerencias desarrolladas a este respecto en la etapa de atención, a la vista de que los beneficios también se hacen extensivos a la última fase del modelo.

Desde un punto de vista semántico, la presencia de incentivos económicos es beneficiosa para la efectividad de conversión, resultado sorprendente dada la ausencia de influencia en las dos etapas anteriores. Como se ha detallado en anteriores párrafos, este hecho puede estar asociado a las actividades realizadas en otros canales de comunicación, o a que la existencia de dichos incentivos implica un posicionamiento favorable de precio en relación con la competencia. Así, en lo que respecta a este factor, y dada la limitada capacidad explicativa del modelo, no resulta prudente ofrecer una recomendación tajante.

Sin embargo, sí que es recomendable incluir elementos que generan sensación de escasez para la mejora la efectividad de conversión y de clic en aquellos países con puntuaciones superiores a 38 en la dimensión orientación al largo plazo, hecho que refuerza la utilización de esta técnica en naciones como España-cuya puntuación es de 48 en esta dimensión.

\subsection{LIMITACIONES DE LA INVESTIGACIÓN}

Pese a la utilización de un método riguroso y a que esta investigación doctoral ha alcanzado los objetivos que se proponía inicialmente, es necesario mencionar ciertas limitaciones que han de ser consideradas a la hora de contextualizar la conclusiones y recomendaciones detalladas en los anteriores párrafos.

En primer lugar, pese al objetivo fijado inicialmente de valorar en su conjunto todos aquellos factores con potencial influencia en la efectividad del e-mail marketing, la muestra utilizada no ha permitido la incorporación de la hora de envío, lo que puede resultar relevante en futuras investigaciones sin esta limitación. Asimismo, y pese a la incorporación de la variable personalización al modelo, el hecho de que un número muy limitado de registros hayan utilizado esta técnica (sólo el $0.5 \%$ de cada muestra) puede haber influido en la ausencia de conclusiones determinantes respecto a la misma. 
En segundo lugar, el estudio de la efectividad de retención de suscriptores se ve limitado por la escasa capacidad explicativa del modelo. Pese a que ha sido posible evaluar la etapa de interés a través del estudio de la efectividad de clic, la ausencia de resultados concluyentes relativos a la tasa de retención de suscriptores ha restado riqueza al análisis, más allá de confirmar los resultados de investigaciones que señalan la relevancia de la influencia directa de las dimensiones culturales en esta etapa.

En tercer lugar, en el modelo de efectividad propuesto en esta investigación doctoral no se ha vinculado ninguna etapa concreta del estudio de la efectividad en el e-mail marketing a la fase de deseo del modelo AIDA, dadas las dificultades metodológicas motivadas por el hecho de que dicha fase ocurra fuera del entorno del e-mail marketing.

Finalmente, la utilización de datos basados en campañas reales ha permitido la obtención de conclusiones a través del análisis de comportamientos implícitos del consumidor. Sin embargo, la ausencia de variables que recojan las intenciones y actitudes del usuario no permite reforzar la robustez de dichas conclusiones a través de datos explícitos, con lo que será necesario tener en cuenta la posibilidad de que alguna de las explicaciones ofrecidas pueda resultar incompleta.

\subsection{LÍNEAS DE INVESTIGACIÓN PARA FUTUROS ESTUDIOS}

A raíz del trabajo teórico y del análisis empírico de esta investigación se abren puertas a nuevas líneas de investigación que desarrollar en el futuro. Por una parte, durante el desarrollo del marco teórico ha resultado necesario delimitar un alcance restringido que permitiera que el tema resultara abordable en el contexto de una investigación doctoral. Asimismo, en la preparación del análisis empírico y la extracción de conclusiones han surgido cuestiones no enteramente resueltas. A continuación, se presenta un resumen de este tipo de situaciones que pueden resultar interesantes para expandir los resultados alcanzados.

En primer lugar, la efectividad de entrega ha quedado excluida del alcance de esta tesis pese a resultar una fase relevante en el desarrollo procesal del e-mail marketing. El estudio empírico de esta etapa requiere un panel con un número elevado de direcciones de correo electrónico o la colaboración de un ISP, dificultades difíciles de salvar pero que, en el caso de ser superadas, permiten acceder a un campo de estudio mayormente inexplorado dada la ausencia de literatura al respecto.

En segundo lugar, esta investigación se ha centrado en los e-mails comerciales, sin abordar el fenómeno del spam o el estudio de los e-mails transaccionales. A la vista de las conclusiones alcanzadas, sería relevante determinar si las actuaciones propuestas sobre los factores de influencia más relevantes tienen influencia en la categorización automática que los filtros de spam de los ISPs realizan sobre los correos electrónicos. Análogamente, el estudio de los factores de influencia en los e-mails transaccionales 
resultaría complementario a esta investigación, puesto que permitiría realizar un contraste en el comportamiento del consumidor en función de la tipología del correo.

En tercer lugar, la repetición del estudio con una muestra que presentara la posibilidad de incluir factores excluidos como la hora de envío - con problemas de colinealidad en esta investigación - o la personalización -con una distribución en la muestra de este trabajo poco favorable a la detección de efectos- aportaría riqueza a la investigación y permitiría determinar la importancia relativa de dichas variables respecto a las ya identificadas.

En cuarto lugar, el estudio teórico de otras fases relevantes de un programa completo de e-mail marketing, como la adquisición de suscriptores o la integración con otras fuentes de datos como herramientas de CRM o DMP -Data Management Platforms-, incrementaría la comprensión de este canal y, combinado con la literatura existente, contribuiría a alcanzar una visión integral del mismo.

En quinto lugar, y en lo que respecta a la etapa de interés, sería relevante realizar un estudio de laboratorio en el que se analizara el comportamiento de los usuarios tras el clic para evaluar la calidad de su interacción con el contenido enlazado. Este enfoque permitiría introducir una escala continua en la medida del interés que aportaría riqueza en comparación con la escala dicotómica -presencia o ausencia de clic- usada en esta tesis.

En sexto lugar, el estudio de la fase de deseo a través de la observación del comportamiento del consumidor tanto en los dominios web del anunciante como en los de compañías competidoras podría arrojar cierta luz sobre la significativa diferencia en valores absolutos entre la tasa de clic y la de conversión. Dicho estudio se podría realizar o bien a través de un panel de consumidores online como los utilizados por compañías de estudios de mercado (Nielsen o Ipsos, por ejemplo), bien a través de plataformas que tengan una visión global del comportamiento de los consumidores online (por ejemplo, Google o Facebook).

Finalmente, el modelo propuesto en el análisis de la retención de suscriptores y de la etapa de acción ha resultado tener un poder predictivo muy limitado. De esta manera, un estudio que abordara estas dos etapas con nuevos factores de influencia no incluidos en esta investigación - por ejemplo, vinculados a la presión promocional percibida en el caso de la retención de suscriptores, en línea con Micheaux (2011)- expandiría los resultados alcanzados.

\subsection{DIFUSIÓN DE RESULTADOS RELACIONADOS CON LA INVESTIGACIÓN}

Publicaciones en revistas: 
- Lorente-Páramo AJ, Hernández-García A, Chaparro-Peláez J (2020a). Influence of cultural dimensions on promotional e-mail effectiveness. Technological Forecasting and Social Change 150, 119788, 1-13.

- Lorente-Páramo AJ, Hernández-García A, Chaparro-Peláez J (2020b). Modelling e-mail marketing effectiveness - An approach based on hierarchy-ofeffects theory. Cuadernos de gestión, 1-27. Artículo aceptado para publicación.

- Lorente-Páramo AJ, Hernández-García A, Chaparro-Peláez J (2020c). Getting your emails opened: attention and e-mail marketing. Journal of Research in Interactive Marketing, 1-29. Artículo en revisión.

Ponencias en congresos:

- Lorente-Páramo AJ, Chaparro-Peláez J, Hernández-García A (2020d). The moderating role of national culture in click-thru rates of e-mail marketing campaigns. $11^{\text {th }}$ Academy of Innovation, Entrepreneurship, and Knowledge (ACIEK 2020).

- Lorente-Páramo AJ, Hernández-García A, Chaparro-Peláez J (2019). Cultural factors for social change: technological effectiveness of e-mail. 10th Innovation, Entrepreneurship and Knowledge Academy Conference (INEKA 2019), 1-21.

- Lorente-Páramo AJ, Hernández-García A, Chaparro-Peláez J (2018). A Conceptual Framework for the Study of E-mail Marketing Effectiveness. 12th International Conference on Industrial Engineering and Industrial Management - XII Congreso de Ingeniería de Organización, 1-8. 


\section{Bibliografía}




\section{BIBLIOGRAFIA}

Abrahams, A. S., \& Deane, J. K. (2010). A multi-industry, longitudinal analysis of the email marketing habits of the largest United States franchise chains. Journal of Direct, Data and Digital Marketing Practice, 11(3), 187-197. https://doi.org/10.1057/dddmp.2009.31

Aiken, L., West, S., \& Reno, R. (1991). Multiple regression: Testing and interpreting interactions (1st ed.). London: Sage.

Albers-Miller, N. D., \& Gelb, B. D. (1996). Business Advertising Appeals as a Mirror of Cultural Dimensions: A Study of Eleven Countries. Journal of Advertising, 25(4), 57-70. https://doi.org/10.1080/00913367.1996.10673512

Andersson, M., Fredriksson, M., \& Berndt, A. (2014). Open or delete: decision-makers' attitudes towards e-mail marketing messages. Advances in Social Sciences Research Journal, 1(3), 133-144. https://doi.org/10.14738/assrj.13.201

Ansari, A., \& Mela, C. F. (2003). E-Customization. Journal of Marketing Research (JMR), 4O(2), 131-145. https://doi.org/10.1509/jmkr.40.2.131.19224

Arnold, J. (2008). Email marketing for dummies (2nd ed.). Hoboken, NJ: Wiley Publishing, Inc.

Ashcroft, L., \& Hoey, C. (2001). PR, marketing and the Internet: implications for information professionals. Library Management, 22(1/2), 68-74. https://doi.org/10.1108/01435120110358952

Baack, D. W., \& Singh, N. (2007). Culture and web communications. Journal of Business Research, 60(3), 181-188. https://doi.org/10.1016/j.jbusres.2006.11.002

Baggott, C. (2011). Email Marketing By the Numbers: How to Use the World's Greatest Marketing Tool to Take Any Organization to the Next Level (1st ed.). Hoboken, NJ: John Wiley \& Sons.

Balakrishnan, R., \& Parekh, R. (2015). Learning to predict subject-line opens for largescale email marketing. In Proceedings - 2014 IEEE International Conference on Big Data, IEEE Big Data 2014 (pp. 579-584). Washington, DC: IEEE. https://doi.org/10.1109/BigData.2014.7004277

Baltas, G. (2003). Determinants of internet advertising effectiveness: an empirical study. International Journal of Market Research, 45(4), 505-513. https://doi.org/10.1177/147078530304500403

Barnes, S. J. (2002). Wireless digital advertising: nature and implications. International Journal of Advertising, 21(3), 399-420. https://doi.org/10.1080/02650487.2002.11104939

Barnham, C. (2008). Instantiation - Reframing brand communication. International Journal of Market Research, 50(2), 203-220. https://doi.org/10.1177/147078530805000205

Barry, T. E., \& Howard, D. J. (1990). A review and critique of the hierarchy of effects 
in advertising. International Journal of Advertising, 9(2), 121-135. https://doi.org/10.1080/02650487.1990.11107138

Baskerville, R. F. (2003). Hofstede never studied culture. Accounting, Organizations and Society, 28(1), 1-14. https://doi.org/10.1016/S0361-3682(01)00048-4

Bauman, A., Bowles, H. R., Huhman, M., Heitzler, C. D., Owen, N., Smith, B. J., \& Reger-Nash, B. (2008). Testing a Hierarchy-of-Effects Model. Pathways from Awareness to Outcomes in the VERB Campaign 2002-2003. American Journal of Preventive Medicine, $34(6 \quad$ SUPPL.), $\quad$ S249-S256. https://doi.org/10.1016/j.amepre.2008.03.015

Bawm, Z. L., \& Nath, R. P. D. (2014). A Conceptual Model for effective email marketing. In 2014 17th International Conference on Computer and Information Technology (ICCIT) (pp. 250-256). Dhaka: IEEE. https://doi.org/10.1109/ICCITechn.2014.7073103

Belch, G. E., \& Belch, M. A. (2003). Advertising and Promotion: An Integrated Marketing Communications Perspective. Learning (6th ed.). New York: McGrawHill.

Berman, R. (2017). Beyond the Last Touch: Attribution in Online Advertising. SSRN ELibrary. https://doi.org/10.2139/ssrn.2384211

Bettman, J. R. (1970). Information Processing Models of Consumer Behavior. Journal of Marketing Research, 7(3), 370-376. https://doi.org/doi:10.2307/3150297

Blodgett, J. G., Bakir, A., \& Rose, G. M. (2008). A test of the validity of Hofstede's cultural framework. Journal of Consumer Marketing, 25, 339-349. https://doi.org/10.1108/07363760810902477

bluehornet. (2013). Consumer views of email marketing. Retrieved from http://info.digitalriver.com/rs/digitalriver/images/Report_Consumer-Views-ofEmail-Marketing_2013_web_(2).pdf

Bonfrer, A., \& Drèze, X. (2009). Real-Time Evaluation of E-mail Campaign Performance. $\quad$ Marketing $\quad$ Science, 28(2), 251-263. https://doi.org/10.1287/mksc.1080.0393

Bowerman, B. L., \& O’Connell, R. (1990). Linear Statistical Models: An Applied Approach (2nd ed.). London: Duxbury Press.

Broussard, G. (2000). How advertising frequency can work to build online advertising effectiveness. International Journal of Market Research, 42(4), 439-458. https://doi.org/10.1177/147078530004200406

Bruner, G. C., \& Kumar, A. (2000). Web Commercials and Advertising Hierarchy-ofEffects. Journal of Advertising Research, 40(1-2), 35-42. https://doi.org/10.2501/JAR-40-1-2-35-42

Carmen, P., \& Nicolae, P. A. (2010). Email marketing campaigns: the easiest path from organizations to consumers - an exploratory assessment. Annals of the University of Oradea, 1, 737-742. 
Cases, A. S., Fournier, C., Dubois, P. L., \& Tanner, J. F. (2010). Web Site spill over to email campaigns: The role of privacy, trust and shoppers' attitudes. Journal of Business Research, 63(9-10), 993-999. https://doi.org/10.1016/j.jbusres.2009.02.028

Chang, H. H., Rizal, H., \& Amin, H. (2013). The determinants of consumer behavior towards email advertisement. Internet Research, 23(3), 316-337. https://doi.org/10.1108/10662241311331754

Chen, Y. L., Kuo, M. H., Wu, S. Y., \& Tang, K. (2009). Discovering recency, frequency, and monetary (RFM) sequential patterns from customers' purchasing data. Electronic Commerce Research and Applications, 8(5), 241-251. https://doi.org/10.1016/j.elerap.2009.03.002

Chittenden, L., \& Rettie, R. (2003). An evaluation of e-mail marketing and factors affecting response. Journal of Targeting Measurement and Analysis for Marketing, 11(3), 203-217. https://doi.org/10.1057/palgrave.jt.5740078

Cohen, J., Cohen, P., West, S., \& Aiken, L. (2003). Applied Multiple Regression/Correlation Analysis for the Behavioral Sciences (3rd ed.). Mahwah, NJ: Lawrence Erlbaum Associates.

Colley, R. H. (1961). Defining advertising goals for measured advertising results. The Association of National Advetisers.

Cook, R. D., \& Weisberg, S. (1982). Residuals and Influence in Regression. Monographs on Statistics and Applied Probability (1st ed.). New York: Chapman \& Hall/CRC.

Cramphorn, S. (2006). How to use advertising to build brands-In search of the philosopher's stone. International Journal of Market Research, 48(3), 255-276. https://doi.org/10.1177/147078530604800303

Cranor, L. F., \& LaMacchia, B. A. (1998). Spam! Communications of the ACM, 41(8), 74-83. https://doi.org/10.1145/280324.280336

DeMooij, M. (2003). Convergence and divergence in consumer behaviour: implications for global advertising. International Journal of Advertising, 22(2), 183-202. https://doi.org/10.1080/02650487.2003.11072848

DeMooij, M. (2011). Consumer behavior and culture: Consequences for global marketing and advertising (2nd ed.). Thousand Oaks, CA: Sage Publications.

DeMooij, M. (2013). On the misuse and misinterpretation of dimensions of national culture. International Marketing Review, 30(3), 253-261. https://doi.org/10.1108/02651331311321990

DeMooij, M. (2014). Global marketing and advertising: Understanding cultural paradoxes (4th ed.). Thousand Oaks, CA: Sage.

DeMooij, M. (2015). Cross-cultural research in international marketing: clearing up some of the confusion. International Marketing Review, 32(6), 646-662. https://doi.org/10.1108/IMR-12-2014-0376 
DeMooij, M., \& Hofstede, G. (2010). The hofstede model: Applications to global branding and advertising strategy and research. International Journal of Advertising, 29(1), 85-110. https://doi.org/10.2501/S026504870920104X

DeMooij, M., \& Hofstede, G. (2011). Cross-Cultural Consumer Behavior : A Review of Research Findings. Journal of International Consumer Marketing, 23(June), 181192. https://doi.org/10.1080/08961530.2011.578057

Diaz, J., Rusu, C., \& Collazos, C. A. (2017). Experimental validation of a set of cultural-oriented usability heuristics: e-Commerce websites evaluation. Computer Standards and Interfaces, 50, 160-178. https://doi.org/10.1016/j.csi.2016.09.013

Dufrene, D. D., Engelland, B. T., Lehman, C. M., \& Pearson, R. A. (2005). Changes in Consumer Attitudes Resulting from Participation in a Permission E-mail Campaign. Journal of Current Issues \& Research in Advertising, 27(1), 65-77. https://doi.org/10.1080/10641734.2005.10505174

Durbin, J., \& Watson, G. S. (1950). Testing for serial correlation in least squares regression I. Biometrika, 37(3-4), 409-428. https://doi.org/10.2307/2332391

Durbin, J., \& Watson, G. S. (1951). Testing for Serial Correlation in Least Squares Regression. II. Biometrika, 38(1/2), 159. https://doi.org/10.2307/2332325

Econsultancy. (2015). State of marketing attribution in Asia Pacific. Retrieved from https://econsultancy.com/reports/state-of-marketing-attribution-in-asia-pacific/

Ellis-Chadwick, F., \& Doherty, N. F. (2012). Web advertising: The role of e-mail marketing. Journal of Business Research, 65(6), 843-848. https://doi.org/10.1016/j.jbusres.2011.01.005

eMarketer. (2012). Email Marketing Benchmarks: Key Data, Trends and Metrics. Retrieved from http://www.emarketer.com/public_media/docs/eMarketer_Email_Marketing_Benc hmarks_Key_Data_Trends_Metrics.pdf

eMarketer. (2018). Email marketing statpack 2018. Retrieved April 3, 2019, from https://contentstorage-

na1.emarketer.com/d7f59ab9d57267498adbd737814239a9p/Email_Marketing_Sta tPack_2018_eMarketer.pdf?st=2019-08-29T11\%3A44\%3A14Z\&se=2019-0829T11\%3A54\%3A14Z\&sp=r\&sv=2018-03-

28\&sr=b\&sig=kxBnACTQa0AJROTP58Ok5eFSwGNc19mRpZkFrACLM7A\%3 $\mathrm{D}$

Engelen, A., \& Brettel, M. (2011). Assessing cross-cultural marketing theory and research. Journal of Business Research, 64(5), 516-523. https://doi.org/10.1016/j.jbusres.2010.04.008

ExactTarget. (2012). Channel preference survey. Retrieved from http://image.exct.net/lib/fe641570776d02757515/m/1/SFF14The2012ChannelPreferenceSurvey.pdf

Fariborzi, E., \& Zahedifard, M. (2012). E-mail Marketing: Advantages , Disadvantages and Improving Techniques. International Journal of E-Education, e-Business, $e$ Management and e-Learning, 2(3), 232-236. 
https://doi.org/10.7763/IJEEEE.2012.V2.116

Faught, K. S., Whitten, D., \& Green, K. W. (2004). Doing Survey Research on the Internet: Yes, Timing Does Matter. Journal of Computer Information Systems, 44(3), 26-34. https://doi.org/10.1080/08874417.2004.11647579

Faul, F., Erdfelder, E., Buchner, A., \& Lang, A. G. (2009). Statistical power analyses using $G^{*}$ Power 3.1: Tests for correlation and regression analyses. Behavior Research Methods, 41(4), 1149-1160. https://doi.org/10.3758/BRM.41.4.1149

Field, A. (2013). Discovering Statistics Using IBM SPSS Statistics (4th ed.). London: Sage.

Florès, L. (2014). How to Measure Digital Marketing (1st ed.). London: Palgrave Macmillan UK. https://doi.org/10.1057/9781137340696

Gardner, B. S. (2011). Responsive web design: Enriching the user experience. Sigma Journal: Inside the Digital Ecosystem, 11(1), 13-19.

Gartner. (2015). Gartner CMO spend survey 2015-2016. Retrieved February 3, 2018, from https://www.gartner.com/smarterwithgartner/digital-marketing-comes-of-agein-gartners-cmo-spend-survey-2015-2016/

Gauzente, C. (2009). Information search and paid results - Proposition and test of a hierarchy-of-effect model. Electronic Markets, 19(2-3), 163-177. https://doi.org/10.1007/s12525-009-0015-1

Ghirvu, A. I. (2013). The AIDA model for Advergames. USV Annals of Economics and Public Administration, 13(1), 90-98.

Goodrich, K. (2011). Anarchy of effects? Exploring attention to online advertising and multiple outcomes. Psychology and Marketing, 28(4), 417-440. https://doi.org/10.1002/mar.20371

Gopal, R. D., Tripathi, A. K., \& Walter, Z. D. (2006). Economics of first-contact email advertising. Decision Support Systems, 42(3), 1366-1382. https://doi.org/10.1016/j.dss.2005.11.004

Groves, E. (2009). The Constant Contact guide to email marketing (1st ed.). Hoboken, NJ: John Wiley \& Sons.

Haq, Z. U. (2009). E-mail advertising: A study of consumer attitude toward e-mail advertising among Indian users. Journal of Retail and Leisure Property, 8(3), 207223. https://doi.org/10.1057/rlp.2009.10

Hartemo, M. (2016). Email marketing in the era of the empowered consumer. Journal of Research in Interactive Marketing, 10(3), 212-230. https://doi.org/10.1108/JRIM-06-2015-0040

Hassan, S., Zaleha, S., Nadzim, A., \& Shiratuddin, N. (2015). Strategic Use of Social Media for Small Business Based on the AIDA Model. Procedia - Social and Behavioral Sciences, 172, 262-269. https://doi.org/10.1016/j.sbspro.2015.01.363

Hayes, A. F. (2013). Introduction to mediation, moderation, and conditional process 
analysis: a regression-based approach (1st ed.). New York: Guilford.

Hedley, S. (2006). A brief history of spam. Information \& Communications Technology Law, 15(3), 223-238. https://doi.org/10.1080/13600830600960758

Hermeking, M. (2006). Culture and Internet Consumption: Contributions from CrossCultural Marketing and Advertising Research. Journal of Computer-Mediated Communication, 11(1), 192-216. https://doi.org/10.1111/j.10836101.2006.00010.x

Hofstede, G. (1980). Culture's Consequences: International Differences in Workrelated Values. Cross-Cultural Research and Methodology series (1st ed.). London: Sage. https://doi.org/10.5465/AME.2004.12689661

Hofstede, G. (2001a). Culture's Consequences: Comparing Values, Behaviors, Institutions, and Organizations Across Nations (2nd ed.). London: SAGE Publications.

Hofstede, G. (2001b). Culture's Recent Consequences: Using Dimension Scores in Theory and Research. International Journal of Cross Cultural Management, 1(1), 11-17. https://doi.org/10.1177/147059580111002

Hofstede, G. (2016). Dimension data matrix. Retrieved July 31, 2017, from http://geerthofstede.com/research-and-vsm/dimension-data-matrix/

Hofstede, G., \& Bond, M. H. (1988). The Confucius connection: From cultural roots to economic growth. Organizational Dynamics, 16(4), 5-21. https://doi.org/10.1016/0090-2616(88)90009-5

Hofstede, G., Hofstede, G. J., \& Minkov, M. (2010). Cultures and Organizations: Sofware of the mind, 3rd ed. Cultures and Organizations (3rd ed.). New York: McGraw-Hill.

Hoppe, M. (1990). A comparative study of country elites: International differences in work-related values and learning and their implications for management training and development (1st ed.). Chapell Hill, NC: University of North Carolina.

House, R. J., Hanges, P. J., Javidan, M., Dorfman, P. W., \& Gupta, V. (2004). Leadership, culture, and organizations: The GLOBE study of 62 societies. Beverly Hills, CA: Sage Publications (1st ed.).

Huey, B. (1999). Advertising's Double Helix: A Proposed New Process Model. Journal of Advertising Research, 39(May), 43-51.

International Telecommunication Union. (2016). Measuring the Information Society Report. Geneva. Retrieved from http://www.itu.int/en/ITUD/Statistics/Documents/publications/misr2016/MISR2016-w4.pdf

Jackson, A., \& DeCormier, R. (1999). E-mail survey response rates: Targeting increases response. Marketing Intelligence \& Planning, 17(3), 135-139. https://doi.org/10.1108/02634509910271588

Jagpal, H. (1981). Measuring Joint Advertising Effects in Multiproduct Firms. Journal of Advertising Research, 21(1), 65-69. https://doi.org/10.1023/A 
Jamalzadeh, M., Behravan, N., \& Masoudi, R. (2012). An Empirical Study of EmailBased Advertisement and its Influence on Consumers 'Attitude. International Review of Management and Marketing, 2(3), 130-138.

Janke, R. (2014). Effects of mentioning the incentive prize in the email subject line on survey response. Evidence Based Library and Information Practice, 9(1), 4-13. https://doi.org/10.18438/B8VW27

Jin, C.-H. (2010). An empirical comparison of online advertising in four countries: Cultural characteristics and creative strategies. Journal of Targeting, Measurement and Analysis for Marketing, 18(3-4), 253-261. https://doi.org/10.1057/jt.2010.18

Johnson, P., \& Neyman, J. (1936). Tests of certain linear hypotheses and their application to some educational problems. Statistical Research Memoirs, 1, 57-93. Retrieved from http://psycnet.apa.org/psycinfo/1936-05538-001

Jolley, W., Lee, A., Mizerski, R., \& Sadeque, S. (2013). Permission email messages significantly increase gambler retention. Journal of Business Research, 66(9), 1617-1622. https://doi.org/10.1016/j.jbusres.2012.12.006

Jordan, P., Mahdian, M., Vassilvitskii, S., \& Vee, E. (2011). The multiple attribution problem in pay-per-conversion advertising. In Lecture Notes in Computer Science (including subseries Lecture Notes in Artificial Intelligence and Lecture Notes in Bioinformatics) (Vol. 6982 LNCS, pp. 31-43). Springer Berlin Heidelberg. https://doi.org/10.1007/978-3-642-24829-0_5

Kahneman, D. (1973). Attention and effort (1st ed.). Englewood Cliffs, NJ: Prentice Hall.

Kale, S., De, S., \& Kreider, N. (2007). Cultural adaptation on the Web: review and implications. GDC Working Papers.

Kale, S. H. (2003). Designing Culturally Compatible Internet Gaming Sites. UNLV Gaming Research \& Review Joumal, 10(1), 41-50.

Karande, K., Almurshidee, K. A., \& Al-Olayan, F. (2006). Advertising standardisation in culturally similar markets. International Journal of Advertising, 25(4), 489-512. https://doi.org/10.1080/02650487.2006.11072985

Keith, T. (2015). Multiple regression and beyond (2nd ed.). New York: Routledge.

Kireyev, P., Pauwels, K., \& Gupta, S. (2016). Do display ads influence search? Attribution and dynamics in online advertising. International Journal of Research in Marketing, 33(3), 475-490. https://doi.org/10.1016/j.ijresmar.2015.09.007

Kirkman, B. L., Lowe, K. B., \& Gibson, C. B. (2006). A quarter century of Culture's Consequences: a review of empirical research incorporating Hofstede's cultural values framework. Journal of International Business Studies, 37(3), 285-320. https://doi.org/10.1057/palgrave.jibs.8400202

Kojima, T., Kimura, T., Yamaji, M., \& Amasaka, K. (2010). Proposal And Development Of The Direct Mail Method PMCI-DM For Effectively Attracting Customers. International Journal of Management \& Information Systems, 14(5), 15-22. https://doi.org/10.19030/ijmis.v14i5.9 
Kotler, P., \& Keller, K. L. (2012). Marketing Management (14th ed.). Boston, MA: Prentice Hall.

Kramer, M. W. (1999). Motivation to Reduce Uncertainty: A Reconceptualization of Uncertainty Reduction Theory. Management Communication Quarterly, 13(2), 305-316. https://doi.org/10.1177/0893318999132007

Kumar, A., \& Salo, J. (2018). Effects of link placements in email newsletters on their click-through rate. Journal of Marketing Communications, 24(5), 535-548. https://doi.org/10.1080/13527266.2016.1147485

Kumar, R., \& Tomkins, A. (2009). A Characterization of Online Search Behavior. Bulleting of the Technical Committee on Data Engineering, IEEE, 32(2), 3-11.

Kuper, A. (2004). The Social Science Encyclopedia (3rd ed.). New York: Routledge. https://doi.org/10.1037/024383

Lagrosen, S. (2005). Effects of the internet on the marketing communication of service companies. Journal of Services Marketing, 19(2), 63-69. https://doi.org/10.1108/08876040510591376

Lavidge, R. J., \& Steiner, G. A. (1961). A Model for Predictive Measurements of Advertising Effectiveness. Journal of Marketing, 25(6), 59. https://doi.org/10.2307/1248516

Lewis, R. A., \& Rao, J. M. (2015). The Unfavorable Economics of Measuring the Returns to Advertising. Quarterly Journal of Economics, 130(4), 1941-1973. https://doi.org/10.1093/qje/qjv023.Advance

Lim, K. H., Lim, E.-P., Jiang, B., \& Achananuparp, P. (2016). Using Online Controlled Experiments to Examine Authority Effects on User Behavior in Email Campaigns. In Proceedings of the 27th ACM Conference on Hypertext and Social Media (pp. 255-260). Halifax: ACM. https://doi.org/10.1145/2914586.2914619

Lin, Y.-S., \& Huang, J.-Y. (2006). Internet blogs as a tourism marketing medium: A case study. Journal of Business Research, 59(10-11), 1201-1205. https://doi.org/10.1016/j.jbusres.2005.11.005

Litmus. (2017). Email Client Market Share. Retrieved October 10, 2018, from https://emailclientmarketshare.com/

Liu, C. L. E., Sinkovics, R. R., Pezderka, N., \& Haghirian, P. (2012). Determinants of Consumer Perceptions toward Mobile Advertising - A Comparison between Japan and Austria. Journal of Interactive Marketing, 26(1), 21-32. https://doi.org/10.1016/j.intmar.2011.07.002

Lodish, L. M., Abraham, M., Kalmenson, S., Livelsberger, J., Lubetkin, B., Richardson, B., \& Stevens, M. E. (1995). How T.V. Advertising Works: A Meta-Analysis of 389 Real World Split Cable T.V. Advertising Experiments. Journal of Marketing Research, 32(2), 125. https://doi.org/10.2307/3152042

Lu, H. P., Fu, H. C., \& Yen, C. H. (2007). A Study of E-mail Marketing: Why Do People Read and Forward E-mail? In G. Maygar, G. Knapp, W. Wojtkowski, G. Wojtkowski, \& J. Zupancic (Eds.), Advances in Information Systems Development 
(pp. 239-249). Boston, MA: Springer US. https://doi.org/10.1007/978-0-38770802-7_20

Lukka, V., \& James, P. T. J. (2014). Attitudes toward Facebook advertising. Journal of Management and Marketing Research, 14, 1-26.

Maclnnis, D. J., \& Jaworski, B. J. (1989, October). Information Processing from Advertisements: Toward an Integrative Framework. Journal of Marketing. https://doi.org/10.2307/1251376

Magnusson, P., Wilson, R. T., Zdravkovic, S., Zhou, J. X., \& Westjohn, S. A. (2008). Breaking through the cultural clutter: A comparative assessment of multiple cultural and institutional frameworks. International Marketing Review, 25(2), 183201. https://doi.org/10.1108/JFM-03-2013-0017

mailermailer. (2016). Email Marketing Metrics Report. Retrieved February 3, 2018, from http://www.mailermailer.com/resources/metrics/2016/how-schedulingaffects-rates.rwp

Marcus, A., \& Gould, E. (2000). Cultural Dimensions and Global Web UI Design. Interactions, 7, 32-46. https://doi.org/10.1145/345190.345238.

Marinova, A., Murphy, J., \& Massey, B. L. (2002). Permission E-mail marketing as a means of targeted promotion. Cornell Hotel and Restaurant Administration Quarterly, 43(1), 61-69. https://doi.org/10.1016/S0010-8804(02)80009-X

Mazaheri, E., Richard, M. O., \& Laroche, M. (2011). Online consumer behavior: Comparing Canadian and Chinese website visitors. Journal of Business Research, 64(9), 958-965. https://doi.org/10.1016/j.jbusres.2010.11.018

McGuire, W. J. (1978). An information-processing model of advertising effectiveness. In H. L. Davis \& A. J. Silk (Eds.), Behavioral and Management Science in Marketing (pp. 156-180). New York: Ronald Press.

Mcsweeney, B. (2002). Hofstede's Model of National Cultural Differences and Their Consequences: A Triumph of Faith - a Failure of Analysis Human Relations. Human Relations, 55(February), 89-118. https://doi.org/10.1177/0018726702551004

Merisavo, M., \& Raulas, M. (2004). The impact of e-mail marketing on brand loyalty. Journal of Product \& Brand Management, 13(7), 498-505. https://doi.org/10.1108/10610420410568435

Merritt, A. (2000). Culture in the Cockpit: Do Hofstede's Dimensions Replicate? Journal of Cross-Cultural Psychology, 31(3), 283-301. https://doi.org/10.1177/0022022100031003001

Micheaux, A. L. (2011). Managing e-mail Advertising Frequency from the Consumer Perspective. Journal of Advertising, 40(4), 45-66. https://doi.org/10.2753/JOA0091-3367400404

Miglautsch, J. (2000). Thoughts on RFM scoring. The Journal of Database Marketing, 8(27), 1-7. https://doi.org/10.1057/palgrave.jdm.3240019 
Mihart, C. (2012). Modelling the Influence of Integrated Marketing Communication on Consumer Behaviour: An Approach based on Hierarchy of Effects Concept. Procedia - Social and Behavioral Sciences, 62, 975-980. https://doi.org/10.1016/j.sbspro.2012.09.166

Miles, J. N. V., \& Shevlin, M. E. (2000). Applying regression and correlation: A guide for students and researchers (1st ed.). Thousand Oaks, CA: Sage Publications.

Minkov, M. (2007). What makes us different and similar: A new interpretation of the World values survey and other cross-cultural data (1st ed.). Sofia: Klasika y Stil Publishing.

Mogoș, R. I., \& Acatrinei, C. (2015). Designing Email Marketing Campaigns - a Data Mining. Annales Universitatis Apulensis Series Oeconomica, 17(1), 15-30.

Möller, J., \& Eisend, M. (2010). A Global Investigation into the Cultural and Individual Antecedents of Banner Advertising Effectiveness. Journal of International Marketing, 18(2), 80-98. https://doi.org/10.1509/jimk.18.2.80

Moriarty, S. (1983). Beyond the Hierarchy of Effects: A Conceptual Framework. Current Issues and Research in Advertising, 6(1), 45-55.

Moriarty, S., Mitchell, N. D., Wells, W. D., Crawford, R., Brennan, L., \& SpenceStone, R. (2012). Advertising \& IMC: Principles and practice (9th ed.). Boston, MA: Prentice Hall.

Mouritzen, P., \& Svara, J. (2002). Leadership at the Apex: Politicians and administrators in Western local governments (1st ed.). Pittsburgh, PA: University of Pittsburgh Press.

Mullen, J., \& Daniels, D. (2009). Email marketing: an hour a day (1st ed.). Indianapolis, IN: John Wiley \& Sons.

Nair, P. S., \& Ramakrishnan, C. (2016). Effect of Hofstede's dimensions on Skin care advertising at the micro level. In Conference on Advances in Computing, Communications and Informatics (ICACCI) (pp. 1496-1502).

Ng, R. (2015). DoubleClick Publisher Blog: Tune in: New partnerships, features for TV broadcasters in DoubleClick. Retrieved November 26, 2016, from https://doubleclick-publishers.googleblog.com/2016/04/tune-in-new-partnershipsfeatures-for.html

Nichols, D. M. (1997). Implicit Rating and Filtering. In Proceedings of the fifth Delos workshops on filtering and collaborative filtering (pp. 31-36). ERCIM. https://doi.org/citeulike-article-id:2583460

Pedhazur, E. J. (1997). Multiple regression in behavioral research: explanation and prediction (3rd ed.). Fort Worth: Harcourt Brace College Publishers. https://doi.org/10.2307/2285468

Petty, R. E., \& Cacioppo, J. T. (1986). The elaboration likelihood model of persuasion. Advances in Experimental Social Psychology, 19, 123-205. https://doi.org/10.1007/978-1-4612-4964-1_1 
Petty, R. E., Cacioppo, J. T., \& Goldman, R. (1981). Personal Involvement as a Determinant of Argument-Based Persuasion. Journal of Personality and Social Psychology, 41(5), 847-855.

Petty, R. E., Cacioppo, J. T., \& Schumann, D. (1983). Central and Peripheral Routes to Advertising Effectiveness: The Moderating Role of The Moderating Role of Involvement. Journal of Consumer Research, 10(2), 135-146. https://doi.org/10.1086/208954

Postma, O. J., \& Brokke, M. (2002). Personalization in practice: The proven effects of personalisation. Journal of Database Marketing, 9, 137-142. https://doi.org/10.1057/palgrave.jdm.3240069

Radicati. (2019). Email Statistics Report, 2019 - 2023. Retrieved from https://www.radicati.com/wp/wp-content/uploads/2018/12/Email-Statistics-Report2019-2023-Executive-Summary.pdf

Real Academia Española. (2014). Diccionario de la lengua española (23 ${ }^{\mathrm{a}}$. Madrid: RAE.

Recabarren, M., Nussbaum, M., \& Leiva, C. (2008). Cultural divide and the Internet. Computers in Human Behavior, 24(6), 2917-2926. https://doi.org/10.1016/j.chb.2008.04.013

Rehman, F. U., Javed, F., Nawaz, T., Ahmed, I. \& Hyder, S. (2014a). Some Insights in the Historical Prospective of Hierarchy of Effects Model: A Short Review. Information Management and Business Review, 6(6), 301-308.

Rehman, F. U., Nawaz, T., Ilyas, M., \& Hyder, S. (2014b). A Comparative Analysis of Mobile and Email Marketing Using AIDA Model. Journal of Basic and Applied Scientific Research, 4(6), 38-49.

Reichhart, P., Pescher, C., \& Spann, M. (2013). A comparison of the effectiveness of email coupons and mobile text message coupons for digital products. Electronic Markets, 23(3), 217-225. https://doi.org/10.1007/s12525-013-0129-3

Rettie, R., \& Chittenden, L. (2003). Email Marketing: Success Factors. Kingston Business School - Occasional Paper Series.

Reutterer, T., Mild, A., Natter, M., \& Taudes, A. (2006). A dynamic segmentation approach for targeting and customizing direct marketing campaigns. Journal of Interactive Marketing, 20(3-4), 43-57. https://doi.org/10.1002/dir.20066

Richardson, R. (2015). Business applications of multiple regressions (2nd ed.). New York: Business Experts Press.

Robinson, H., Wysocka, A., \& Hand, C. (2007). Internet advertising effectiveness: the effect of design on click-through rates for banners. International Journal of Advertising: The Review of Marketing Communications, 26(4), 527-541. https://doi.org/10.1080/02650487.2007.11073031

Rogers, E. (1962). Diffusion of Innovations (1st ed.). New York: The Free Press.

Rutz, O. J., \& Bucklin, R. E. (2011). From Generic to Branded: A Model of Spillover in 
Paid Search Advertising. Journal of Marketing Research, 48(1), 87-102. https://doi.org/10.1509/jmkr.48.1.87

Sahni, N. S., Wheeler, S. C., \& Chintagunta, P. (2016). Personalization in Email Marketing: The Role of Non-Informative Advertising Content. SSRN eLibrary. https://doi.org/10.2139/ssrn.2725251

Sahni, N. S., Wheeler, S. C., \& Chintagunta, P. (2018). Personalization in Email Marketing. $\quad$ Marketing Science, 37(2), 236-258. https://doi.org/10.1287/mksc.2017.1066

San-José-Cabezudo, R., \& Camarero-Izquierdo, C. (2012). Determinants of OpeningForwarding E-Mail Messages. Journal of Advertising, 41(2), 97-112. https://doi.org/10.2753/JOA0091-3367410207

Scholten, M. (1996). Lost and found: The information-processing model of advertising effectiveness. Journal of Business Research, 37(2), 97-104. https://doi.org/10.1016/0148-2963(96)00058-6

Schwartz, S. (1994). Beyond individualism/collectivism: New dimensions of values. In U. U. Kim, H. C. Triandis, Ç. Kâğitçibaşi, S.-C. Choi, \& G. Yoon (Eds.), Individualism and Collectivism: Theory Application and Methods (pp. 85-119). Thousand Oaks, CA: Sage Publications.

Sekaran, U. (1983). Methodological and Theoretical Issues and Advancements in CrossCultural Research. Journal of International Business Studies, 14(2), 61-73. https://doi.org/10.1057/palgrave.jibs.8490519

Shane, S. (1995). Uncertainty Avoidance and the Preference for Innovation Championing Roles. Journal of International Business Studies, 26(1), 47-68. https://doi.org/10.1057/palgrave.jibs.8490165

Shao, X., \& Li, L. (2011). Data-driven multi-touch attribution models. Proceedings of the 17th ACM SIGKDD International. Retrieved from http://dl.acm.org/citation.cfm?id=2020453

Shuey, K. N. (2014). The effects of discount level and scarcity on the perceived product value in e-mail advertising. Texas Tech University.

Sigurdsson, V., Hinriksson, H., \& Menon, R. G. V. (2016). Operant Behavioral Economics for E-mail Marketing: An Experiment Based on the Behavioral Perspective Model Testing the Effectiveness of Motivational Operation, Utilitarian and Informational Stimuli. Managerial and Decision Economics, 37(4-5), 337344. https://doi.org/10.1002/mde.2725

Sigurdsson, V., Menon, R. G. V., Sigurdarson, J. P., Kristjansson, J. S., \& Foxall, G. R. (2013). A test of the behavioral perspective model in the context of an e-mail marketing experiment. The Psychological Record, 63(2), 295-308. https://doi.org/10.11133/j.tpr.2013.63.2.005

Simon, S. J., \& Peppas, S. C. (2004). An examination of media richness theory in product Web site design: an empirical study. Info, 6(4), 270-281. https://doi.org/10.1108/14636690410555672 
Singh, N., Fassott, G., Chao, M. C. H., \& Hoffmann, J. A. (2006). Understanding international web site usage. International Marketing Review, 23(1), 83-97. https://doi.org/10.1108/02651330610646304

Singh, N., Zhao, H., \& Hu, X. (2003). Cultural Adaptation on the Web: A Study of American Companies' Domestic and Chinese Websites. Journal of Global Information Management, 11(3), 63-80. https://doi.org/10.4018/jgim.2003070104

Sivakumar, K., \& Nakata, C. (2001). The stampede toward Hofstede's framework: Avoiding the sample design pit in cross-cultural research. Journal of International Business Studies, 32(3), 555-574. https://doi.org/10.1057/palgrave.jibs.8490984

Smart, K., \& Cappel, J. (2003). Assessing the response to and success of email marketing promotions. Issues in Information Systems, 4(1), 309-315.

Smith, R. (2012). Distinct word length frequencies: distributions and symbol entropies. Glottometrics, 23(1), 7-22.

Smith, R. E., Chen, J., \& Yang, X. (2008). The Impact of Advertising Creativity on the Hierarchy of Effects. Journal of Advertising, 37(4), 47-61. https://doi.org/10.2753/JOA0091-3367370404

Soares, A. M., Farhangmehr, M., \& Shoham, A. (2007). Hofstede's dimensions of culture in international marketing studies. Journal of Business Research, 60(3), 277-284. https://doi.org/10.1016/j.jbusres.2006.10.018

Solomon, M. R., Bamossy, G., Askegaard, S., \& Hogg, M. (2013). Consumer behaviour: a European perspective. (5th ed.). Harlow: Pearson.

Solomon, M. R., \& Rabolt, N. J. (2009). Consumer behavior: in fashion (2nd ed.). Boston, MA: Prentice Hall.

Steenkamp, J.-B. (2001). The role of national culture in international marketing research. International Marketing Review, 18(1), 30-44. https://doi.org/10.1108/02651330110381970

Strong, E. K. J. (1925). Theories of selling. Journal of Applied Psychology, 9(1), 75-86. https://doi.org/10.1037/h0070123

Su, K. W., Huang, P. H., Chen, P. H., \& Li, Y. T. (2016). The impact of formats and interactive modes on the effectiveness of mobile advertisements. Journal of Ambient Intelligence and Humanized Computing, 7(6), 817-827. https://doi.org/10.1007/s12652-016-0343-x

Taras, V., Kirkman, B. L., \& Steel, P. (2010). Examining the impact of culture's consequences: A three-decade, multilevel, meta-analytic review of Hofstede's cultural value dimensions. Journal of Applied Psychology, 95, 405-439. https://doi.org/10.1037/a0018938

Tellis, G., Chandy, R., \& MacInnis, D. (2005). Modeling the microeffects of television advertising: Which ad works, when, where, for how long, and why? Marketing Science, 24(3), 359-366. https://doi.org/10.1287/mksc.1050.0159

Tellis, G. J. (1997). Effective frequency: One exposure or three factors? Journal of 
Advertising Research, 37(4), 75-80.

Tellis, G. J., Chandy, R. K., \& Thaivanich, P. (2000). Which Ad Works, When, Where, and How Often? Modeling the Effects of Direct Television Advertising. Journal of Marketing Research, 37(1), 32-46. https://doi.org/10.1509/jmkr.37.1.32.18716

Tezinde, T., Smith, B., \& Murphy, J. (2002). Getting permission: Exploring factors affecting permission marketing. Journal of Interactive Marketing, 16(4), 28-36. https://doi.org/10.1002/dir.10041

Theerthaana, P., \& Sharad, S. (2014). A Study to Improve the Response in Email Campaigning by Comparing Data Mining Segmentation Approaches in Aditi Technologies. International Journal of Management and Business Research, 4(4), 273-293.

Thompson, B. (1999). Common Methodology Mistakes in Educational Research, Revisited, along with a Primer on Both Effect Sizes and the Bootstrap. In Annual Meeting of the American Educational Reseach Association (pp. 1-126).

Timokhina, G., Wagner, R., \& Urkmez, T. (2015). Cross-Cultural Variations in Consumer Behaviour: Literature Review. In B. Constantin, A. Zbuchea, F. Pinzaru, E.-M. Vătămănescu, \& R.-D. Leon (Eds.), Strategica International Academic Conference, Bucharest (pp. 740-750).

Ting, Y.-S. (2012). E-Newsletter as a marketing tool for hospitality and travel firms to retain customers. African Journal of Business Management, 6(12), 4551-4558. https://doi.org/10.5897/AJBM11.2620

Tufte, E. R. (1995). Envisioning information (5th ed.). Cheshire: Graphics Press.

Ur Rehman, F., Javed, F., Nawaz, T., Ahmed, I., \& Hyder, S. (2014). Some Insights in the Historical Prospective of Hierarchy of Effects Model: A Short Review. Information Management and Business Review, 6(6), 301-308.

van Nimwegen, T. (2002). Global Banking, Global Values: The In-house Reception of the Corporate Values of ABN AMRO. Delft: Eburon.

Vishwanath, A. (2003). Comparing Online Information Effects: A Cross-Cultural Comparison of Online Information and Uncertainty Avoidance. Communication Research, 30(6), 579-598. https://doi.org/10.1177/0093650203257838

Vriens, M., Scheer, H. R. Van Der, Hoekstra, J. C., \& Bult, J. R. (1998). Conjoint experiments for direct mail response optimization. European Journal of Marketing, 32(3/4), 323-339. https://doi.org/10.1108/03090569810204625

Wang, Y., \& Sun, S. (2010). Examining the role of beliefs and attitudes in online advertising. International Marketing Review, 27(1), 87-107. https://doi.org/10.1108/02651331011020410

White, T. B., Zahay, D. L., Thorbjornsen, H., \& Shavitt, S. (2008). Getting too personal: Reactance to highly personalized email solicitations. Marketing Letters, 19(1), 39-50. https://doi.org/10.1007/s11002-007-9027-9

Wijaya, B. S. (2015). The Development Of Hierarchy Of Effects Model In Advertising. 
International Research Journal of Business Studies, 5(1), 73-85. https://doi.org/10.21632/irjbs.5.1.73-85

Wilson, E. V., Hall-Phillips, A., \& Djamasbi, S. (2015). Cognitive predictors of consumers' intention to comply with social marketing email appeals. Computers in Human Behavior, 52, 307-314. https://doi.org/10.1016/j.chb.2015.06.014

Wood, N. T., \& Burkhalter, J. N. (2014). Tweet this, not that: A comparison between brand promotions in microblogging environments using celebrity and companygenerated tweets. Journal of Marketing Communications, 20(1-2), 129-146. https://doi.org/10.1080/13527266.2013.797784

Wu, J., Li, K. J., \& Liu, J. S. (2018). Bayesian Inference for Assessing Effects of Email Marketing Campaigns. Journal of Business \& Economic Statistics, 36(2), 253-266. https://doi.org/10.1080/07350015.2016.1141096

Yancey, A., Cole, B., Brown, R., Williams, J., Hillier, A., Kline, R., \& McCarthy, W. (2009). A Cross-Sectional Prevalence Study of Ethnically Targeted and General Audience Outdoor Obesity-Related Advertising. Milbank Quarterly, 87(1), 155184. https://doi.org/10.1111/j.1468-0009.2009.00551.x

Yoo, C. Y., Kim, K., \& Stout, P. A. (2004). Assessing the Effects of Animation in Online Banner Advertising: Hierarchy of Effects Model. Journal of Interactive Advertising, 4(2), 49-60. https://doi.org/10.1080/15252019.2004.10722087

Zhang, J., Beatty, S., \& Walsh, G. (2008). Review and future directions of crosscultural consumer services research. Journal of Business Research, 61(3), 211224. https://doi.org/10.1016/j.jbusres.2007.06.003

Zikmund, W., Babin, B., Carr, J., \& Griffin, M. (2013). Business research methods (8th ed.). Boston, MA: Cengage Learning.

Zviran, M., Te'eni, D., \& Gross, Y. (2006). Does color in email make a difference? Communications of the ACM, 49(4), 94-99. https://doi.org/10.1145/1121949.1121954 
Apéndice 


\section{APÉNDICE}

\section{RESUMEN DE HIPÓTESIS}

\section{ETAPA DE ATENCIÓN}

- H11: Longitud asunto $\rightarrow$ Atención

- H11B: Individualismo-colectivismo modera longitud asunto $\rightarrow$ Atención

○ H11C: Masculinidad-feminidad modera longitud asunto $\rightarrow$ Atención

- H11D: Aversión a la incertidumbre modera longitud asunto $\rightarrow$ Atención

○ H11E: Orientación al largo plazo modera longitud asunto $\rightarrow$ Atención

- H12: Caracteres especiales $\rightarrow$ Atención

○ H12B: Individualismo-colectivismo modera caracteres especiales $\rightarrow$ Atención

- H13: Números asunto $\rightarrow$ Atención

- H14: Contenido asunto $\rightarrow$ Atención

- H14A: Distancia al poder modera contenido asunto $\rightarrow$ Atención

- H14B: Individualismo-colectivismo modera contenido asunto $\rightarrow$ Atención

- H14C: Masculinidad-feminidad modera contenido asunto $\rightarrow$ Atención

- H15: Frecuencia $\rightarrow$ Atención

- H15B: Individualismo-colectivismo modera frecuencia $\rightarrow$ Atención

- H16: Día de la semana $\rightarrow$ Atención

- H17: Hora de envío $\rightarrow$ Atención

- H18: Personalización $\rightarrow$ Atención

○ H18B: Individualismo-colectivismo modera personalización $\rightarrow$ Atención

- H19: Segmentación $\rightarrow$ Atención

- H19B: Individualismo-colectivismo modera segmentación $\rightarrow$ Atención

- H19D: Aversión a la incertidumbre modera segmentación $\rightarrow$ Atención 


\section{ETAPA DE INTERÉS}

- H21: Longitud texto $\rightarrow$ Interés

- H21B: Individualismo-colectivismo modera longitud texto $\rightarrow$ Interés

- H21C: Masculinidad-feminidad modera longitud texto $\rightarrow$ Interés

- H21D: Aversión a la incertidumbre modera longitud texto $\rightarrow$ Interés

- H21E: Orientación al largo plazo modera longitud texto $\rightarrow$ Interés

- H22: Número de imágenes $\rightarrow$ Interés

○ H22B: Individualismo-colectivismo modera número de imágenes $\rightarrow$ Interés

- H22C: Masculinidad-feminidad modera número de imágenes $\rightarrow$ Interés

○ H22D: Aversión a la incertidumbre modera número de imágenes $\rightarrow$ Interés

○ H22E: Orientación al largo plazo modera número de imágenes $\rightarrow$ Interés

- H23: Número de enlaces $\rightarrow$ Interés

○ H23B: Individualismo-colectivismo modera número de enlaces $\rightarrow$ Interés

- H23C: Masculinidad-feminidad modera número de enlaces $\rightarrow$ Interés

- H23D: Aversión a la incertidumbre modera número de enlaces $\rightarrow$ Interés

- H23E: Orientación al largo plazo modera número de enlaces $\rightarrow$ Interés

- H24: Incentivos económicos $\rightarrow$ Interés

- H24A: Distancia al poder modera incentivos económicos $\rightarrow$ Interés

- H24B: Individualismo-colectivismo modera incentivos económicos $\rightarrow$ Interés

○ H24C: Masculinidad-feminidad modera incentivos económicos $\rightarrow$ Interés

- H25: Sensación de escasez $\rightarrow$ Interés

- H25A: Distancia al poder modera sensación de escasez $\rightarrow$ Interés

- H25B: Individualismo-colectivismo modera sensación de escasez $\rightarrow$ Interés

- H25C: Masculinidad-feminidad modera sensación de escasez $\rightarrow$ Interés

- H25D: Aversión a la incertidumbre modera sensación de escasez $\rightarrow$ Interés

○ H25E: Orientación al largo plazo modera sensación de escasez $\rightarrow$ Interés

- H26: Frecuencia $\rightarrow$ Interés

○ H26B: Individualismo-colectivismo modera frecuencia $\rightarrow$ Interés

- H27: Personalización $\rightarrow$ Interés

- H27B: Individualismo-colectivismo modera personalización $\rightarrow$ Interés

- H28: Segmentación $\rightarrow$ Interés

○ H28B: Individualismo-colectivismo modera segmentación $\rightarrow$ Interés 
○ H28D: Aversión a la incertidumbre modera segmentación $\rightarrow$ Interés 


\section{ETAPA DE ACCIÓN}

- H31: Incentivos económicos $\rightarrow$ Acción

- H31A: Distancia al poder modera incentivos económicos $\rightarrow$ Acción

- H31B: Individualismo-colectivismo modera incentivos económicos $\rightarrow$ Acción

- H31C: Masculinidad-feminidad modera incentivos económicos $\rightarrow$ Acción

- H32: Sensación de escasez $\rightarrow$ Acción

- H32A: Distancia al poder modera sensación de escasez $\rightarrow$ Acción

○ H32B: Individualismo-colectivismo modera sensación de escasez $\rightarrow$ Acción

○ H32C: Masculinidad-feminidad modera sensación de escasez $\rightarrow$ Acción

- H32D: Aversión a la incertidumbre modera sensación de escasez $\rightarrow$ Acción

- H32E: Orientación al largo plazo modera sensación de escasez $\rightarrow$ Acción

- H33: Personalización $\rightarrow$ Acción

- H33B: Individualismo-colectivismo modera personalización $\rightarrow$ Acción

- H34: Segmentación $\rightarrow$ Acción

- H34B: Individualismo-colectivismo modera segmentación $\rightarrow$ Acción

○ H34D: Aversión a la incertidumbre modera segmentación $\rightarrow$ Acción 


\section{ACRÓNIMOS}

- AACC: contenido asunto - acción

- ABON: contenido asunto - bonus

- ACAR: caracteres especiales en asunto

- ACAR_INDIC: interacción entre caracteres especiales en asunto y dimensión individualismo-colectivismo centrada

- ACON: contenido asunto - concurso

- ACON_MASCC: interacción entre contenido asunto - concurso y dimensión masculinidad-feminidad centrada

- ACPR: contenido asunto - concurso y promoción

○ ACPR_MASCC: interacción entre contenido asunto - concurso y promoción y dimensión masculinidad-feminidad centrada

- ADES: contenido asunto - descuento

- ADES_DISTC: interacción entre contenido asunto - descuento y dimensión distancia al poder centrada

- ADES_INDIC: interacción entre contenido asunto - descuento y dimensión individualismo-colectivismo centrada

- ADES_MASCC: interacción entre contenido asunto - descuento y dimensión masculinidad-feminidad centrada

- ADTE: contenido asunto - descuento de temporada

- ADTE_DISTC: interacción entre contenido asunto - descuento de temporada y dimensión distancia al poder centrada

- ADTE_INDIC: interacción entre contenido asunto - descuento de temporada y dimensión individualismo-colectivismo centrada

- ADTE_MASCC: interacción entre contenido asunto - descuento de temporada y dimensión masculinidad-feminidad centrada

- AEVE: contenido asunto - evento

- ALON: longitud de asunto

- ALONC: longitud de asunto centrado

- ALONC_AVERC: interacción entre longitud de asunto centrado y dimensión aversión a la incertidumbre centrada

- ALONC_INDIC: interacción entre longitud de asunto centrado y dimensión individualismo-colectivismo centrada

- ALONC_MASCC: interacción entre longitud de asunto centrado y dimensión masculinidad-feminidad centrada

- ALONC_ORIEC: interacción entre longitud de asunto centrado y dimensión orientación al largo plazo centrada

- ANOT: contenido asunto - noticias

- ANUM: números en asunto 
- AOTR: contenido asunto - otro

- APRO: contenido asunto - producto

- AREG: contenido asunto - regalo

- ATEA: contenido asunto - teaser

- ATEM: contenido asunto - temporada

- ATEM_DISTC: interacción entre contenido asunto - temporada y dimensión distancia al poder centrada

- AVER: aversión a la incertidumbre

- AVERC: dimensión aversión a la incertidumbre centrada

- DIAD: día de la semana - domingo

- DIAJ: día de la semana - jueves

- DIAL: día de la semana - lunes

- DIAM: día de la semana - miércoles

- DIAS: día de la semana - sábado

- DIAV: día de la semana - viernes

- DIST: distancia al poder

- DISTC: dimensión distancia al poder centrada

- EENL: número de enlaces e-mail

- EENLC: número de enlaces e-mail centrado

- EENLC_AVERC: interacción entre número de enlaces e-mail centrado y dimensión aversión a la incertidumbre centrada

- EENLC_INDIC: interacción entre número de enlaces e-mail centrado y dimensión individualismo-colectivismo centrada

- EENLC_MASCC: interacción entre número de enlaces e-mail centrado y dimensión masculinidad-feminidad centrada

- EENLC_ORIEC: interacción entre número de enlaces e-mail centrado y dimensión orientación al largo plazo centrada

- EESC: sensación de escasez e-mail

- EESC_AVERC: interacción entre sensación de escasez e-mail y dimensión aversión a la incertidumbre centrada

- EESC_DISTC: interacción entre sensación de escasez e-mail y dimensión distancia al poder centrada

- EESC_INDIC: interacción entre sensación de escasez e-mail y dimensión individualismo-colectivismo centrada

- EESC_MASCC: interacción entre sensación de escasez e-mail y dimensión masculinidad-feminidad centrada

○ EESC_ORIEC: interacción entre sensación de escasez e-mail y dimensión orientación al largo plazo centrada

- EIMA: número de imágenes e-mail 
- EIMAC: número de imágenes e-mail centrado

- EIMAC_AVERC: interacción entre número de imágenes e-mail centrado y dimensión aversión a la incertidumbre centrada

- EIMAC_INDIC: interacción entre número de imágenes e-mail centrado y dimensión individualismo-colectivismo centrada

- EIMAC_MASCC: interacción entre número de imágenes e-mail centrado y dimensión masculinidad-feminidad centrada

- EIMAC_ORIEC: interacción entre número de imágenes e-mail centrado y dimensión orientación al largo plazo centrada

- EINC: incentivos económicos e-mail

- EINC_DISTC: interacción entre incentivos económicos e-mail y dimensión distancia al poder centrada

- EINC_INDIC: interacción entre incentivos económicos e-mail y dimensión individualismo-colectivismo centrada

- EINC_MASCC: interacción entre incentivos económicos e-mail y dimensión masculinidad-feminidad centrada

- ELON: longitud texto e-mail

- ELONC: longitud texto e-mail centrado

- ELONC_AVERC: interacción entre longitud texto e-mail centrado y dimensión aversión a la incertidumbre centrada

- ELONC_INDIC: interacción entre longitud texto e-mail centrado y dimensión individualismo-colectivismo centrada

- ELONC_MASCC: interacción entre longitud texto e-mail centrado y dimensión masculinidad-feminidad centrada

- ELONC_ORIEC: interacción entre longitud texto e-mail centrado y dimensión orientación al largo plazo centrada

- FREC: frecuencia

- FRECC: frecuencia centrada

- FRECC_INDIC: interacción entre frecuencia centrada y dimensión individualismo-colectivismo centrada

- HO00: hora de envío - 00

- HO01: hora de envío - 01

- HO02: hora de envío - 02

- HO03: hora de envío - 03

- HO04: hora de envío - 04

- HO05: hora de envío - 05

- HO06: hora de envío - 06

- HO07: hora de envío - 07

- HO08: hora de envío - 08 
- HO10: hora de envío - 10

- HO11: hora de envío - 11

- HO12: hora de envío - 12

- HO13: hora de envío - 13

- HO14: hora de envío - 14

- HO15: hora de envío - 15

- HO16: hora de envío - 16

- HO17: hora de envío - 17

- HO18: hora de envío - 18

- HO19: hora de envío - 19

- HO20: hora de envío - 20

- HO21: hora de envío - 21

- HO22: hora de envío - 22

- HO23: hora de envío - 23

- INDI: individualismo-colectivismo

- INDIC: dimensión individualismo-colectivismo centrada

- LNCR: logaritmo neperiano de efectividad de conversión

- LNCTOR: logaritmo neperiano de efectividad de clic

- LNOR: logaritmo neperiano de efectividad de apertura

- LNUR: logaritmo neperiano de efectividad de retención de suscriptores

- MASC: masculinidad-feminidad

- MASCC: dimensión masculinidad-feminidad centrada

- ORIE: orientación al largo plazo

- ORIEC: dimensión orientación al largo plazo centrada

- PERS: personalización

- PERS_INDIC: interacción entre personalización y dimensión individualismo-colectivismo centrada

- SEGM: segmentación

○ SEGM_AVERC: interacción entre segmentación y dimensión aversión a la incertidumbre centrada

- SEGM_INDIC: interacción entre segmentación y dimensión individualismo-colectivismo centrada 